US Army Corps of Engineers ${ }_{\circledast}$

Engineer Research and

Development Center

\title{
CSTORM-MS Storm Surge and Wave Modeling Comparison for Proposed Dyke Marsh Promontory Restoration
}

Thomas C. Massey, Yan Ding, Margaret Owensby,

October 2018

Greg Slusarczyk, and Mary A. Bryant

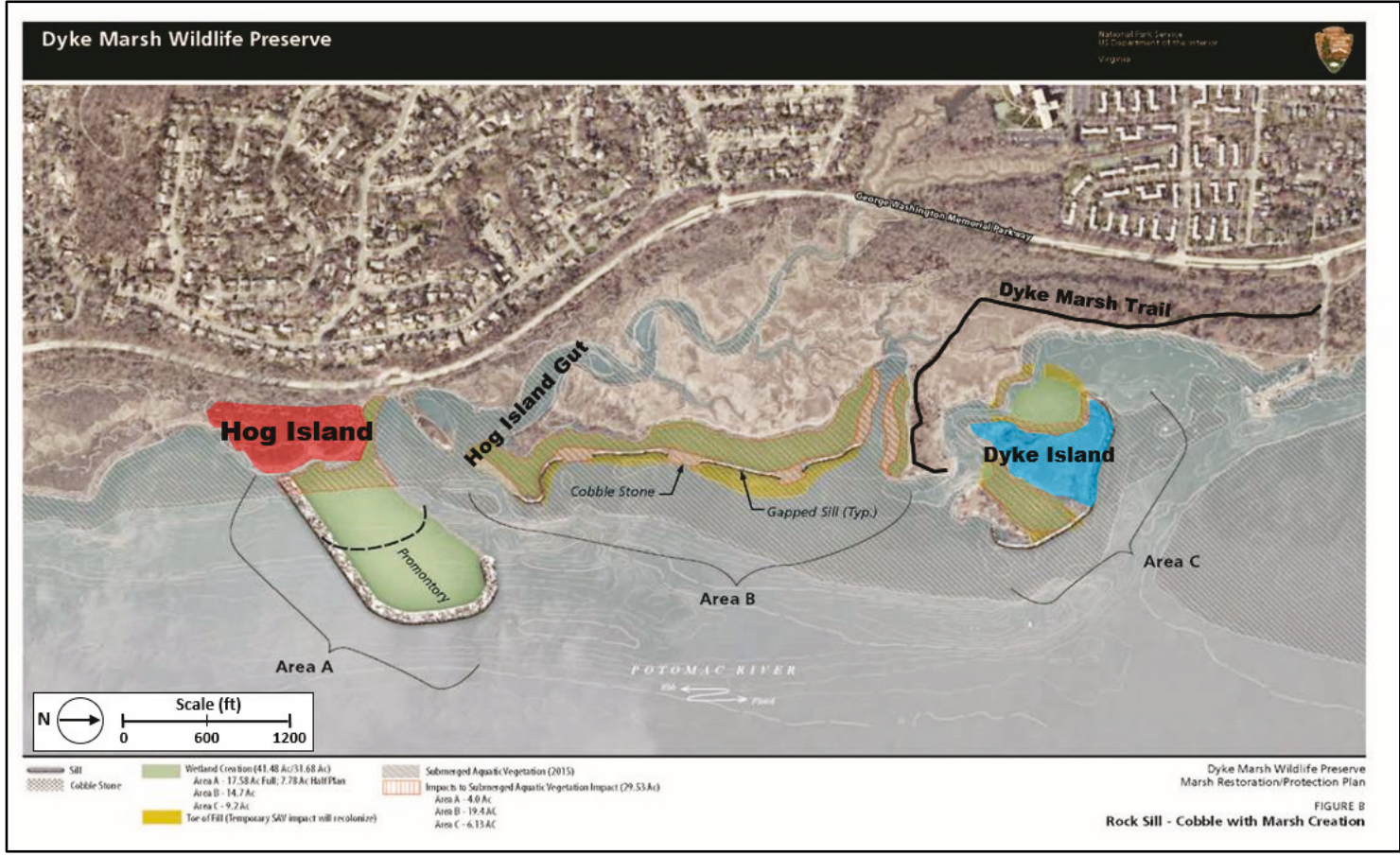


The U.S. Army Engineer Research and Development Center (ERDC) solves the nation's toughest engineering and environmental challenges. ERDC develops innovative solutions in civil and military engineering, geospatial sciences, water resources, and environmental sciences for the Army, the Department of Defense, civilian agencies, and our nation's public good. Find out more at www.erdc.usace.army.mil.

To search for other technical reports published by ERDC, visit the ERDC online library at http://acwc.sdp.sirsi.net/client/default. 


\section{CSTORM-MS Storm Surge and Wave Modeling Comparison for Proposed Dyke Marsh Promontory Restoration}

Thomas C. Massey, Yan Ding, Margaret Owensby, Greg Slusarczyk, and Mary A. Bryant

Coastal and Hydraulics Laboratory

U.S. Army Engineer Research and Development Center 3909 Halls Ferry Road

Vicksburg, MS 39180-6199

Final report

Approved for public release; distribution is unlimited.

Prepared for U.S. Army Corps of Engineers, Baltimore District

2 Hopkins Plaza, Baltimore MD 21201

Under Project No. 327615, “Dyke Marsh Hydrodynamic Modeling Project” 


\section{Abstract}

The U.S. Army Corps of Engineers, Baltimore District (NAB), is currently engaged in the Dyke Marsh Project for the National Park Service. Dyke Marsh is located along the Potomac River south of Alexandria, VA. The U.S. Army Engineer Research and Development, Coastal and Hydraulics Laboratory, conducted a numerical modeling study to compute differences in hydrodynamic conditions (water surface elevations, depth-averaged water velocities, and wave heights, periods, and directions) between existing conditions and seven alternative with-project conditions for Dyke Marsh. Modeling results suggested that several of the alternative withproject condition designs were viable in terms of the NAB goals to provide protection to the marsh from damaging waves and currents. All the designs decreased wave heights in the shadow zones of the structures, and none significantly altered water levels. The shorter-length project designs provided reasonable levels of protection to the marsh while not significantly increasing water velocities on the opposite (eastern) shoreline of the Potomac River. Detailed model results from each of the alternative with-project condition designs are presented herein.

DISCLAIMER: The contents of this report are not to be used for advertising, publication, or promotional purposes. Citation of trade names does not constitute an official endorsement or approval of the use of such commercial products. All product names and trademarks cited are the property of their respective owners. The findings of this report are not to be construed as an official Department of the Army position unless so designated by other authorized documents. 


\section{Contents}
Abstract ii
Figures and Tables.
...v
Preface .XV
Unit Conversion Factors ..xvi

1 Introduction. 1

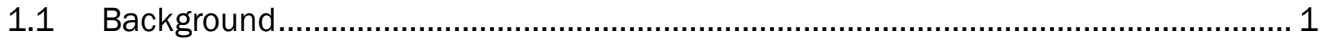

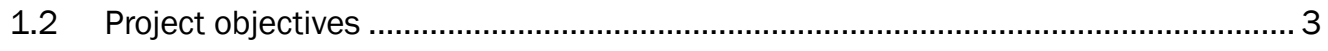

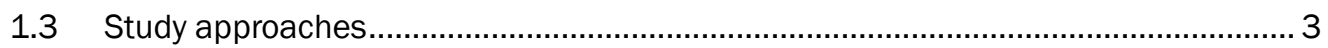

2 Storm Selections....................................................................................................................... 8

3 Coastal Storm Modeling System (CSTORM-MS) ...............................................................12

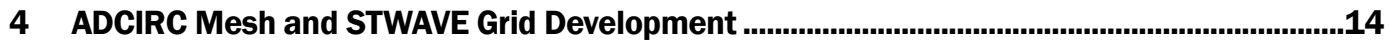

4.1 Configurations of proposed structures.................................................................... 14

4.2 Computational domains and grids .................................................................. 18

4.2.1 Grids for full promontories with-project alternatives ......................................... 18

4.2.2 Grids for groin-only with-project alternatives..................................................... 23

4.3 Bathymetric and topographic data sources ......................................................... 25

4.4 Physical forcing conditions................................................................................ 27

4.5 Model parameters for nodal attributes ........................................................ 27

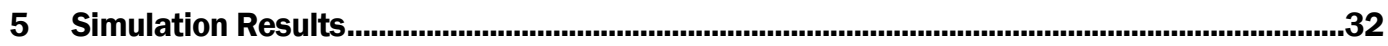

5.1 Results for evaluation of the proposed fully enclosed promontories ......................32

5.1.1 Maximum storm surge results.............................................................................. 33

5.1.2 Maximum depth-averaged storm water velocity results for the fully

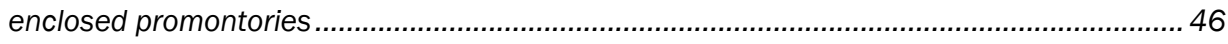

5.1.3 Maximum significant wave height storm results for the fully enclosed

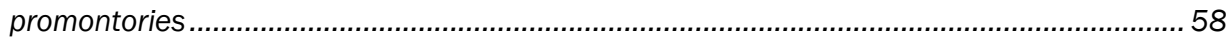

5.1.4 Difference in maximum significant wave height storm results for the fully

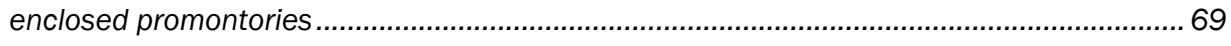

5.1.5 Time series plots for select locations north of the promontory............................. 89

5.1.6 Tables of values at select locations north and east of the promontory with difference plots of maximum significant wave height ..................................................97

5.1.7 Simulation results for average river flows and long-term tides under constant wind conditions................................................................................................... 103

5.2 Results for evaluation of the proposed groins ....................................................133

5.2.1 Maximum storm surge results for groin-only designs .........................................134

5.2.2 Maximum storm depth averaged water velocity results groin-only designs.................145

5.2.3 Storm significant wave height results................................................................156

5.2.4 Differences in maximum significant wave height for groin-only designs.............165 
5.2.5 Time series of hydrodynamic variables and maximum wave heights at selected locations for groin only designs

5.2.6 Simulation results for long-term tidal and river flows under constant wind conditions for groin-only designs.

6 Summary.

References

Appendix

\section{Report Documentation Page}




\section{Figures and Tables}

\section{Figures}

Figure 1-1. Diagram map showing Dyke Marsh and concept renderings of possible project alternatives. The portion in red represents the remainder of the historic promontory, called Hog Island, while Dyke Island is colored blue.

Figure 1-2. Existing NACCS ADCIRC mesh color contours of topography and bathymetry for Potomac River and close-up view around Dyke Marsh. The black dots are the save points used in the NACCS study (Coastal Hazard System [CHS] save points).

Figure 1-3. Existing NACCS ADCIRC mesh for the Potomac River, with Dyke Marsh region indicated in detail on right. The USGS hydrologic station No. 1646500 is shown in the figure.

Figure 2-1. Hurricane tracks of Isabel (2003) and Sandy (2012)...

Figure 2-2. Storm tracks for the six SYN TP storms selected as surrogate storms for the 5-,

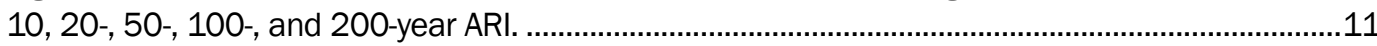

Figure 4-1. Layouts of proposed promontories (sills in yellow; groins in green/blue).........................16

Figure 4-2. Layouts of proposed groins. ..........................................................................................17

Figure 4-3. Outline plot showing the boundary of the ADCIRC mesh. ............................................19

Figure 4-4. Outline plot showing the boundary of the ADCIRC mesh and the highresolution STWAVE grid box (in red) for the area near Dyke Marsh. .20

Figure 4-5. Computational domain boundaries and topo-bathymetry for the Potomac River

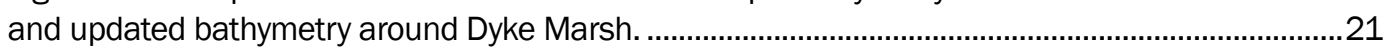

Figure 4-6. Close-up view of grids in Dyke Marsh area with structures............................................22

Figure 4-7. Close-up view of ADCIRC grids in Dyke Marsh with groins................................................24

Figure 4-8. Topo-bathymetric data points surveyed in 2009, 2012, and 2016...............................26

Figure 4-9. USGS NED one-third arc-second topographic data. .......................................................26

Figure 4-10. Merged scattered topo-bathymetric data points. ...........................................................2

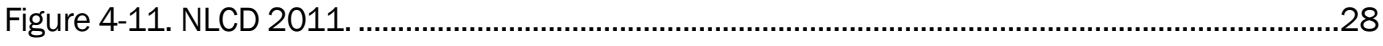

Figure 4-12. Spatial distribution of Manning's $n$ around the area of Dyke Marsh. ..........................30

Figure 4-13. Average horizontal eddy viscosity. .............................................................................31

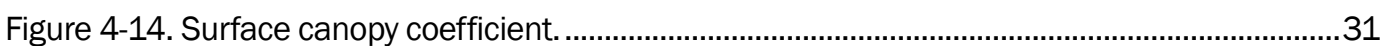

Figure 5-1. Average maximum storm surges at the offshore of Dyke Marsh. …………....................34

Figure 5-2. Map of the Dyke Marsh area. Arrows indicate directions from which winds blowing would have the potential to create larger wind-waves due to larger fetches.

Figure 5-3. Color contour plot showing the topography (positive) and bathymetry (negative) values along with an outline of the longest promontory structure and the locations of five selected time series locations.

Figure 5-4. Map of the selected station output locations and the proposed promontory structures.

Figure 5-5. Map of selected station output locations east of the Potomac River Channel and the proposed promontory structures.

Figure 5-6. Monthly discharge and seasonal average at Potomac River, Little Falls, 
Figure 5-7. Refined computational grid (20 ft resolution in the Dyke Marsh). ............................. 105

Figure 5-8. Comparisons of water surface elevations and velocities at Stn 1. Water elevations are almost the same in all cases.

Figure 5-9. Differences in velocity magnitude (ft/s) at Stn 1 with and without structures

Figure 5-10. Comparisons of water surface elevations (ft) and velocities (ft/s) at Stn 2.

Water elevations are almost the same in all cases. 110

Figure 5-11. Differences in velocity magnitude (ft/s) at Stn 2 with and without structures.

Figure 5-12. Comparisons of water surface elevations (ft) and velocities (ft/s) at Stn 3. Water elevations are almost the same in all cases. 111

Figure 5-13. Differences in velocity magnitude (ft/s) at Stn 3 with and without structures.

Figure 5-14. Comparisons of water surface elevations (ft) and velocities (ft/s) at Stn 4. Water elevations are almost the same in all cases. 112

Figure 5-15. Differences in velocity magnitude (ft/s) at Stn 4 with and without structures. 112

Figure 5-16. Comparisons of water surface elevations (ft) and velocities (ft/s) at Stn 5. Water elevations are almost the same in all cases.... 113

Figure 5-17. Differences in velocity magnitude (ft/s) at Stn 5 with and without structures. 113

Figure 5-18. Comparisons of water surface elevations (ft) and velocities (ft/s) at Stn 6. Water elevations are almost the same in all cases. 114

Figure 5-19. Differences in velocity magnitude (ft/s) at Stn 6 with and without structures. ......... 114

Figure 5-20. Comparisons of water surface elevations (ft) and velocities (ft/s) at Stn 13. Water elevations are almost the same in all cases. 115

Figure 5-21. Differences in velocity magnitude (ft/s) at Stn 13 with and without structures.

Figure 5-22. Comparisons of water surface elevations (ft) and velocities (ft/s) at Stn 15. Water elevations are almost the same in all cases.

Figure 5-23. Differences in velocity magnitude (ft/s) at Stn 15 with and without structures.

Figure 5-24. Comparisons of water surface elevations (ft) and velocities (ft/s) at Stn 17. Water elevations are almost the same in all cases.

Figure 5-25. Differences in velocity magnitude (ft/s) at Stn 17 with and without structures.

Figure 5-26. Comparisons of velocities at Stn 1 under the low flow conditions. 118

Figure 5-27. Comparisons of velocities at Stn 2 under the low flow conditions............................. 118

Figure 5-28. Comparisons of velocities at Stn 3 under the low flow conditions. ............................ 119

Figure 5-29. Comparisons of velocities at Stn 4 under the low flow conditions. ............................ 119

Figure 5-30. Comparisons of velocities at Stn 5 under the low flow conditions. ........................... 120

Figure 5-31. Comparisons of velocities at Stn 6 under the low flow conditions.............................. 120

Figure 5-32. Comparisons of velocities at Stn 13 under the low flow conditions............................ 121

Figure 5-33. Comparisons of velocities at Stn 15 under the low flow conditions.......................... 121

Figure 5-34. Comparisons of velocities at Stn 17 under the low flow conditions. ......................... 121

Figure 5-35. Comparisons of velocities at Stn 18 under the low flow conditions.......................... 122

Figure 5-36. Current ellipses at Stn 3 by 20 mph wind from five directions. ................................ 124

Figure 5-37. Flow velocity magnitudes at Stn 3 by $20 \mathrm{mph}$ wind from five directions..................... 124 
Figure 5-38. Time series of significant wave heights, water levels, and wind speed at Stn 3

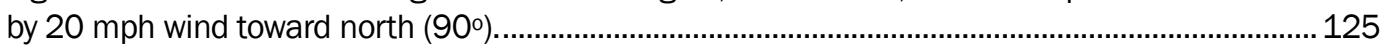

Figure 5-39. Current ellipses at Stn 5 by $20 \mathrm{mph}$ wind from five directions. ................................ 125

Figure 5-40. Flow velocity magnitudes at Stn 5 by $20 \mathrm{mph}$ wind from five directions................... 126

Figure 5-41. Time series of significant wave heights, water levels, and wind speed at Stn 5 by $20 \mathrm{mph}$ wind from south (90 degrees)..................................................................................... 126

Figure 5-42. Current ellipses at Stn 15 by $20 \mathrm{mph}$ wind from five directions................................ 127

Figure 5-43. Flow velocity magnitudes at Stn 15 by $20 \mathrm{mph}$ wind from five directions. ................ 127

Figure 5-44. Time series of significant wave heights, water levels, and wind speed at Stn

15 by 20 mph northerly wind $\left(90^{\circ}\right)$......................................................................................... 128

Figure 5-45. The 18 selected locations. ................................................................................177

Figure 5-46. Time series of significant wave height $(a, b)$, water level (c, d), and wind speed $(\mathrm{e}, \mathrm{f})$ at Stns 4 and 6 for HIS ET Storm No. 0001............................................................ 178

Figure 5-47. Time series of significant wave height (a, b), water level (c, d), and wind speed (e, f) at Stns 4 and 6 for HIS ET Storm No. 0008.

Figure 5-48. Time series of significant wave height $(a, b)$, water level (c, d), and wind speed (e, f) at Stns 4 and 6 for HIS TP Storm No. 0001 (Hurricane Sandy 2012).

Figure 5-49. Time series of significant wave height $(a, b)$, water level (c, d), and wind speed (e, f) at Stns 4 and 6 for SYN TP Storm No. 0028.

Figure 5-50. Comparisons of water levels (ft) and velocities (ft/s) at Stn 1 for groins................... 189

Figure 5-51. Differences in velocity magnitude (ft/s) at Stn 1 with and without structures........... 190

Figure 5-52. Comparisons of water levels (ft) and velocities (ft/s) at Stn 2 for groins................... 190

Figure 5-53. Differences in velocity magnitude (ft/s) at Stn 2 with and without structures. ......... 191

Figure 5-54. Comparisons of water levels (ft) and velocities (ft/s) at Stn 3 for groins................... 191

Figure 5-55. Differences in velocity magnitude (ft/s) at Stn 3 with and without structures. ......... 192

Figure 5-56. Comparisons of water levels (ft) and velocities (ft/s) at Stn 4 for groins................... 192

Figure 5-57. Differences in velocity magnitude (ft/s) at Stn 4 with and without structures........... 193

Figure 5-58. Comparisons of water levels (ft) and velocities (ft/s) at Stn 5 for groins. ................... 193

Figure 5-59. Differences in velocity magnitude (ft/s) at Stn 5 with and without structures. ......... 194

Figure 5-60. Comparisons of water levels (ft) and velocities (ft/s) at Stn 6 for groins.................... 194

Figure 5-61. Differences in velocity magnitude (ft/s) at Stn 6 with and without structures........... 195

Figure 5-62. Comparisons of water levels (ft) and velocities (ft/s) at Stn 13 for groins.................. 195

Figure 5-63. Differences in velocity magnitude (ft/s) at Stn 13 with and without

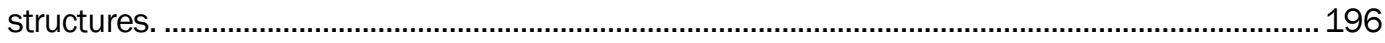

Figure 5-64. Current Ellipses at Stn 3 by 20 mph wind from six directions................................... 198

Figure 5-65. Flow velocity magnitudes at Stn 3 by $20 \mathrm{mph}$ wind from six directions. .................... 198

Figure 5-66. Time series of significant wave heights and water levels at Stn 3 by $20 \mathrm{mph}$

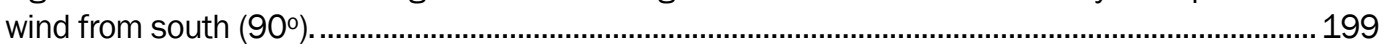

Figure 5-67. Current Ellipses at Stn 5 by 20 mph wind from six directions................................... 199

Figure 5-68. Flow velocity magnitudes at Stn 5 by $20 \mathrm{mph}$ wind from six directions. ....................200

Figure 5-69. Time series of significant wave heights and water levels at Stn 5 by $20 \mathrm{mph}$ wind from south $\left(90^{\circ}\right)$................................................................................................................ 200

Figure 5-70. Current Ellipses at Stn 15 by 20 mph wind from six directions. ................................ 201 
Figure 5-71. Flow velocity magnitudes at Stn 15 by $20 \mathrm{mph}$ wind from six directions. 201

Figure 5-72. Time series of significant wave heights and water levels at Stn 15 by $20 \mathrm{mph}$ wind from south $\left(90^{\circ}\right)$.

\section{Tables}

Table 2-1. ARI values for surge and significant wave height (Hs) at NACCS Save Point 14607.

Table 2-2. Significant wave height statistics at NACCS station 14607 for the HIS ET storms.

Table 2-3. Selected HIS storms and SYN storms (abbreviations defined beneath last row of table)

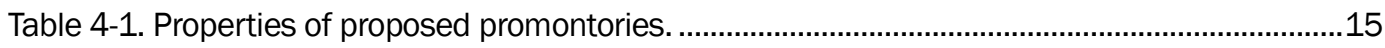

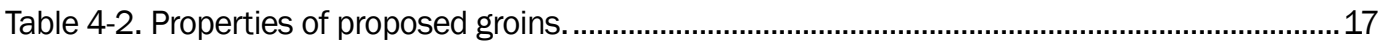

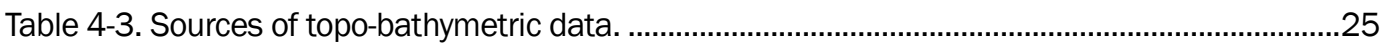

Table 4-4. Manning's $n$ values for NLCD 2011 classification. ..........................................................29

Table 5-1. Maximum water surface elevations for HIS ET Storm No. 0001 for five mesh configurations (with without-project structures). ..........................................................................35

Table 5-2. Difference in maximum water surface elevations for HIS ET Storm No. 0001 between project and existing conditions (Project - Existing)................................................................36

Table 5-3. Maximum water surface elevations for HIS ET Storm No. 0008 for five mesh configurations (with without-project structures).

Table 5-4. Maximum water surface elevations for HIS ET Storm No. 0038 for five mesh configurations (with and without structures)...

Table 5-5. Maximum water surface elevations for HIS ET Storm No. 0051 for five mesh configurations.

Table 5-6. Maximum water surface elevations for HIS ET Storm No. 0054 for five mesh configurations.

Table 5-7. Maximum water surface elevations for HIS TP Storm No. 0001 (Hurricane Sandy 2012) for five mesh configurations.

Table 5-8. Maximum water surface elevations for HIS TP Storm No. 0003 (Hurricane Isabel 2003) for five mesh configurations.

Table 5-9. Maximum water surface elevations for SYN TP Storm No. 0005 for five mesh configurations.

Table 5-10. Maximum water surface elevations for SYN TP Storm No. 0028 for five mesh configurations.

Table 5-11. Maximum water surface elevations for SYN TP Storm No. 0110) for five mesh configurations.

Table 5-12. Maximum water velocity color contour plots for HIS ET Storm No. 0001 for five mesh configurations.

Table 5-13. Difference in maximum water velocity for HIS ET Storm No. 0001 between project and existing conditions (Project - Existing)...

Table 5-14. Maximum water velocity color contour plots for HIS ET Storm No. 0008 for five mesh configurations.

Table 5-15. Maximum water velocity color contour plots for HIS ET Storm No. 0038 for five mesh configurations. 
Table 5-16. Maximum water velocity color contour plots for HIS ET Storm No. 0051 for five mesh configurations

Table 5-17. Maximum water velocity color contour plots for HIS ET Storm No. 0054 for five mesh configurations.

Table 5-18. Maximum water velocity color contour plots for HIS TP Storm No. 0001

(Hurricane Sandy 2012) for five mesh configurations.

Table 5-19. Maximum water velocity color contour plots for HIS TP Storm No. 0003

(Hurricane Isabel 2003) for five mesh configurations.

Table 5-20. Maximum water velocity color contour plots for SYN TP Storm No. 0005 for five mesh configurations.

Table 5-21. Maximum water velocity color contour plots for SYN TP Storm No. 0028 for five mesh configurations.

Table 5-22. Maximum water velocity color contour plots for SYN TP Storm 0110 for five mesh configurations.

Table 5-23. Summary of maximum significant wave height (Hs, max) results and dominant wind directions in Dyke Marsh for every storm.

Table 5-24. Maximum significant wave height for HIS ET Storm No. 0001 for five mesh configurations (with and without structures).

Table 5-25. Maximum significant wave height for HIS ET Storm No. 0008 for five mesh configurations.

Table 5-26. Maximum significant wave height color contour plots for HIS ET Storm No. 0038 for five mesh configurations.

Table 5-27. Maximum significant wave height color contour plots for HIS ET Storm No.

0051 for five mesh configurations.

Table 5-28. Maximum significant wave height color contour plots for HIS ET Storm No. 0054 for five mesh configurations.

Table 5-29. Maximum significant wave height color contour plots for HIS TP Storm No. 0001 (Hurricane Sandy 2012) for five mesh configurations.

Table 5-30. Maximum significant wave height color contour plots for HIS TP Storm No. 0003 (Hurricane Isabel 2003) for five mesh configurations.

Table 5-31. Maximum significant wave height color contour plots for SYN TP Storm No.

0005 for five mesh configurations.

Table 5-32. Maximum significant wave height color contour plots for SYN TP Storm No. 0028 for five mesh configurations.

Table 5-33. Maximum significant wave height color contour plots for SYN TP Storm No. 0110 for five mesh configurations.

Table 5-34. Difference (ft) in maximum significant wave height for HIS ET Storm No. 0001 between project and existing conditions (Project - Existing). Note that the plot at right side is a close-up view with a narrow range of scales.

Table 5-35. Difference in maximum significant wave height for HIS ET Storm No. 0008 between project and existing conditions (Project - Existing). Note that the plot at right side is a close-up view with a narrow range of scales.

Table 5-36. Difference in maximum significant wave height for HIS ET Storm No. 0038 between project and existing conditions (Project - Existing). Note that the plot at right side is a close-up view with a narrow range of scales. 
Table 5-37. Difference in maximum significant wave height for HIS ET Storm No. 0051 between project and existing conditions (Project - Existing). Note that the plot at right side is a close-up view with a narrow range of scales.

Table 5-38. Difference in maximum significant wave height for HIS ET Storm No. 0054 between project and existing conditions (Project - Existing). Note that the plot at right side is a close-up view with a narrow range of scales.

Table 5-39. Difference in maximum significant wave height for HIS TP Storm No. 0001 (Sandy 2012) between project and existing conditions (Project - Existing). Note that the plot at right side is a close-up view with a narrow range of scales.

Table 5-40. Difference in maximum significant wave height for HIS TP Storm No. 0003 (Isabel 2003) between project and existing conditions (Project - Existing). Note that the plot at right side is a close-up view with a narrow range of scales.

Table 5-41. Difference in maximum significant wave height for SYN TP Storm No. 0005 between project and existing conditions (Project - Existing). Note that the plot at right side is a close-up view witha narrow range of scales.

Table 5-42. Difference in maximum significant wave height for SYN TP Storm No. 0028 between project and existing conditions (Project - Existing). Note that the plot at right side is a close-up view with a narrow range of scales.

Table 5-43. Difference in maximum significant wave height for SYN TP Storm No. 0110 between project and existing conditions (Project - Existing). Note that the plot at right side is a close-up view with a narrow range of scales.

Table 5-44. Locations and bed elevations of selected stations.

Table 5-45. Time series plots for (a, b) significant wave height, (c, d) water level, and (e, f) wind speed at two selected locations, 674 and 792 for HIS ET Storm No. 0001. Note that wave snap was given once every 30 minutes.

Table 5-46. Time series plots for (a, b) significant wave height, (c, d) water level, and (e, f) wind speed at two selected locations, 674 and 792 for HIS ET Storm No. 0008. Make note of the different ranges on each plot.

Table 5-47. Time series plots for (a, b) significant wave height, (c, d) water level, and (e, f) wind speed at two selected locations, 674 and 792 for HIS TP Storm No. 0001 (Hurricane Sandy 2012). Note that in (c) between snaps 85 and 125, the water levels went dry and are not plotted. Make note of the different ranges on each plot.

Table 5-48. Time series plots for (a, b) significant wave height, (c, d) water level, and (e, f) wind speed at two selected locations, 674 and 792 for HIS TP Storm No. 0003 (Hurricane Isabel 2003).

Table 5-49. Time series plots for (a, b) significant wave height, (c, d) water level, and (e, f) wind speed at two selected locations, 674 and 792 for SYN TP Storm No. 0005.

Table 5-50. Time series plots for (a, b) significant wave height, (c, d) water level, and (e, f) wind speed at two selected locations, 674 and 792 for SYN TP Storm No. 0028.

Table 5-51. Comparison of maximum significant wave heights (Hs, max) for the four promontory installations with Hs, max for the existing conditions (Hurricane Sandy 2012) at 18 station locations. The column DM01E presents the values of Hs, max.

Table 5-52. Hurricane Sandy maximum water level (column DM01E) for the existing conditions grid at 18 station locations along with the difference in maximum water levels between with-project and existing (Project-Existing) conditions.

Table 5-53. Hurricane Sandy maximum water velocity (column DM01E) for the existing conditions grid at 18 station locations along with the difference in maximum water velocity between with-project and existing (Project-Existing) conditions. 
Table 5-54. Hurricane Isabel (2003) maximum significant wave height (column DM01E) for the existing conditions grid at 18 station locations along with the difference in maximum significant wave heights between with-project and existing (Project-Existing) conditions.

Table 5-55. HIS ET Storm No. 0008 (3/11/1952) maximum significant wave height (column DM01E) for the existing conditions grid at 18 station locations along with the difference in maximum significant wave heights between with-project and existing (Project-Existing) conditions.

Table 5-56. HIS ET Storm No. 0008 (3/11/1952) maximum water level (column DM01E) for the existing conditions grid at 18 station locations along with the difference in maximum water levels between with-project and existing (Project-Existing) conditions.

Table 5-57. HIS ET Storm No. 0008 (3/11/1952) maximum water velocity (column $\mathrm{DM} 01 \mathrm{E})$ for the existing conditions grid at 18 station locations along with the difference in maximum water velocity between with-project and existing (Project-Existing) conditions.

Table 5-58. Computational conditions for simulating long-term tidal flows and wind-driven waves.

Table 5-59. Maximum significant wave height values in feet at the 18 locations under spring tides and high river flows.

Table 5-60. Reduction rate of maximum significant wave height at the 18 locations under spring tides and high river flows.

Table 5-61. Maximum significant wave height values in feet at the 18 locations under summer tides and low river flows.

Table 5-62. Reduction rate of maximum significant wave height at the 18 locations under summer tides and low river flows.

Table 5-63. Maximum water surface elevations for HIS ET Storm No. 0001 for four mesh configurations (existing conditions and three groin-only alternatives).

Table 5-64. Difference in maximum water surface elevations for HIS ET Storm No. 0001 for all three with-project groin mesh configurations (Project - Existing).

Table 5-65. Maximum water surface elevations for HIS ET Storm No. 0008 for four mesh configurations.

Table 5-66. Maximum water surface elevations for HIS ET Storm No. 0038 for four mesh configurations.

Table 5-67. Maximum water surface elevations for HIS ET Storm No. 0051 for four mesh configurations.

Table 5-68. Maximum water surface elevations for HIS ET Storm No. 0054 for four mesh configurations.

Table 5-69. Maximum water surface elevations for SYN TP Storm No. 0005 for four mesh configurations.

Table 5-70. Maximum water surface elevations for SYN TP Storm No. 0028 for four mesh configurations.

Table 5-71. Maximum water surface elevations for SYN TP Storm No. 0110 for four mesh configurations.

Table 5-72. Maximum water surface elevations for HIS TP Storm No. 0001 (Hurricane Sandy 2012) for four mesh configurations.

Table 5-73. Maximum water surface elevations for HIS TP Storm No. 0003 (Hurricane Isabel 2003) for four mesh configurations. 
Table 5-74. Maximum water velocity color contour plots for HIS ET Storm No. 0001 for four mesh configurations.

Table 5-75. Difference in maximum water velocity for HIS ET Storm No. 0001 for all three with-project groin-only mesh configurations (Project - Existing). .

Table 5-76. Maximum water velocity color contour plots for HIS ET Storm No. 0008 for four mesh configurations.

Table 5-77. Maximum water velocity color contour plots for HIS ET Storm No. 0038 for four mesh configurations.

Table 5-78. Maximum water velocity color contour plots for HIS ET Storm No. 0051 for four mesh configurations

Table 5-79. Maximum water velocity color contour plots for HIS ET Storm No. 0054 for four mesh configurations

Table 5-80. Maximum water velocity color contour plots for SYN TP Storm No. 0005 for four mesh configurations.

Table 5-81. Maximum water velocity color contour plots for SYN TP Storm No. 0028 for four mesh configurations.

Table 5-82. Maximum water velocity color contour plots for SYN TP Storm No. 0110 for four mesh configurations.

Table 5-83. Maximum water velocity color contour plots for HIS TP Storm No. 0001 (Hurricane Sandy 2012) for four mesh configurations.

Table 5-84. Maximum water velocity color contour plots for HIS TP Storm No. 0003 (Hurricane Isabel 2003) for four mesh configurations.

Table 5-85. Maximum significant wave height (Hs, max) color contour plots for HIS ET

Storm No. 0001 for four mesh configurations.

Table 5-86. Maximum significant wave height (Hs, max) color contour plots for HIS ET Storm No. 0008 for four mesh configurations.

Table 5-87. Maximum significant wave height color contour plots for HIS ET Storm No. 0038 for four mesh configurations.

Table 5-88. Maximum significant wave height color contour plots for HIS ET Storm No. 0051 for four mesh configurations.

Table 5-89. Maximum significant wave height color contour plots for HIS ET Storm No. 0054 for four mesh configurations.

Table 5-90. Maximum significant wave height color contour plots for SYN TP Storm No. 0005 for four mesh configurations.

Table 5-91. Maximum significant wave height color contour plots for SYN TP Storm No. 0028 for four mesh configurations.

Table 5-92. Maximum significant wave height color contour plots for SYN TP Storm No. 0110 for four mesh configurations.

Table 5-93. Maximum significant wave height color contour plots for HIS TP Storm No. 0001 (Hurricane Sandy 2012) for four mesh configurations.

Table 5-94. Maximum significant wave height color contour plots for HIS TP Storm No. 0003 (Hurricane Isabel 2003) for four mesh configurations.

Table 5-95. Difference in maximum significant wave height for SYN TP Storm No. 0005 for all three with-project structure mesh configurations (Project - Existing). Note that the color axis range has been decreased to bring out differences. 
Table 5-96. Difference in maximum significant wave height for SYN TP Storm No. 0028 for all three with-project structure only mesh configurations (Project - Existing). Note that the color axis range has been decreased to bring out differences.

Table 5-97. Difference in maximum significant wave height for SYN TP Storm No. 0110 for all three with-project structure only mesh configurations (Project - Existing). Note that the color axis range has been decreased to bring out differences...

Table 5-98. Difference in maximum significant wave height for HIS ET Storm No. 0001 for all three with-project groin-only mesh configurations (Project - Existing). Note that the color axis range has been decreased to bring out details.

Table 5-99. Difference in maximum significant wave height for HIS ET Storm No. 0008 for all three with-project groin-only mesh configurations (Project - Existing). Note that the color axis range has been decreased to bring out details.

Table 5-100. Difference in maximum significant wave height for HIS ET Storm No. 0038 for all three with-project groin-only mesh configurations (Project - Existing). Note that the color axis range has been decreased to bring out details.

Table 5-101. Difference in maximum significant wave height for HIS ET Storm No. 0051 for all three with-project groin-only mesh configurations (Project - Existing). Note that the color axis range has been decreased to bring out details.

Table 5-102. Difference in maximum significant wave height for HIS ET Storm No. 0054 for all three with-project groin-only mesh configurations (Project - Existing). Note that the color axis range has been decreased to bring out details.

Table 5-103. Difference in maximum significant wave height for HIS TP Storm No. 0001 (Hurricane Sandy 2012) for all three with-project groin-only mesh configurations (Project Existing). Note that the color axis range has been decreased to bring out details...

Table 5-104. Difference in maximum significant wave height for HIS TP Storm No. 0003 (Hurricane Isabel 2003) for all three with-project groin-only mesh configurations (Project Existing). Note that the color axis range has been decreased to bring out details.

Table 5-105. Differences in significant wave heights (ft) for HIS ET Storm No. 0001 at the 18 selected locations among the cases with and without the groins.

Table 5-106. Differences in significant wave heights (ft) for HIS ET Storm No. 0008 at the 18 selected locations among the cases with and without the groins.

Table 5-107. Differences in significant wave heights (ft) for HIS ET Storm No. 0038 at the 18 selected locations among the cases with and without the groins..

Table 5-108. Differences in significant wave heights (ft) for HIS ET Storm No. 0051 at the 18 selected locations among the cases with and without the groins.

Table 5-109. Differences in significant wave heights (ft) for HIS ET Storm No. 0054 at the 18 selected locations among the cases with and without the groins...

Table 5-110. Differences in significant wave heights (ft) for HIS TP Storm No. 0001

(Hurricane Sandy 2012) at the 18 selected locations among the cases with and without the groins.

Table 5-111. Differences in significant wave heights (ft) for HIS TP Storm No. 0003

(Hurricane Isabel 2003) at the 18 selected locations among the cases with and without the groins.

Table 5-112. Differences in significant wave heights (ft) for SYN TP Storm No. 0005 at the 18 selected locations among the cases with and without the groins. 186

Table 5-113. Differences in significant wave heights (ft) for SYN TP Storm No. 0028 at the 18 selected locations among the cases with and without the groins.. 
Table 5-114. Differences in significant wave heights (ft) for SYN TP Storm No. 0110 at the 18 selected locations among the cases with and without the groins. NA means results not available.

Table 5-115. Maximum significant wave height values in feet at the 18 locations under spring tides and high river flow.

Table 5-116. Reduction Rate of maximum significant wave height at the 18 locations under spring tides and high river flow. ..

Table 5-117. Maximum significant wave height values in feet at the 18 locations under summer tides and low river flow.

Table 5-118. Reduction Rate of maximum significant wave height at the 18 locations under summer tides and low river flow. 


\section{Preface}

This study was conducted for the U.S. Army Corps of Engineers, Baltimore District, under Project No. 327615, "Dyke Marsh Hydrodynamic Modeling Project.” The technical monitor was Mr. Daniel Risley.

The work was performed by the Coastal Processes Branch (HFC) of the Flood and Storm Protection Division (CF), U.S. Army Engineer Research and Development Center, Coastal and Hydraulics Laboratory (ERDCCHL). At the time of publication of this report, Ms. Ashley Frey was Chief, CEERD-HF-C; Dr. Cary Talbot was Chief, CEERD-HF; and Dr. Julie Rosati, CEERD-HZT, was the Technical Director for Flood and Coastal Systems Research and Development. The Acting Director of ERDC-CHL was Mr. Jeffrey Eckstein, and the Acting Deputy Director was Mr. John T. Tucker III.

COL Ivan P. Beckman was the Commander of ERDC, and Dr. David W. Pittman was the Director. 


\section{Unit Conversion Factors}

\begin{tabular}{|l|l|l|}
\hline Multiply & By & To Obtain \\
\hline cubic feet & 0.02831685 & cubic meters \\
\hline degrees (angle) & 0.01745329 & radians \\
\hline feet & 0.3048 & meters \\
\hline inches & 0.0254 & meters \\
\hline miles per hour & 0.44704 & meters per second \\
\hline square feet & 0.09290304 & square meters \\
\hline
\end{tabular}




\section{Introduction}

\subsection{Background}

The National Park Service (NPS) is sponsoring the U.S. Army Corps of Engineers (USACE), Baltimore District (NAB), to evaluate seven alternative with-project conditions intended to partially restore Dyke Marsh to pre-1940s/1950s conditions and prevent further loss of marsh. Dyke Marsh is located between Mount Vernon, VA, and Alexandria, VA, on the Potomac River. Historically, there was a natural promontory structure located at Dyke Marsh, but in the 1940s/1950s, it was mined for gravels and sands. Since that time, the adjacent wetland areas have been degrading. The intent of the NPS project is (1) to rebuild a promontory structure that protects the existing wetlands from further degradation and (2) to investigate the potential to expand the wetland area and associated protective measures identified in the seven alternatives. Figure 1-1 shows a diagram map of Dyke Marsh and concept renderings of potential withproject alternatives.

To evaluate the alternatives, the hydrodynamic modeling needed to include a riverine and coastal component along with a wave fetch analysis as major storms have been known to propagate up the Potomac to this location. Existing model results from a Finite Element Surface Water Modeling System (FESWMS) (Froehlich 1989; FESWMS 2017) application that was available to the NAB is now defunct and only considered the riverine and coastal cases without wave fetch. However, the FESWMS model data were used as reference information. The only wave fetch analysis available to NAB was conducted by the U.S. Geological Survey (USGS) in Open File Report 2010-1269 (Litwin et al. 2011), which utilized the fetch net analysis equations in a desktop study but without any numerical modeling. The North Atlantic Coast Comprehensive Study (NACCS) numerical modeling (Cialone et al. 2015) data set produced by the U.S. Army Engineer Research and Development Center, Coastal and Hydraulics Laboratory, included the Dyke Marsh study area. Three save point locations from the NACCS study are within the immediate Dyke Marsh project area. The NACCS statistical data at those locations were used to provide return periods of storm surge water level and significant wave height that were used in the selection of the storm conditions used to perform the present numerical study. 
Figure 1-1. Diagram map showing Dyke Marsh and concept renderings of possible project alternatives. The portion in red represents the remainder of the historic promontory, called Hog Island, while Dyke Island is colored blue.

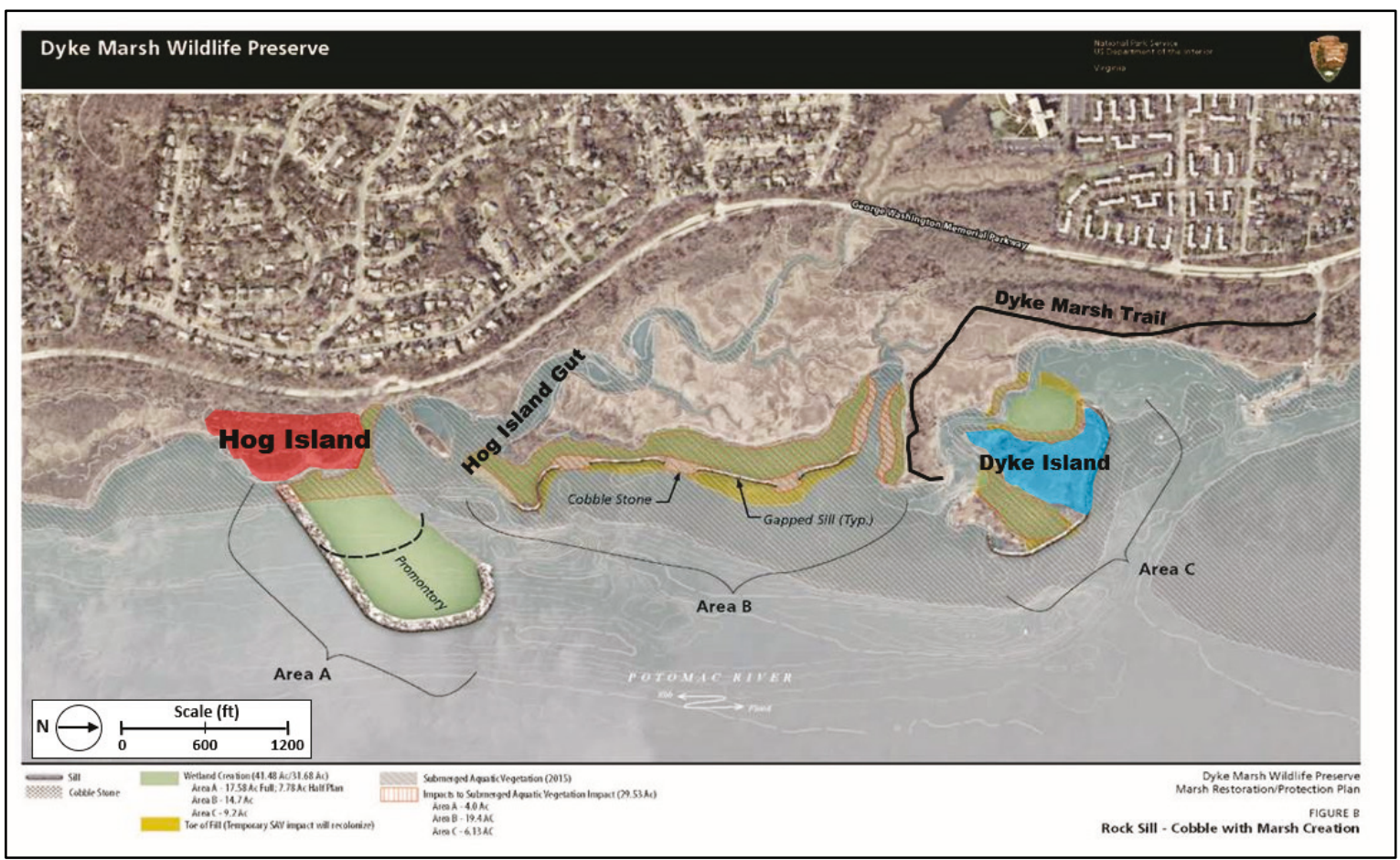

The following study objectives that pertain to the CHL statement of work were extracted from the overall project management plan and Inter Agency Agreement between the USACE and the NPS. The overall goal of the project is to restore the tidal freshwater marsh and other associated wetland habitats that have been lost or impacted in the Dyke Marsh Wildlife Preserve on the Potomac River in Virginia. The NPS project will reconstruct and protect the productive emergent wetlands that were dredged or lost due to erosion. The NPS project also seeks to maintain the integrity and health of the existing marsh. Once completed, restoration will allow the dynamic tidal freshwater Dyke Marsh Preserve to function, provide ecosystem services and wildlife habitat, and offer recreation opportunities.

The involvement of the USACE to provide this assistance is authorized by Section 86(a) of the Water Resources Development Act of 1974 (P.L. 93251), and Section 5147 of the Water Resources Development Act of 2007 (P.L. 110-114).

Present-day erosion rates at Dyke Marsh Preserve are estimated to be 1.5 to 2 acres per year (Litwin et al. 2013). Wave action from northerly directed storms is currently eroding the marsh shoreline westward 6 to 8 feet (ft) per year (Litwin et al. 2013). Also, had Hurricane Sandy hit the 
Washington, DC, metropolitan area more directly, it likely would have caused devastating erosion to the entire marsh area and shoreline, placing the overall sustainability of the marsh at risk.

The project design is intended to ensure the stability of the remaining 50 acres of emergent marsh within Dyke Marsh Preserve and create emergent wetlands within its historic boundaries, giving the marsh resiliency against high storm surge and tidal events, thus protecting adjacent park and private real estate interests.

\subsection{Project objectives}

The two primary objectives are to (1) re-establish hydrologic conditions that would protect Hog Island Gut (see Figure 1-1) and (2) redirect erosive flows through the establishment of a breakwater/groin. The marsh would be restored to the historic marsh boundary in a phased approach (including other adjacent areas within NPS jurisdictional boundaries) with the exception of the area immediately around the marina west of Dyke Island (Figure 1-1). Phased restoration would continue until a sustainable marsh is established and meets the overall goals of the project. The historic boundaries lie between the historic promontory and Dyke Island, the triangular island off the end of the Dyke Marsh Trail (Figure 1-1). The outer edges of the containment cell structures would be placed close to the existing shoreline along the Potomac River.

\subsection{Study approaches}

The Coastal Storm Modeling System (CSTORM-MS) (Massey et al. 2012; Cialone et al. 2015) was used for simulating hydrodynamic variables such as waves, water surface elevations (surges and tides), and currents in the project area (Dyke Marsh including extended computational domain as shown in Figure 1-2). The CSTORM-MS is an integrated numerical simulation system including a suite of high-fidelity storm modeling tools that include the deep water wave model known as WAM (Komen et al. 1994), a circulation and surge model known as ADCIRC (Luettich et al. 1992; Westerink et al. 2008), and a nearshore wave model known as STWAVE (Smith et al. 2001; Smith, 2007; Massey et al. 2011). The CSTORM system allows for ADCIRC and STWAVE to run in coupled model so that each model supplies information to the other during runtime. The CSTORM system as a whole supports a wide range of coastal engineering needs for simulating tropical and extratropical storms, wind, wave, and water levels. 
Figure 1-2. Existing NACCS ADCIRC mesh color contours of topography and bathymetry for Potomac River and close-up view around Dyke Marsh. The black dots are the save points used in the NACCS study (Coastal Hazard System [CHS] save points).

(a) Computational domain boundaries and topo-bathymetry for the Potomac River.

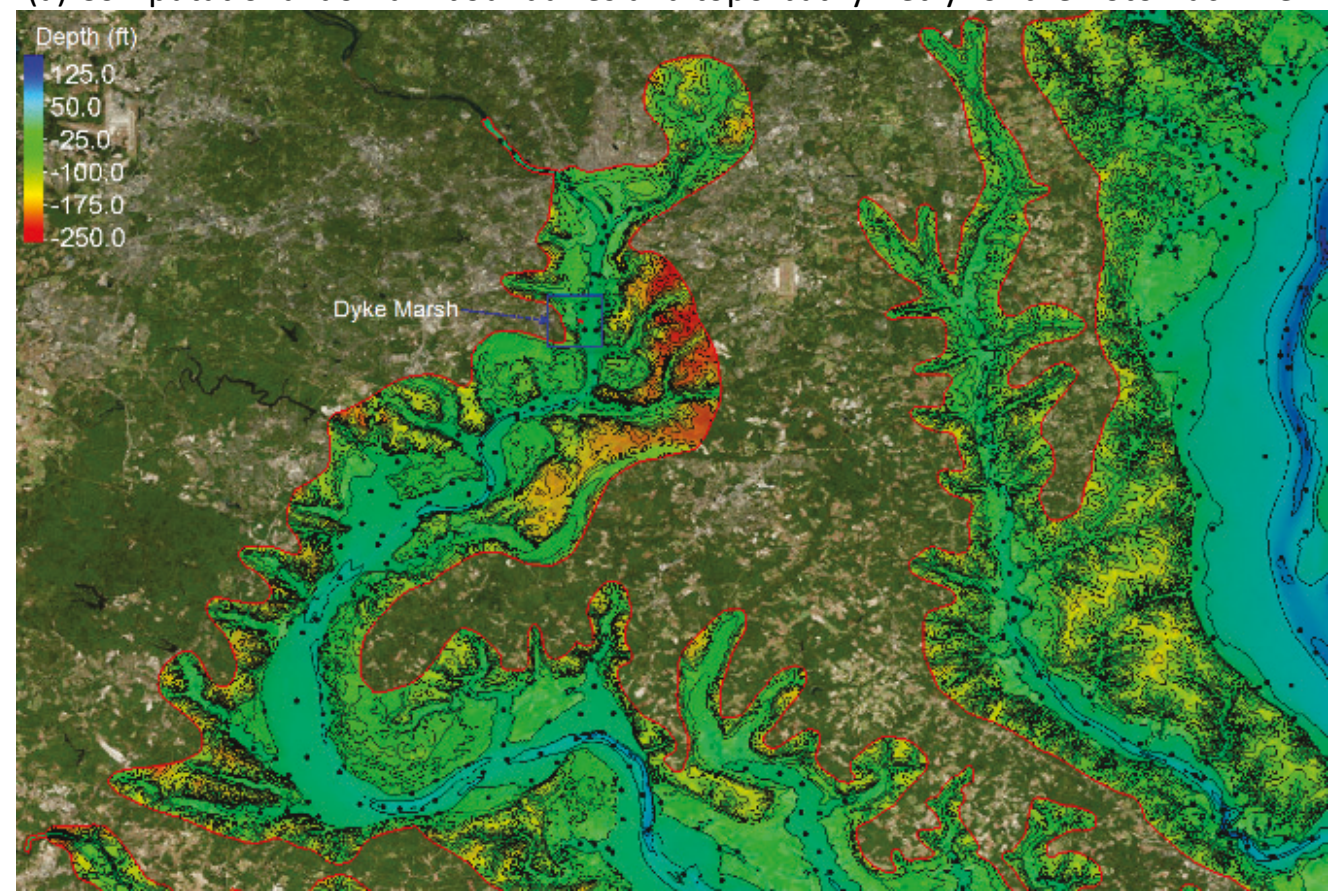

Note: Black dots indicate CHS save points.

(b) Bathymetry around Dyke Marsh.

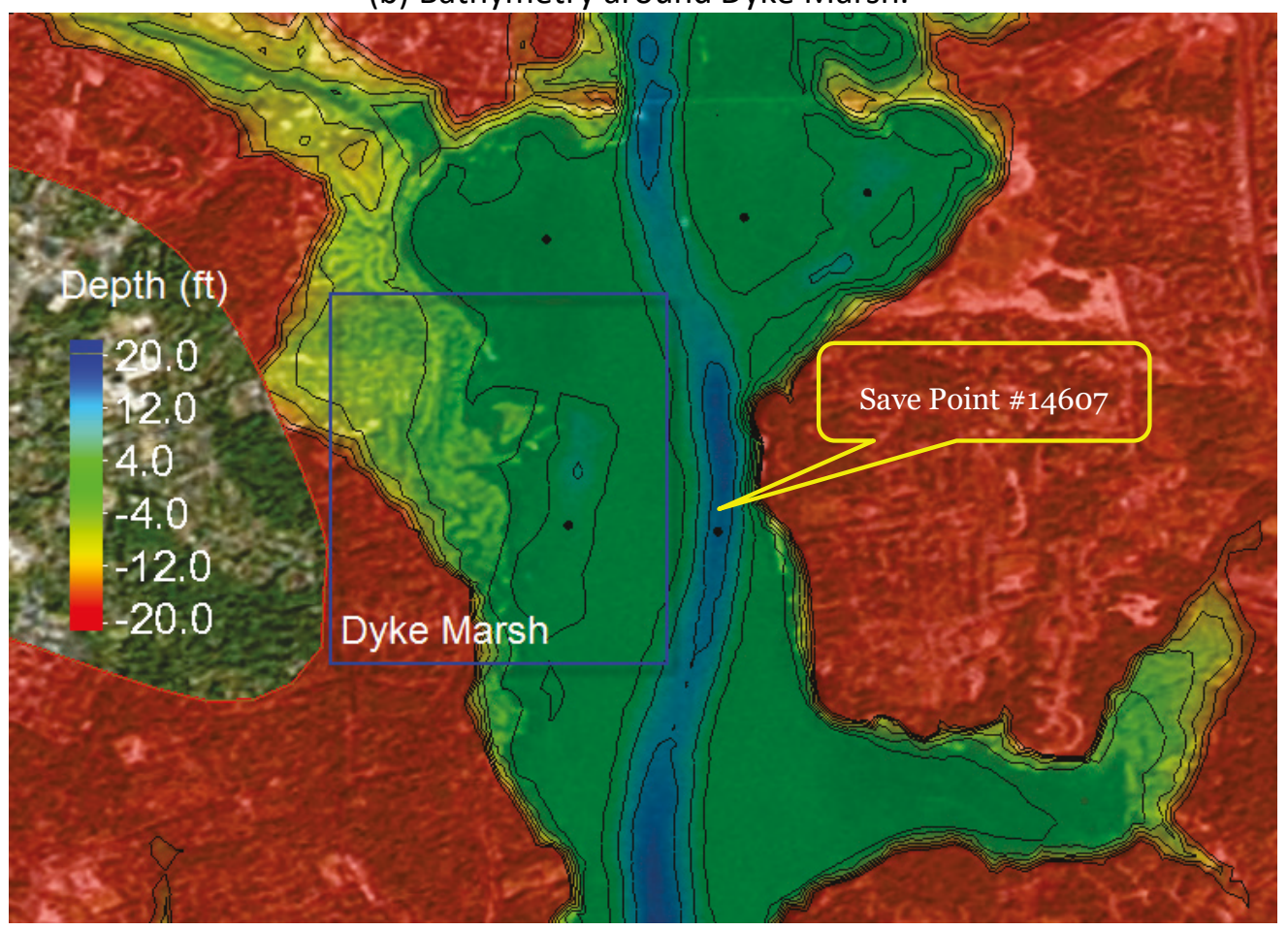


The overall objective of this numerical modeling study is to provide hydrodynamic responses to the existing condition (without-project) and seven alternative with-project conditions that can be used to evaluate potential improvements in hydrodynamic conditions. Of particular importance was determining the magnitude of wave heights and water velocity changes in the marsh areas, as well as any changes to water velocities on the eastern shore of the Potomac River.

The waves and water levels in the present condition (without-project) for this study were initially obtained from the Coastal Hazards System (CHS) (Nadal-Caraballo et al. 2015), a database of storm and water response, and constitute the responses from a collection of synthetic tropical (SYN TP) and historical extratropical (HIS ET) CSTORM storms modeled for the NACCS that span practical probability space. Response statistics included in the CHS are the peak water level and peak wave height, the associated wave period and direction, and mean annual recurrence intervals along with epistemic uncertainty characterized with various confidence levels. Figure 1-2 shows the topography/bathymetry color contours from the NACCS ADCIRC mesh (Cialone et al. 2015) along with the save point locations where CHS data are available, referred to as CHS save points.

For this study, the NACCS ADCIRC mesh and STWAVE grid both needed to be refined to analyze the project level alternatives. The NACCS ADCIRC mesh resolution in the Dyke Marsh area (see Figure 1-3) is approximately 164 to 328 feet (ft), and the STWAVE grid has a $328 \mathrm{ft}$ cell resolution. To represent the with-project alternatives, the existing ADCIRC mesh was refined for the Dyke Marsh region to an element spacing of approximately $16 \mathrm{ft}$ in some locations. Similarly, the STWAVE grid spacing was refined to a cell spacing of approximately 16 to $33 \mathrm{ft}$. A second nested STWAVE domain was required due to increased computational demands from the ADCIRC elemental spacing reduction to $16 \mathrm{ft}$. Once the base without-project mesh and grids were adequately refined, they were used to generate seven additional with-project condition meshes/grids. Care was taken to ensure that the base mesh had enough resolution to represent the seven alternative with-project designs (i.e., four full promontory alternatives and three groins) so that differences between the without-project and with-project meshes are minimized. In this way, when the differences in the hydrodynamic model results are computed, there will be more certainty that the differences are due to inclusion of the project design and not significantly influenced by changes in mesh resolution. 
Figure 1-3. Existing NACCS ADCIRC mesh for the Potomac River, with Dyke Marsh region indicated in detail on right. The USGS hydrologic station No. 1646500 is shown in the figure.

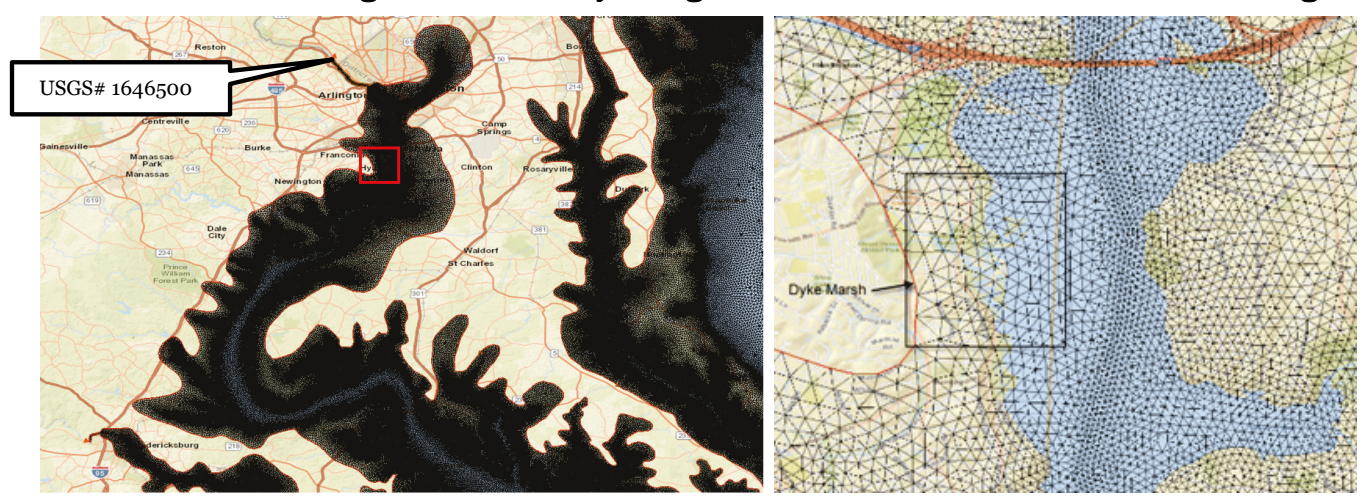

A set of six proxy SYN TP storms that directly impact the Dyke Marsh area from the NACCS study were selected to represent the 10-, 15-, 25-, 50-, 100-, and 200-year return period values for peak water levels and wave heights that do not necessarily occur in the same storm events. In addition, five HIS ET and two historical tropical (HIS TP) storms from the NACCS study that significantly impact the Dyke Marsh area were also used as proxy storms. The CSTORM-MS was used to tightly couple the ADCIRC and STWAVE simulations. In addition to the 13 proxy storms, two nonstorm event scenarios (tide and rivers flow only) were considered based on two selected tide periods, one for a spring tide and the other for a neap tide. These non-storm event simulations were for a 1-month simulation period and included Potomac River discharges as well. The flow rate for the river was set in consultation with NAB to represent typical flow conditions and is discussed in more detail in Section 5.1.7. Initially, the 2-month-long tide/river simulations were performed without wind forcing and thus did not have wave forcing. However, wind wave-induced erosion of the marsh area resulting from winds from the north, north-east, east, south, south-west, and south-east (directions with the greatest fetch lengths) required investigation. Six sets of idealized wind fields, oriented in these six compass directions, were created and used as additional forcing conditions for the tides/river forcing simulations mentioned above so that the effect of typical waves could be examined. Having considered 13 proxy storms and eight non-storm events (two long-term tide periods along with six steady uniform winds), in total over 162 simulations were made (65 runs for proxy storms, 1 for long-term tide, and 96 for combined conditions of steady wind, tide, and river flow). A total of nine ADCIRC grids were generated: two base (existing condition) grids with different resolutions, four full promontory alternatives, and three groin-only alternatives. Analysis of hydrodynamic conditions for these forcing 
scenarios were performed, and differences between the base withoutproject and the seven alternative with-project condition peak water level envelopes, circulation patterns, wave conditions were quantified. 


\section{Storm Selections}

A subset of storms from the NACCS (Cialone et al. 2015) were selected for use in evaluating the project alternatives in this study. This included two HIS TP events: Hurricane Isabel, which occurred in 2003 (HIS TP Storm No. 0003), and Hurricane Sandy (HIS TP Storm No. 0001), which occurred in 2012. Storm tracks for these two events are shown in Figure 2-1. These HIS TP storms were selected because Isabel was a major storm that impacted this area and generated northerly erosive waves at Dyke Marsh (Litwin et al. 2013), and Sandy was a recent storm that caused southerly waves at the project site. In addition, a set of six SYN TP cyclones were selected for simulation from the set of 1050 synthetic storms from the NACCS. These six SYN TP events were selected based on average recurrence interval (ARI) analysis for the Dyke Marsh project site to be surrogate storms that produced the 5-, 10-, 20-, 50-, 100-, and 200-year return period values of storm surges and significant wave heights (Table 2-1). Note that the same storms do not necessarily produce the ARI for both surge and waves. In the table, both the mean and the $90 \%$ confidence limit (CL) values are presented for each return period. The SYN TP storms selected were storm numbers 0005, 0146, 0028, 0078, 0110, and 0144 representing the $5^{-}, 10^{-}, 20-$, 50-, 100-, and 200-year ARI, respectively (Figure 2-2). Two of these storms (0144 and 0146) have identical tracks but different forward speeds. Storms were segregated into three spatial regions (Regions 1-3) and by landfalling and bypassing criterion (see Cialone et al. [2015] for further details). In addition to the tropical cyclone storms, five HIS ET storms from the 100 ET storms simulated in the NACCS were also selected to be surrogate events for the Dyke Marsh area based on significant wave heights. The HIS ET storms in general produce lower surge and wave heights in the Dyke Marsh area than the 5-year mean ARI for significant wave heights. Each of the ET storms were placed into one of five binned bands (Table 2-2) based on their simulated significant wave height at NACCS save point location $14607\left(77.033^{\circ} \mathrm{W}, 38.76463^{\circ} \mathrm{N}\right.$ ) (as shown in Figure 1-2(b)) near Dyke Marsh. All the selected HIS, ET, and SYN storms for the present study are listed in Table 2-3. 
Figure 2-1. Hurricane tracks of Isabel (2003) and Sandy (2012).

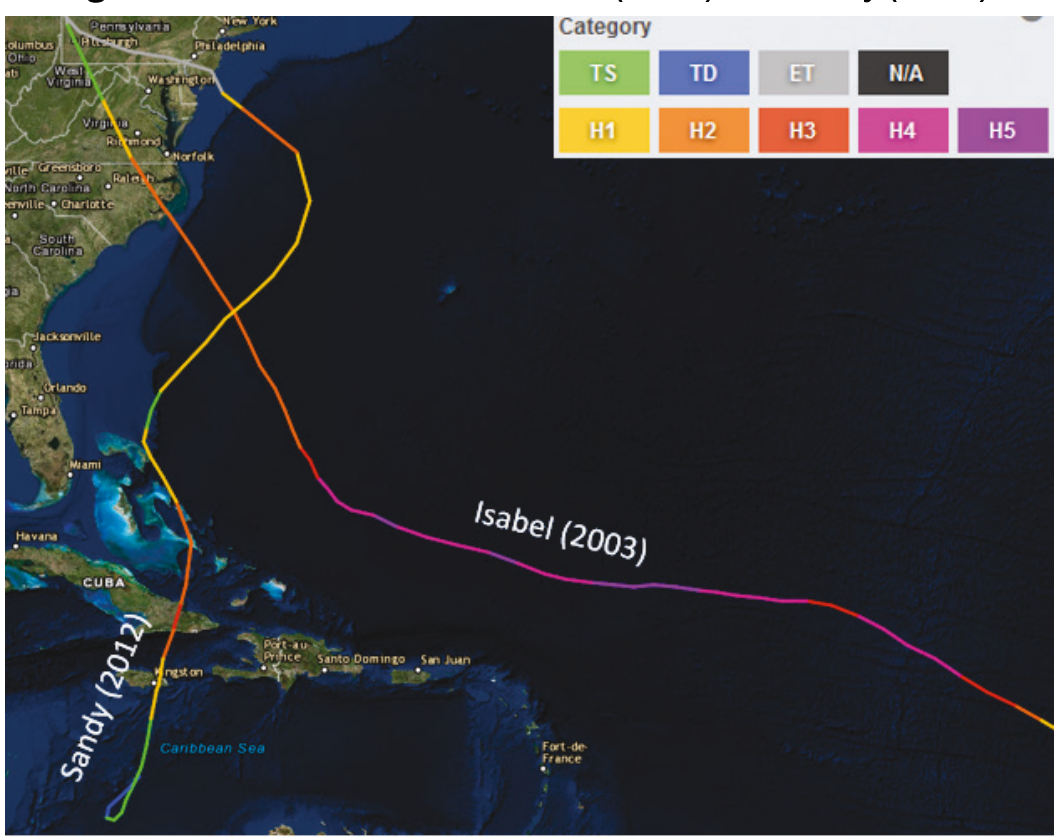

Table 2-1. ARI values for surge and significant wave height (Hs) at NACCS Save Point 14607.

\begin{tabular}{|l|l|l|l|l|}
\hline Years & Mean Surge (ft) & $\begin{array}{c}90 \% \text { CL Surge } \\
(\mathrm{ft})\end{array}$ & Mean Hs (ft) & $\begin{array}{c}90 \% \text { CL Hs } \\
(\mathrm{ft})\end{array}$ \\
\hline 1 & 2.0 & 4.7 & 2.1 & 6.2 \\
\hline 2 & 2.7 & 5.2 & 2.4 & 6.6 \\
\hline 5 & 3.7 & 6.0 & 2.7 & 6.9 \\
\hline 10 & 4.4 & 6.7 & 2.9 & 7.0 \\
\hline 20 & 5.2 & 7.6 & 3.1 & 7.2 \\
\hline 50 & 6.2 & 9.0 & 3.3 & 7.4 \\
\hline 100 & 7.2 & 10.2 & 3.5 & 7.6 \\
\hline 200 & 8.5 & 11.5 & 3.7 & 7.8 \\
\hline 500 & 10.3 & 13.3 & 4.0 & 8.1 \\
\hline 1000 & 11.6 & 14.7 & 4.2 & 8.4 \\
\hline 2000 & 12.9 & 16.0 & 4.5 & 8.6 \\
\hline 5000 & 14.4 & 17.5 & 4.8 & 9.0 \\
\hline 10000 & 15.3 & 18.4 & 5.1 & 9.3 \\
\hline
\end{tabular}

Note: $\mathrm{CL}=$ confidence limit 
Table 2-2. Significant wave height statistics at NACCS station 14607 for the HIS ET storms.

\begin{tabular}{|l|c|c|c|c|c|}
\hline Bin Range (ft) & {$[0.0,0.66)$} & {$[0.66,0.98)$} & {$[0.98,1,31)$} & {$[1.31,1.64)$} & {$[1.64,2.3]$} \\
\hline Mean (ft) & 0.52 & 0.80 & 1.08 & 1.41 & 1.77 \\
\hline Minimum (ft) & 0.33 & 0.66 & 0.99 & 1.32 & 1.67 \\
\hline Maximum (ft) & 0.65 & 0.98 & 1.18 & 1.49 & 1.88 \\
\hline Selected Storm & 0038 & 0054 & 0051 & 0001 & 0008 \\
\hline Storm Date & $04 / 26 / 1978$ & $01 / 23 / 1987$ & $02 / 13 / 1985$ & $01 / 25 / 1938$ & $03 / 11 / 1952$ \\
\hline
\end{tabular}

Table 2-3. Selected HIS storms and SYN storms (abbreviations defined beneath last row of table).

\begin{tabular}{|l|l|l|l|}
\hline Storm Type & Year/Month & Storm Name & Storm No. \\
\hline Tropical & $2012 / 09$ & Sandy & HIS TP-0001 \\
\hline Tropical & $2003 / 07$ & Isabel & HIS TP-0003 \\
\hline Extratropical & $1938 / 01$ & ET-0001 & HIS ET-0001 \\
\hline Extratropical & $1952 / 03$ & ET-0008 & HIS ET-0008 \\
\hline Extratropical & $1978 / 04$ & ET-0038 & HIS ET-0038 \\
\hline Extratropical & $1985 / 02$ & ET-0051 & HIS ET-0051 \\
\hline Extratropical & $1987 / 01$ & ET-0054 & HIS ET-0054 \\
\hline Synthetic & N/A & SYN-TP-0005 & SYN TP-0005 \\
\hline Synthetic & N/A & SYN-TP-0028 & SYN TP-0028 \\
\hline Synthetic & N/A & SYN-TP-0078 & SYN TP-0078 \\
\hline Synthetic & N/A & SYN-TP-0110 & SYN TP-0110 \\
\hline Synthetic & N/A & SYN-TP-0144 & SYN TP-0144 \\
\hline Synthetic & N/A & SYN-TP-0146 & SYN TP-0146 \\
\hline
\end{tabular}

HIS ET = historical extra-tropical storm HIS TP $=$ historical tropical storm (hurricane) SYN TP = synthetic tropical storm 
Figure 2-2. Storm tracks for the six SYN TP storms selected as surrogate storms for the 5-, 10, 20-, 50-, 100-, and 200-year ARI.

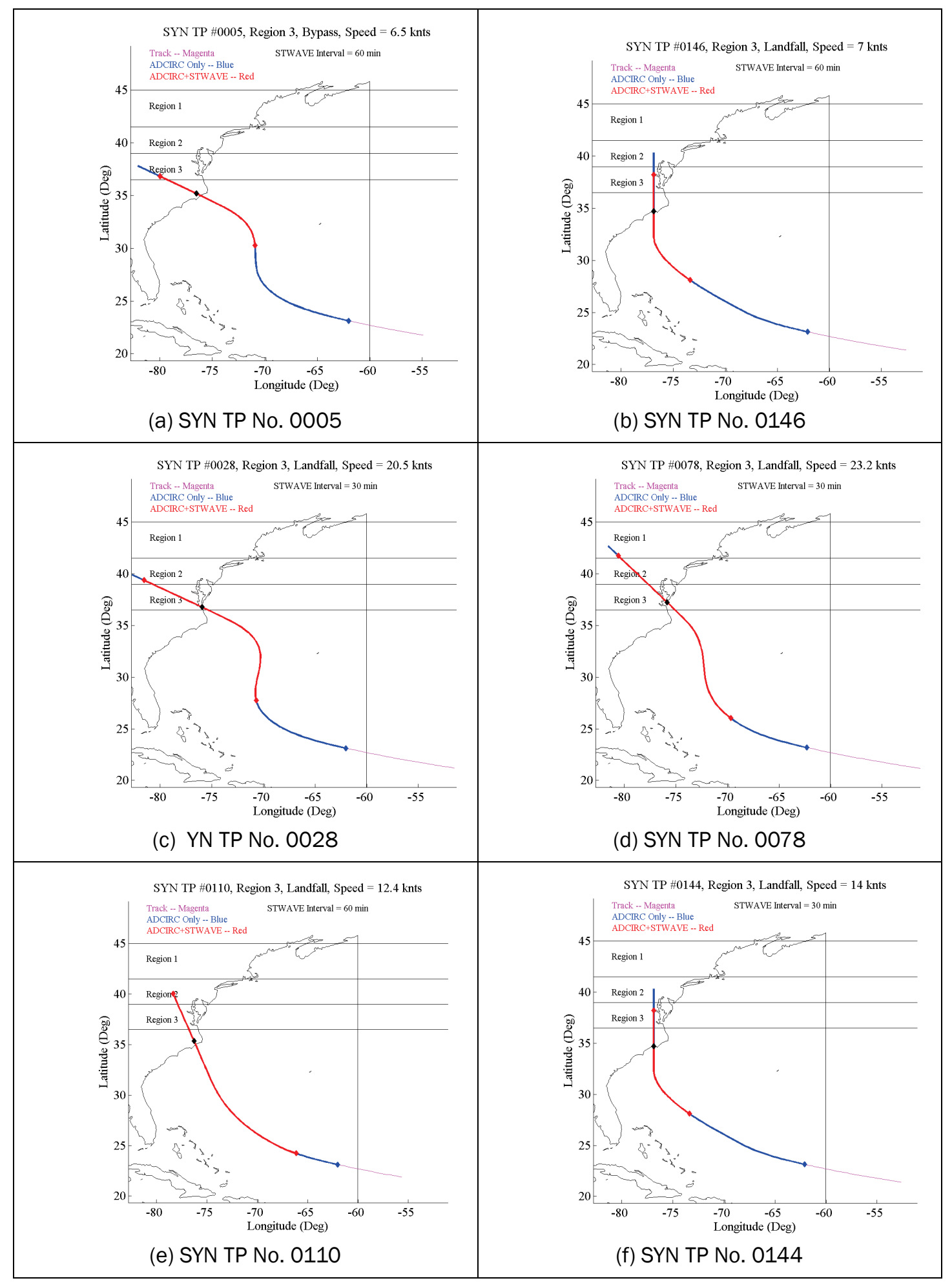




\section{Coastal Storm Modeling System (CSTORM-MS)}

The CSTORM-MS (Massey et al. 2012; Cialone et al. 2015) is a comprehensive methodology and system of highly skilled and highly resolved numerical models used to simulate coastal storms. Analysis of CSTORM-MS model results can be used to assess flood damage risk to coastal communities. With physics-based modeling capabilities, CSTORMMS integrates a suite of high-fidelity storm modeling tools that can support a wide range of coastal engineering needs for simulating TP and ET storms, wind, wave, and water levels and for representing the coastal response, including erosion, breaching, and accretion due to the storms. CSTORM-MS rigorously represents the underlying physical processes involved in coastal storm modeling and makes use of a powerful and user-friendly graphical user interface (GUI) within the Surface Water Modeling System (SMS). The CSTORM-MS GUIs within SMS allow for efficient configuration of models that are generally applicable to a wide range of modeling scenarios and are required for accurate risk assessment of coastal storms. For the NACCS numerical modeling study, the primary modeling emphasis was to produce wind, surge, and wave frequencies in the coastal zone. Accordingly, the CSTORM-MS was applied with the following models:

- Steady-state Spectral Wave (STWAVE) model (Smith et al. 2001; Smith 2007; Massey et al. 2011) to provide the nearshore wave conditions including local wind-generated waves.

- Advance Circulation (ADCIRC) model (Luettich et al. 1992; Westerink et al. 2008) to simulate the surge and circulation response to the storms. The ADCIRC and STWAVE models were applied in a tightly coupled mode using the CSTORM-MS coupling framework.

- Wave Model (WAM) (Komen et al. 1994) for producing offshore deepwater wave boundary conditions for the nearshore steady-state wave model STWAVE.

Note that for the Dyke Marsh study, WAM was not used as only two STWAVE domains were used, neither of which connected to the open ocean and did not use boundary conditions. Additional details of the STWAVE grids is provided later in the report. The CSTORM-MS coupling framework options used for the Dyke Marsh study are the same as those used in the NACCS numerical modeling study, which tightly linked the 
ADCIRC and STWAVE models to allow for dynamic interaction between surge and waves. The ADCIRC model provided the STWAVE model with updated water surface elevations along with wind fields, and in turn, the STWAVE model provided ADCIRC with gradients of wave radiation stresses. The execution of each model and the interchange of information between the models were controlled by the CSTORM-MS coupling framework. This type of coupling system is referred to as being tightly coupled, meaning the information exchange between models takes place via computer memory to allow for fast and efficient sharing of information. In addition, ADCIRC and STWAVE can each produce a file record of the input conditions that were supplied to them by the coupler, which is useful for quality control purposes. 


\section{ADCIRC Mesh and STWAVE Grid Development}

\subsection{Configurations of proposed structures}

There were two types of project structures proposed for comparative analysis of hydrodynamic conditions in the study area of Dyke Marsh: (1) a fully enclosed promontory and (2) a groin (or breakwater) only. This chapter will describe the details of the project alternatives and the methods of incorporating the features into the ADCIRC and STWAVE model domains.

Each of the four fully enclosed promontory designs contains a hookshaped structure along with an enclosing sill along the northern portion of the promontory. The northern sills are lower crested than the rest of the structure. Figure 4-1 shows two layouts of the fully enclosed promontory designs: a longer promontory as in Figure 4-1(a) and a shorter one as in Figure 4-1(b). A brief summary on the design parameters that includes crest elevations, lengths, sill heights, and structure layouts (shapefile information) is given in Table 4-1. In particular, for the fully enclosed promontories, two groin crest heights were investigated, one with a crest elevation of $5.00 \mathrm{ft}$ above mean low water (MLW) and the second with a higher crest elevation of $9.55 \mathrm{ft}$ above MLW. Regardless of the groin crest elevations for the fully enclosed promontory designs, the northern sill height was kept at $3.00 \mathrm{ft}$ above MLW. As a result, a total of four fully enclosed promontory layouts were used for the with-project simulations.

The second type of structure studied was a groin, which has a simpler shape to implement in the model than compared to the full promontory designs. Three layouts for the groin-only designs were used in the study. As shown in Figure 4-2, two linear groins with different orientations relative to the shoreline and one curved groin were used for studying their potential ability to alter the hydrodynamics in the wetland of the Dyke Marsh due to storm surge and waves. Detailed design parameters for the groin-only designs are listed in Table 4-2. It can be seen that the length of the groin-only designs are close to the axis length of the longer fully enclosed promontory designs, but the crest is kept at $5.00 \mathrm{ft}$ above MLW for the entire length of the structure. Accordingly, the groin-only designs may provide a similarly sized area of reduced waves to the wetland in the lee of the structure as the full promontory design. 
For this study, a total of seven proposed design structure layouts were modeled in addition to the existing conditions (without-project) case.

Table 4-1. Properties of proposed promontories.

\begin{tabular}{|c|c|c|c|c|c|c|}
\hline No. & Description & $\begin{array}{l}\text { Crest Elevation } \\
\text { above MLW (ft) }\end{array}$ & $\begin{array}{l}\text { Axis } \\
\text { Length } \\
\text { (ft)* }\end{array}$ & Layout & $\begin{array}{c}\text { ADCIRC } \\
\text { Grid Name }\end{array}$ & $\begin{array}{l}\text { Shape File Name** and } \\
\text { Structure Property }\end{array}$ \\
\hline 1 & $\begin{array}{l}\text { Existing condition } \\
\text { (no structure } \\
\text { installed) }\end{array}$ & N/A & N/A & N/A & DM01E & No Structure \\
\hline 2 & $\begin{array}{l}\text { Longer } \\
\text { promontory with } \\
\text { lower crest } \\
\text { elevation }\end{array}$ & $\begin{array}{l}5.00 \text { groin and } \\
3.00 \text { low sill }\end{array}$ & 1,602 & $\begin{array}{l}\text { Figure } \\
4-1(a)\end{array}$ & DM01P1 & $\begin{array}{l}\text { DykeMarsh Breakwater } \\
\text { 5_OOMLW DykeMarsh Sill } \\
\text { 3_00MLW }\end{array}$ \\
\hline 3 & $\begin{array}{l}\text { Longer } \\
\text { promontory with } \\
\text { higher crest } \\
\text { elevation }\end{array}$ & $\begin{array}{l}9.55 \text { groin and } \\
3.00 \text { low sill }\end{array}$ & 1,602 & $\begin{array}{l}\text { Figure } \\
4-1(a)\end{array}$ & DM01P2 & $\begin{array}{l}\text { DykeMarsh Breakwater } \\
\text { 9_55MLW DykeMarsh Sill } \\
\text { 3_00MLW }\end{array}$ \\
\hline 4 & $\begin{array}{l}\text { Shorter } \\
\text { promontory with } \\
\text { lower crest } \\
\text { elevation }\end{array}$ & $\begin{array}{l}5.00 \text { groin and } \\
3.00 \text { low sill }\end{array}$ & 960 & $\begin{array}{l}\text { Figure } \\
4-1(b)\end{array}$ & DM01P3 & $\begin{array}{l}\text { DykeMarsh Short Breakwater } \\
\text { 9_55MLW } \\
\text { DykeMarsh ShortSill 3_00MLW }\end{array}$ \\
\hline 5 & $\begin{array}{l}\text { Shorter } \\
\text { promontory with } \\
\text { higher crest } \\
\text { elevation }\end{array}$ & $\begin{array}{l}9.55 \text { groin and } \\
3.00 \text { low sill }\end{array}$ & 960 & $\begin{array}{l}\text { Figure } \\
4-1(b)\end{array}$ & DM01P4 & $\begin{array}{l}\text { DykeMarsh Short Breakwater } \\
\text { 9_55MLW } \\
\text { DykeMarsh ShortSill 3_00MLW }\end{array}$ \\
\hline
\end{tabular}

Note:

* The length was measured from the river bank to the tip of structures based on shape files by ArcMap.

** The shapefiles of promontory layouts were provided by USACE-NAB.. 
Figure 4-1. Layouts of proposed promontories (sills in yellow; groins in green/blue).

(a) Long promontory.

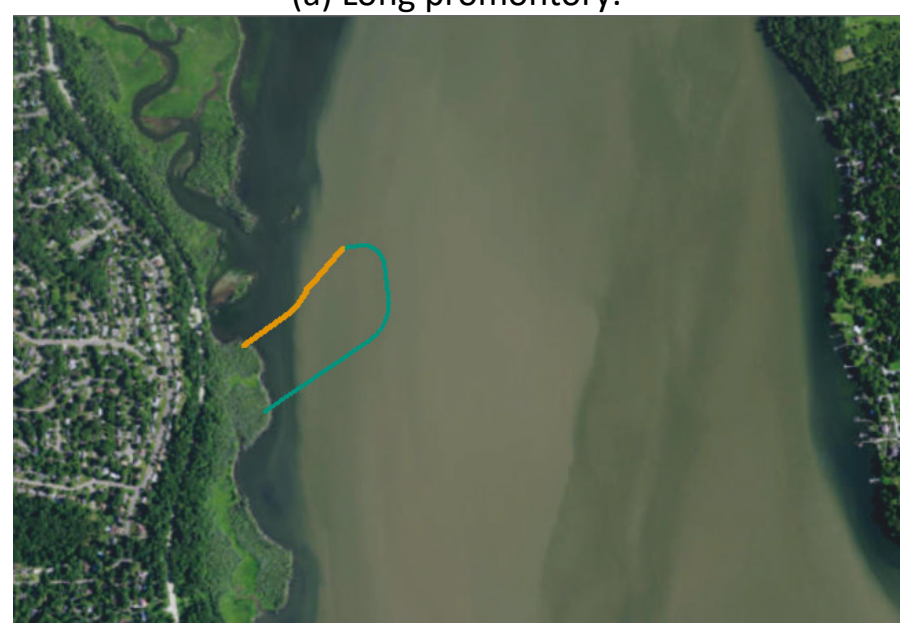

(b) Short promontory.

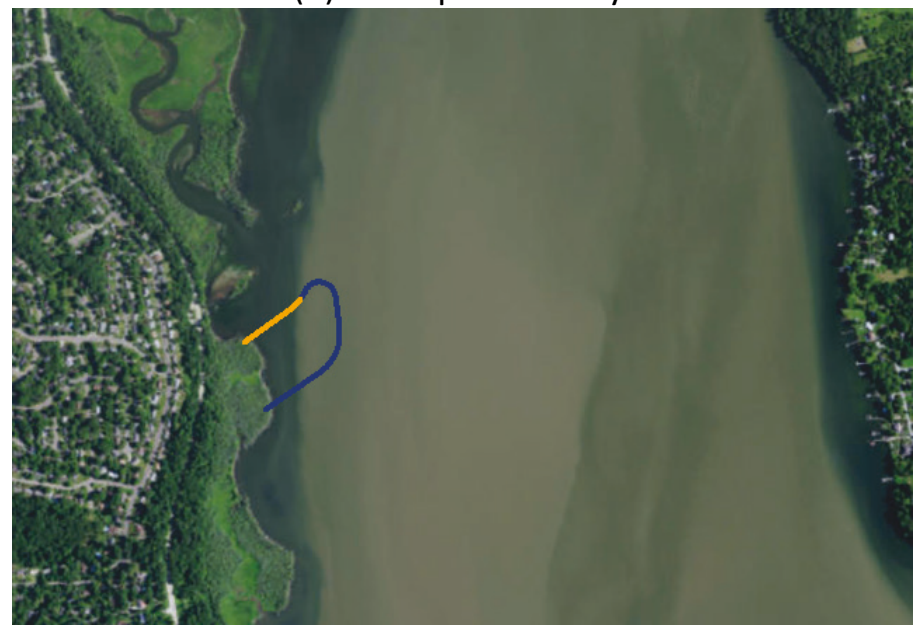

(c) Comparison of two promontory layouts.

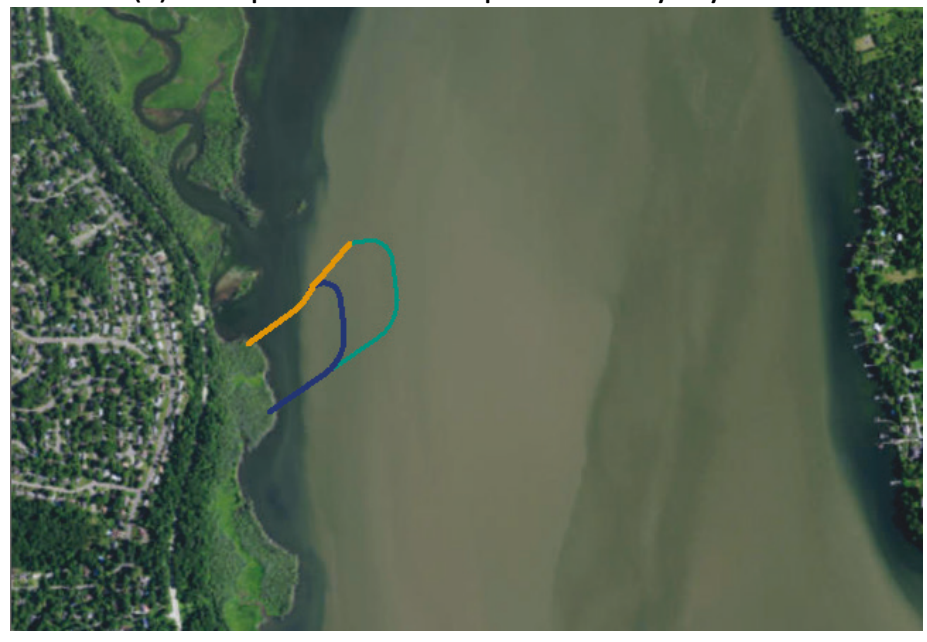


Table 4-2. Properties of proposed groins.

\begin{tabular}{|l|l|l|l|l|l|l|}
\hline No. & $\begin{array}{l}\text { Structure } \\
\text { Name* }\end{array}$ & $\begin{array}{l}\text { Crest Elevation } \\
\text { above MLW (ft) }\end{array}$ & $\begin{array}{l}\text { Groin } \\
\text { Length** } \\
\text { (ft) }\end{array}$ & Layout & $\begin{array}{l}\text { ADCIRC Grid } \\
\text { Name }\end{array}$ & $\begin{array}{l}\text { Shape File Name Structure } \\
\text { Property }\end{array}$ \\
\hline 6 & Groin Alt 1 & 5.00 & 1,500 & $\begin{array}{l}\text { Figure 4-2 } \\
\text { (a) }\end{array}$ & DM01P6 & $\begin{array}{l}\text { Breakwater Alt 1_50 } \\
\text { degrees }\end{array}$ \\
\hline 7 & $\begin{array}{l}\text { Groin Alt 2 } \\
\text { (curved) }\end{array}$ & 5.00 & 1,528 & $\begin{array}{l}\text { Figure 4-2 } \\
\text { (b) }\end{array}$ & DM01P7 & Breakwater Alt 2_curved \\
\hline 8 & Groin Alt 3 & 5.00 & 1,570 & $\begin{array}{l}\text { Figure 4-2 } \\
\text { (c) }\end{array}$ & DM01P8 & $\begin{array}{l}\text { Breakwater Alt 3_75 } \\
\text { degrees }\end{array}$ \\
\hline
\end{tabular}

Note:

*When associated with a following number, "Alt" = Alternative.

**The length was measured from the river bank to the tip of structures based on shape files by ArcMap.

Figure 4-2. Layouts of proposed groins.

(a) Groin Alt 1 (50 degrees).

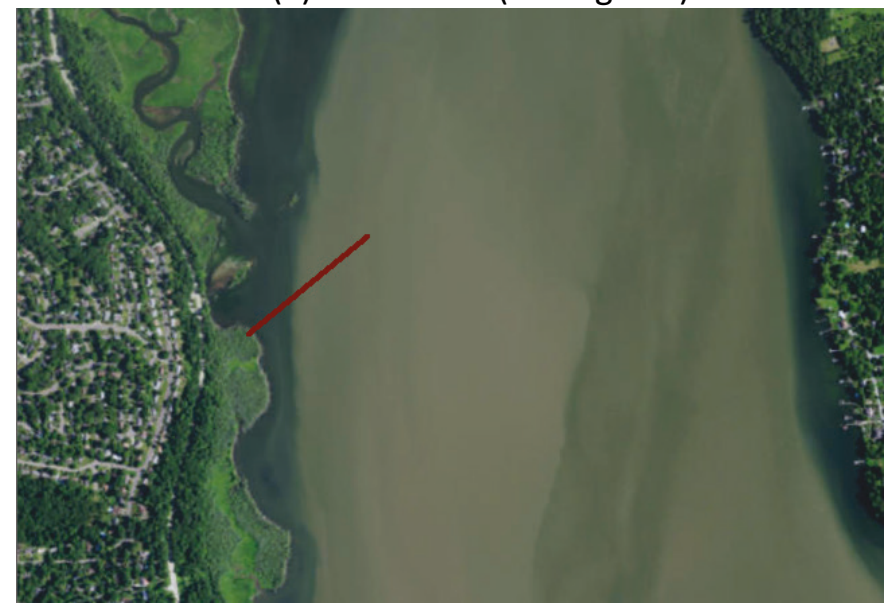

(c) Groin Alt 3 (75 degrees).

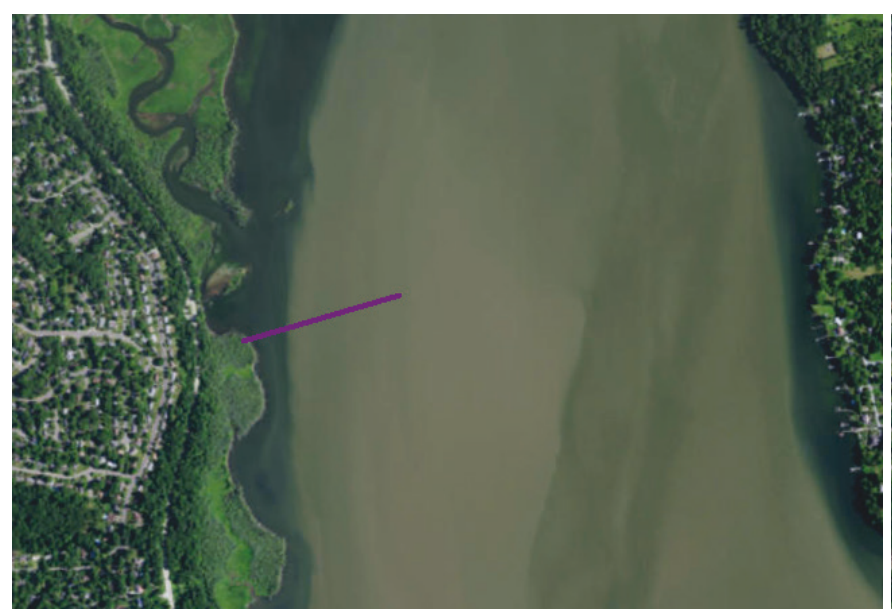

(b) Groin Alt 2 (curved).

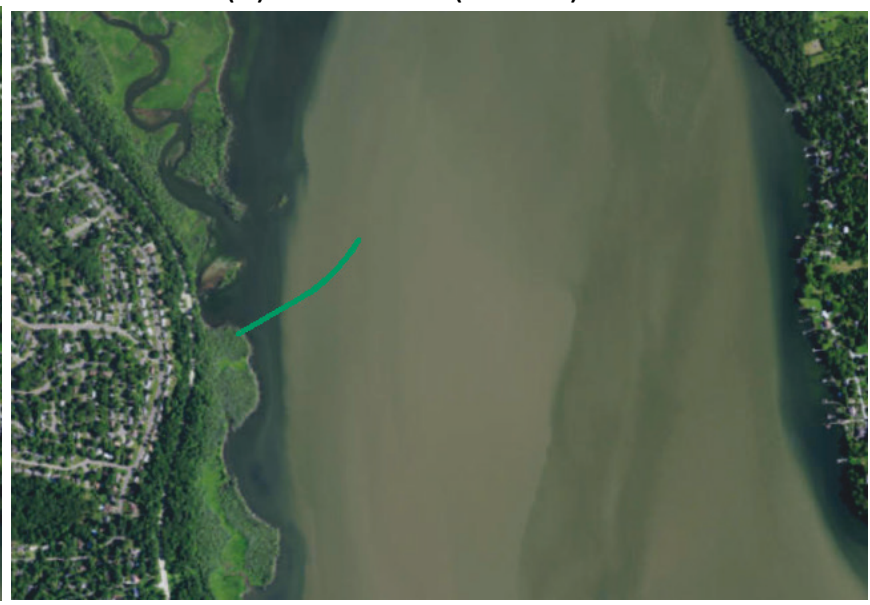

(d) Comparison of the three project structures (groins). 


\subsection{Computational domains and grids}

This section of the report describes details of the ADCIRC mesh and STWAVE grids used for the simulations.

\subsubsection{Grids for full promontories with-project alternatives}

There are a total of five ADCIRC meshes and five STWAVE grids that represent the (1) existing conditions (without-project) of the Dyke Marsh and is referred to as DMo1E; (2) with-project long promontory with lower heights, referred to as DMo1P1; (3) with-project long promontory with higher heights, referred to as DMo1P2; (4) with-project short promontory with lower heights, referred to as DMo1P3; and (5) with-project short promontory with higher heights, referred to as DMo1P4. The configurations of the project promontories are depicted in Figure 4-1. As presented in Figure 4-3, the computational domain for this study contains the North Atlantic Coasts, the Gulf of Mexico, and the Caribbean Sea, which has the same boundary as the NACCS ADCIRC mesh (Cialone et al. 2015). Two, new without-project ADCIRC meshes were created by refining the NACCS ADCIRC mesh. In the Dyke Marsh area (Figure 4-4), the NACCS ADCIRC mesh was refined to add more detail, with a minimum resolution of approximately $39 \mathrm{ft}$ near the proposed structures for storm surge simulations and a minimum resolution of approximately $20 \mathrm{ft}$ for non-storm event simulations. The $20 \mathrm{ft}$ non-storm meshes were designed to capture more fine details for typical conditions rather than the largescale event flow features during a storm event. All structures were considered when adding resolution first to the base mesh (DMo1E) so that when the with-project conditions were added, differences in mesh node locations between the different alternatives would be kept to a minimum. The structures were all added as "weir-pairs" in the ADCIRC mesh, which allows thin structures to be modeled as sub-grid features. Weir-pair structures in ADCIRC allow for water to flow over the structure when the water elevations exceed the weir elevation, but instead of solving the full set of shallow water equations, a weir flow formula is used. This sub-grid scale formulation for weir-pairs prevents the model from transitioning from sub- to super-critical flows during the course of the simulation, which would cause the ADCIRC model to become unstable. In addition, high-resolution lidar and bathymetric survey data of the study area provided by NAB were incorporated into all the meshes (Figure 4-5) and grid configurations. In comparison with the original bathymetry of the NACCS grid shown in 1-2(b), the new higher-resolution meshes include 
more details of bathymetrical features in the area of Dyke marsh (see Figure 4-5b). Three close-up views of meshes in the Dyke Marsh area are presented in Figure 4-6: (a) for the current conditions without proposed structures (DMo1E), (b) for a long promontory incorporated (DMo1P1 or DMo1P2), and (c) for a short promontory incorporated (DMo1P3 or DMo1P4).

The original STWAVE grid from the NACCS study for the Washington, DC, area was retained for this study with a resolution of approximately $328 \mathrm{ft}$. In addition, a nested STWAVE grid was created with a smaller extent and cell resolution of approximately $33 \mathrm{ft}$ to more accurately represent the project area.

All storm events were simulated using the CSTORM-MS with coupled ADCIRC and STWAVE models.

Figure 4-3. Outline plot showing the boundary of the ADCIRC mesh.

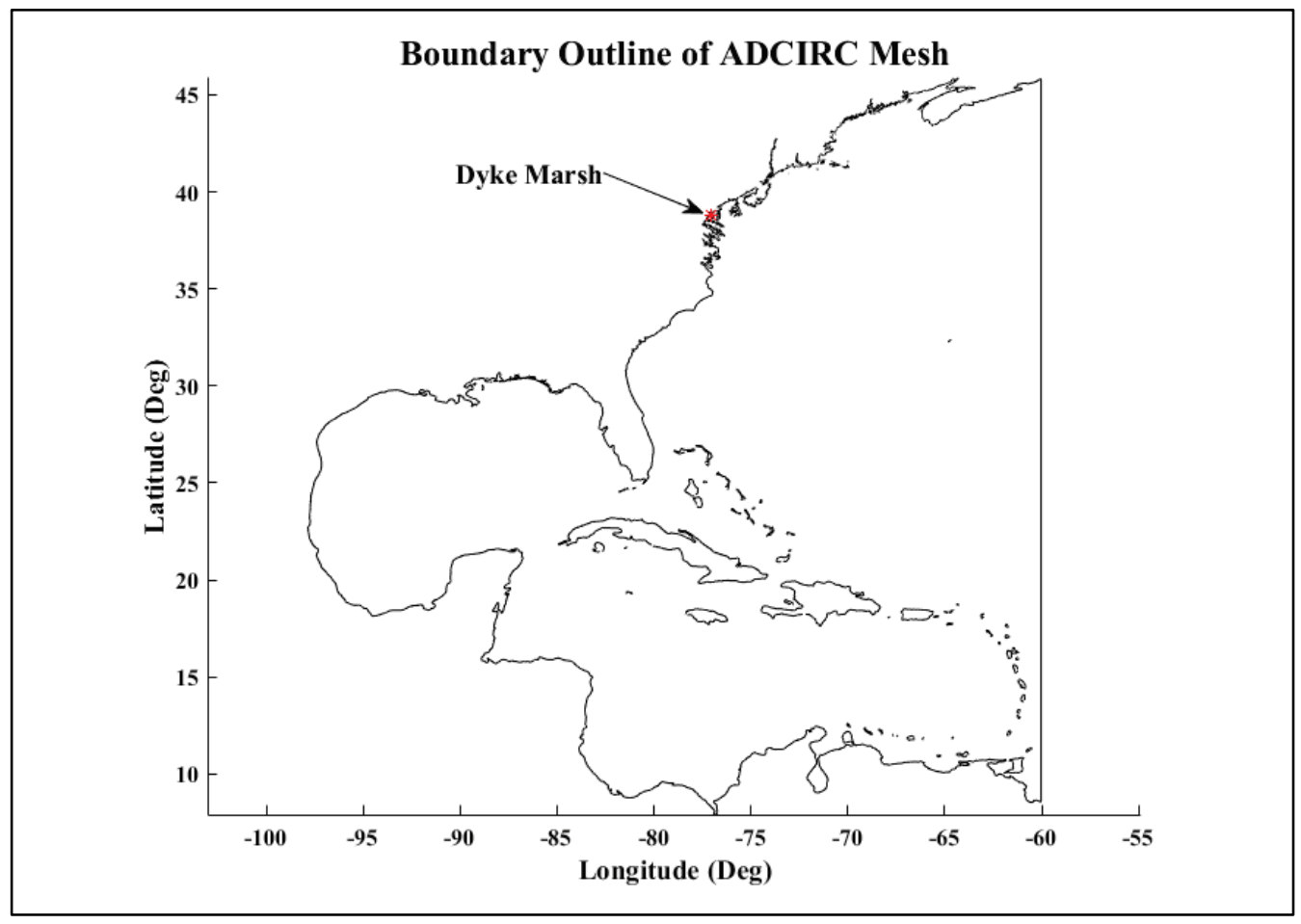


Figure 4-4. Outline plot showing the boundary of the ADCIRC mesh and the high-resolution STWAVE grid box (in red) for the area near Dyke Marsh.

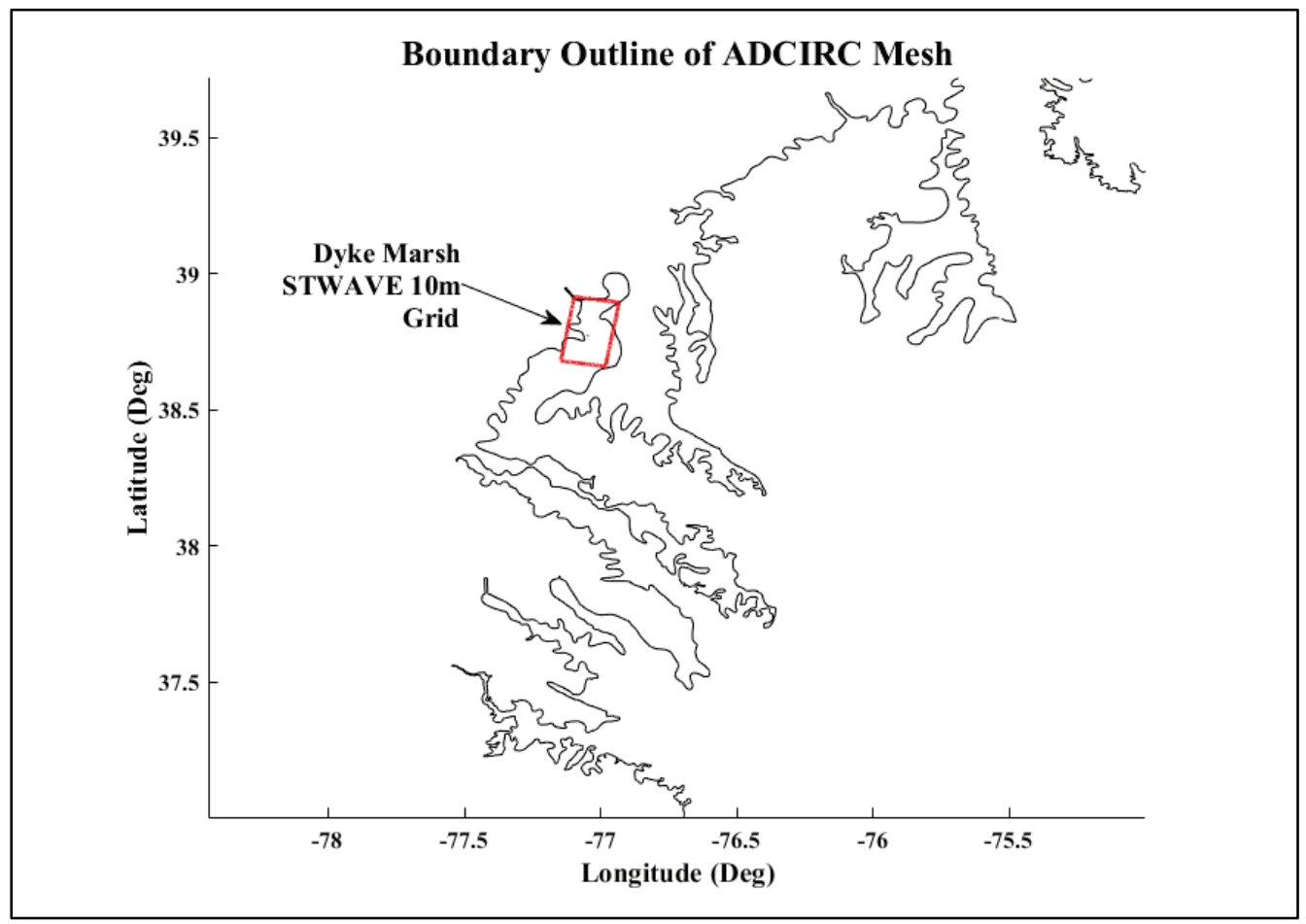


Figure 4-5. Computational domain boundaries and topo-bathymetry for the Potomac River and updated bathymetry around Dyke Marsh.

(a) Computational domain boundaries and topo-bathymetry for the Potomac River.

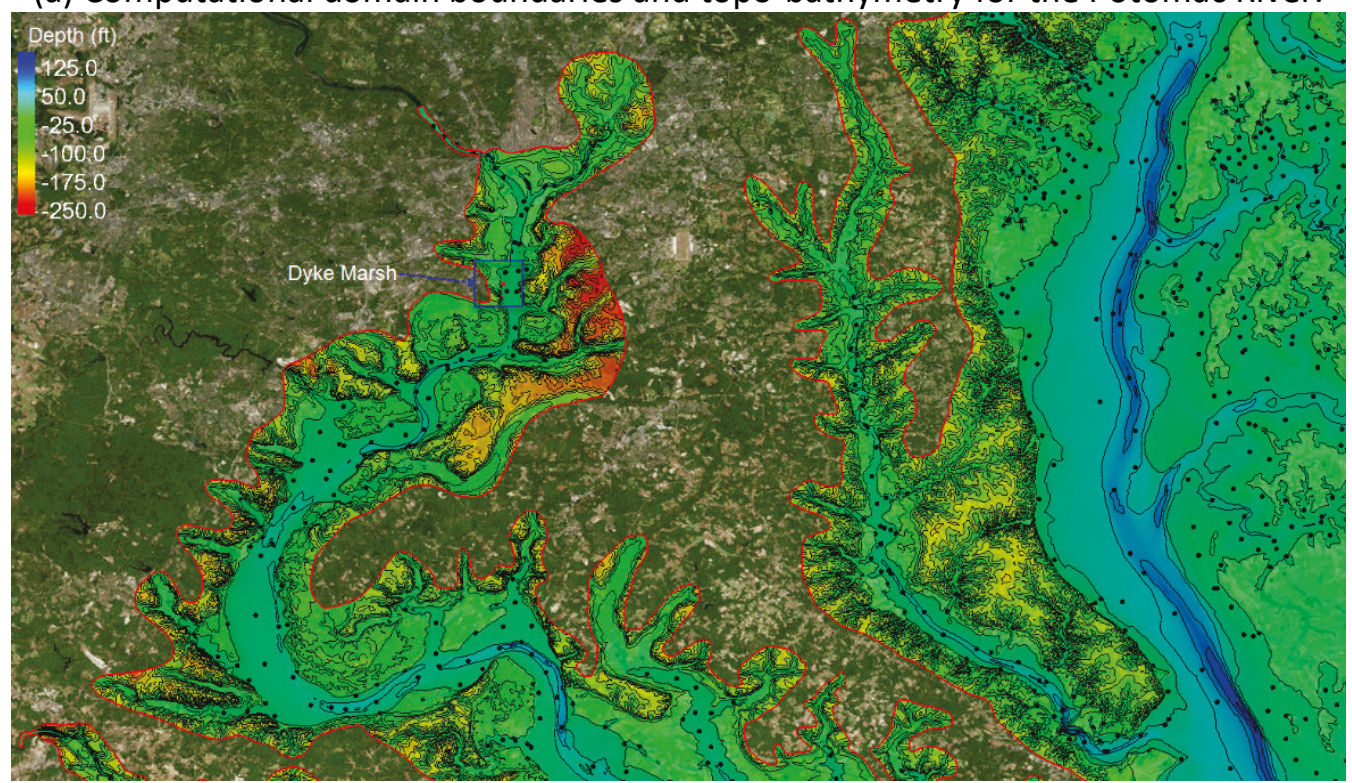

Note: Black dots indicate locations of NACCS save points.

(b) Updated bathymetry on right shows the area around Dyke Marsh.

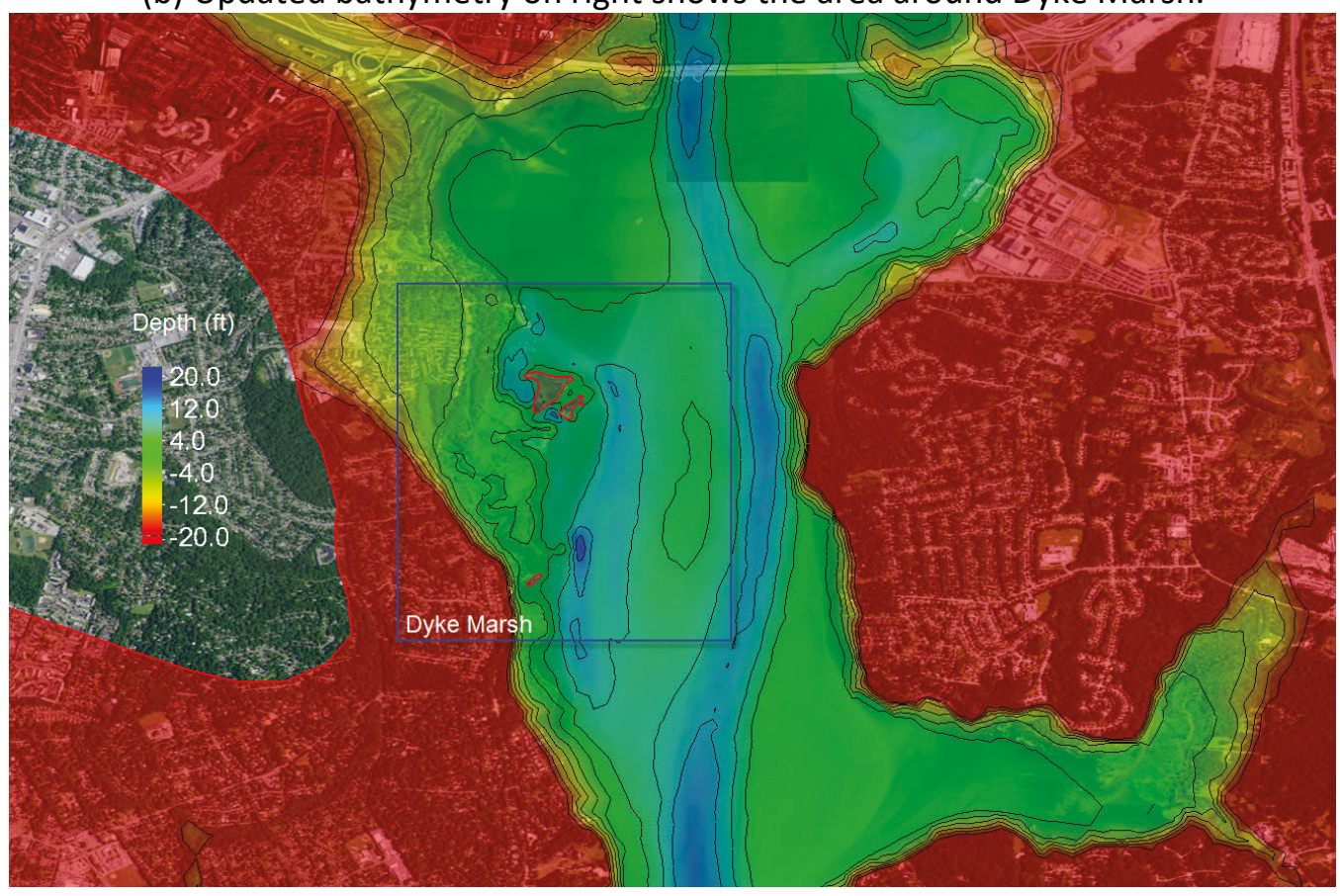


Figure 4-6. Close-up view of grids in Dyke Marsh area with structures.

(a) No structure (current conditions).

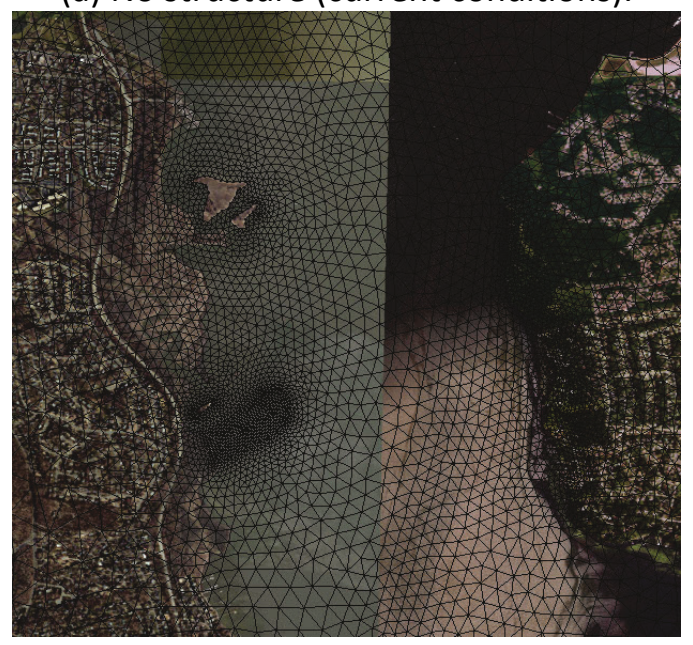

(b) Long promontory.

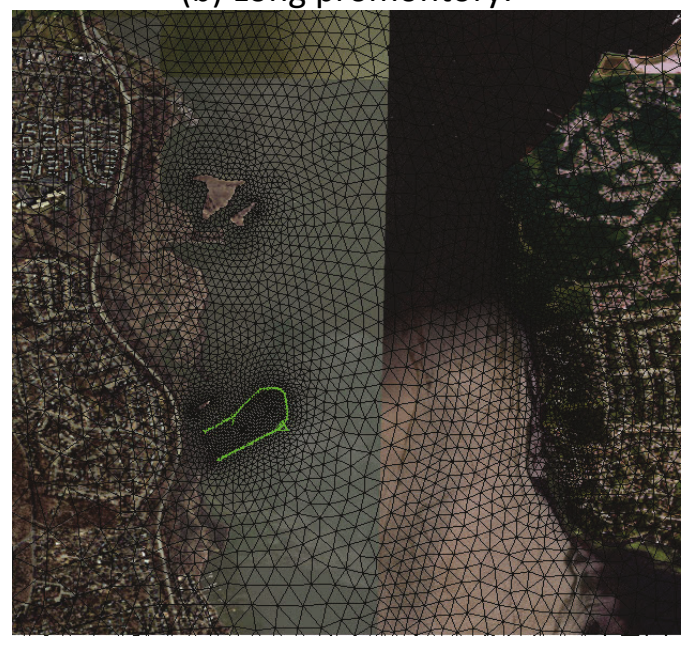

(c) Short promontory.

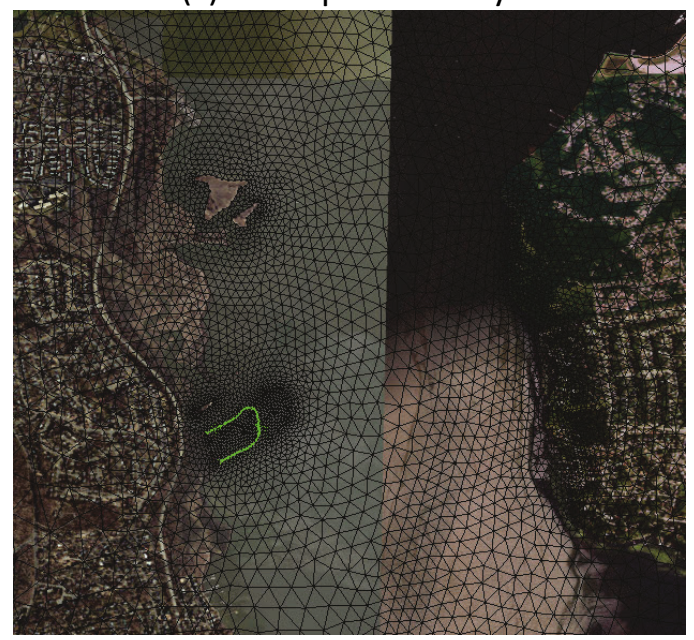




\subsubsection{Grids for groin-only with-project alternatives}

For incorporation of the three proposed groins, the same without-project condition ADCIRC grid (DMo1E) was used, and three additional ADCIRC grids were created by incorporating the three groin structures as weir-pair features. As presented in Table 4-2, the grid DMo1P6 represents the mesh with Groin Alt $^{1} 1$ (50 degrees); DMo1P7 represents the mesh with Groin Alt 2 (curved); and DMo1P8 represents Groin Alt 3 (75 degrees). Close-up views of the three ADCIRC meshes in the Dyke Marsh area with groin structures included (light green color) are shown in Figure 4-7 for (a) Groin Alt 1, (b) Groin Alt 2 (curved), and (c) Groin Alt 3. It can be seen that the lengths of the structures are similar, but the orientation and shapes (straight or curved) of the structure are slightly different.

The depth files in the STWAVE grids were also updated to represent these with-project alternatives as well as the updated lidar and bathymetric survey data from NAB.

${ }^{1}$ When associated with a following number, "Alt" = Alternative. 
Figure 4-7. Close-up view of ADCIRC grids in Dyke Marsh with groins.

(a) Groin Alt 1 (50 degrees).

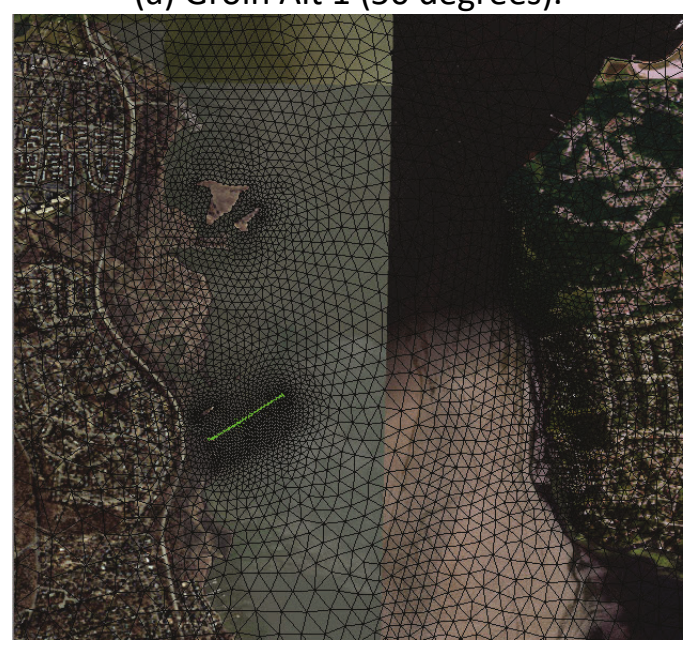

(b) Groin Alt 2 (curved).

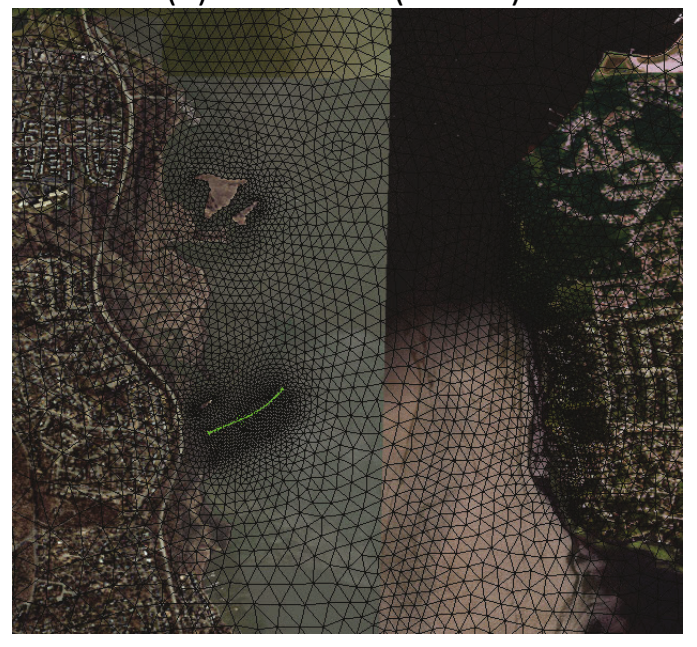

(c) Groin Alt 3 (75 degrees).

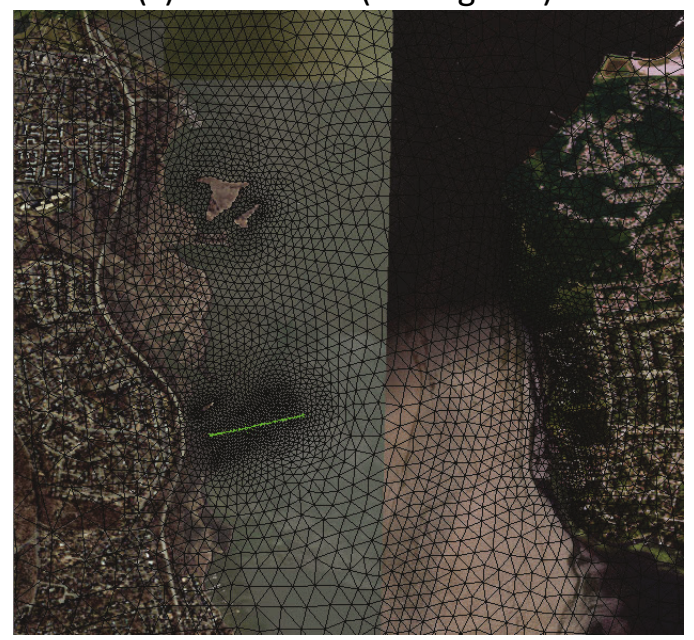




\subsection{Bathymetric and topographic data sources}

Three topo-bathymetric data sources were used in the study, including (1) the existing NACCS ADCIRC depth grid, (2) bathymetry survey data and lidar data provided by NAB (USACE NAB; NPS 2009; UMCES 2012), and (3) U.S. Geological Survey (USGS-NED 2016) topographic data. The data properties (type, spatial resolution, and datum) of the original datasets are listed in Table 4-3. The NACCS ADCIRC mesh did not have sufficient spatial resolution to represent the shape of the marshland, the channels in the wetland, the river beds, or the proposed alterative projects; therefore, these features were represented by incorporating the second and third data sources.

As shown in Figure 4-8, newly surveyed topo-bathymetric data in the Dyke Marsh area covered the wetland and marsh, the shoreline (edge of the marsh), and nearshore areas and the Potomac River. The USGS-NED (2016) in the area was also used to fill in inland data gaps (Figure 4-9 and Figure 4-10).

The topo-bathymetric survey data and USGS-NED data had various vertical datums and were therefore converted to mean sea level (MSL) using the National Oceanic and Atmospheric Administration (NOAA) Vertical Datum Transformation tool (NOAA 2016) for application to the meshes used in this study.

Table 4-3. Sources of topo-bathymetric data.

\begin{tabular}{|l|l|l|l|l|}
\hline Data Name & Data Type & Spatial Resolution & Datum & Reference \\
\hline $\begin{array}{l}\text { NACCS ADCIRC } \\
\text { Mesh }\end{array}$ & $\begin{array}{l}\text { Finite elemental } \\
\text { mesh }\end{array}$ & $\begin{array}{l}\text { Varying } \\
\text { approximately from } \\
33 \text { to } 3280 \mathrm{ft}\end{array}$ & MSL & $\begin{array}{l}\text { Cialone et al. } \\
\text { (2015) }\end{array}$ \\
\hline $\begin{array}{l}\text { Survey Point Data } \\
\text { (2009-2016) }\end{array}$ & Point data & Approximately 25 ft & MLW & $\begin{array}{l}\text { NPS, USACE NAB } \\
\text { (footnote, } \\
\text { preceding page) }\end{array}$ \\
\hline $\begin{array}{l}\text { Survey Point Data } \\
\text { (2012) }\end{array}$ & Lidar data & 25 ft & MLW & $\begin{array}{l}\text { UMCES (footnote, } \\
\text { preceding page) }\end{array}$ \\
\hline $\begin{array}{l}\text { USGS-NED } \\
\text { Topographic Data }\end{array}$ & $\begin{array}{l}\text { Digital elevation } \\
\text { model (DEM) }\end{array}$ & $\begin{array}{l}\text { One-third arc-second } \\
\text { (approximately 33 ft) }\end{array}$ & NAVD88 & $\begin{array}{l}\text { USGS-NED } \\
\text { (2016) }\end{array}$ \\
\hline
\end{tabular}


Figure 4-8. Topo-bathymetric data points surveyed in 2009, 2012, and 2016.

(a) Zero elevation point (2009).

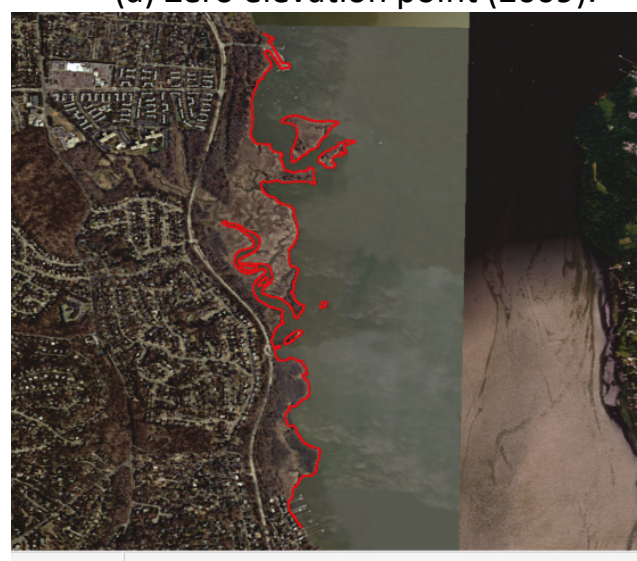

(b) Nearshore point (2009).

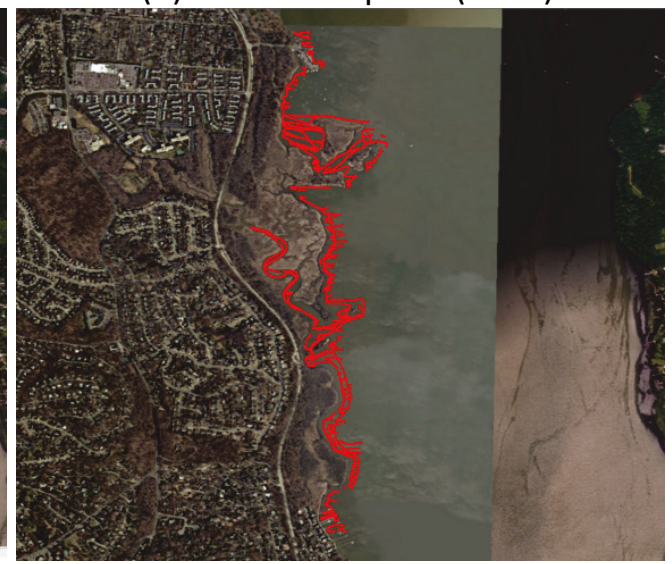

(c) Bathymetry point (2016).

(d) Lidar $25 \mathrm{ft}$ grid point (2012).
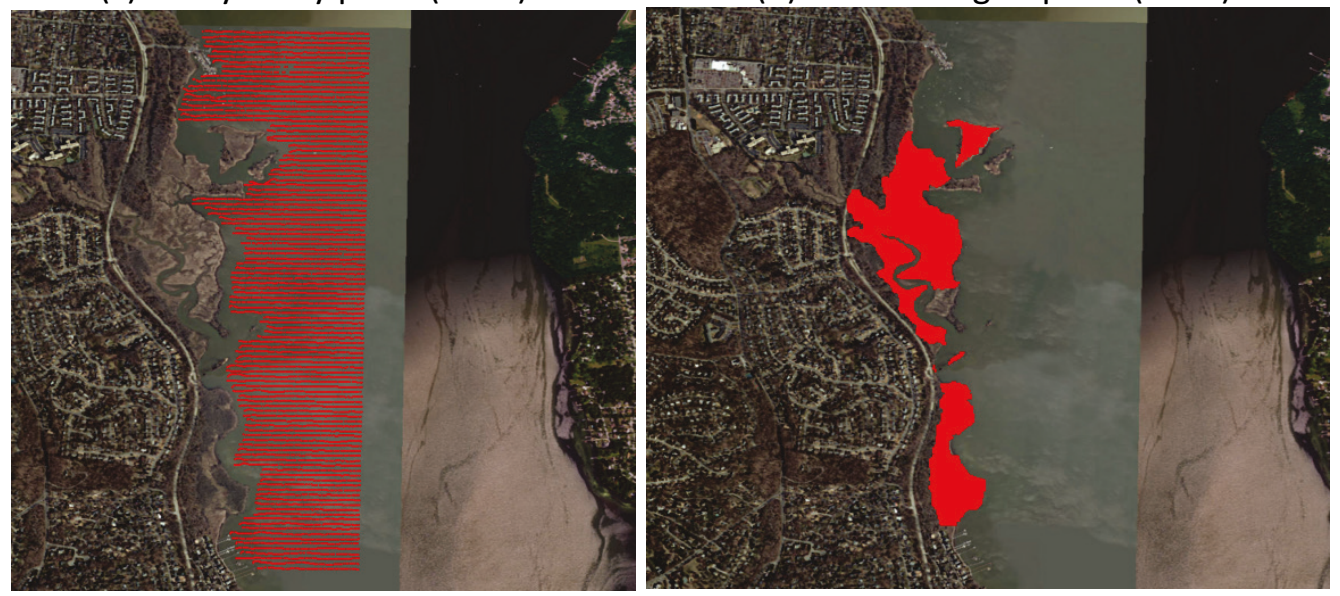

Figure 4-9. USGS NED one-third arc-second topographic data.

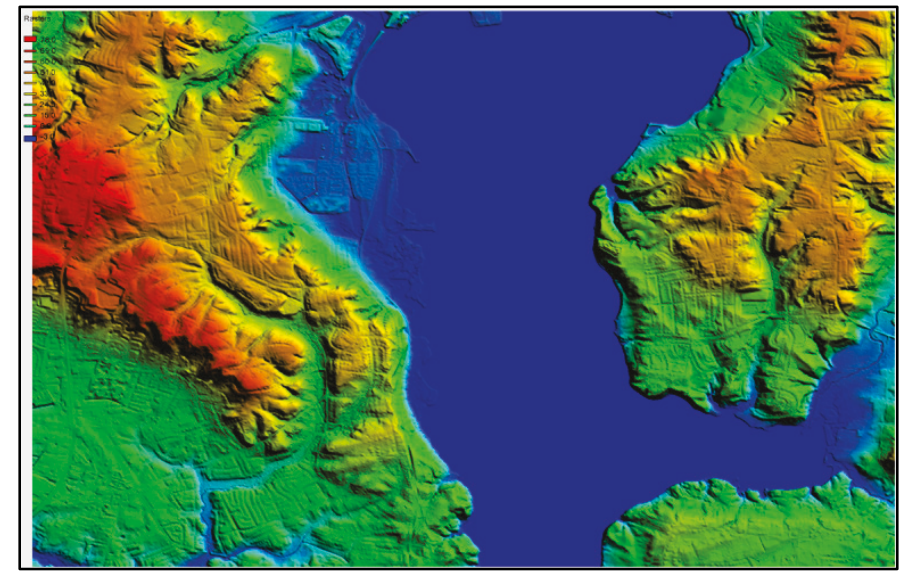


Figure 4-10. Merged scattered topo-bathymetric data points.

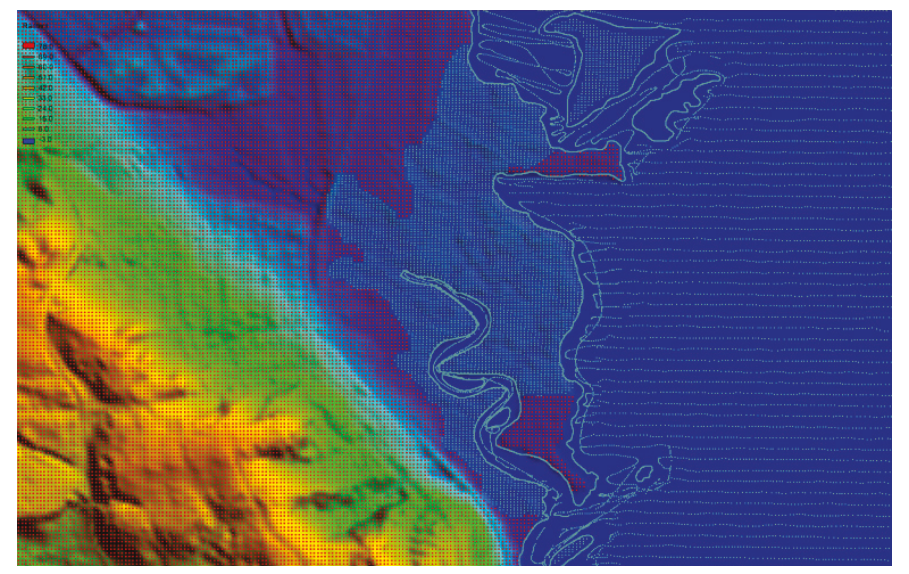

Note: light blue for the survey data (2009-2016); red color for USGS-NED data.

\subsection{Physical forcing conditions}

For all the storm condition simulations, no tidal forcing was applied, and the same statistical river discharges for the rivers (including the Potomac River) used in the NACCS study were retained (Cialone et al. 2015). For example, for production simulations for SYN storms, a production flow discharge rate in the Potomac River of approximately 134,000 ft3/s was used. A Garratt wind drag formulation (Garratt 1977) was applied, and no wind multiplier was used. For all the SYN TP storms, a steric adjustment to the initial water level datum of $0.33 \mathrm{ft}$ was added to represent the average thermal expansion of the water column during hurricane season. For the HIS storms, date-specific steric adjustments were added to the initial water level datum and are the same as those applied in the NACCS study.

\subsection{Model parameters for nodal attributes}

The bottom friction coefficient or Manning's $n$ is specified at each computational node of the ADCIRC mesh to represent flow resistance due to bed roughness, vegetation, and land cover and land use (LCLU). In this study, the ADCIRC mesh initially used the existing Manning's $n$ values as applied in the NACCS ADCIRC mesh. However, with finer spatial resolution added in the Dyke Marsh area, the Manning's $n$ values were updated based on types of LCLU in the area. 
The most recent LCLU data were obtained from the 2011 National Land Cover Database (NLCD) (NLCD 2016; Homer et al. 2015). The types of LCLU for the study area are given in Figure 4-11, where it is shown that the major land cover type in the Dyke Marsh is woody wetland. The new values of Manning's $n$ for the grid are based on the NLCD land classification (Table 4-4). A nodal distribution of Manning's $n$ values around the area of Dyke Marsh is presented in Figure 4-12, where the $n$ value in the river is 0.02 and the values in the Dyke Marsh vary from 0.025 to 0.09 , to represent the LCLU data in the area.

Figure 4-11. NLCD 2011.

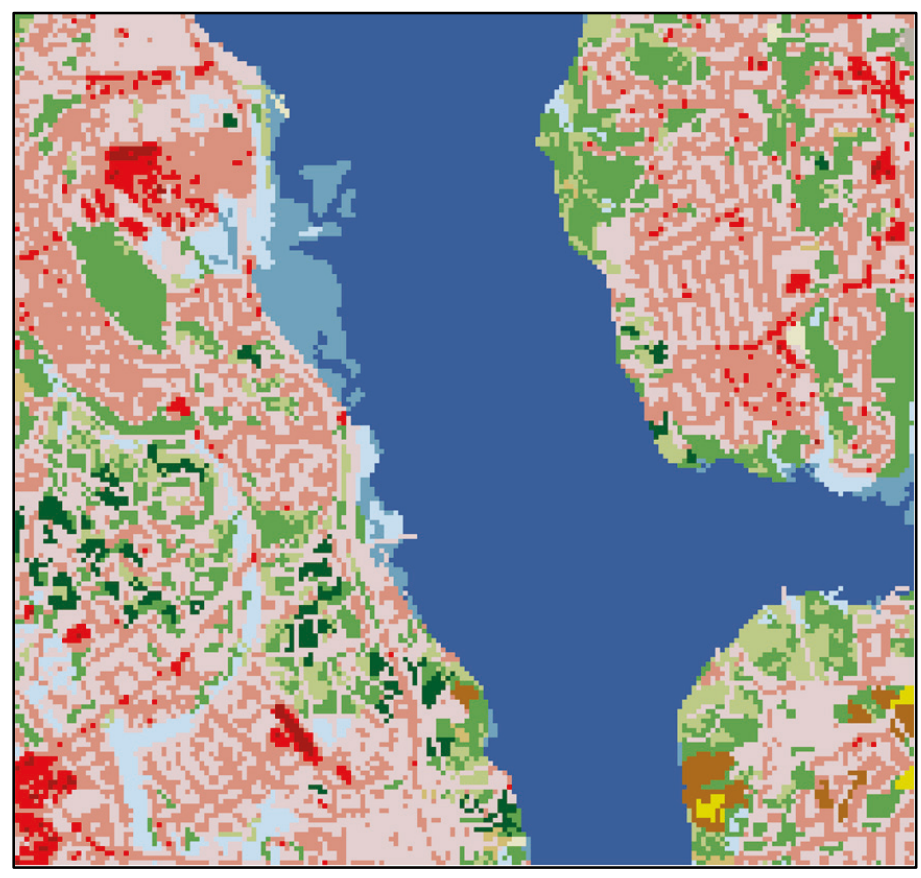

NLCD Land Cover Classification Legend

11 Open Water

12 Perennial Ice/ Snow

21 Developed, Open Space

22 Developed, Low Intensity

23 Developed, Medium Intensity

24 Developed, High Intensity

31 Barren Land (Rock/Sand/Clay)

41 Deciduous Fores

42 Evergreen Forest

43 Mixed Forest

52 Shrub/Scrub

71 Grassland/Herbaceous

81 Pasture/Hay

82 Cultivated Crops

90 Woody Wetlands

95 Emergent Herbaceous Wetlands 
Table 4-4. Manning's $n$ values for NLCD 2011 classification.

\begin{tabular}{|c|c|c|}
\hline NLCD Class & Description & Manning's $n$ \\
\hline 11 & Open Water & 0.020 \\
\hline 12 & Perennial Ice/Snow & 0.010 \\
\hline 21 & Developed-Open Space & 0.020 \\
\hline 22 & Developed - Low Intensity & 0.050 \\
\hline 23 & Developed - Medium Intensity & 0.100 \\
\hline 24 & Developed - High Intensity & 0.150 \\
\hline 31 & Barren Land (Rock/Sand/Clay) & 0.090 \\
\hline 32 & Unconsolidated Shore & 0.040 \\
\hline 41 & Deciduous Forest & 0.100 \\
\hline 42 & Evergreen Forest & 0.110 \\
\hline 43 & Mixed Forest & 0.100 \\
\hline 51 & Dwarf Scrub & 0.040 \\
\hline 52 & Shrub/Scrub & 0.050 \\
\hline 71 & Grassland/Herbaceous & 0.034 \\
\hline 72 & Sedge/Herbaceous & 0.030 \\
\hline 73 & Lichens & 0.027 \\
\hline 74 & Moss & 0.025 \\
\hline 81 & Pasture/Hay & 0.033 \\
\hline 82 & Cultivated Crops & 0.037 \\
\hline 90 & Woody Wetlands & 0.100 \\
\hline 91 & Palustrine Forested Wetland & 0.100 \\
\hline 92 & Palustrine Scrub/Shrib Wetland & 0.048 \\
\hline 93 & Estuarine Forested Wetland & 0.100 \\
\hline 94 & Estuarine Scrub/Shrub Wetland & 0.048 \\
\hline 95 & Emergent Herbaceous Wetlands & 0.045 \\
\hline 96 & Palustrine Emergent Wetland (Persistant) & 0.045 \\
\hline 97 & Estuarine Emergent Wetland & 0.045 \\
\hline 98 & Palustrine Aquatic Bed & 0.015 \\
\hline 99 & Estuarine Aquatic Bed & 0.015 \\
\hline
\end{tabular}


Figure 4-12. Spatial distribution of Manning's $n$ around the area of Dyke Marsh.

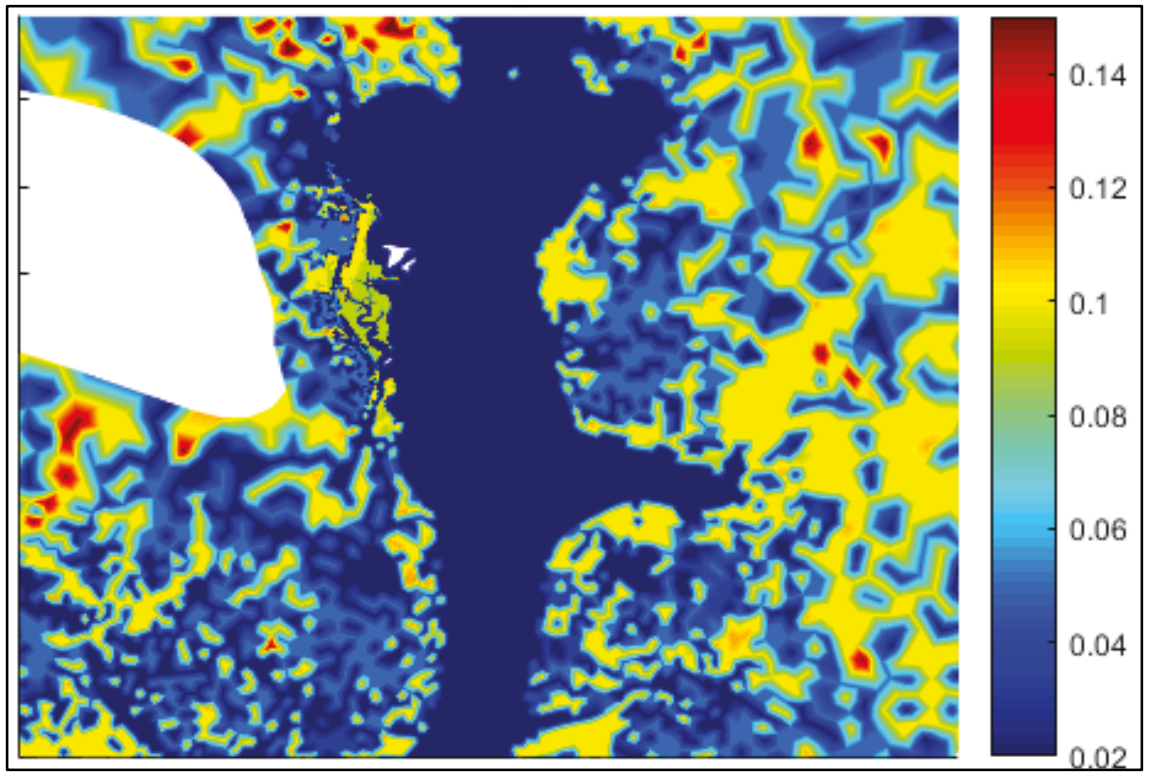

In addition to the Manning's $n$ values, the other spatially varying model input parameters used in this study include lateral horizontal eddy viscosity coefficients, primitive weighting coefficients for the Generalized Wave-Continuity Equation (GWCE), canopy coefficients to turn on/off winds over a given region, and directional surface wind reduction factors. These are all standard model input parameters used by the ADCIRC model for storm surge simulations whenever such data are available. Again, the values used in the NACCS study (Cialone et al. 2015) formed the starting point values for these variables.

The lateral horizontal eddy viscosity coefficient and primitive weighting coefficient for the GWCE were variables that were adjusted to account for the finer-resolution meshes and updated bathymetric values required to represent the Dyke Marsh features in the present study. As shown in Figure 4-13, the average horizontal eddy viscosity varies in the area of Dyke Marsh varies from approximately $43 \mathrm{ft}^{2} / \mathrm{s}\left(4.0 \mathrm{~m}^{2} / \mathrm{s}\right)$ in water nodes to approximately $108 \mathrm{ft}^{2} / \mathrm{s}\left(10 \mathrm{~m}^{2} / \mathrm{s}\right)$ in land.

The spatial distribution of the surface canopy coefficient around the Dyke Marsh (Figure 4-14) was updated based on the latest LCLU data as shown in Figure 4-11. Only two values were assigned to the surface canopy coefficients: zero and one. Nodes that reside in heavily forested areas are assigned a coefficient of zero indicating no wind energy transfer to the water column whereas a coefficient of one is specified for all other areas. 
This has the effect of setting winds to zero in heavily forested areas. The surface directional effective roughness length variable is used to make adjustments to the winds based on aggregate land use types in 12 directional bands around each node. The surface directional effective roughness was also updated according to the change of land cover in the Dyke Marsh area. For the details on calculation of the directional wind reduction, refer to Westerink et al. (2008).

Figure 4-13. Average horizontal eddy viscosity.

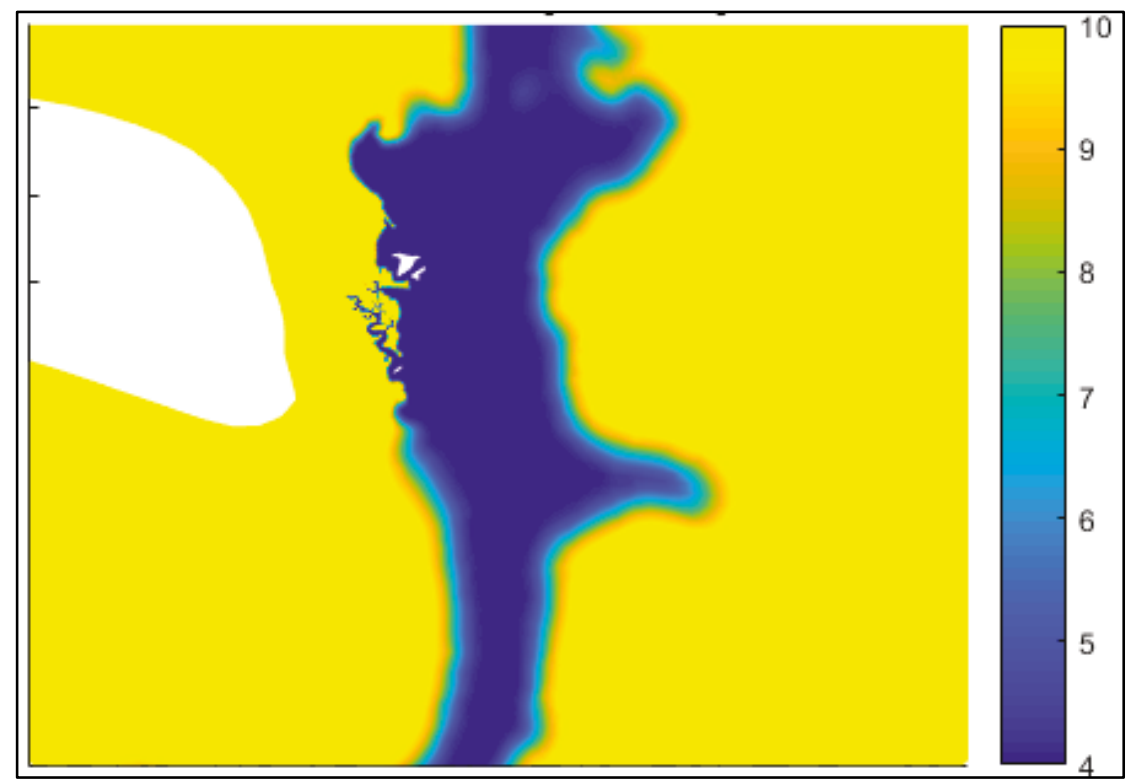

Figure 4-14. Surface canopy coefficient.

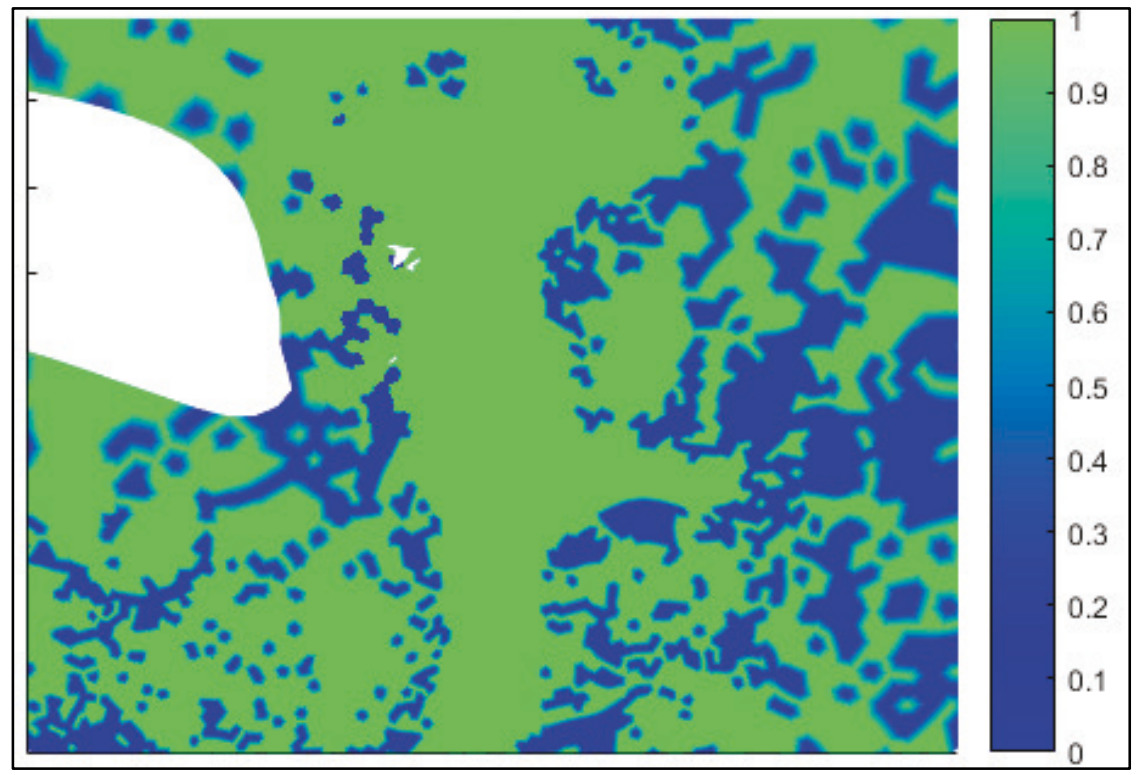




\section{Simulation Results}

\subsection{Results for evaluation of the proposed fully enclosed promontories}

Model results for each of the storm simulations are presented in this section. In particular, maximum values over the entire simulation period are given for water surface elevations, water velocities, and significant wave heights at every computation node in the grids. Spatial distributions of these maximum variables are presented in Table 5-1 through Table 5-43, focusing on the Dyke Marsh study area. In general, the local gradients of computed maximum water surface elevations along the Potomac River near the Dyke Marsh are relatively small (e.g., see the change of maximum water levels in Table 5-2 for HIS TP storm No. 0001). The main reasons for this minor variation of maximum water levels are (1) the study site is far from the coast so that the flows of storm surges propagating from the ocean will be significantly decelerated, (2) average river slope in the local river reach of the Potomac River near the Dyke Marsh is relatively small (less than 0.1\%), and (3) the river discharge is relatively lower in the HIS and SYN storms so that no significant backwater occurs in the study area.

However, because the volume occupied by the structures is relatively small compared to the river cross section, it will not drastically change flow conveyance in the river reach but will alter the near field flows around the structures themselves. It is expected that the velocities around the structures will increase and the main river flows may be redirected toward the opposite river bank. Changes in maximum depth-averaged water velocities show increases around the end of the promontory structures, in addition to decreased flow in the lee of the project structures (e.g., see the changes in Table 5-13 for HIS ET storm No. 0001). The longer structures also cause increased velocities on the eastern side of the Potomac River.

The most significant changes between the existing (without-project) conditions and with-project alternatives are seen in the maximum significant wave heights (Table 5-24 through Table 5-43). In general, storms (e.g., Isabel [2003], HIS ET storm No. 0008) that had peak winds blowing toward the north and northwest showed statistically significant changes (decreases) in wave height in the lee (north) of the promontory structures (see a summary on dominant wind direction in Dyke Marsh in Table 5-23). Similarly, storms that had significant winds blowing toward 
the south (e.g., Sandy [2012], HIS ET storm No. 0054) showed reduced waves to the south of the structure, which is beyond the area of interest. These general wave reduction patterns were to be expected, and the differences between the alterative with-project designs are shown in the series of color contour plots. Color contour plots of peak storm surge water levels are shown in Table 5-1 through Table 5-11 for the existing withoutproject conditions and the four full promontory alternatives. Color contour plots of maximum water velocity for the same five conditions are shown in Table 5-12 through Table 5-22. Maximum significant wave height color contour plots are shown in Table 5-24 through Table 5-33. The plots for differences in maximum significant wave height between the existing conditions and the designs are given in Table 5-34 through Table 5-43. Note that the plots on the right-hand side of the tables are close-up views with a narrower range of color axis scales.

For all the plots, a background image showing the surrounding topography has been added to help with orientation to the project area. The available background image selected for use within the SMS was unfortunately pieced together from two different resolution images with different color shadings (e.g., figures in Table 5-1). This causes the solution color contour plots to appear to have a crease or line running from top to bottom down the middle of the image. That crease does not exist within the solution and is only an artifact of the background image. Color axis labels have been included for each of the images, with the color axis range selected to highlight local differences in the solutions for each of the alternatives. In some cases, the color variation represents a difference of only a few inches, so changes may appear to be more significant than changes that would warrant consideration as a potential significant effect of the alternative.

\subsubsection{Maximum storm surge results}

Maximum simulated storm surge is used as a representative physical quantity to represent the maximum extent of flooding and inundation due to storms. Comparing maximum storm surges between the present geomorphic conditions in the Dyke Marsh and all of the project conditions will provide a means of evaluating the impacts of each of the project configurations on hydrodynamic conditions.

Based on the simulated results of storm surges driven by the total of 13 storms (2 HIS, 5 ET, and 6 SYN storms), it has been observed that the maximum storm surges are not significantly changed (or the gradients of 
maximum surges are close to zero) with the project alternatives in place. For example, as shown in Table 5-1, the maximum surge by storm HIS ET No. 0001 is approximately $4.81 \mathrm{ft}$ near the Dyke Marsh for all five configurations (with- and without-project conditions) and the difference of storm surge between each project condition and the no-project condition is less than 0.5 inch (in.)) (Table 5-2). The differences in maximum water levels between the existing and project conditions are small, and plots for the difference in water levels for the storm HIS ET No. 0001 are presented here as an example. Similar patterns of water surfaces with small changes in maximum water level around the study area in response to the other nine storms are shown in Table 5-3 to Table 5-11. Those tables are presented in the order of the storm numbers from HIS ET storms, HIS TP storms, and SYN TP storms. As expected, the maximum storm surges vary with storm conditions. Figure 5-1 presents the average maximum storm surges measured offshore of Dyke Marsh. It indicates that the storm SYN TP No. 0110 can increase the local water level more than $10 \mathrm{ft}$, but the storm HIS ET No. 0054 only induced $1.38 \mathrm{ft}$ of surge, which is the smallest storm surge of the storms that were simulated. Numerical values of the maximum storm surges and their difference between the project and no-project conditions can be found in Section 5.1.6.

Figure 5-1. Average maximum storm surges at the offshore of Dyke Marsh.

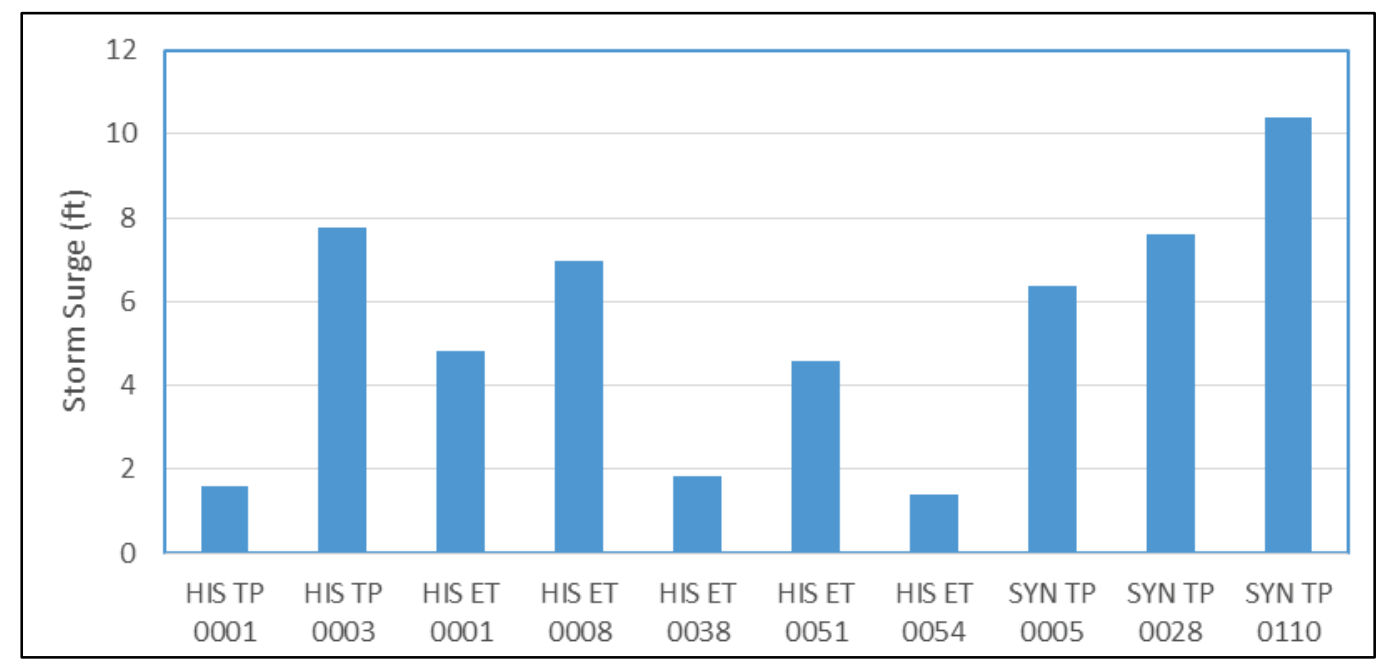


Table 5-1. Maximum water surface elevations for HIS ET Storm No. 0001 for five mesh configurations (with without-project structures).

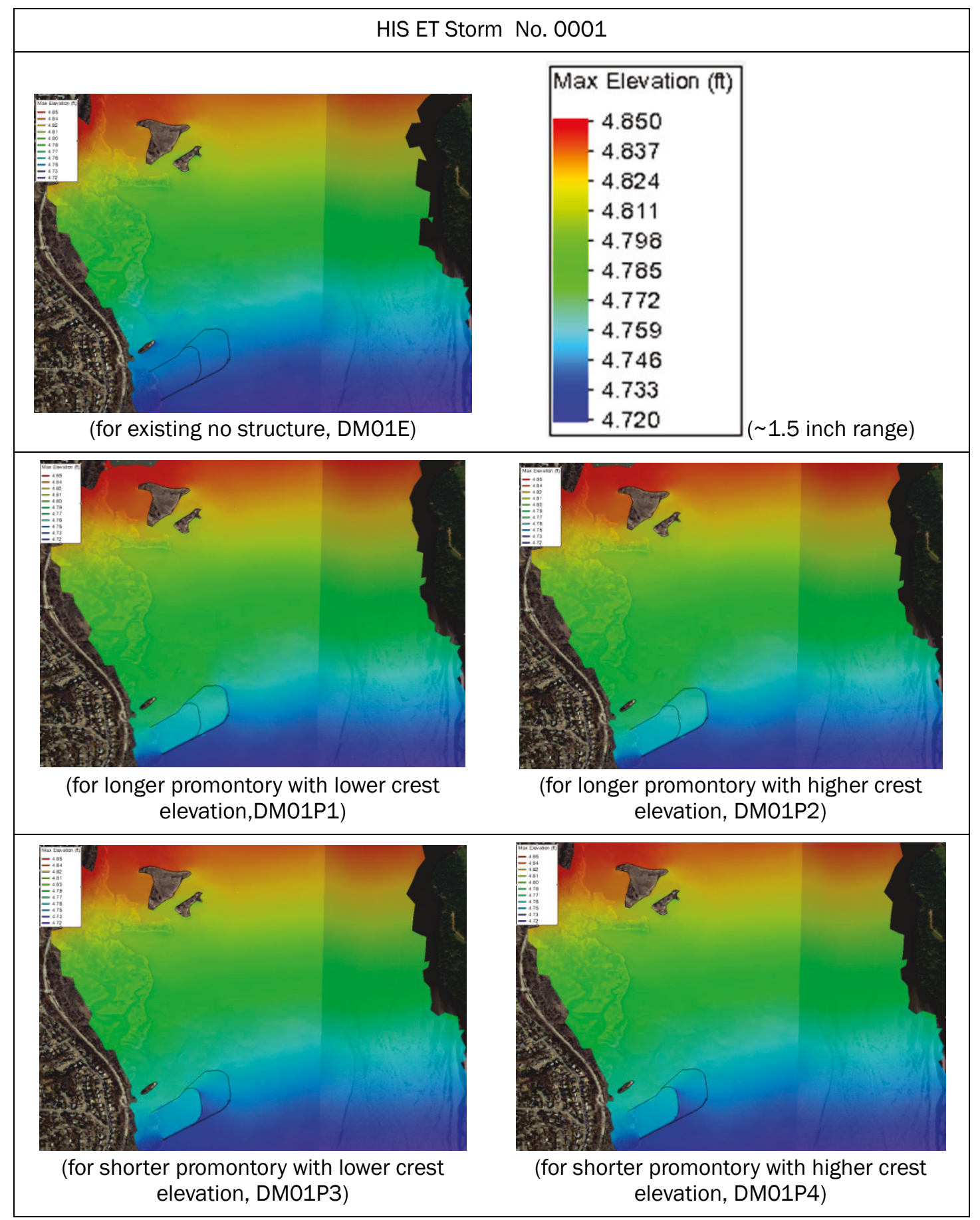


Table 5-2. Difference in maximum water surface elevations for HIS ET Storm No. 0001 between project and existing conditions (Project - Existing).

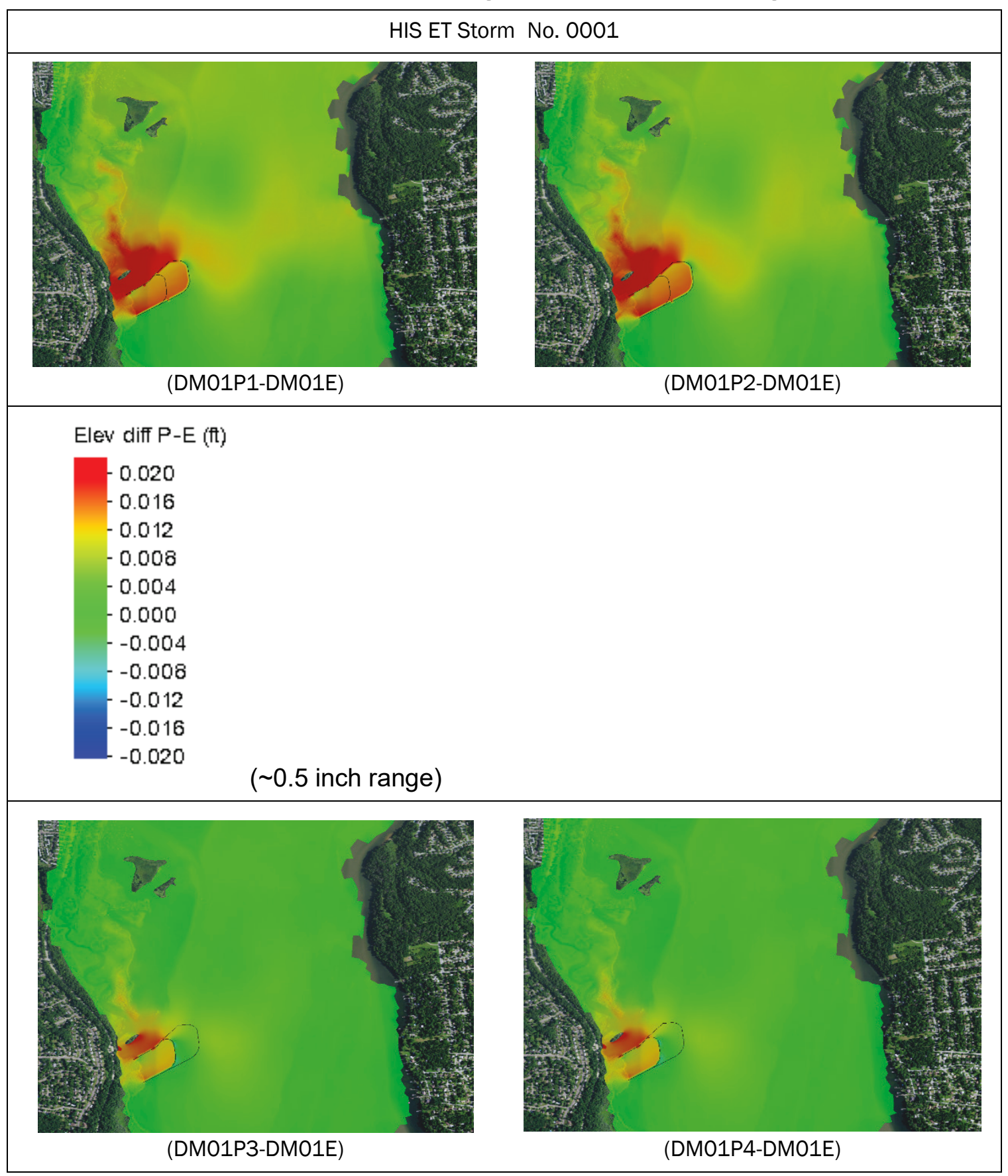


Table 5-3. Maximum water surface elevations for HIS ET Storm No. 0008 for five mesh configurations (with without-project structures).

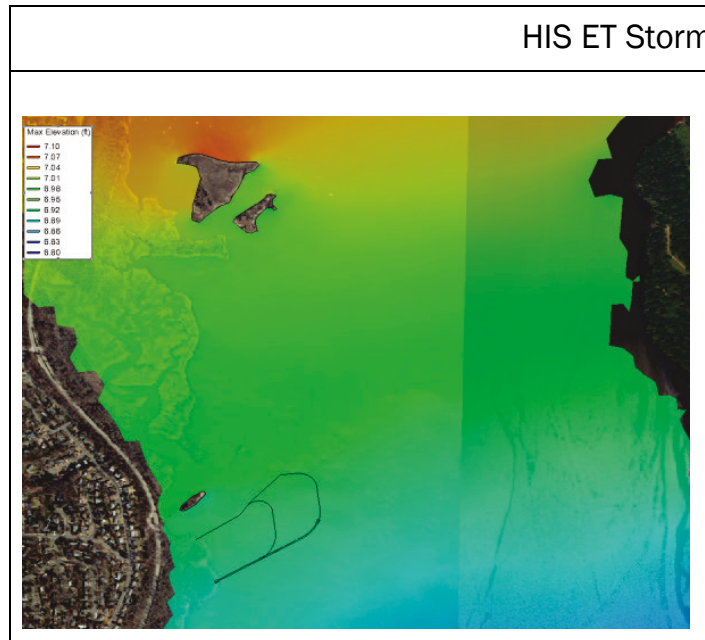

(Existing condition, DM01E)
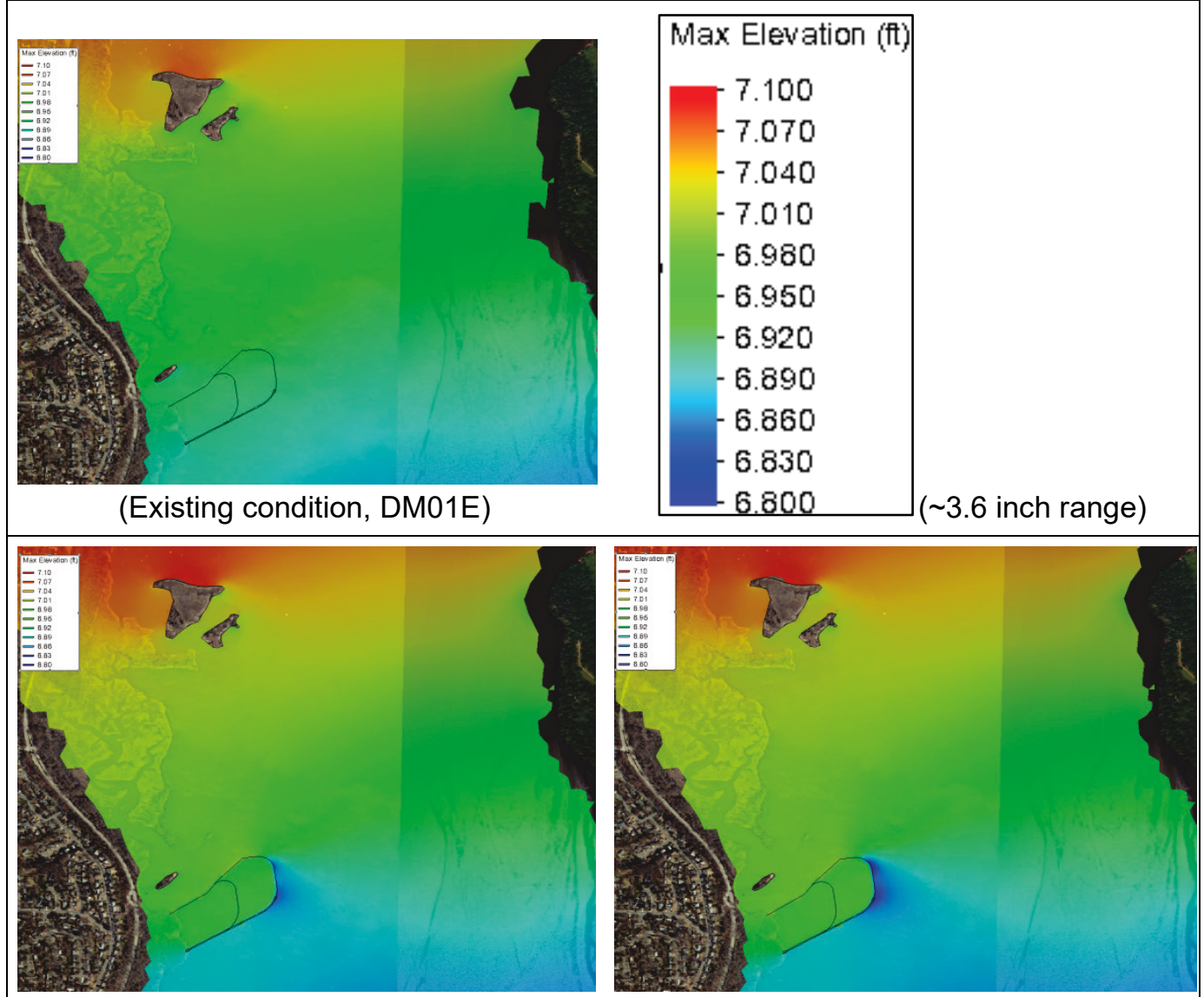

(for longer promontory with lower crest elevation, DM01P1)

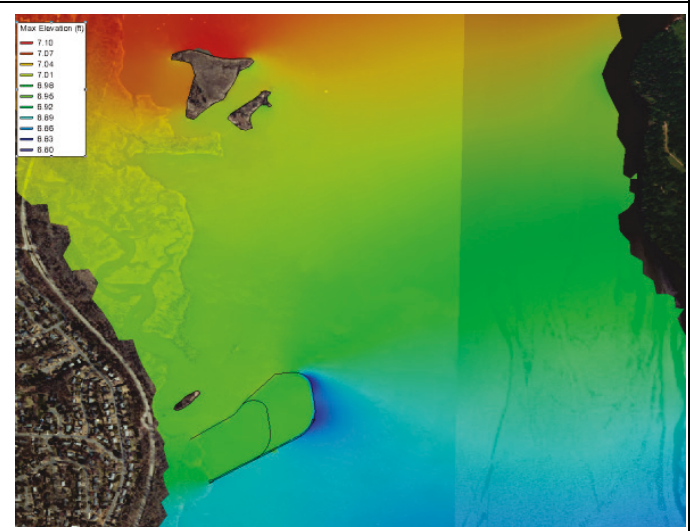

(for longer promontory with higher crest elevation, DM01P2)

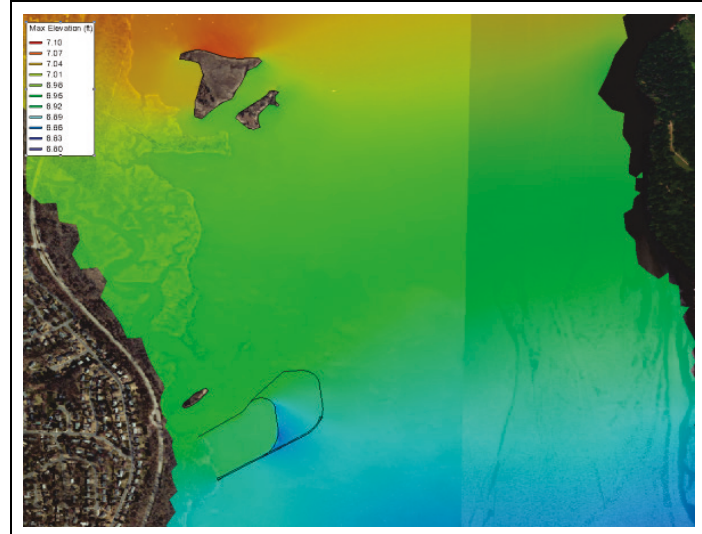

(for shorter promontory with lower crest elevation, DM01P3)

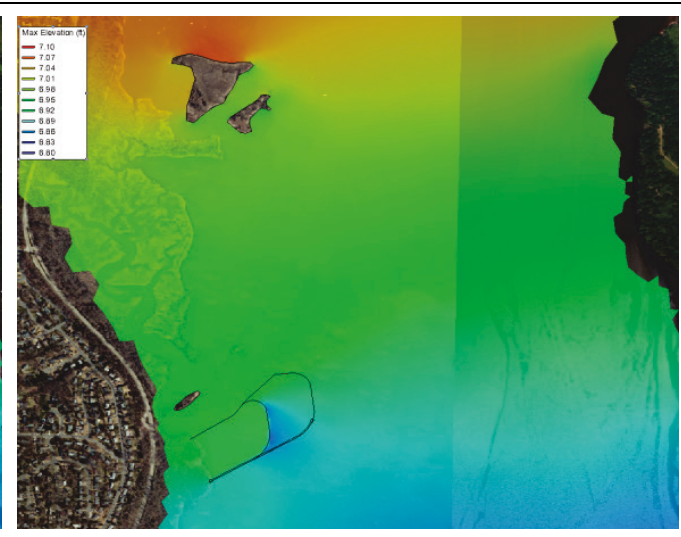

(for shorter promontory with higher crest elevation, DM01P4) 
Table 5-4. Maximum water surface elevations for HIS ET Storm No. 0038 for five mesh configurations (with and without structures).

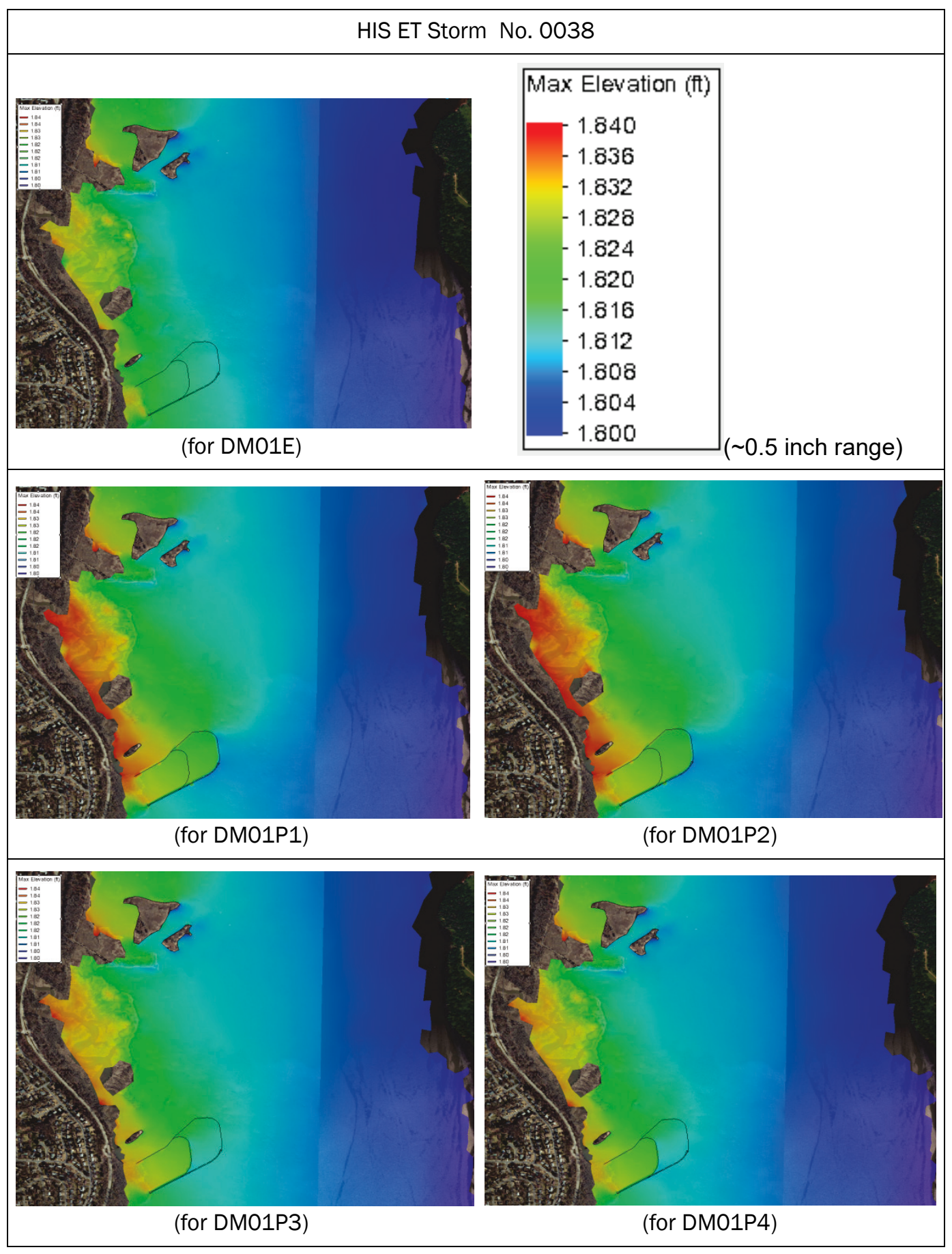


Table 5-5. Maximum water surface elevations for HIS ET Storm No. 0051 for five mesh configurations.

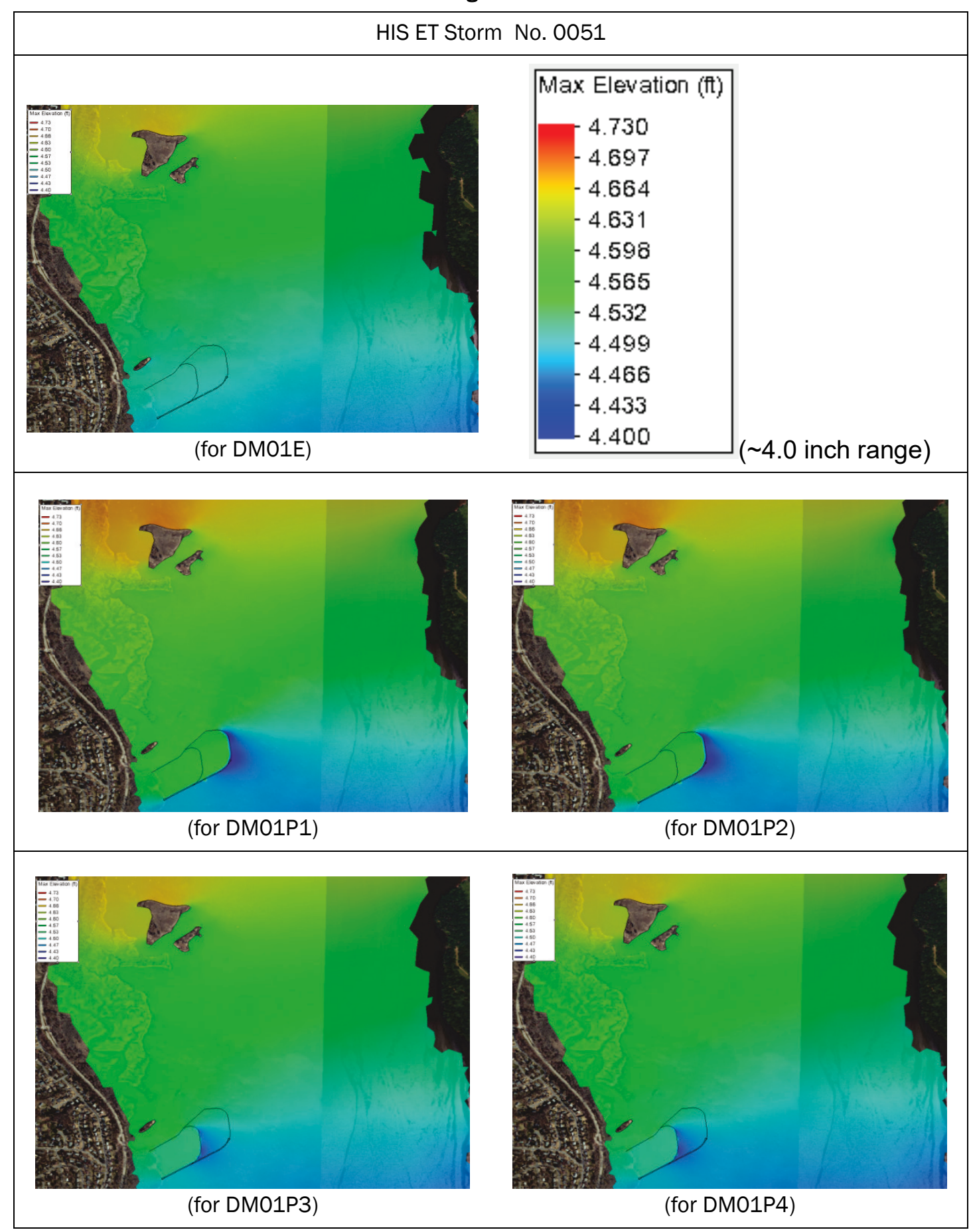


Table 5-6. Maximum water surface elevations for HIS ET Storm No. 0054 for five mesh configurations.

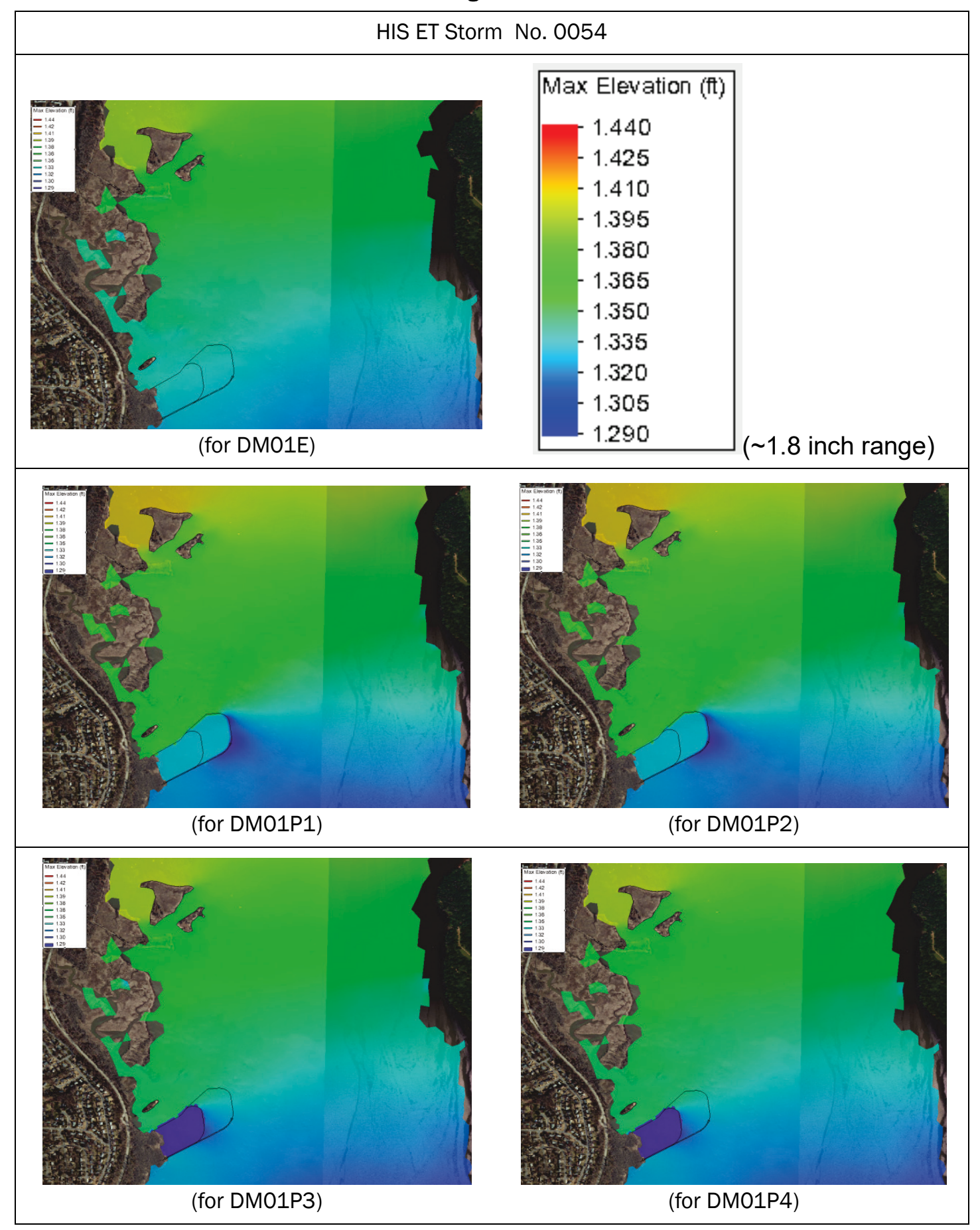


Table 5-7. Maximum water surface elevations for HIS TP Storm No. 0001 (Hurricane Sandy 2012) for five mesh configurations.

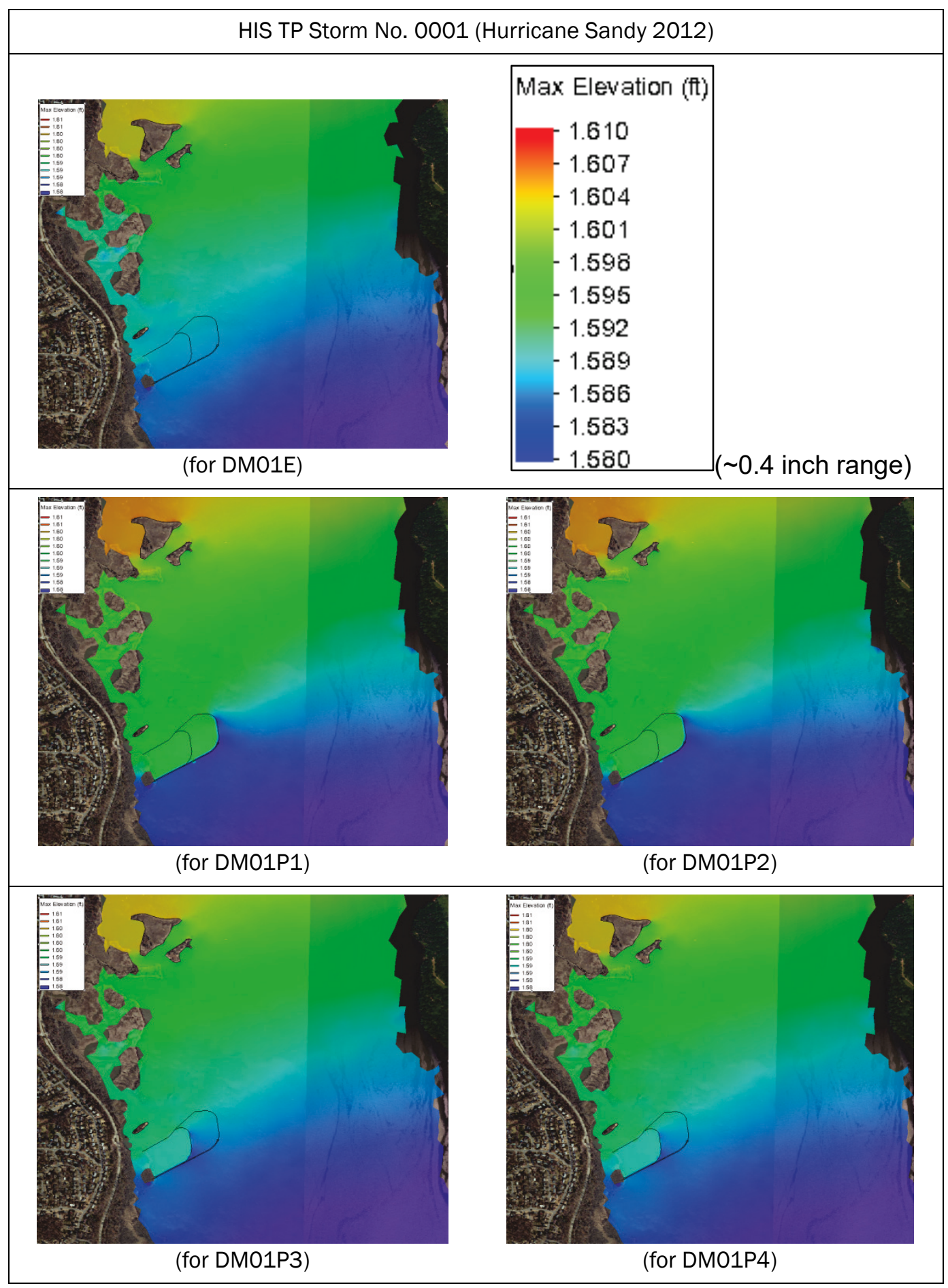


Table 5-8. Maximum water surface elevations for HIS TP Storm No. 0003 (Hurricane Isabel 2003) for five mesh configurations.

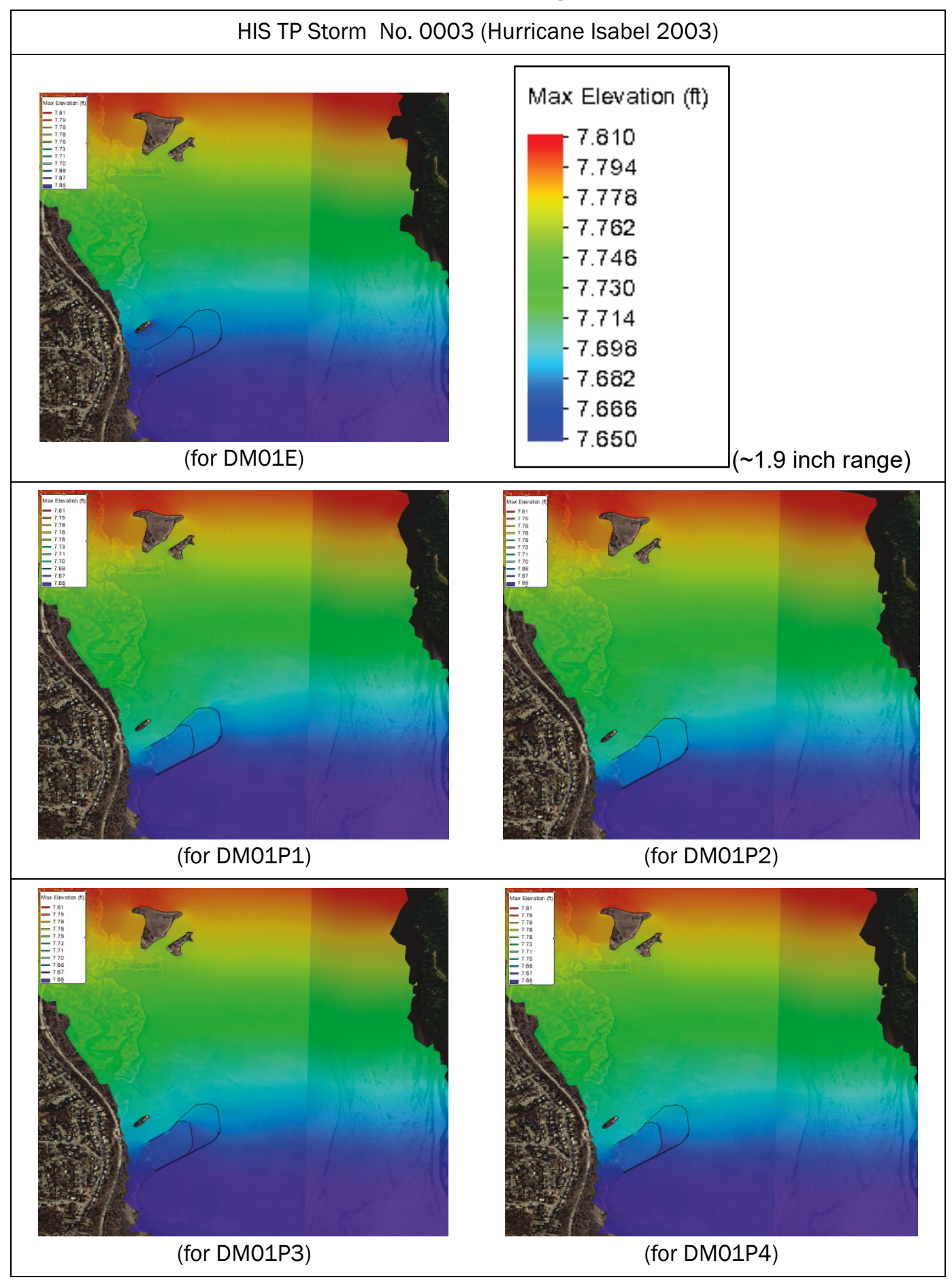


Table 5-9. Maximum water surface elevations for SYN TP Storm No. 0005 for five mesh configurations.

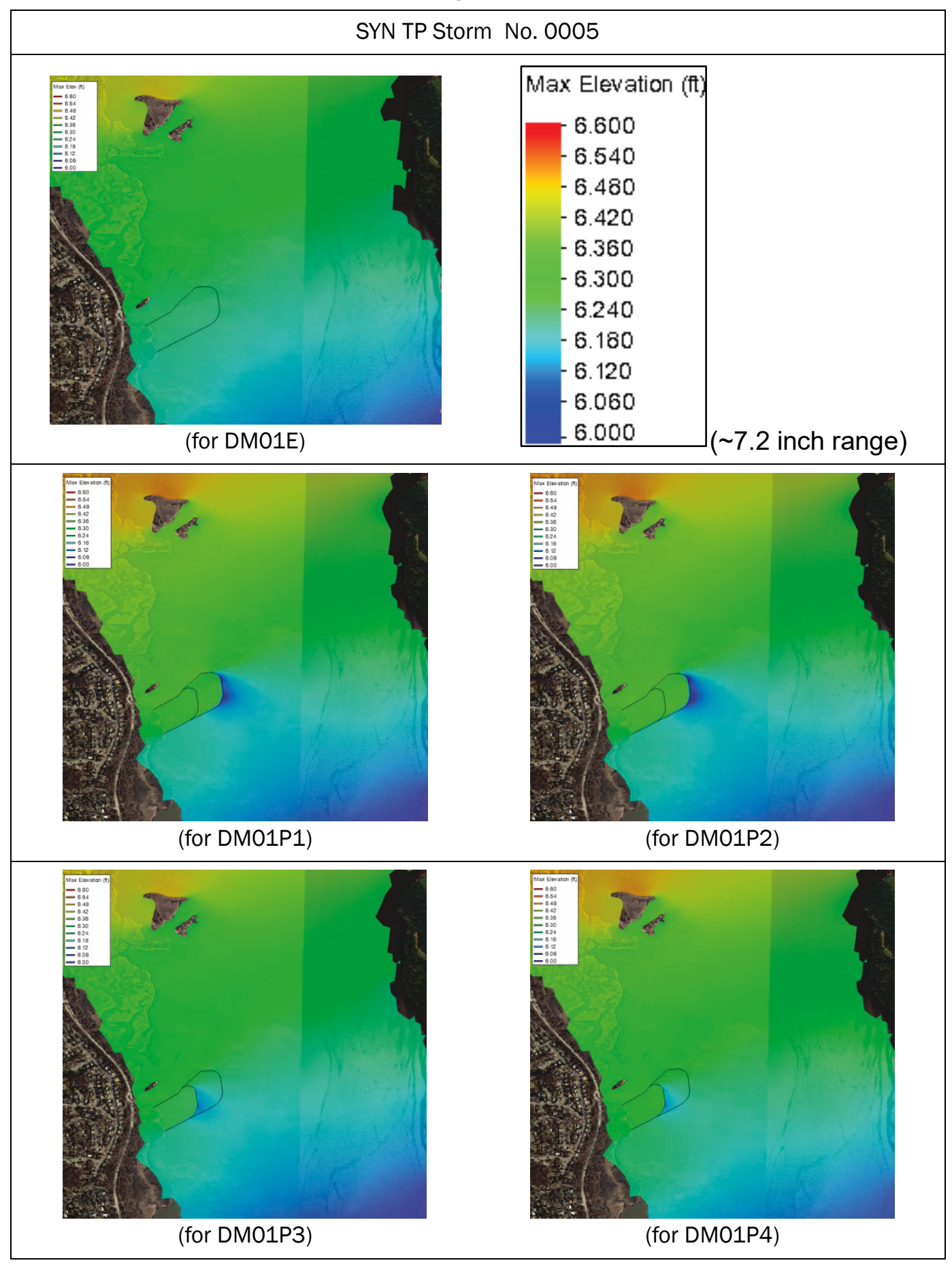


Table 5-10. Maximum water surface elevations for SYN TP Storm No. 0028 for five mesh configurations.

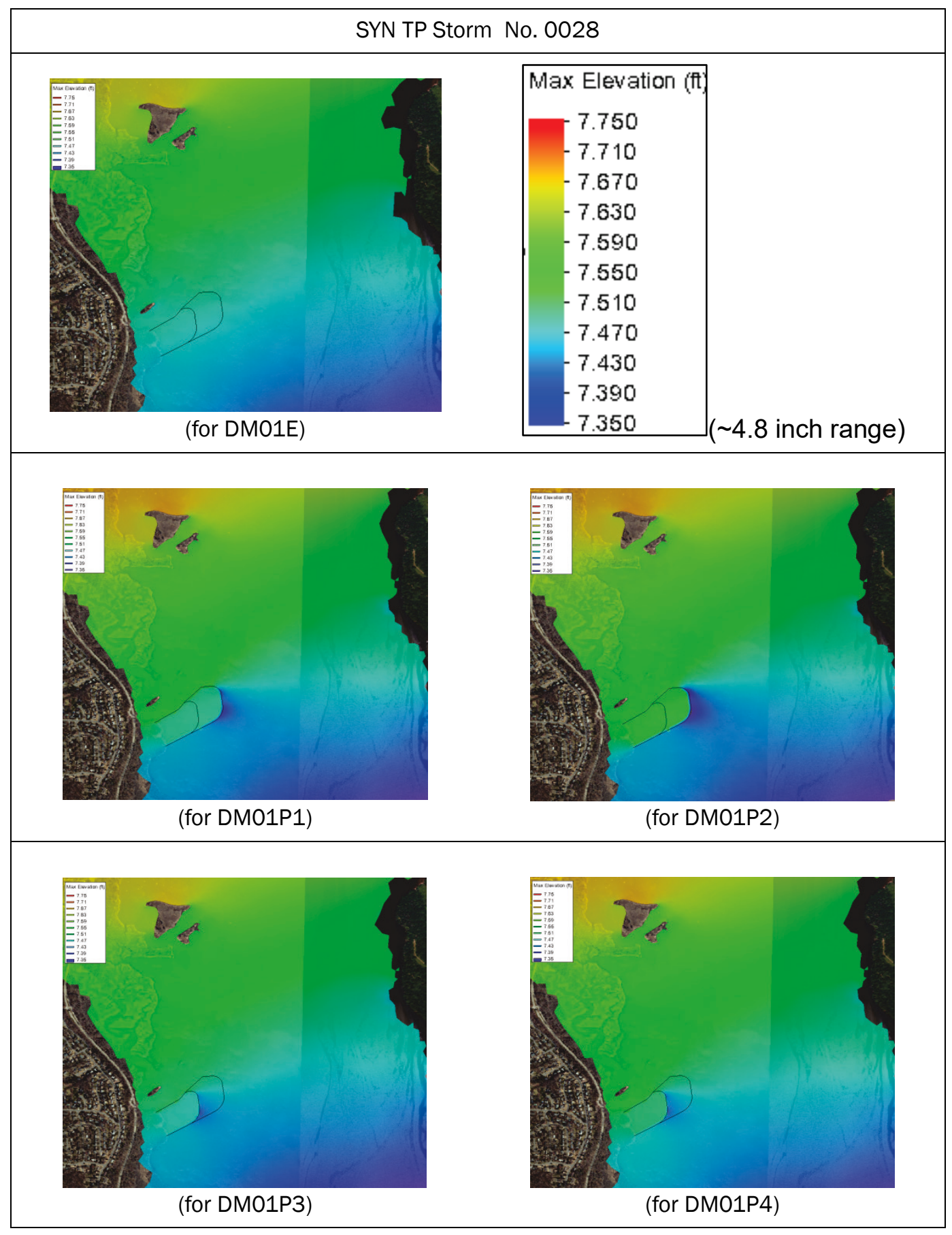


Table 5-11. Maximum water surface elevations for SYN TP Storm No. 0110) for five mesh configurations.

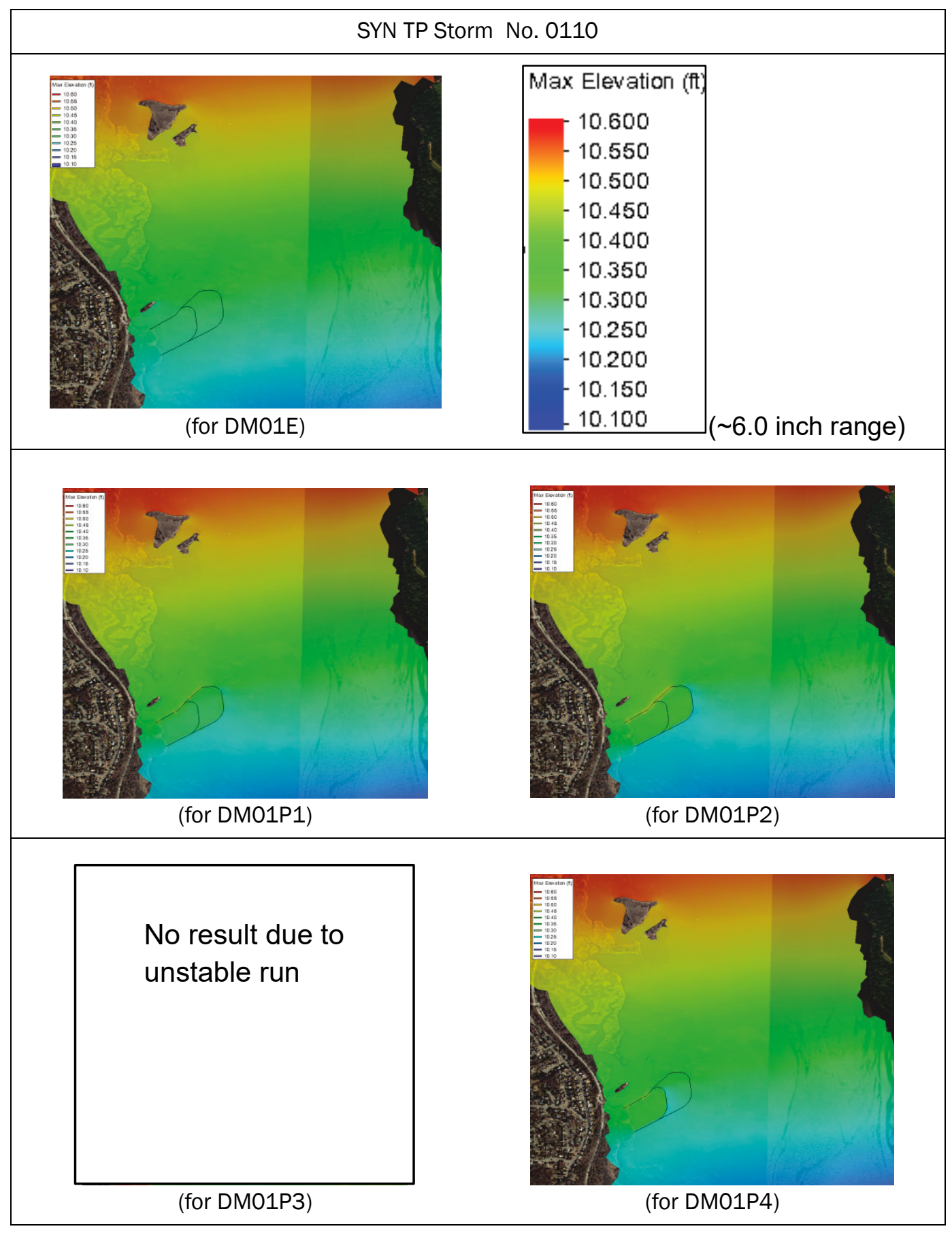




\subsubsection{Maximum depth-averaged storm water velocity results for the fully enclosed promontories}

Local flow fields will be altered due to installation of the design structures (promontories) and the corresponding changes of the river cross section, with generally faster local flow velocities around the structures than those in the present condition (grid: DMo1E). Strong flow velocity is a concern as local scouring around the structures could occur. It is therefore necessary to examine the changes of flow fields and local velocities in the area of Dyke Marsh.

For 10 selected storms (5 HIS ET, 2 HIS TP, and 3 SYN TP; see Figure 5-1 for the storm names), maximum depth-averaged flow velocity magnitudes around the designed promontories are presented in Table 5-12 to Table 5 -22. It is noted that 3 storms of the 13 initially selected did not produce stable model results for all with-project conditions. With consultation from $\mathrm{NAB}$, those three storms were not deemed critical to the outcome of the modeling study. By comparing the flow patterns illustrated by spatial distributions from the model results, local water velocities around the ends of the promontories increase, as expected. Conversely, the velocities at the base of the structures (near the shore-connected location) are reduced, due to the promontory sills acting as a breakwater, blocking part of the longitudinal flow through the structures. For example, for HIS ET Storm No. 0001, Table 5-13 presents the differences in the magnitude of existing condition and with-project maximum water velocity, with approximately $0.5 \mathrm{ft} / \mathrm{s}$ of velocity increase around the ends of the promontories. The longer promontories (DMo1P1 and DMo1P2) cause a slightly faster water flow at the tip than the shorter promontories (DMo1P3 and DMo1P4), but at the upstream side of the promontory base, the velocity magnitude can be $1.5 \mathrm{ft} / \mathrm{s}$ faster than that with no structure. Numerical values of the maximum velocity magnitudes and the differences between the project and no-project conditions can be found in Section 5.1.6. 
Table 5-12. Maximum water velocity color contour plots for HIS ET Storm No. 0001 for five mesh configurations.

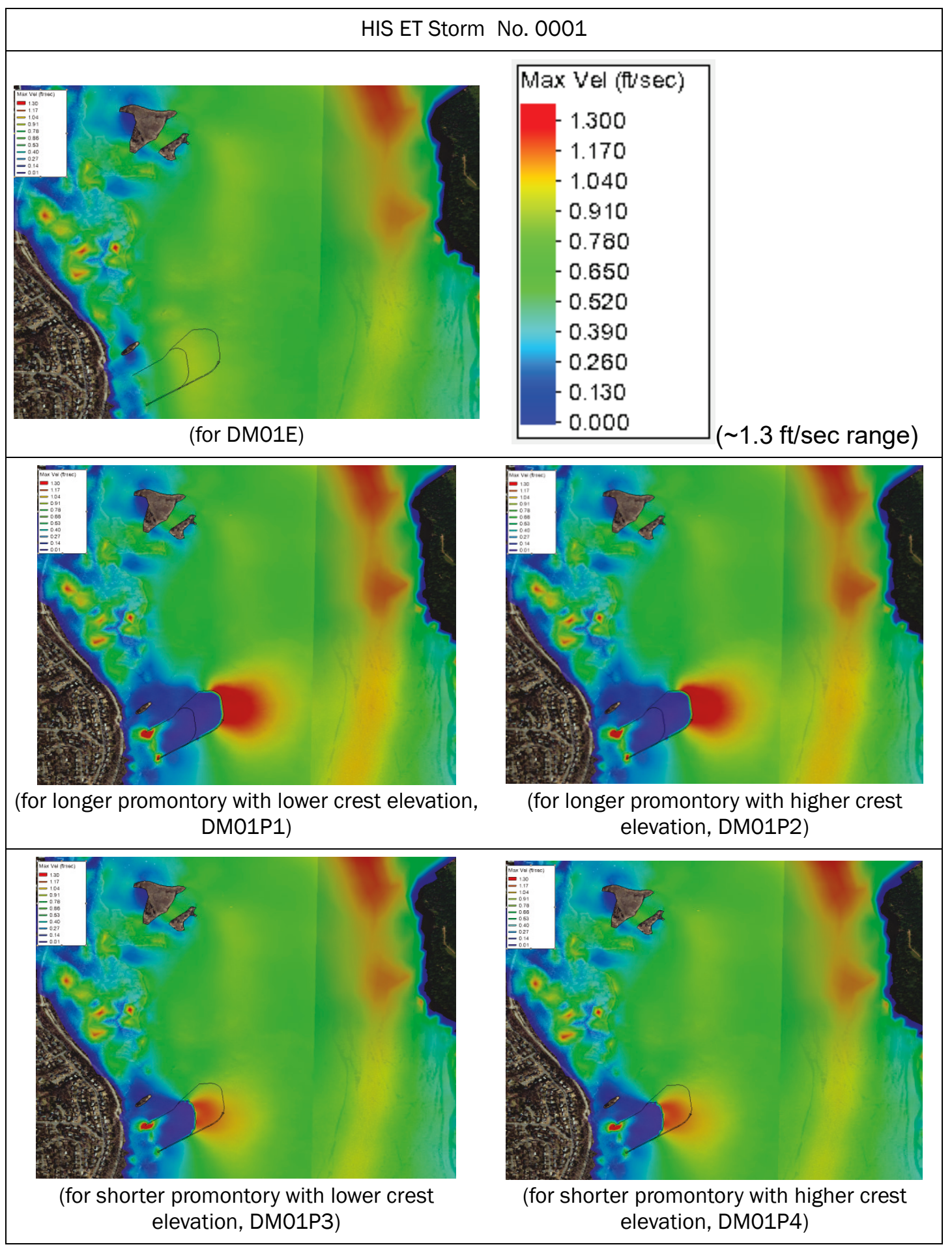


Table 5-13. Difference in maximum water velocity for HIS ET Storm No. 0001 between project and existing conditions (Project - Existing).

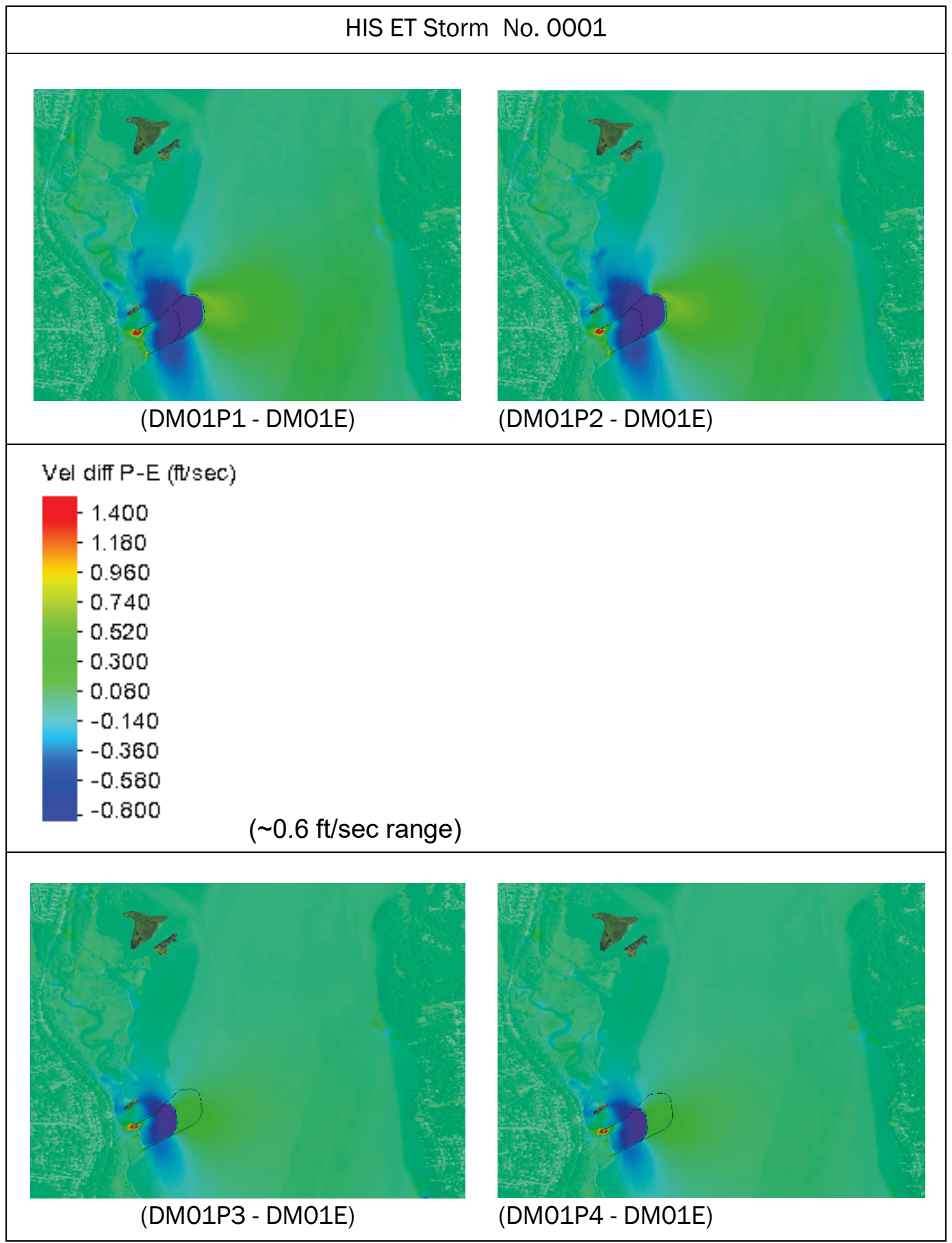


Table 5-14. Maximum water velocity color contour plots for HIS ET Storm No. 0008 for five mesh configurations.

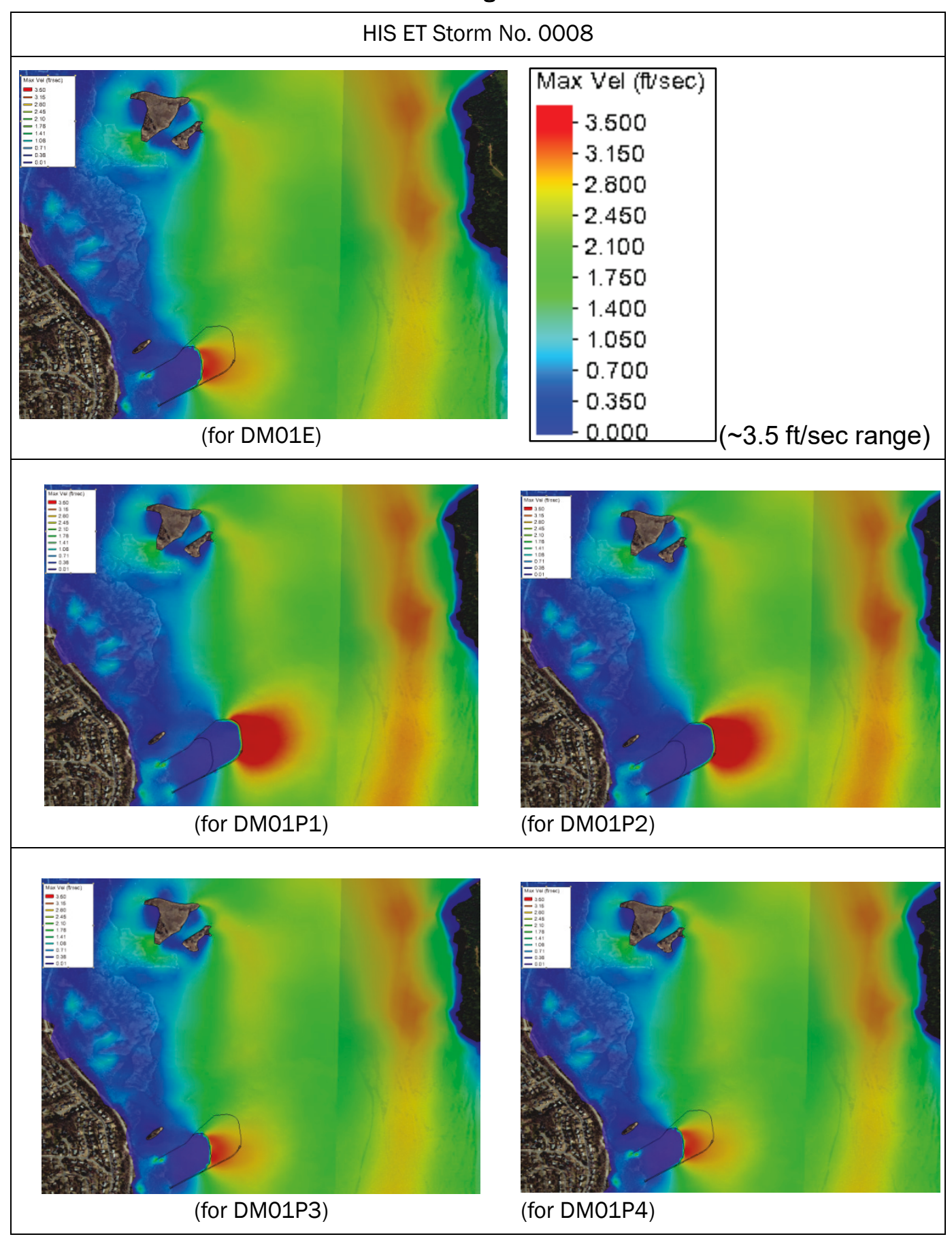


Table 5-15. Maximum water velocity color contour plots for HIS ET Storm No. 0038 for five mesh configurations.

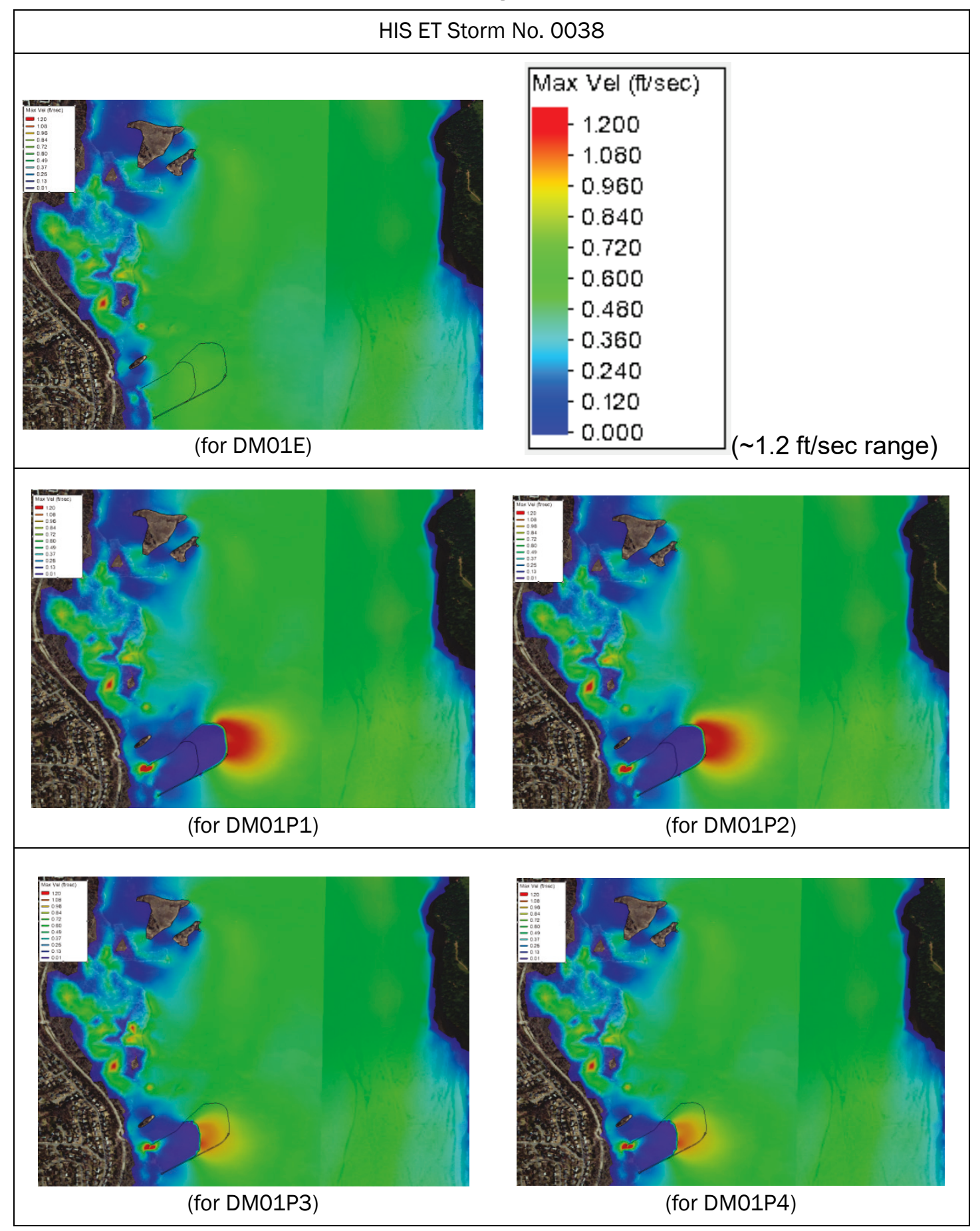


Table 5-16. Maximum water velocity color contour plots for HIS ET Storm No. 0051 for five mesh configurations.

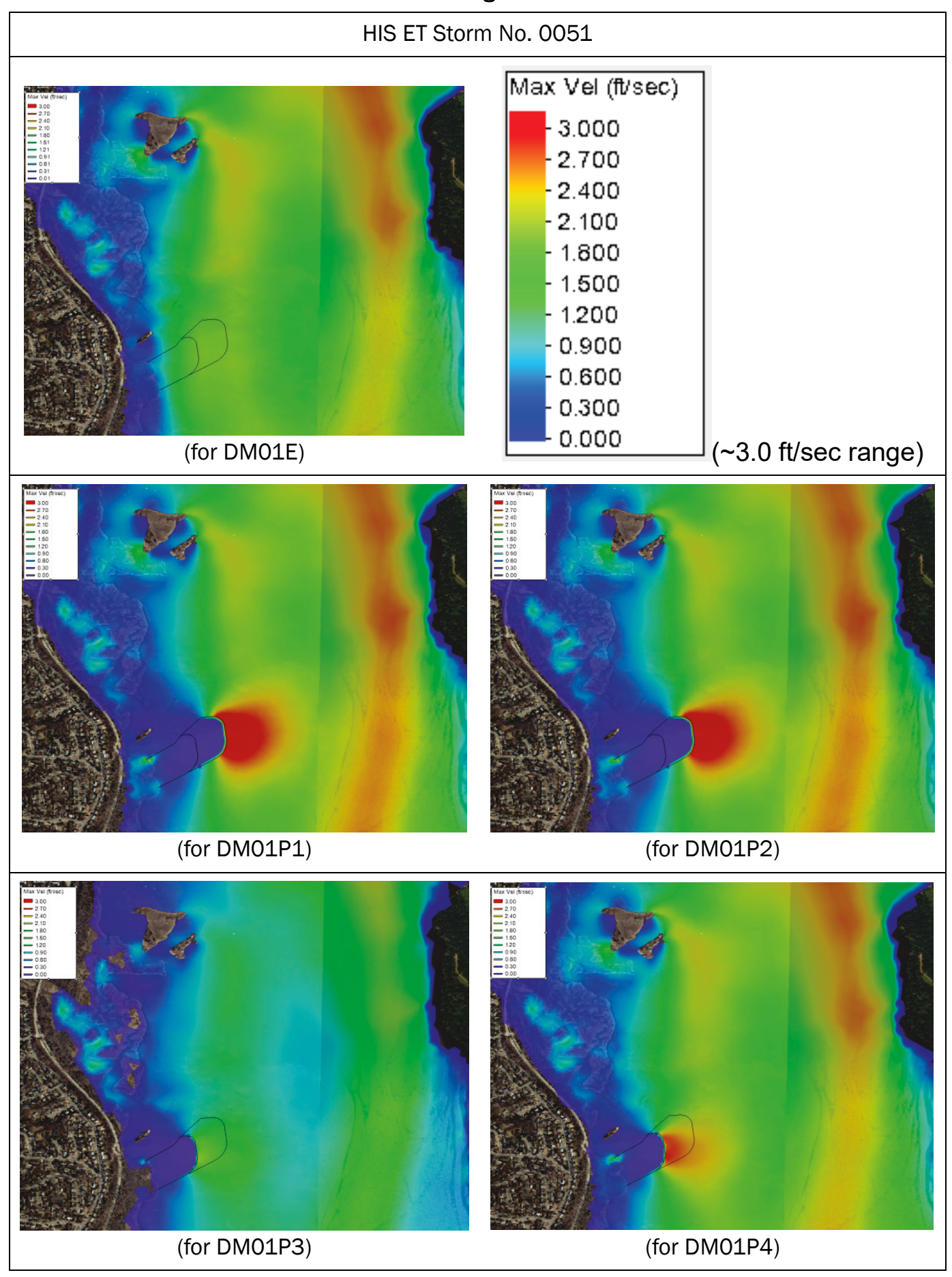


Table 5-17. Maximum water velocity color contour plots for HIS ET Storm No. 0054 for five mesh configurations.

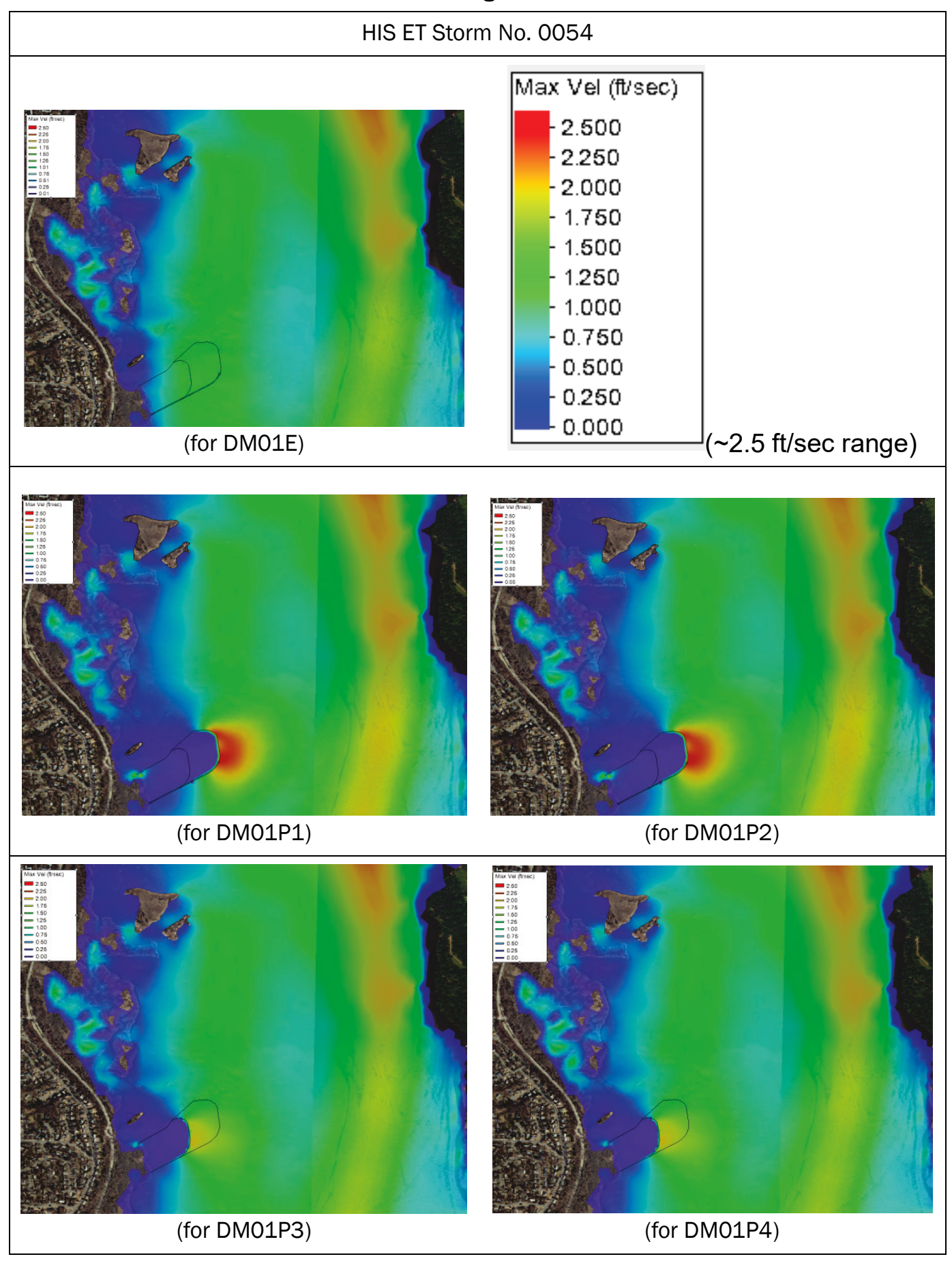


Table 5-18. Maximum water velocity color contour plots for HIS TP Storm No. 0001 (Hurricane Sandy 2012) for five mesh configurations.

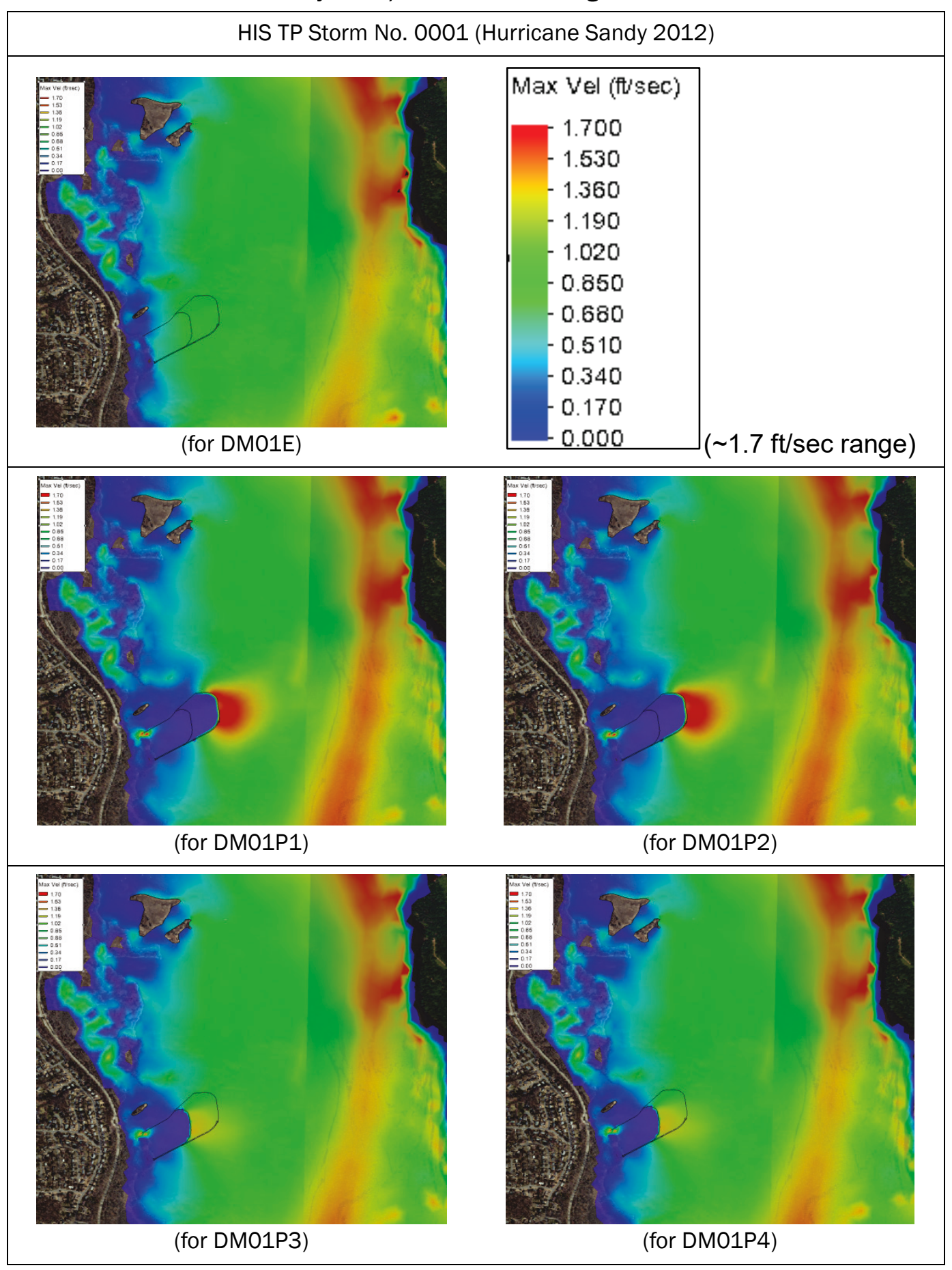


Table 5-19. Maximum water velocity color contour plots for HIS TP Storm No. 0003 (Hurricane Isabel 2003) for five mesh configurations.

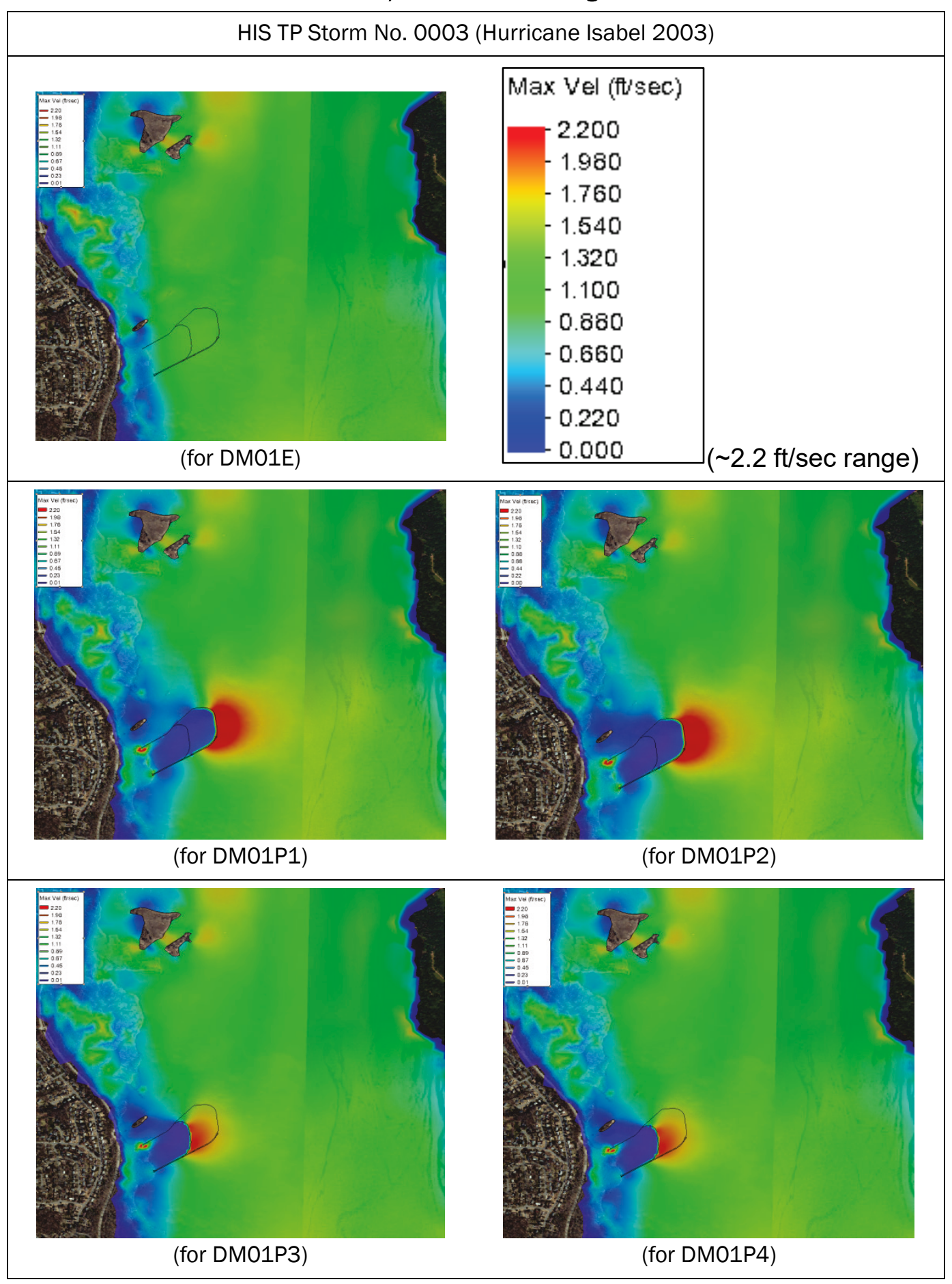


Table 5-20. Maximum water velocity color contour plots for SYN TP Storm No. 0005 for five mesh configurations.

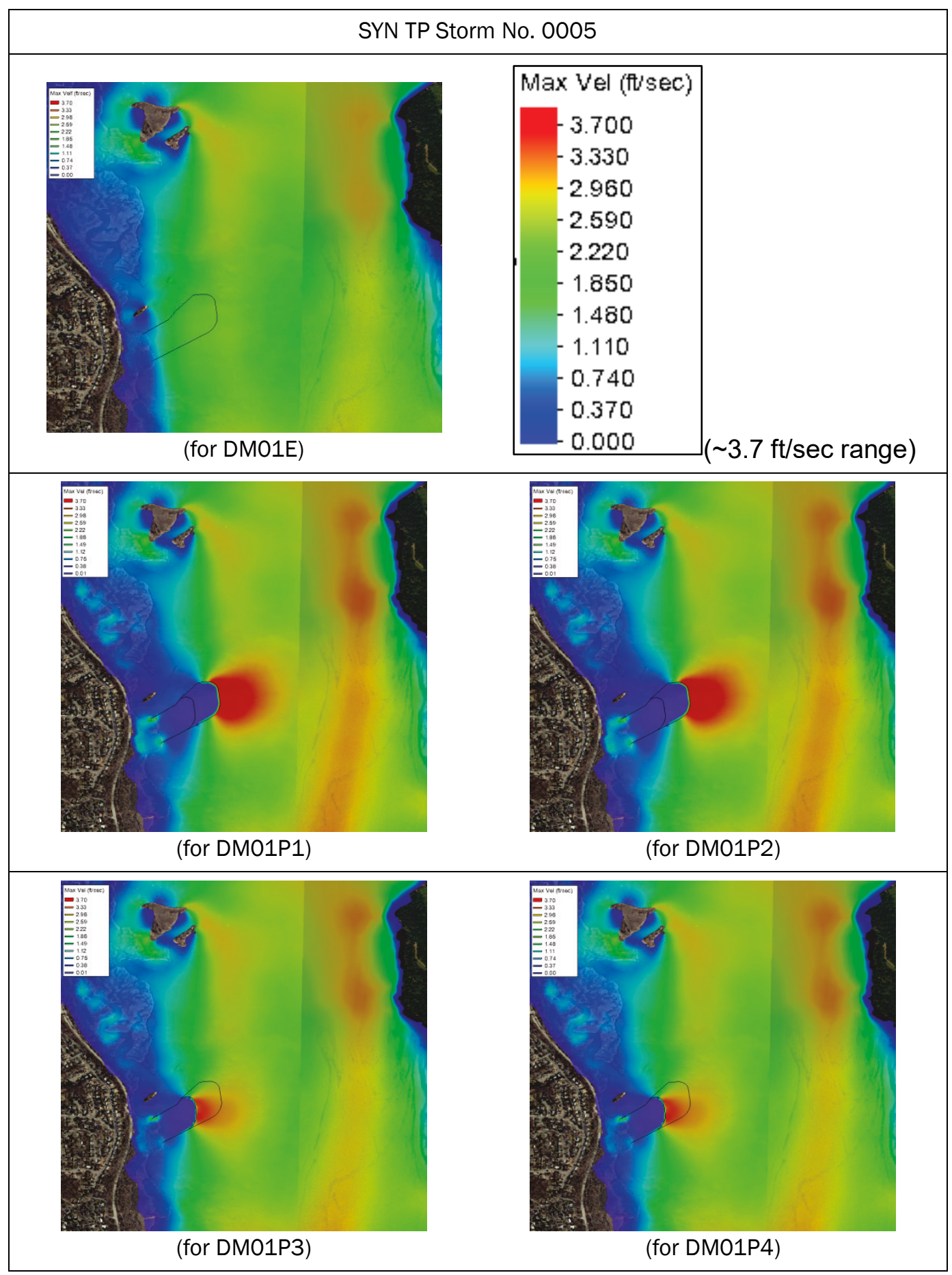


Table 5-21. Maximum water velocity color contour plots for SYN TP Storm No. 0028 for five mesh configurations.

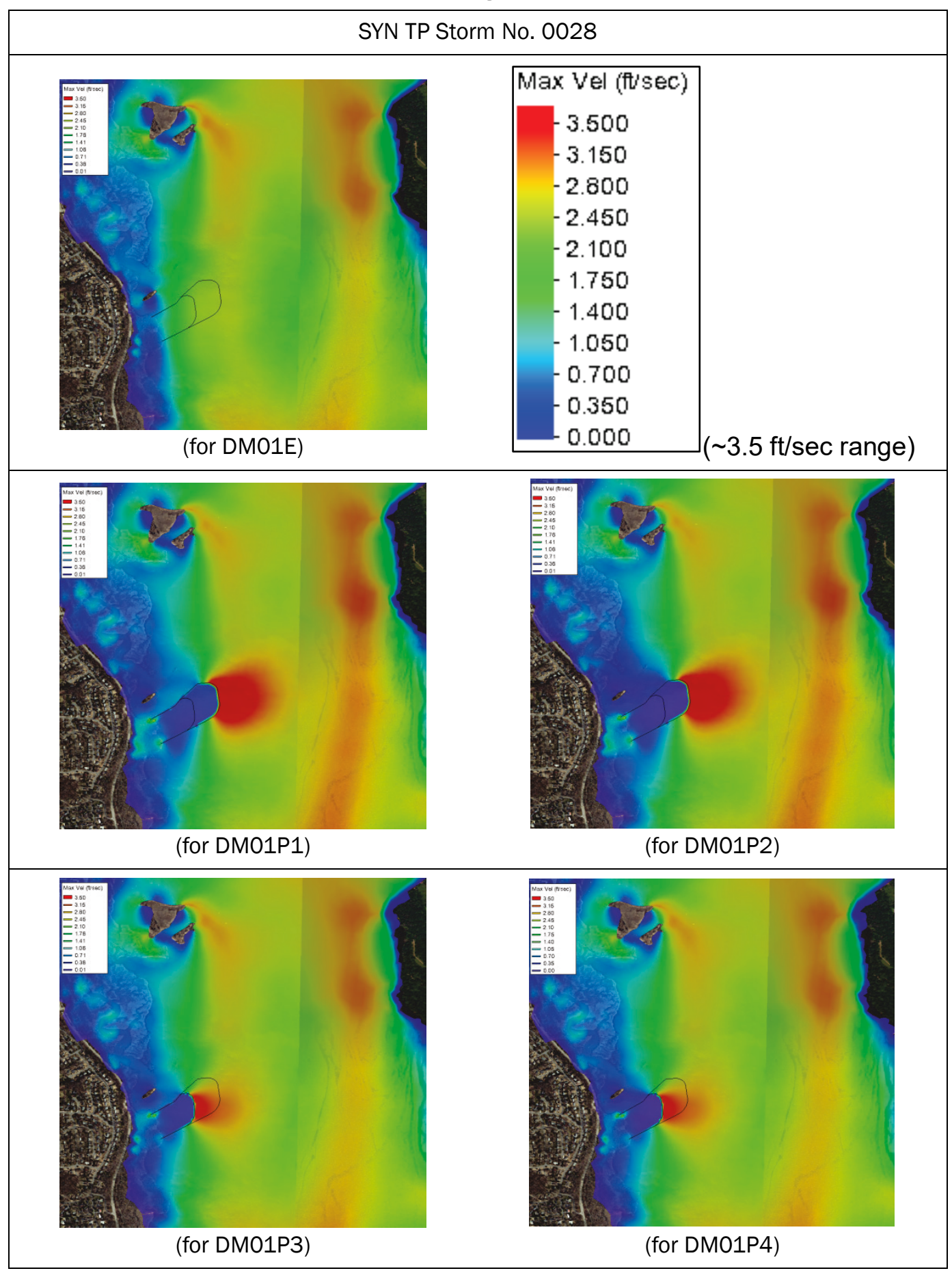


Table 5-22. Maximum water velocity color contour plots for SYN TP Storm 0110 for five mesh configurations.

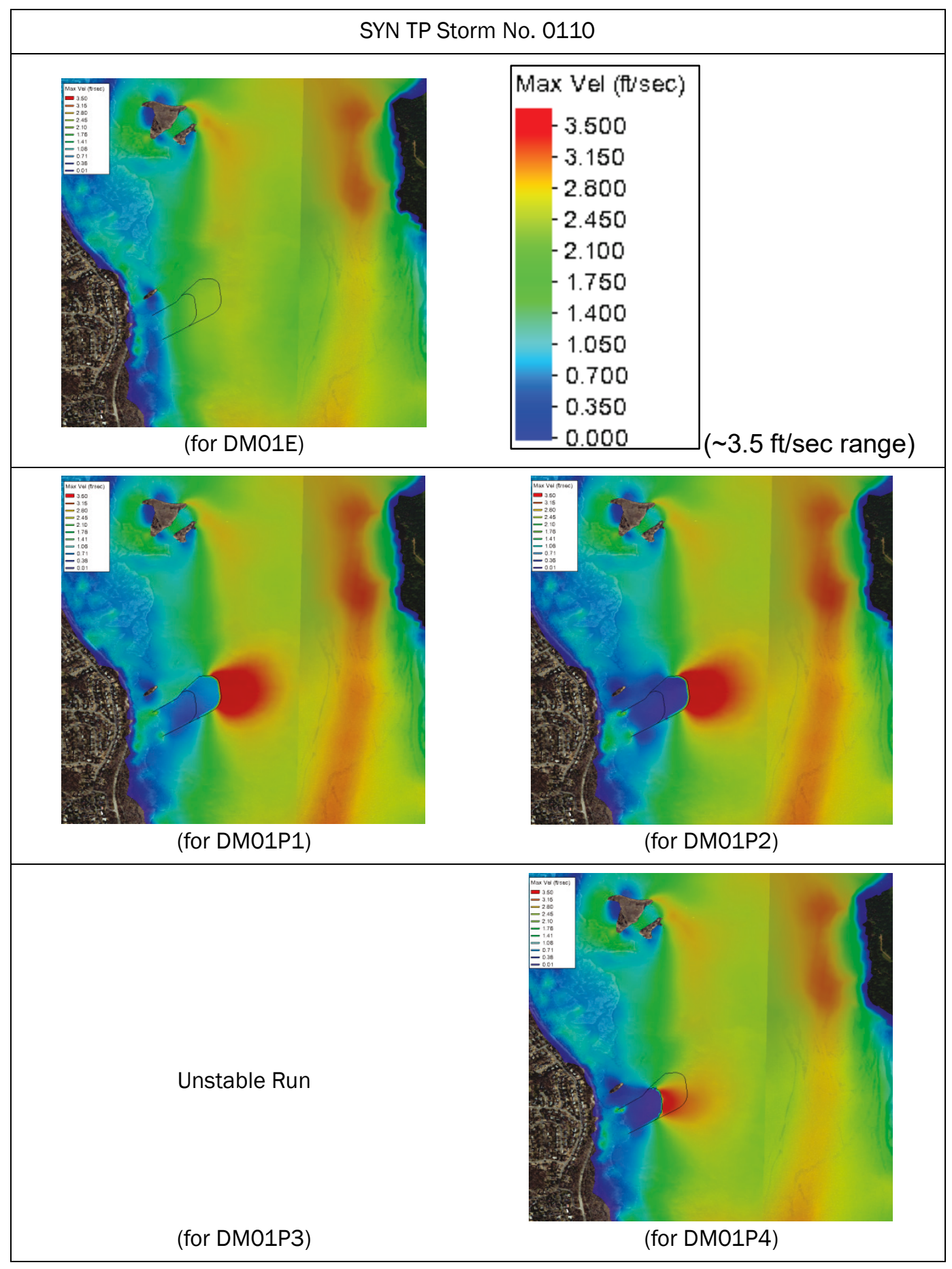




\subsubsection{Maximum significant wave height storm results for the fully enclosed promontories}

Hurricane winds induce surface water waves that propagate along the dominant wind direction. Generally, waves in the area of Dyke Marsh are closely correlated with the hurricane wind speed and the dominant direction. Figure 5-2 presents a map for the Dyke Marsh area; notice that winds blowing toward the southwest (red arrow marked by the letter A), northwest (red arrow marked by the letter B), and due north (red arrow marked by the letter $\mathrm{C}$ ) have the potential of inducing larger wind-waves due to longer fetch lengths from open water leading up to the marsh area. In this section, maximum significant wave heights distributions are presented in Table 5-24 through Table 5-33. A brief summary on winddominant directions of the selected storms is given in Table 5-23. Most of the storms generate winds blowing predominantly toward the north in the area. Only three of the storms (HIS ET No. 0038, HIS ET No. 0054, and HIS TP No. 0001) cause winds blowing predominantly toward the south.

Figure 5-2. Map of the Dyke Marsh area. Arrows indicate directions from which winds blowing would have the potential to create larger wind-waves due to larger fetches.

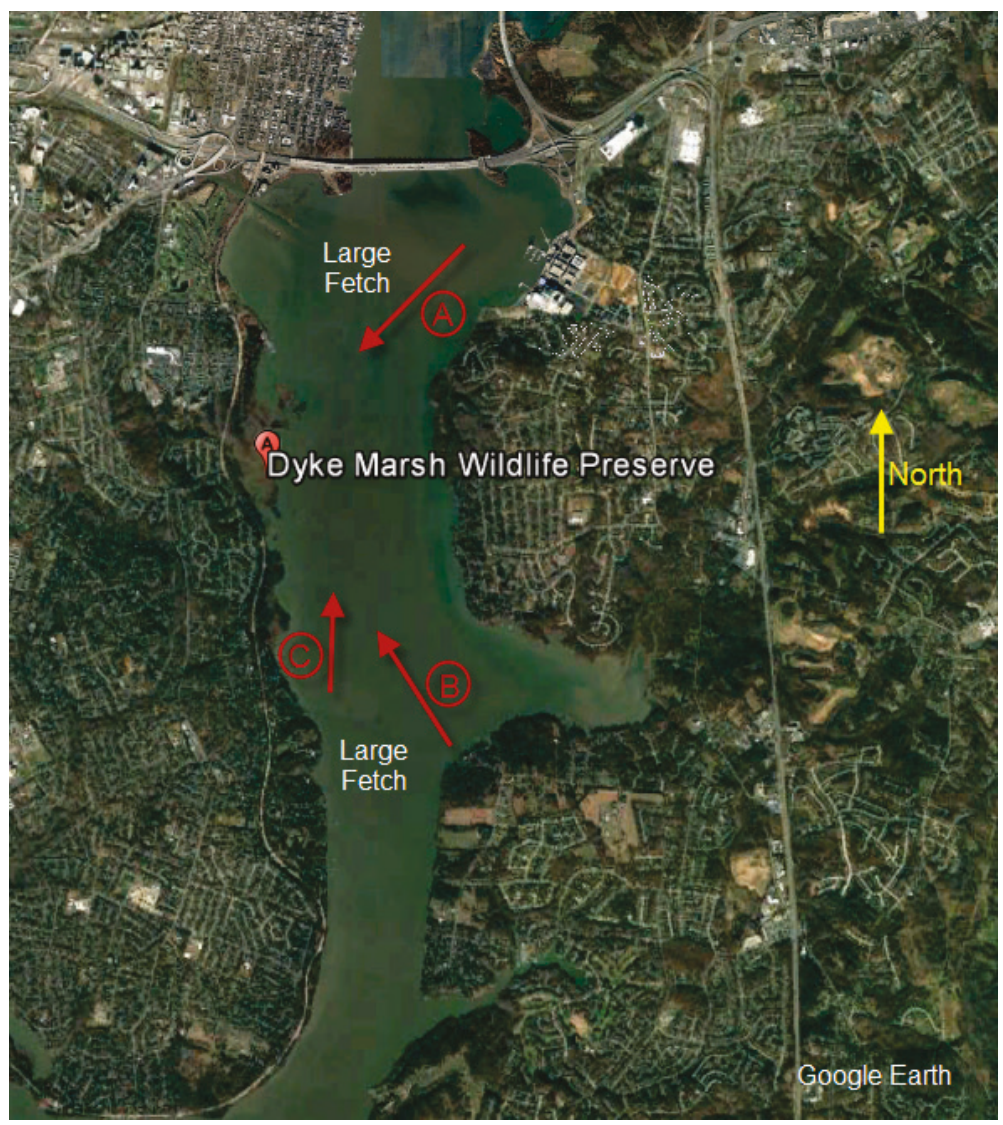


With winds blowing toward the north, waves in the lee of the structure (north of the structure), where the marsh area is desired to be protected, are reduced because of protection from each promontory (e.g., Table 5-24, Table 5-25). The longer promontories (DMo1P1 and DMo1P2) provide a greater area of protection than the shorter ones (DMo1P3 and DMo1P4). With winds blowing toward the southwest (e.g., with HIS ET Storm No. o038, the dominant wind direction was toward the southwest) the wind direction is from the eastern river bank to the west bank and from north to south. Due to the geometry of the Potomac River in that area, there is a large fetch where local wind waves can grow in height and be directed into the shoreline areas of Dyke Marsh (Table 5-26) where the marsh area is located. In these wind direction cases, the promontories are unable to provide protection from the waves. For a wind blowing toward the southeast, such as observed for HIS ET Storm No. 0054, the open water fetch for generating local wind waves is toward the eastern bank. In this case, the marsh area of Dyke Marsh receives much less wave energy. Similarly, a wind blowing toward the south, such as in the case of Hurricane Sandy (2012) (HIS TP No. 0001), generates relatively small waves directed into the marsh shorelines of Dyke Marsh (Table 5-29), and the promontories have little impact.

Table 5-23. Summary of maximum significant wave height (Hs, max) results and dominant wind directions in Dyke Marsh for every storm.

\begin{tabular}{l|c|c|c|}
\hline Storm & $\begin{array}{c}\text { Dominant Wind } \\
\text { Direction Toward }\end{array}$ & $\begin{array}{c}\text { Distributions of } \\
\text { Hs, max }\end{array}$ & $\begin{array}{c}\text { Difference in Hs, max between with- } \\
\text { and without-structure conditions }\end{array}$ \\
\hline HIS ET No. 0001 & N & Table 5-24 & Table 5-34 \\
\hline HIS ET No. 0008 & SW & Table 5-25 & Table 5-35 \\
\hline HIS ET No. 0038 & N & Table 5-26 5-27 & Table 5-36 \\
\hline HIS ET No. 0051 & SE & Table 5-28 & Table 5-37 \\
\hline HIS ET No. 0054 & S & Table 5-29 & Table 5-39 \\
\hline $\begin{array}{l}\text { HIS TP No. 0001 } \\
\text { (Sandy 2012) }\end{array}$ & N & Table 5-30 & Table 5-40 \\
\hline $\begin{array}{l}\text { HIS TP No. 0003 } \\
\text { (Isabel 2003) }\end{array}$ & NW & Table 5-31 & Table 5-41 \\
\hline $\begin{array}{l}\text { SYN TP No. 0005 } \\
\text { SYN TP No. 0028 }\end{array}$ & NW & Table 5-32 & Table 5-42 \\
\hline $\begin{array}{l}\text { SYN TP No. 0110 } \\
\text { SY N }\end{array}$ & Table 5-33 & Table 5-43 \\
$\begin{array}{l}\text { Note: } \\
\text { HIS ET = historical extra-tropical storm } \\
\text { HIS TP = historical tropical storm (hurricane) } \\
\text { SYN TP = synthetic tropical storm }\end{array}$
\end{tabular}


Table 5-24. Maximum significant wave height for HIS ET Storm No. 0001 for five mesh configurations (with and without structures).

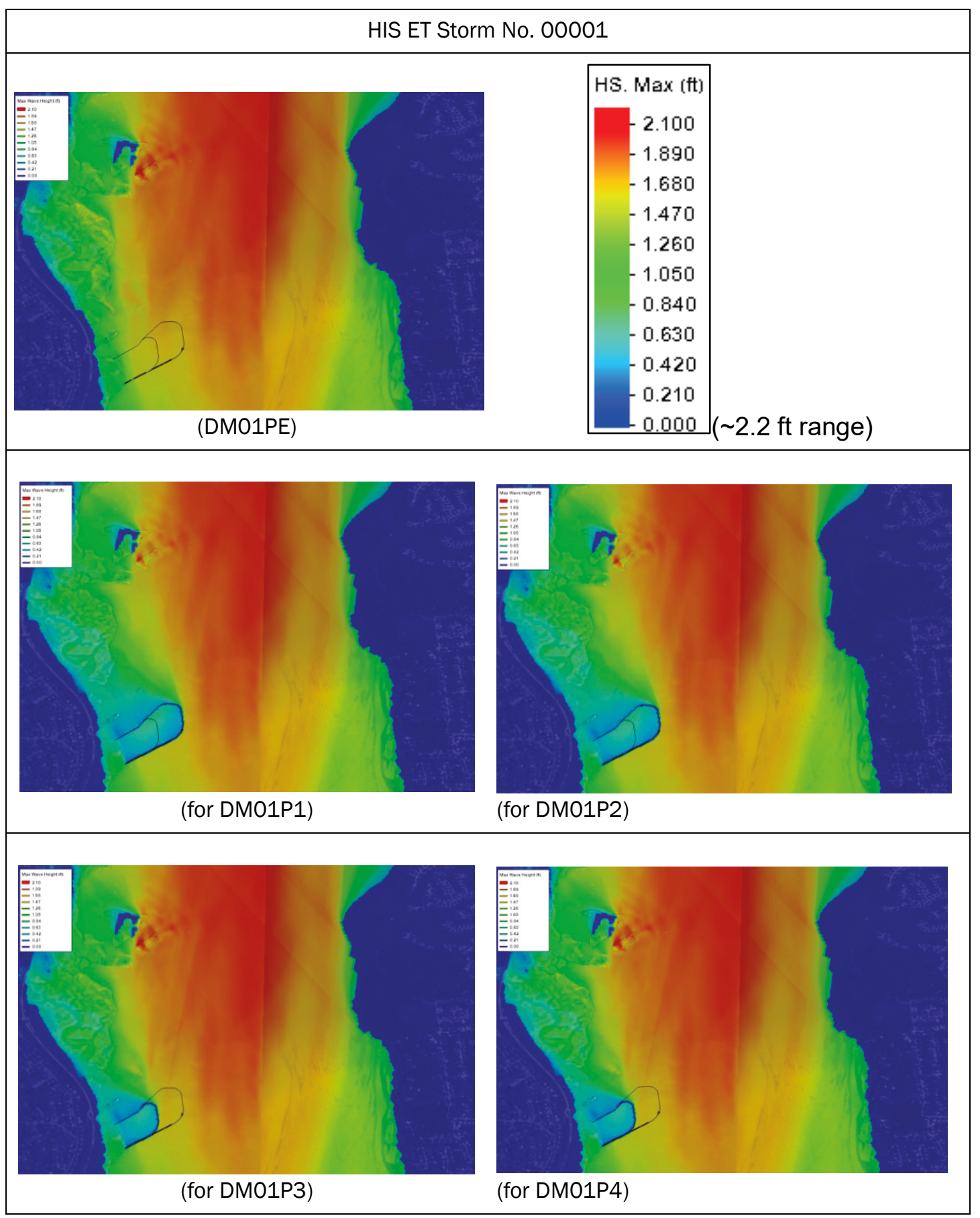


Table 5-25. Maximum significant wave height for HIS ET Storm No. 0008 for five mesh configurations.

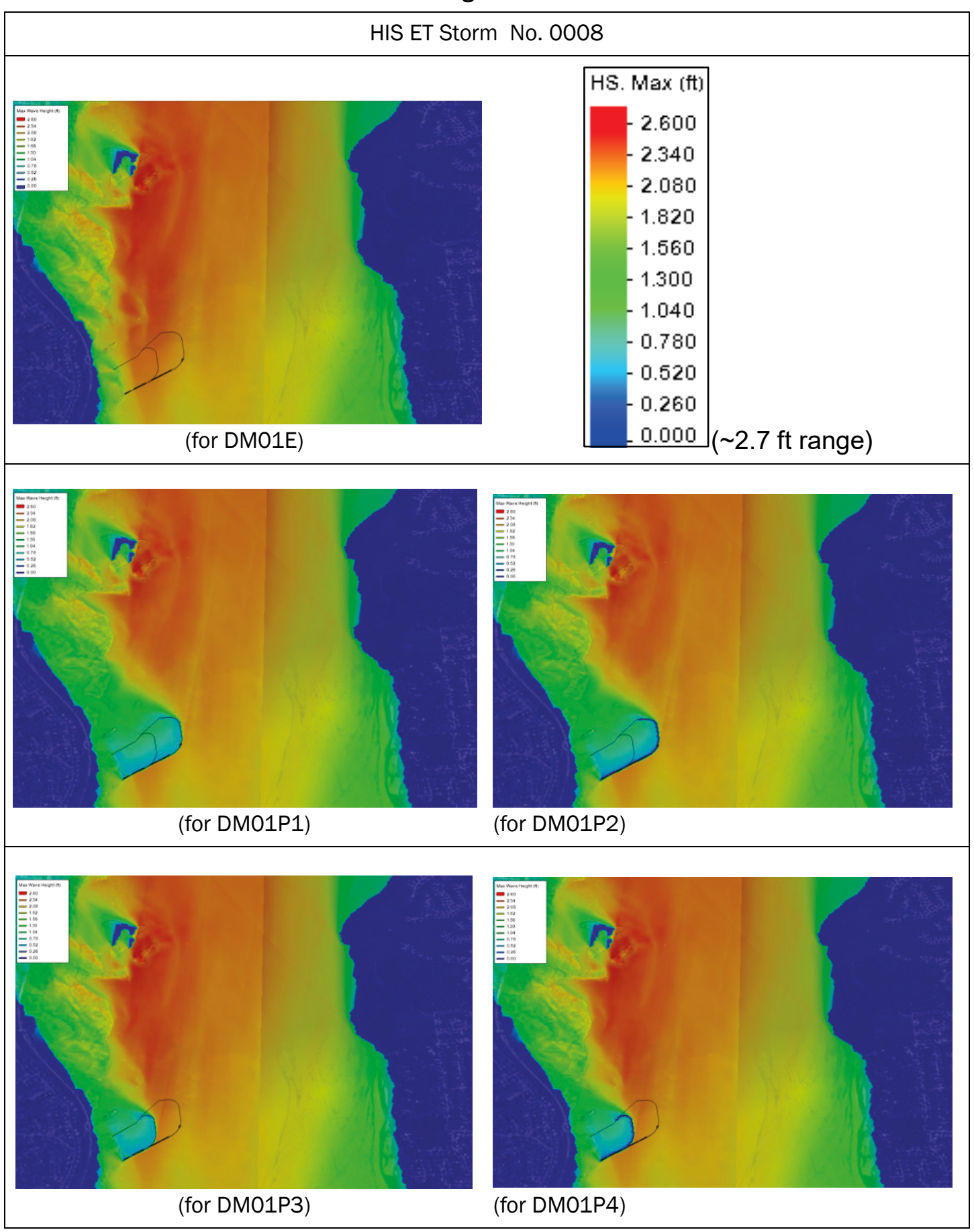


Table 5-26. Maximum significant wave height color contour plots for HIS ET Storm No. 0038 for five mesh configurations.

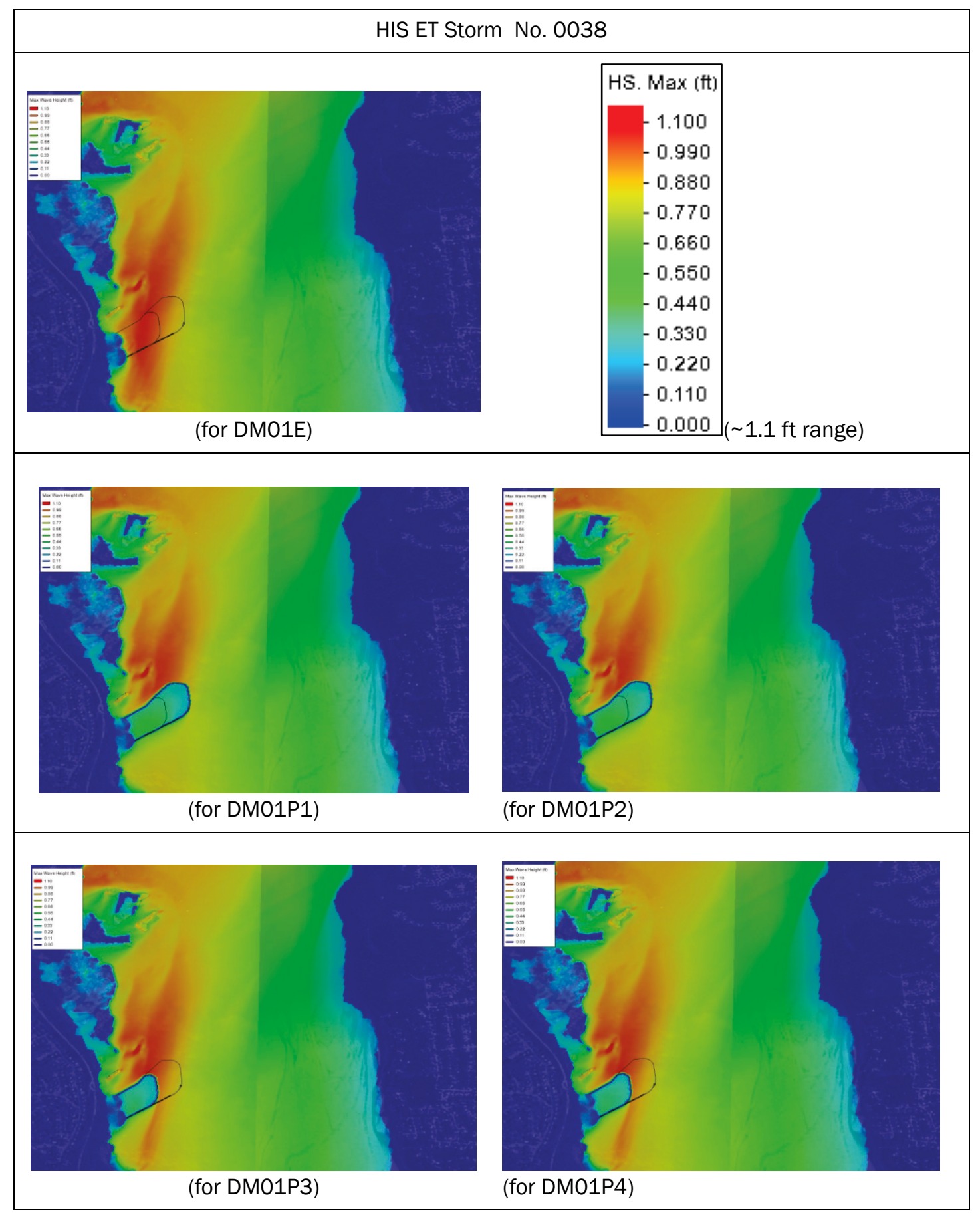


Table 5-27. Maximum significant wave height color contour plots for HIS ET Storm No. 0051 for five mesh configurations.

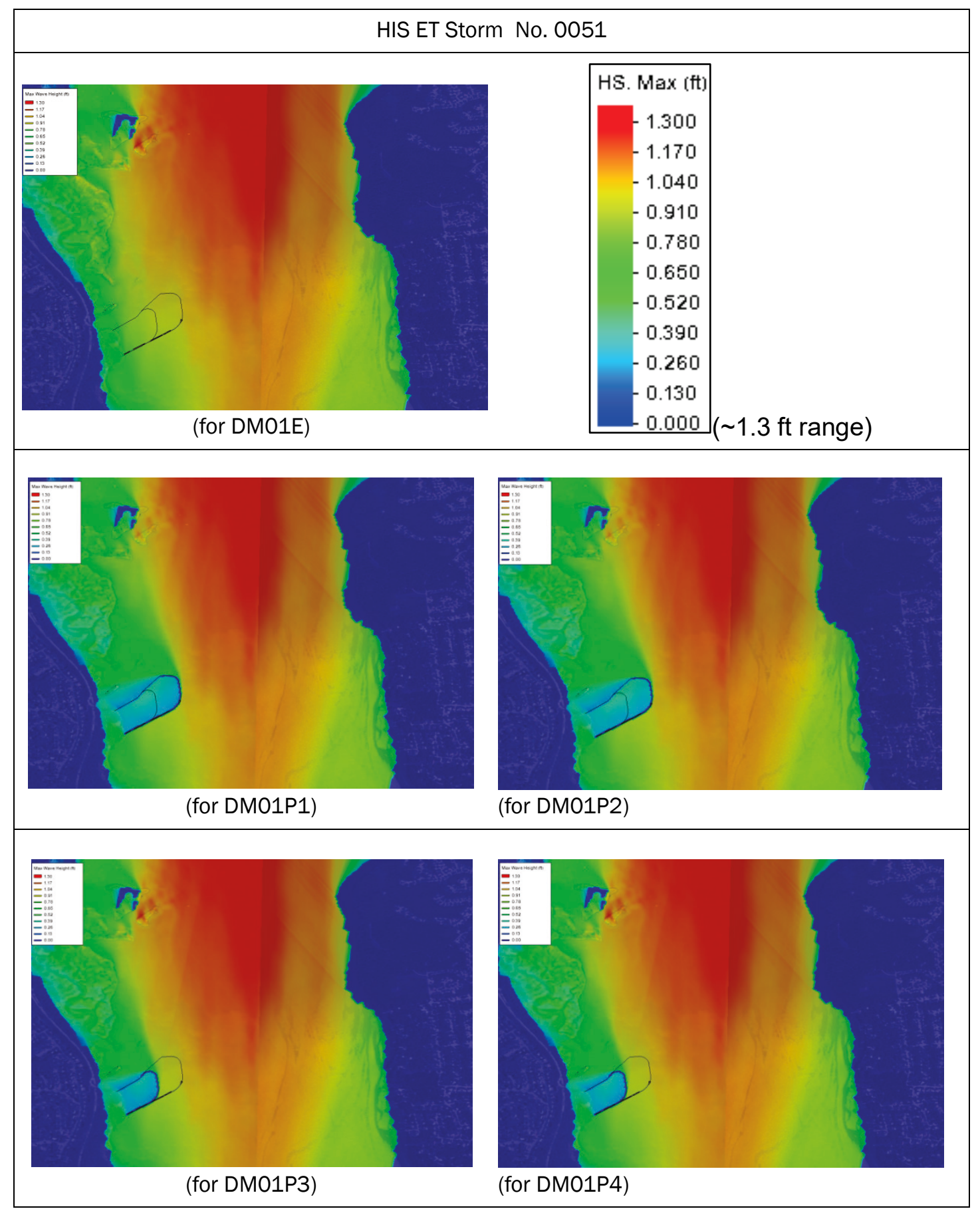


Table 5-28. Maximum significant wave height color contour plots for HIS ET Storm No. 0054 for five mesh configurations.

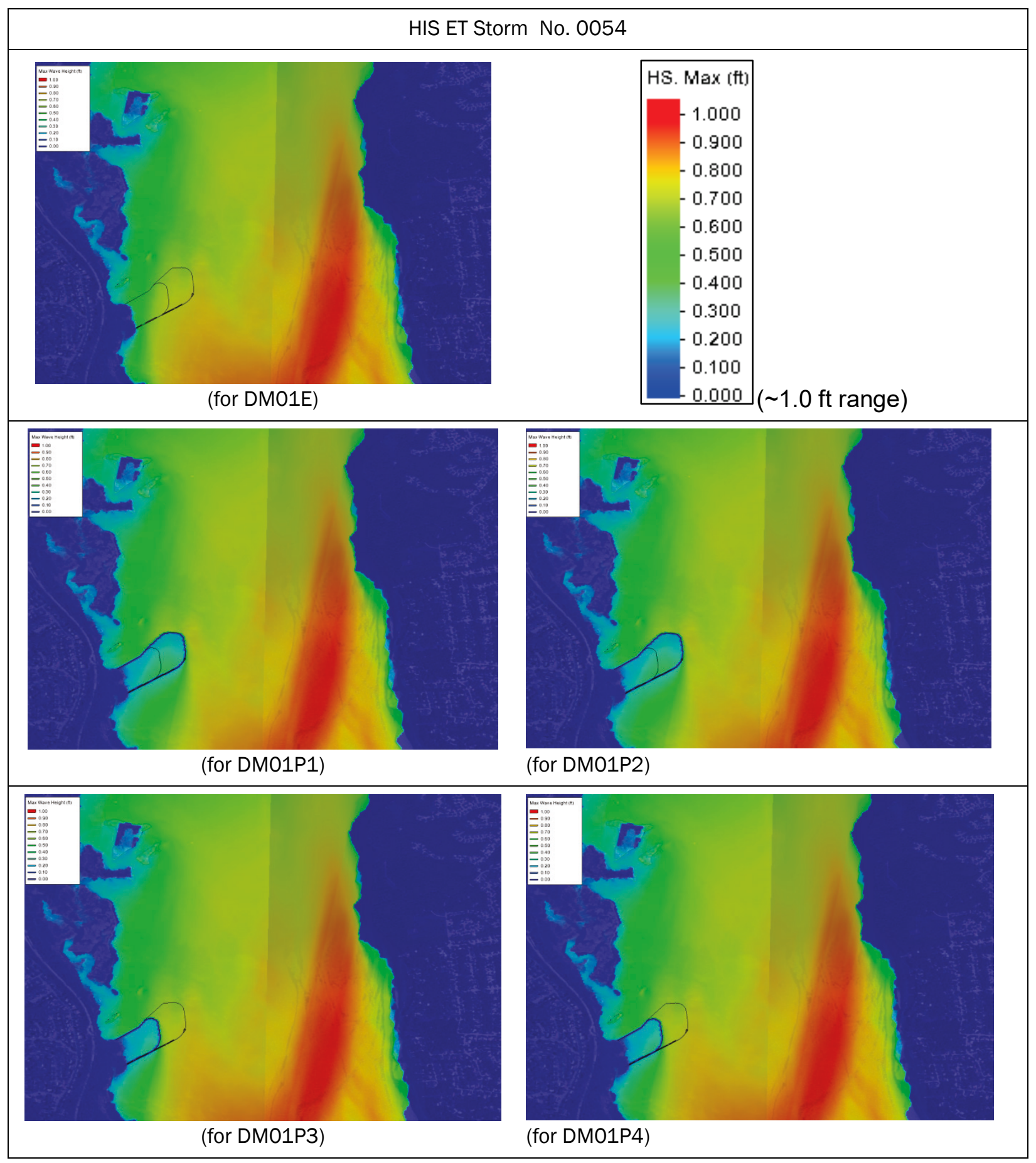


Table 5-29. Maximum significant wave height color contour plots for HIS TP Storm No. 0001 (Hurricane Sandy 2012) for five mesh configurations.

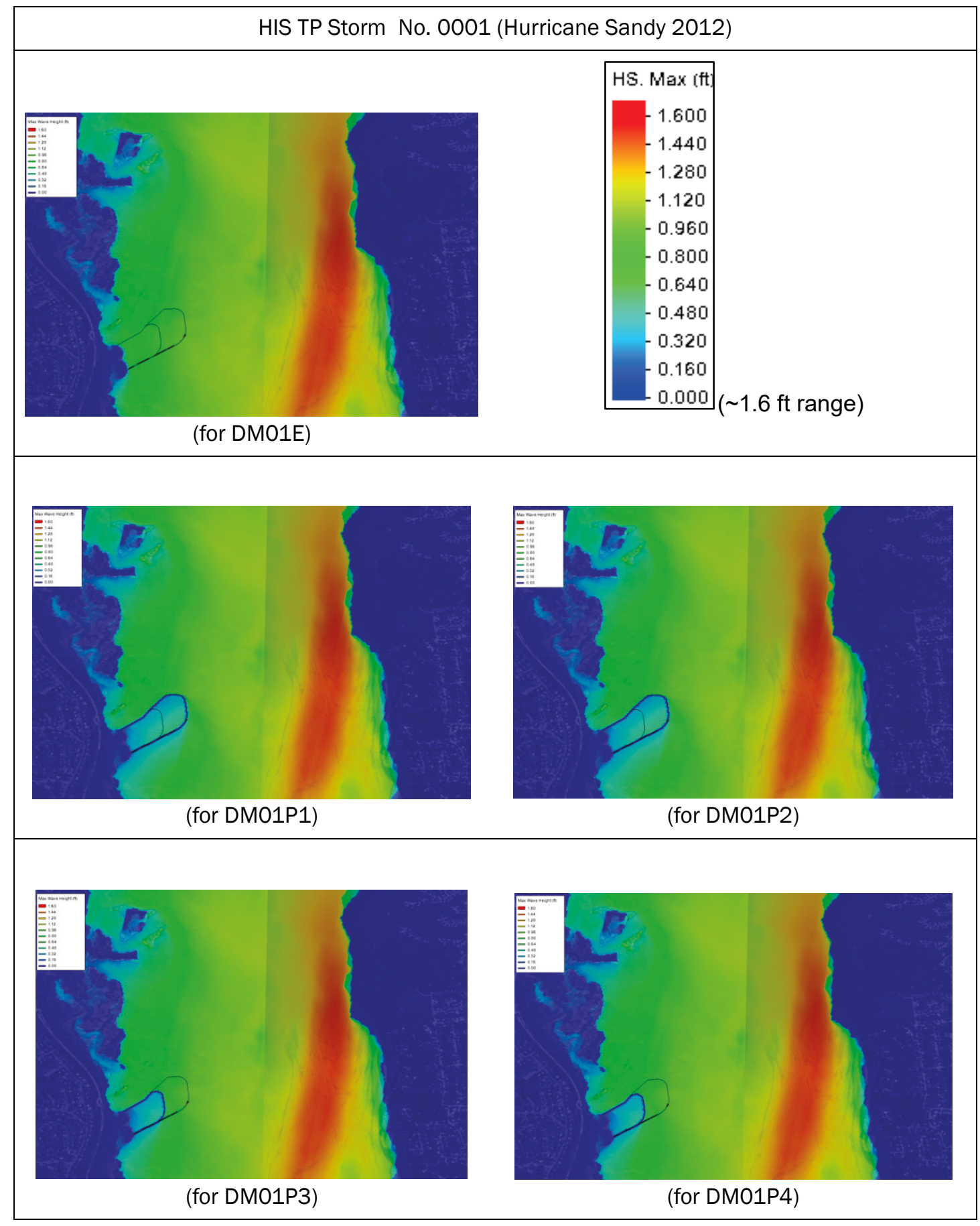


Table 5-30. Maximum significant wave height color contour plots for HIS TP Storm No. 0003 (Hurricane Isabel 2003) for five mesh configurations.

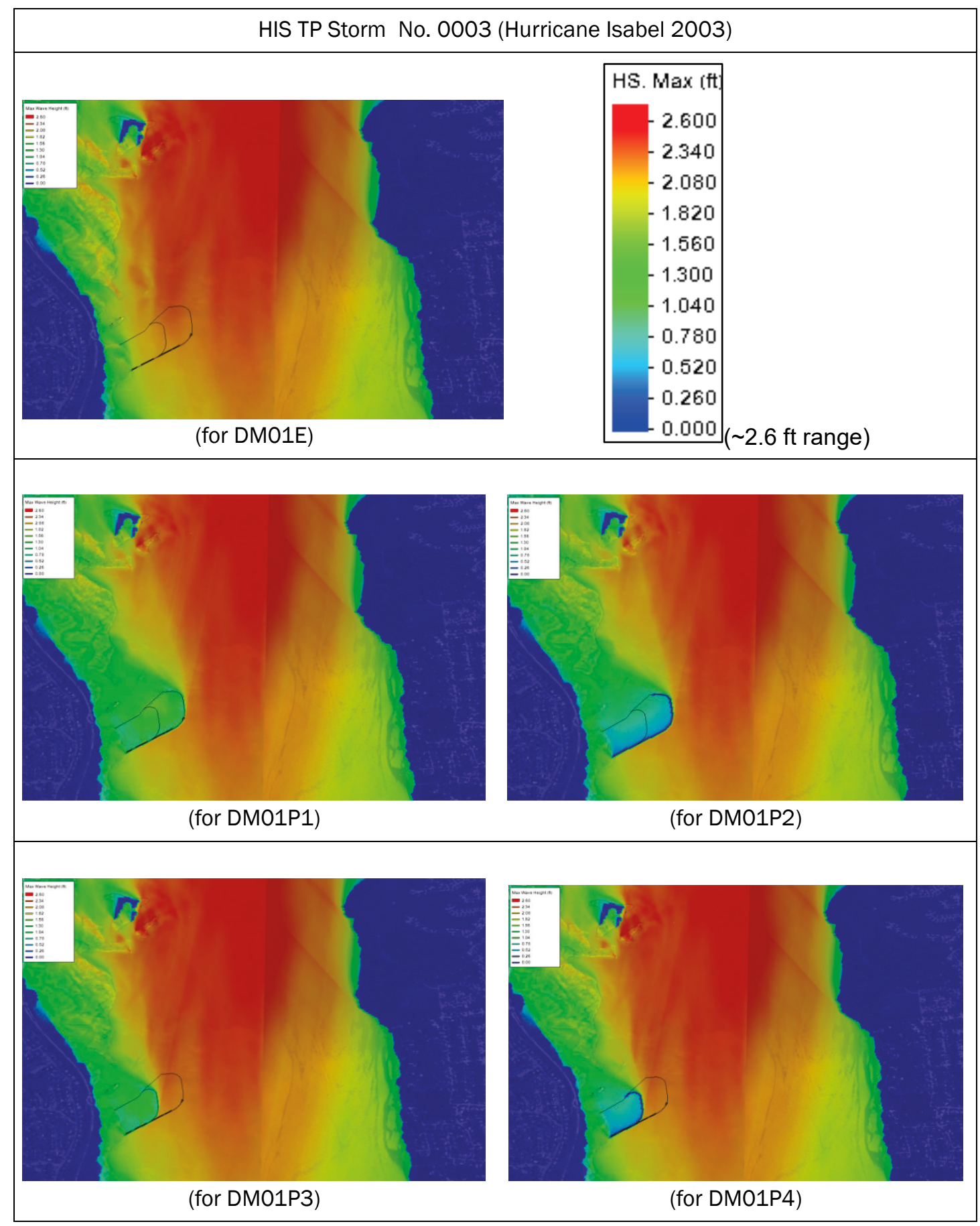


Table 5-31. Maximum significant wave height color contour plots for SYN TP Storm No. 0005 for five mesh configurations.

\begin{tabular}{|c|c|}
\hline \multicolumn{2}{|c|}{ SYN TP Storm No. 0005} \\
\hline$\left\{\begin{array}{l}\text { (for DM01E) } \\
\text { (f) }\end{array}\right.$ & $\left.$\begin{tabular}{|r|} 
HS. Max (ft) \\
-0.900 \\
-0.810 \\
-0.720 \\
-0.630 \\
-0.540 \\
-0.450 \\
-0.360 \\
-0.270 \\
-0.180 \\
-0.090 \\
0.000
\end{tabular}\right|$_{(\sim 0.9 \mathrm{ft} \text { range })}$ \\
\hline 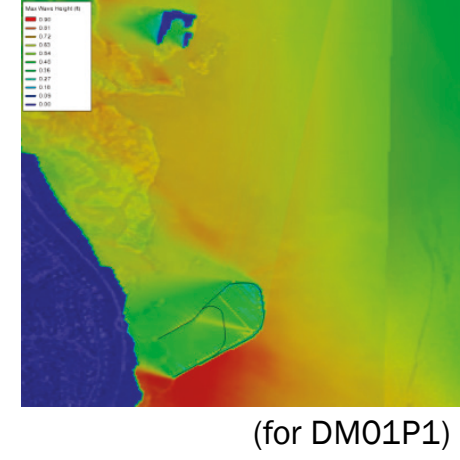 & (for DM01P2) \\
\hline 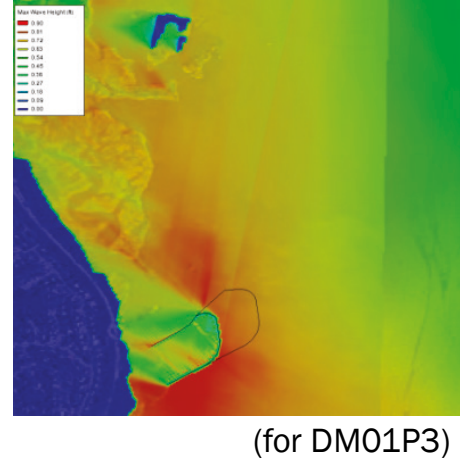 & (for DM01P4) \\
\hline
\end{tabular}


Table 5-32. Maximum significant wave height color contour plots for SYN TP Storm No. 0028 for five mesh configurations.

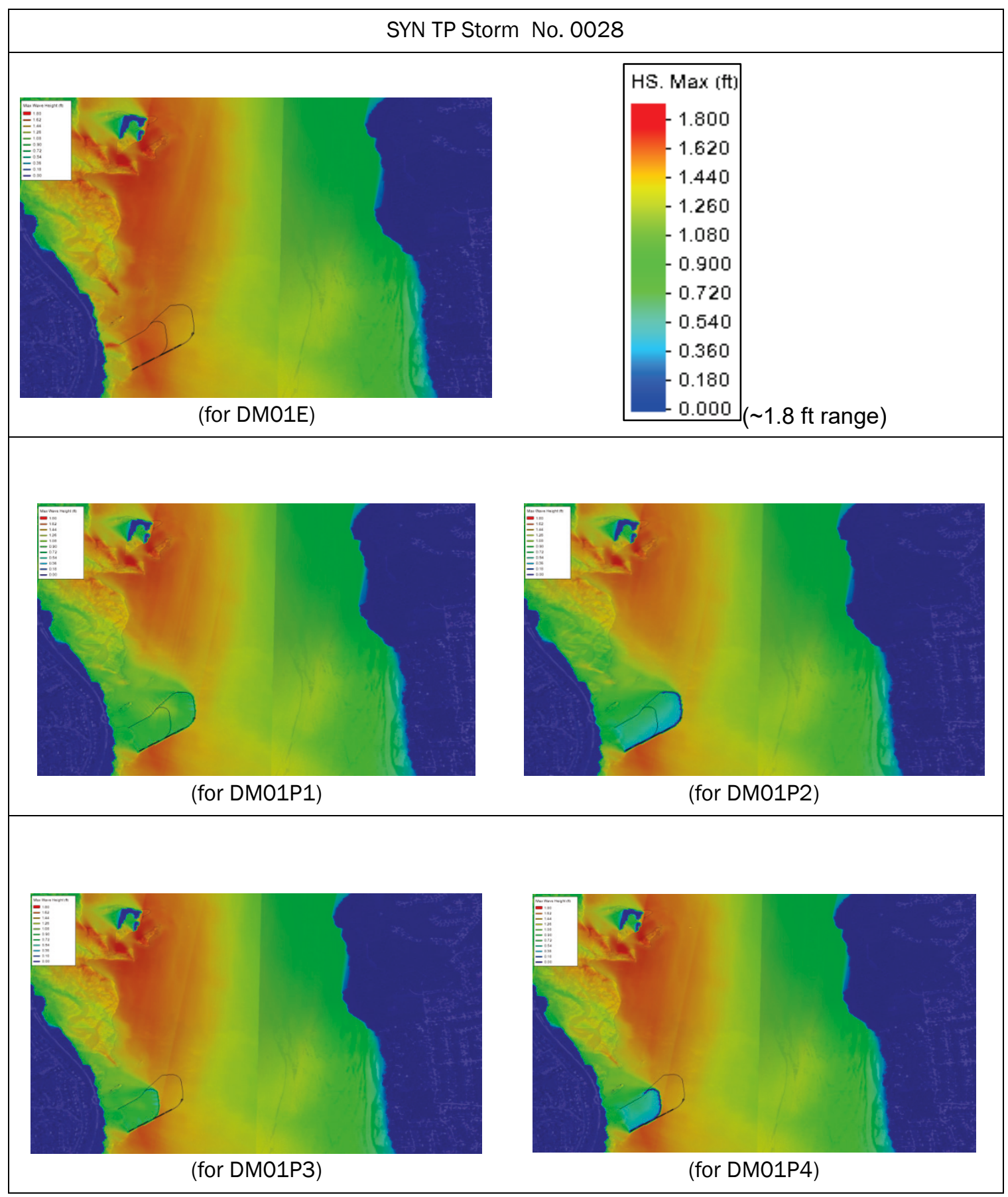


Table 5-33. Maximum significant wave height color contour plots for SYN TP Storm No. 0110 for five mesh configurations.

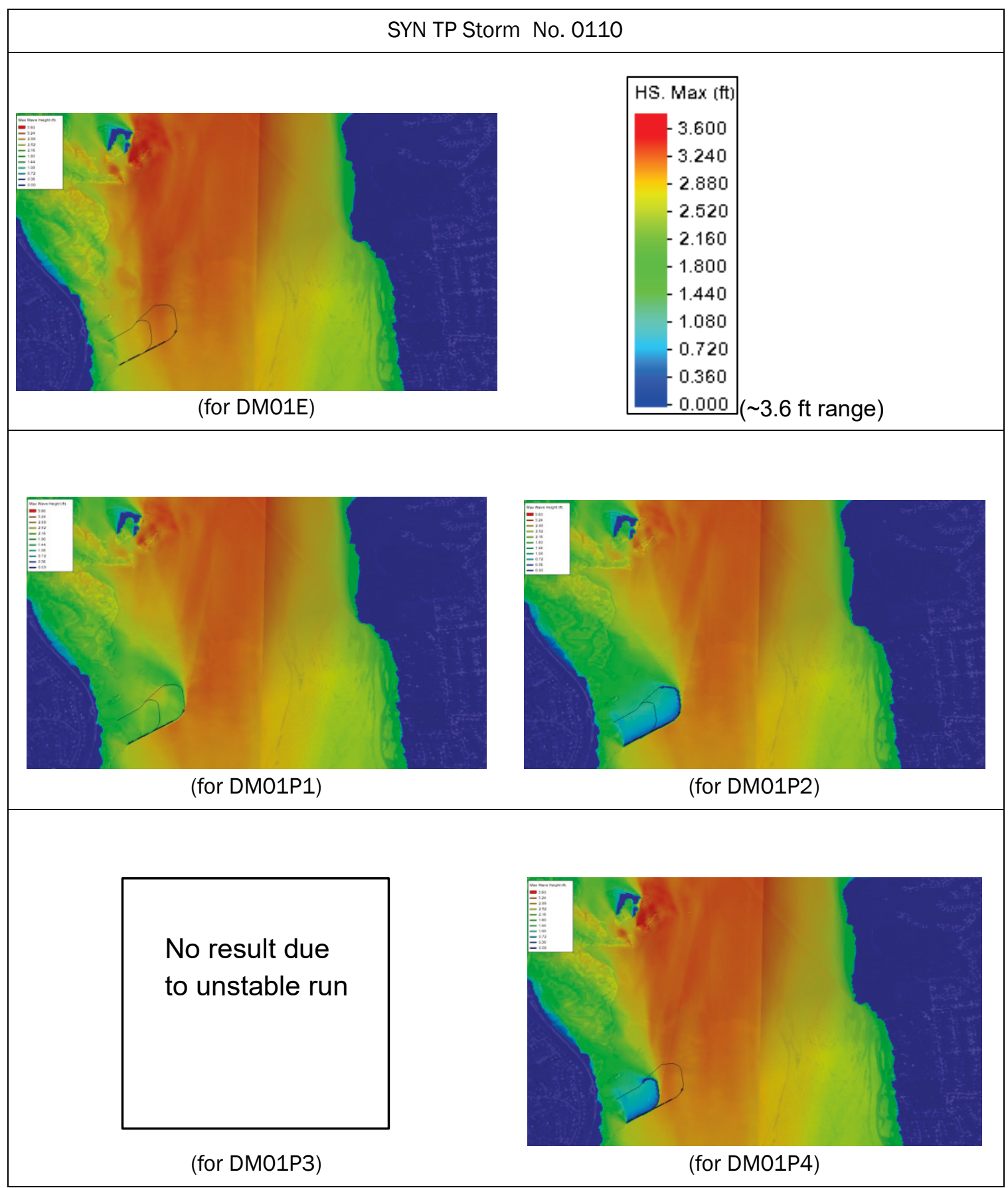

\subsubsection{Difference in maximum significant wave height storm results for the fully enclosed promontories}

Differences in maximum significant wave heights between project and existing conditions for the selected 10 storms (see Table 5-23 for the storm names) are given in Table 5-34 through Table 5-43. For each storm, the 
differences in significant wave height are visualized in two view windows: one shows an area including the structure and Dyke Marsh, and another focuses on a closeup of the promontory. For the northward-directed wind, the promontories are able to reduce wave heights in the lee more than 1.o ft by HIS ET Storm No. 0001 (Table 5-34) to $2.0 \mathrm{ft}$ by SYN TP No. 0110 (Table 5-43). For the southward wind, waves in the lee of structure (in the south) are decreased up to $0.3 \mathrm{ft}$ by HIS ET Storm No. 0054 (Table 5-38). Some numerical values of the wave heights and the differences are given in Section 5.1.6.

Table 5-34. Difference (ft) in maximum significant wave height for HIS ET Storm No. 0001 between project and existing conditions (Project - Existing). Note that the plot at right side is a close-up view with a narrow range of scales.

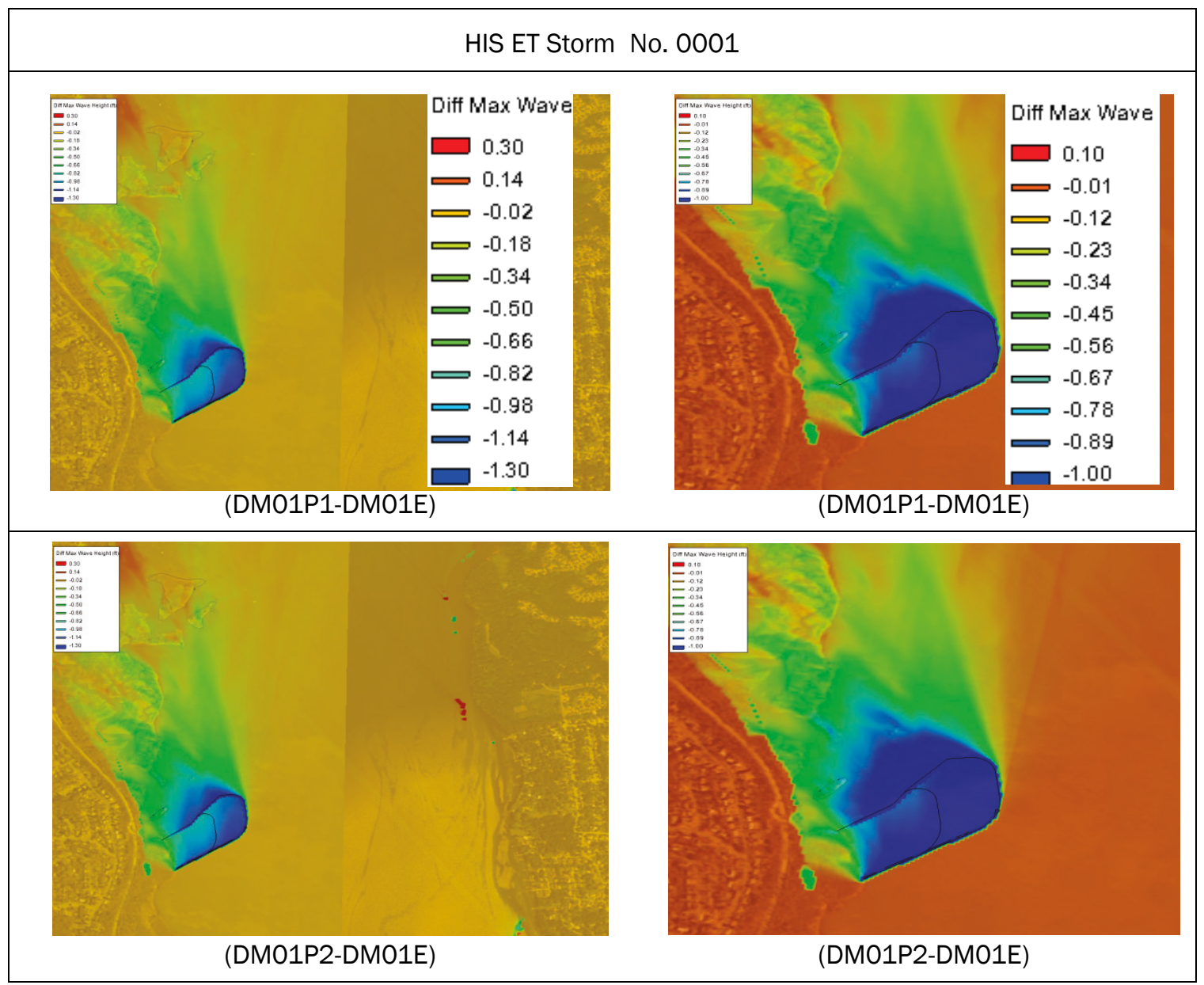




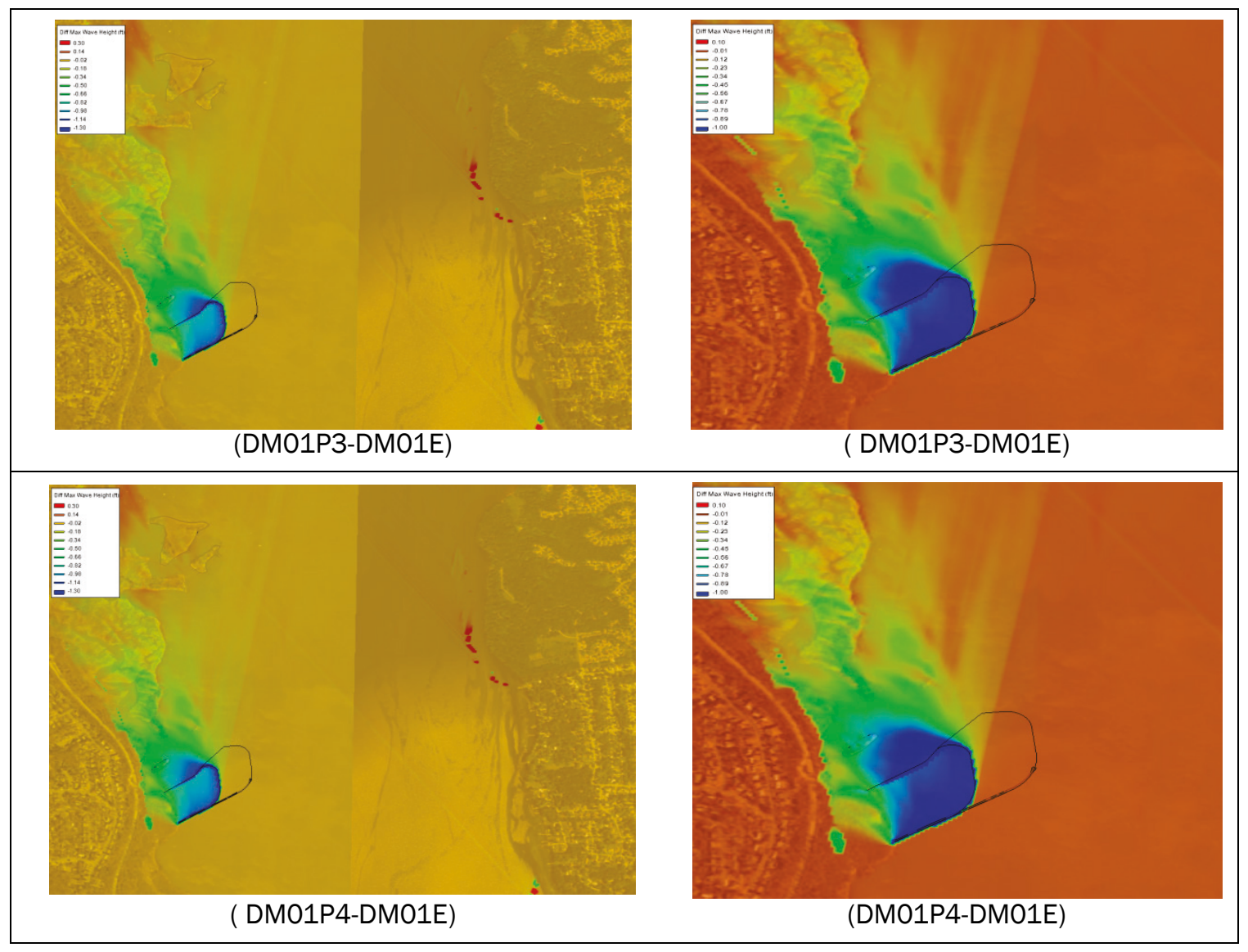


Table 5-35. Difference in maximum significant wave height for HIS ET Storm No. 0008 between project and existing conditions (Project - Existing). Note that the plot at right side is a close-up view with a narrow range of scales.

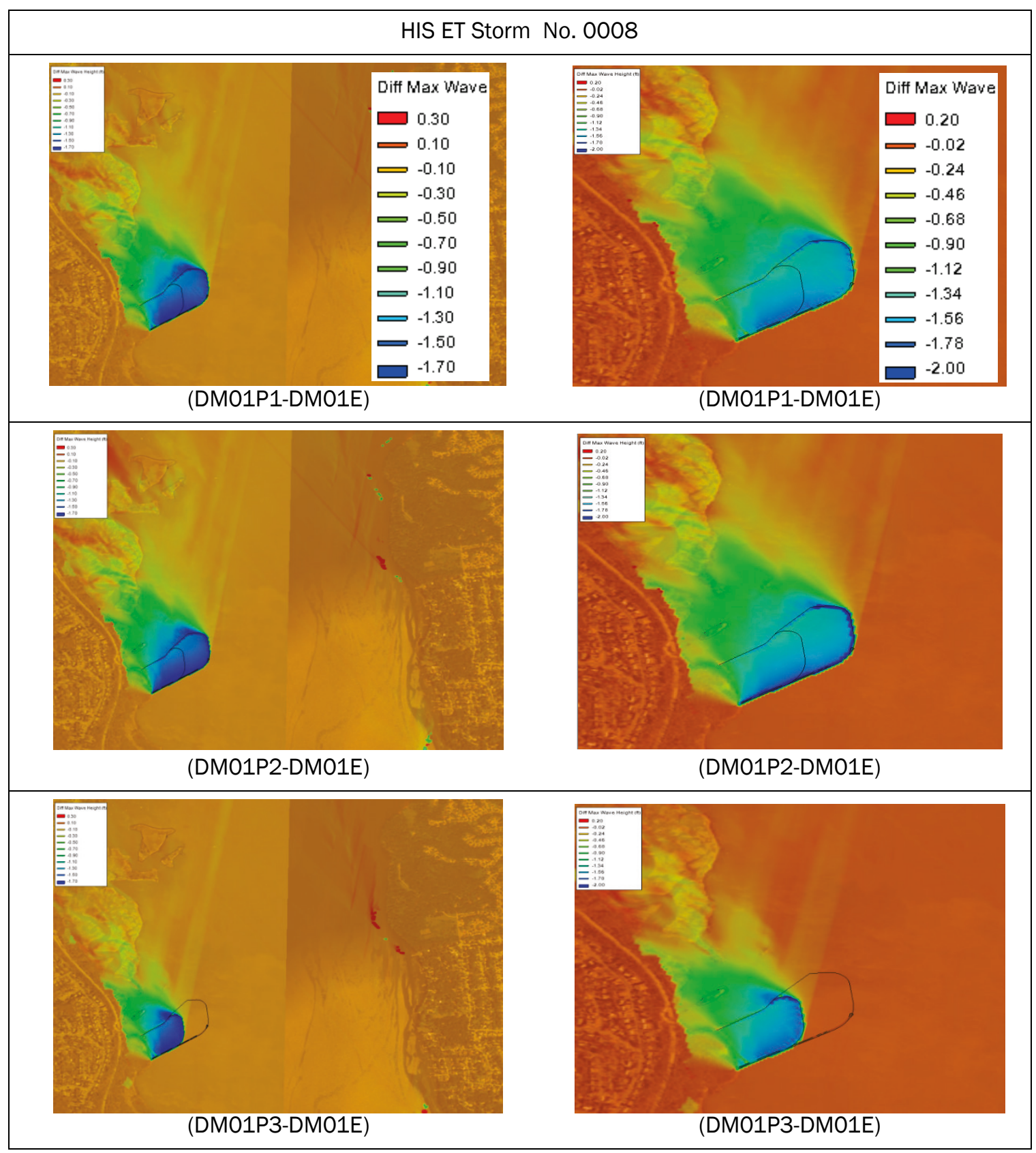




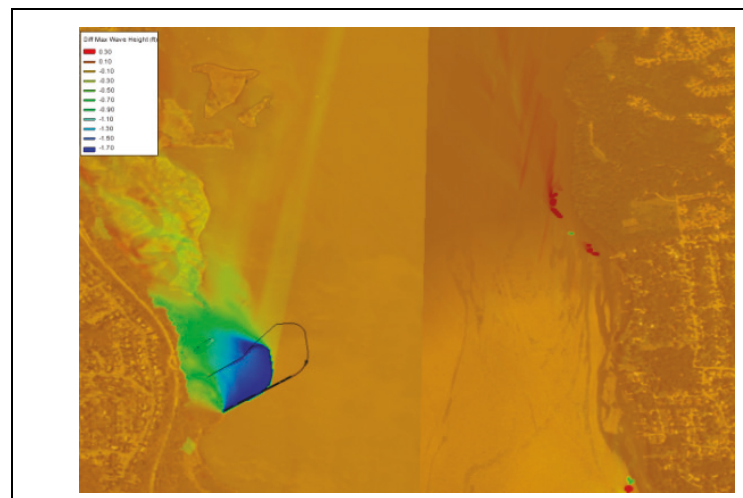

(DM01P4-DM01E)

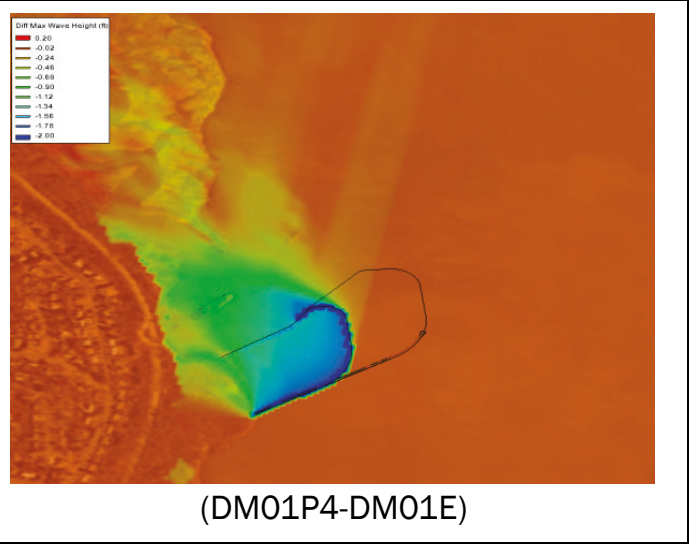


Table 5-36. Difference in maximum significant wave height for HIS ET Storm No. 0038 between project and existing conditions (Project - Existing). Note that the plot at right side is a close-up view with a narrow range of scales.

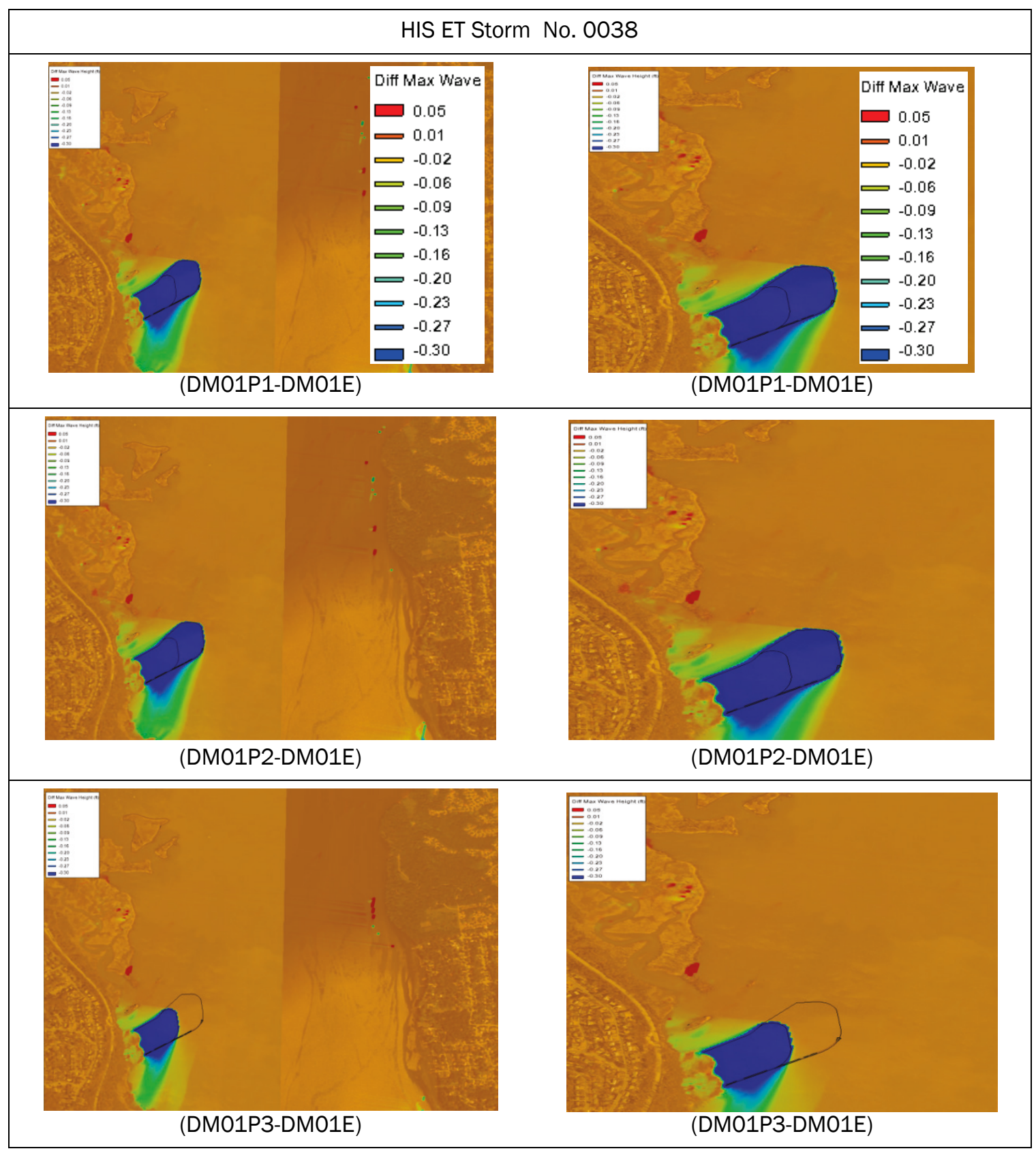




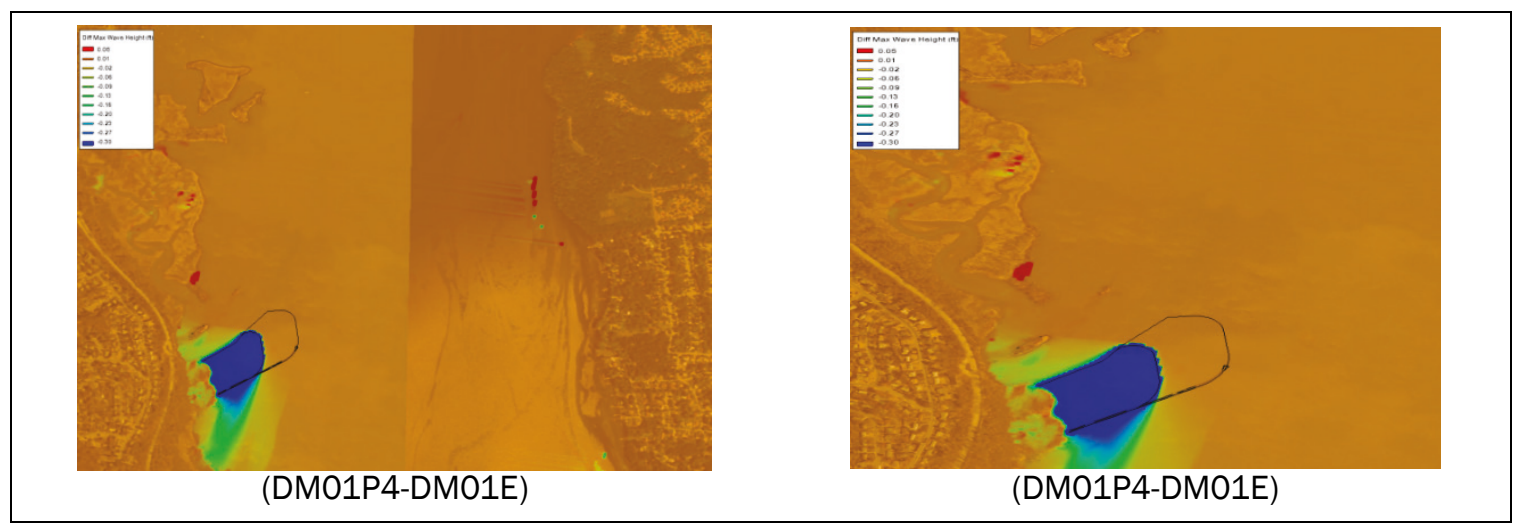


Table 5-37. Difference in maximum significant wave height for HIS ET Storm No. 0051 between project and existing conditions (Project - Existing). Note that the plot at right side is a close-up view with a narrow range of scales.

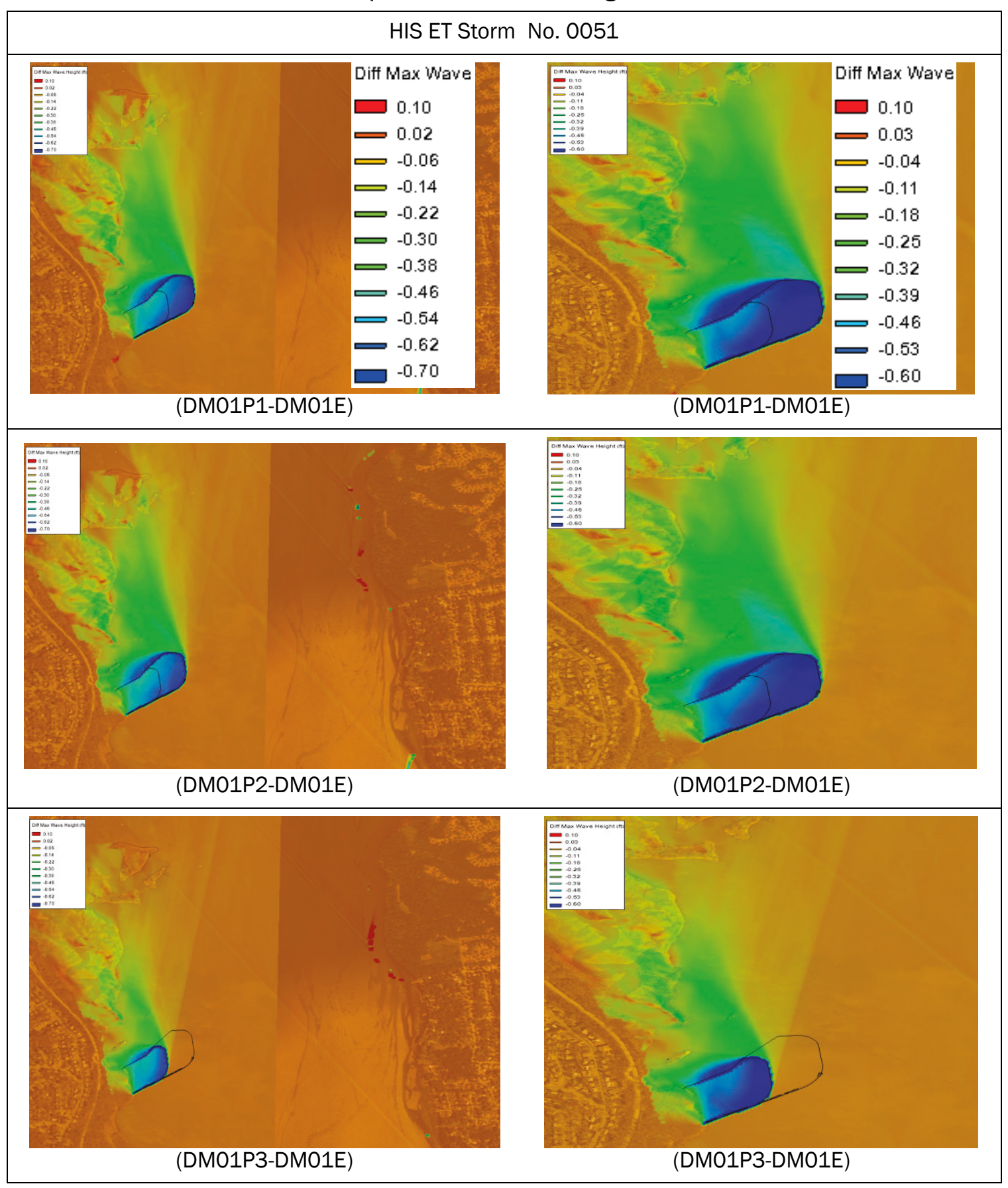




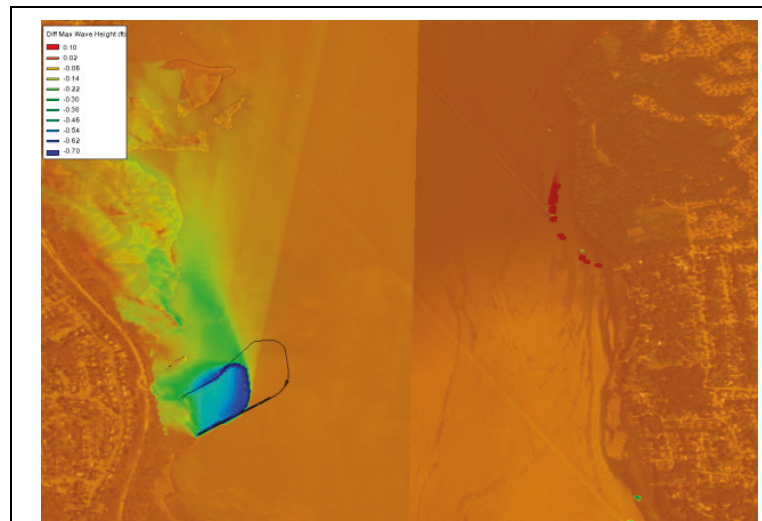

(DM01P4-DM01E)

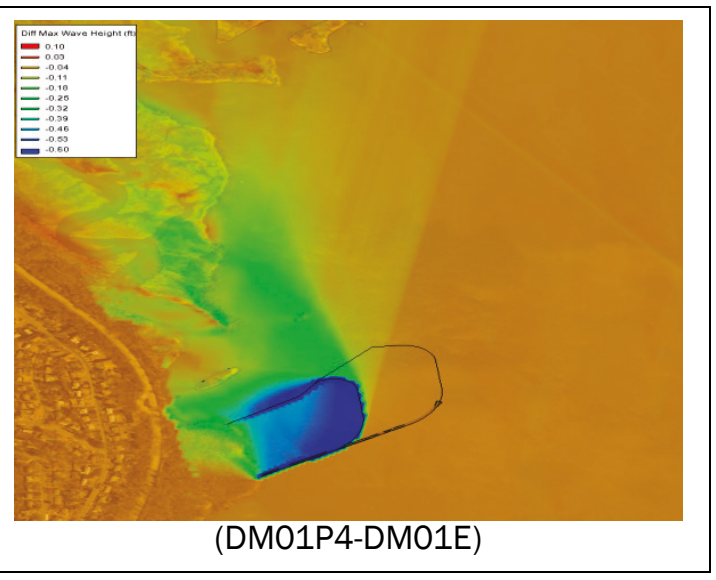


Table 5-38. Difference in maximum significant wave height for HIS ET Storm No. 0054 between project and existing conditions (Project - Existing). Note that the plot at right side is a close-up view with a narrow range of scales.

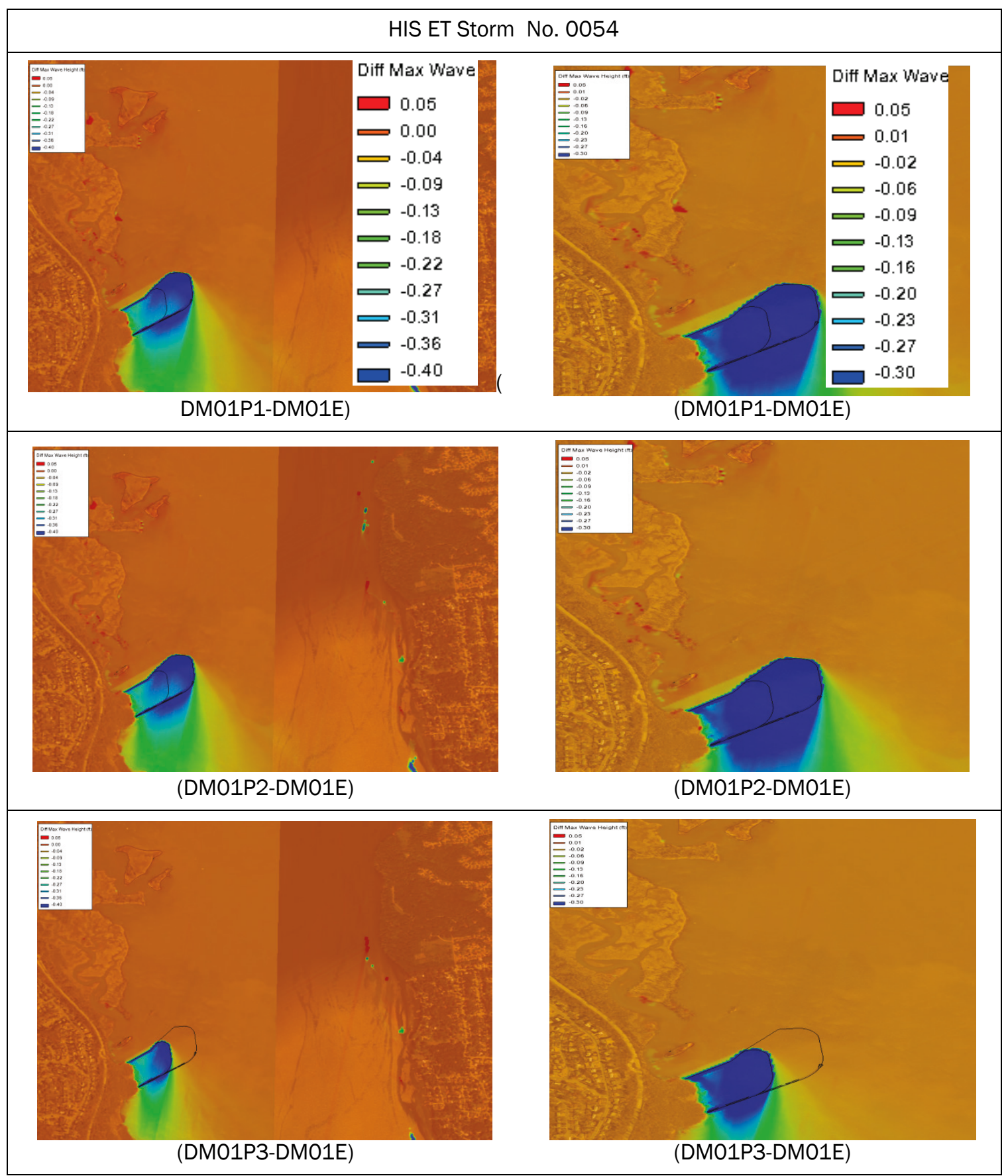



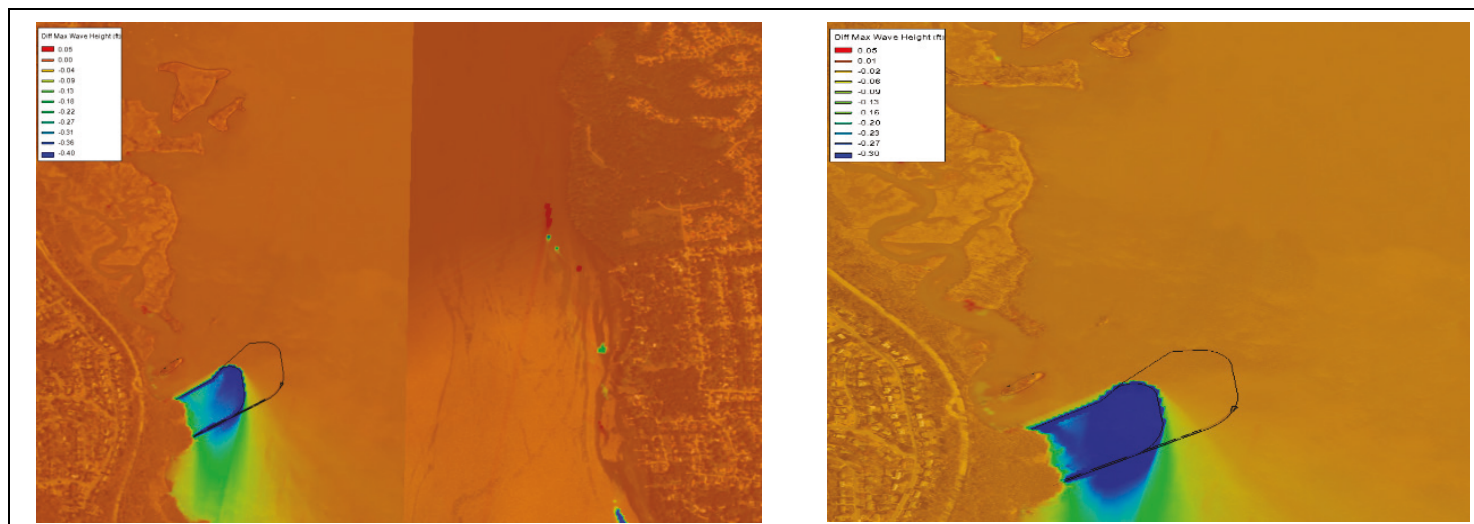

(DM01P4-DM01E)

(DM01P4-DM01E) 
Table 5-39. Difference in maximum significant wave height for HIS TP Storm No. 0001 (Sandy 2012) between project and existing conditions (Project - Existing). Note that the plot at right side is a close-up view with a narrow range of scales.

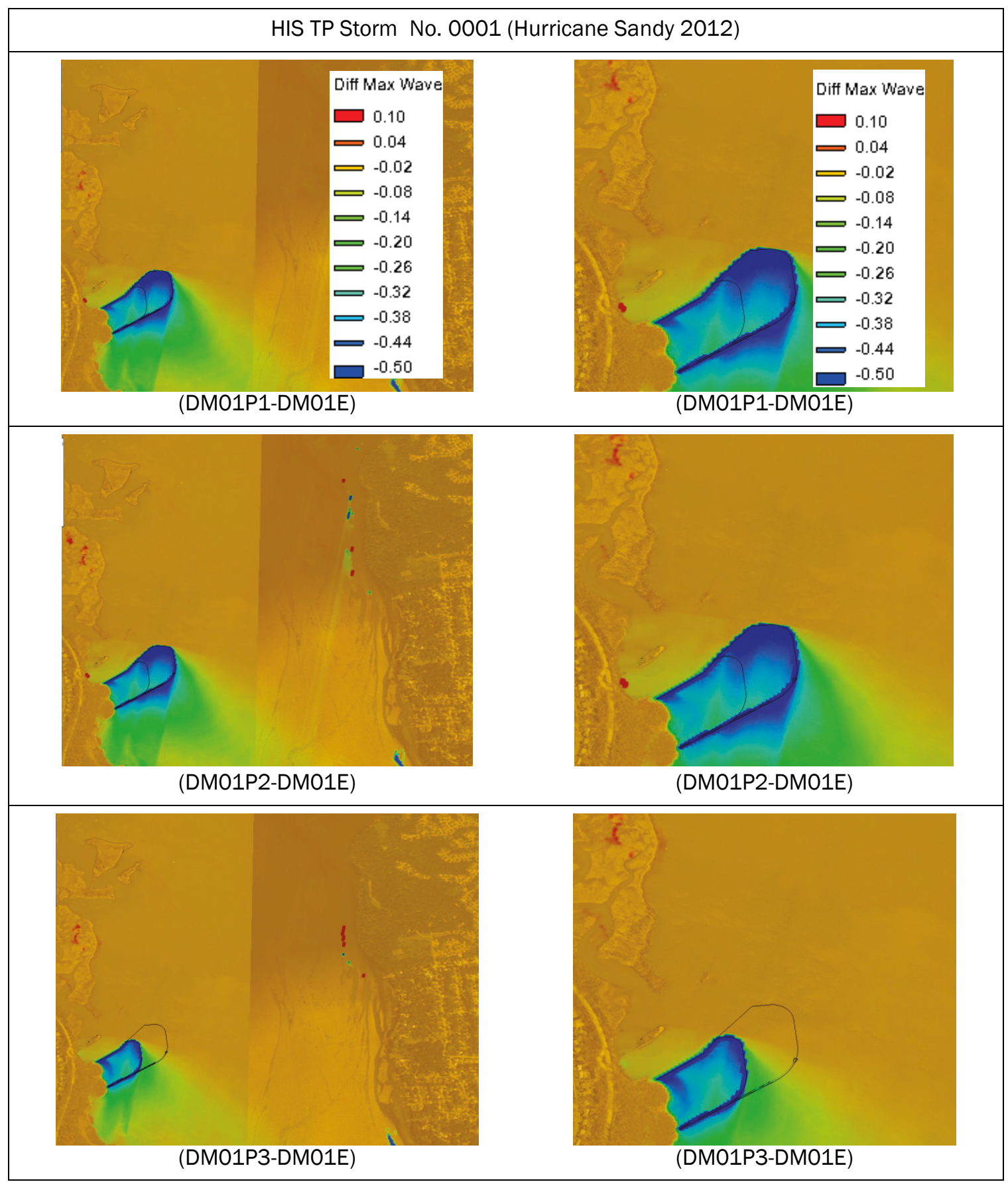




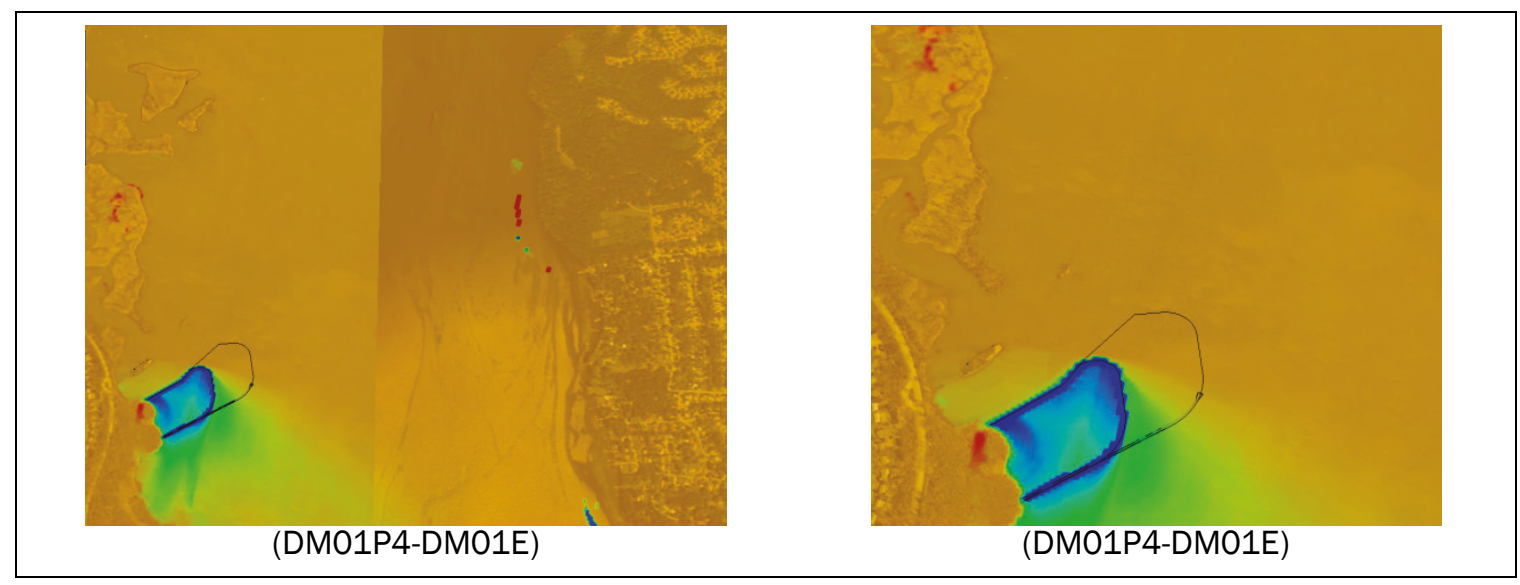


Table 5-40. Difference in maximum significant wave height for HIS TP Storm No. 0003 (Isabel 2003) between project and existing conditions (Project - Existing). Note that the plot at right side is a close-up view with a narrow range of scales.

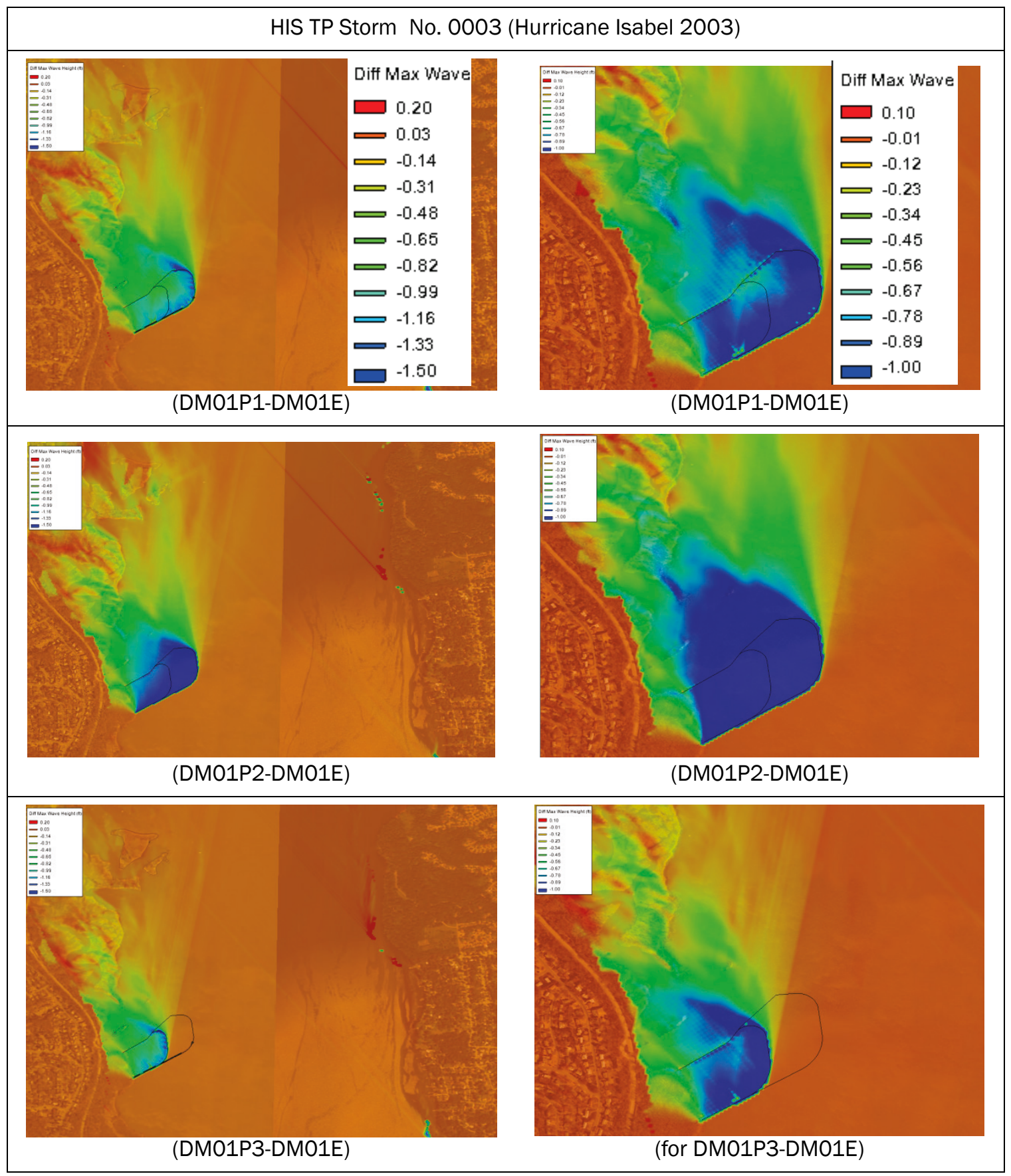




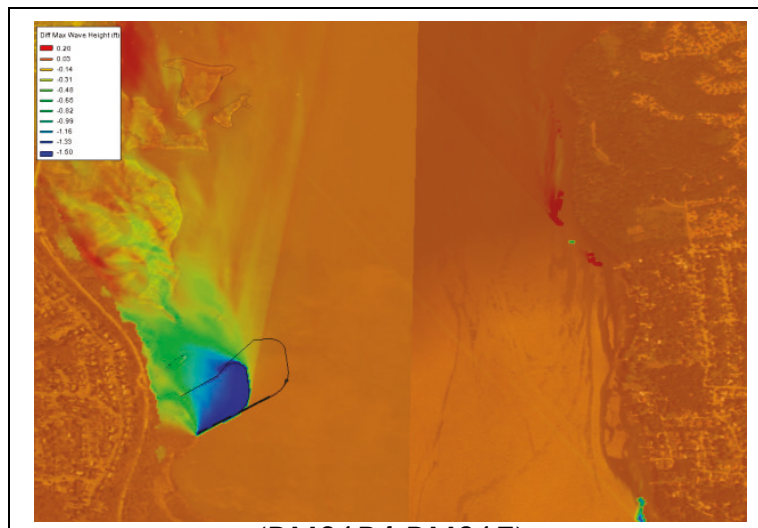

(DM01P4-DM01E)

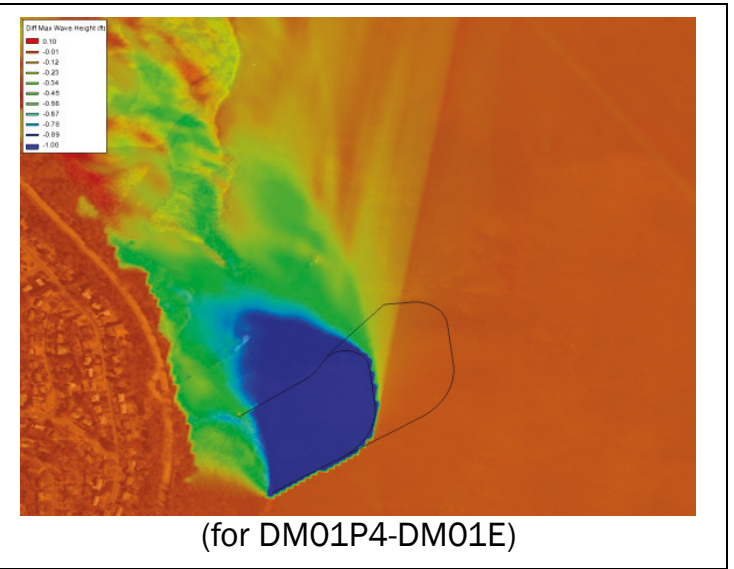


Table 5-41. Difference in maximum significant wave height for SYN TP Storm No. 0005 between project and existing conditions (Project - Existing). Note that the plot at right side is a close-up view witha narrow range of scales.

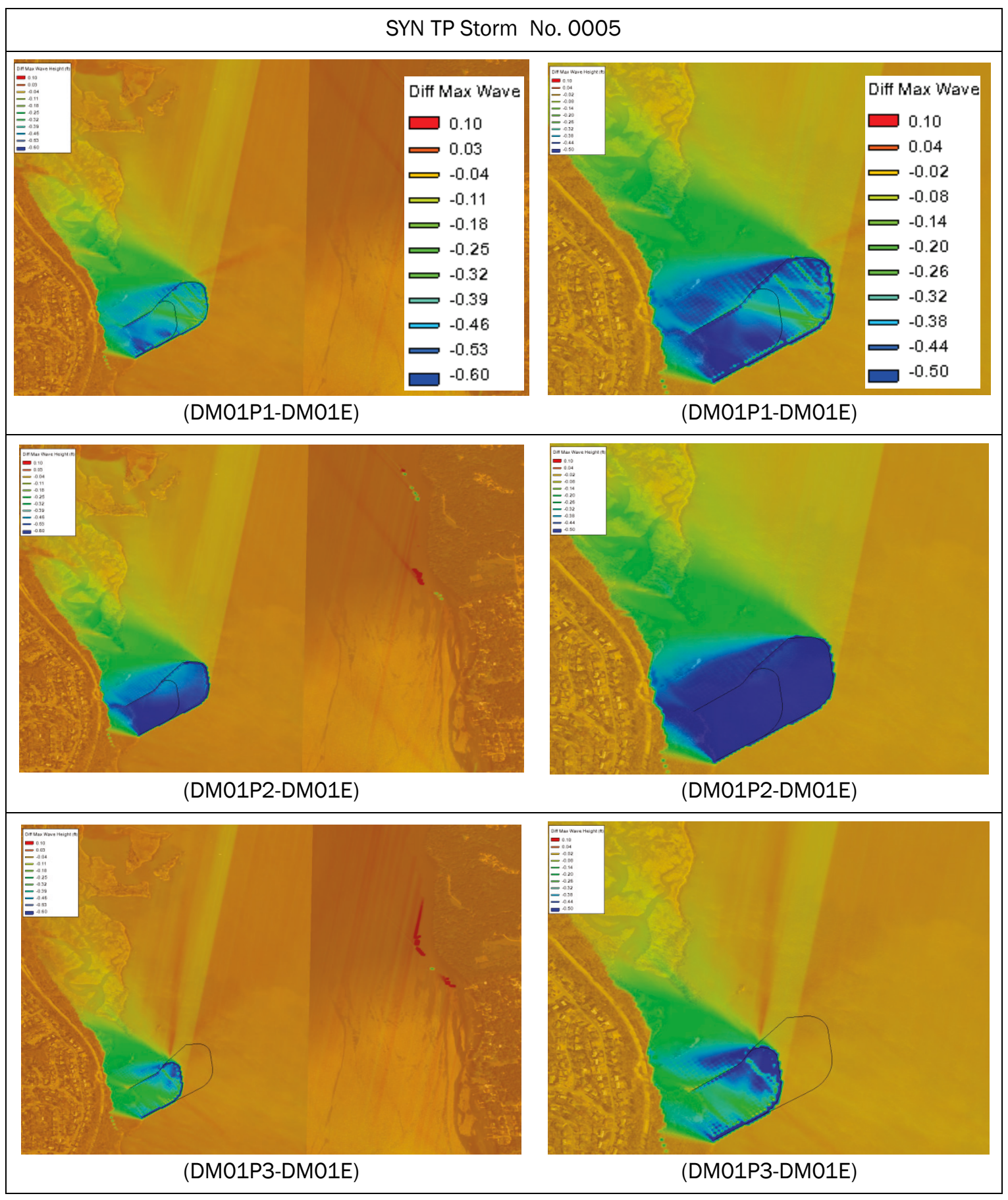




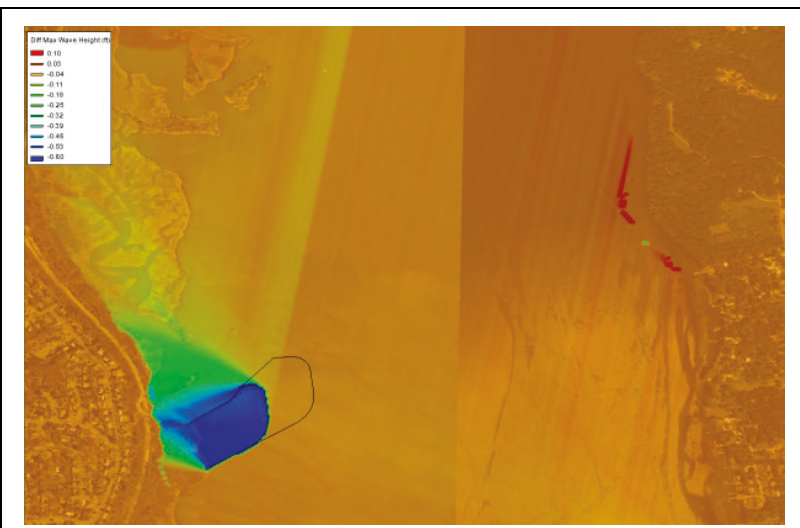

(DM01P4-DM01E)

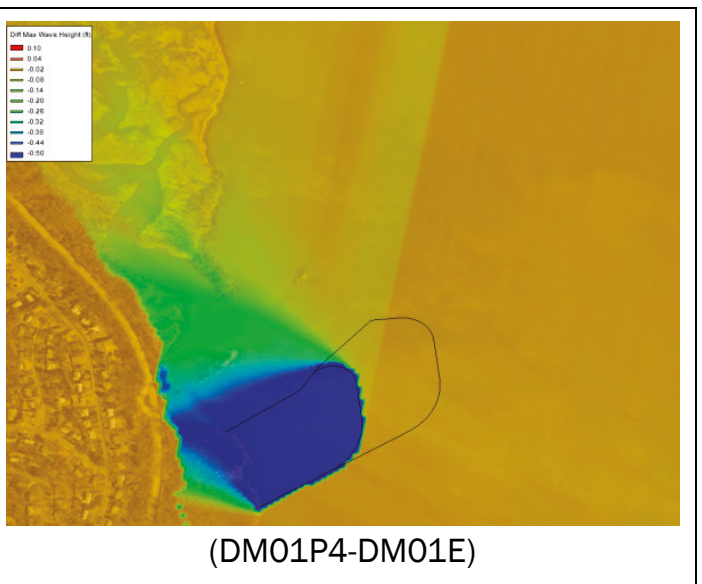


Table 5-42. Difference in maximum significant wave height for SYN TP Storm No. 0028 between project and existing conditions (Project - Existing). Note that the plot at right side is a close-up view with a narrow range of scales.

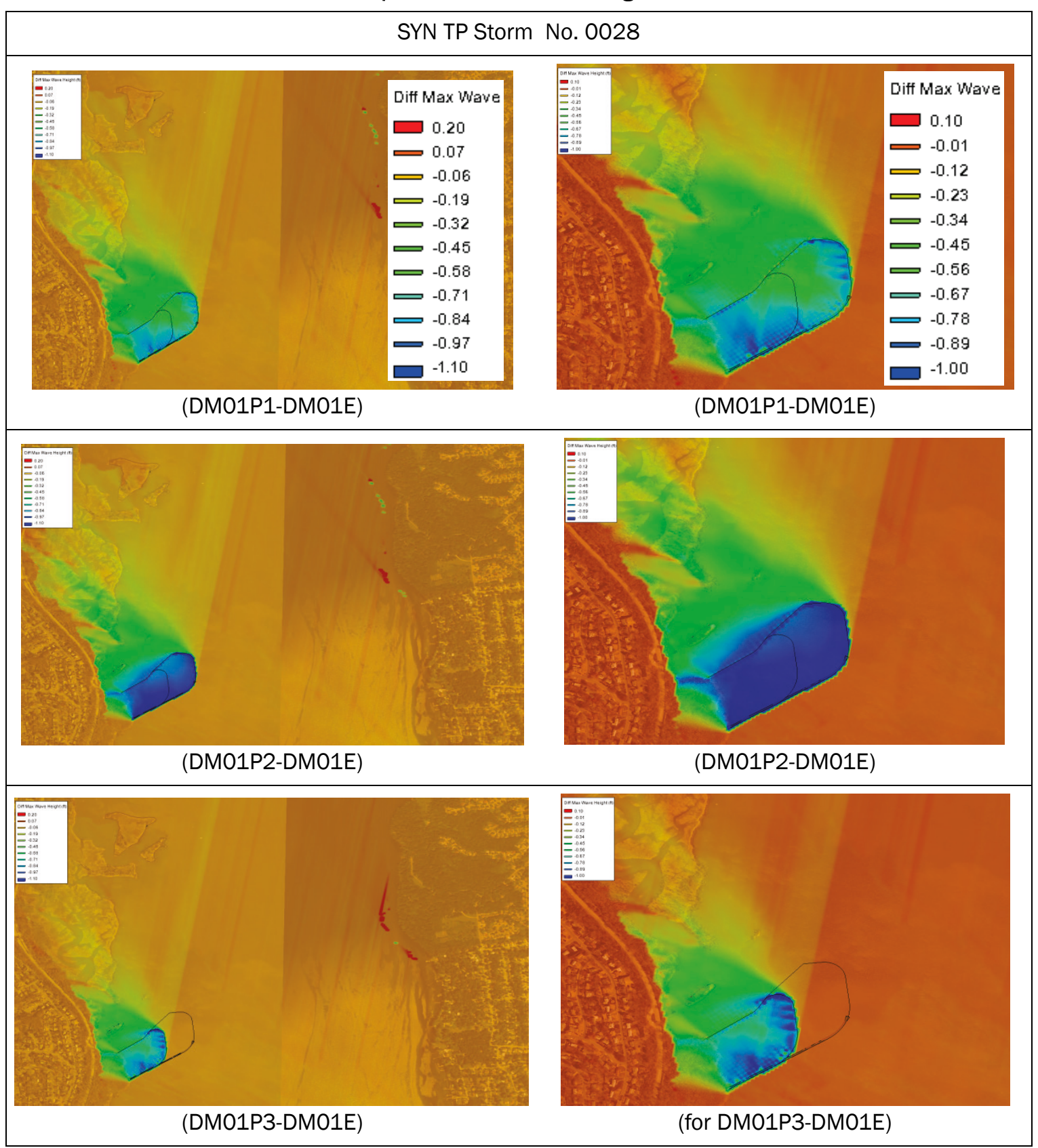




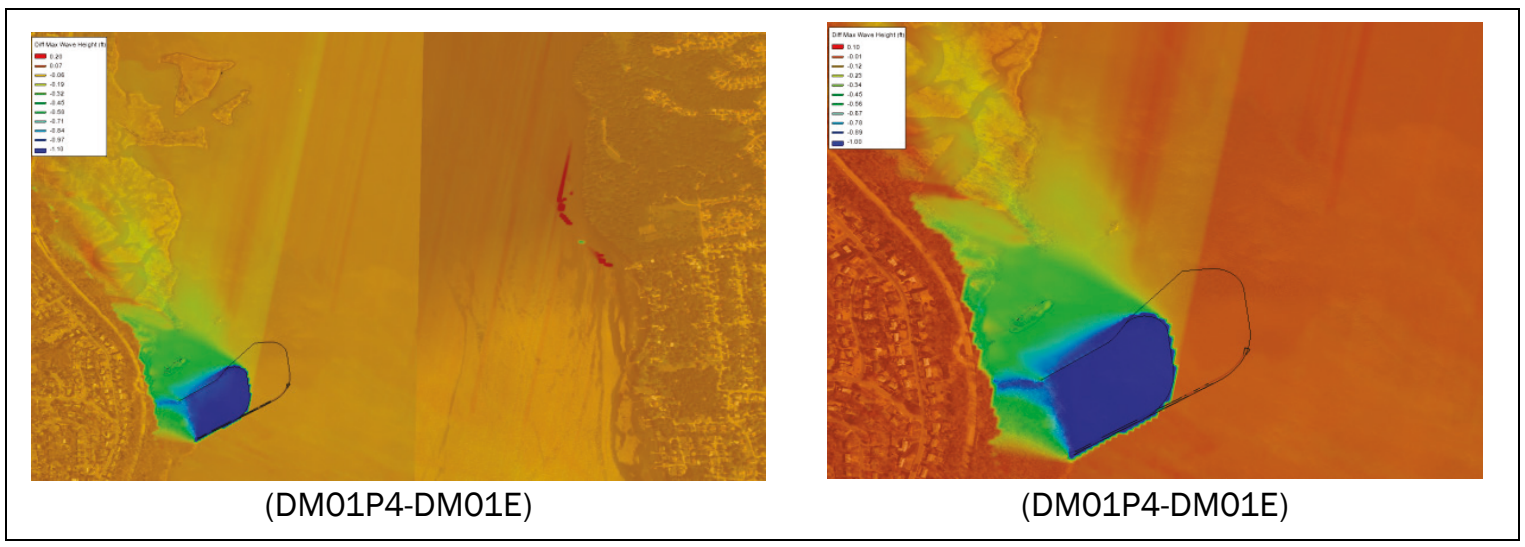


Table 5-43. Difference in maximum significant wave height for SYN TP Storm No. 0110 between project and existing conditions (Project - Existing). Note that the plot at right side is a close-up view with a narrow range of scales.

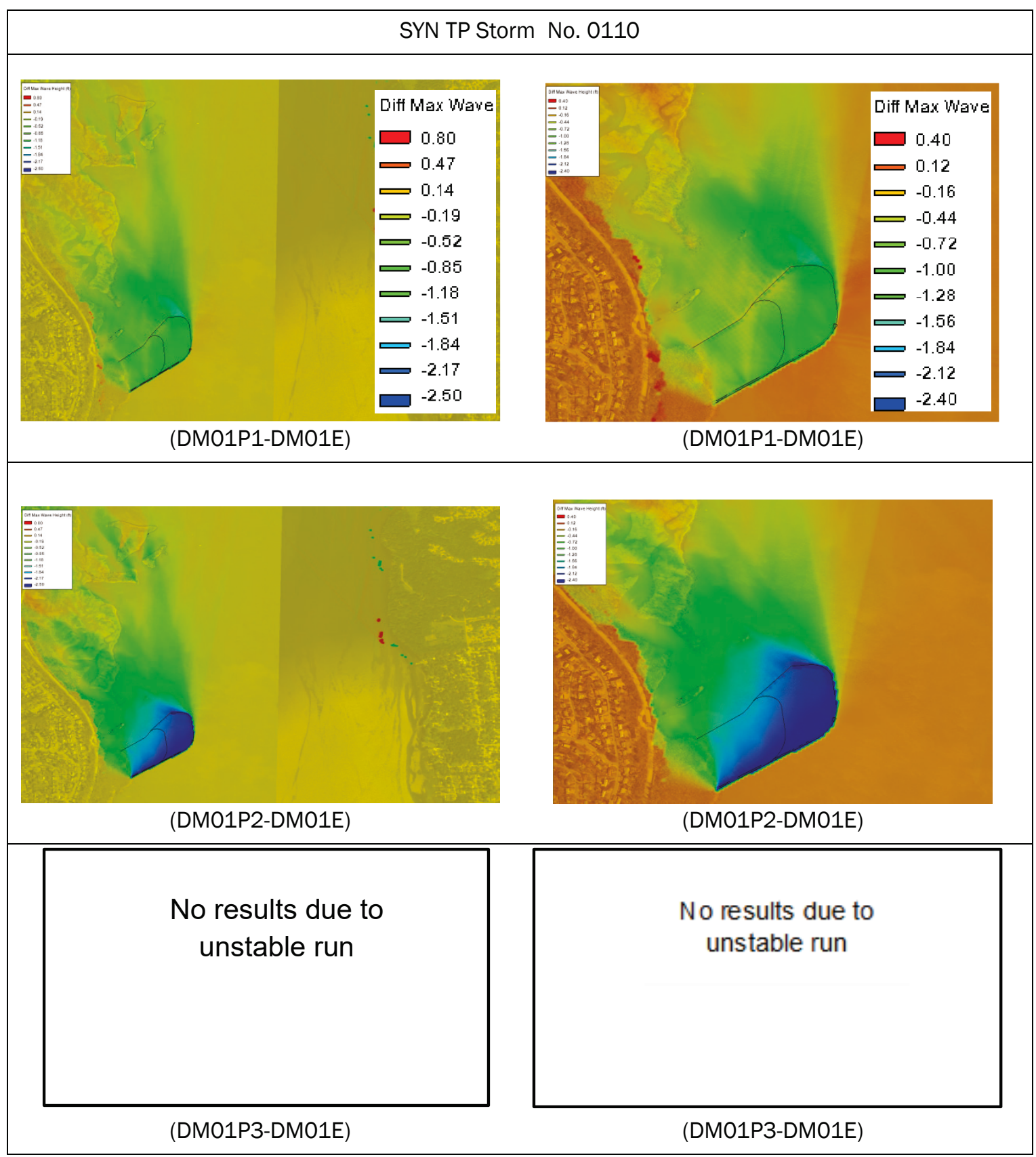




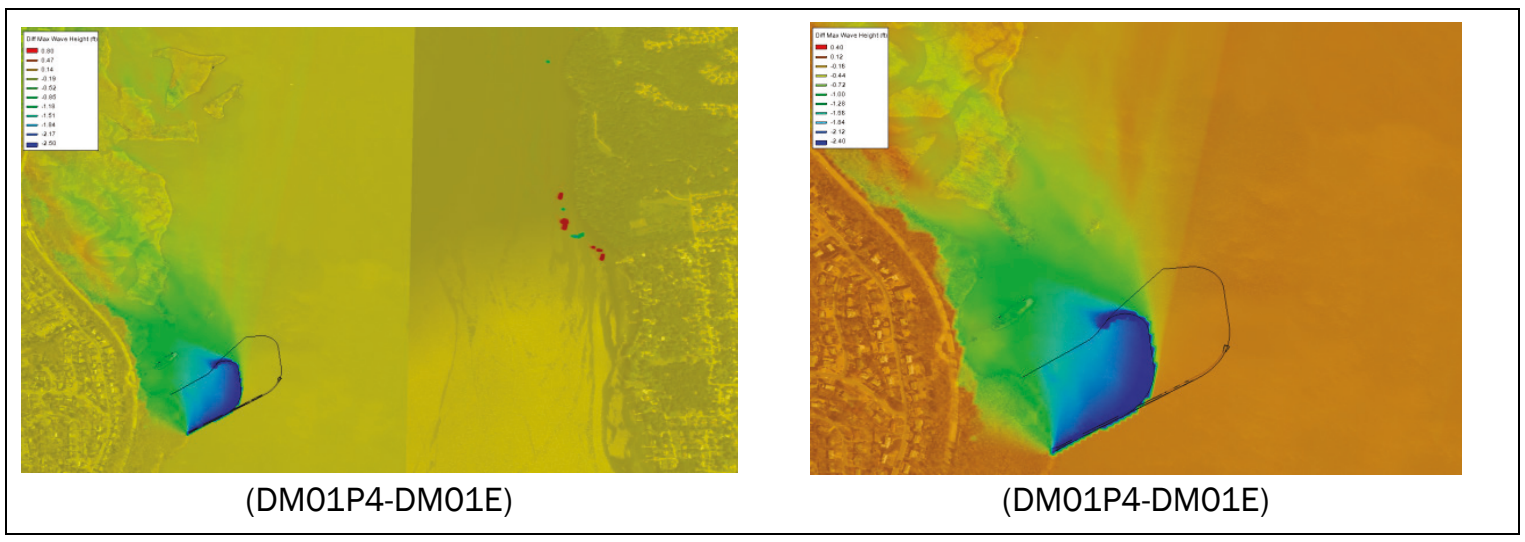

\subsubsection{Time series plots for select locations north of the promontory}

In Figure 5-3, a color contour plot of the local bathymetry and topography is shown along with five selected point locations north of the promontory structure. The locations and bed elevations of the selected stations are presented in Table 5-44, in which the still water depths vary from $1.4 \mathrm{ft}$ to $10.1 \mathrm{ft}$. In Table 5-45 through Table 5-50 a set of time series plots showing water levels, significant wave heights, and wind magnitudes are shown for locations that are near the marsh edge labeled 674 and 792 in Figure 5-3. Note that point location 674 is in shallower water and closer to the western shoreline than point 792. Results are shown for HIS ET Storm No. 0001 and 0008, HIS TP Storm No. 0001 (Sandy) and 0003 (Isabel), and SYN TP storms No. 0005 and 0028. Again, the water surface elevations do not change significantly at these two locations for any of the storms shown due to the larger scale nature of the storm surges inundating the structure. Wind magnitudes are included to aid in referencing when the peak of the storm occurs at these locations. Notice that for HIS TP Storm No. 0003 (Isabel in 2003, shown in Table 50), the significant wave heights not only show a decrease in magnitude but also a decrease in duration for all project alternatives. For SYN TP Storm No. 0028, a reduction in significant wave heights can be seen prior to the arrival of the peak winds as well as during the peak of the wind event.

Table 5-44. Locations and bed elevations of selected stations.

\begin{tabular}{|c|c|c|c|}
\hline Station No. & Longitude (deg) & Latitude (deg) & Bed Elevation (ft) \\
\hline 674 & -77.04745 & 38.76295 & -1.44 \\
\hline 733 & -77.04687 & 38.76295 & -4.76 \\
\hline 792 & -77.04629 & 38.75397 & -5.77 \\
\hline 851 & -77.04571 & 38.76295 & -6.27 \\
\hline 910 & -77.04513 & 38.76295 & -10.1 \\
\hline
\end{tabular}


Figure 5-3. Color contour plot showing the topography (positive) and bathymetry (negative) values along with an outline of the longest promontory structure and the locations of five selected time series locations.

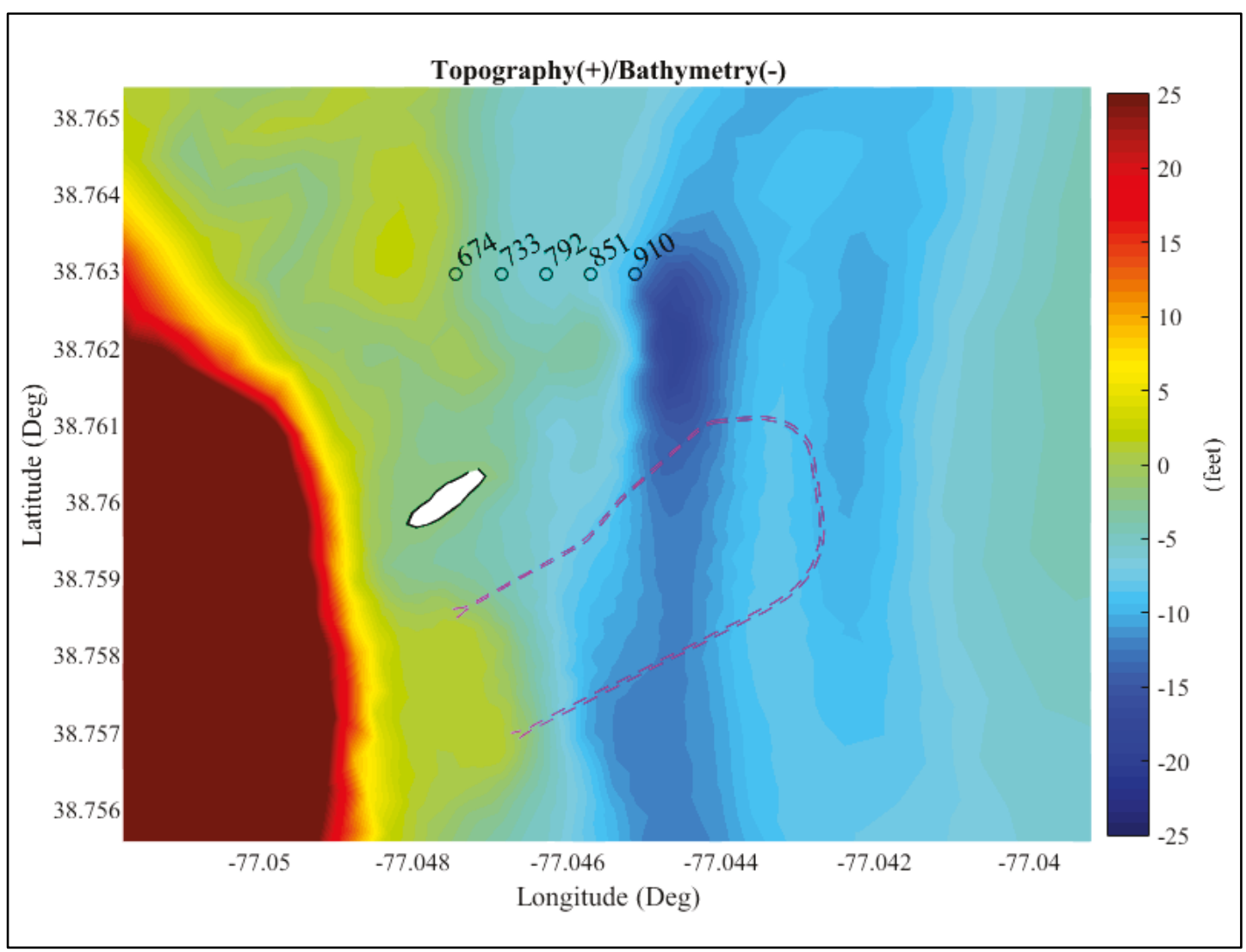


Table 5-45. Time series plots for (a, b) significant wave height, $(c, d)$ water level, and $(e, f)$ wind speed at two selected locations, 674 and 792 for HIS ET Storm No. 0001. Note that wave snap was given once every 30 minutes.

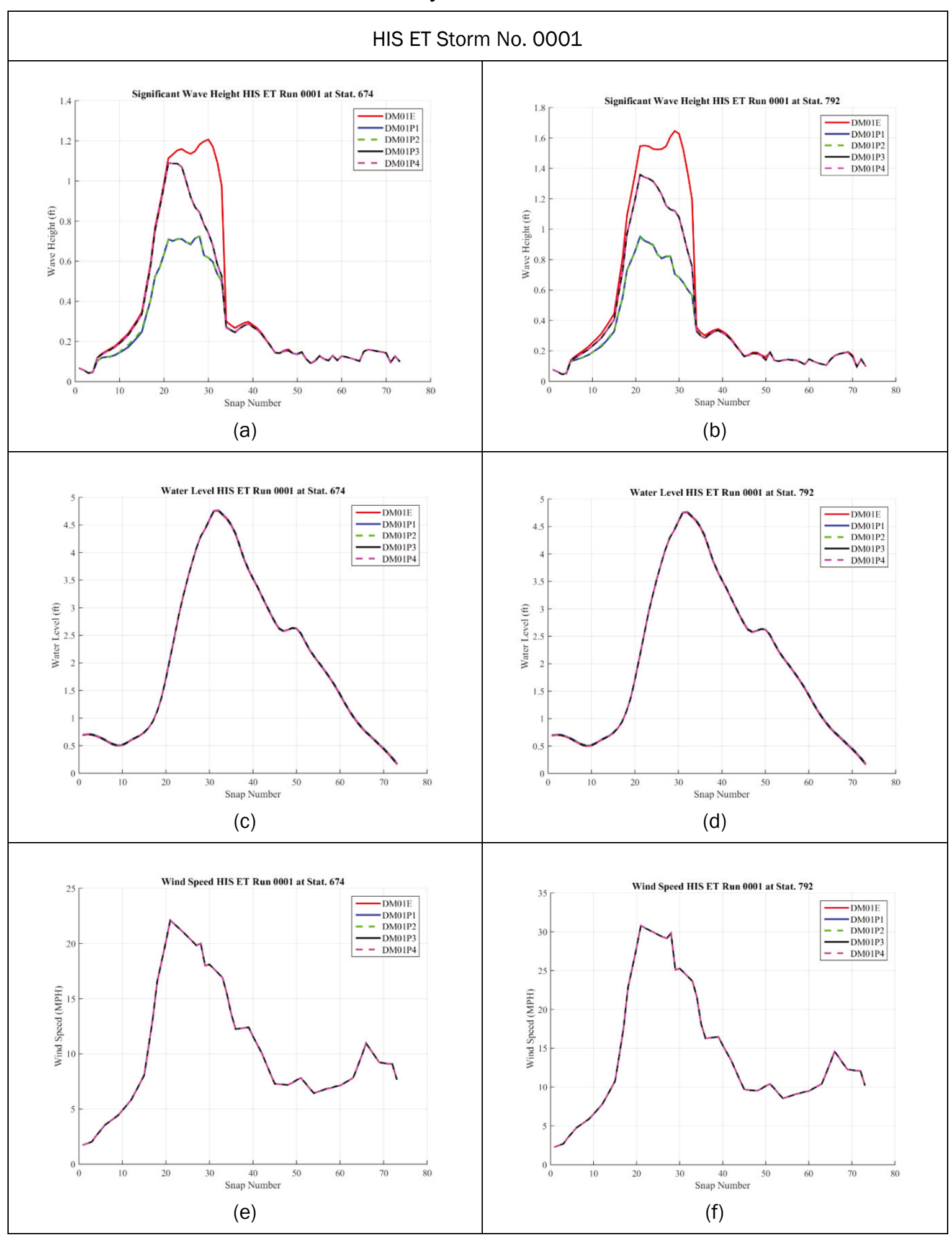


Table 5-46. Time series plots for (a, b) significant wave height, (c, d) water level, and (e, f) wind speed at two selected locations, 674 and 792 for HIS ET Storm No. 0008. Make note of the different ranges on each plot.

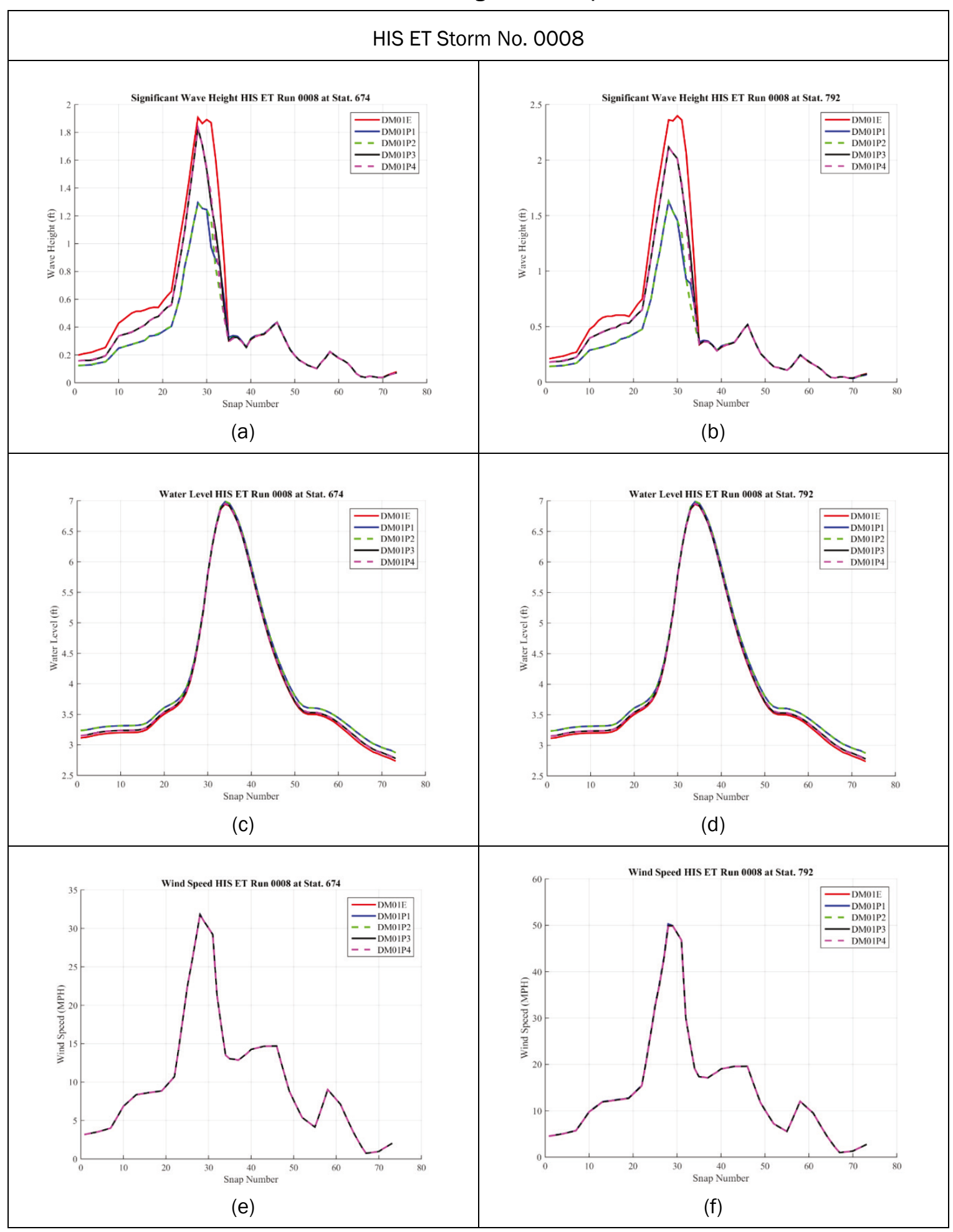


Table 5-47. Time series plots for (a, b) significant wave height, (c, d) water level, and (e, f) wind speed at two selected locations, 674 and 792 for HIS TP Storm No. 0001 (Hurricane Sandy 2012). Note that in (c) between snaps 85 and 125, the water levels went dry and are not plotted. Make note of the different ranges on each plot.

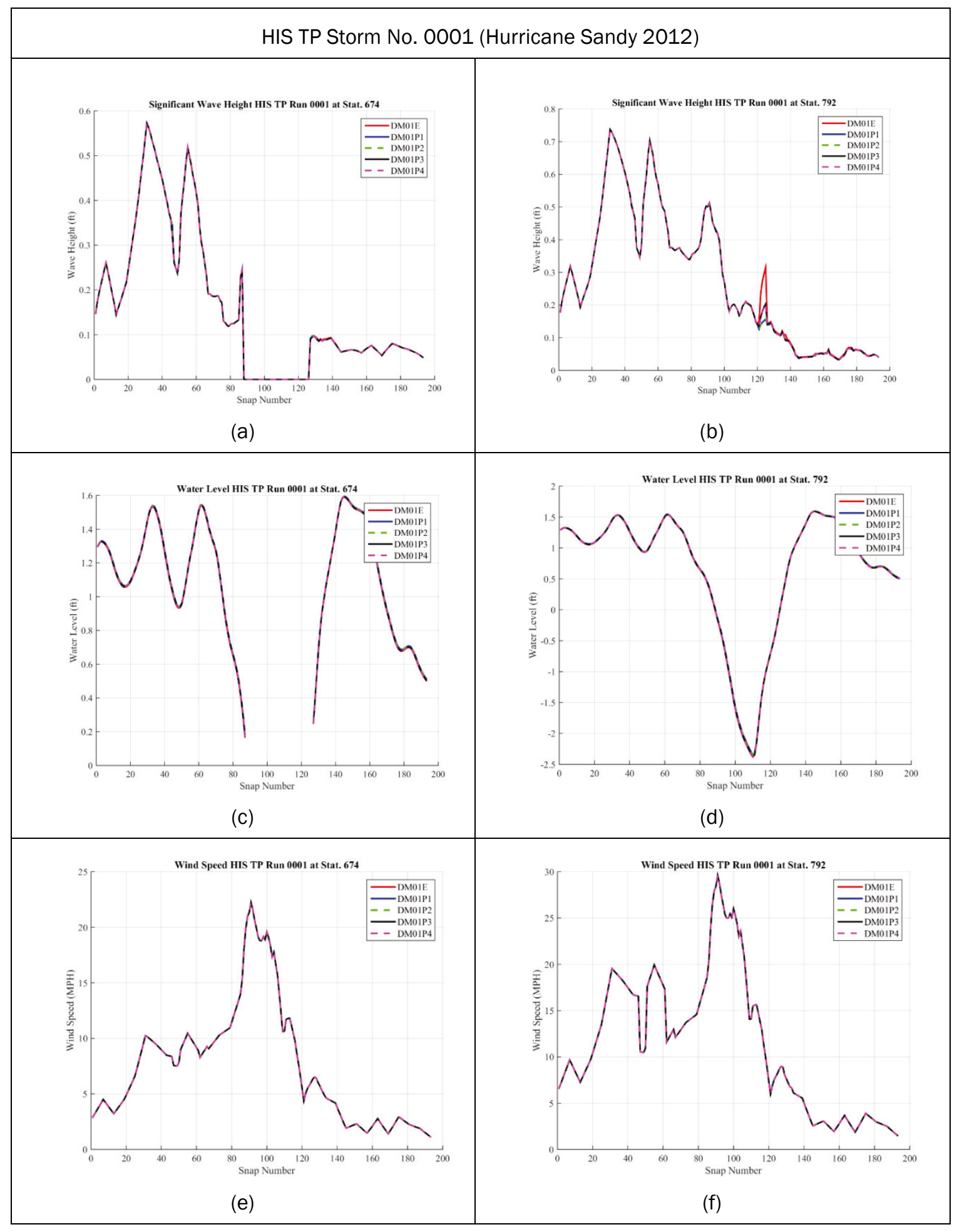


Table 5-48. Time series plots for (a, b) significant wave height, (c, d) water level, and (e, f) wind speed at two selected locations, 674 and 792 for HIS TP Storm No. 0003 (Hurricane Isabel 2003).

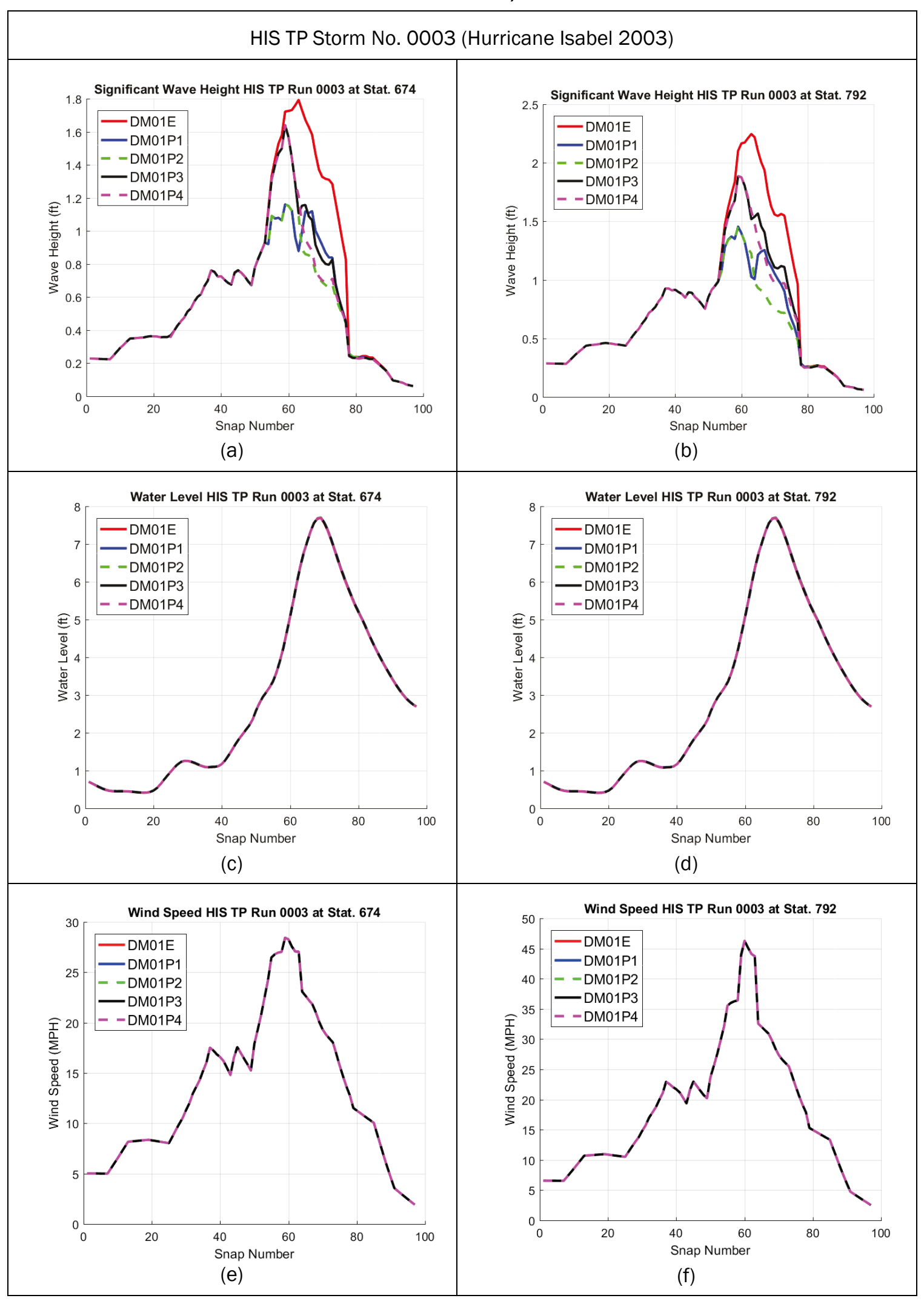


Table 5-49. Time series plots for (a, b) significant wave height, (c, d) water level, and (e, f) wind speed at two selected locations, 674 and 792 for SYN TP Storm No. 0005.

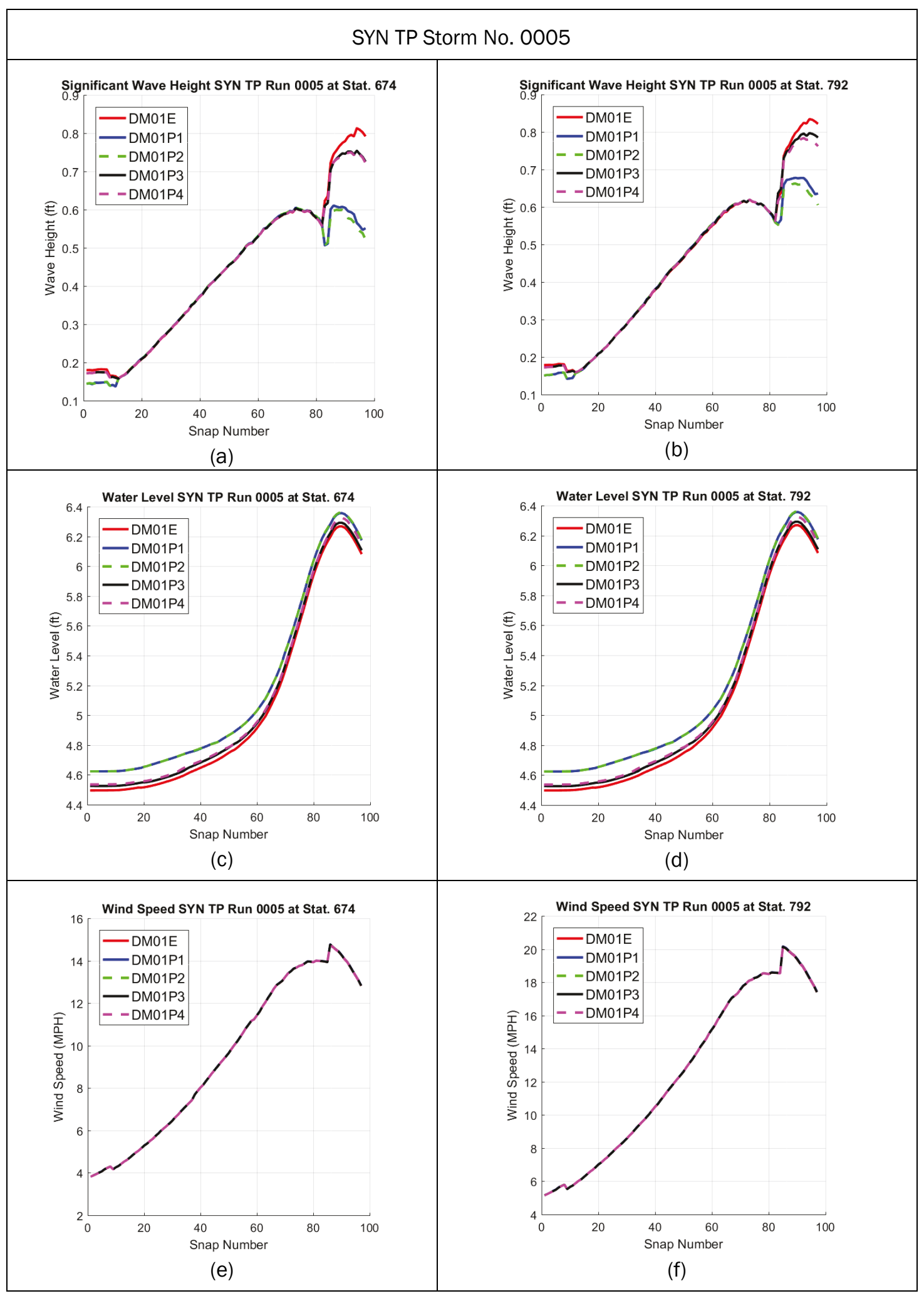


Table 5-50. Time series plots for (a, b) significant wave height, (c, d) water level, and (e, f) wind speed at two selected locations, 674 and 792 for SYN TP Storm No. 0028.

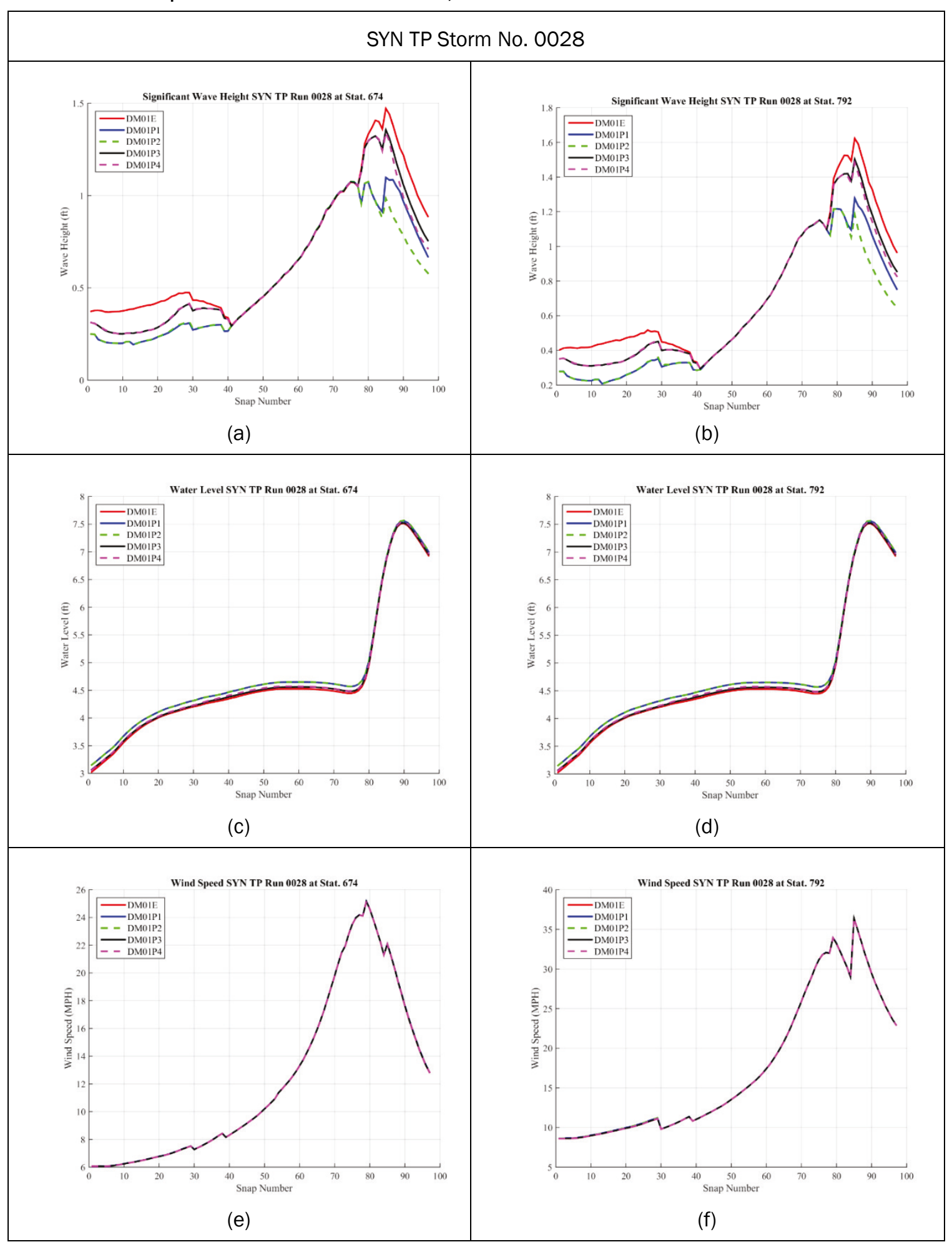




\subsubsection{Tables of values at select locations north and east of the promontory with difference plots of maximum significant wave height}

An additional set of 18 point locations were selected around the promontory area as well as to the north and to the east of the promontory, as shown in Figure 5-4 and Figure 5-5. At these points, the peak significant wave height values over the course of the simulation are tabulated in Table 5-51 through Table 5-57 for ease of comparison between the different alternatives. Results from three storms are given: HIS TP Storms No. 0001 (Sandy 2012) and No. 0003 (Isabel 2003) and HIS ET Storm No. 0008 from 1952. As shown in Table 5-23, these storms have dominant winds from different directions: the first one (Sandy) has a dominant wind direction toward the south in the area of Dyke Marsh while the dominant wind direction of the latter two is towards the north. This serves to show how changes in flow and waves on either side of the with-project alternatives behave depending on wind direction.

Figure 5-4. Map of the selected station output locations and the proposed promontory structures.

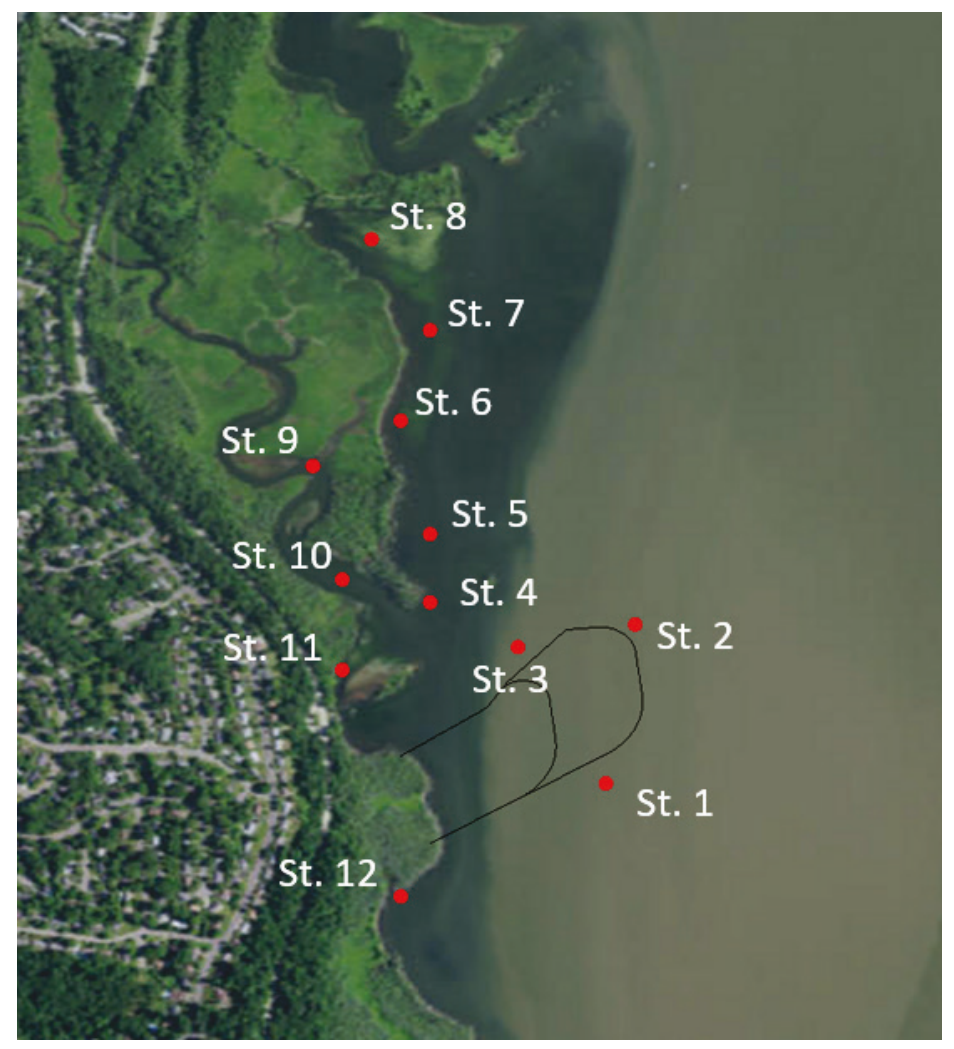


Figure 5-5. Map of selected station output locations east of the Potomac River Channel and the proposed promontory structures.

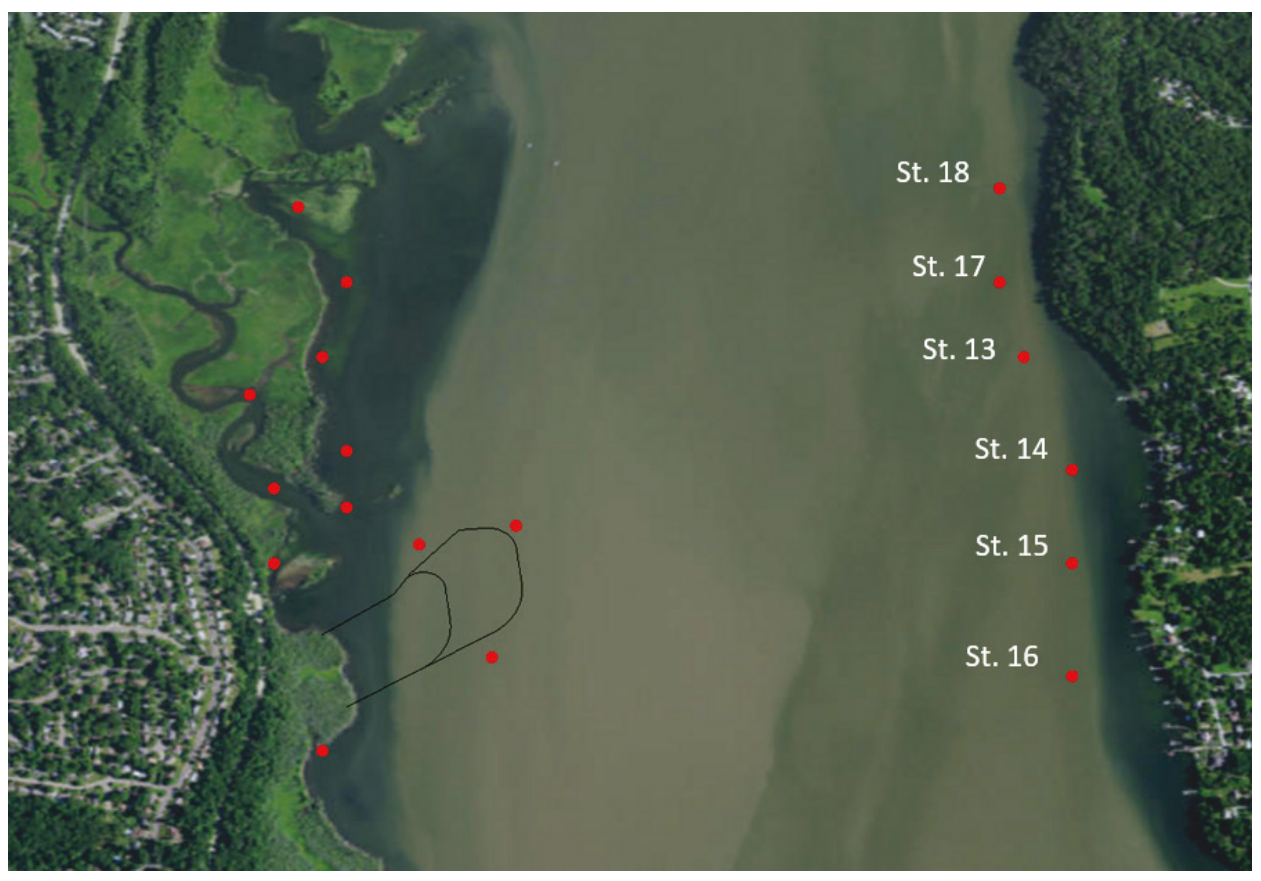

Table 5-51. Comparison of maximum significant wave heights (Hs, max) for the four promontory installations with Hs, max for the existing conditions (Hurricane Sandy 2012) at 18 station locations. The column DM01E presents the values of Hs, max.

\begin{tabular}{|c|c|c|c|c|c|c|c|c|c|}
\hline \multicolumn{9}{|c|}{ Difference in Maximum Significant Wave Height (ft) From DM01E (Proj - Exist) } & \\
\hline \multirow{3}{*}{ Station\Grid } & \multirow{3}{*}{ DM01E } & \multicolumn{6}{|c|}{ Historical Tropical 1 (Sandy 2012) } & & \\
\hline & & \multicolumn{2}{|c|}{ DM01P1-DM01E } & \multicolumn{2}{|c|}{ DM01P2-DM01E } & \multicolumn{2}{|c|}{ DM01P3-DM01E } & \multicolumn{2}{|c|}{ DM01P4-DM01E } \\
\hline & & Value $(\mathrm{ft})$ & Rate (\%) & Value $(\mathrm{ft})$ & Rate $(\%$ & Value $(\mathrm{ft})$ & Rate $(\%$ & Value $(\mathrm{ft})$ & Rate (\%) \\
\hline 1 & 0.914 & -0.455 & $-49.8 \%$ & -0.458 & $-50.1 \%$ & -0.133 & $-14.5 \%$ & -0.134 & $-14.6 \%$ \\
\hline 2 & 0.916 & -0.001 & $-0.1 \%$ & -0.001 & $-0.1 \%$ & 0.000 & $0.0 \%$ & 0.000 & $0.0 \%$ \\
\hline 3 & 0.738 & -0.011 & $-1.5 \%$ & -0.011 & $-1.5 \%$ & 0.000 & $0.0 \%$ & 0.000 & $0.0 \%$ \\
\hline 4 & 0.669 & 0.000 & $0.1 \%$ & 0.000 & $0.1 \%$ & 0.000 & $0.0 \%$ & 0.000 & $0.0 \%$ \\
\hline 5 & 0.719 & 0.001 & $0.1 \%$ & 0.001 & $0.1 \%$ & 0.000 & $0.1 \%$ & 0.000 & $0.0 \%$ \\
\hline 6 & 0.579 & 0.000 & $0.0 \%$ & 0.000 & $0.0 \%$ & 0.002 & $0.3 \%$ & 0.000 & $0.0 \%$ \\
\hline 7 & 0.597 & 0.000 & $0.0 \%$ & 0.000 & $0.0 \%$ & 0.000 & $0.0 \%$ & 0.000 & $0.0 \%$ \\
\hline 8 & 0.394 & 0.000 & $0.1 \%$ & 0.000 & $0.1 \%$ & 0.000 & $0.0 \%$ & 0.000 & $0.0 \%$ \\
\hline 9 & 0.235 & 0.000 & $0.0 \%$ & 0.000 & $0.0 \%$ & 0.000 & $0.0 \%$ & 0.000 & $0.0 \%$ \\
\hline 10 & 0.285 & 0.000 & $0.1 \%$ & 0.000 & $0.1 \%$ & 0.000 & $0.1 \%$ & 0.000 & $0.1 \%$ \\
\hline 11 & Dry & Dry & & Dry & & Dry & & Dry & \\
\hline 12 & 0.370 & -0.050 & $-13.4 \%$ & -0.051 & $-13.7 \%$ & -0.035 & $-9.4 \%$ & -0.035 & $-9.4 \%$ \\
\hline 13 & 0.420 & -0.001 & $-0.3 \%$ & -0.001 & $-0.3 \%$ & Dry & & Dry & \\
\hline 14 & 0.895 & 0.002 & $0.2 \%$ & 0.002 & $0.2 \%$ & 0.001 & $0.1 \%$ & 0.001 & $0.1 \%$ \\
\hline 15 & 0.997 & 0.001 & $0.1 \%$ & 0.001 & $0.1 \%$ & 0.001 & $0.1 \%$ & 0.001 & $0.1 \%$ \\
\hline 16 & 1.110 & -0.001 & $-0.1 \%$ & -0.001 & $-0.1 \%$ & 0.000 & $0.0 \%$ & 0.000 & $0.0 \%$ \\
\hline 17 & 1.211 & -0.077 & $-6.4 \%$ & -0.077 & $-6.4 \%$ & 0.001 & $0.1 \%$ & 0.001 & $0.1 \%$ \\
\hline 18 & 0.597 & -0.002 & $-0.4 \%$ & -0.002 & $-0.4 \%$ & 0.000 & $0.0 \%$ & 0.000 & $0.0 \%$ \\
\hline
\end{tabular}


Table 5-52. Hurricane Sandy maximum water level (column DM01E) for the existing conditions grid at 18 station locations along with the difference in maximum water levels between with-project and existing (Project-Existing) conditions.

\begin{tabular}{|c|c|c|c|c|c|}
\hline \multicolumn{6}{|c|}{$\begin{array}{c}\text { Difference in Max. Water Level (ft) from DM01E (Proj - Exist) } \\
\text { HIS TP } 0001 \text { (Hurricane Sandy 2012) }\end{array}$} \\
\hline Station \Grid & DM01E & DM01P1 & DM01P2 & DM01P3 & DM01P4 \\
\hline 1 & 1.586 & -0.003 & -0.003 & -0.002 & -0.001 \\
\hline 2 & 1.588 & 0.000 & 0.000 & 0.001 & 0.001 \\
\hline 3 & 1.588 & 0.007 & 0.007 & 0.002 & 0.002 \\
\hline 4 & 1.589 & 0.006 & 0.006 & 0.002 & 0.003 \\
\hline 5 & 1.591 & 0.005 & 0.005 & 0.001 & 0.002 \\
\hline 6 & 1.592 & 0.004 & 0.004 & 0.001 & 0.002 \\
\hline 7 & 1.593 & 0.004 & 0.003 & 0.001 & 0.001 \\
\hline 8 & 1.594 & 0.004 & 0.003 & 0.001 & 0.001 \\
\hline 9 & 1.590 & 0.006 & 0.006 & 0.002 & 0.003 \\
\hline 10 & 1.589 & 0.006 & 0.006 & 0.002 & 0.002 \\
\hline 11 & Dry & Dry & Dry & Dry & Dry \\
\hline 12 & 1.584 & -0.001 & -0.001 & 0.000 & 0.000 \\
\hline 13 & 1.584 & 0.002 & 0.001 & 0.000 & 0.000 \\
\hline 14 & 1.585 & 0.001 & 0.001 & 0.000 & 0.001 \\
\hline 15 & 1.583 & 0.000 & 0.000 & 0.000 & 0.000 \\
\hline 16 & 1.581 & 0.000 & 0.000 & 0.000 & 0.000 \\
\hline 17 & 1.587 & 0.002 & 0.002 & 0.001 & 0.001 \\
\hline 18 & 1.592 & 0.002 & 0.002 & 0.001 & 0.001 \\
\hline
\end{tabular}


Table 5-53. Hurricane Sandy maximum water velocity (column DM01E) for the existing conditions grid at 18 station locations along with the difference in maximum water velocity between with-project and existing (Project-Existing) conditions.

\begin{tabular}{|c|c|c|c|c|c|}
\hline \multicolumn{6}{|c|}{$\begin{array}{c}\text { Difference in Max Velocity (fps) from DM01E (Project - Existing) } \\
\text { HIS TP } 0001 \text { (Hurricane Sandy 2012) }\end{array}$} \\
\hline Station \Grid & DM01E & DM01P1 & DM01P2 & DM01P3 & DM01P4 \\
\hline 1 & 0.84 & 0.13 & 0.13 & 0.29 & 0.29 \\
\hline 2 & 0.82 & 0.73 & 0.73 & 0.06 & 0.06 \\
\hline 3 & 0.77 & -0.63 & -0.63 & -0.27 & -0.27 \\
\hline 4 & 0.47 & -0.17 & -0.17 & -0.09 & -0.09 \\
\hline 5 & 0.40 & -0.13 & -0.13 & -0.04 & -0.04 \\
\hline 6 & 0.40 & -0.03 & -0.03 & -0.01 & -0.01 \\
\hline 7 & 0.49 & -0.03 & -0.03 & -0.01 & -0.01 \\
\hline 8 & 0.08 & 0.00 & 0.00 & 0.00 & 0.00 \\
\hline 9 & 0.39 & 0.01 & -0.01 & 0.01 & 0.00 \\
\hline 10 & 0.50 & 0.00 & 0.01 & 0.00 & 0.00 \\
\hline 11 & 0.14 & -0.02 & -0.02 & -0.03 & -0.03 \\
\hline 12 & 0.11 & -0.01 & -0.01 & 0.00 & 0.00 \\
\hline 13 & 1.17 & 0.03 & 0.03 & -0.08 & -0.08 \\
\hline 14 & 1.05 & 0.00 & 0.00 & 0.00 & -0.01 \\
\hline 15 & 1.32 & -0.03 & -0.03 & -0.04 & -0.04 \\
\hline 16 & 1.12 & 0.01 & 0.01 & 0.00 & 0.00 \\
\hline 17 & 0.84 & 0.13 & 0.13 & 0.29 & 0.29 \\
\hline 18 & 0.82 & 0.73 & 0.73 & 0.06 & 0.06 \\
\hline
\end{tabular}


Table 5-54. Hurricane Isabel (2003) maximum significant wave height (column DM01E) for the existing conditions grid at 18 station locations along with the difference in maximum significant wave heights between with-project and existing (Project-Existing) conditions.

\begin{tabular}{|c|c|c|c|c|c|c|c|c|c|}
\hline \multirow{4}{*}{ Station\Grid } & \multicolumn{9}{|c|}{ Difference in Maximum Significant Wave Height (ft) From DM01E (Proj - Exist) } \\
\hline & \multirow[b]{2}{*}{ DM01E } & \multicolumn{6}{|c|}{ Historical Tropical 3 (Hurricane Isabel 2003) } & \multirow{2}{*}{\multicolumn{2}{|c|}{ DM01P4-DM01E }} \\
\hline & & \multicolumn{2}{|c|}{ DM01P1-DM01E } & \multicolumn{2}{|c|}{ DM01P2-DM01E } & \multicolumn{2}{|c|}{ DM01P3-DM01E } & & \\
\hline & Value (ft) & Value (ft) & Rate (\%) & Value $(\mathrm{ft})$ & Rate (\%) & Value $(\mathrm{ft})$ & Rate (\%) & Value (ft) & Rate (\%) \\
\hline 1 & 2.199 & 0.000 & $0.0 \%$ & 0.000 & $0.0 \%$ & 0.000 & $0.0 \%$ & 0.000 & $0.0 \%$ \\
\hline 2 & 2.314 & -0.530 & $-22.9 \%$ & -0.535 & $-23.1 \%$ & -0.008 & $-0.3 \%$ & -0.012 & $-0.5 \%$ \\
\hline 3 & 2.214 & -0.838 & $-37.8 \%$ & -1.318 & $-59.5 \%$ & -0.478 & $-21.6 \%$ & -0.472 & $-21.3 \%$ \\
\hline 4 & 1.977 & -0.762 & $-38.6 \%$ & -0.953 & $-48.2 \%$ & -0.477 & $-24.1 \%$ & -0.480 & $-24.3 \%$ \\
\hline 5 & 2.077 & -0.795 & $-38.3 \%$ & -0.796 & $-38.3 \%$ & -0.285 & $-13.7 \%$ & -0.284 & $-13.7 \%$ \\
\hline 6 & 1.875 & -0.137 & $-7.3 \%$ & -0.138 & $-7.4 \%$ & -0.087 & $-4.6 \%$ & -0.087 & $-4.6 \%$ \\
\hline 7 & 2.207 & -0.252 & $-11.4 \%$ & -0.252 & $-11.4 \%$ & -0.092 & $-4.2 \%$ & -0.092 & $-4.2 \%$ \\
\hline 8 & 1.897 & -0.055 & $-2.9 \%$ & -0.055 & $-2.9 \%$ & -0.014 & $-0.7 \%$ & -0.014 & $-0.8 \%$ \\
\hline 9 & 1.601 & -0.351 & $-22.0 \%$ & -0.353 & $-22.0 \%$ & -0.194 & $-12.1 \%$ & -0.198 & $-12.3 \%$ \\
\hline 10 & 1.486 & -0.380 & $-25.6 \%$ & -0.424 & $-28.5 \%$ & -0.319 & $-21.5 \%$ & -0.321 & $-21.6 \%$ \\
\hline 11 & 1.413 & -0.329 & $-23.3 \%$ & -0.365 & $-25.8 \%$ & -0.353 & $-25.0 \%$ & -0.375 & $-26.6 \%$ \\
\hline 12 & 1.543 & 0.001 & $0.1 \%$ & 0.001 & $0.1 \%$ & 0.001 & $0.1 \%$ & 0.001 & $0.1 \%$ \\
\hline 13 & 1.811 & 0.001 & $0.0 \%$ & 0.001 & $0.0 \%$ & -0.001 & $0.0 \%$ & 0.000 & $0.0 \%$ \\
\hline 14 & 1.613 & 0.008 & $0.5 \%$ & -0.002 & $-0.1 \%$ & 0.003 & $0.2 \%$ & -0.002 & $-0.1 \%$ \\
\hline 15 & 1.640 & 0.005 & $0.3 \%$ & -0.001 & $0.0 \%$ & 0.006 & $0.4 \%$ & 0.000 & $0.0 \%$ \\
\hline 16 & 1.701 & -0.003 & $-0.2 \%$ & -0.004 & $-0.3 \%$ & 0.001 & $0.1 \%$ & -0.001 & $-0.1 \%$ \\
\hline 17 & 1.645 & 0.003 & $0.2 \%$ & 0.001 & $0.1 \%$ & 0.054 & $3.3 \%$ & 0.053 & $3.3 \%$ \\
\hline 18 & 1.608 & -0.005 & $-0.3 \%$ & -0.010 & $-0.6 \%$ & 0.023 & $1.4 \%$ & 0.017 & $1.1 \%$ \\
\hline
\end{tabular}

Table 5-55. HIS ET Storm No. 0008 (3/11/1952) maximum significant wave height (column DM01E) for the existing conditions grid at 18 station locations along with the difference in maximum significant wave heights between with-project and existing (Project-Existing) conditions.

\begin{tabular}{|c|c|c|c|c|c|c|c|c|c|}
\hline \multirow{4}{*}{ Station\Grid } & \multicolumn{9}{|c|}{ Difference in Maximum Significant Wave Height (ft) From DM01E (Proj - Exist) } \\
\hline & \multirow{3}{*}{ DM01E } & \multicolumn{5}{|c|}{ Historical Extra-Tropical 8 (1952) } & & \multirow{2}{*}{\multicolumn{2}{|c|}{ DM01P4-DM01E }} \\
\hline & & \multicolumn{2}{|c|}{ DM01P1-DM01E } & \multicolumn{2}{|c|}{ DM01P2-DM01E } & \multicolumn{2}{|c|}{ DM01P3-DM01E } & & \\
\hline & & Value $(\mathrm{ft})$ & Rate (\%) & Value $(\mathrm{ft})$ & Rate (\%) & Value $(\mathrm{ft})$ & Rate (\%) & Value $(\mathrm{ft})$ & Rate (\%) \\
\hline 1 & 2.132 & 0.004 & $0.2 \%$ & 0.004 & $0.2 \%$ & 0.004 & $0.2 \%$ & 0.004 & $0.2 \%$ \\
\hline 2 & 2.213 & -0.220 & $-9.9 \%$ & -0.227 & $-10.2 \%$ & -0.002 & $-0.1 \%$ & -0.002 & $-0.1 \%$ \\
\hline 3 & 2.319 & -1.446 & $-62.4 \%$ & -1.388 & $-59.9 \%$ & -0.386 & $-16.7 \%$ & -0.381 & $-16.4 \%$ \\
\hline 4 & 2.127 & -1.001 & $-47.0 \%$ & -1.001 & $-47.0 \%$ & -0.463 & $-21.8 \%$ & -0.465 & $-21.9 \%$ \\
\hline 5 & 2.260 & -0.826 & $-36.5 \%$ & -0.828 & $-36.6 \%$ & -0.250 & $-11.1 \%$ & -0.249 & $-11.0 \%$ \\
\hline 6 & 2.073 & -0.113 & $-5.5 \%$ & -0.114 & $-5.5 \%$ & -0.111 & $-5.3 \%$ & -0.110 & $-5.3 \%$ \\
\hline 7 & 2.371 & -0.198 & $-8.4 \%$ & -0.198 & $-8.4 \%$ & -0.048 & $-2.0 \%$ & -0.047 & $-2.0 \%$ \\
\hline 8 & 2.093 & -0.051 & $-2.4 \%$ & -0.050 & $-2.4 \%$ & -0.011 & $-0.5 \%$ & -0.010 & $-0.5 \%$ \\
\hline 9 & 1.645 & -0.259 & $-15.8 \%$ & -0.261 & $-15.8 \%$ & -0.150 & $-9.1 \%$ & -0.154 & $-9.4 \%$ \\
\hline 10 & 1.568 & -0.393 & $-25.0 \%$ & -0.396 & $-25.2 \%$ & -0.276 & $-17.6 \%$ & -0.277 & $-17.7 \%$ \\
\hline 11 & 1.618 & -0.583 & $-36.1 \%$ & -0.584 & $-36.1 \%$ & -0.590 & $-36.5 \%$ & -0.596 & $-36.8 \%$ \\
\hline 12 & 1.719 & 0.000 & $0.0 \%$ & 0.000 & $0.0 \%$ & 0.000 & $0.0 \%$ & 0.000 & $0.0 \%$ \\
\hline 13 & 1.544 & -0.027 & $-1.7 \%$ & -0.027 & $-1.8 \%$ & -0.012 & $-0.8 \%$ & -0.012 & $-0.8 \%$ \\
\hline 14 & 1.239 & -0.005 & $-0.4 \%$ & \begin{tabular}{|c|}
-0.005 \\
\end{tabular} & $-0.4 \%$ & 0.006 & $0.5 \%$ & 0.007 & $0.5 \%$ \\
\hline 15 & 1.264 & -0.010 & $-0.8 \%$ & -0.010 & $-0.8 \%$ & 0.004 & $0.3 \%$ & 0.004 & $0.3 \%$ \\
\hline 16 & 1.283 & -0.027 & $-2.1 \%$ & -0.027 & $-2.1 \%$ & -0.017 & $-1.3 \%$ & -0.017 & $-1.3 \%$ \\
\hline 17 & 1.321 & 0.006 & $0.4 \%$ & 0.005 & $0.4 \%$ & 0.112 & $8.4 \%$ & 0.111 & $8.4 \%$ \\
\hline 18 & 1.296 & -0.009 & $-0.7 \%$ & -0.011 & $-0.8 \%$ & 0.027 & $2.1 \%$ & 0.026 & $2.0 \%$ \\
\hline
\end{tabular}


Table 5-56. HIS ET Storm No. 0008 (3/11/1952) maximum water level (column DM01E) for the existing conditions grid at 18 station locations along with the difference in maximum water levels between with-project and existing (Project-Existing) conditions.

\begin{tabular}{|c|c|c|c|c|c|}
\hline \multicolumn{6}{|c|}{$\begin{array}{l}\text { Difference in Max. Water Level (ft) from DM01E (Project - Existing) } \\
\text { HIS ET } 0008 \text { (1952) }\end{array}$} \\
\hline Station \Grid & DM01E & DM01P1 & DM01P2 & DM01P3 & DM01P4 \\
\hline 1 & 6.907 & -0.025 & -0.029 & -0.028 & -0.028 \\
\hline 2 & 6.929 & -0.016 & -0.040 & 0.000 & 0.000 \\
\hline 3 & 6.929 & 0.058 & 0.062 & 0.016 & 0.017 \\
\hline 4 & 6.938 & 0.047 & 0.052 & 0.014 & 0.018 \\
\hline 5 & 6.950 & 0.038 & 0.042 & 0.008 & 0.012 \\
\hline 6 & 6.960 & 0.033 & 0.036 & 0.006 & 0.009 \\
\hline 7 & 6.972 & 0.029 & 0.031 & 0.004 & 0.006 \\
\hline 8 & 6.983 & 0.026 & 0.029 & 0.003 & 0.005 \\
\hline 9 & 6.961 & 0.034 & 0.037 & 0.006 & 0.009 \\
\hline 10 & 6.947 & 0.041 & 0.045 & 0.011 & 0.014 \\
\hline 11 & 6.938 & 0.046 & 0.051 & 0.015 & 0.019 \\
\hline 12 & 6.898 & -0.014 & -0.014 & -0.008 & -0.006 \\
\hline 13 & 6.932 & 0.010 & 0.009 & -0.002 & 0.000 \\
\hline 14 & 6.919 & 0.009 & 0.007 & -0.003 & -0.001 \\
\hline 15 & 6.904 & 0.004 & 0.003 & -0.004 & -0.003 \\
\hline 16 & 6.880 & -0.001 & -0.003 & -0.006 & -0.005 \\
\hline 17 & 6.941 & 0.013 & 0.012 & 0.001 & 0.003 \\
\hline 18 & 6.975 & 0.017 & 0.018 & -0.001 & 0.001 \\
\hline
\end{tabular}


Table 5-57. HIS ET Storm No. 0008 (3/11/1952) maximum water velocity (column DM01E) for the existing conditions grid at 18 station locations along with the difference in maximum water velocity between with-project and existing (Project-Existing) conditions.

\begin{tabular}{|c|c|c|c|c|c|}
\hline \multicolumn{6}{|c|}{$\begin{array}{c}\text { Difference in Max Velocity (fps*) from DM01E (Project - Existing) } \\
\text { HIS ET } 0008 \text { (1952) }\end{array}$} \\
\hline Station\Grid & DM01E & DM01P1 & DM01P2 & DM01P3 & DM01P4 \\
\hline 1 & 2.20 & -0.17 & 0.17 & 0.68 & 0.67 \\
\hline 2 & 2.21 & 1.66 & 1.66 & 0.16 & 0.16 \\
\hline 3 & 1.94 & -1.44 & -1.62 & -0.68 & -0.68 \\
\hline 4 & 1.04 & -0.63 & -0.74 & -0.43 & -0.43 \\
\hline 5 & 0.91 & -0.43 & -0.49 & -0.23 & -0.24 \\
\hline 6 & 0.57 & -0.10 & -0.10 & -0.04 & -0.04 \\
\hline 7 & 0.89 & -0.14 & -0.14 & -0.05 & -0.05 \\
\hline 8 & 0.55 & -0.02 & -0.02 & -0.01 & -0.01 \\
\hline 9 & 0.44 & -0.06 & -0.07 & -0.03 & -0.03 \\
\hline 10 & 0.57 & -0.16 & -0.16 & -0.11 & -0.11 \\
\hline 11 & 0.69 & -0.36 & -0.36 & -0.34 & -0.34 \\
\hline 12 & 0.25 & 0.18 & 0.17 & 0.07 & 0.07 \\
\hline 13 & 1.80 & 0.22 & 0.22 & 0.07 & 0.08 \\
\hline 14 & 1.20 & 0.18 & 0.18 & 0.05 & 0.05 \\
\hline 15 & 1.51 & 0.24 & 0.24 & 0.07 & 0.07 \\
\hline 16 & 1.57 & 0.19 & 0.19 & 0.05 & 0.06 \\
\hline 17 & 2.24 & 0.18 & 0.18 & -0.02 & -0.02 \\
\hline 18 & 1.77 & 0.04 & 0.04 & 0.03 & 0.02 \\
\hline
\end{tabular}

$\mathrm{fps}=$ feet per second

\subsubsection{Simulation results for average river flows and long-term tides under constant wind conditions}

A series of non-storm event conditions were simulated to investigate hydrodynamic responses at the proposed promontories to average Potomac River flows (low and high), long-term tides, and constant wind forcing from various directions. Those conditions are assumed to emulate typical conditions over the study area. For each with-project alternative structure layout, a two-step process for the hydrodynamic simulations was carried out: (1) compute a 1-month tidal simulation with two average river 
flows (a low flow and a high spring flow) but without wind or wave forcing and (2) repeat a 1-day portion of the longer tide and river flow computation with the inclusion of constant wind forcing and the resulting wind-waves. Two wind speed values and six different wind directions for the constant wind fields were considered.

To determine average low and high flows in the Potomac River, long-term monthly discharge records of the river were obtained at the USGS hydrologic station (USGS No. 01646500, Potomac River near Washington, DC, Little Falls Pump Station, as shown in Figure 1-3). Average spring discharges from February to May and average summer discharges from July to September were calculated based on a recent monthly flow dataset (2011-2016) and an 87-year dataset (1930-2016) (Figure 5-6). Finally, two average seasonal river flows were selected from the recent 6-year data records: a spring averaged discharge of approximately 19,700 cubic feet per second (cfs), and a summer averaged discharge of approximately 4,100 cfs to represent high and low river flows in the river, respectively.

Figure 5-6. Monthly discharge and seasonal average at Potomac River, Little Falls, Washington, DC.

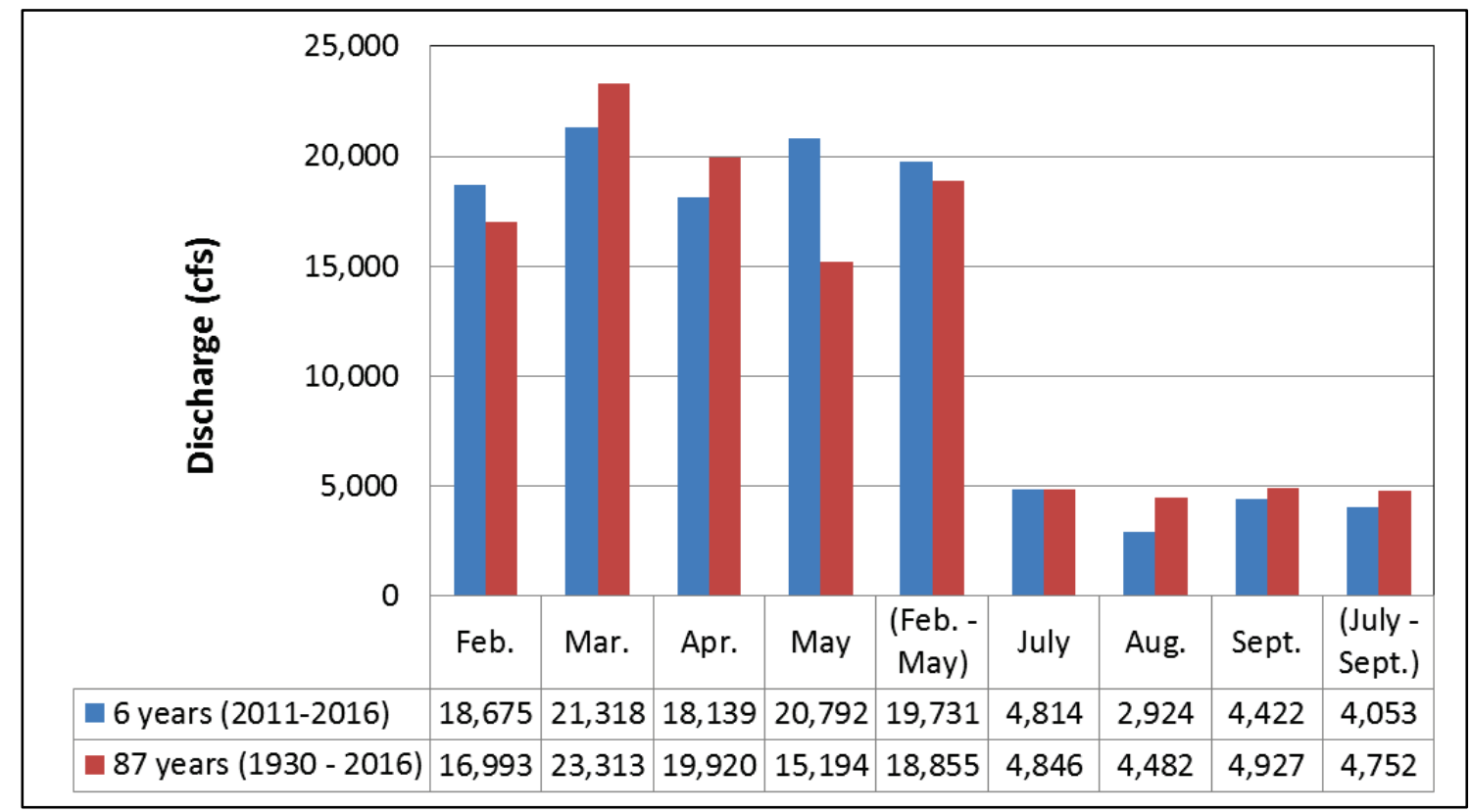

A 1-month tidal simulation from 04/25/2013 to 5/31/2013 was used to represent the spring high flow rate condition, and another month-long tidal simulation from $06 / 25 / 2011$ to $7 / 31 / 2011$ was used for the averaged neap low flow condition. 
For all the long-term (1-month tidal flow simulations), a total of eight new computational ADCIRC meshes, one for base and seven with-project alternatives, were generated by further refining the storm surge ADCIRC meshes in the Dyke Marsh (see Figure 4-6b), keeping the resolution in the rest of the Potomac River watershed unchanged and coarsening the grids in the other river watersheds and basins contained in the overall ADCIRC domain. The spatial resolution of the refined grid in the Dyke Marsh is approximately $20 \mathrm{ft}$, which is better able to represent flow through the wetland than the storm surge meshes. This is important because under storm surge conditions, the wetlands are typically completely inundated. However, during normal events, that is not the case, and more refined representations of flow features are required. Figure 5-7 gives a close-up of a refined computational mesh in the study area for a long promontory representation.

Figure 5-7. Refined computational grid (20 ft resolution in the Dyke Marsh).

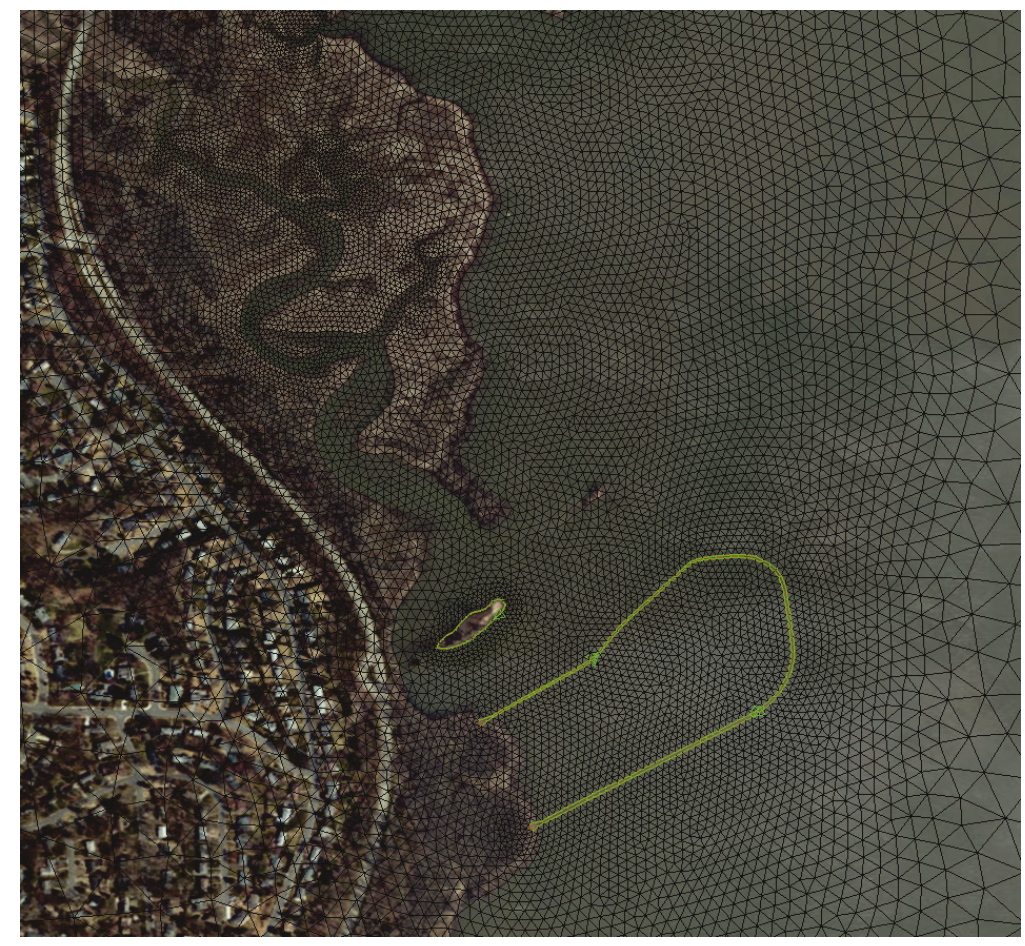

A set of 12 constant wind fields were generated by combining two wind speed values (20 $\mathrm{mph}$ and $30 \mathrm{mph}$ ) with six wind directions from southwest $\left(45^{\circ}\right)$, south $\left(90^{\circ}\right)$, southeast $\left(135^{\circ}\right)$, east $\left(180^{\circ}\right)$, northeast $\left(225^{\circ}\right)$, and north $\left(270^{\circ}\right)$. The degree associated with a wind direction is the angle measured counterclockwise from the $x$-axis of the ADCIRC grid coordinates (i.e., the east direction). 
A summary of the computational conditions used for simulating 1-month tidal flows and non-storm wind-driven waves is presented in Table 5-58. As no flow over the structures is expected for these non-storm events, with either low or high crest elevation, only structures with the higher crest level ( $9.55 \mathrm{ft}$ above MSL) were investigated (five of seven with-project conditions). Through the two-step simulation process mentioned above, first, twelve 1-month tidal simulations with constant river flow (high or low) were made. In the second step, by using the final high flows (at the end of the computational period), as the initial conditions for every designed layout of the Dyke Marsh, 12 constant wind fields were applied to compute 1-day-long wind-driven waves. As a result, a total of 120 winddriven wave simulations (12 winds applied to 5 with-project grids for two river flows) were completed in addition to the 12 simulations for the without-project case.

Table 5-58. Computational conditions for simulating long-term tidal flows and wind-driven waves.

\begin{tabular}{|l|c|l|c|l|}
\hline Grid Name & River Flow (cfs) & Tide Period & $\begin{array}{c}\text { Wind Speed } \\
\text { (miles per hour) }\end{array}$ & $\begin{array}{l}\text { Wind Direction } \\
\text { (from)* }\end{array}$ \\
\hline $\begin{array}{l}\text { DM01E (existing } \\
\text { condition) }\end{array}$ & 19,731 & $\begin{array}{l}04 / 25 / 2013 \\
-5 / 31 / 2013\end{array}$ & 20.0 & $\mathrm{SW}\left(45^{\circ}\right)$ \\
\hline $\begin{array}{l}\text { DM01P2 (Long } \\
\text { Promontory) }\end{array}$ & 4,053 & $\begin{array}{l}06 / 25 / 2011 \\
-7 / 31 / 2011\end{array}$ & 30.0 & $\mathrm{~S}\left(90^{\circ}\right)$ \\
\hline $\begin{array}{l}\text { DM01P4 (Short } \\
\text { Promontory) }\end{array}$ & & $\mathrm{SE}\left(135^{\circ}\right)$ \\
\hline DM01P6 (Groin Alt 1) & & $\mathrm{E}\left(180^{\circ}\right)$ \\
\cline { 1 - 1 } DM01P7 (Groin Alt 2) & & $\mathrm{NE}\left(225^{\circ}\right)$ \\
\cline { 1 - 1 } DM01P8 (Groin Alt 3) & & $\mathrm{N}\left(270^{\circ}\right)$ \\
\hline
\end{tabular}

* The degree associated with a wind direction is the angle measured counterclockwise from the $x$-axis of the ADCIRC grid coordinates.

\subsubsection{Results for long-term tidal flows}

Construction of in-stream structures in a tidal river reach such as the one around the Dyke Marsh will alter river flows and tidal flows. In general, a newly constructed groin tends to redirect river flows away from the structure and also changes directions of tidal currents in the area of the structure. Numerical models for predicting tidal flows before and after the inclusion of structures can quantify the differences in hydrodynamic variables (water surface elevation and depth-averaged flow velocities) between the conditions with and without the structure in place. 
In the 1-month tidal simulations with a spring high flow discharge in the river, comparisons were made of the computed water levels and velocities at the 18 selected stations, which are marked in Figure 5-4 and Figure 5-5. For example, Figure 5-8 presents a comparison of water levels and velocities at Station (Stn) 1 from Day 30 to 35. Stn 1 is located in approximately an $8 \mathrm{ft}$ water depth immediately downstream from the promontory. Even though the length of the longer promontory is approximately one-third of the river width ( $\sim 1$ mile), no significant differences are found in water levels at this station among the current condition (no structure) and four proposed promontories. However, the river flows at this point are changed and can best be seen in tidal ellipse plots. A tidal ellipse plot is a common way of representing magnitude and direction of tidal currents over a given tidal cycle. Over a tidal cycle, if one plotted current vectors from a common location over time, the heads of those current vectors would typically trace out an ellipse. As shown in the current ellipses in Figure 5-8, tidal flow directions are sequentially turned from a stream-wise direction (no structure, current condition) to the NNE by the shorter promontory (DMo1P3 or $\mathrm{P}_{4}$ ) and to the northeast by the longer one (DMo1P1 or P2). In particular the shorter structural layout increased the tidal flow velocity up to 30\% (Figure 5-9). The longer structure causes a change in tidal flow phase, but no significant changes in its magnitude. From the tidal flow simulations, because of no overtopping through the design structures, it is found that the same layout of promontories (either the longer or shorter one) with two different crest heights makes no significance differences in water levels and velocities at all 18 selected observation stations.

Flows are also changed around the promontory. At Stn 2 (Figure 5-10 and Figure 5-11), which is located at the tip of the longer promontory at approximately a $10 \mathrm{ft}$ water depth, the tidal flow directions follow the curvature of the structure, turning from the north-south direction to the northwest-southeast direction. Flow velocities also increase in comparison to the without-project condition.

Stn 3 is placed on the upstream side of the structures, very close to the low sill (3 ft above MSL). As shown in Figure 5-12 and Figure 5-13, the longer promontory reduces the tidal current magnitude to $10 \%$ of the velocity of the without-project case. The shorter promontory also reduces the tidal velocity of the without-project condition to $65 \%$ of the without-project case. 
In the shadow region of the structures, tidal flows are decreased to a certain degree. At Stn 4 (Figure 5-14 and Figure 5-15), which is close to the shoreline of the marsh, the tidal current is reduced to $20 \%$ and to $65 \%$, respectively, of the without-project conditions by the longer structures and the shorter ones. At Stn 5 (Figure 5-16 and Figure 5-17), a similar amount of velocity reductions can be observed. At Stn 6 (Figure 5-18 and Figure $5-19$ ), only a small amount of velocity reduction is found.

In general, the shorter alterative ( $\mathrm{DMo1}_{3}$ or $\left.\mathrm{P}_{4}\right)$ may only reduce flows in its shadow region below $S t n 6$. The longer promontory may provide a wider area of reduced wave heights for the wetland on its leeward side up to the shoreline where Stn 6 is located.

Possible impacts of the structures on the eastern bank were also analyzed by comparing hydrodynamic variables (water levels and velocities) with and without the inclusion of structures. For example, at Stn 13 (Figure 5-20 and Figure 5-21), approximately a 20\% velocity reduction can be observed due to the structures. At Stn 15 and 17 (Figure 5-22 through Figure 5-25), the structures only alter the phases of tidal currents, not velocity magnitudes.

Under the conditions of the summer low flow in the Potomac River, similar reduction effects on tidal velocities can be observed at the western bank (Figure 5-26 through Figure 5-31) and the eastern bank (Figure 5-32 through Figure 5-35). 
Figure 5-8. Comparisons of water surface elevations and velocities at Stn 1. Water elevations are almost the same in all cases.

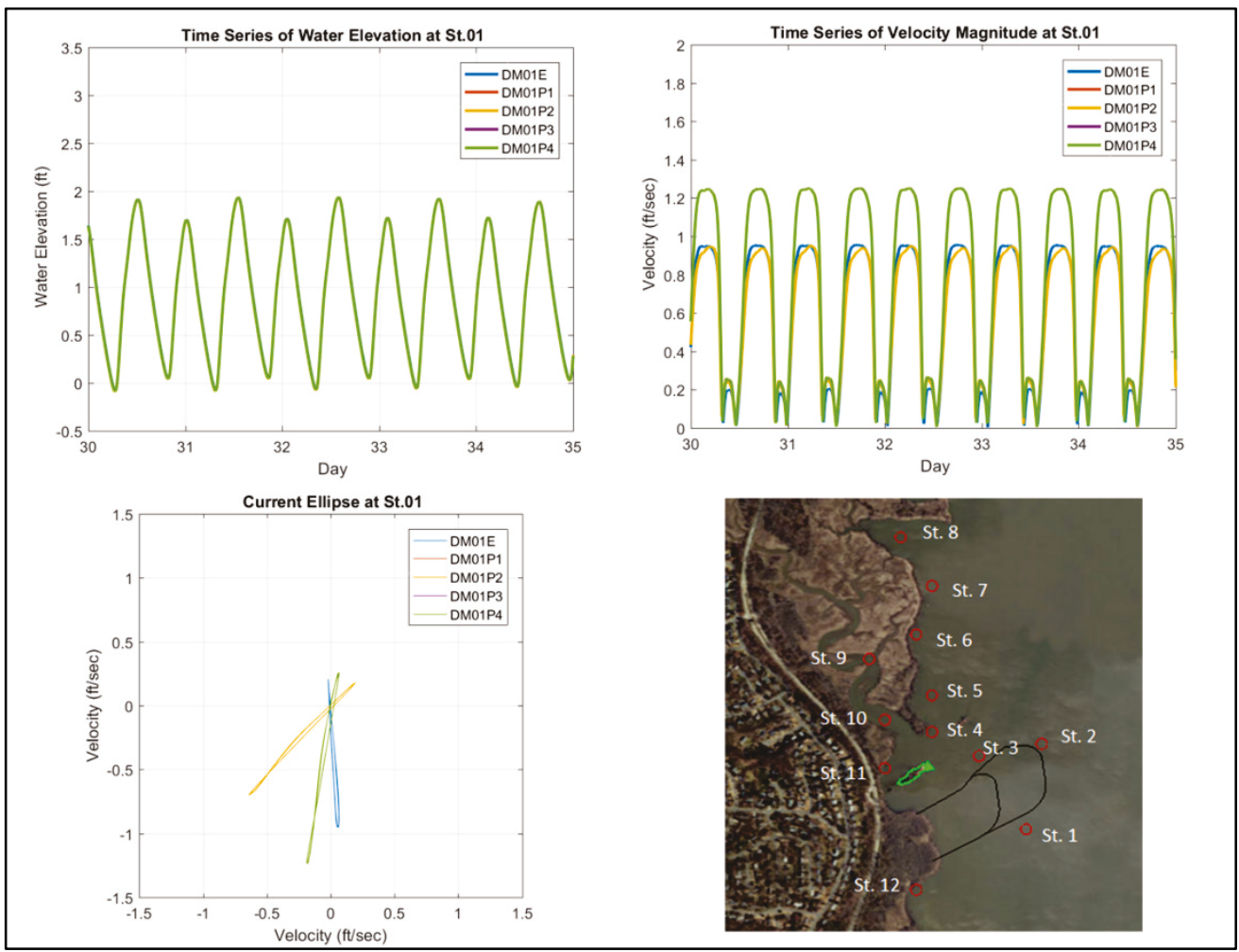

Figure 5-9. Differences in velocity magnitude (ft/s) at Stn 1 with and without structures.

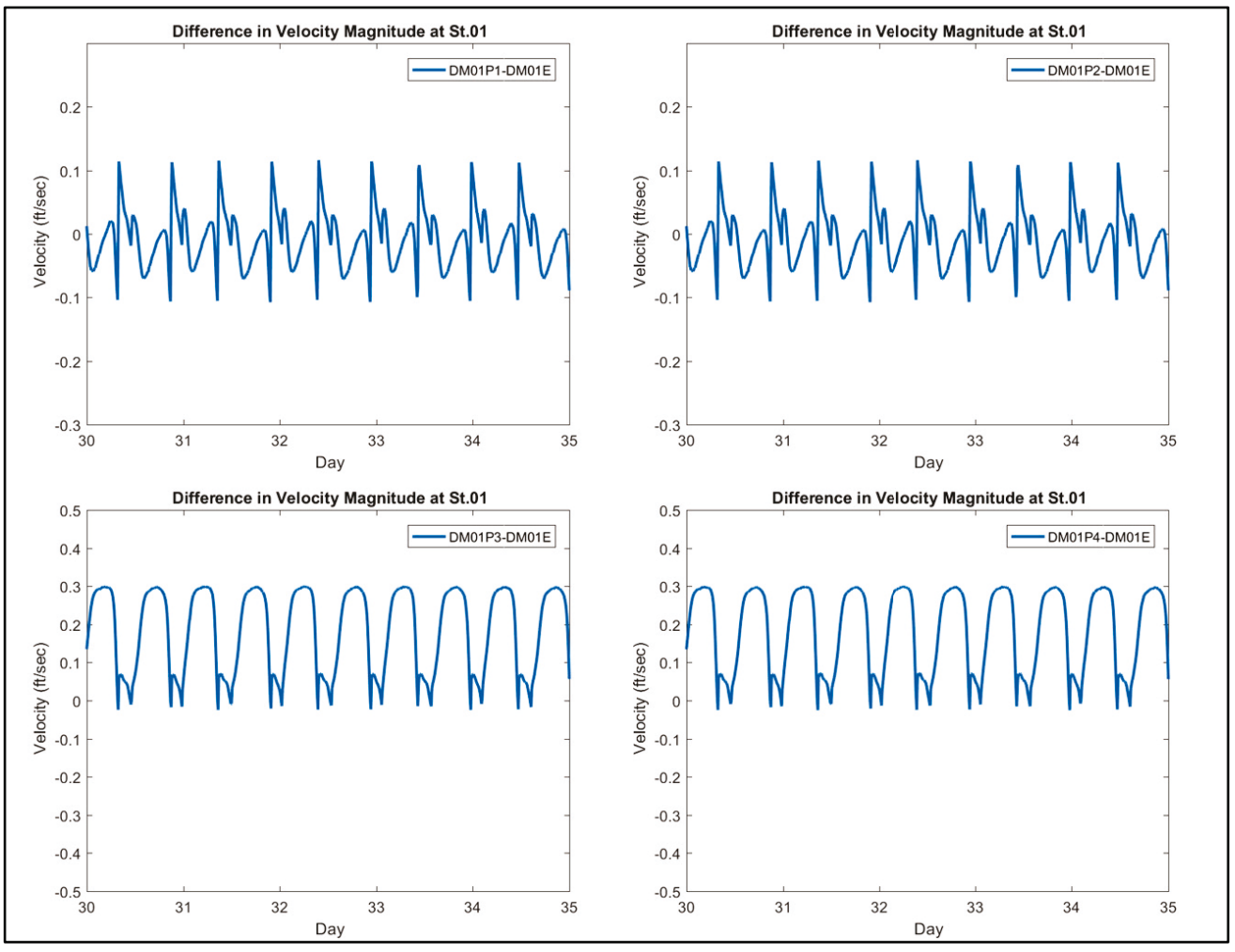


Figure 5-10. Comparisons of water surface elevations $(\mathrm{ft})$ and velocities $(\mathrm{ft} / \mathrm{s})$ at $\mathrm{Stn} 2$. Water elevations are almost the same in all cases.

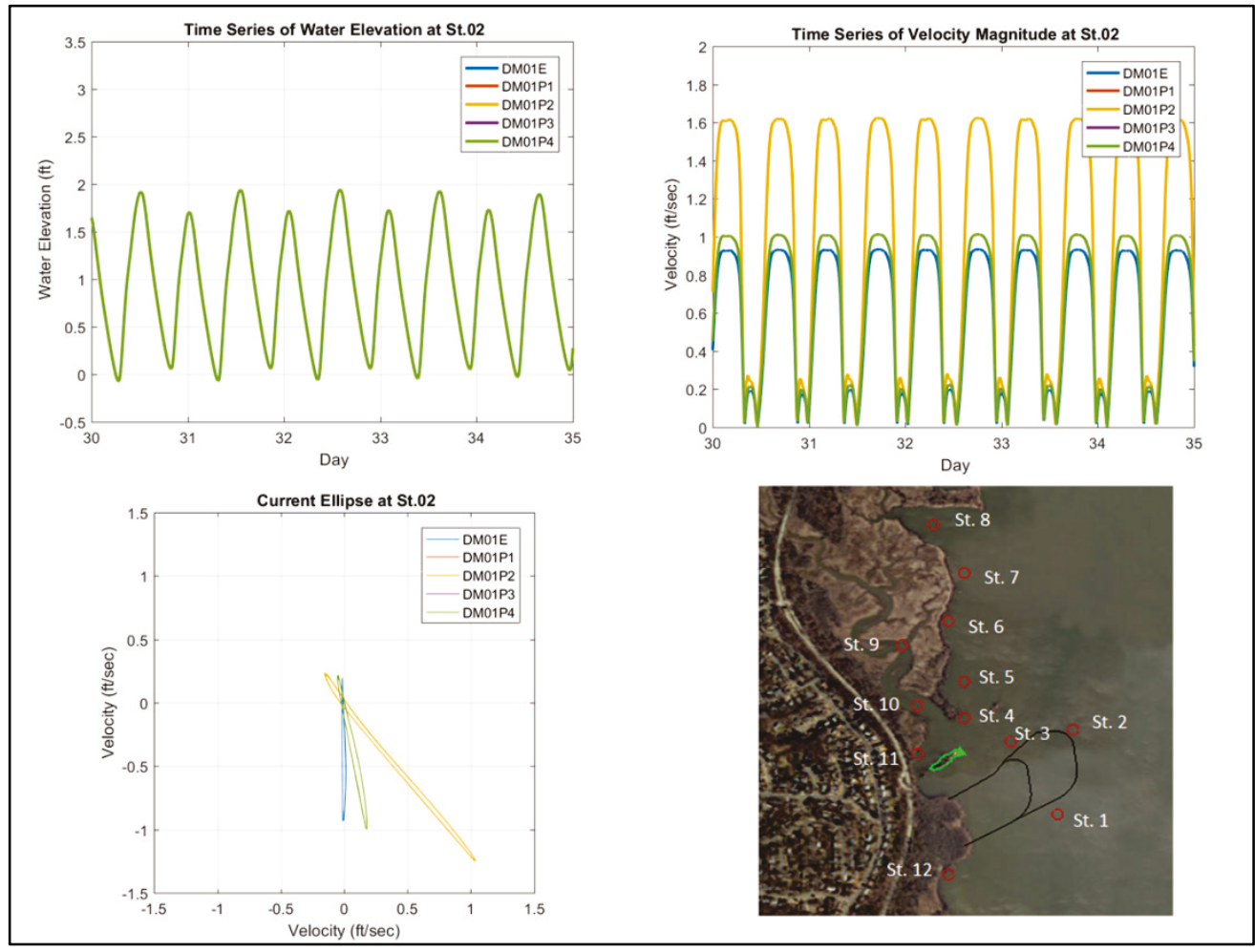

Figure 5-11. Differences in velocity magnitude (ft/s) at Stn 2 with and without structures.

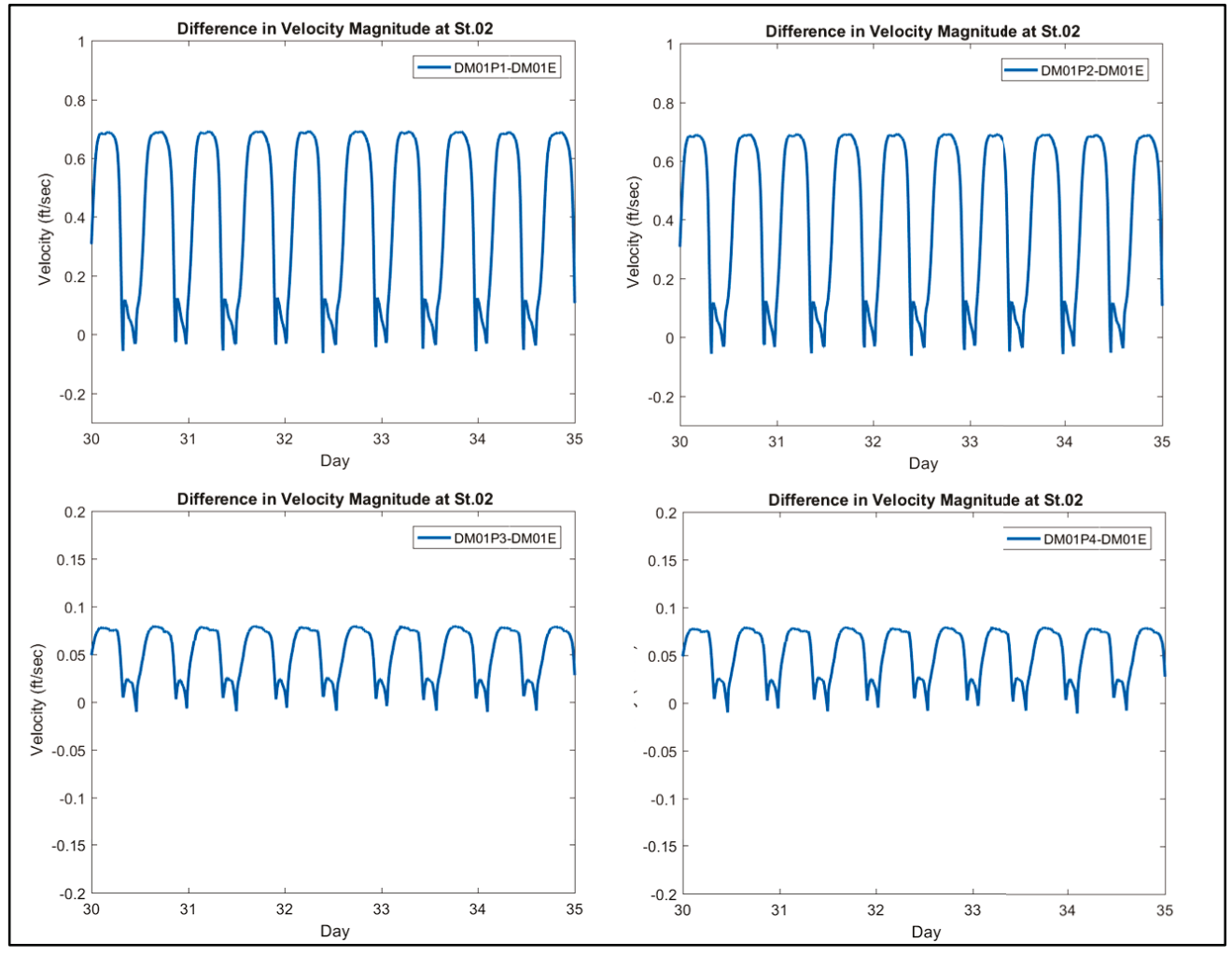


Figure 5-12. Comparisons of water surface elevations $(\mathrm{ft})$ and velocities $(\mathrm{ft} / \mathrm{s})$ at $\mathrm{Stn} 3$. Water elevations are almost the same in all cases.

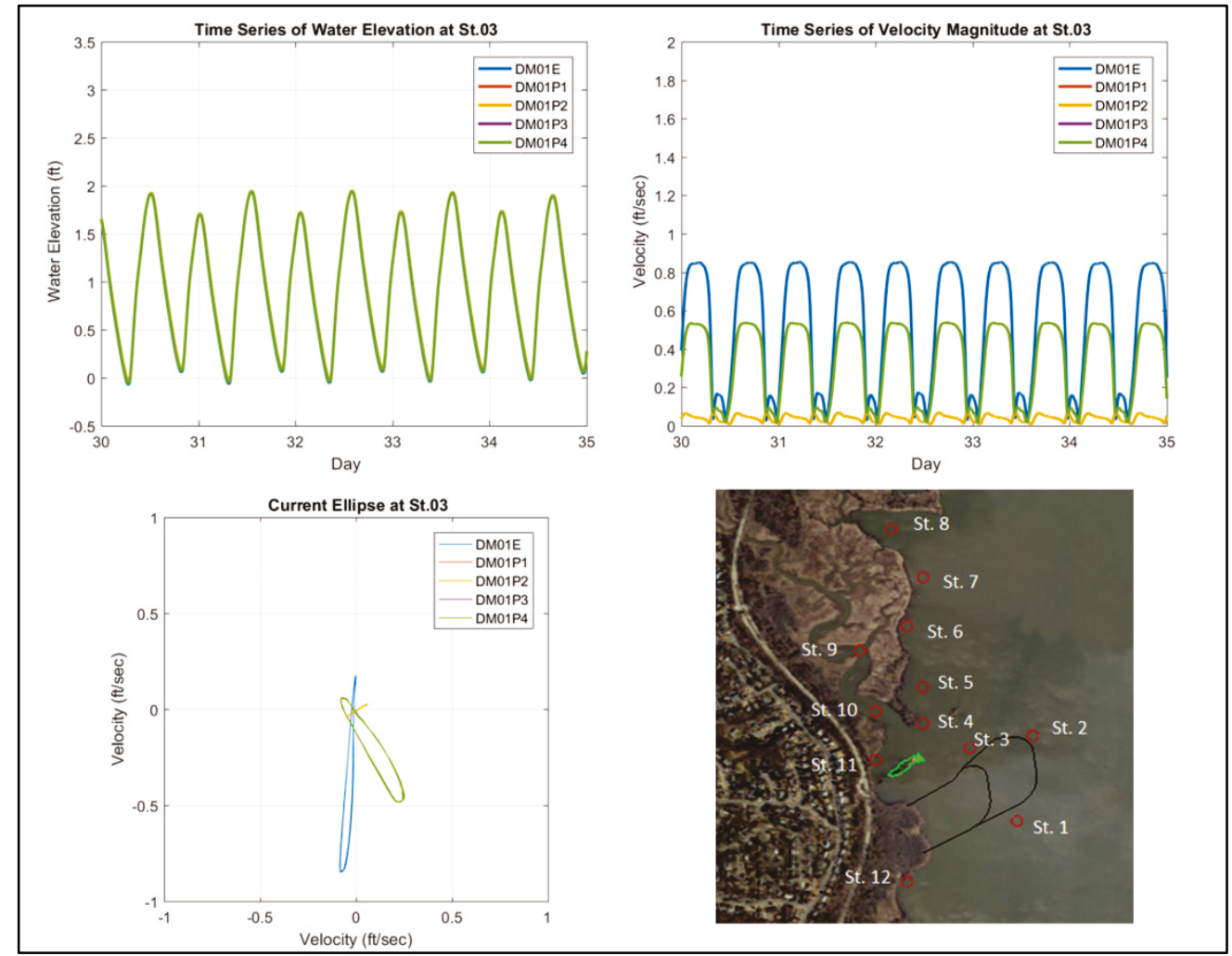

Figure 5-13. Differences in velocity magnitude (ft/s) at Stn 3 with and without structures.

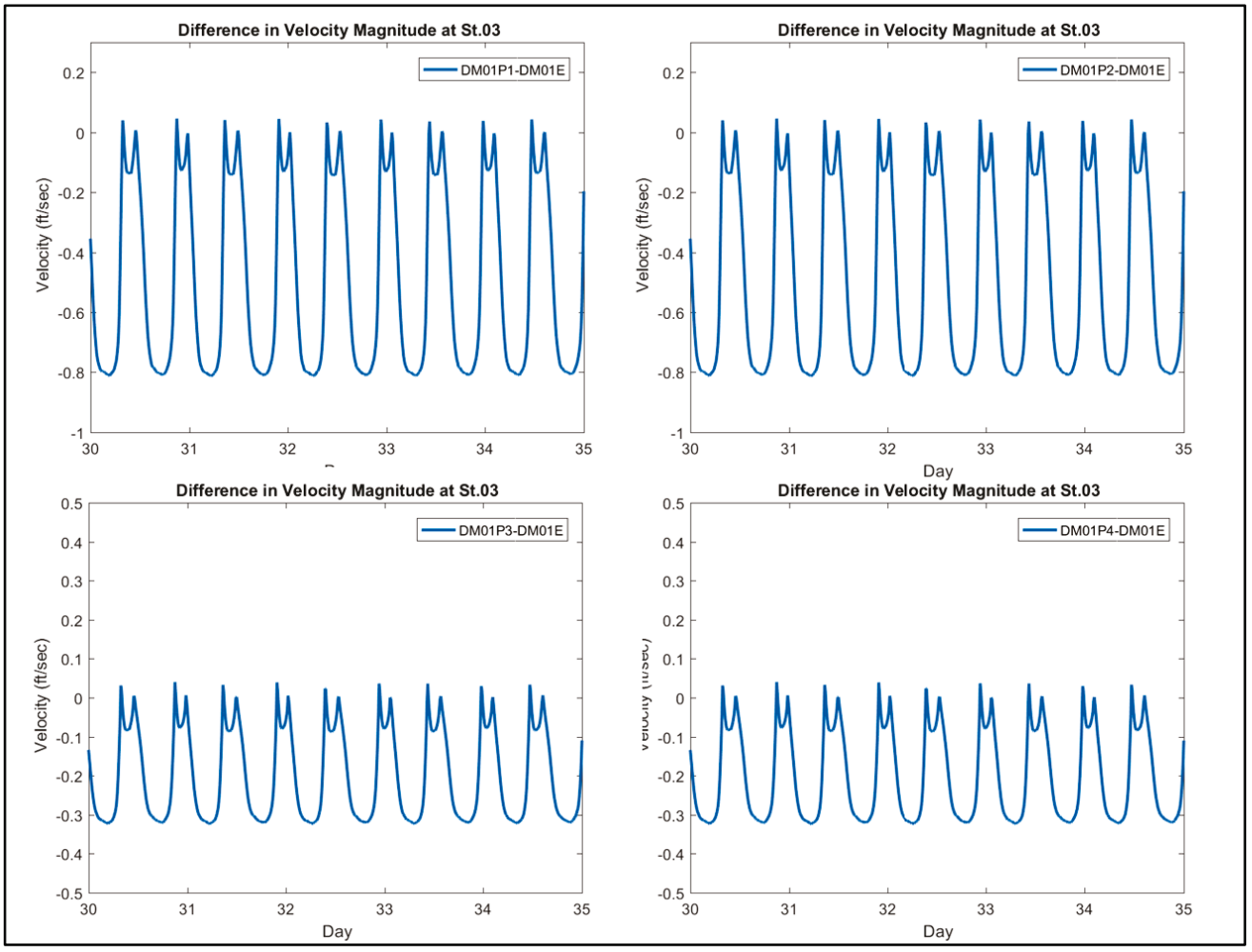


Figure 5-14. Comparisons of water surface elevations $(\mathrm{ft})$ and velocities $(\mathrm{ft} / \mathrm{s})$ at $\mathrm{Stn} 4$. Water elevations are almost the same in all cases.

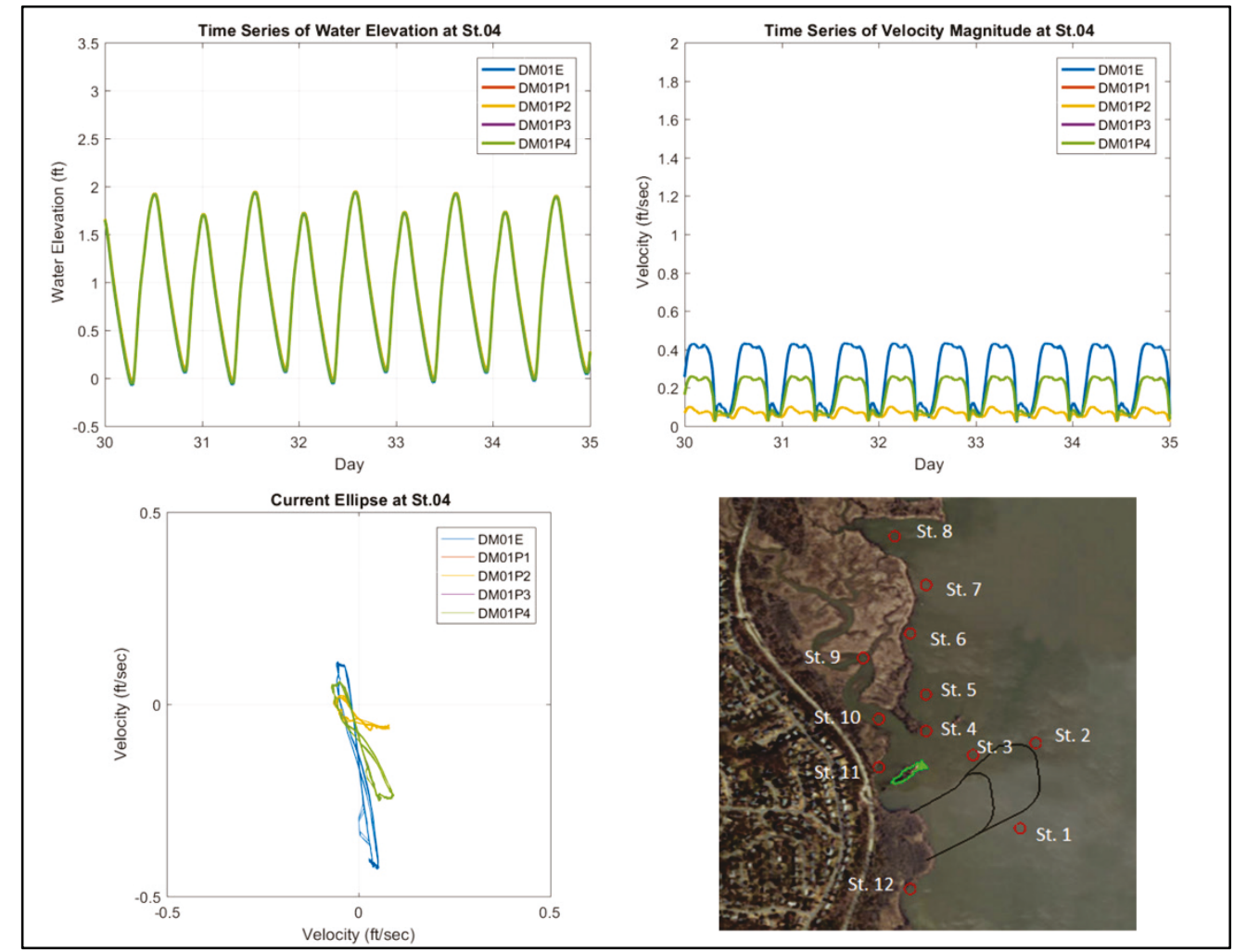

Figure 5-15. Differences in velocity magnitude (ft/s) at Stn 4 with and without structures.

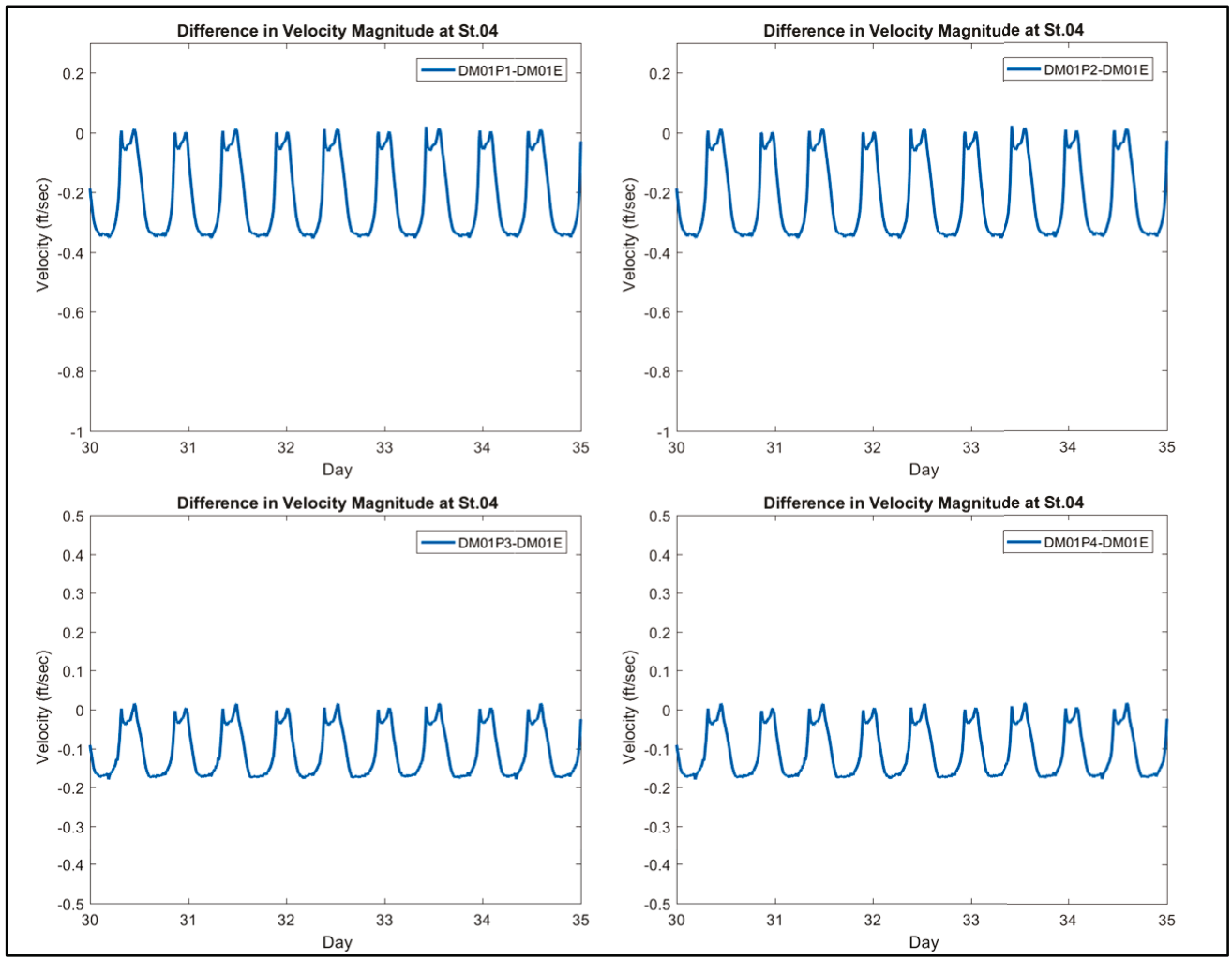


Figure 5-16. Comparisons of water surface elevations $(\mathrm{ft})$ and velocities $(\mathrm{ft} / \mathrm{s})$ at $\mathrm{Stn} 5$. Water elevations are almost the same in all cases.

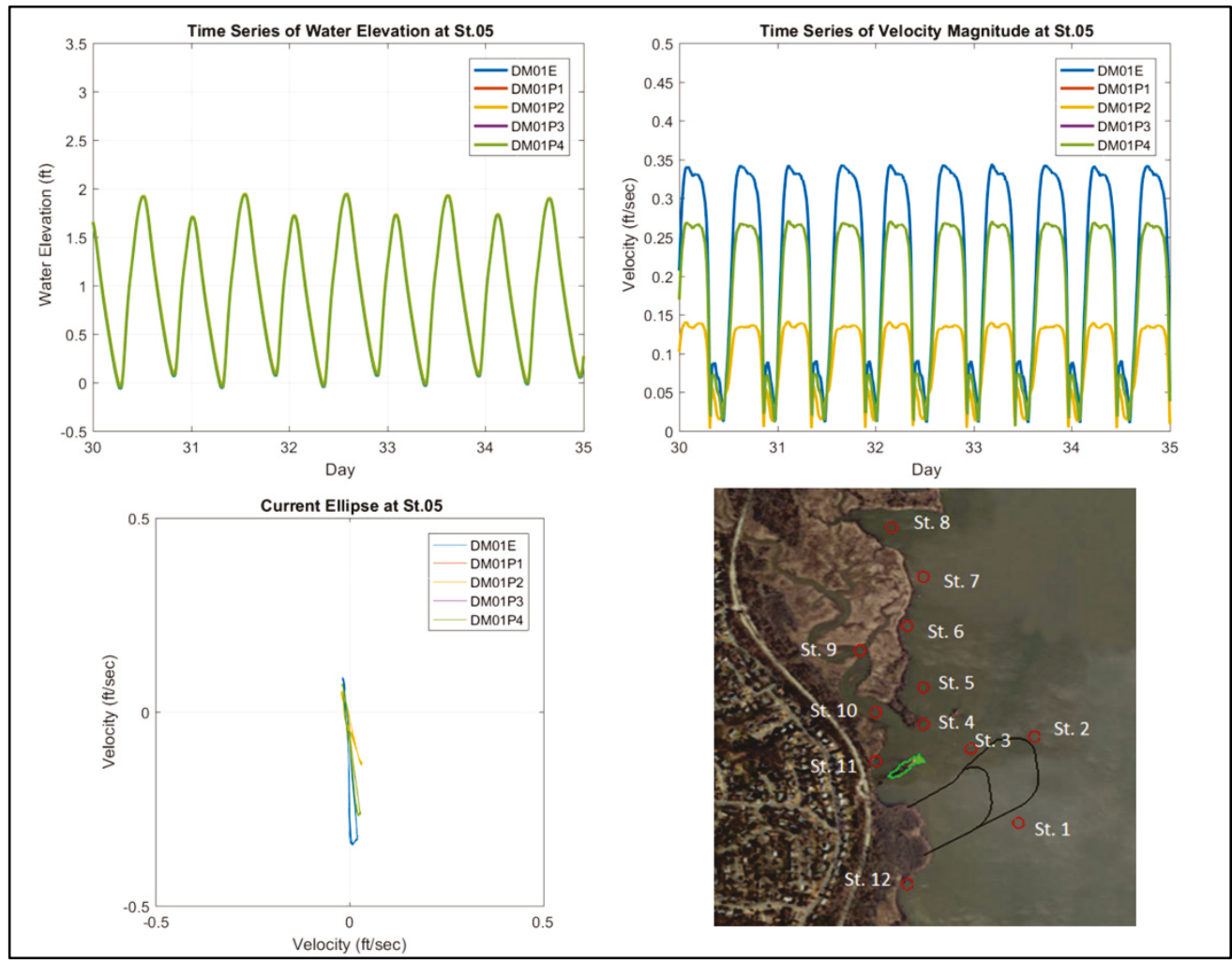

Figure 5-17. Differences in velocity magnitude (ft/s) at Stn 5 with and without structures.

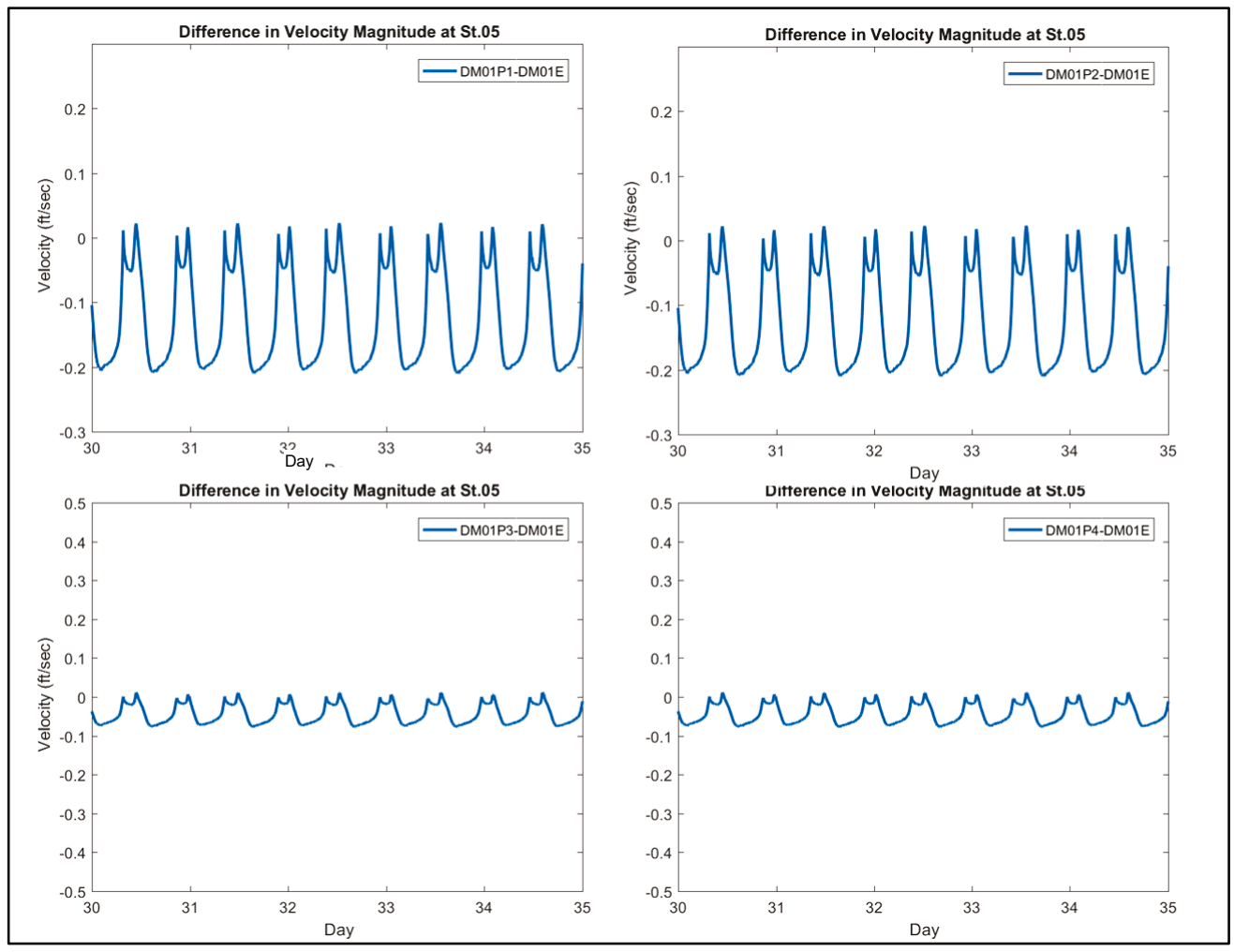


Figure 5-18. Comparisons of water surface elevations $(\mathrm{ft})$ and velocities $(\mathrm{ft} / \mathrm{s})$ at $\mathrm{Stn}$ 6. Water elevations are almost the same in all cases.

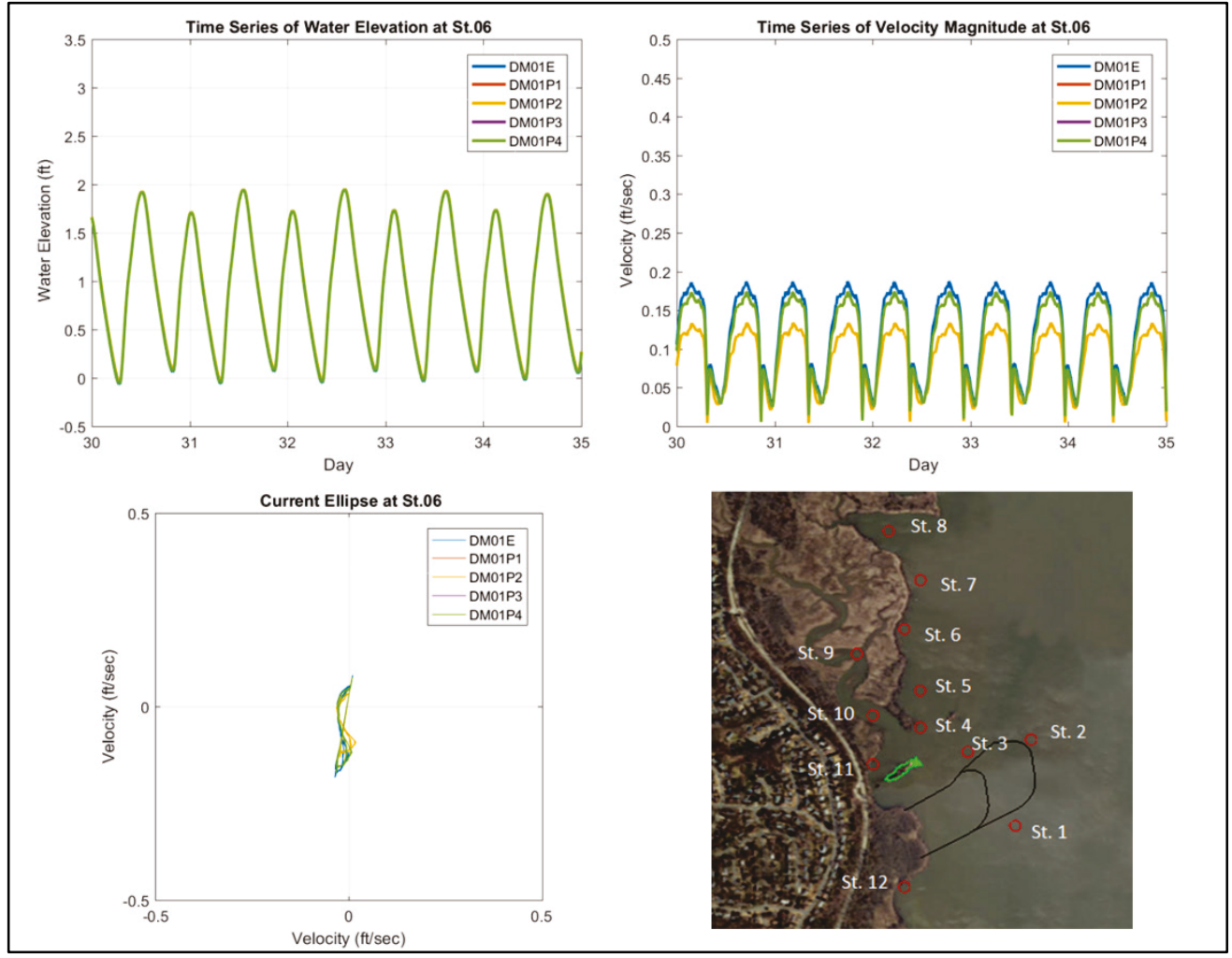

Figure 5-19. Differences in velocity magnitude (ft/s) at Stn 6 with and without structures.

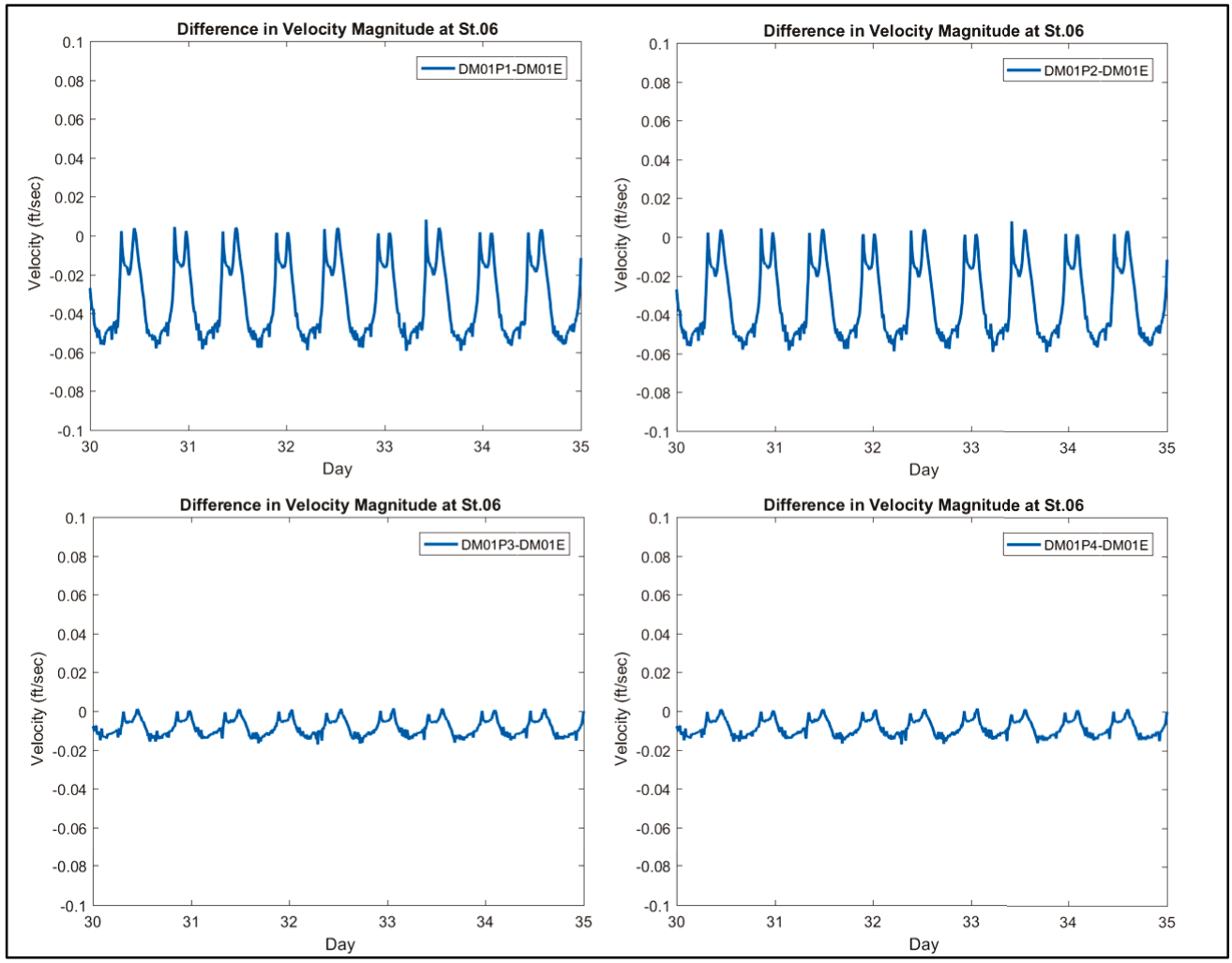


Figure 5-20. Comparisons of water surface elevations $(\mathrm{ft})$ and velocities $(\mathrm{ft} / \mathrm{s})$ at $\mathrm{Stn} 13$. Water elevations are almost the same in all cases.

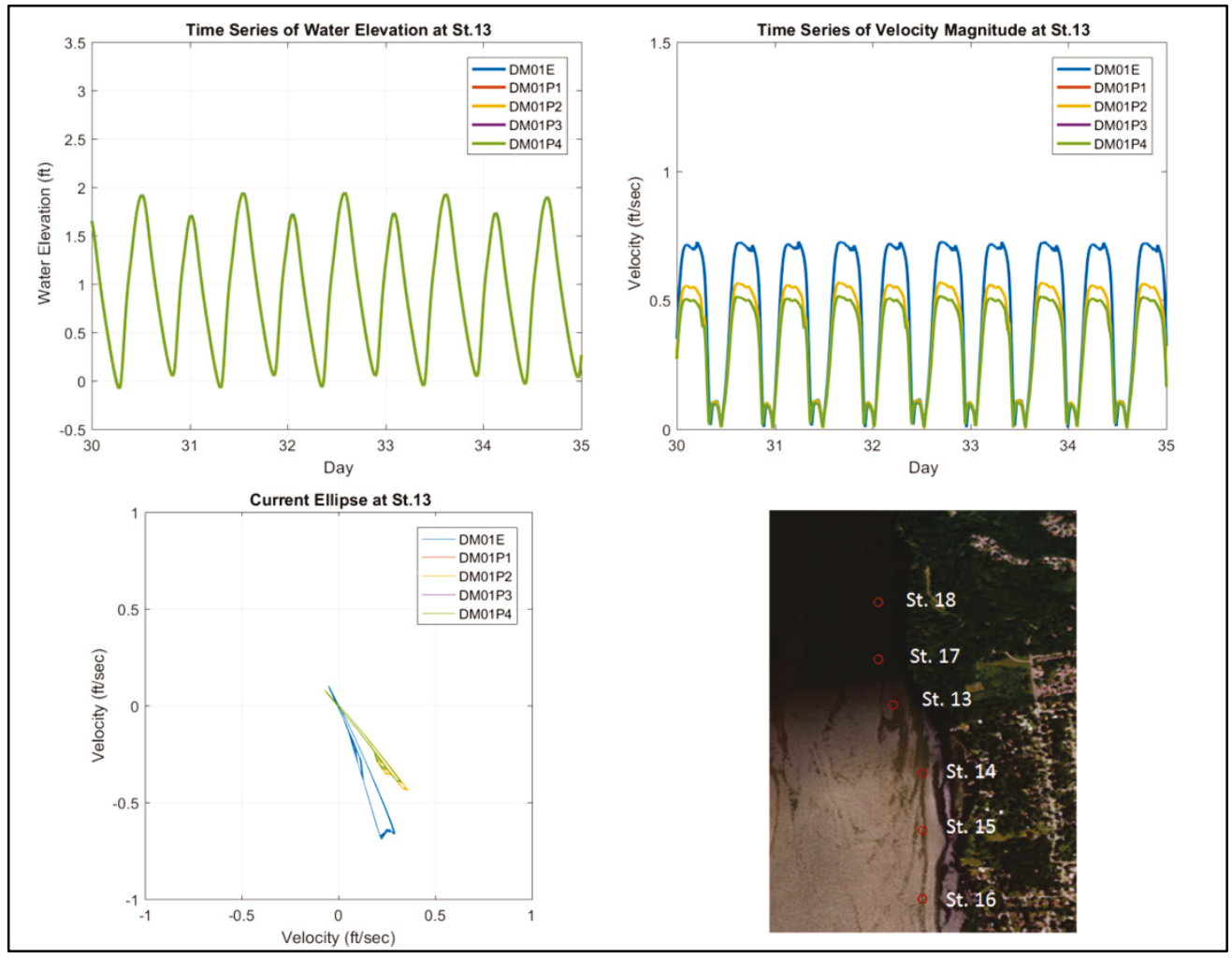

Figure 5-21. Differences in velocity magnitude (ft/s) at Stn 13 with and without structures.

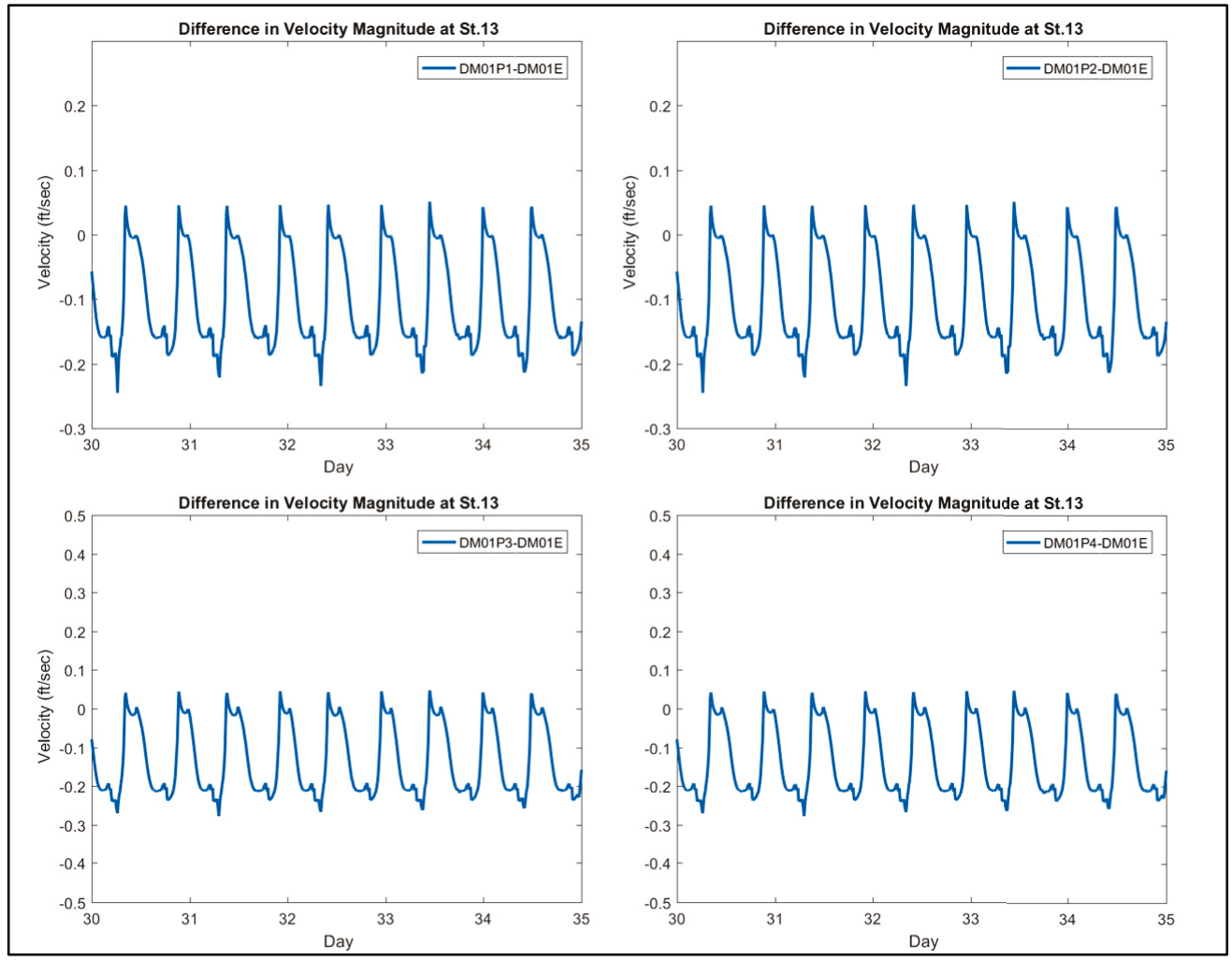


Figure 5-22. Comparisons of water surface elevations (ft) and velocities (ft/s) at Stn 15. Water elevations are almost the same in all cases.

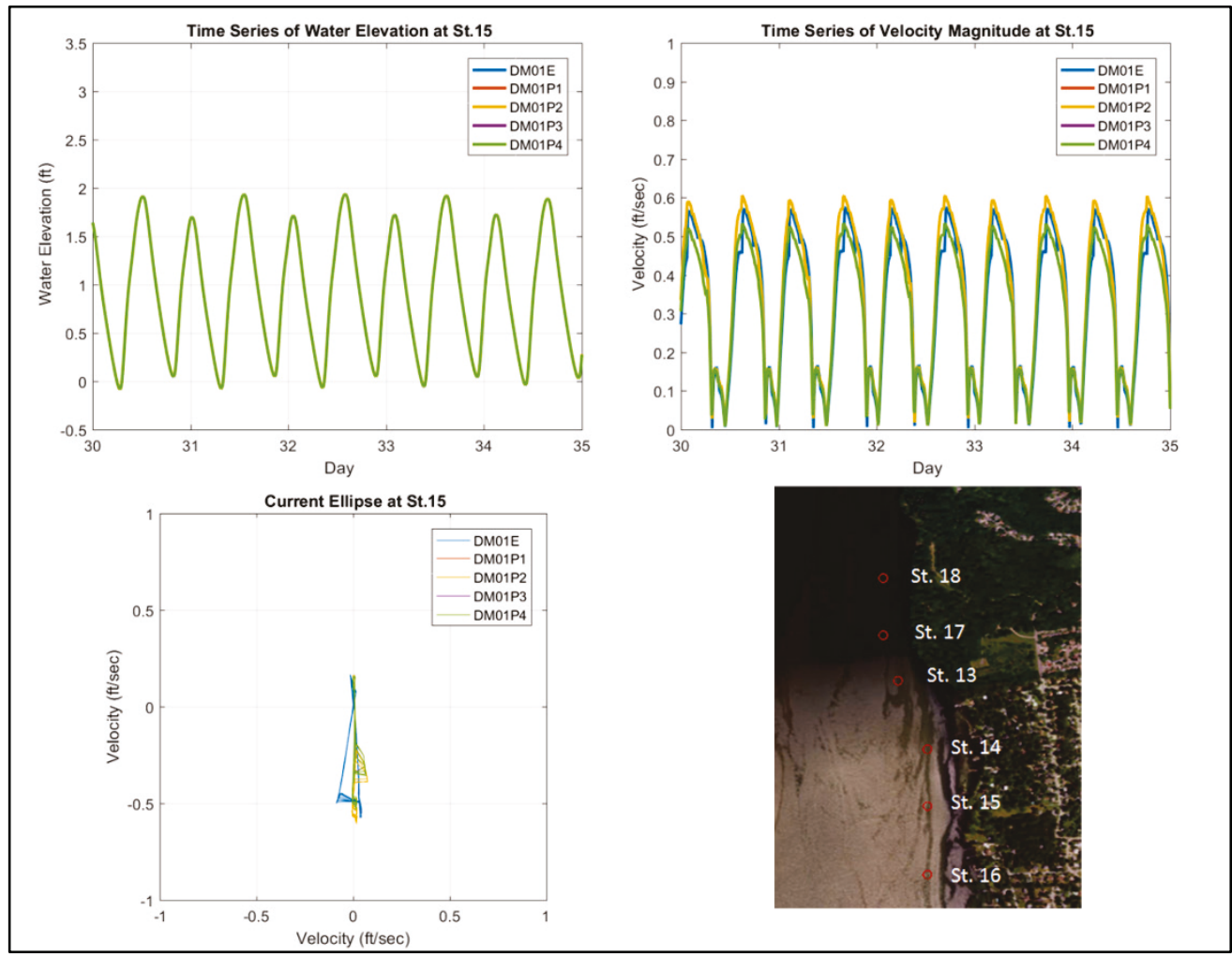

Figure 5-23. Differences in velocity magnitude (ft/s) at Stn 15 with and without structures.

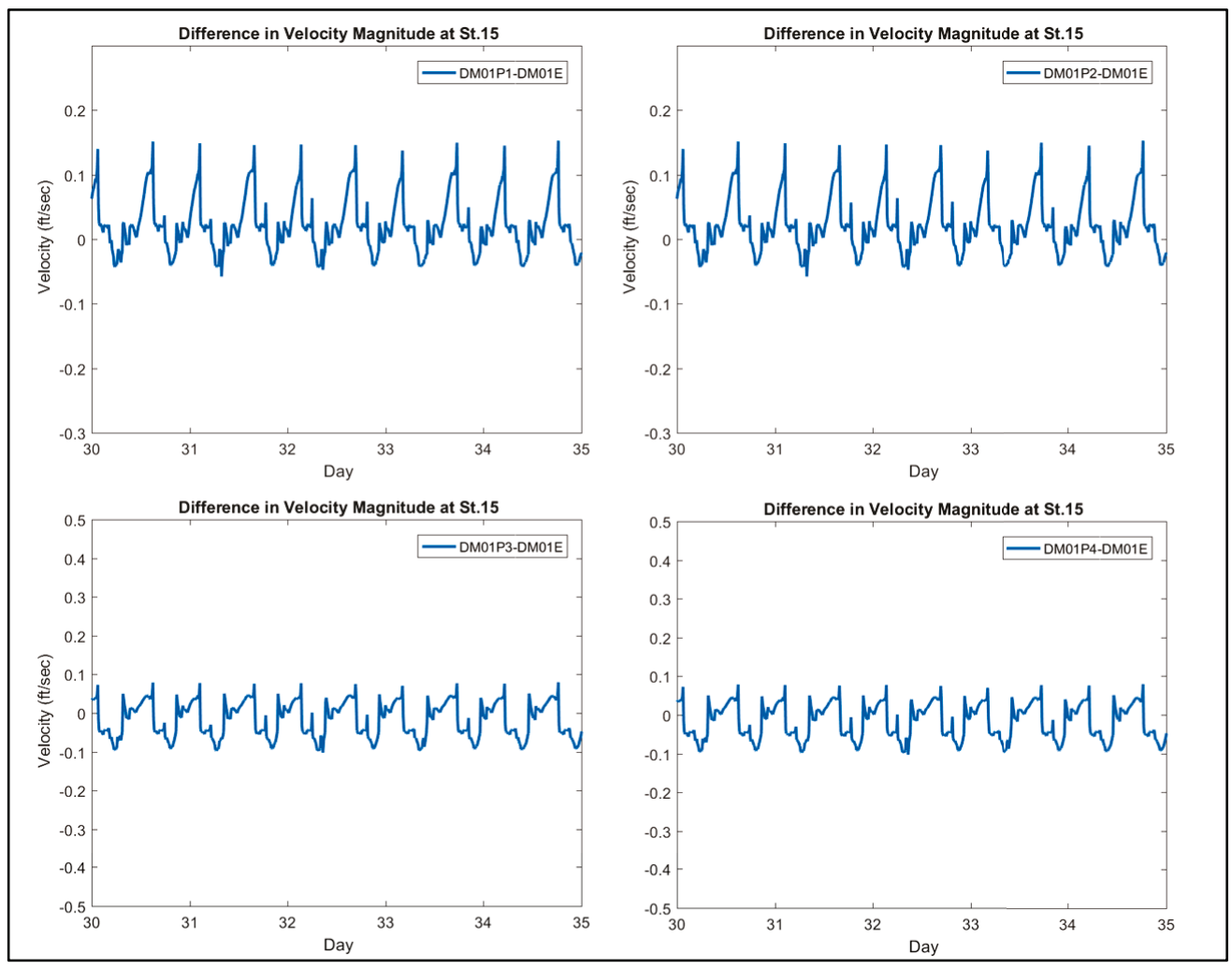


Figure 5-24. Comparisons of water surface elevations (ft) and velocities (ft/s) at Stn 17. Water elevations are almost the same in all cases.

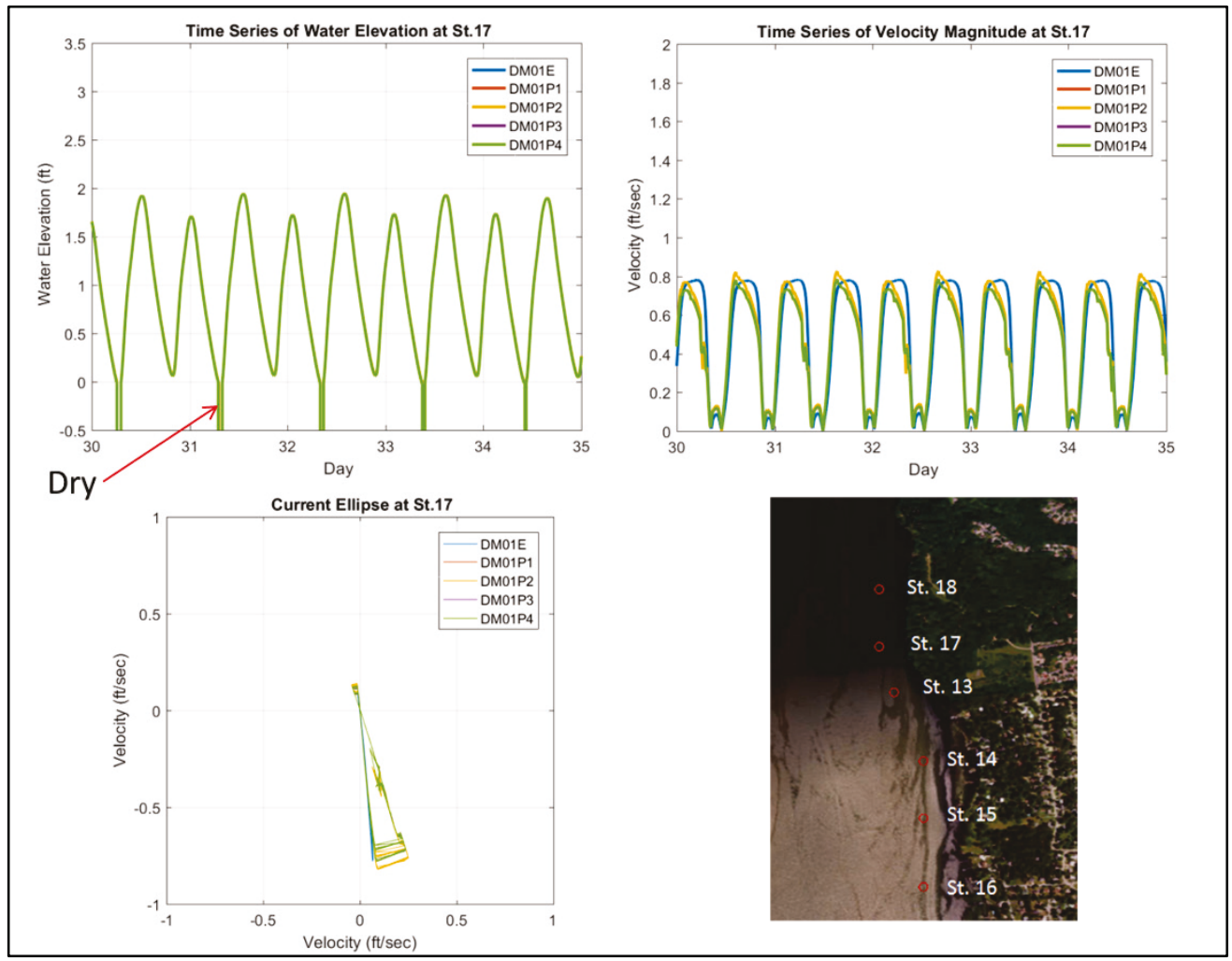

Figure 5-25. Differences in velocity magnitude (ft/s) at Stn 17 with and without structures.

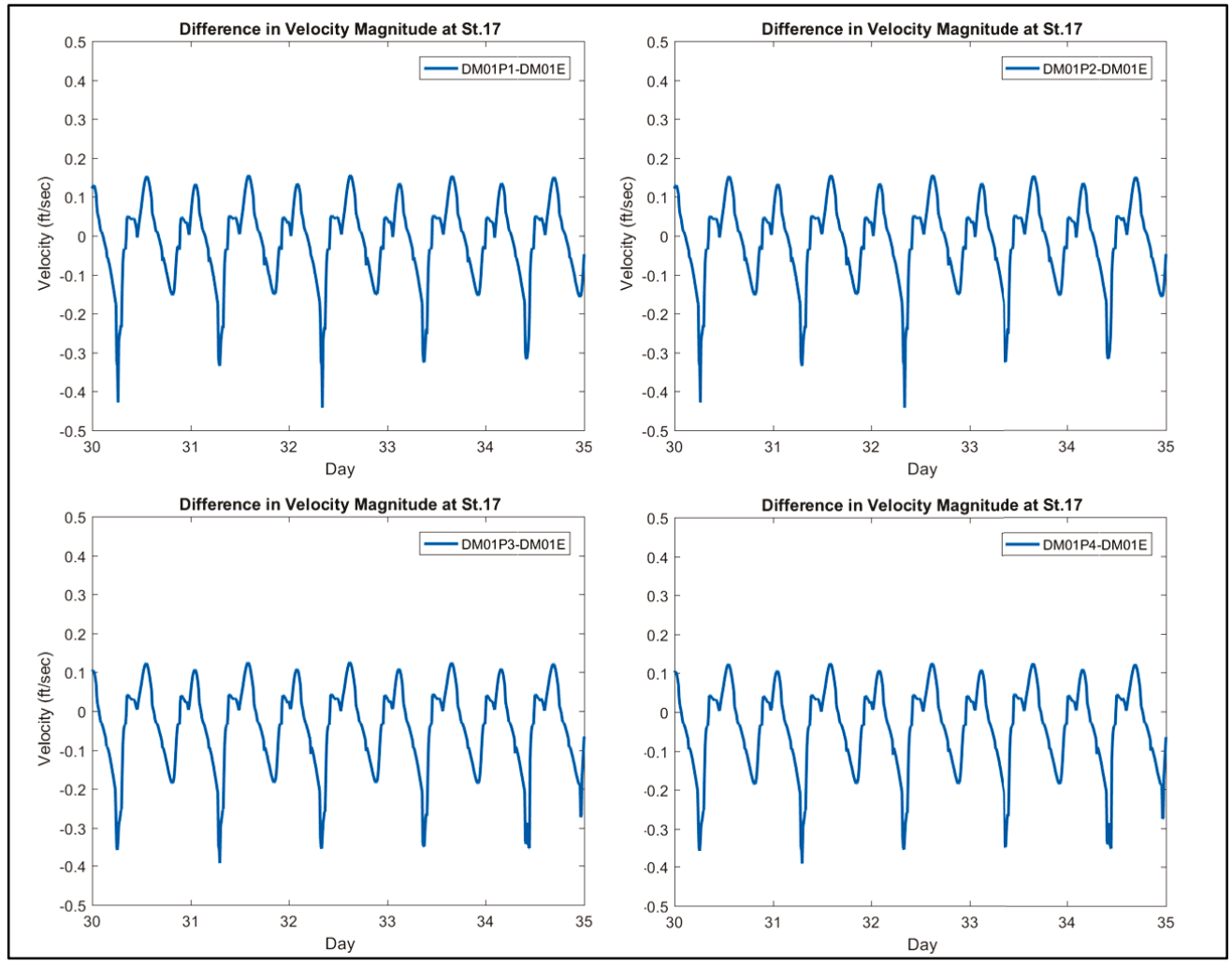


Figure 5-26. Comparisons of velocities at Stn 1 under the low flow conditions.

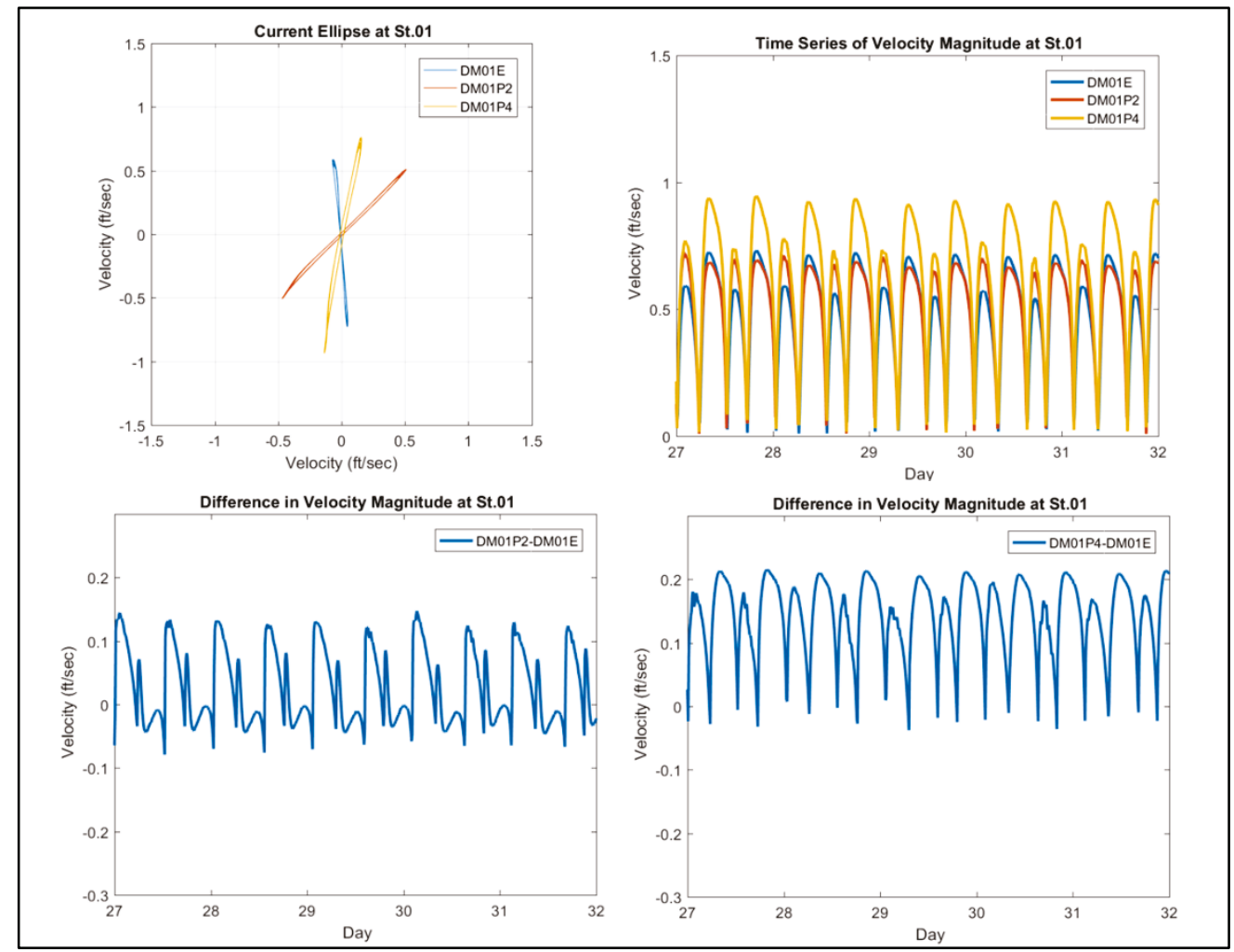

Figure 5-27. Comparisons of velocities at Stn 2 under the low flow conditions.

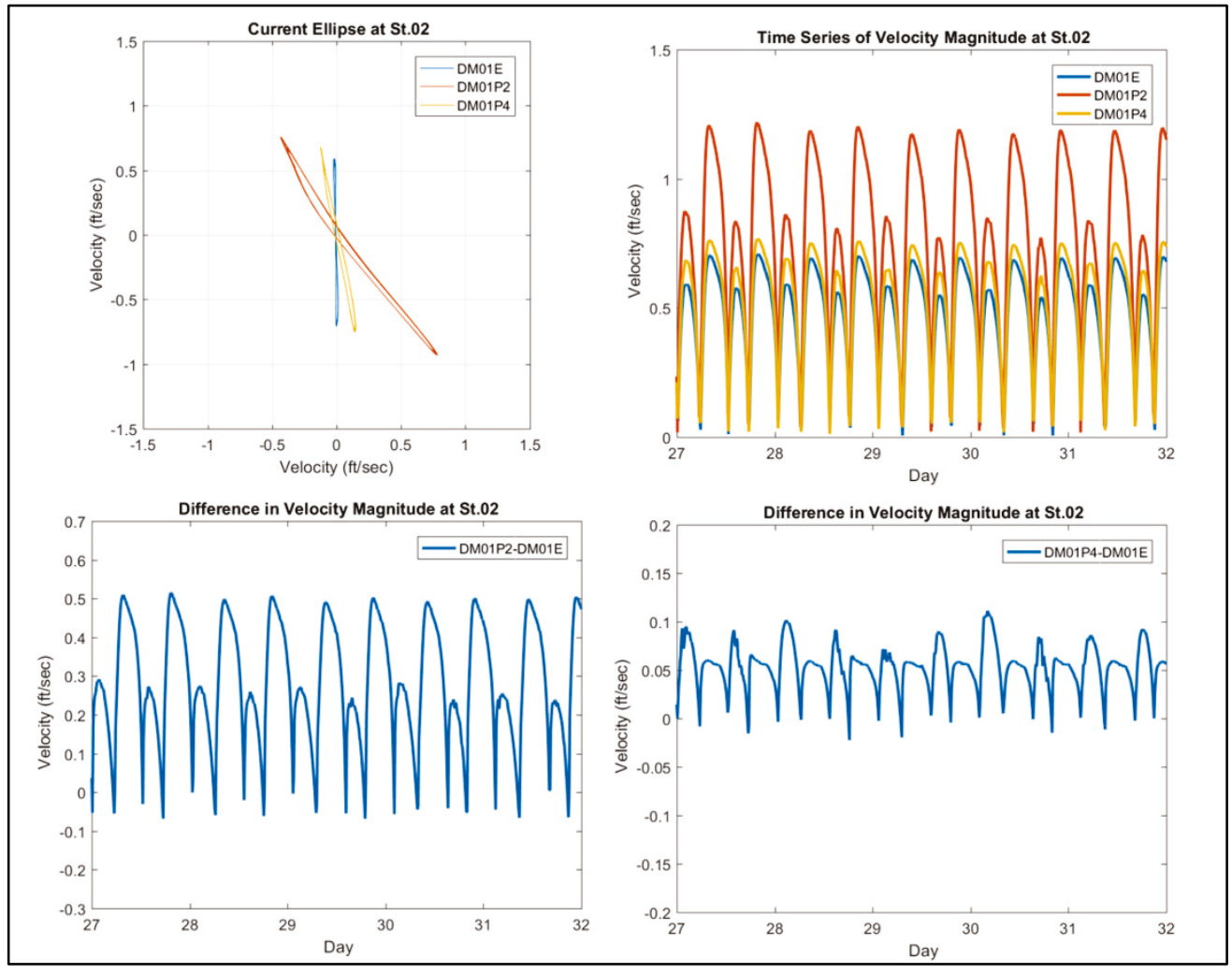


Figure 5-28. Comparisons of velocities at Stn 3 under the low flow conditions.

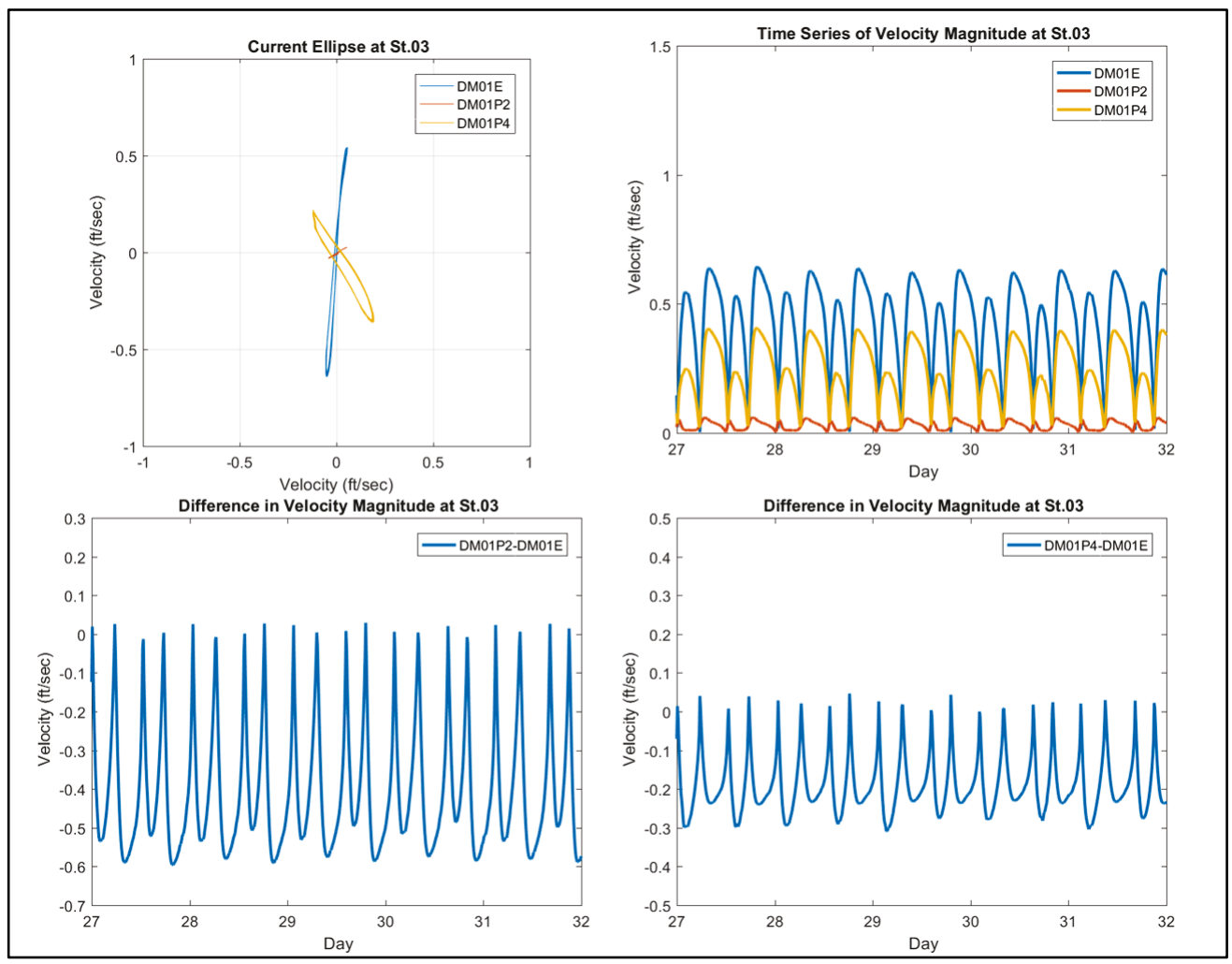

Figure 5-29. Comparisons of velocities at Stn 4 under the low flow conditions.

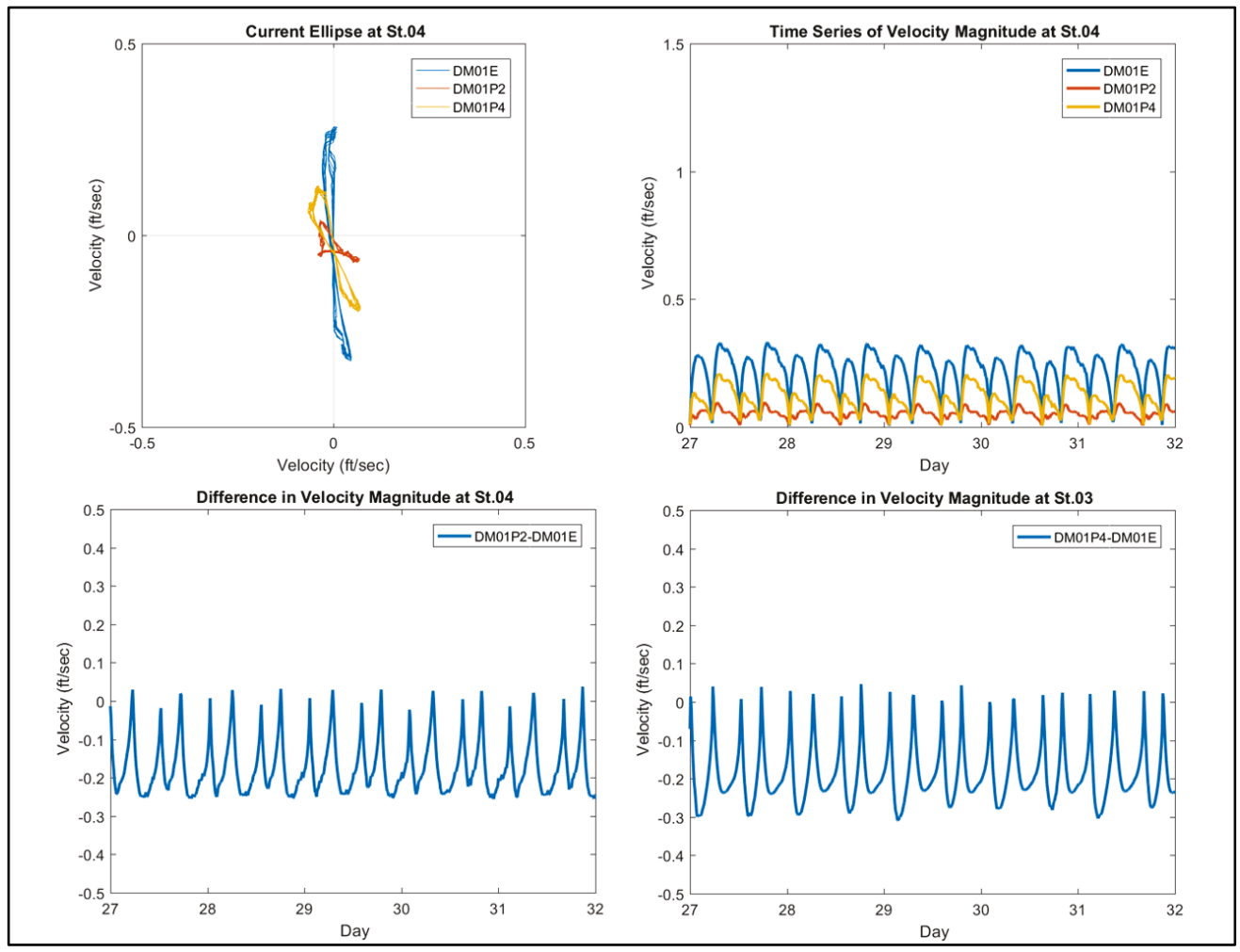


Figure 5-30. Comparisons of velocities at Stn 5 under the low flow conditions.

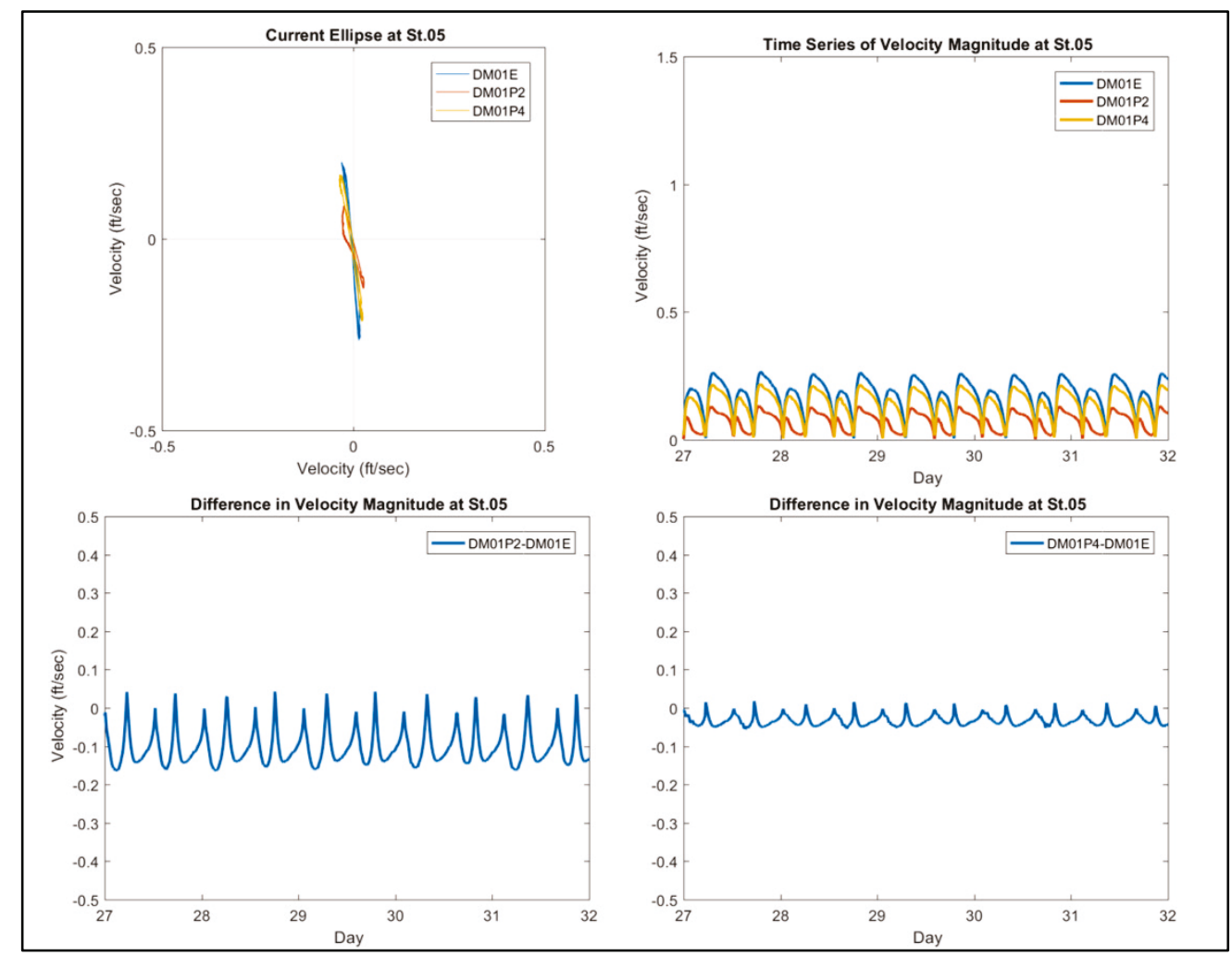

Figure 5-31. Comparisons of velocities at Stn 6 under the low flow conditions.

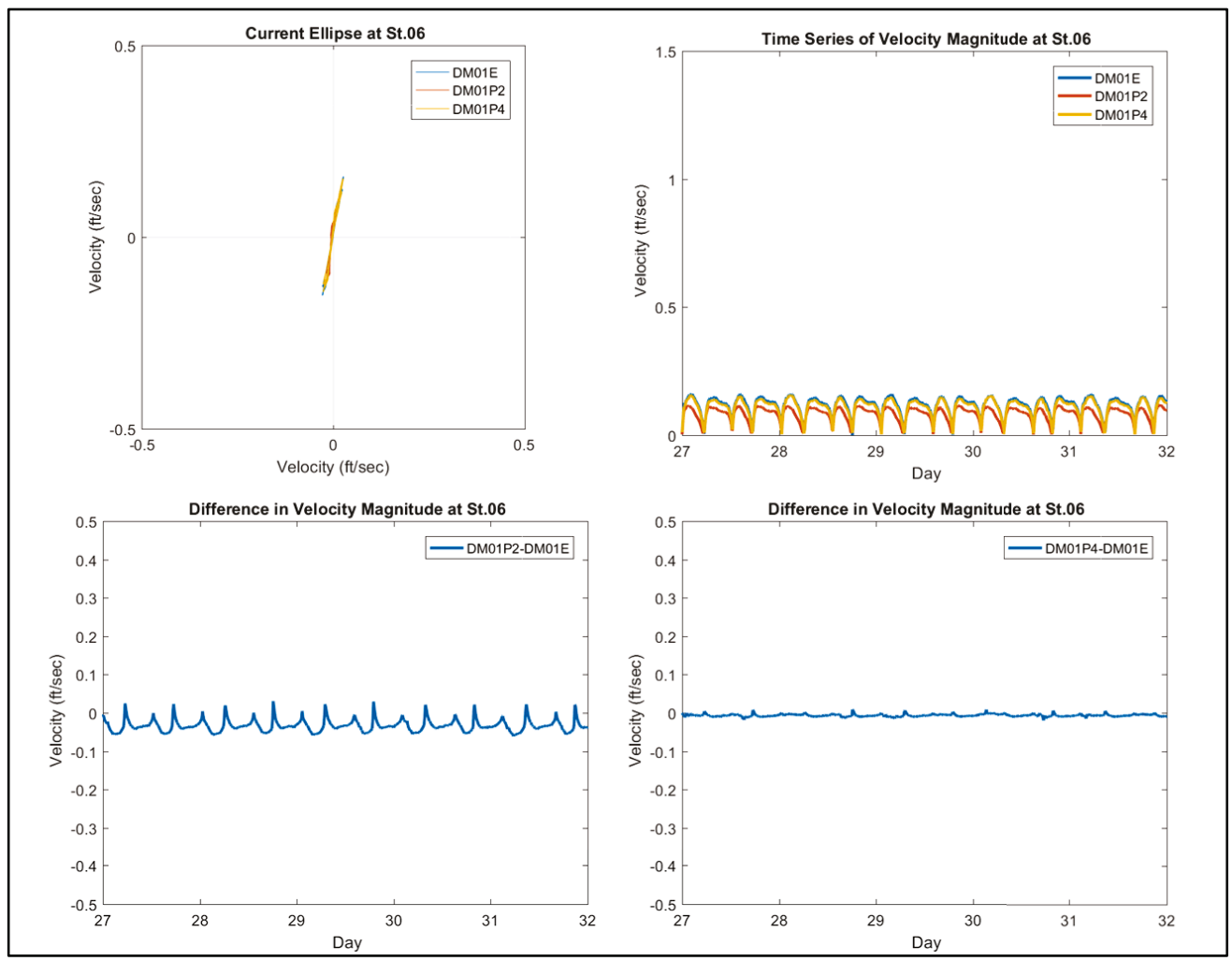


Figure 5-32. Comparisons of velocities at Stn 13 under the low flow conditions.

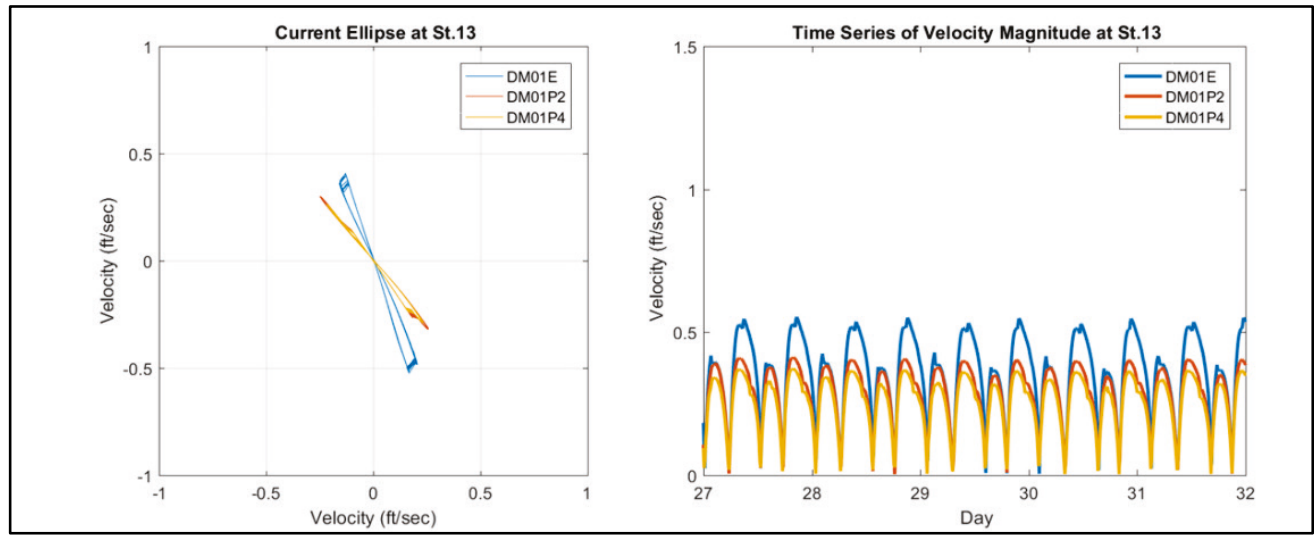

Figure 5-33. Comparisons of velocities at Stn 15 under the low flow conditions.

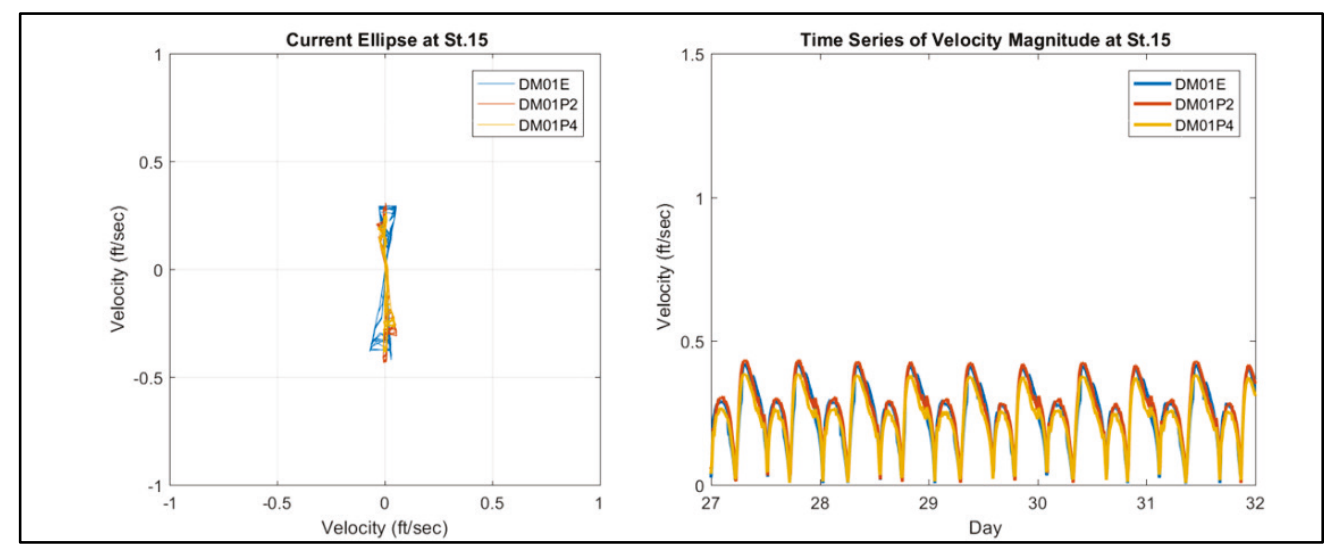

Figure 5-34. Comparisons of velocities at Stn 17 under the low flow conditions.

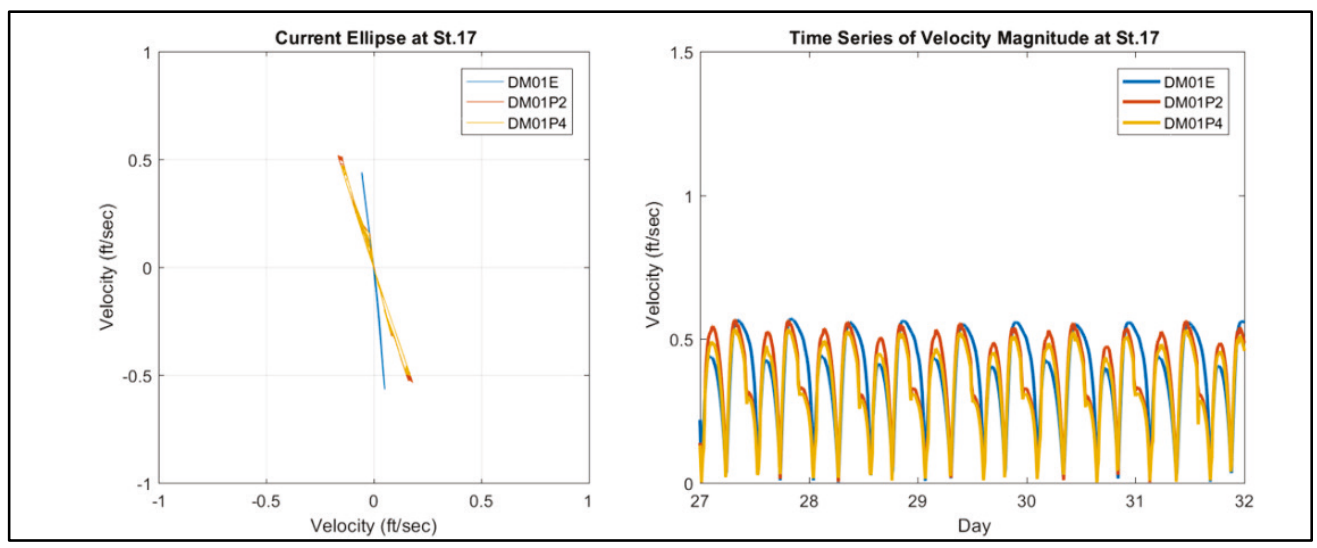


Figure 5-35. Comparisons of velocities at Stn 18 under the low flow conditions.

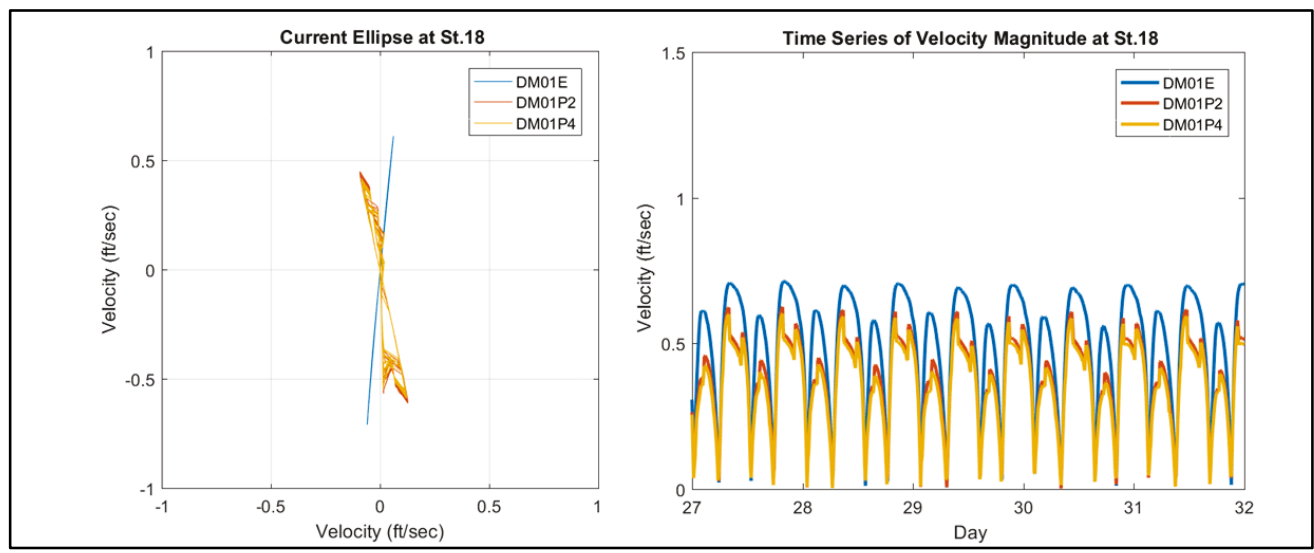

\subsubsection{Results on wind-driven waves}

Simulations of wind-driven waves were made to examine the hydrodynamic responses to constant wind fields from several wind directions. As listed in Table 5-58, a total of 72 wind-driven wave simulations were carried out; half of the simulations were for investigating the promontory designs under spring tides with high river flows and the other for neap tides and low river flows. In each case, the simulation was initiated from the previous tidal and river flows only simulations at the beginning of the 3oth day of the simulation (ADCIRC hot start feature). The simulation duration was 1 day under a constant wind field, keeping other hydrological conditions (tides and river flow) unchanged. In doing so, a fetch-limited, wind-driven wave field can be established in the Dyke Marsh.

By examining model results at several monitoring stations, the winds from different directions cause changes in water levels, river flow velocities (including tidal currents), and waves. For example, at Stn 3, located upstream of the promontories, magnitudes of tidal currents are reduced by the structures (Figure 5-37), and the tidal current directions are also altered (Figure 5-36). Under the northerly wind (from the south), the significant wave heights are lower than those in cases without a structure (Figure 5-38), as the promontory provides shelter in its shadow area against the south-wind-induced waves. Similar reduction effects on flows and waves can be found at other stations at the western bank of the marsh (e.g., Figure 5-39-Figure 5-41 for Stn 5). However, the tidal current directions at Stn 5 are not changed much since it is farther away from the promontory. Along the eastern bank, the structures induce a limited influence on flows and waves (e.g., Figure 5-42 through Figure 5-44 for Stn 15). 
Under the spring tides and high flow conditions $(19,700 \mathrm{cfs})$ for all the wind-driven wave simulations with and without structures, the computed maximum significant wave height values are provided in Table 5-59. The numerical values in the table can be used to confirm reduction rates of wave heights for the promontories.

To quantify the effectiveness of the structures for reducing wave energy, Table 5-60 provides reduction rates of the maximum wave heights for each structure under those wind conditions, in comparison with the present condition (DMo1E). The wave height reduction rate $(R)$ is calculated by the equation

$$
R=\frac{H_{i}-H_{o i}}{H_{o i}}
$$

where $H_{i}$ represents the maximum significant wave height at a location in the case of an installed structure, $H_{o i}$ denotes the maximum significant wave height at the same location under the current condition (no structure installed). The $R$ value will be negative if the structure reduces wave height at that location.

For the low river flow condition $(4,100 \mathrm{cfs})$, the maximum wave height values at the 18 stations are listed in Table 5-61. The values of wave heights for the low flow are slightly smaller than those for the high flow. Table 5-62 gives the wave reduction rates at the 18 selected stations for two promontory designs under 12 wind conditions. 
Figure 5-36. Current ellipses at Stn 3 by $20 \mathrm{mph}$ wind from five directions.

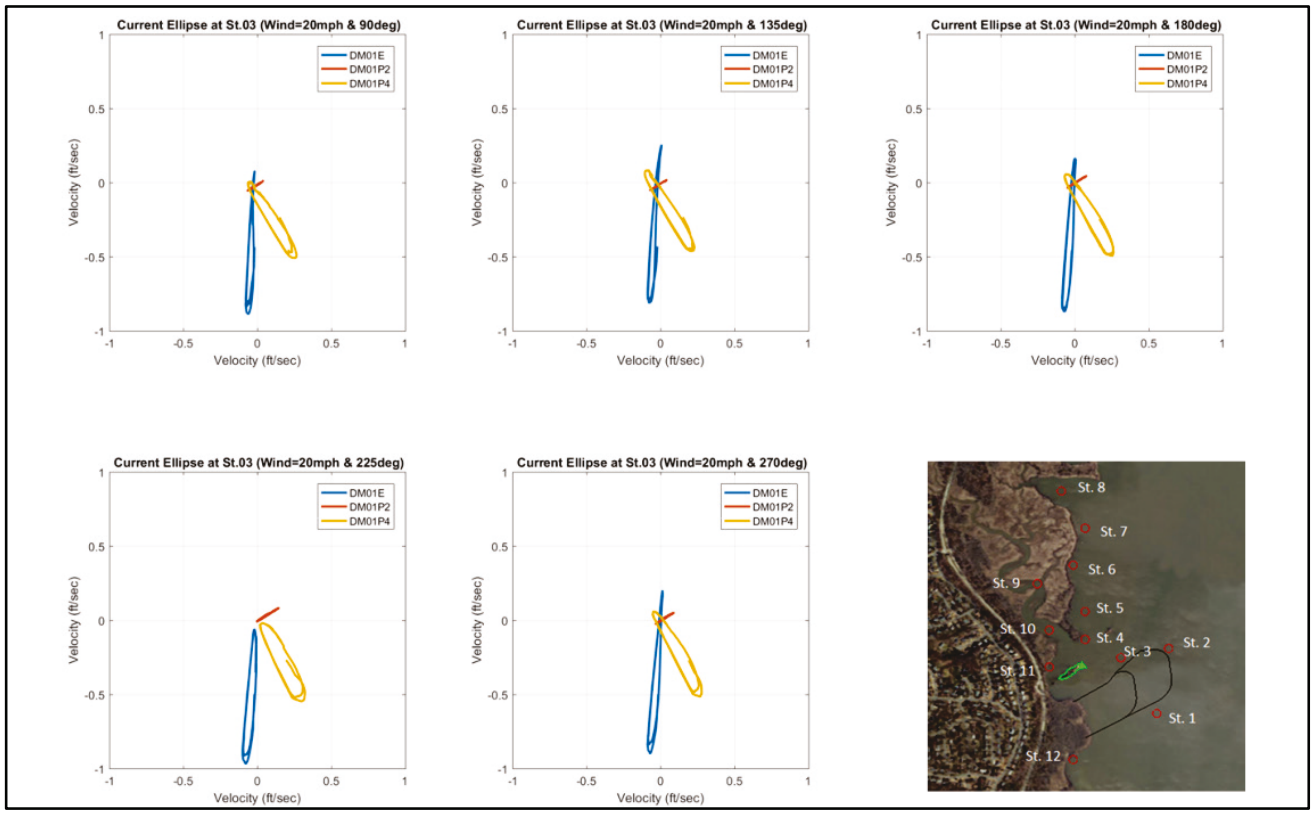

Figure 5-37. Flow velocity magnitudes at Stn 3 by $20 \mathrm{mph}$ wind from five directions.

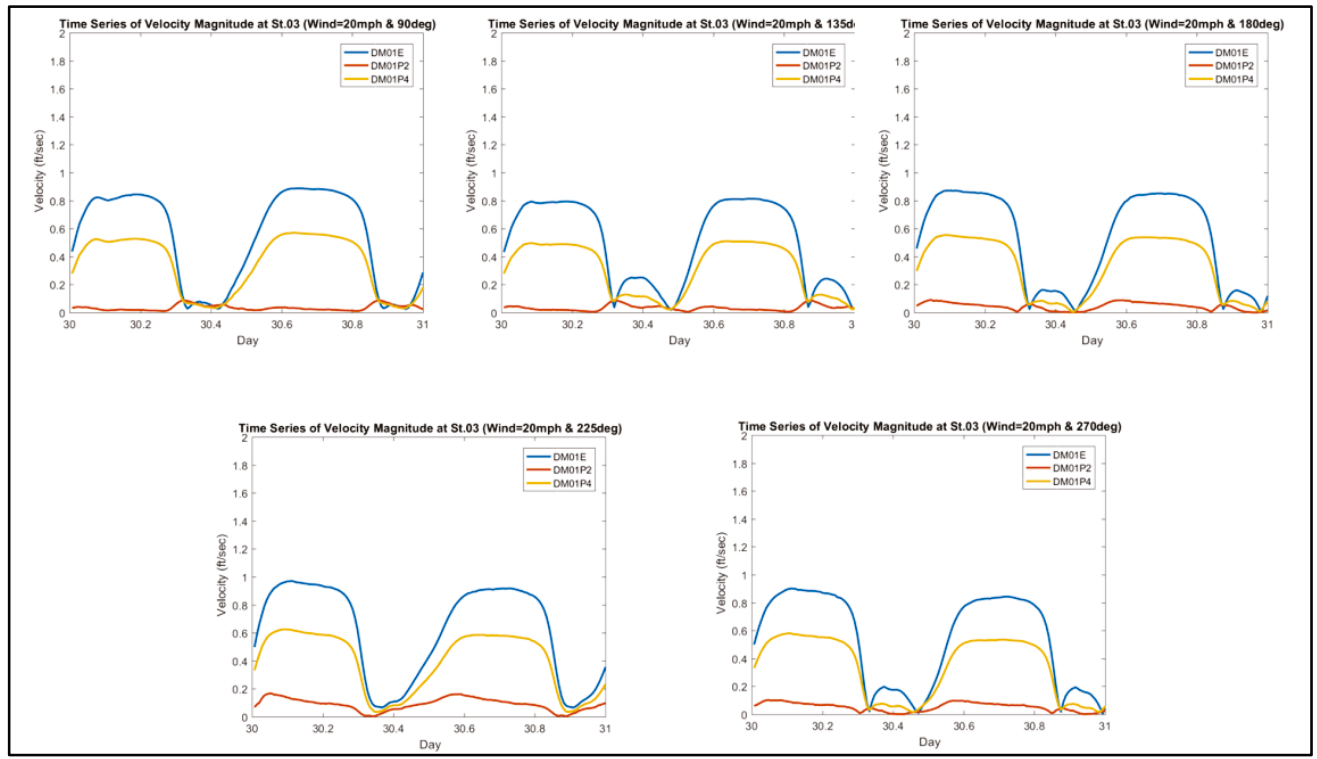


Figure 5-38. Time series of significant wave heights, water levels, and wind speed at Stn 3 by $20 \mathrm{mph}$ wind toward north $\left(90^{\circ}\right)$.

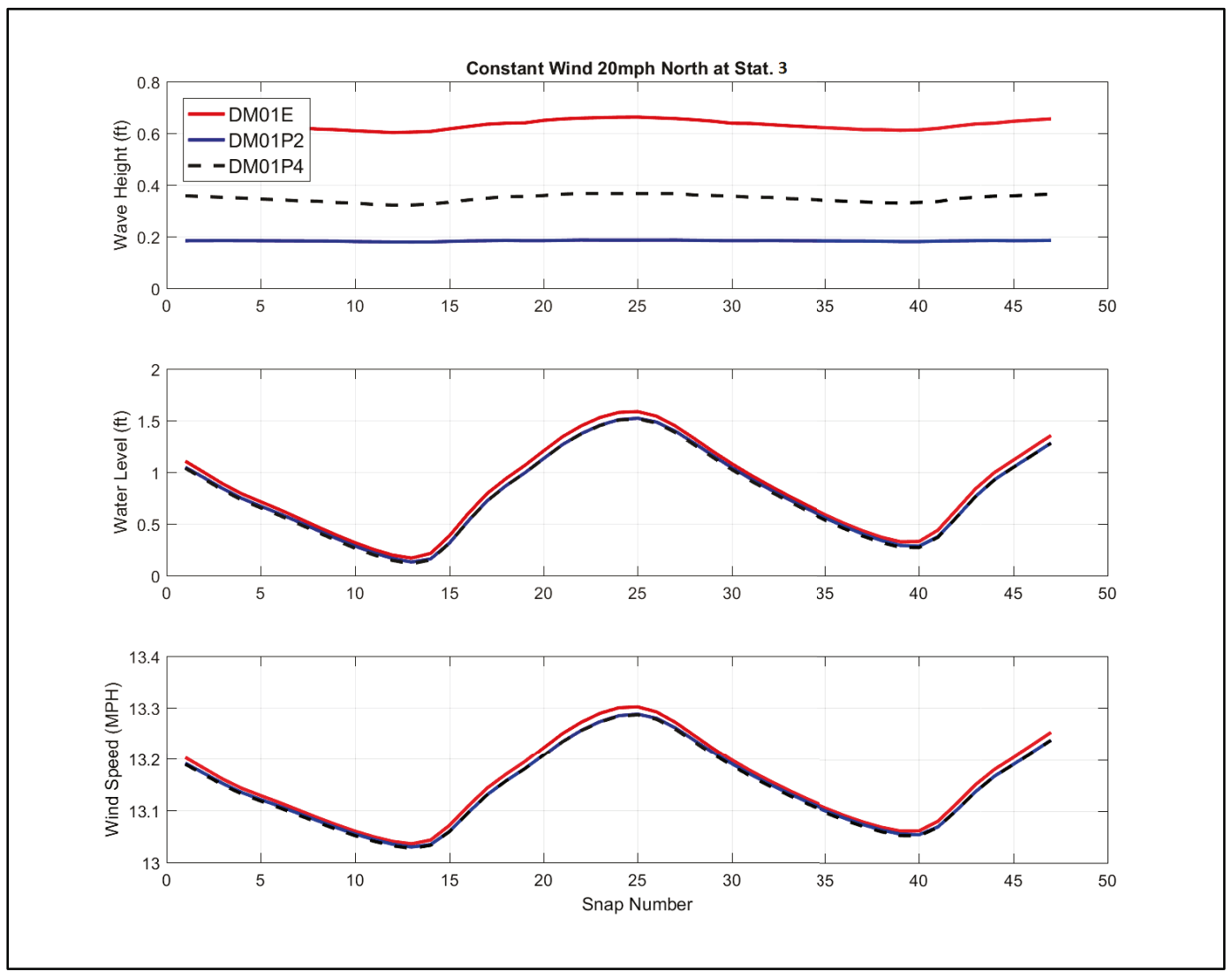

Figure 5-39. Current ellipses at Stn 5 by $20 \mathrm{mph}$ wind from five directions.

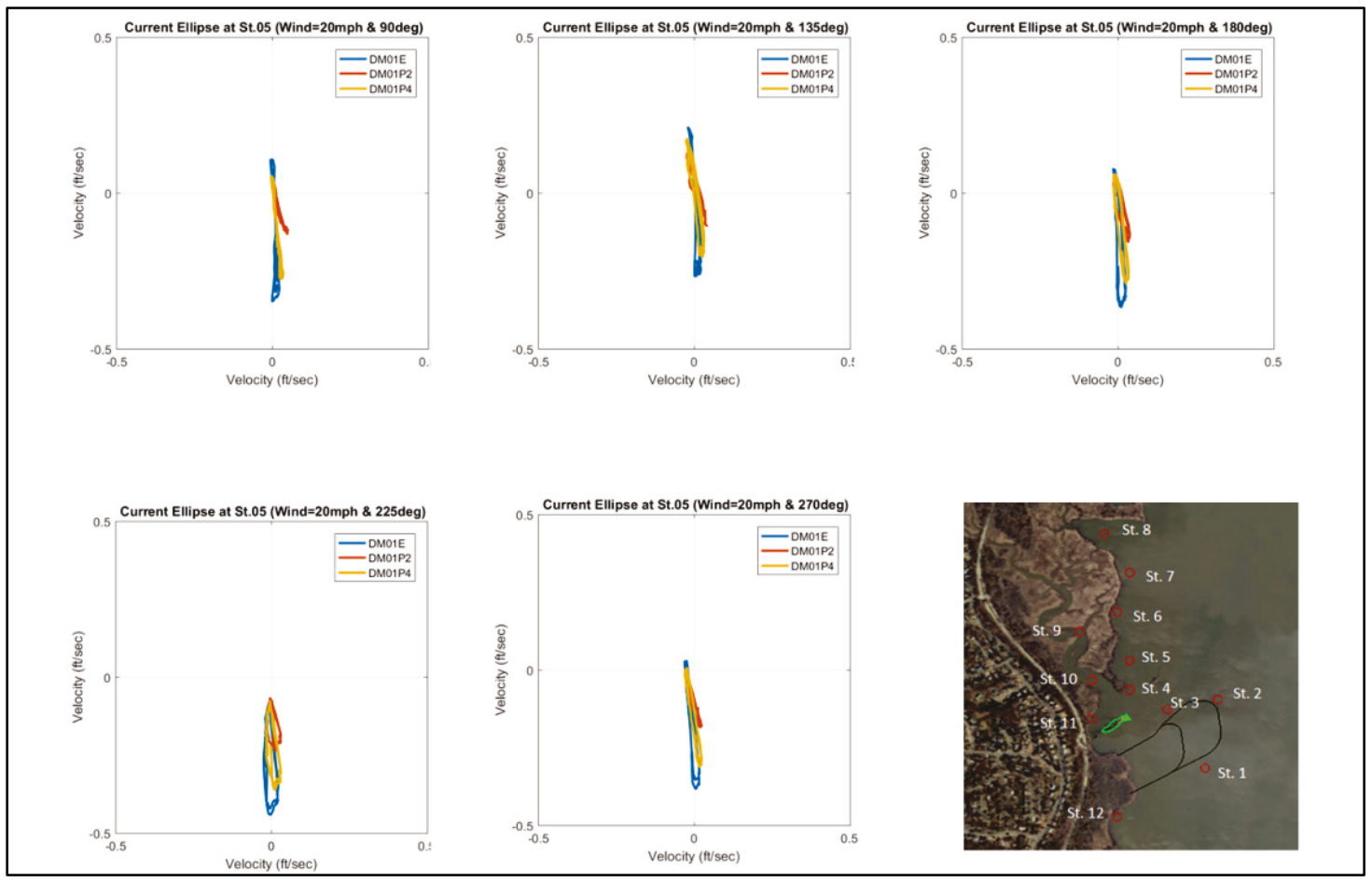


Figure 5-40. Flow velocity magnitudes at Stn 5 by $20 \mathrm{mph}$ wind from five directions.

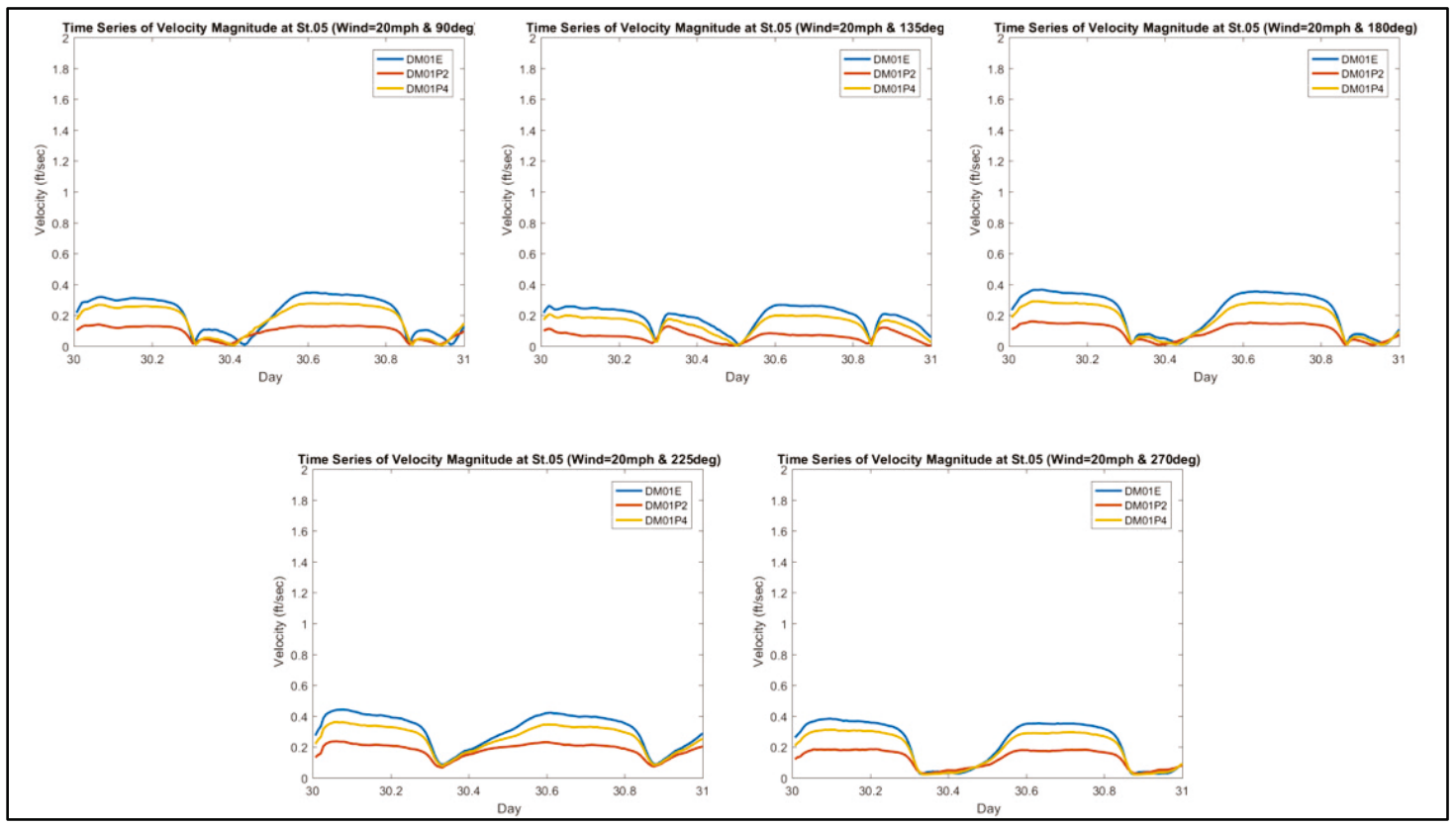

Figure 5-41. Time series of significant wave heights, water levels, and wind speed at Stn 5 by $20 \mathrm{mph}$ wind from south ( 90 degrees).
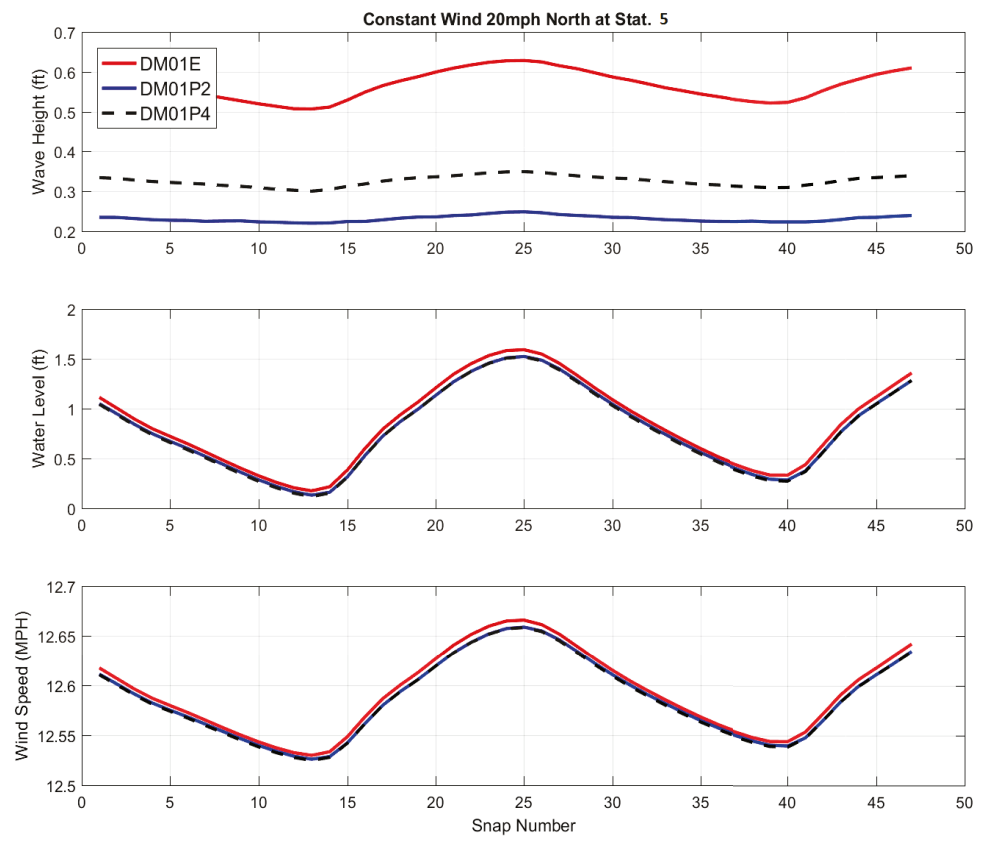
Figure 5-42. Current ellipses at Stn 15 by $20 \mathrm{mph}$ wind from five directions.

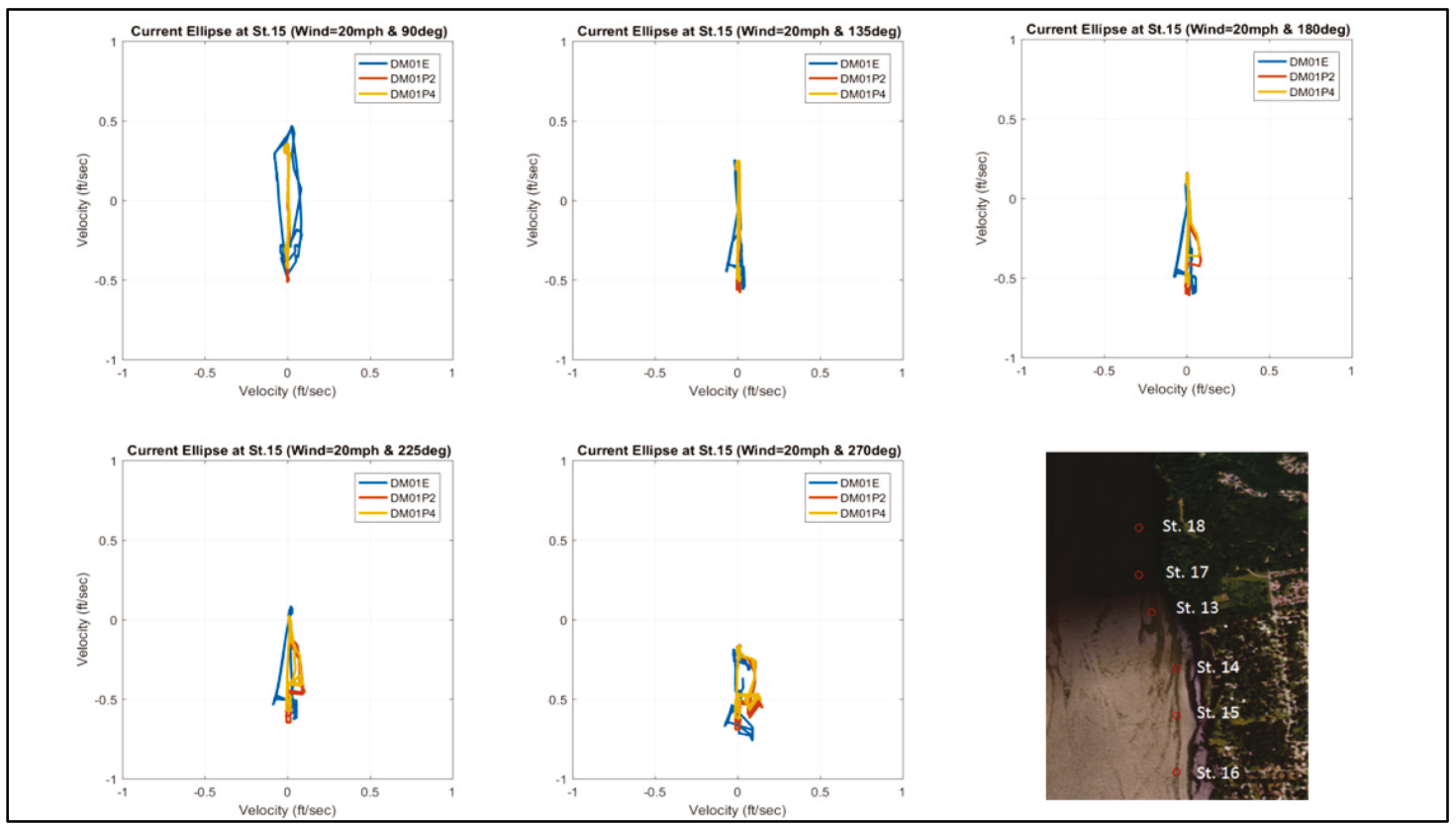

Figure 5-43. Flow velocity magnitudes at Stn 15 by $20 \mathrm{mph}$ wind from five directions.

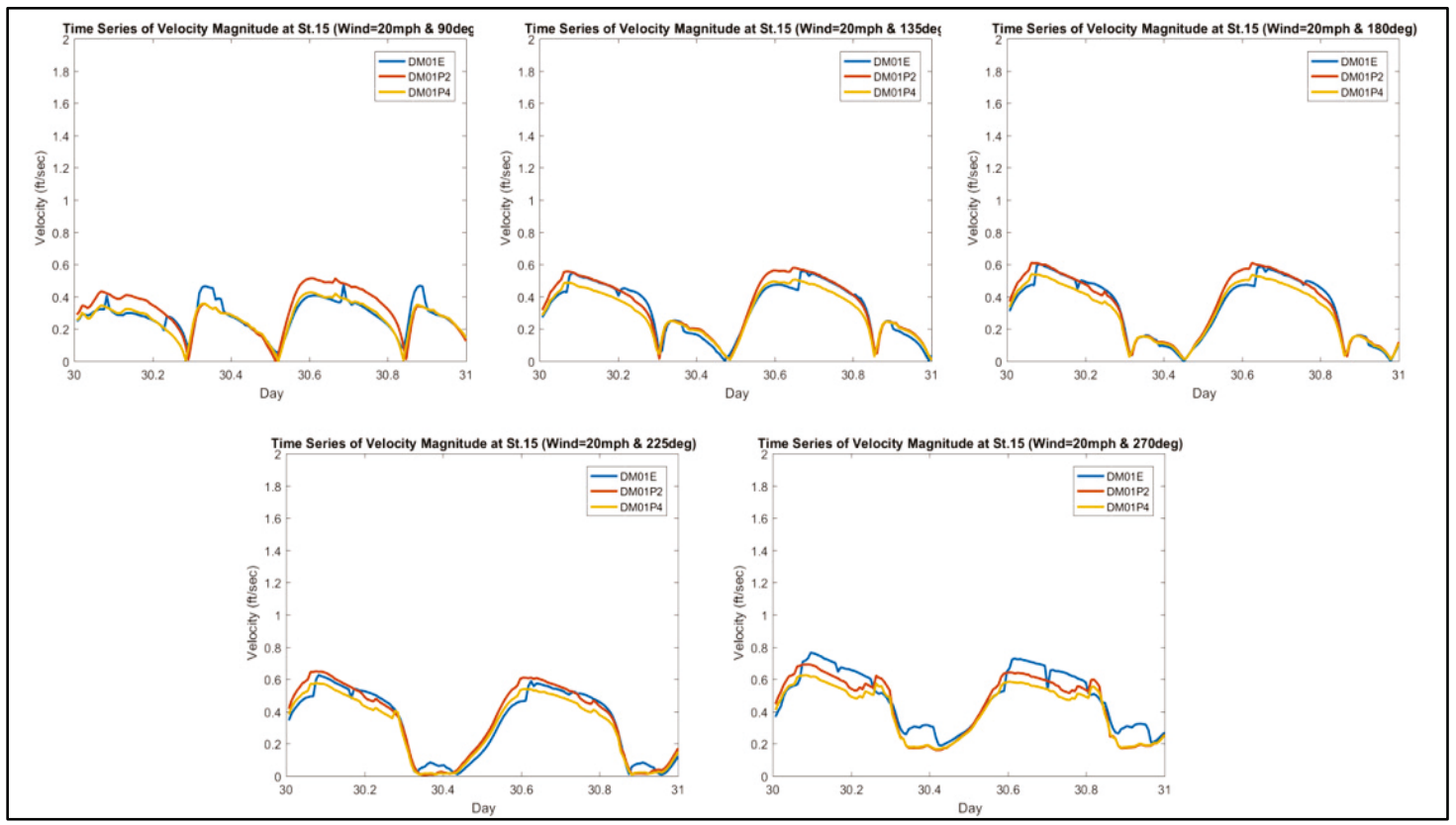


Figure 5-44. Time series of significant wave heights, water levels, and wind speed at Stn 15 by $20 \mathrm{mph}$ northerly wind $\left(90^{\circ}\right)$.
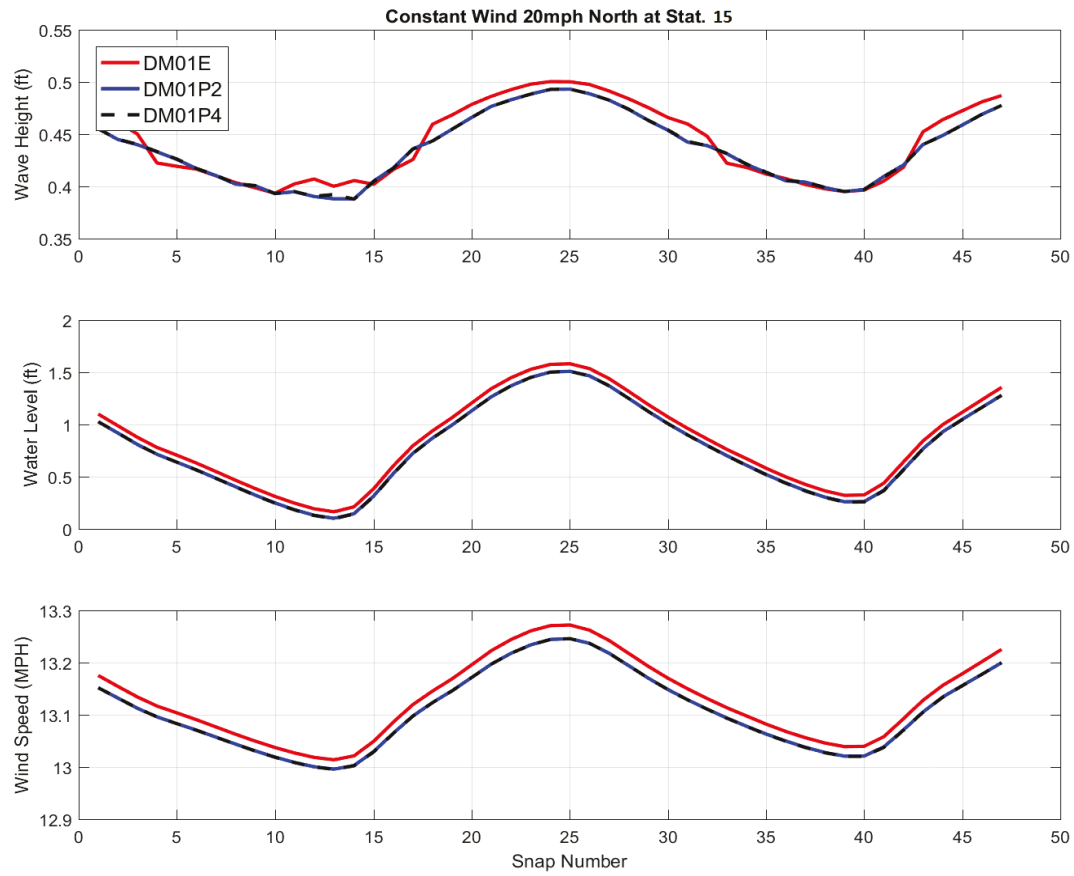
Table 5-59. Maximum significant wave height values in feet at the 18 locations under spring tides and high river flows.

\begin{tabular}{|c|c|c|c|c|c|c|c|c|c|c|c|c|c|c|c|c|c|c|c|}
\hline Wind & Structure St. & 1 & 2 & 3 & 4 & 5 & 6 & 7 & 8 & 9 & 10 & 11 & 12 & 13 & 14 & 15 & 16 & 17 & 18 \\
\hline \multirow{3}{*}{ 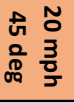 } & DM01E & 0.268 & 0.301 & 0.239 & 0.224 & 0.186 & 0.157 & 0.186 & 0.191 & 0.179 & 0.198 & 0.167 & 0.087 & 0.444 & 0.453 & 0.459 & 0.461 & 0.000 & 0.460 \\
\hline & \begin{tabular}{|l|} 
DM01P2 \\
\end{tabular} & 0.246 & 0.213 & 0.208 & 0.214 & 0.183 & 0.155 & 0.184 & 0.190 & 0.179 & 0.196 & 0.166 & 0.087 & 0.000 & 0.450 & 0.459 & 0.459 & 0.475 & 0.484 \\
\hline & DM01P4 & 0.249 & 0.287 & 0.210 & 0.213 & 0.183 & 0.156 & 0.185 & 0.191 & 0.179 & 0.196 & 0.166 & 0.087 & 0.000 & 0.452 & 0.459 & 0.460 & 0.479 & 0.487 \\
\hline \multirow{3}{*}{ 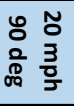 } & DM01E & 0.670 & 0.726 & 0.659 & 0.597 & 0.622 & 0.529 & 0.668 & 0.422 & 0.186 & 0.309 & 0.193 & 0.299 & 0.333 & 0.477 & 0.497 & 0.538 & 0.000 & 0.398 \\
\hline & DM01P2 & 0.670 & 0.496 & 0.186 & 0.226 & 0.249 & 0.254 & 0.446 & 0.352 & 0.178 & 0.197 & 0.176 & 0.299 & 0.000 & 0.474 & 0.493 & 0.537 & 0.636 & 0.665 \\
\hline & DM01P4 & 0.670 & 0.723 & 0.366 & 0.239 & 0.350 & 0.393 & 0.585 & 0.404 & 0.178 & 0.201 & 0.176 & 0.299 & 0.000 & 0.474 & 0.493 & 0.537 & 0.637 & 0.666 \\
\hline \multirow{3}{*}{ 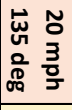 } & DM01E & 0.559 & 0.584 & 0.655 & 0.611 & 0.643 & 0.599 & 0.656 & 0.578 & 0.189 & 0.387 & 0.484 & 0.479 & 0.199 & 0.250 & 0.266 & 0.296 & 0.000 & 0.233 \\
\hline & DM01P2 & 0.558 & 0.524 & 0.247 & 0.276 & 0.413 & 0.528 & 0.599 & 0.560 & 0.188 & 0.263 & 0.204 & 0.479 & 0.000 & 0.260 & 0.280 & 0.314 & 0.298 & 0.311 \\
\hline & DM01P4 & 0.558 & 0.580 & 0.553 & 0.465 & 0.566 & 0.570 & 0.641 & 0.572 & 0.188 & 0.311 & 0.207 & 0.479 & 0.000 & 0.260 & 0.280 & 0.314 & 0.298 & 0.311 \\
\hline \multirow{3}{*}{ 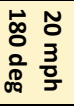 } & DM01E & 0.351 & 0.342 & 0.368 & 0.376 & 0.390 & 0.369 & 0.367 & 0.335 & 135 & 0.203 & 0.360 & 0.366 & 0.146 & 0.161 & 0.157 & 0.169 & 0.000 & 0.160 \\
\hline & DM01P2 & 0.348 & 0.342 & 0.235 & 0.373 & 0.390 & 0.370 & 0.369 & 0.335 & 141 & 0.197 & .273 & 0.364 & 0.000 & 0.157 & 0.160 & 0.180 & 0.156 & 0.167 \\
\hline & DM01P4 & 0.350 & 0.342 & 0.368 & 0.375 & 0.389 & 0.370 & 0.369 & 0.335 & .141 & 0.203 & .319 & 0.365 & 0.000 & .157 & .160 & 0.180 & 0.156 & 0.166 \\
\hline \multirow{3}{*}{ 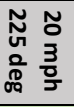 } & DM01E & 0.569 & 0.607 & 0.714 & 0.672 & 0.751 & 0.630 & 0.647 & 0.375 & .145 & 0.262 & .410 & 0.414 & 0.166 & .188 & 192 & 0.201 & 0.000 & 0.181 \\
\hline & DM01P2 & 0.461 & 0.611 & 0.671 & 0.672 & 0.751 & 0.633 & 0.646 & 0.375 & 0.145 & 0.267 & 399 & 0.401 & 0.000 & .175 & .194 & 0.200 & 0.190 & 0.197 \\
\hline & DM01P4 & 0.570 & 0.611 & 0.714 & 0.672 & 0.751 & 0.632 & 0.646 & 0.375 & 0.145 & 0.263 & .407 & 0.401 & 0.000 & .175 & 194 & 0.200 & .190 & 0.197 \\
\hline \multirow{3}{*}{\begin{tabular}{|ll}
$\tilde{N}$ & $\tilde{0}$ \\
0 & 0 \\
0 & 3 \\
0 & 0 \\
0 & 0 \\
0
\end{tabular}} & DM01E & 0.779 & 0.702 & 0.662 & 0.502 & 0.494 & 0.387 & 0.423 & 0.215 & 0.160 & 0.197 & .263 & 0.295 & 0.184 & .320 & .422 & 0.489 & .000 & 0.421 \\
\hline & DM01P2 & 0.394 & 0.702 & 0.659 & 0.502 & 0.496 & 0.389 & 0.423 & 0.216 & 0.160 & 0.197 & 0.260 & 0.255 & 0.000 & .309 & 0.424 & 0.490 & 0.469 & 0.438 \\
\hline & DM01P4 & 0.770 & 0.702 & 0.662 & 0.502 & 0.496 & 0.391 & 0.423 & 0.215 & 0.160 & 0.197 & 0.261 & 0.261 & 0.000 & 0.309 & 0.424 & 0.490 & 0.469 & 0.438 \\
\hline \multirow{3}{*}{ 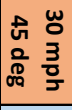 } & DM01E & 0.460 & 0.505 & 0.405 & 0.358 & 0.331 & 0.220 & 0.298 & 0.317 & 0.298 & 0.297 & 0.230 & 0.100 & 0.737 & 0.737 & 0.749 & 0.750 & 0.000 & 0.770 \\
\hline & DM01P2 & 0.438 & 0.306 & 0.351 & 0.342 & 0.316 & 0.216 & 0.290 & 0.317 & 0.296 & 0.293 & 0.226 & 0.101 & 0.771 & 0.734 & 0.749 & 0.748 & 0.783 & 0.803 \\
\hline & DM01P4 & 0.441 & 0.454 & 0.354 & 0.342 & 0.317 & 0.218 & 0.293 & 0.317 & 0.296 & 0.293 & 0.226 & 0.100 & 0.776 & 0.736 & 0.748 & 0.748 & 0.790 & 0.808 \\
\hline \multirow{3}{*}{ 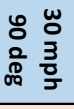 } & DM01E & 1.152 & 1.218 & 1.117 & 0.969 & 1.040 & 0.866 & 1.092 & 0.724 & 0.451 & 0.528 & 0.363 & 0.520 & 0.907 & 0.807 & 0.824 & 0.902 & 0.995 & 0.620 \\
\hline & DM01P2 & 1.152 & 0.799 & 0.271 & 0.375 & 0.440 & 0.451 & 0.724 & 0.607 & 0.360 & 0.349 & 0.242 & 0.520 & 0.898 & 0.799 & 0.826 & 0.898 & 0.933 & 0.959 \\
\hline & DM01P4 & 1.152 & 1.213 & 0.582 & 0.400 & 0.604 & 0.650 & 0.954 & 0.690 & 0.400 & 0.359 & 0.243 & 0.520 & 0.898 & 0.799 & 0.826 & 0.898 & 0.934 & 0.963 \\
\hline \multirow{3}{*}{ 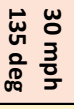 } & DM01E & 0.951 & 1.005 & 1.113 & 0.995 & 1.068 & 0.981 & 1.089 & 0.946 & 0.287 & 0.606 & 0.814 & 0.800 & 0.281 & 0.386 & 0.436 & 0.495 & 0.000 & 0.315 \\
\hline & DM01P2 & 0.949 & 0.907 & 0.340 & 0.426 & 0.669 & 0.892 & 0.998 & 0.927 & 0.316 & 0.433 & 0.351 & 0.800 & 0.000 & 0.408 & 0.437 & 0.498 & 0.450 & 0.483 \\
\hline & DM01P4 & 0.950 & 0.999 & 0.938 & 0.782 & 0.948 & 0.940 & 1.065 & 0.937 & 0.300 & 0.516 & 0.353 & 0.800 & 0.000 & 0.408 & 0.437 & 0.498 & 0.450 & 0.483 \\
\hline \multirow{3}{*}{ 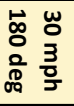 } & DM01E & 0.613 & 0.597 & 0.644 & 0.638 & 0.671 & 0.629 & 0.630 & 0.573 & 0.194 & 0.320 & 0.631 & 0.613 & 0.189 & 0.223 & 0.224 & 0.245 & 0.000 & 0.208 \\
\hline & DM01P2 & 0.610 & 0.601 & 0.361 & 0.634 & 0.672 & 0.630 & 0.633 & 0.575 & 0.182 & 0.304 & 0.462 & 0.615 & 0.000 & 0.221 & 0.225 & 0.261 & 0.209 & 0.219 \\
\hline & DM01P4 & 0.615 & 0.601 & 0.646 & 0.642 & 0.671 & 0.630 & 0.633 & 0.575 & 0.194 & 0.322 & 0.539 & 0.617 & 0.000 & 0.221 & 0.225 & 0.261 & 0.209 & 0.218 \\
\hline \multirow{3}{*}{ 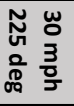 } & DM01E & 0.921 & 0.972 & 1.128 & 1.014 & 1.180 & 0.972 & 1.054 & 0.596 & 0.230 & 0.335 & 0.622 & 0.643 & 0.216 & 0.265 & 0.275 & 0.294 & 0.000 & 0.240 \\
\hline & DM01P2 & 0.759 & 0.975 & 1.069 & 1.017 & 1.182 & 0.977 & 1.056 & 0.596 & 0.230 & 0.342 & 0.612 & 0.641 & 0.000 & 0.254 & 0.282 & 0.293 & 0.261 & 0.272 \\
\hline & DM01P4 & 0.908 & 0.974 & 1.130 & 1.015 & 1.181 & 0.976 & 1.055 & 0.595 & 0.229 & 0.339 & 0.624 & 0.649 & 0.000 & 0.255 & 0.282 & 0.294 & 0.261 & 0.272 \\
\hline \multirow{3}{*}{ 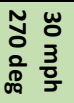 } & DM01E & 1.273 & 1.139 & 1.065 & 0.817 & 0.816 & 0.631 & 0.688 & 0.313 & 0.210 & 0.284 & 0.389 & 0.456 & 0.239 & 0.519 & 0.674 & 0.781 & 0.000 & 0.676 \\
\hline & DM01P2 & 0.607 & 1.140 & 1.061 & 0.818 & 0.818 & 0.635 & 0.688 & 0.313 & 0.211 & 0.287 & 0.386 & 0.359 & 0.000 & 0.509 & 0.682 & 0.788 & 0.736 & 0.700 \\
\hline & DM01P4 & 1.256 & 1.139 & 1.067 & 0.817 & 0.817 & 0.635 & 0.688 & 0.313 & 0.210 & 0.285 & 0.390 & 0.374 & 0.000 & 0.509 & 0.682 & 0.788 & 0.735 & 0.700 \\
\hline
\end{tabular}


Table 5-60. Reduction rate of maximum significant wave height at the 18 locations under spring tides and high river flows.

\begin{tabular}{|c|c|c|c|c|c|c|c|c|c|c|c|c|c|c|c|c|c|c|c|}
\hline Wind & Structure St. & 1 & 2 & 3 & 4 & 5 & 6 & 7 & 8 & 9 & 10 & 11 & 12 & 13 & 14 & 15 & 16 & 17 & 18 \\
\hline \multirow{3}{*}{ 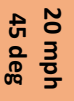 } & DM01E & 0.268 & 0.301 & 0.239 & 0.224 & 0.186 & 0.157 & 0.186 & 0.191 & 0.179 & 0.198 & 0.167 & 0.087 & 0.444 & 0.453 & 0.459 & 0.461 & 0.000 & 0.460 \\
\hline & DM01P2 & $-8 \%$ & $-29 \%$ & $-13 \%$ & $-5 \%$ & $-2 \%$ & $-2 \%$ & $-1 \%$ & $0 \%$ & $0 \%$ & $-1 \%$ & $0 \%$ & $0 \%$ & Dry & $-1 \%$ & $0 \%$ & $0 \%$ & N/A & $5 \%$ \\
\hline & DM01P4 & $-7 \%$ & $-5 \%$ & $-12 \%$ & $-5 \%$ & $-2 \%$ & $-1 \%$ & $-1 \%$ & $0 \%$ & $0 \%$ & $-1 \%$ & $0 \%$ & $0 \%$ & Dry & $0 \%$ & $0 \%$ & $0 \%$ & N/A & $6 \%$ \\
\hline \multirow{3}{*}{ 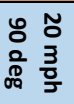 } & DM01E & 0.670 & 0.726 & 0.659 & 0.597 & 0.622 & 0.529 & 0.668 & 0.422 & 0.186 & 0.309 & 0.193 & 0.299 & 0.333 & 0.477 & 0.497 & 0.538 & 0.000 & 0.398 \\
\hline & DM01P2 & $0 \%$ & $-32 \%$ & $-72 \%$ & $-62 \%$ & $-60 \%$ & $-52 \%$ & $-33 \%$ & $-17 \%$ & $-4 \%$ & $-36 \%$ & $-9 \%$ & $0 \%$ & Dry & $-1 \%$ & $-1 \%$ & $0 \%$ & N/A & $67 \%$ \\
\hline & DM01P4 & $0 \%$ & $0 \%$ & $-44 \%$ & $-60 \%$ & $-44 \%$ & $-26 \%$ & $-12 \%$ & $-4 \%$ & $-4 \%$ & $-35 \%$ & $-9 \%$ & $0 \%$ & Dry & $-1 \%$ & $-1 \%$ & $0 \%$ & N/A & $67 \%$ \\
\hline \multirow{3}{*}{ 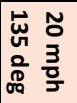 } & DM01E & 0.559 & 0.584 & 0.655 & 0.611 & 0.643 & 0.599 & 0.656 & 0.578 & 0.189 & 0.387 & 0.484 & 0.479 & 0.199 & 0.250 & 0.266 & 0.296 & 0.000 & 0.233 \\
\hline & DM01P2 & $0 \%$ & $-10 \%$ & $-62 \%$ & $-55 \%$ & $-36 \%$ & $-12 \%$ & $-9 \%$ & $-3 \%$ & $-1 \%$ & $-32 \%$ & $-58 \%$ & $0 \%$ & Dry & $4 \%$ & $5 \%$ & $6 \%$ & N/A & $33 \%$ \\
\hline & DM01P4 & $0 \%$ & $-1 \%$ & $-16 \%$ & $-24 \%$ & $-12 \%$ & $-5 \%$ & $-2 \%$ & $-1 \%$ & $-1 \%$ & $-20 \%$ & $-57 \%$ & $0 \%$ & Dry & $4 \%$ & $5 \%$ & $6 \%$ & N/A & $33 \%$ \\
\hline \multirow{3}{*}{ 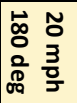 } & DM01E & 0.351 & 0.342 & 0.368 & 0.376 & 0.390 & 0.369 & 0.367 & 0.335 & 0.135 & 0.203 & 0.360 & 0.366 & 0.146 & 0.161 & 0.157 & 0.169 & 0.000 & 0.160 \\
\hline & DM01P2 & $-1 \%$ & $0 \%$ & $-36 \%$ & $-1 \%$ & $0 \%$ & $0 \%$ & $1 \%$ & $0 \%$ & $4 \%$ & $-3 \%$ & $-24 \%$ & $-1 \%$ & Dry & $-3 \%$ & $2 \%$ & $7 \%$ & N/A & $4 \%$ \\
\hline & DM01P4 & $0 \%$ & $0 \%$ & $0 \%$ & $0 \%$ & $0 \%$ & $0 \%$ & $1 \%$ & $0 \%$ & $4 \%$ & $0 \%$ & $-11 \%$ & $0 \%$ & Dry & $-3 \%$ & $2 \%$ & $7 \%$ & $N / A$ & $4 \%$ \\
\hline \multirow{3}{*}{ 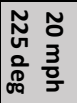 } & DM01E & 0.569 & 0.607 & 0.714 & 0.672 & 0.751 & 0.630 & 0.647 & 0.375 & 0.145 & 0.262 & 0.410 & 0.414 & 0.166 & 0.188 & 0.192 & 0.201 & 0.000 & 0.181 \\
\hline & DM01P2 & $-19 \%$ & $1 \%$ & $-6 \%$ & $0 \%$ & $0 \%$ & $0 \%$ & $0 \%$ & $0 \%$ & $0 \%$ & $2 \%$ & $-3 \%$ & $-3 \%$ & Dry & $-7 \%$ & $1 \%$ & $-1 \%$ & N/A & $9 \%$ \\
\hline & DM01P4 & $0 \%$ & $1 \%$ & $0 \%$ & $0 \%$ & $0 \%$ & $0 \%$ & $0 \%$ & $0 \%$ & $0 \%$ & $0 \%$ & $-1 \%$ & $-3 \%$ & Dry & $-7 \%$ & $1 \%$ & $-1 \%$ & N/A & $9 \%$ \\
\hline \multirow{3}{*}{ 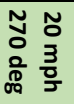 } & DM01E & 0.779 & 0.702 & 0.662 & 0.502 & 0.494 & 0.387 & 0.423 & 0.215 & 0.160 & 0.197 & 0.263 & 0.295 & 0.184 & 0.320 & 0.422 & 0.489 & 0.000 & 0.421 \\
\hline & DM01P2 & $-50 \%$ & $0 \%$ & $0 \%$ & $0 \%$ & $0 \%$ & $1 \%$ & $0 \%$ & $0 \%$ & $0 \%$ & $0 \%$ & $-1 \%$ & $-14 \%$ & Dry & $-4 \%$ & $0 \%$ & $0 \%$ & N/A & $4 \%$ \\
\hline & DM01P4 & $-1 \%$ & $0 \%$ & $0 \%$ & $0 \%$ & $0 \%$ & $1 \%$ & $0 \%$ & $0 \%$ & $0 \%$ & $0 \%$ & $-1 \%$ & $-12 \%$ & Dry & $-4 \%$ & $0 \%$ & $0 \%$ & N/A & $4 \%$ \\
\hline \multirow{3}{*}{ 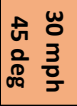 } & DM01E & 0.460 & 0.505 & 0.405 & 0.358 & 0.331 & 0.220 & 0.298 & 0.317 & 0.298 & 0.297 & 0.230 & 0.100 & 0.737 & 0.737 & 0.749 & 0.750 & 0.000 & 0.770 \\
\hline & DM01P2 & $-5 \%$ & $-39 \%$ & $-13 \%$ & $-4 \%$ & $-5 \%$ & $-2 \%$ & $-3 \%$ & $0 \%$ & $-1 \%$ & $-1 \%$ & $-2 \%$ & $0 \%$ & $5 \%$ & $0 \%$ & $0 \%$ & $0 \%$ & N/A & $4 \%$ \\
\hline & DM01P4 & $-4 \%$ & $-10 \%$ & $-13 \%$ & $-4 \%$ & $-4 \%$ & $-1 \%$ & $-2 \%$ & $0 \%$ & $-1 \%$ & $-1 \%$ & $-2 \%$ & $0 \%$ & $5 \%$ & $0 \%$ & $0 \%$ & $0 \%$ & N/A & $5 \%$ \\
\hline \multirow{3}{*}{ 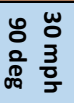 } & DM01E & 1.152 & 1.218 & 1.117 & 0.969 & 1.040 & 0.866 & 1.092 & 0.724 & 0.451 & 0.528 & 0.363 & 0.520 & 0.907 & 0.807 & 0.824 & 0.902 & 0.000 & 0.620 \\
\hline & DM01P2 & $0 \%$ & $-34 \%$ & $-76 \%$ & $-61 \%$ & $-58 \%$ & $-48 \%$ & $-34 \%$ & $-16 \%$ & $-20 \%$ & $-34 \%$ & $-33 \%$ & $0 \%$ & $-1 \%$ & $-1 \%$ & $0 \%$ & $0 \%$ & N/A & $55 \%$ \\
\hline & DM01P4 & $0 \%$ & $0 \%$ & $-48 \%$ & $-59 \%$ & $-42 \%$ & $-25 \%$ & $-13 \%$ & $-5 \%$ & \begin{tabular}{|l|}
$-11 \%$ \\
\end{tabular} & $-32 \%$ & $-33 \%$ & $0 \%$ & $-1 \%$ & $-1 \%$ & $0 \%$ & $0 \%$ & N/A & $55 \%$ \\
\hline \multirow{3}{*}{ 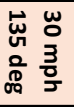 } & DM01E & 0.951 & 1.005 & 1.113 & 0.995 & 1.068 & 0.981 & 1.089 & 0.946 & 0.287 & 0.606 & 0.814 & 0.800 & 0.281 & 0.386 & 0.436 & 0.495 & 0.000 & 0.315 \\
\hline & DM01P2 & $0 \%$ & $-10 \%$ & $-69 \%$ & $-57 \%$ & $-37 \%$ & $-9 \%$ & $-8 \%$ & $-2 \%$ & $10 \%$ & $-29 \%$ & $-57 \%$ & $0 \%$ & Dry & $6 \%$ & $0 \%$ & $1 \%$ & $\mathrm{~N} / \mathrm{A}$ & $54 \%$ \\
\hline & DM01P4 & $0 \%$ & $-1 \%$ & $-16 \%$ & $-21 \%$ & $-11 \%$ & $-4 \%$ & $-2 \%$ & $-1 \%$ & $4 \%$ & $-15 \%$ & $-57 \%$ & $0 \%$ & Dry & $6 \%$ & $0 \%$ & $1 \%$ & $\mathrm{~N} / \mathrm{A}$ & $54 \%$ \\
\hline \multirow{3}{*}{ 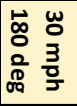 } & DM01E & 0.613 & 0.597 & 0.644 & 0.638 & 0.671 & 0.629 & 0.630 & 0.573 & 0.194 & 0.320 & 0.631 & 0.613 & 0.189 & 0.223 & 0.224 & 0.245 & 0.000 & 0.208 \\
\hline & DM01P2 & $0 \%$ & $1 \%$ & $-44 \%$ & $-1 \%$ & $0 \%$ & $0 \%$ & $1 \%$ & $0 \%$ & $-6 \%$ & $-5 \%$ & $-27 \%$ & $0 \%$ & Dry & $-1 \%$ & $1 \%$ & $7 \%$ & $\mathrm{~N} / \mathrm{A}$ & $5 \%$ \\
\hline & DM01P4 & $0 \%$ & $1 \%$ & $0 \%$ & $1 \%$ & $0 \%$ & $0 \%$ & $1 \%$ & $0 \%$ & $0 \%$ & $1 \%$ & $-14 \%$ & $1 \%$ & Dry & $-1 \%$ & $1 \%$ & $7 \%$ & $\mathrm{~N} / \mathrm{A}$ & $5 \%$ \\
\hline \multirow{3}{*}{$\begin{array}{ll}N & w \\
N & 0 \\
0 & 3 \\
0 & 3 \\
0 & \frac{1}{3}\end{array}$} & DM01E & 0.921 & 0.972 & 1.128 & 1.014 & 1.180 & 0.972 & 1.054 & 0.596 & 0.230 & 0.335 & 0.622 & 0.643 & 0.216 & 0.265 & 0.275 & 0.294 & 0.000 & 0.240 \\
\hline & DM01P2 & $-18 \%$ & $0 \%$ & $-5 \%$ & $0 \%$ & $0 \%$ & $0 \%$ & $0 \%$ & $0 \%$ & $0 \%$ & $2 \%$ & $-2 \%$ & $0 \%$ & Dry & $-4 \%$ & $3 \%$ & $0 \%$ & N/A & $14 \%$ \\
\hline & DM01P4 & $-1 \%$ & $0 \%$ & $0 \%$ & $0 \%$ & $0 \%$ & $0 \%$ & $0 \%$ & $0 \%$ & $0 \%$ & $1 \%$ & $0 \%$ & $1 \%$ & Dry & $-4 \%$ & $3 \%$ & $0 \%$ & $\mathrm{~N} / \mathrm{A}$ & $14 \%$ \\
\hline \multirow{3}{*}{ 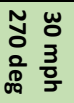 } & DM01E & 1.273 & 1.139 & 1.065 & 0.817 & 0.816 & 0.631 & 0.688 & 0.313 & 0.210 & 0.284 & 0.389 & 0.456 & 0.239 & 0.519 & 0.674 & 0.781 & 0.000 & 0.676 \\
\hline & DM01P2 & $-52 \%$ & $0 \%$ & $0 \%$ & $0 \%$ & $0 \%$ & $1 \%$ & $0 \%$ & $0 \%$ & $0 \%$ & $1 \%$ & $-1 \%$ & $-21 \%$ & Dry & $-2 \%$ & $1 \%$ & $1 \%$ & $\mathrm{~N} / \mathrm{A}$ & $4 \%$ \\
\hline & \begin{tabular}{|l|l|l|} 
MM01P4 \\
\end{tabular} & $-1 \%$ & $0 \%$ & $0 \%$ & $0 \%$ & $0 \%$ & $1 \%$ & $0 \%$ & $0 \%$ & $0 \%$ & $0 \%$ & $0 \%$ & $-18 \%$ & Dry & $-2 \%$ & $1 \%$ & $1 \%$ & N/A & $3 \%$ \\
\hline
\end{tabular}


Table 5-61. Maximum significant wave height values in feet at the 18 locations under summer tides and low river flows.

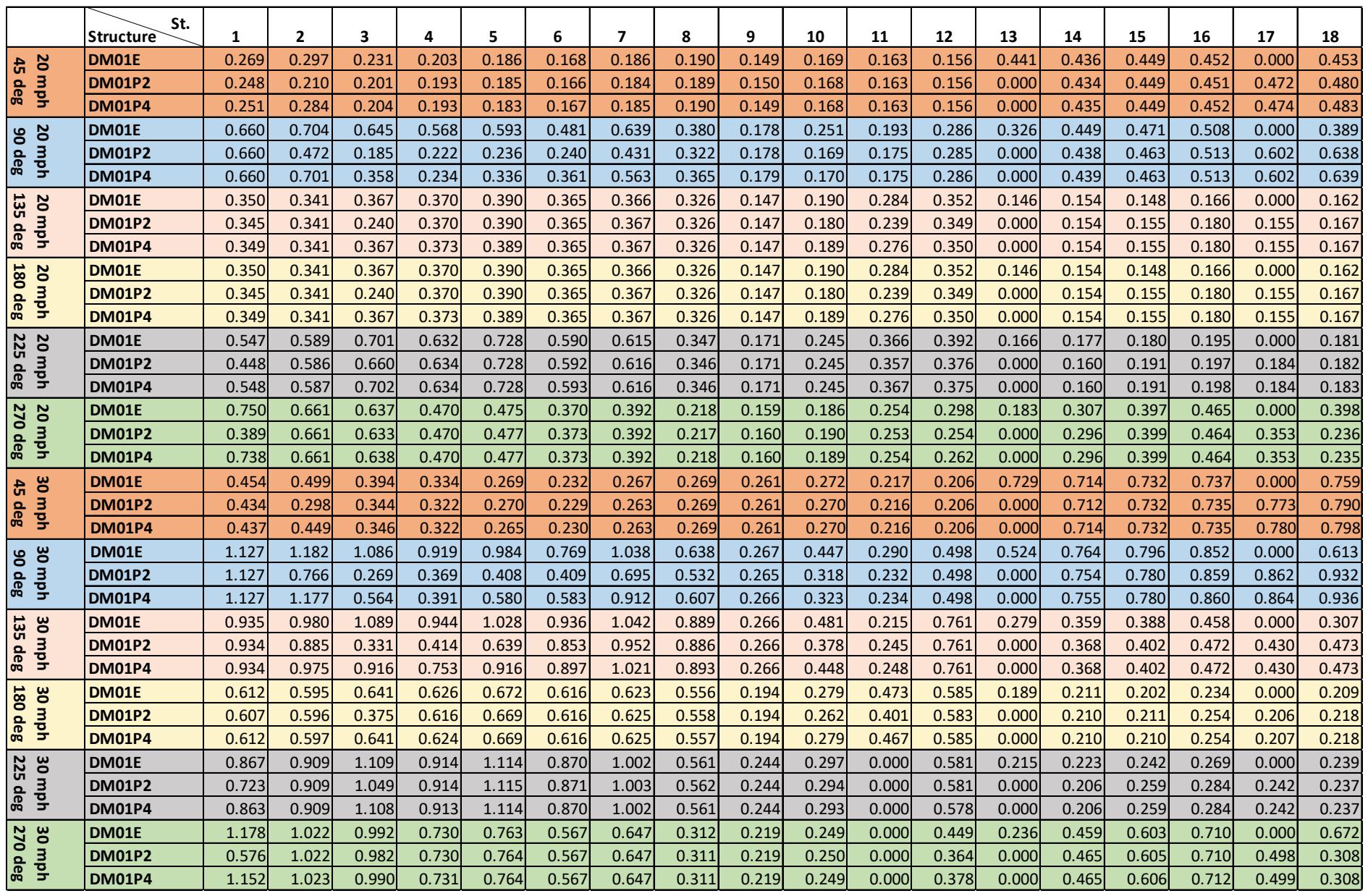


Table 5-62. Reduction rate of maximum significant wave height at the 18 locations under summer tides and low river flows.

\begin{tabular}{|c|c|c|c|c|c|c|c|c|c|c|c|c|c|c|c|c|c|c|c|}
\hline & Structure St. & 1 & 2 & 3 & 4 & 5 & 6 & 7 & 8 & 9 & 10 & 11 & 12 & 13 & 14 & 15 & 16 & 17 & 18 \\
\hline \multirow{3}{*}{ 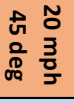 } & DM01E & 0.269 & 0.297 & 0.231 & 0.203 & 0.186 & 0.168 & 0.186 & 0.190 & 0.149 & 0.169 & 0.163 & 0.156 & 0.441 & 0.436 & 0.449 & 0.452 & 0.000 & 0.453 \\
\hline & DM01P2 & $-8 \%$ & $-29 \%$ & $-13 \%$ & $-5 \%$ & $0 \%$ & $-1 \%$ & $-1 \%$ & $0 \%$ & $1 \%$ & $-1 \%$ & $0 \%$ & $0 \%$ & Dry & $-1 \%$ & $0 \%$ & $0 \%$ & $\mathrm{~N} / \mathrm{A}$ & $6 \%$ \\
\hline & DM01P4 & $-7 \%$ & $-5 \%$ & $-12 \%$ & $-5 \%$ & $-1 \%$ & $-1 \%$ & $0 \%$ & $0 \%$ & $0 \%$ & $-1 \%$ & $0 \%$ & $0 \%$ & Dry & $0 \%$ & $0 \%$ & $0 \%$ & N/A & $6 \%$ \\
\hline \multirow{3}{*}{ 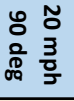 } & DM01E & 0.660 & 0.704 & 0.645 & 0.568 & 0.593 & 0.481 & 0.639 & 0.380 & 0.178 & 0.251 & 0.193 & 0.286 & 0.326 & 0.449 & 0.471 & 0.508 & 0.000 & 0.389 \\
\hline & DM01P2 & $0 \%$ & $-33 \%$ & $-71 \%$ & $-61 \%$ & $-60 \%$ & $-50 \%$ & $-33 \%$ & $-15 \%$ & $0 \%$ & $-33 \%$ & $-9 \%$ & $0 \%$ & Dry & $-2 \%$ & $-2 \%$ & $1 \%$ & N/A & $64 \%$ \\
\hline & DM01P4 & $0 \%$ & $0 \%$ & $-44 \%$ & $-59 \%$ & $-43 \%$ & $-25 \%$ & $-12 \%$ & $-4 \%$ & $1 \%$ & $-33 \%$ & $-9 \%$ & $0 \%$ & Dry & $-2 \%$ & $-2 \%$ & $1 \%$ & N/A & $65 \%$ \\
\hline \multirow{3}{*}{ 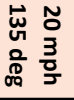 } & DM01E & 0.350 & 0.341 & 0.367 & 0.370 & 0.390 & 0.365 & 0.366 & 0.326 & 0.147 & 0.190 & 0.284 & 0.352 & 0.146 & 0.154 & 0.148 & 0.166 & 0.000 & 0.162 \\
\hline & DM01P2 & $-1 \%$ & $0 \%$ & $-35 \%$ & $0 \%$ & $0 \%$ & $0 \%$ & $0 \%$ & $0 \%$ & $0 \%$ & $-5 \%$ & $-16 \%$ & $-1 \%$ & Dry & $0 \%$ & $5 \%$ & $8 \%$ & N/A & $3 \%$ \\
\hline & DM01P4 & $0 \%$ & $0 \%$ & $0 \%$ & $1 \%$ & $0 \%$ & $0 \%$ & $0 \%$ & $0 \%$ & $0 \%$ & $-1 \%$ & $-3 \%$ & $-1 \%$ & Dry & $0 \%$ & $5 \%$ & $9 \%$ & $\mathrm{~N} / \mathrm{A}$ & $3 \%$ \\
\hline \multirow{3}{*}{ 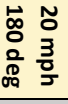 } & DM01E & 0.350 & 0.341 & 0.367 & 0.370 & 0.390 & 0.365 & 0.366 & 0.326 & 0.147 & 0.190 & 0.284 & 0.352 & 0.146 & 0.154 & 0.148 & 0.166 & 0.000 & 0.162 \\
\hline & DM01P2 & $-1 \%$ & $0 \%$ & $-35 \%$ & $0 \%$ & $0 \%$ & $0 \%$ & $0 \%$ & $0 \%$ & $0 \%$ & $-5 \%$ & $-16 \%$ & $-1 \%$ & Dry & $0 \%$ & $5 \%$ & $8 \%$ & $\mathrm{~N} / \mathrm{A}$ & $3 \%$ \\
\hline & DM01P4 & $0 \%$ & $0 \%$ & $0 \%$ & $1 \%$ & $0 \%$ & $0 \%$ & $0 \%$ & $0 \%$ & $0 \%$ & $-1 \%$ & $-3 \%$ & $-1 \%$ & Dry & $0 \%$ & $5 \%$ & $9 \%$ & $\mathrm{~N} / \mathrm{A}$ & $3 \%$ \\
\hline \multirow{3}{*}{ 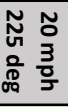 } & DM01E & 0.547 & 0.589 & 0.701 & 0.632 & 0.728 & 0.590 & 0.615 & 0.347 & 0.171 & 0.245 & 0.366 & 0.392 & 0.166 & 0.177 & 0.180 & 0.195 & 0.000 & 0.181 \\
\hline & DM01P2 & $-18 \%$ & $0 \%$ & $-6 \%$ & $0 \%$ & $0 \%$ & $0 \%$ & $0 \%$ & $0 \%$ & $0 \%$ & $0 \%$ & $-2 \%$ & $-4 \%$ & Dry & $-10 \%$ & $6 \%$ & $1 \%$ & $\mathrm{~N} / \mathrm{A}$ & $1 \%$ \\
\hline & DM01P4 & $0 \%$ & $0 \%$ & $0 \%$ & $0 \%$ & $0 \%$ & $0 \%$ & $0 \%$ & $0 \%$ & $0 \%$ & $0 \%$ & $0 \%$ & $-4 \%$ & Dry & $-10 \%$ & $6 \%$ & $2 \%$ & N/A & $1 \%$ \\
\hline \multirow{3}{*}{$\begin{array}{l}\tilde{N} \\
0 \\
0 \\
0 \\
0 \\
0 \\
0\end{array}$} & DM01E & 0.750 & .661 & 0.637 & 0.470 & 0.475 & 0.370 & 0.392 & 0.218 & 0.159 & 0.186 & 0.254 & 0.298 & 0.183 & 0.307 & 0.397 & 0.465 & 0.000 & 0.398 \\
\hline & DM01P2 & $-48 \%$ & $0 \%$ & $-1 \%$ & $0 \%$ & $0 \%$ & $1 \%$ & $0 \%$ & $0 \%$ & $0 \%$ & $2 \%$ & $-1 \%$ & $-15 \%$ & Dry & $-4 \%$ & $1 \%$ & $0 \%$ & $\mathrm{~N} / \mathrm{A}$ & $-41 \%$ \\
\hline & DM01P4 & $-2 \%$ & $0 \%$ & $0 \%$ & $0 \%$ & $0 \%$ & $1 \%$ & $0 \%$ & $0 \%$ & $0 \%$ & $2 \%$ & $0 \%$ & $-12 \%$ & Dry & $-4 \%$ & $1 \%$ & $0 \%$ & N/A & $-41 \%$ \\
\hline \multirow{3}{*}{ 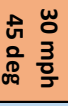 } & DM01E & 0.454 & 0.499 & 0.394 & 0.334 & 0.269 & 0.232 & 0.267 & 0.269 & 0.261 & 0.272 & 0.217 & 0.206 & 0.729 & 0.714 & 0.732 & 0.737 & 0.000 & 0.759 \\
\hline & DM01P2 & $-4 \%$ & $-40 \%$ & $-13 \%$ & $-4 \%$ & $0 \%$ & $-1 \%$ & $-1 \%$ & $0 \%$ & $0 \%$ & $-1 \%$ & $0 \%$ & $0 \%$ & Dry & $0 \%$ & $0 \%$ & $0 \%$ & N/A & $4 \%$ \\
\hline & DM01P4 & $-4 \%$ & $-10 \%$ & $-12 \%$ & $-4 \%$ & $-2 \%$ & $-1 \%$ & $-2 \%$ & $0 \%$ & $0 \%$ & $-1 \%$ & $0 \%$ & $0 \%$ & Dry & $0 \%$ & $0 \%$ & $0 \%$ & N/A & $5 \%$ \\
\hline \multirow{3}{*}{ 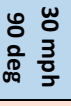 } & DM01E & 1.127 & 1.182 & 1.086 & 0.919 & 0.984 & 0.769 & 1.038 & 0.638 & 0.267 & 0.447 & 0.290 & 0.498 & 0.524 & 0.764 & 0.796 & 0.852 & 0.000 & 0.613 \\
\hline & DM01P2 & $0 \%$ & $-35 \%$ & $-75 \%$ & $-60 \%$ & $-59 \%$ & $-47 \%$ & $-33 \%$ & $-17 \%$ & $-1 \%$ & $-29 \%$ & $-20 \%$ & $0 \%$ & Dry & $-1 \%$ & $-2 \%$ & $1 \%$ & N/A & $52 \%$ \\
\hline & DM01P4 & $0 \%$ & $0 \%$ & $-48 \%$ & $-57 \%$ & $-41 \%$ & $-24 \%$ & $-12 \%$ & $-5 \%$ & $0 \%$ & $-28 \%$ & $-19 \%$ & $0 \%$ & Dry & $-1 \%$ & $-2 \%$ & $1 \%$ & N/A & $53 \%$ \\
\hline \multirow{3}{*}{ 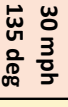 } & DM01E & 0.935 & 0.980 & 1.089 & 0.944 & 1.028 & 0.936 & 1.042 & 0.889 & 0.266 & 0.481 & 0.215 & 0.761 & 0.279 & 0.359 & 0.388 & 0.458 & 0.000 & 0.307 \\
\hline & DM01P2 & $0 \%$ & $-10 \%$ & $-70 \%$ & $-56 \%$ & $-38 \%$ & $-9 \%$ & $-9 \%$ & $0 \%$ & $0 \%$ & $-21 \%$ & $14 \%$ & $0 \%$ & Dry & $2 \%$ & $4 \%$ & $3 \%$ & $\mathrm{~N} / \mathrm{A}$ & $54 \%$ \\
\hline & DM01P4 & $0 \%$ & $-1 \%$ & $-16 \%$ & $-20 \%$ & $-11 \%$ & $-4 \%$ & $-2 \%$ & $0 \%$ & $0 \%$ & $-7 \%$ & $15 \%$ & $0 \%$ & Dry & $3 \%$ & $4 \%$ & $3 \%$ & $\mathrm{~N} / \mathrm{A}$ & $54 \%$ \\
\hline \multirow{3}{*}{ 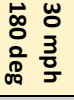 } & DM01E & 0.612 & 0.595 & 0.641 & 0.626 & 0.672 & 0.616 & 0.623 & 0.556 & 0.194 & 0.279 & 0.473 & 0.585 & 0.189 & 0.211 & 0.202 & 0.234 & 0.000 & 0.209 \\
\hline & DM01P2 & $-1 \%$ & $0 \%$ & $-42 \%$ & $-2 \%$ & $0 \%$ & $0 \%$ & $0 \%$ & $0 \%$ & $0 \%$ & $-6 \%$ & $-15 \%$ & $0 \%$ & Dry & $0 \%$ & $5 \%$ & $8 \%$ & $\mathrm{~N} / \mathrm{A}$ & $5 \%$ \\
\hline & DM01P4 & $0 \%$ & $0 \%$ & $0 \%$ & $0 \%$ & $0 \%$ & $0 \%$ & $0 \%$ & $0 \%$ & $0 \%$ & $0 \%$ & $-1 \%$ & $0 \%$ & Dry & $0 \%$ & $4 \%$ & $8 \%$ & $\mathrm{~N} / \mathrm{A}$ & $5 \%$ \\
\hline \multirow{3}{*}{ 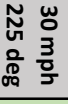 } & DM01E & 0.867 & 0.909 & 1.109 & 0.914 & 1.114 & 0.870 & 1.002 & 0.561 & 0.244 & 0.297 & 0.000 & 0.581 & 0.215 & 0.223 & 0.242 & 0.269 & 0.000 & 0.239 \\
\hline & DM01P2 & $-17 \%$ & $0 \%$ & $-5 \%$ & $0 \%$ & $0 \%$ & $0 \%$ & $0 \%$ & $0 \%$ & $0 \%$ & $-1 \%$ & $\mathrm{~N} / \mathrm{A}$ & $0 \%$ & Dry & $-8 \%$ & $7 \%$ & $5 \%$ & $\mathrm{~N} / \mathrm{A}$ & $-1 \%$ \\
\hline & DM01P4 & $0 \%$ & $0 \%$ & $0 \%$ & $0 \%$ & $0 \%$ & $0 \%$ & $0 \%$ & $0 \%$ & $0 \%$ & $-1 \%$ & $\mathrm{~N} / \mathrm{A}$ & $-1 \%$ & Dry & $-8 \%$ & $7 \%$ & $5 \%$ & N/A & $-1 \%$ \\
\hline \multirow{3}{*}{ 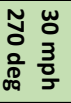 } & DM01E & 1.178 & 1.022 & 0.992 & 0.730 & 0.763 & 0.567 & 0.647 & 0.312 & 0.219 & 0.249 & 0.000 & 0.449 & 0.236 & 0.459 & 0.603 & 0.710 & 0.000 & 0.672 \\
\hline & DM01P2 & $-51 \%$ & $0 \%$ & $-1 \%$ & $0 \%$ & $0 \%$ & $0 \%$ & $0 \%$ & $0 \%$ & $0 \%$ & $0 \%$ & $\mathrm{~N} / \mathrm{A}$ & $-19 \%$ & Dry & $1 \%$ & $0 \%$ & $0 \%$ & $\mathrm{~N} / \mathrm{A}$ & $-54 \%$ \\
\hline & DM01P4 & $-2 \%$ & $0 \%$ & $0 \%$ & $0 \%$ & $0 \%$ & $0 \%$ & $0 \%$ & $0 \%$ & $0 \%$ & $0 \%$ & N/A & $-16 \%$ & Dry & $1 \%$ & $1 \%$ & $0 \%$ & $\mathrm{~N} / \mathrm{A}$ & $-54 \%$ \\
\hline
\end{tabular}




\subsection{Results for evaluation of the proposed groins}

The same set of storm conditions that were simulated for the four full promontory alternatives were repeated for the three groin-only alternatives. Color contour plots representing the maximum storm surge water levels (Table 5-63 through Table 5-73), maximum depth-averaged water velocities (Table 5-74 through Table 5-84), maximum significant wave heights (Table 5-85 through Table 5-94), and the difference in maximum significant wave height (Table 5-95 through Table 5-104) are presented. Results for these three groin-only simulations follow similar patterns to the full promontory simulation results. Maximum storm surge water levels are largely unchanged between existing and with-alternative cases, with differences ranging from approximately 0.17 to $0.67 \mathrm{ft}$ ( 2 to 8 inches), which is within the error tolerance of the model. Table 5-75 presents examples of the differences in maximum water levels with and without structures installed.

Water velocities increase around the end of the groins as would be expected, and for the longest two groins (DMo1P8 followed by DMo1P6), velocities increase more on the eastern side of the Potomac River than with the shorter groin represented in $\mathrm{DMo1P}_{7}$ (e.g., see Table 5-75 for the difference in maximum water velocity for HIS ET Storm No. 0001.

Differences in the significant wave height results showed the most notable changes of the modeled quantities, showing up to a $60 \%$ reduction in significant wave heights. Again, the location of the reduction either to the north or south of the groin depended on the direction of the peak winds, with winds out of the south and southeast resulting in wave height reductions to the north of the groin, in the area of the marsh. Winds from the north and northwest generated lower wave heights south of the groin and did not significantly change wave heights north of the groin. 


\subsubsection{Maximum storm surge results for groin-only designs}

Table 5-63. Maximum water surface elevations for HIS ET Storm No. 0001 for four mesh configurations (existing conditions and three groin-only alternatives).

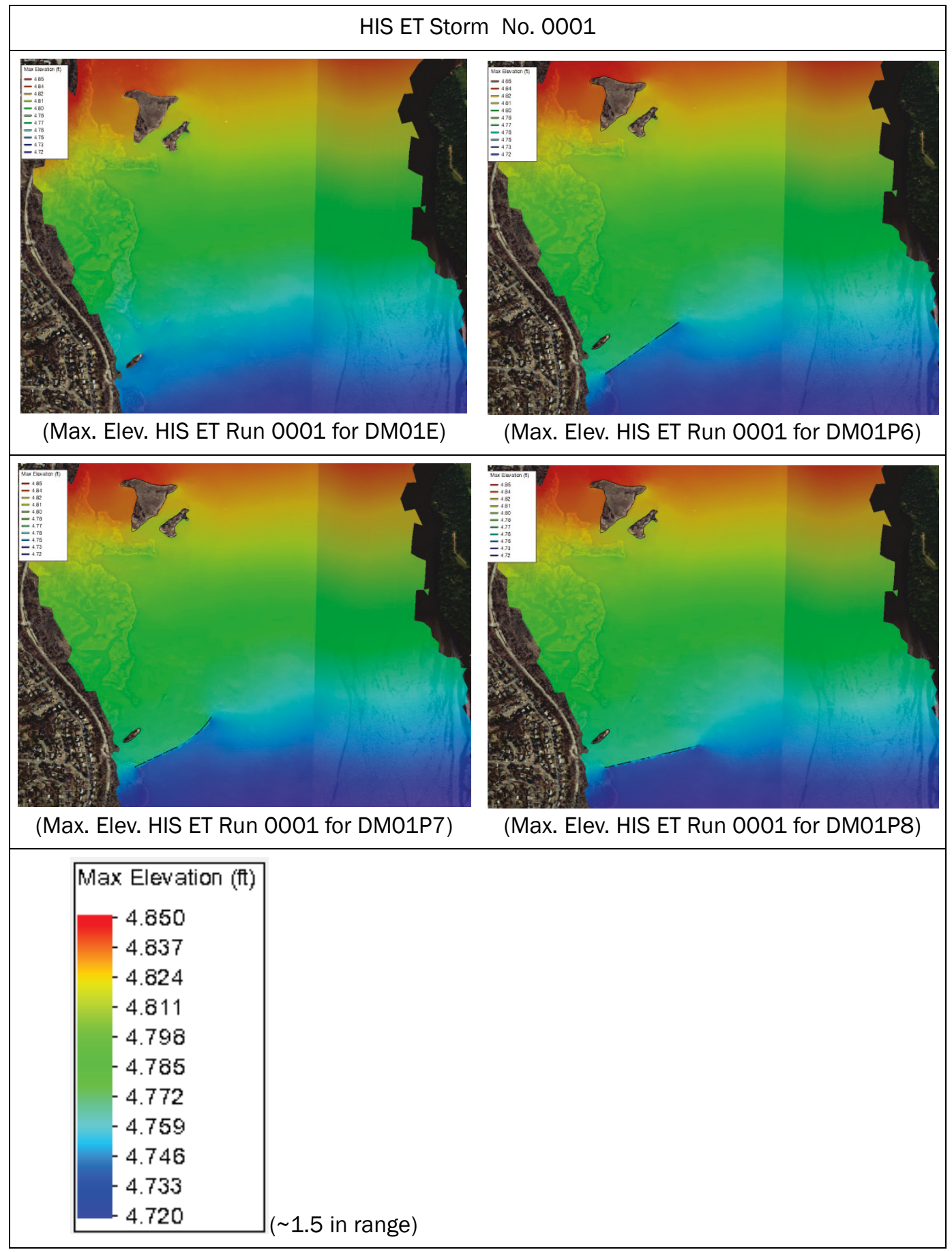


Table 5-64. Difference in maximum water surface elevations for HIS ET Storm No. 0001 for all three with-project groin mesh configurations (Project - Existing).

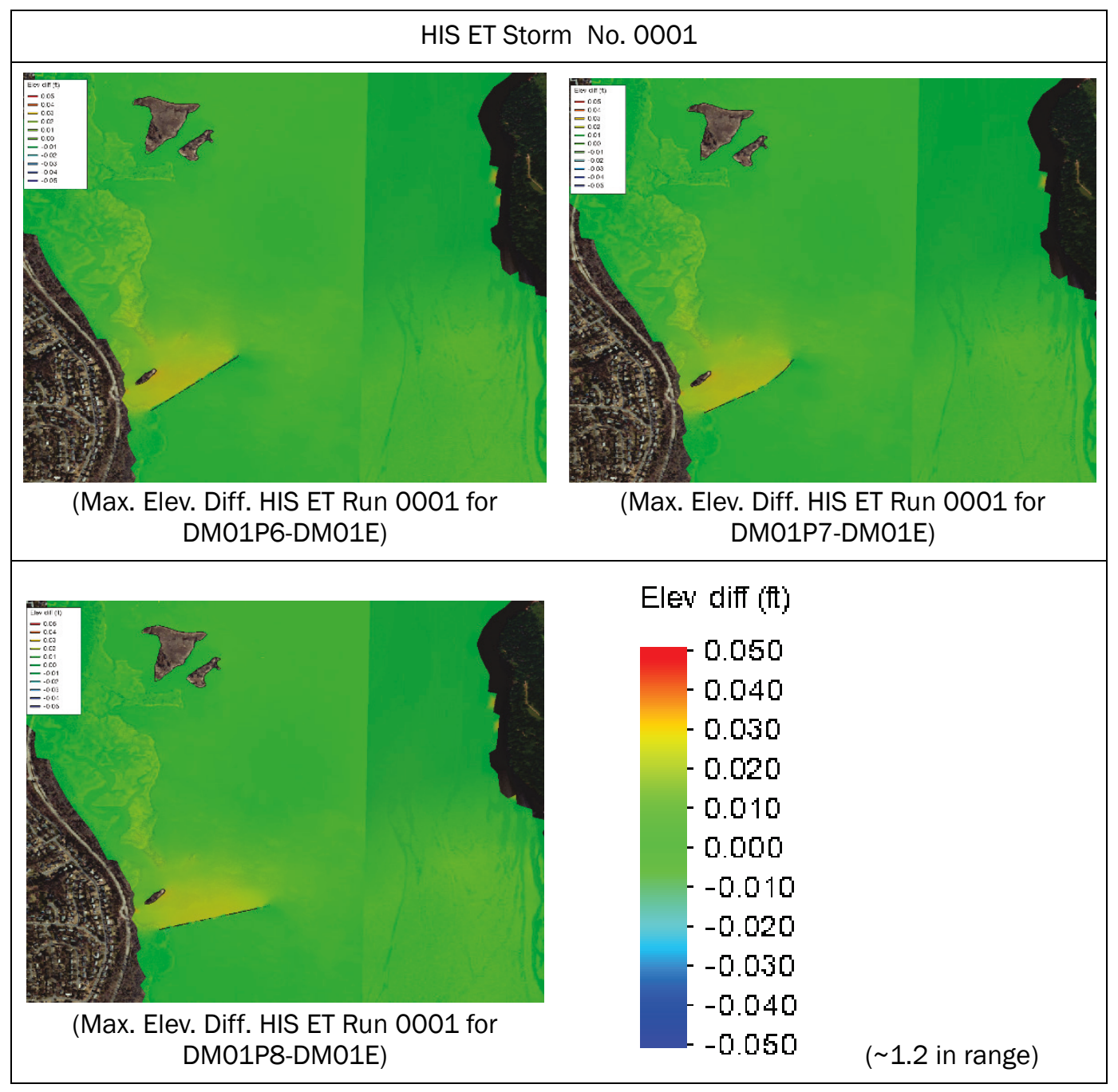


Table 5-65. Maximum water surface elevations for HIS ET Storm No. 0008 for four mesh configurations.

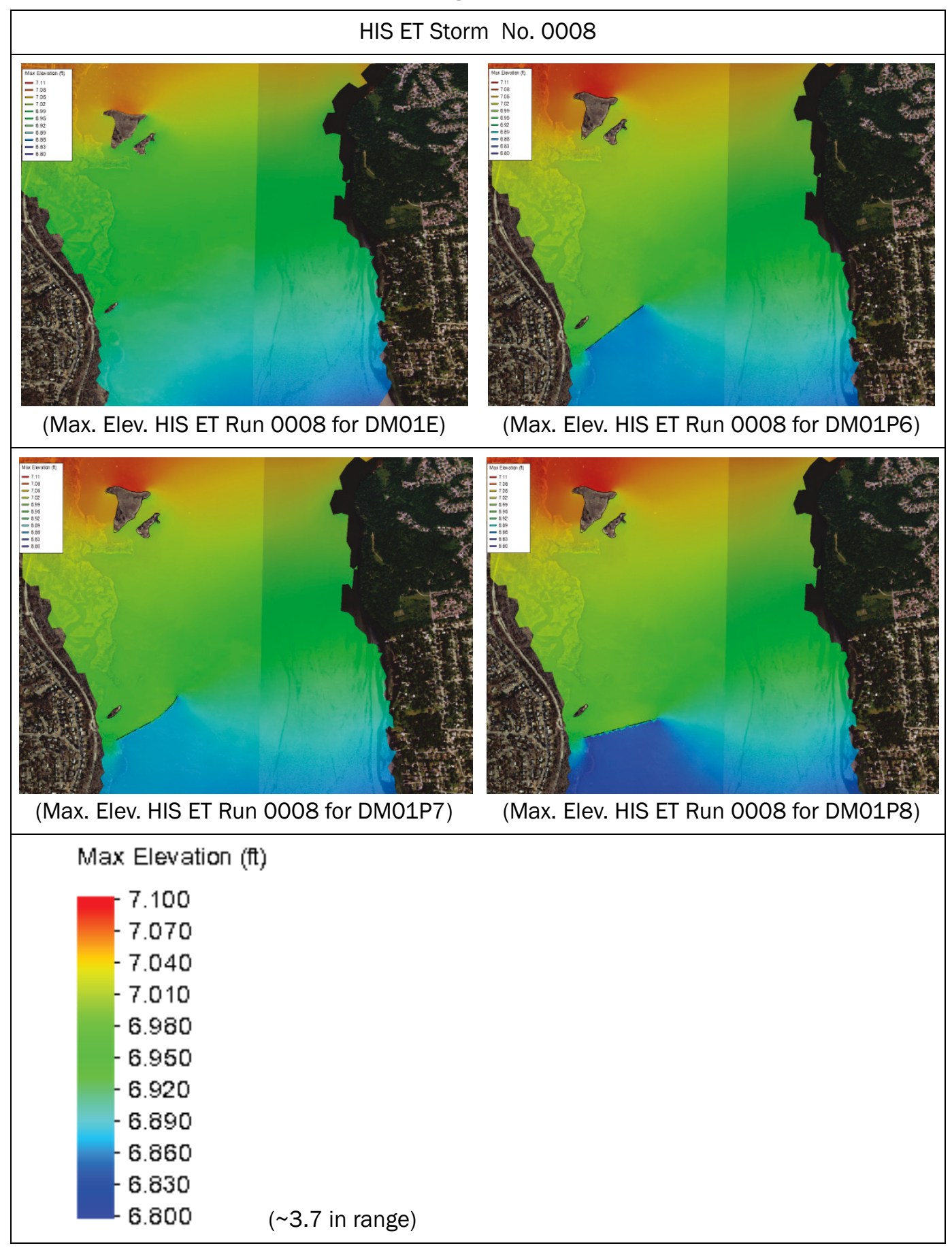


Table 5-66. Maximum water surface elevations for HIS ET Storm No. 0038 for four mesh configurations.

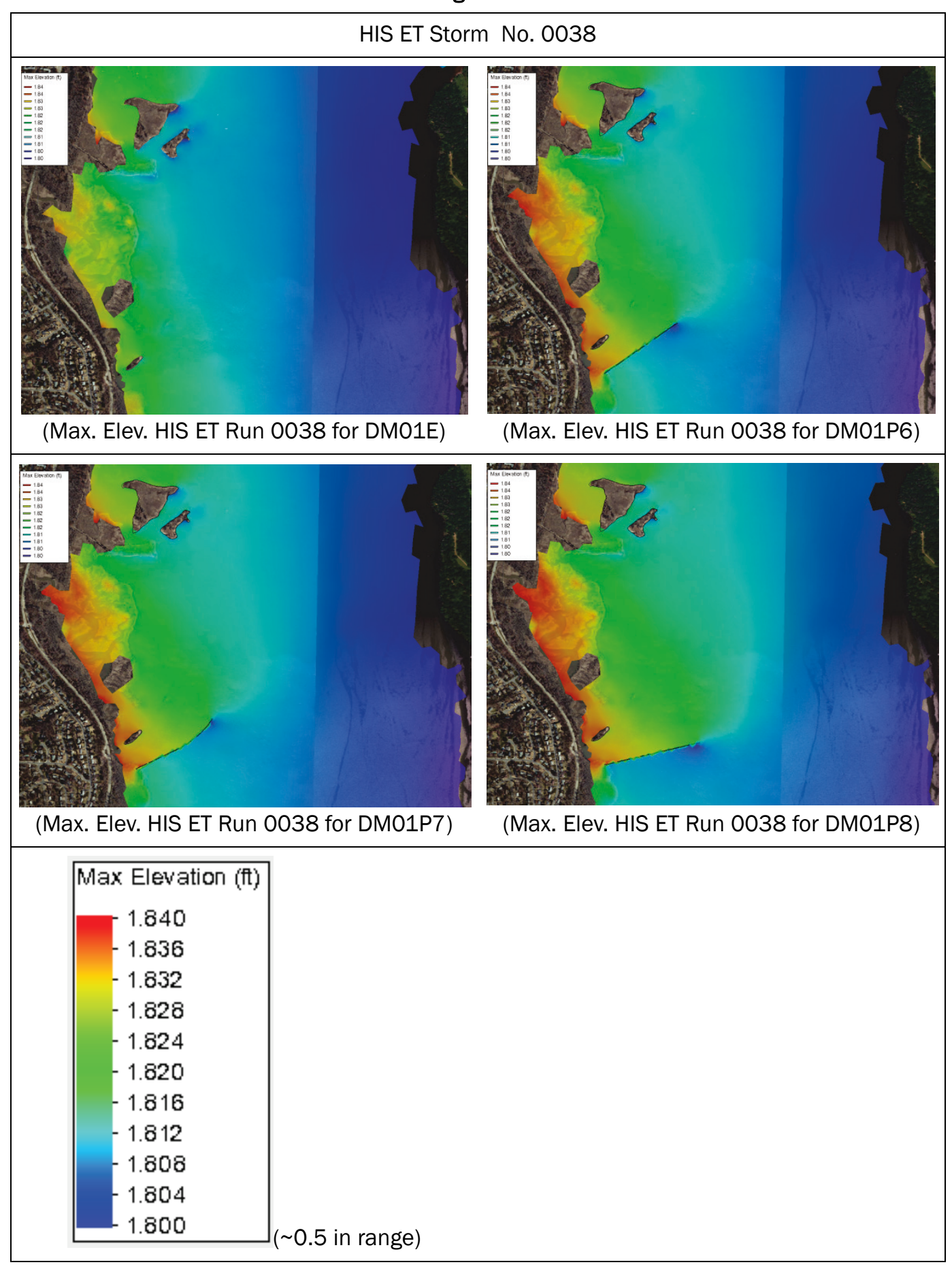


Table 5-67. Maximum water surface elevations for HIS ET Storm No. 0051 for four mesh configurations.

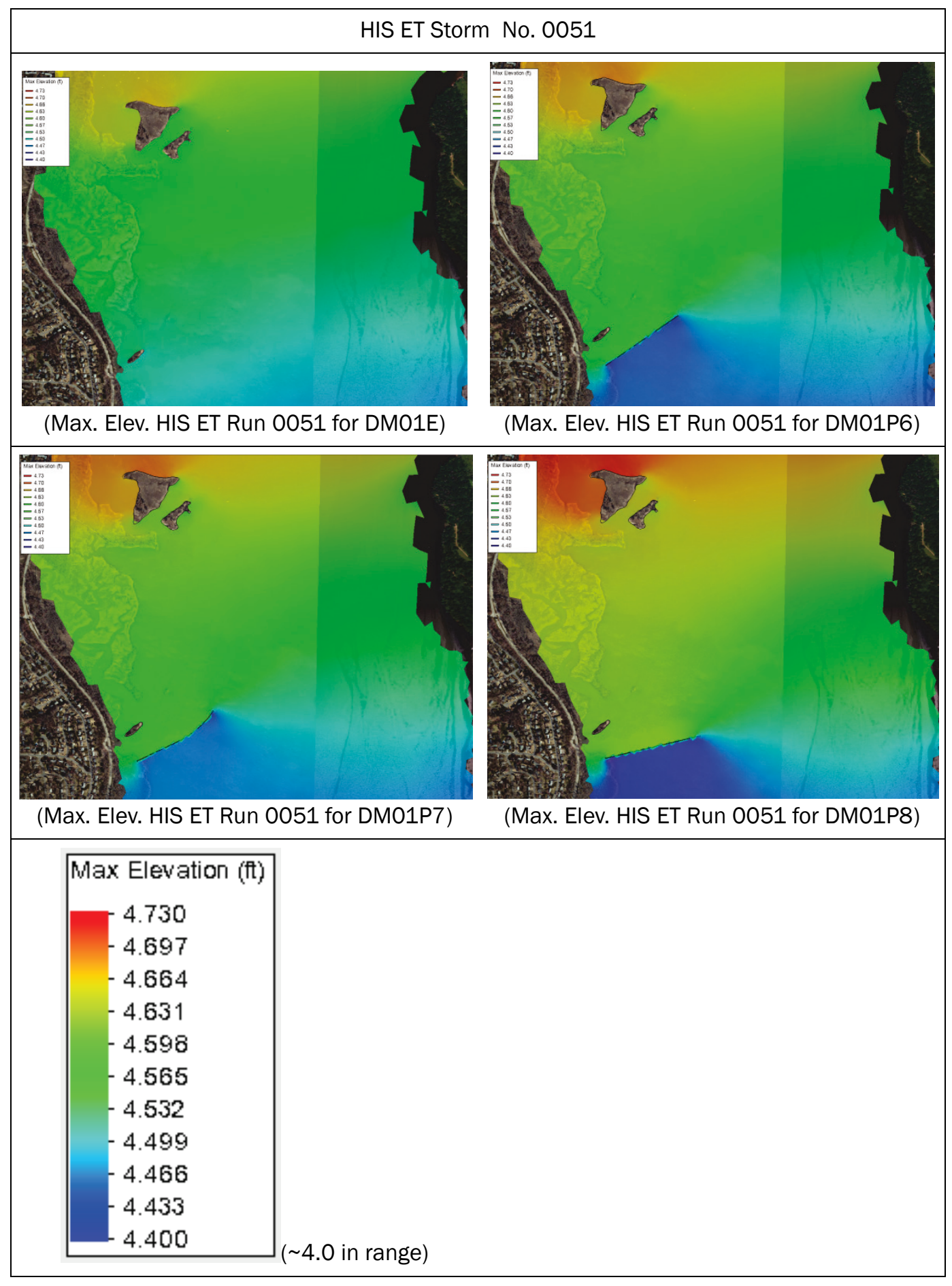


Table 5-68. Maximum water surface elevations for HIS ET Storm No. 0054 for four mesh configurations.

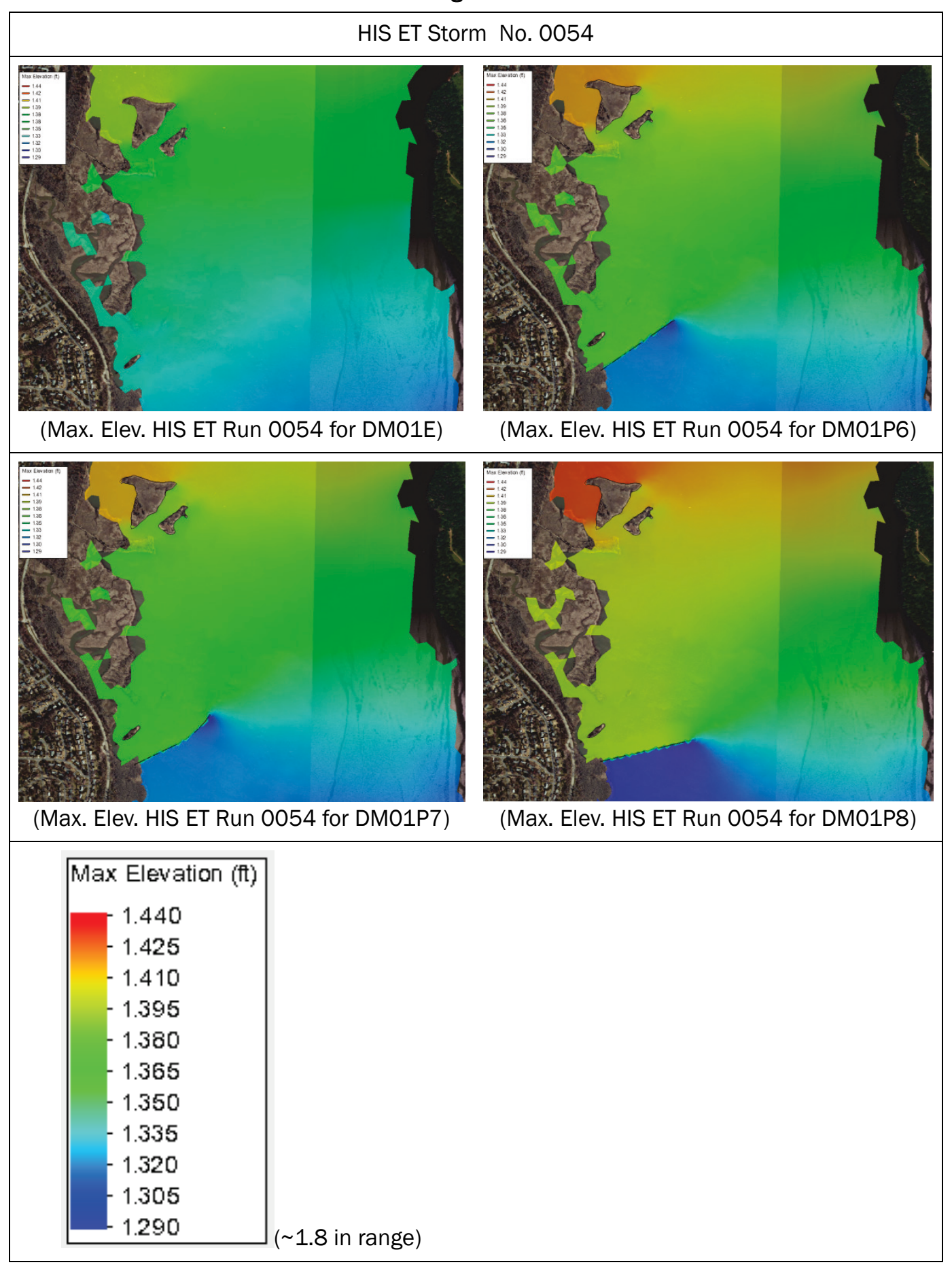


Table 5-69. Maximum water surface elevations for SYN TP Storm No. 0005 for four mesh configurations.

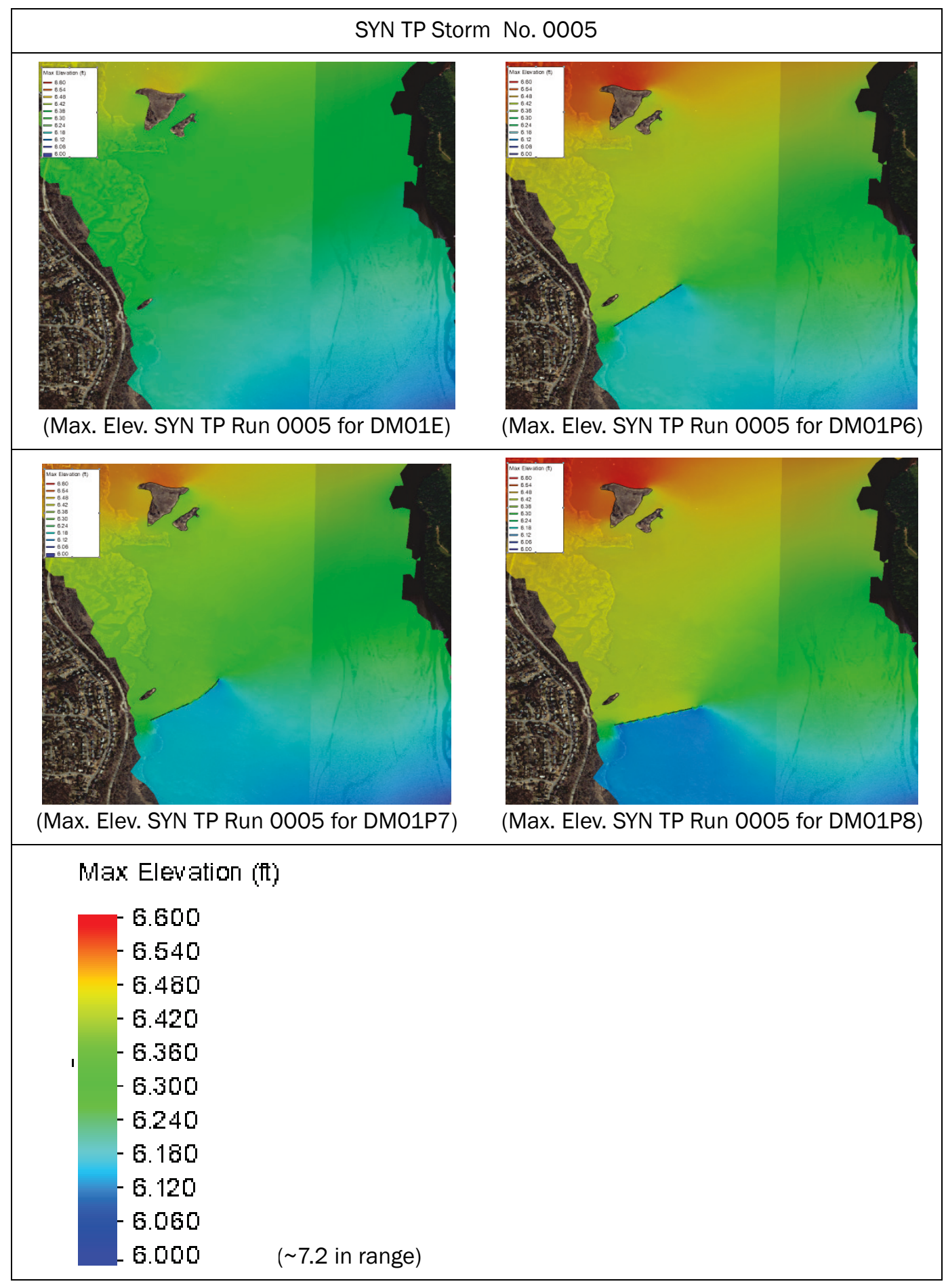


Table 5-70. Maximum water surface elevations for SYN TP Storm No. 0028 for four mesh configurations.

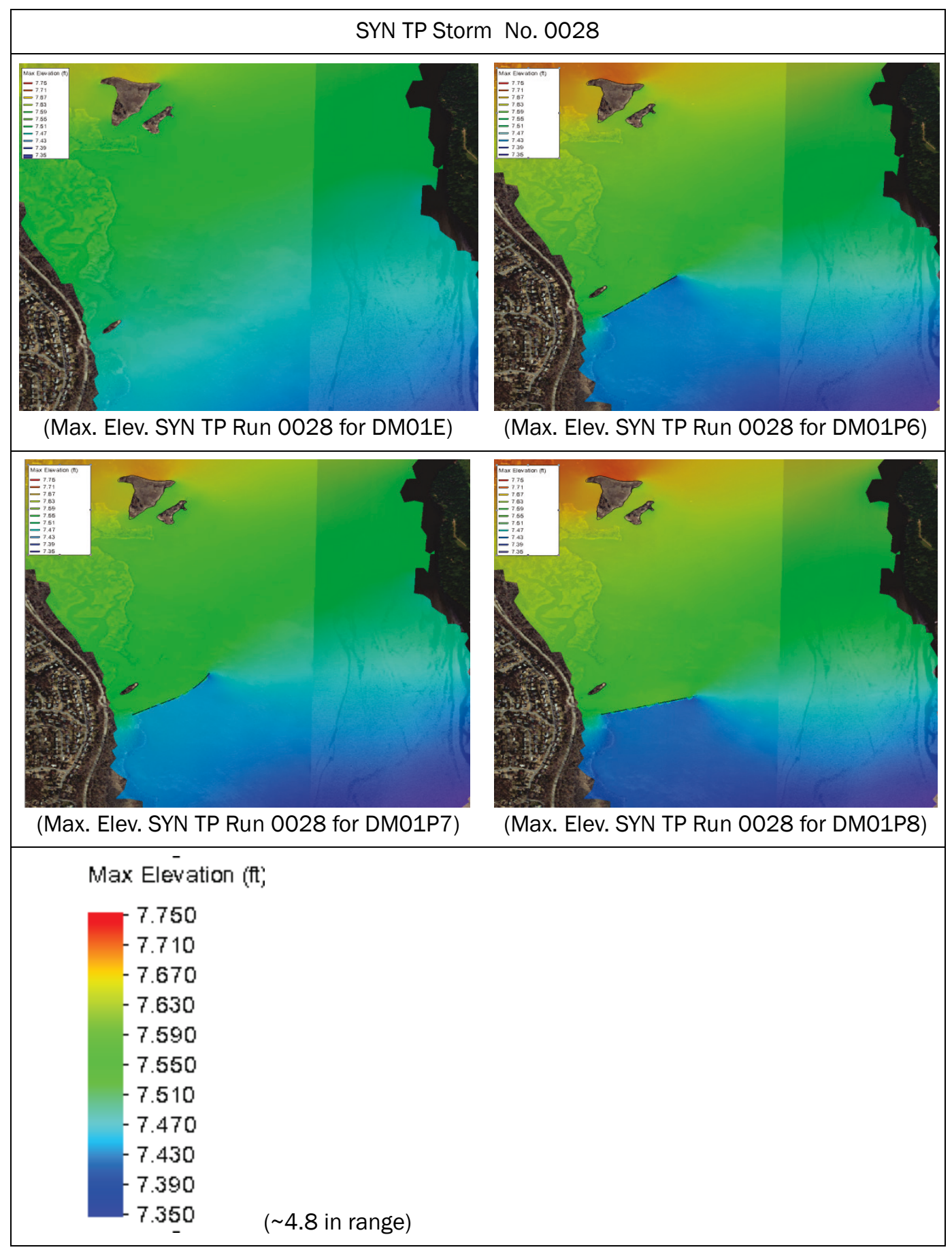


Table 5-71. Maximum water surface elevations for SYN TP Storm No. 0110 for four mesh configurations.

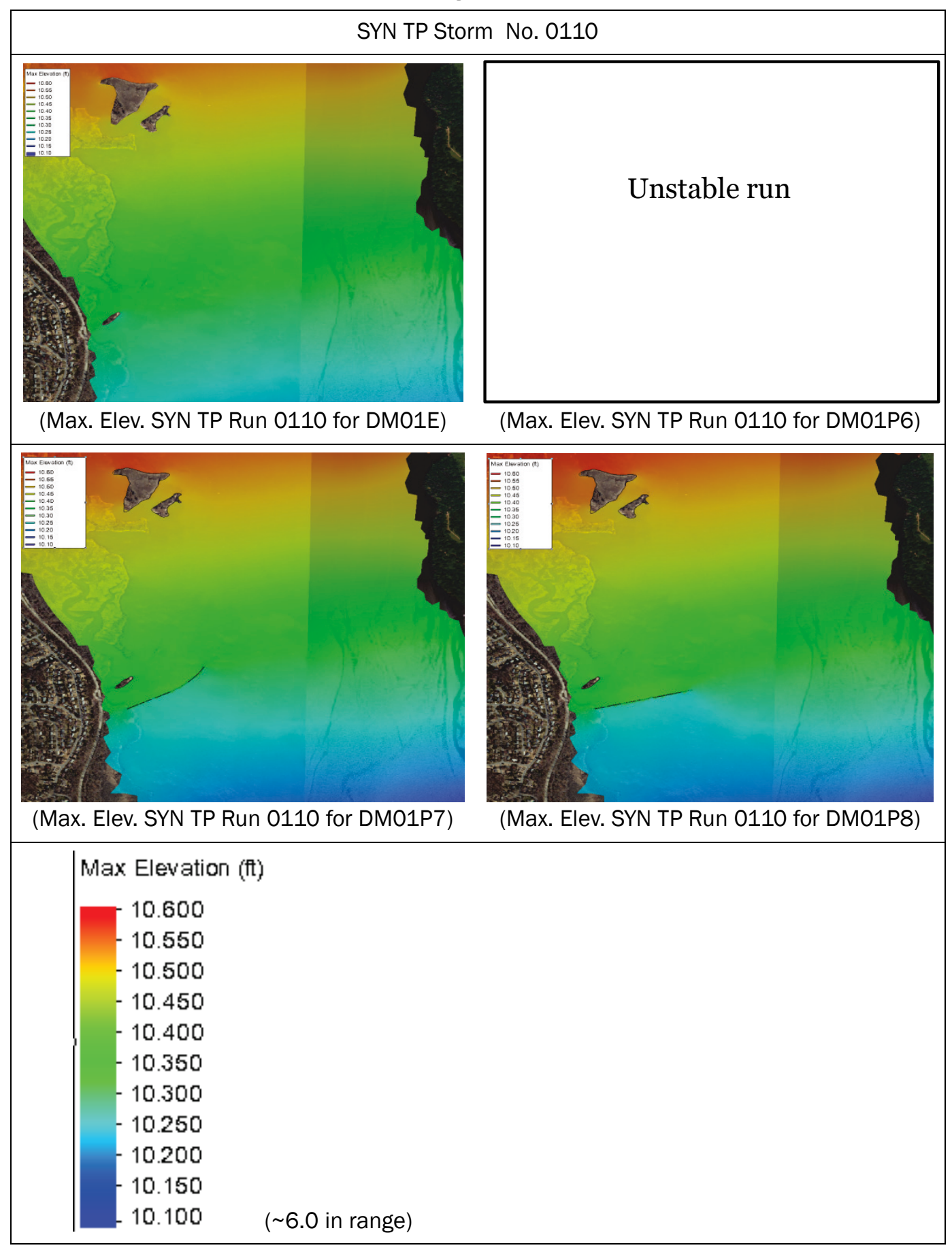


Table 5-72. Maximum water surface elevations for HIS TP Storm No. 0001 (Hurricane Sandy 2012) for four mesh configurations.

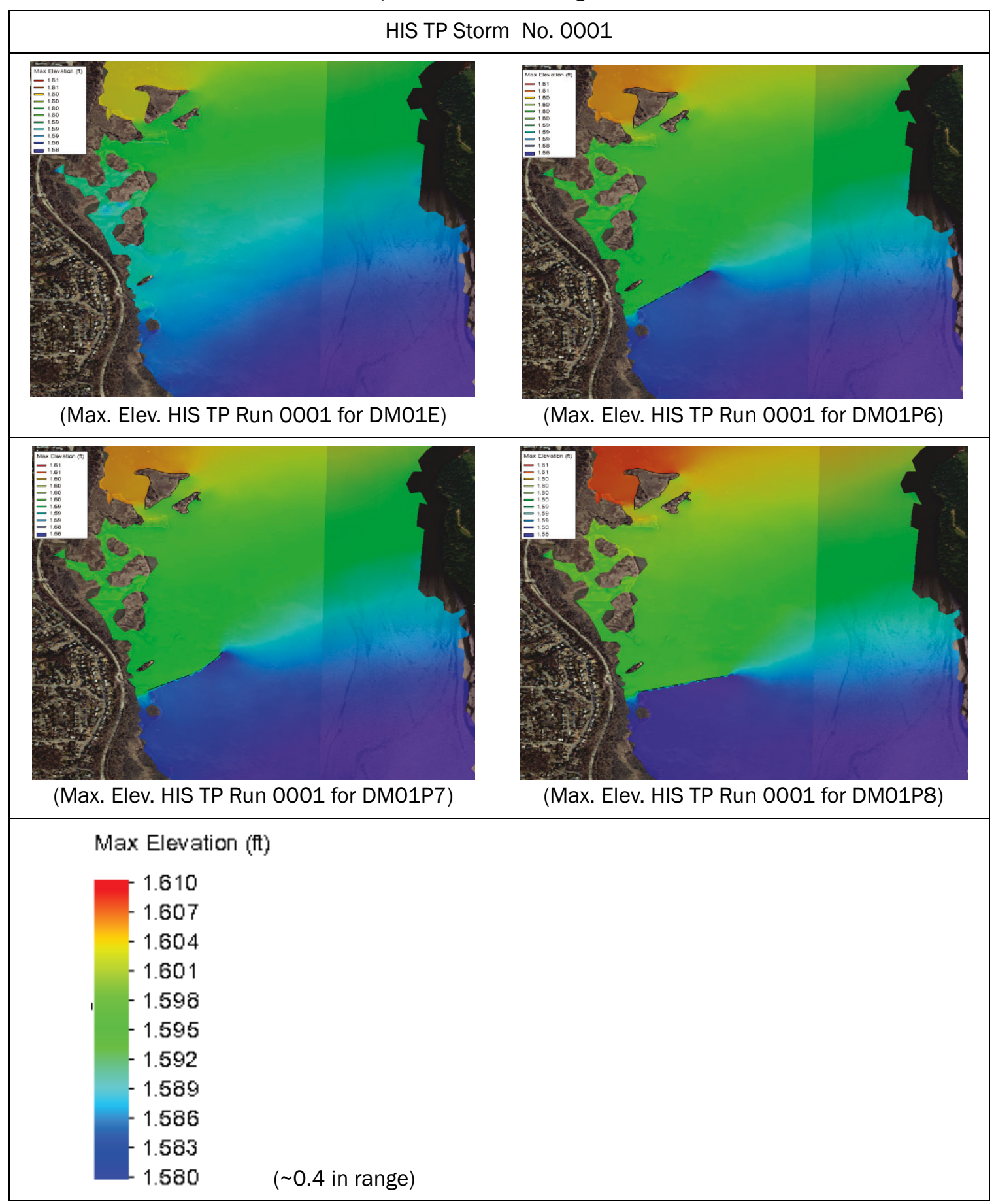


Table 5-73. Maximum water surface elevations for HIS TP Storm No. 0003 (Hurricane Isabel 2003) for four mesh configurations.

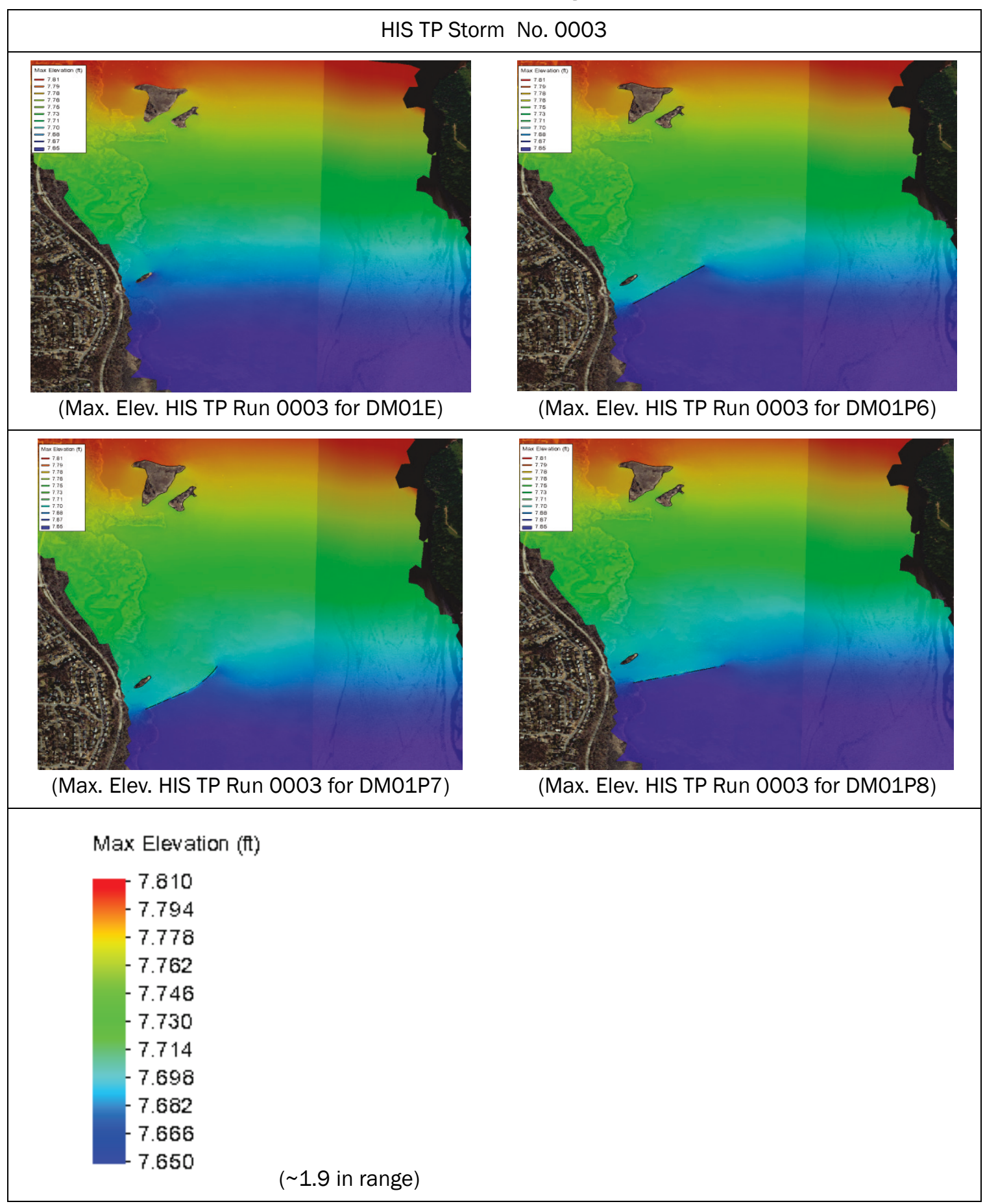




\subsubsection{Maximum storm depth averaged water velocity results groin-only designs}

Table 5-74. Maximum water velocity color contour plots for HIS ET Storm No. 0001 for four mesh configurations.

\begin{tabular}{|c|c|c|}
\hline & & \\
\hline
\end{tabular}


Table 5-75. Difference in maximum water velocity for HIS ET Storm No. 0001 for all three with-project groin-only mesh configurations (Project - Existing).

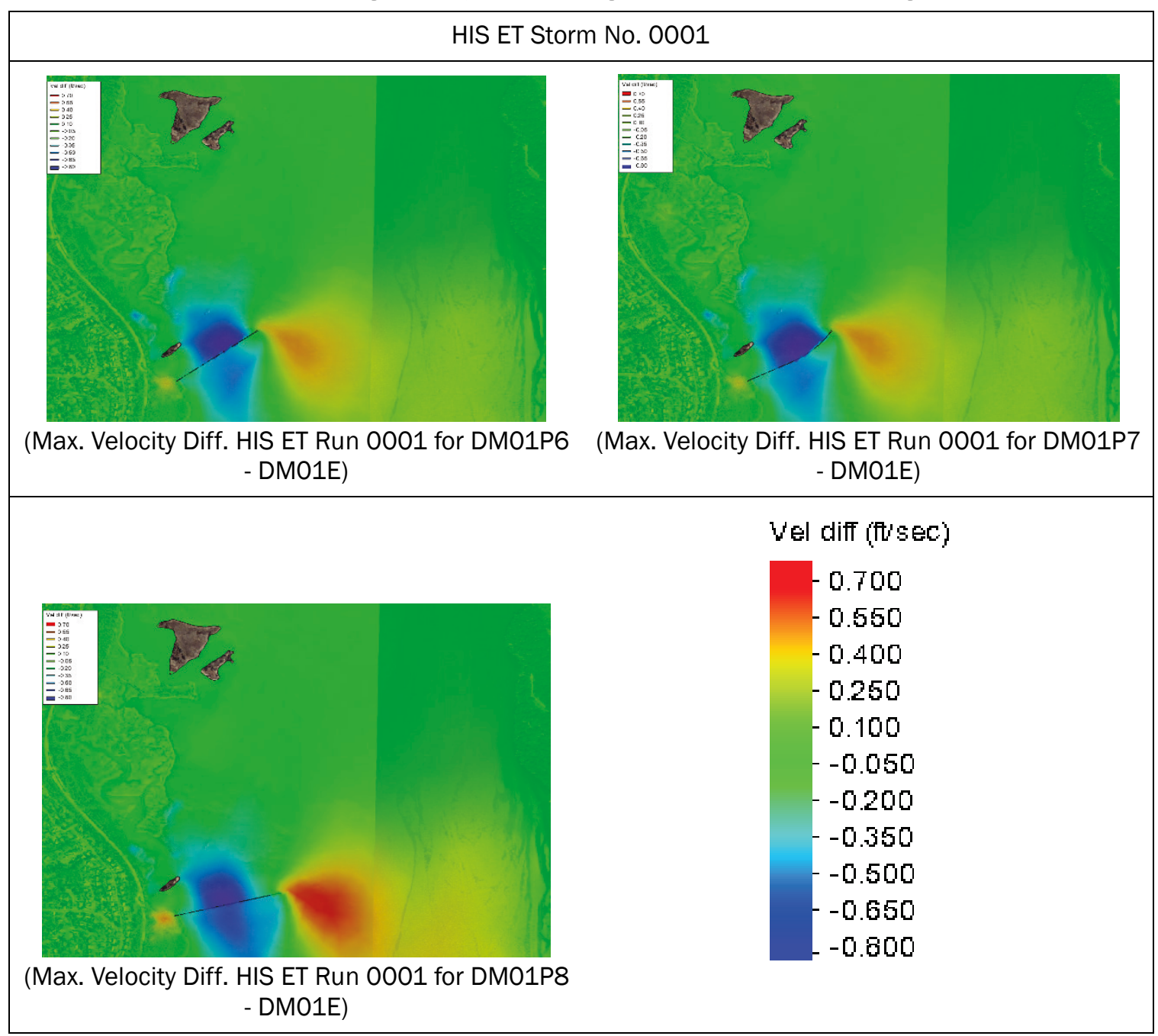


Table 5-76. Maximum water velocity color contour plots for HIS ET Storm No. 0008 for four mesh configurations.

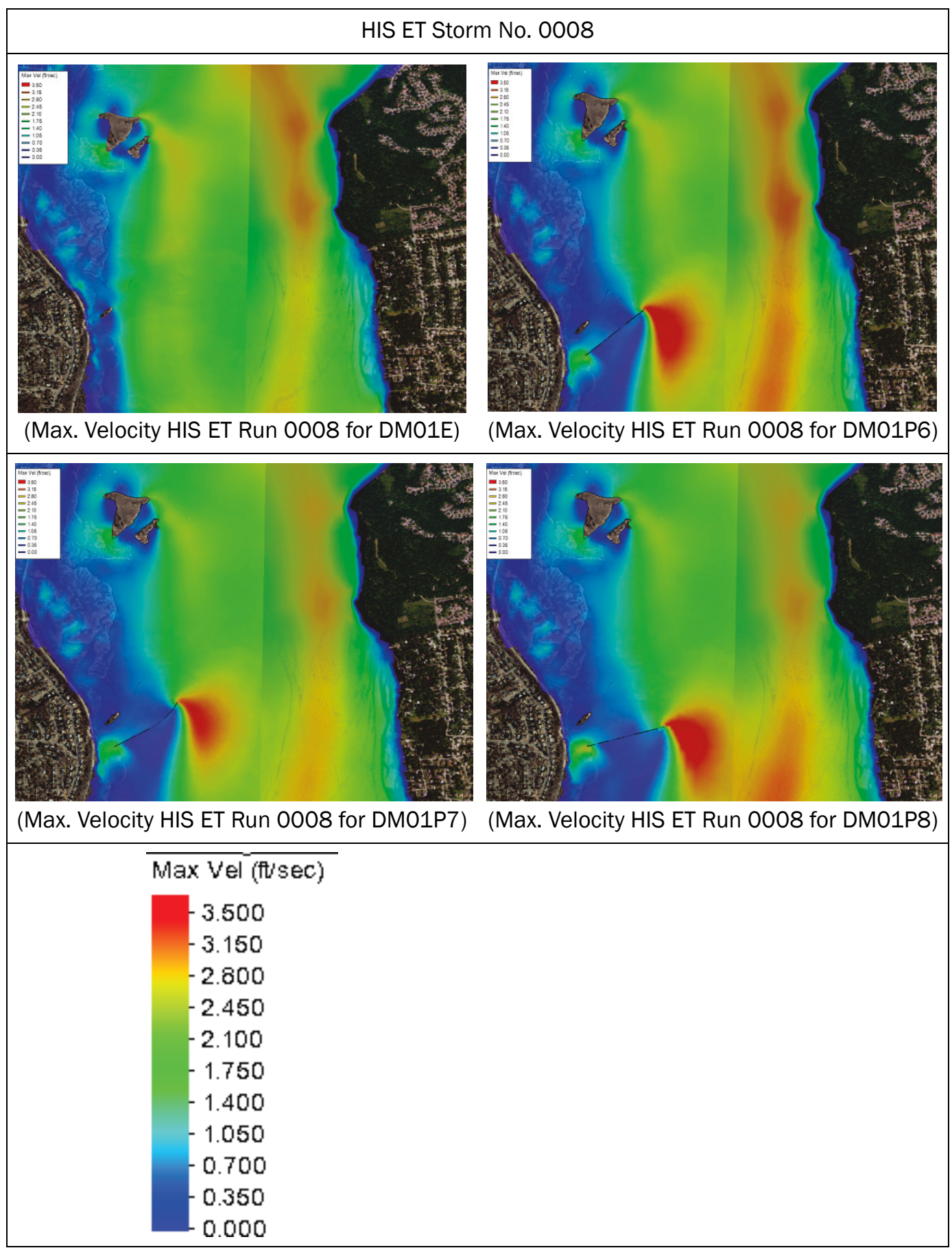


Table 5-77. Maximum water velocity color contour plots for HIS ET Storm No. 0038 for four mesh configurations.

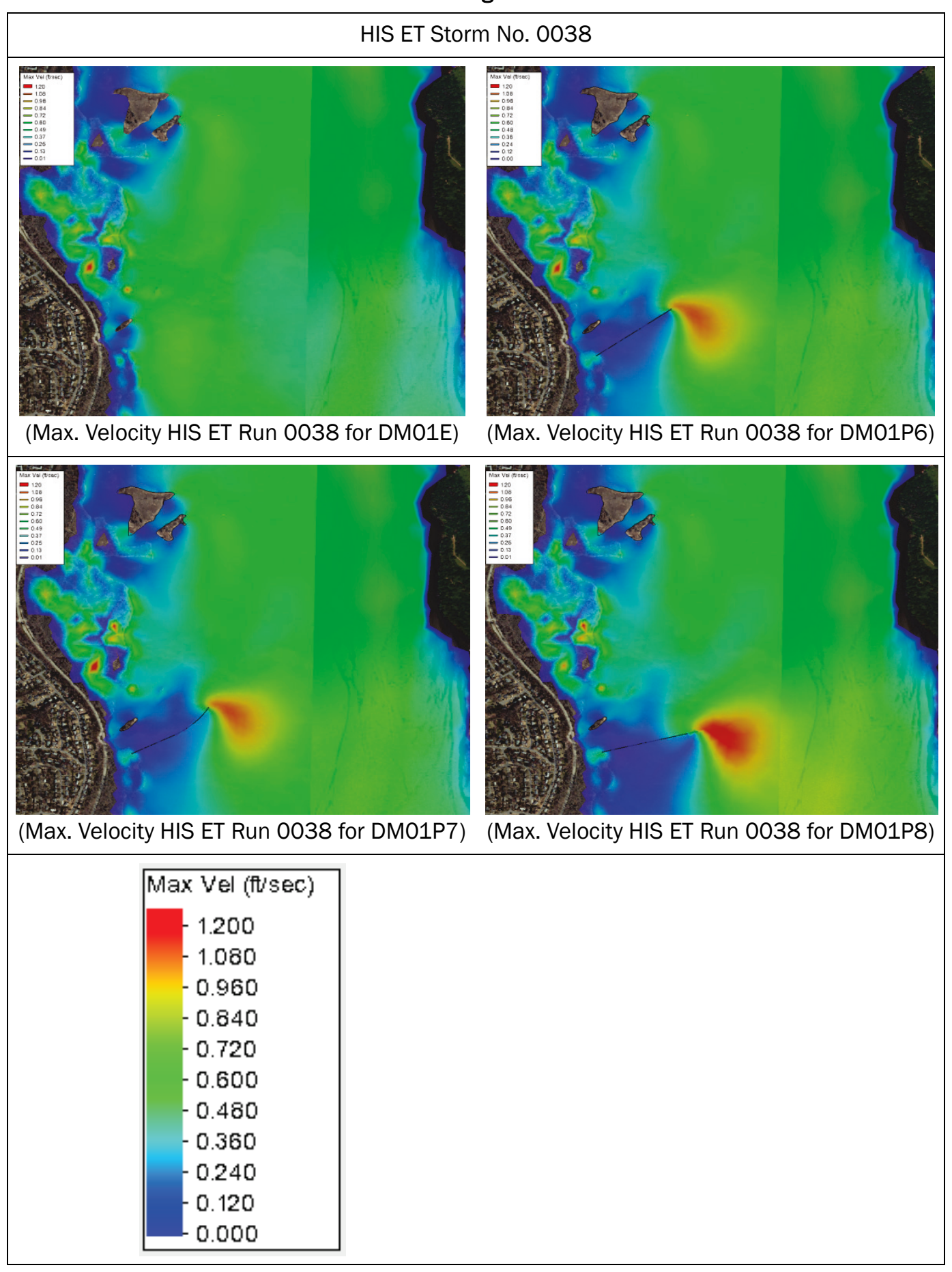


Table 5-78. Maximum water velocity color contour plots for HIS ET Storm No. 0051 for four mesh configurations

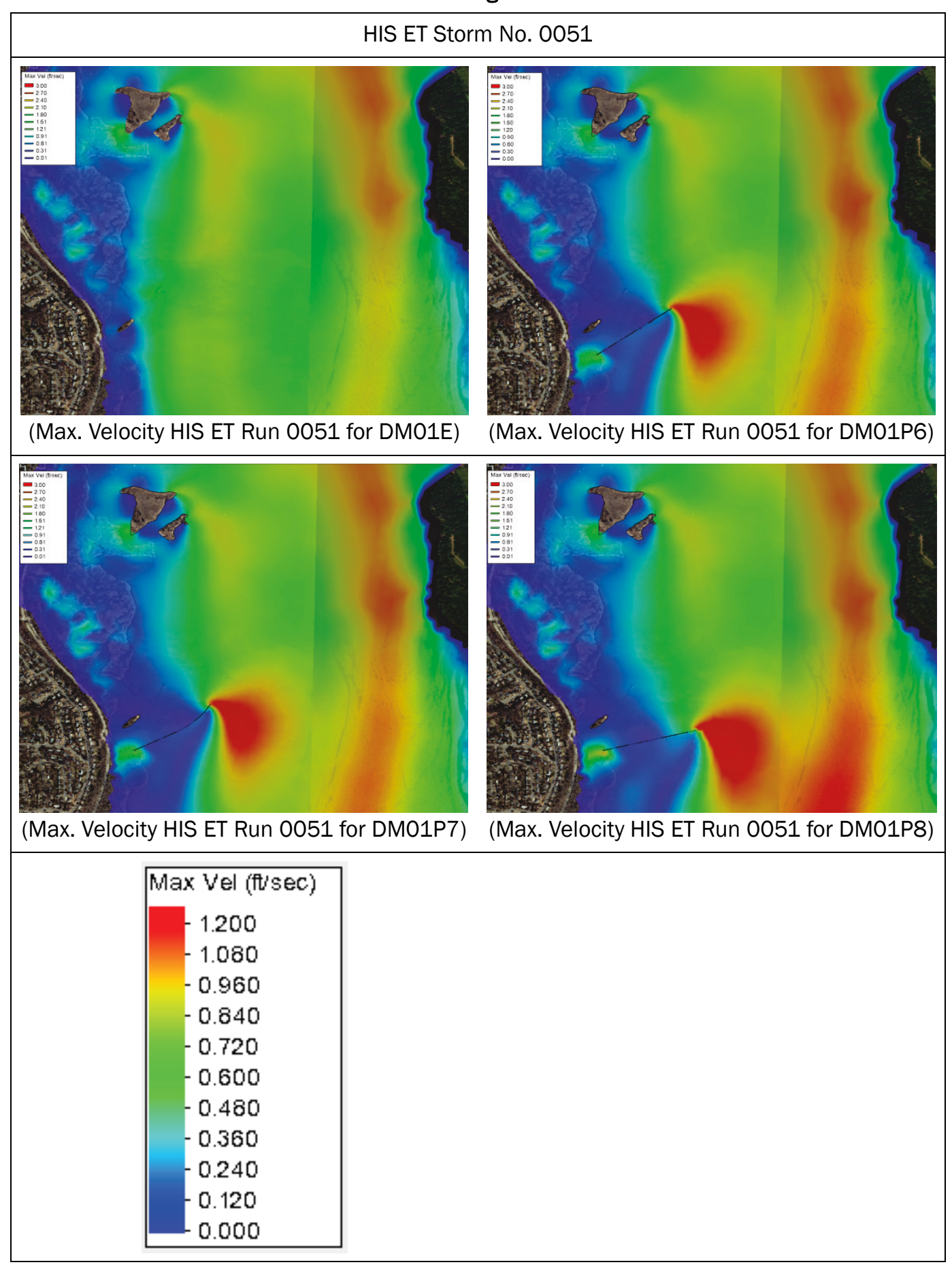


Table 5-79. Maximum water velocity color contour plots for HIS ET Storm No. 0054 for four mesh configurations

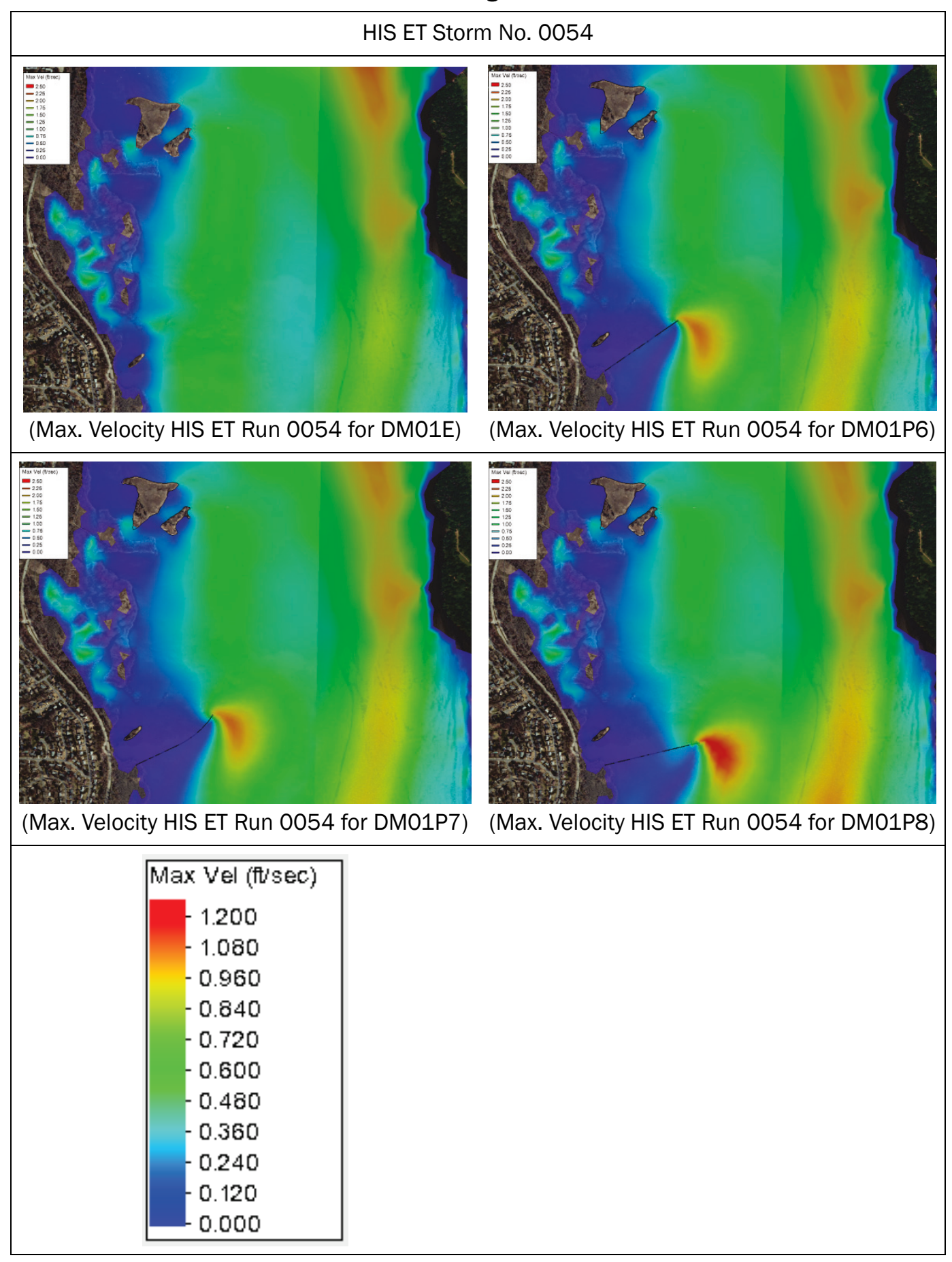


Table 5-80. Maximum water velocity color contour plots for SYN TP Storm No. 0005 for four mesh configurations.

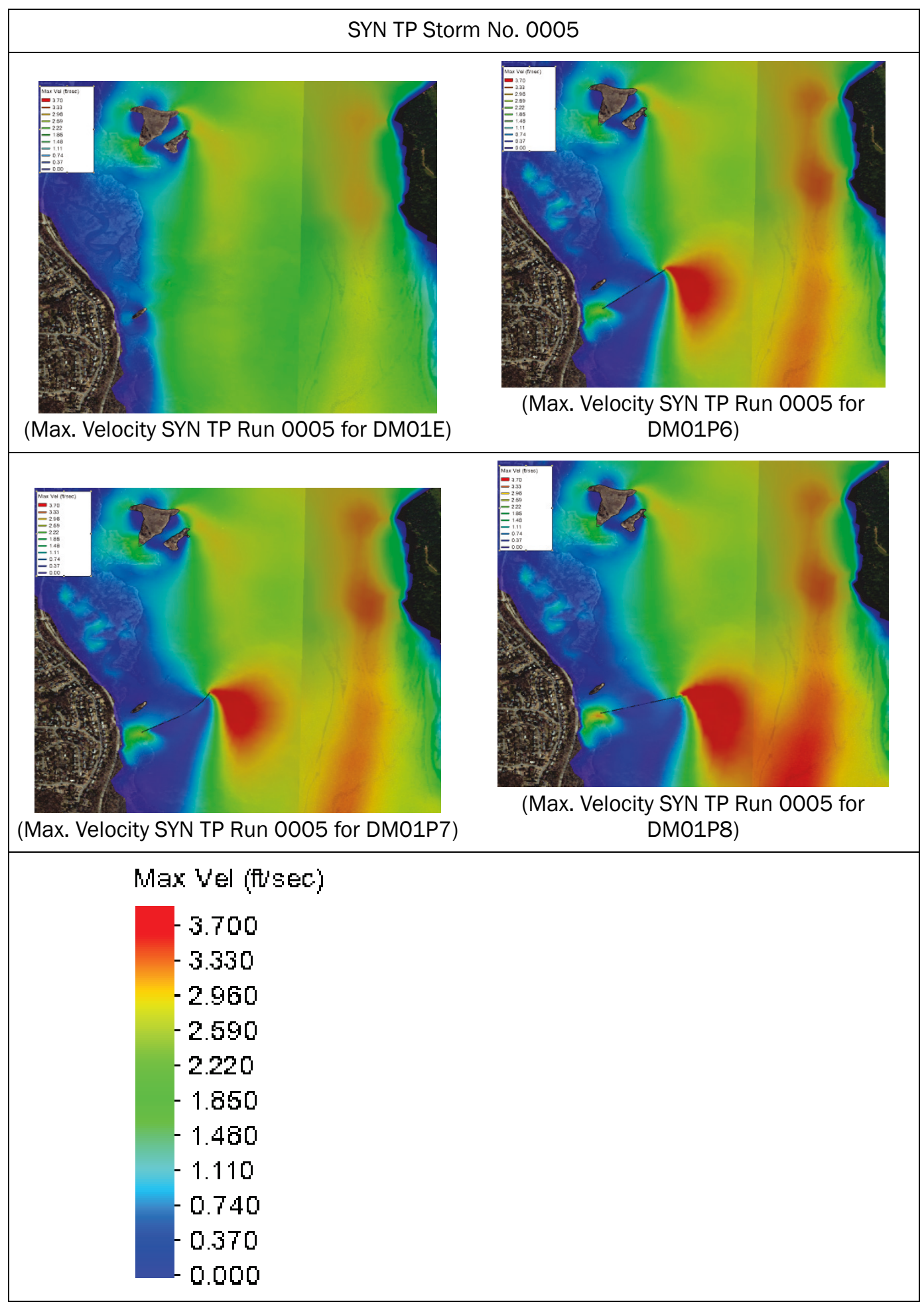


Table 5-81. Maximum water velocity color contour plots for SYN TP Storm No. 0028 for four mesh configurations.

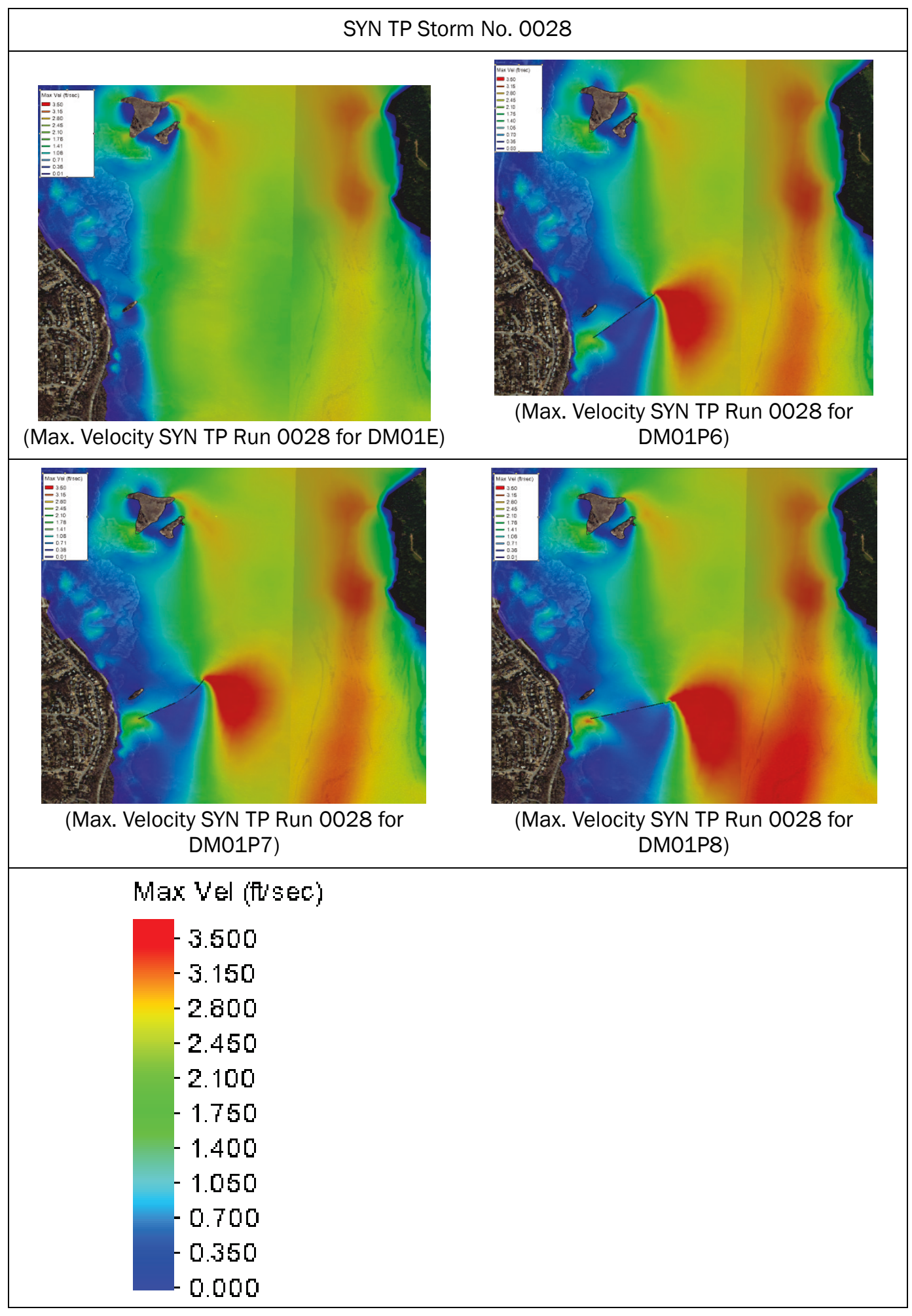


Table 5-82. Maximum water velocity color contour plots for SYN TP Storm No. 0110 for four mesh configurations.

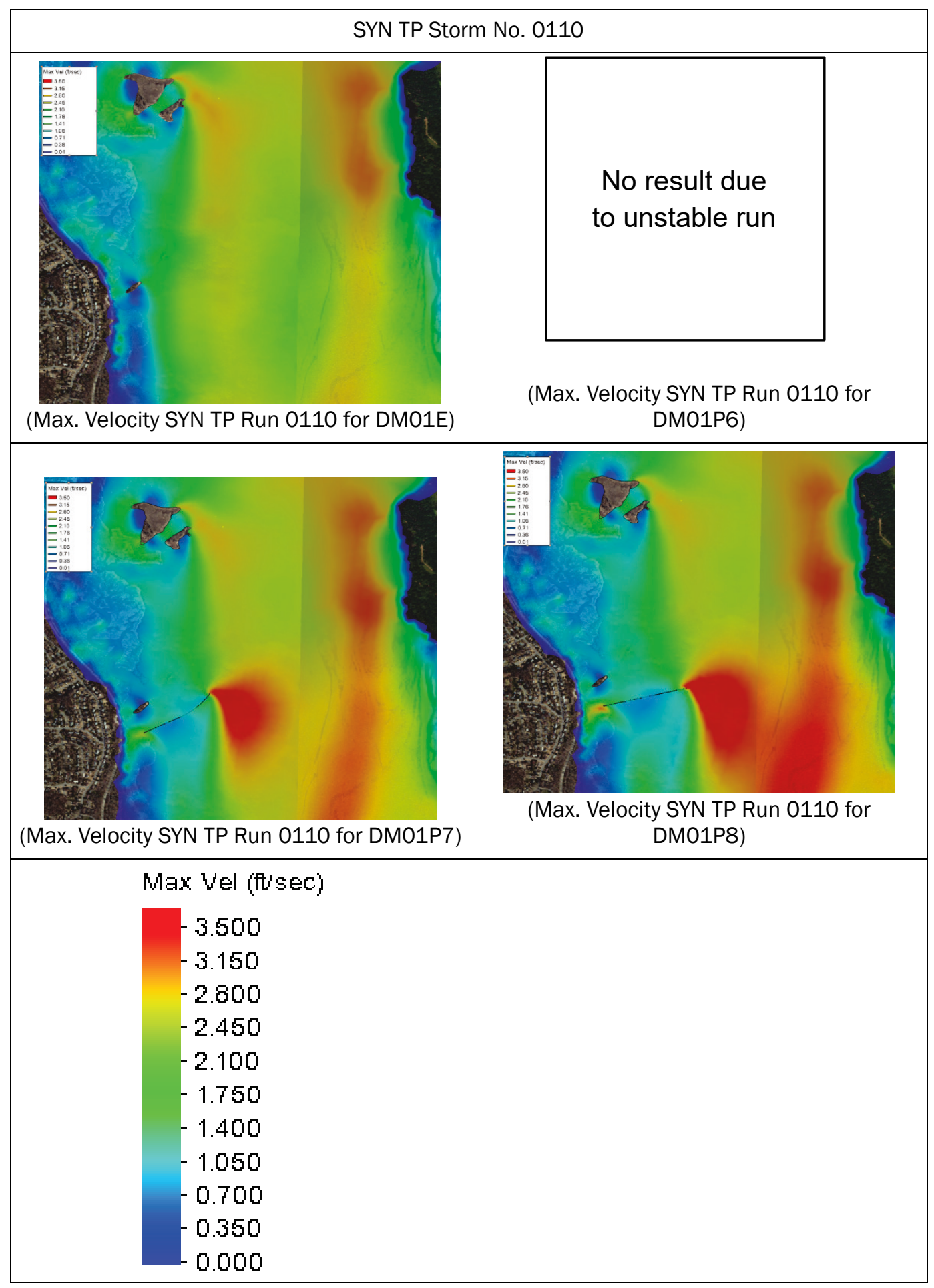


Table 5-83. Maximum water velocity color contour plots for HIS TP Storm No. 0001 (Hurricane Sandy 2012) for four mesh configurations.

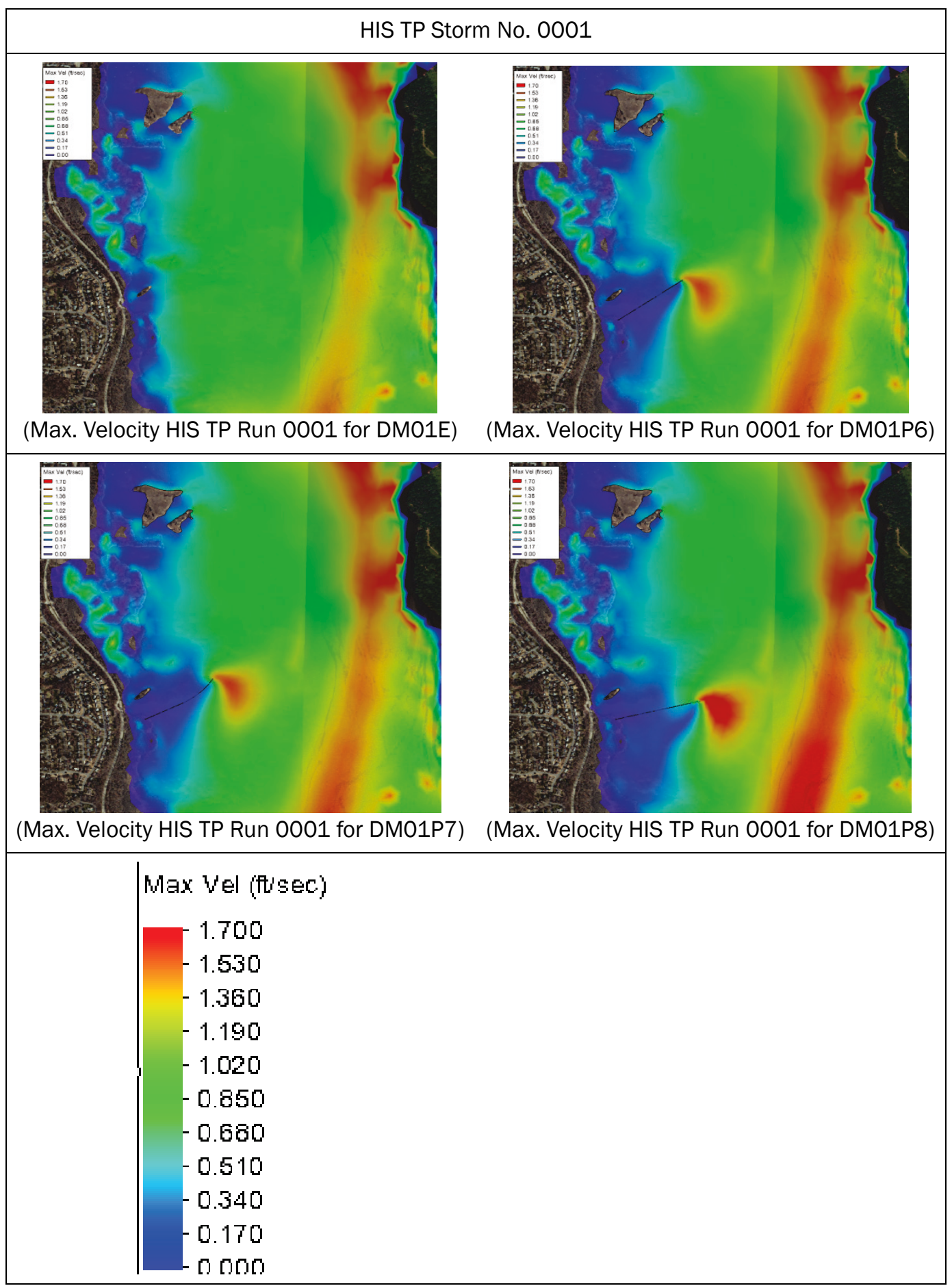


Table 5-84. Maximum water velocity color contour plots for HIS TP Storm No. 0003 (Hurricane Isabel 2003) for four mesh configurations.

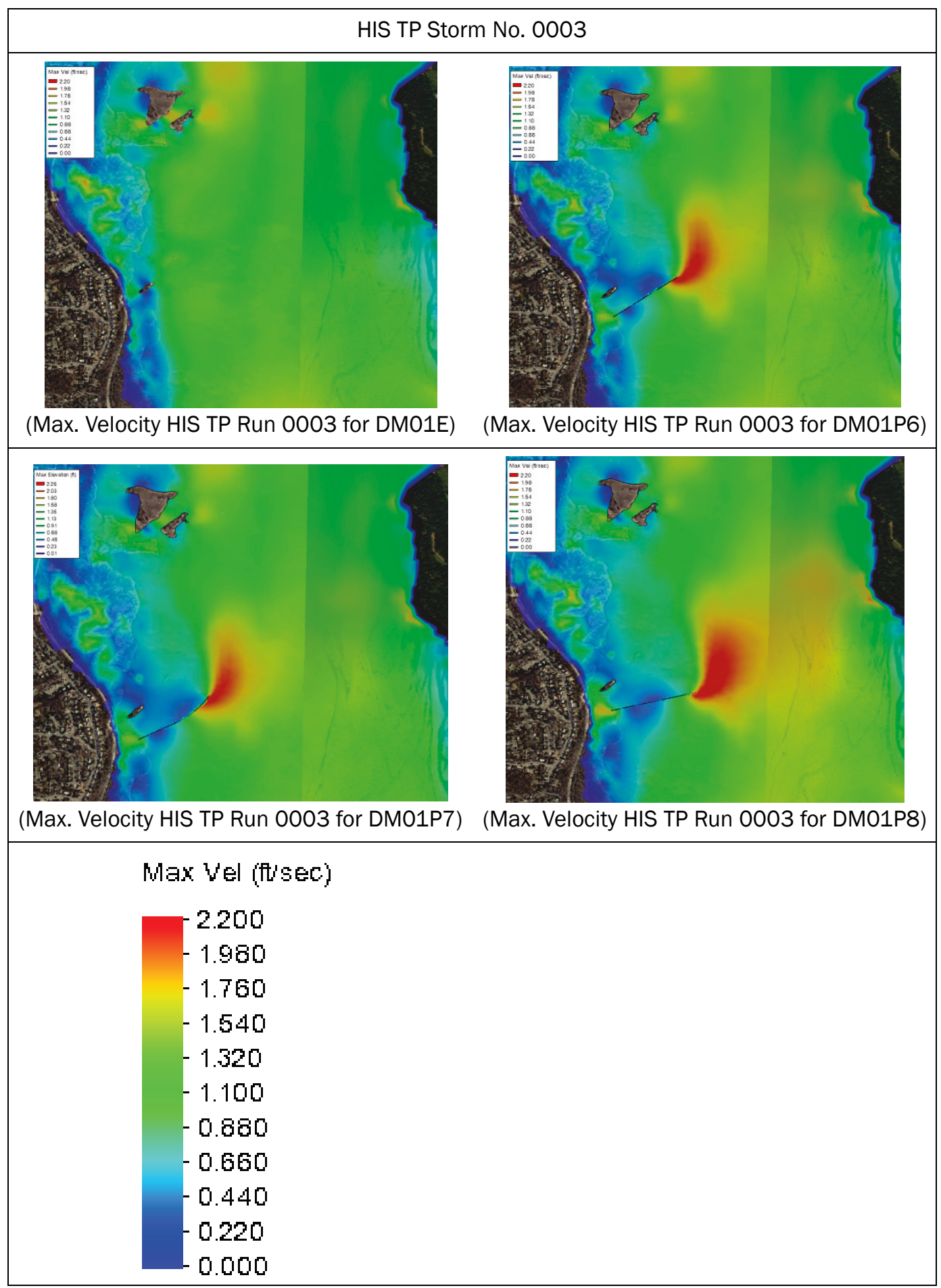




\subsubsection{Storm significant wave height results}

Table 5-85. Maximum significant wave height (Hs, max) color contour plots for HIS ET Storm No. 0001 for four mesh configurations.

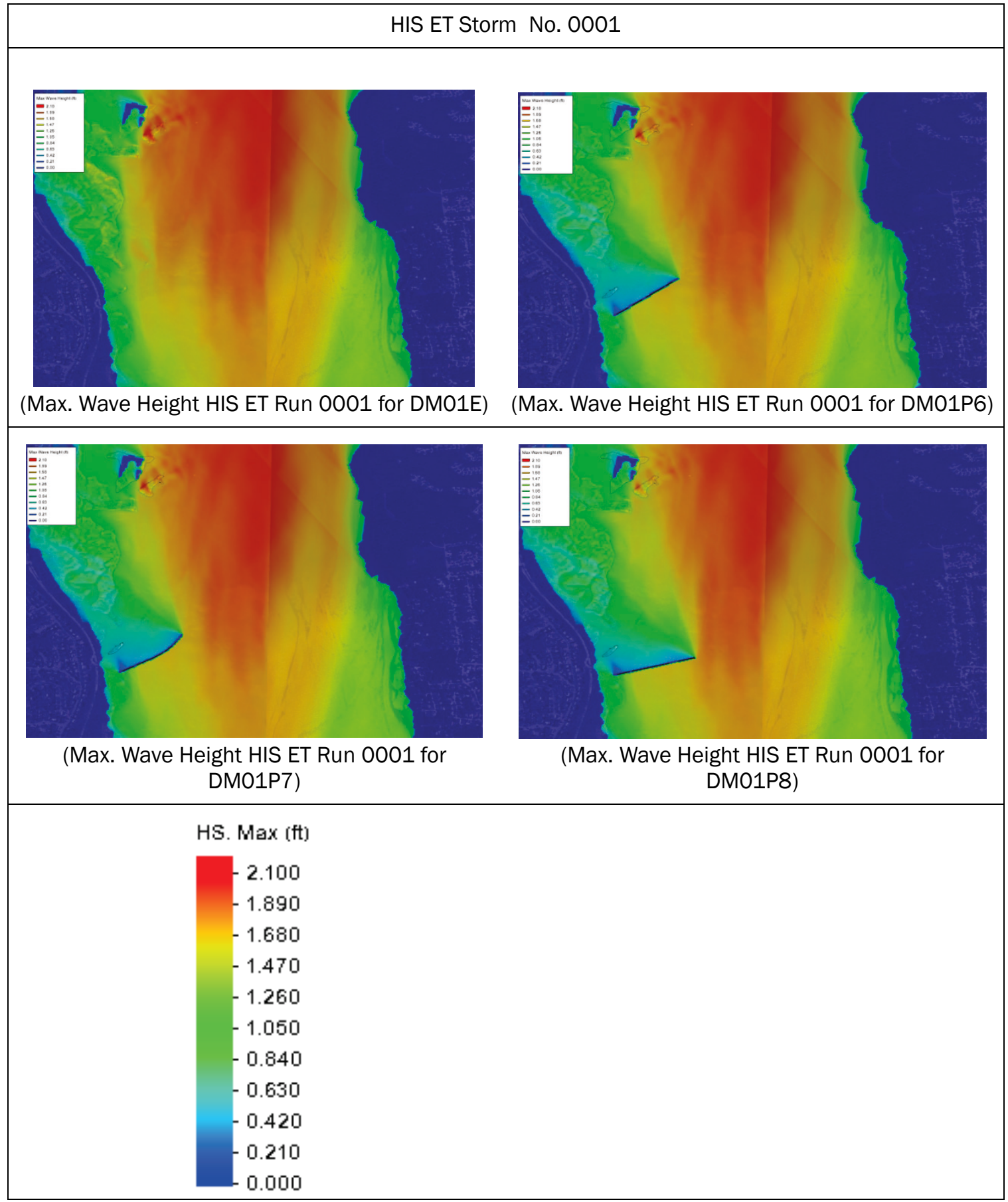


Table 5-86. Maximum significant wave height (Hs, max) color contour plots for HIS ET Storm No. 0008 for four mesh configurations.

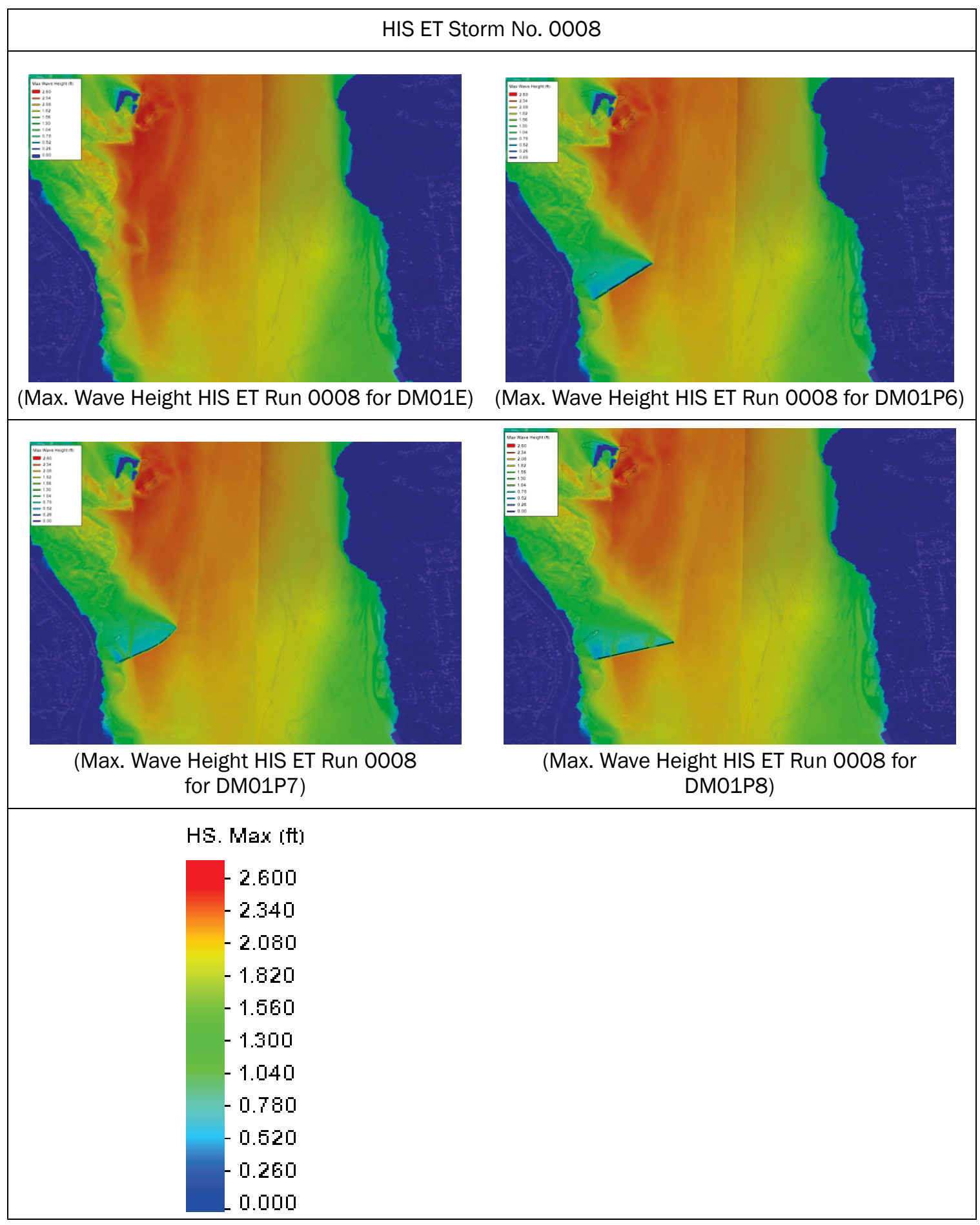


Table 5-87. Maximum significant wave height color contour plots for HIS ET Storm No. 0038 for four mesh configurations.

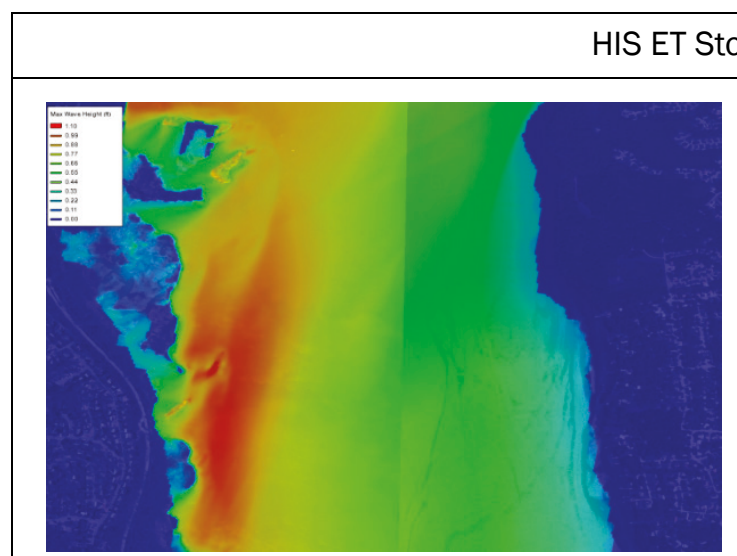

(Max. Wave Height HIS ET Run 0038 for DM01E)

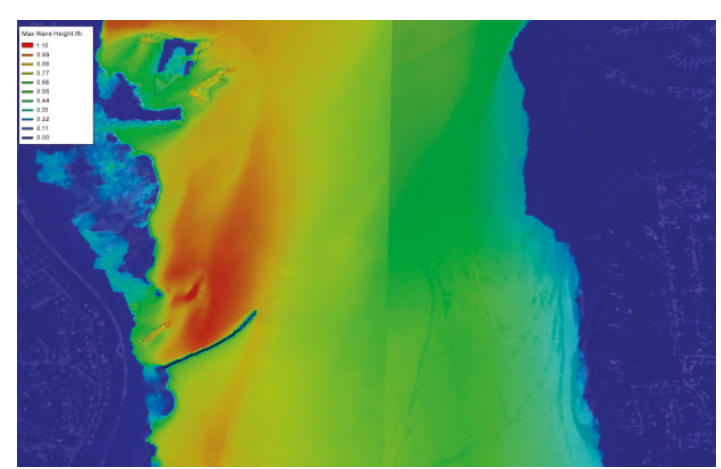

(Max. Wave Height HIS ET Run 0038 for DM01P7)

HS. Max (ft)

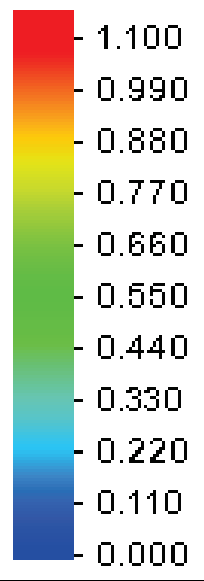

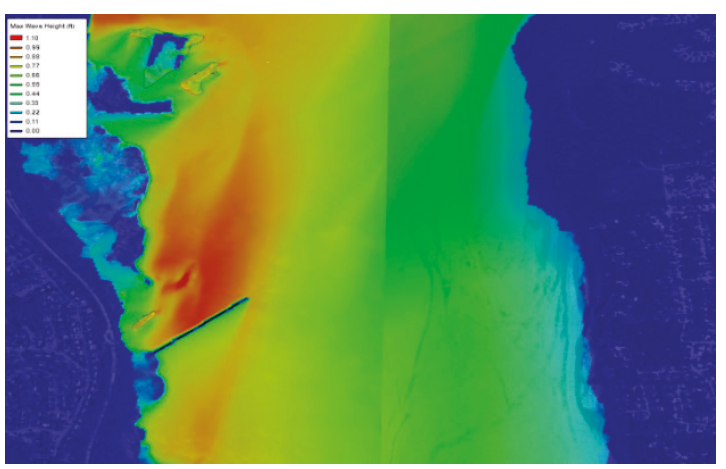

(Max. Wave Height HIS ET Run 0038 for DM01P6)

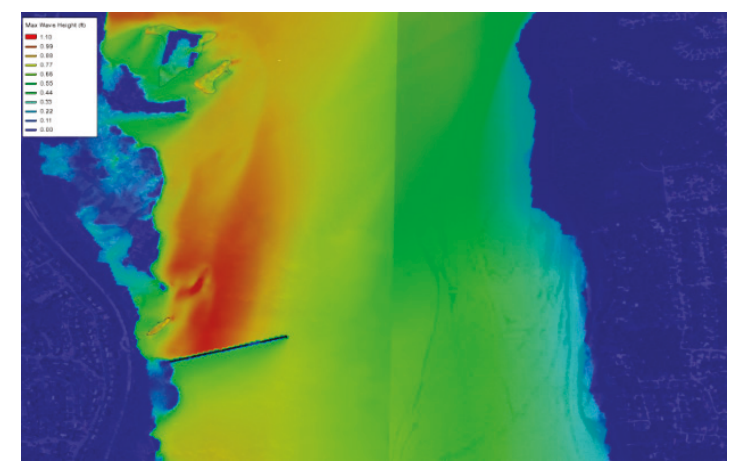

(Max. Wave Height HIS ET Run 0038 for DM01P8)

\begin{tabular}{|c|c|}
\hline HS. Max (ft) \\
-1.100 \\
-0.990 \\
-0.880 \\
-0.770 \\
-0.660 \\
-0.550 \\
-0.440 \\
-0.330 \\
-0.220 \\
-0.110 \\
-0.000 \\
\hline
\end{tabular}


Table 5-88. Maximum significant wave height color contour plots for HIS ET Storm No. 0051 for four mesh configurations.

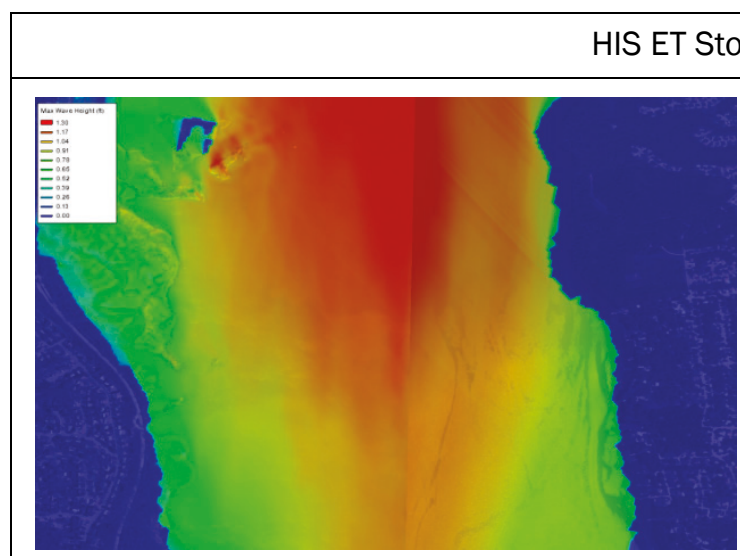

(Max. Wave Height HIS ET Run 0051 for DM01E)

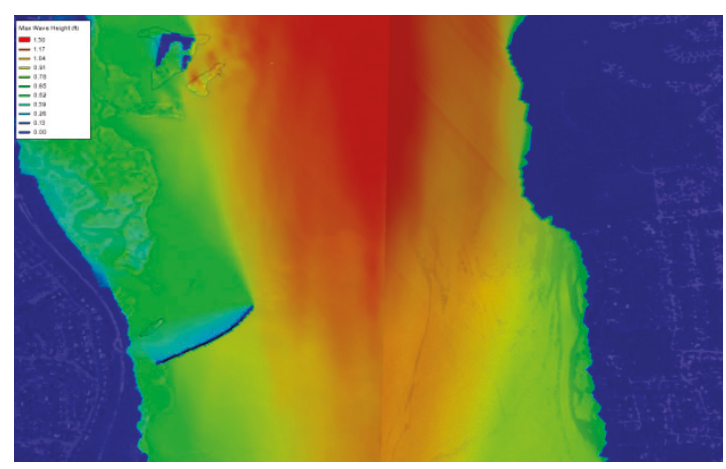

(Max. Wave Height HIS ET Run 0051 for DM01P7)

HS. Max (ft)

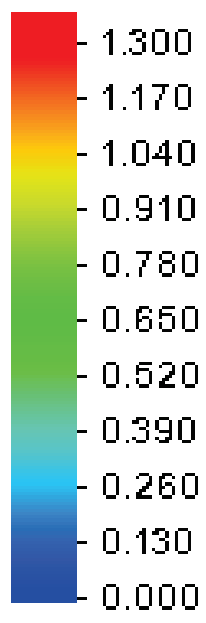

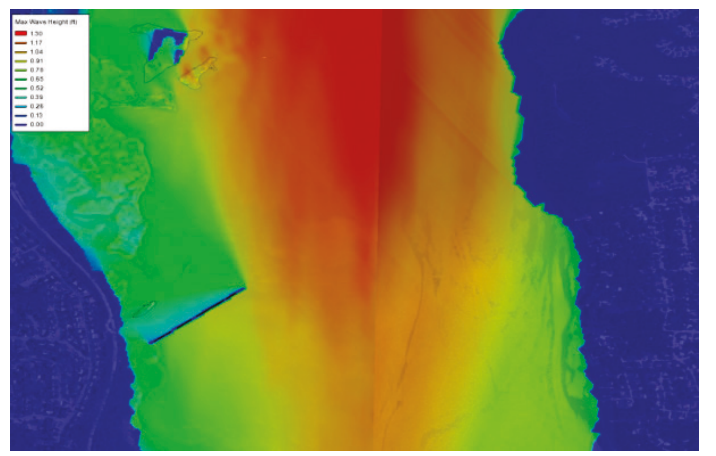

((Max. Wave Height HIS ET Run 0051 for DM01P6)

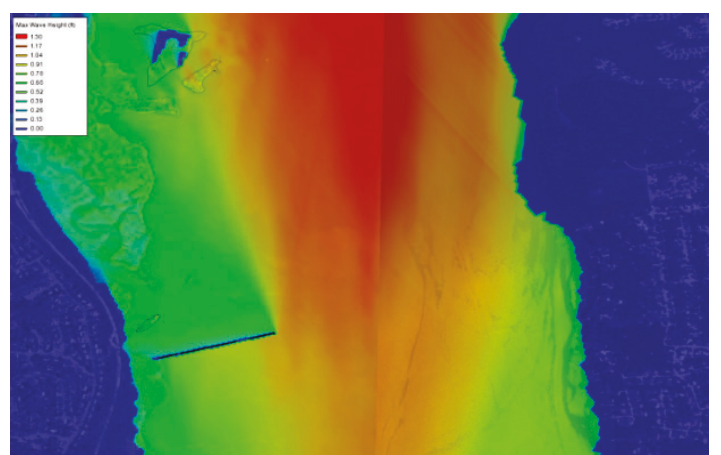

(Max. Wave Height HIS ET Run 0051 for DM01P8)

\begin{tabular}{|c|c|}
\hline HS. Max (ft) \\
-1.300 \\
-1.170 \\
-1.040 \\
-0.910 \\
-0.780 \\
-0.650 \\
-0.520 \\
-0.390 \\
-0.260 \\
-0.130 \\
0.000
\end{tabular}


Table 5-89. Maximum significant wave height color contour plots for HIS ET Storm No. 0054 for four mesh configurations.

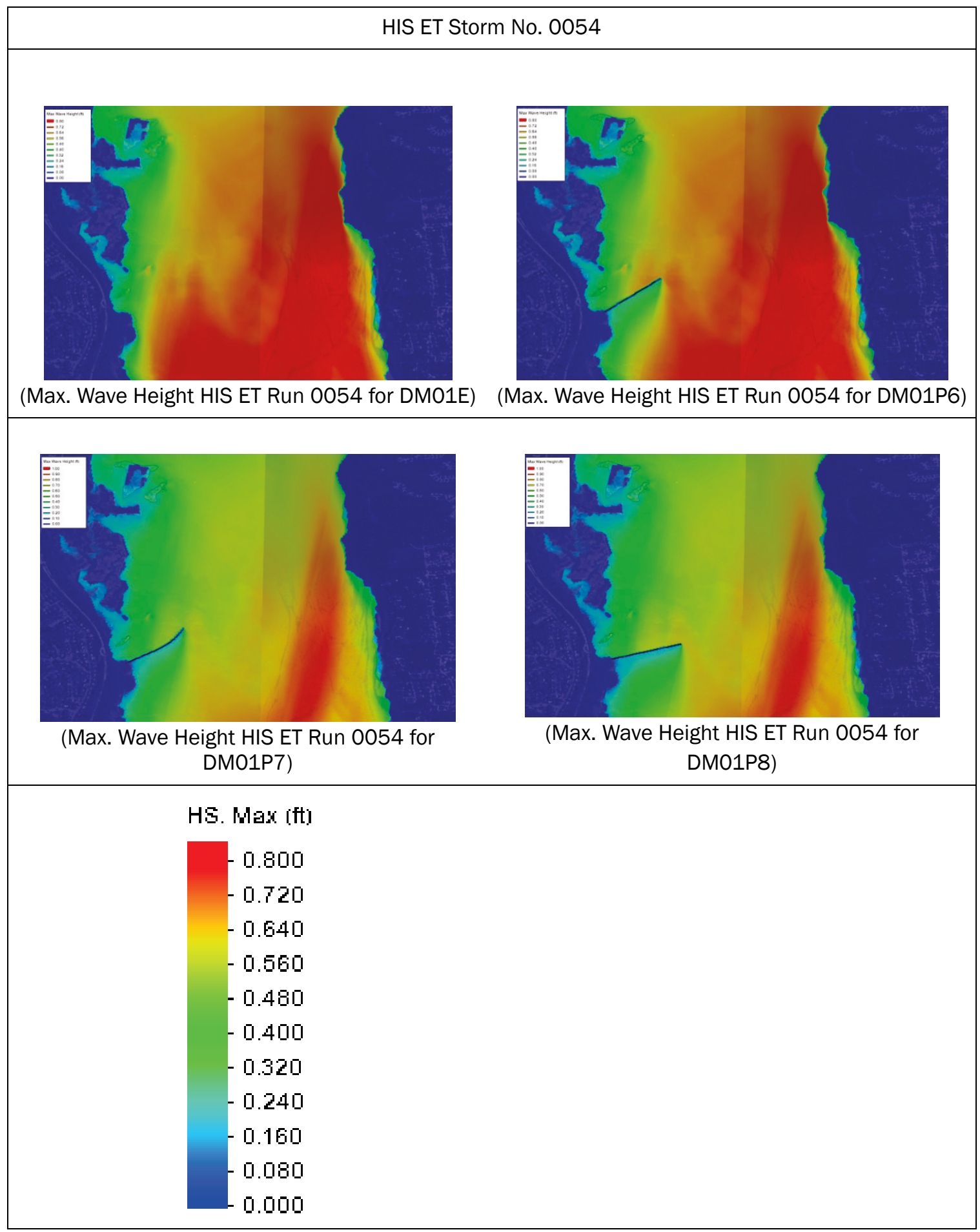


Table 5-90. Maximum significant wave height color contour plots for SYN TP Storm No. 0005 for four mesh configurations.

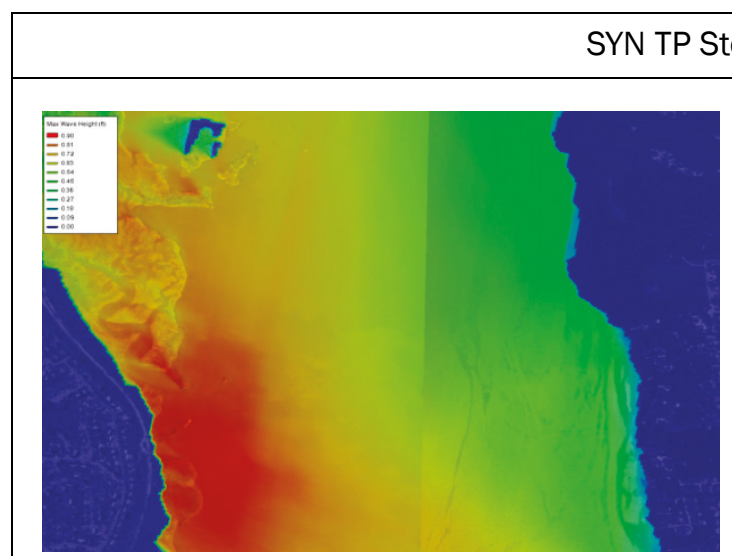

(Max. Wave Height SYN TP Run 0005 for DM01E)

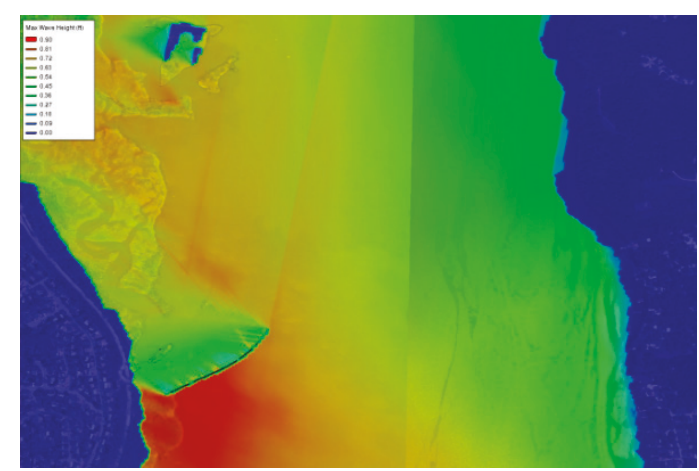

(Max. Wave Height SYN TP Run 0005 for DM01P7)

HS. Max (ft)

0.900

0.810

$-0.720$

$-0.630$

0.540

$-0.450$

$-0.360$

$-0.270$

$-0.180$

0.090

0.000

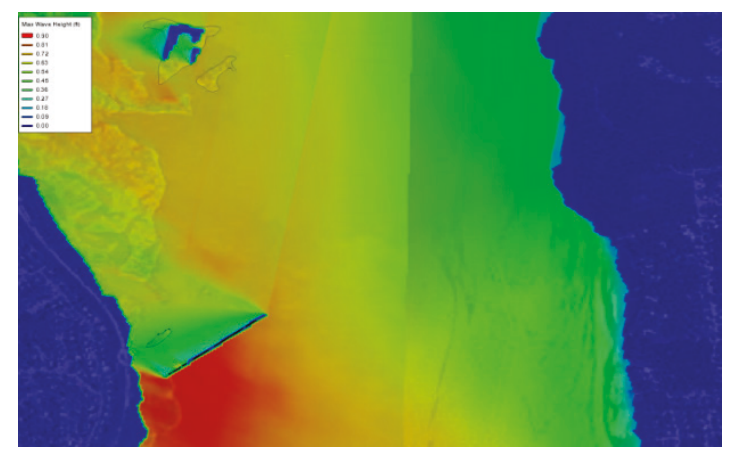

(Max. Wave Height SYN TP Run 0005 for DM01P6)

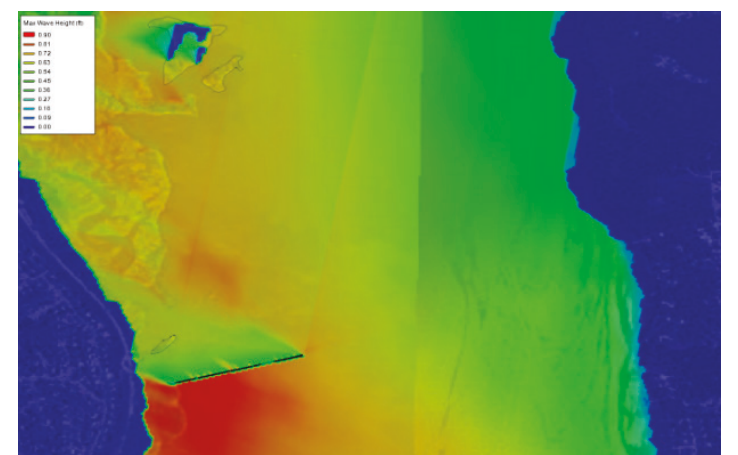

(Max. Wave Height SYN TP Run 0005 for DM01P8) 
Table 5-91. Maximum significant wave height color contour plots for SYN TP Storm No. 0028 for four mesh configurations.

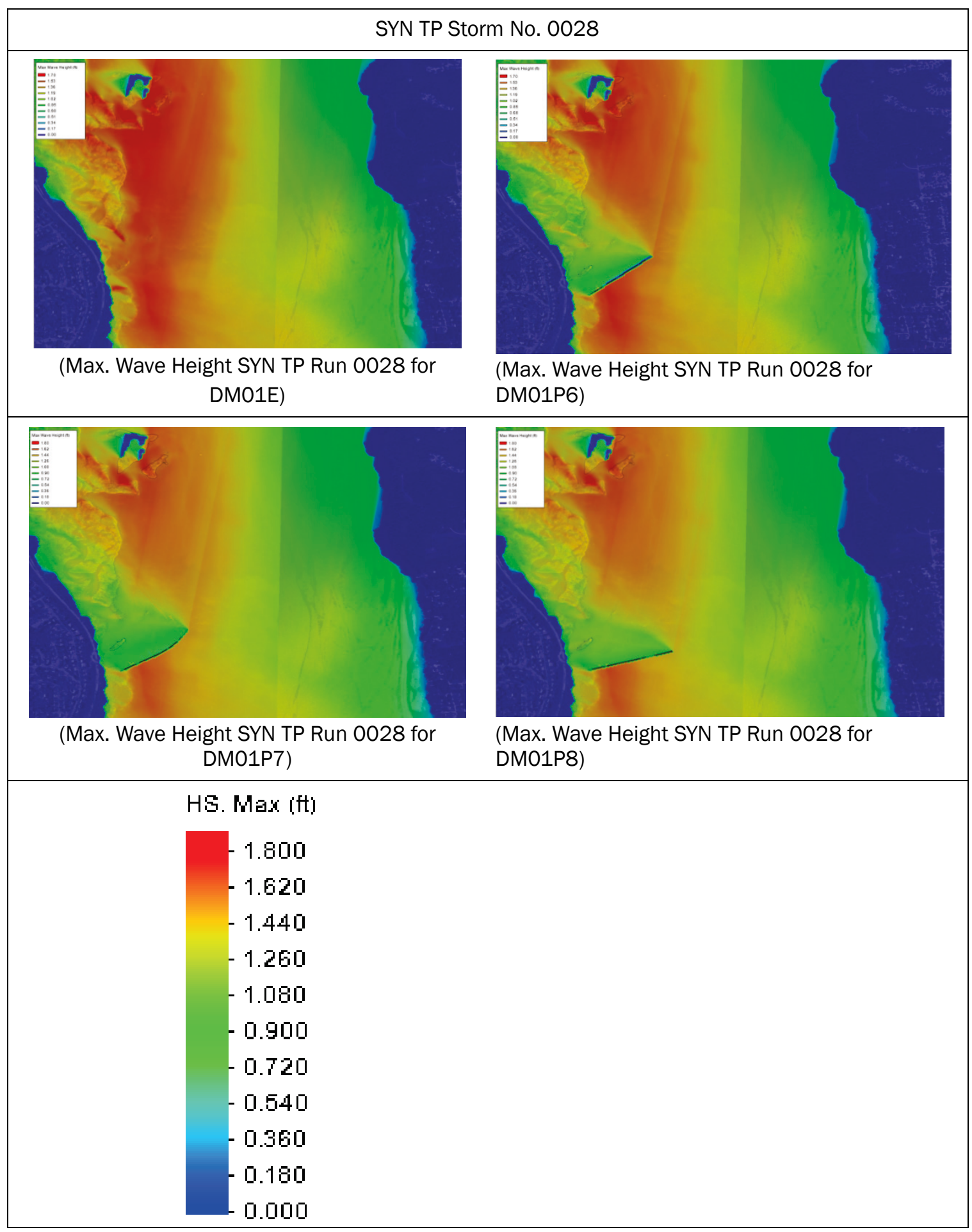


Table 5-92. Maximum significant wave height color contour plots for SYN TP Storm No. 0110 for four mesh configurations.

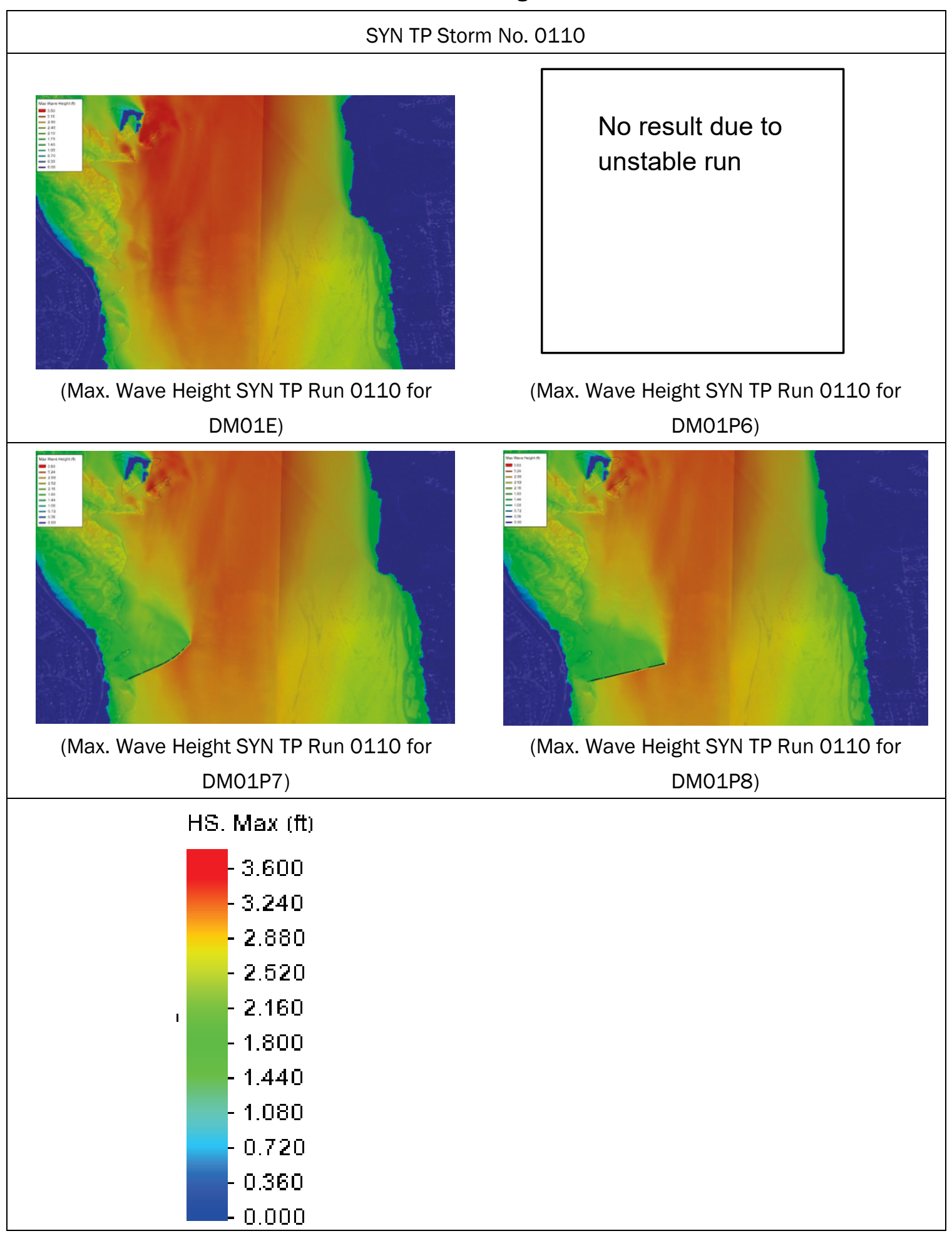


Table 5-93. Maximum significant wave height color contour plots for HIS TP Storm No. 0001 (Hurricane Sandy 2012) for four mesh configurations.

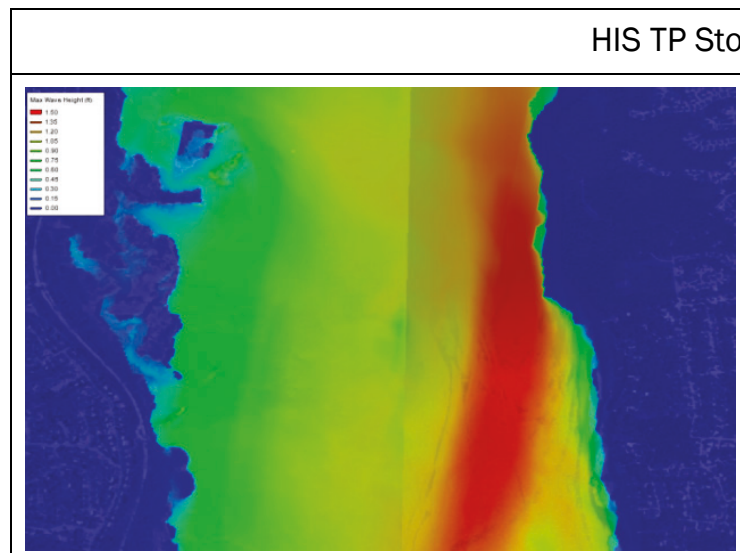

(Max. Wave Height HIS TP Run 0001 for DM01E)

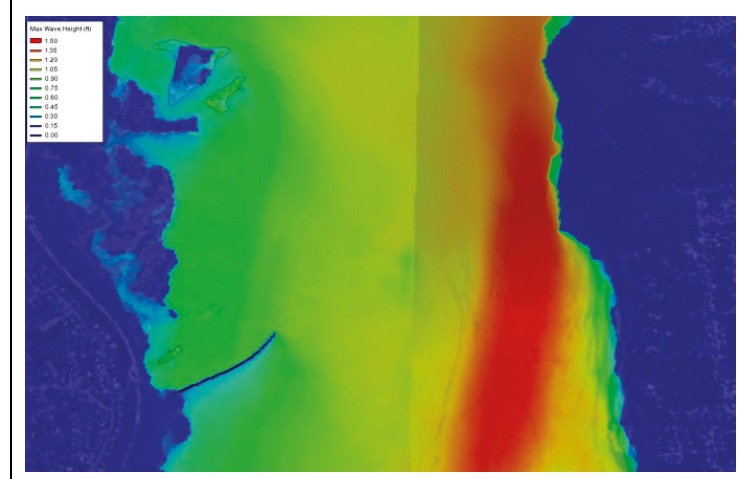

(Max. Wave Height HIS TP Run 0001 for DM01P7)

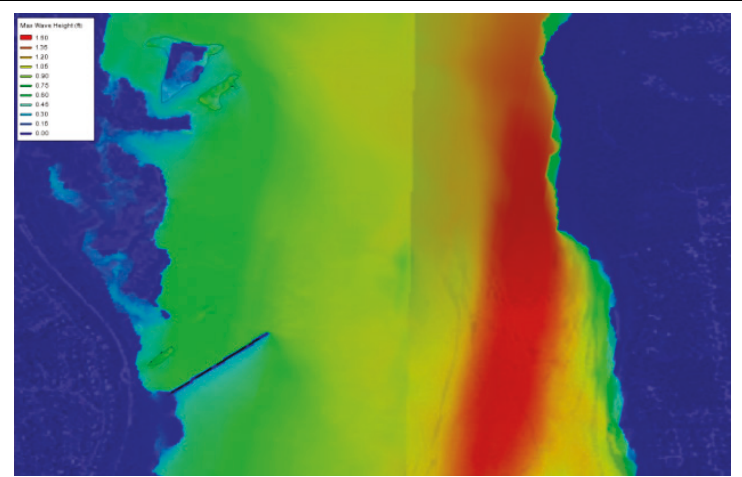

(Max. Wave Height HIS TP Run 0001 for DM01P6)

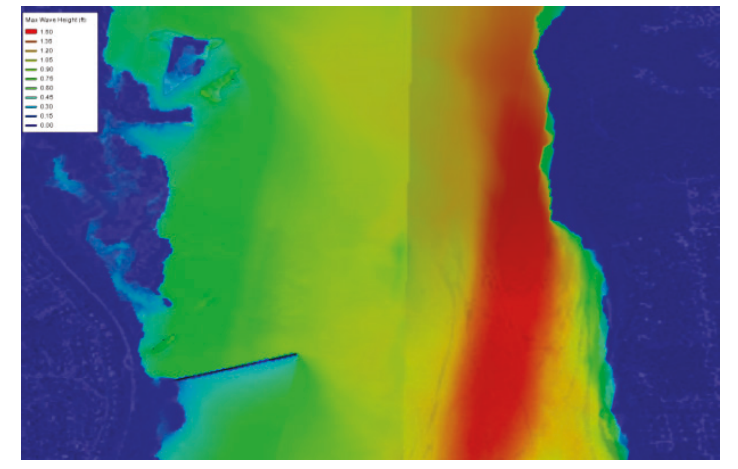

(Max. Wave Height HIS TP Run 0001 for DM01P8)

HS. Max (ft)

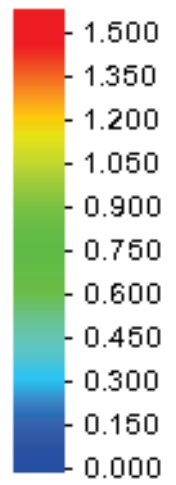


Table 5-94. Maximum significant wave height color contour plots for HIS TP Storm No. 0003 (Hurricane Isabel 2003) for four mesh configurations.

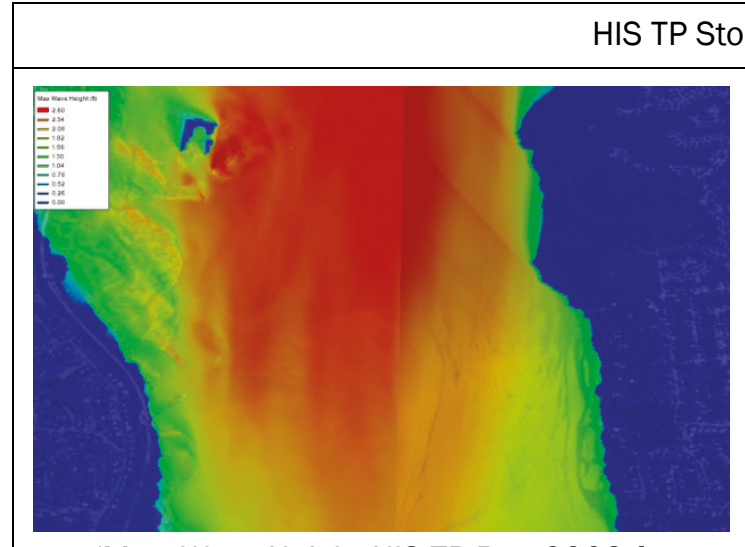

(Max. Wave Height HIS TP Run 0003 for DM01E)

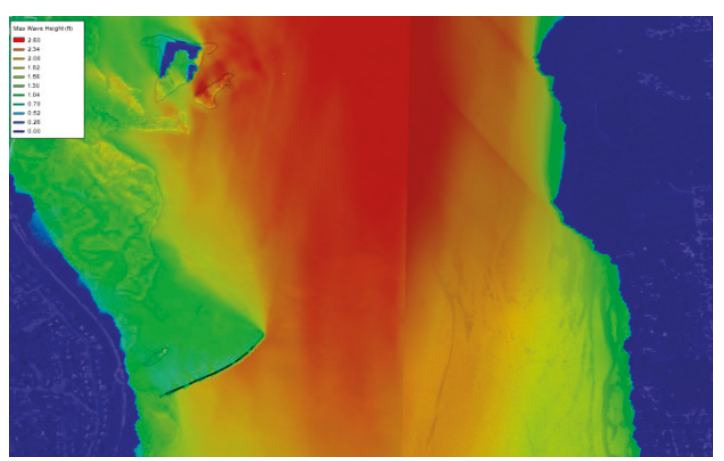

(Max. Wave Height HIS TP Run 0003 for DM01P7)

HS. Max (ft:

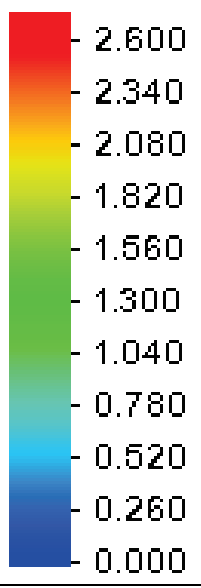

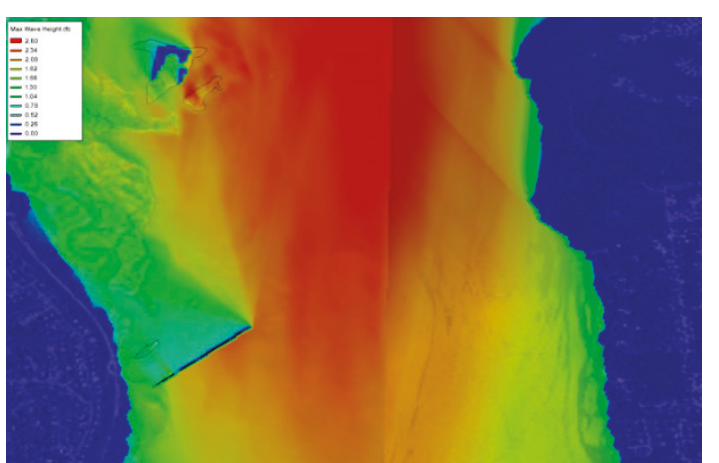

(Max. Wave Height HIS TP Run 0003 for DM01P6)

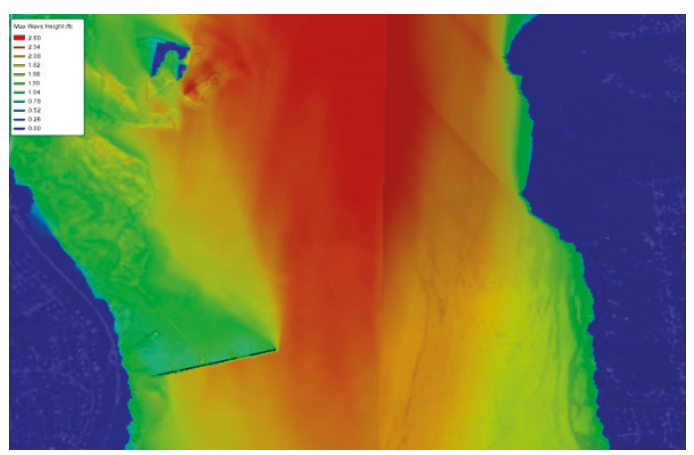

(Max. Wave Height HIS TP Run 0003 for DM01P8)

\begin{tabular}{|r|r|}
\hline HS. Max $(\mathrm{ft}:$ \\
-2.600 \\
-2.340 \\
-2.080 \\
-1.820 \\
-1.560 \\
-1.300 \\
-1.040 \\
-0.780 \\
-0.520 \\
-0.260 \\
0.000
\end{tabular}

\subsubsection{Differences in maximum significant wave height for groin-only designs}

The following figures present differences in maximum significant wave heights for the groin-only with-project designs. For each storm, the 
differences in significant wave height are visualized in two view windows: one shows an area including the structure and Dyke Marsh while another focuses on a closeup of the groin.

Table 5-95. Difference in maximum significant wave height for SYN TP Storm No. 0005 for all three with-project structure mesh configurations (Project - Existing). Note that the color axis range has been decreased to bring out differences.

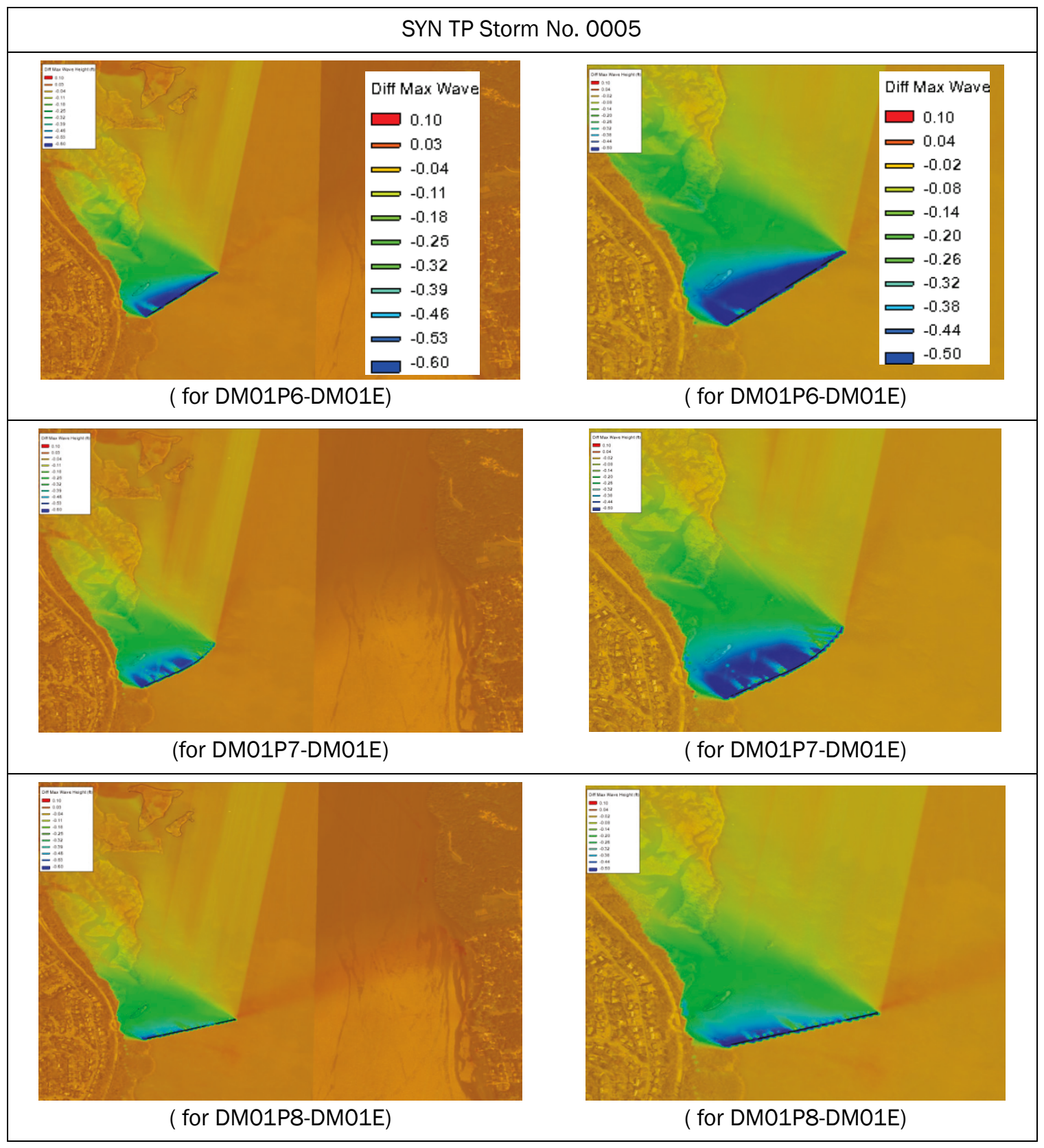


Table 5-96. Difference in maximum significant wave height for SYN TP Storm No. 0028 for all three with-project structure only mesh configurations (Project - Existing). Note that the color axis range has been decreased to bring out differences.

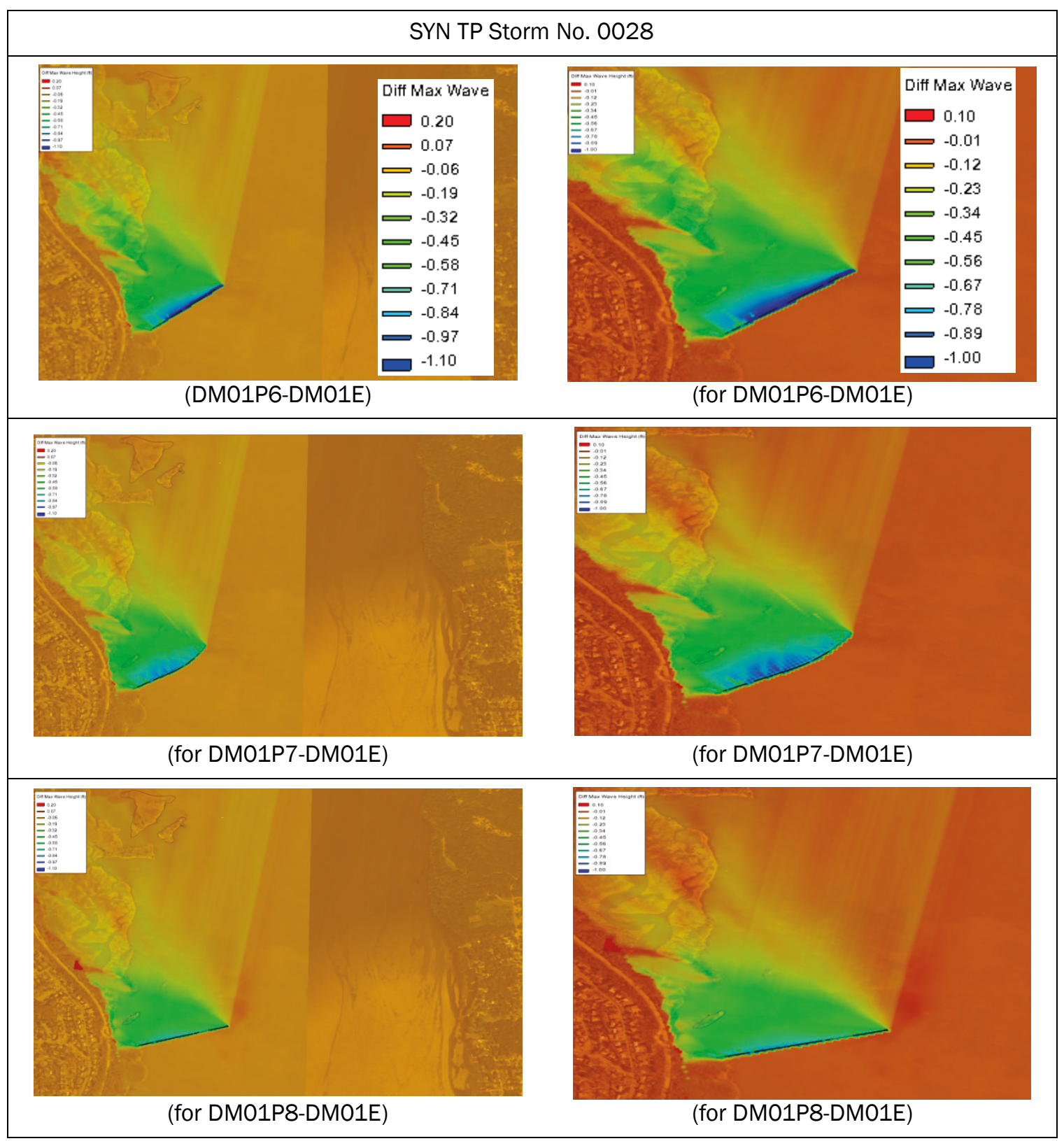


Table 5-97. Difference in maximum significant wave height for SYN TP Storm No. 0110 for all three with-project structure only mesh configurations (Project - Existing). Note that the color axis range has been decreased to bring out differences

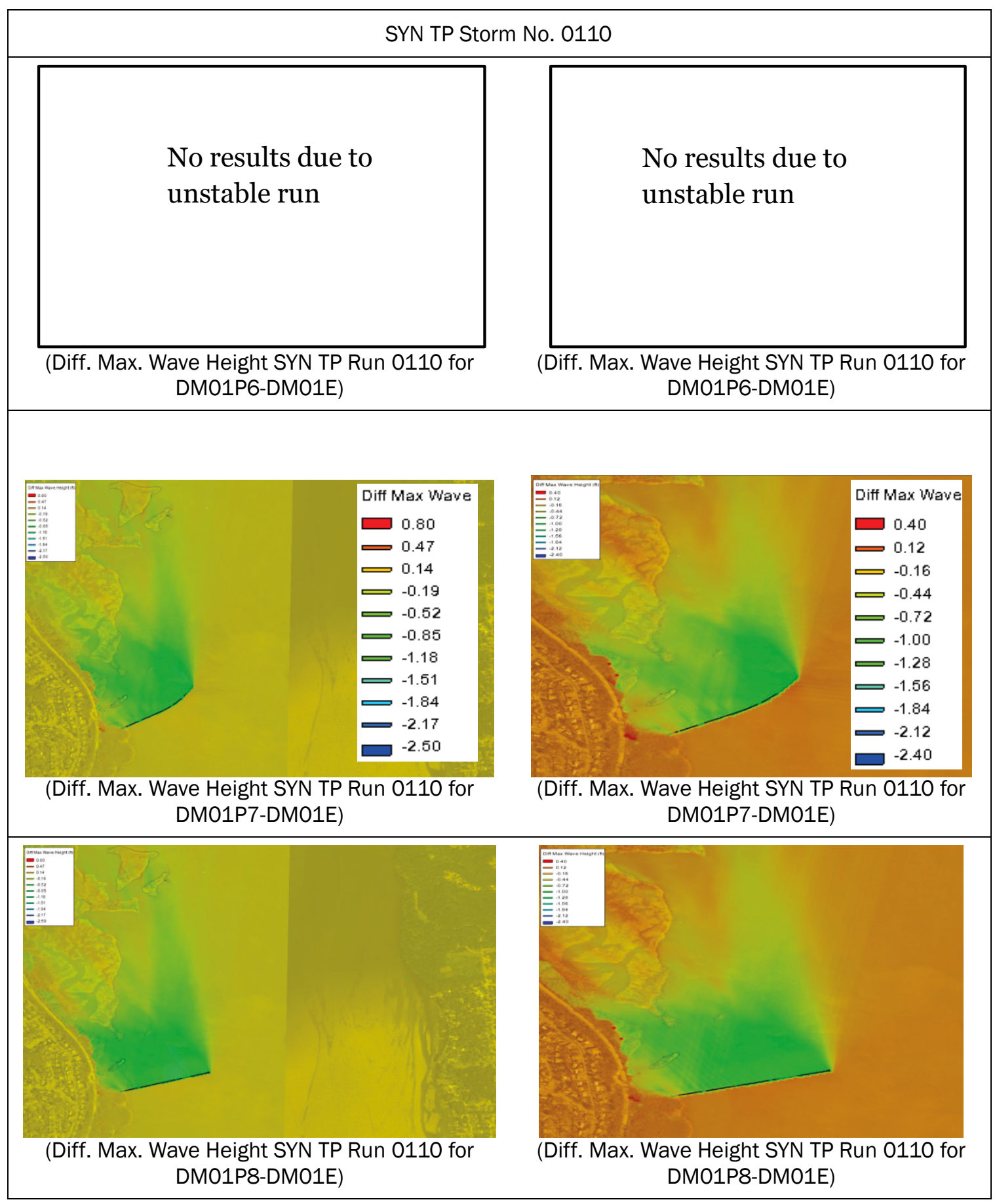


Table 5-98. Difference in maximum significant wave height for HIS ET Storm No. 0001 for all three with-project groin-only mesh configurations (Project - Existing). Note that the color axis range has been decreased to bring out details.

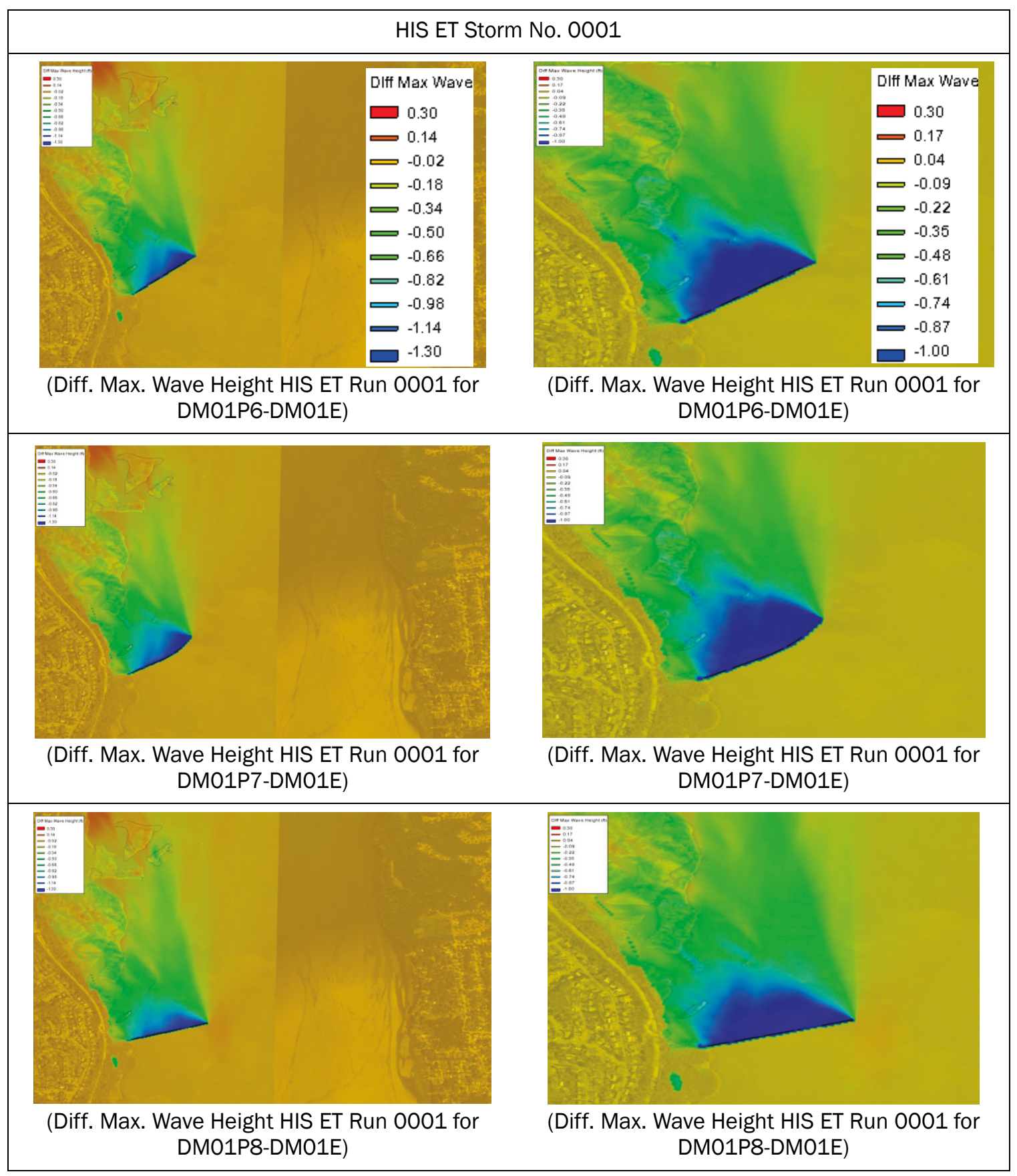


Table 5-99. Difference in maximum significant wave height for HIS ET Storm No. 0008 for all three with-project groin-only mesh configurations (Project - Existing). Note that the color axis range has been decreased to bring out details.

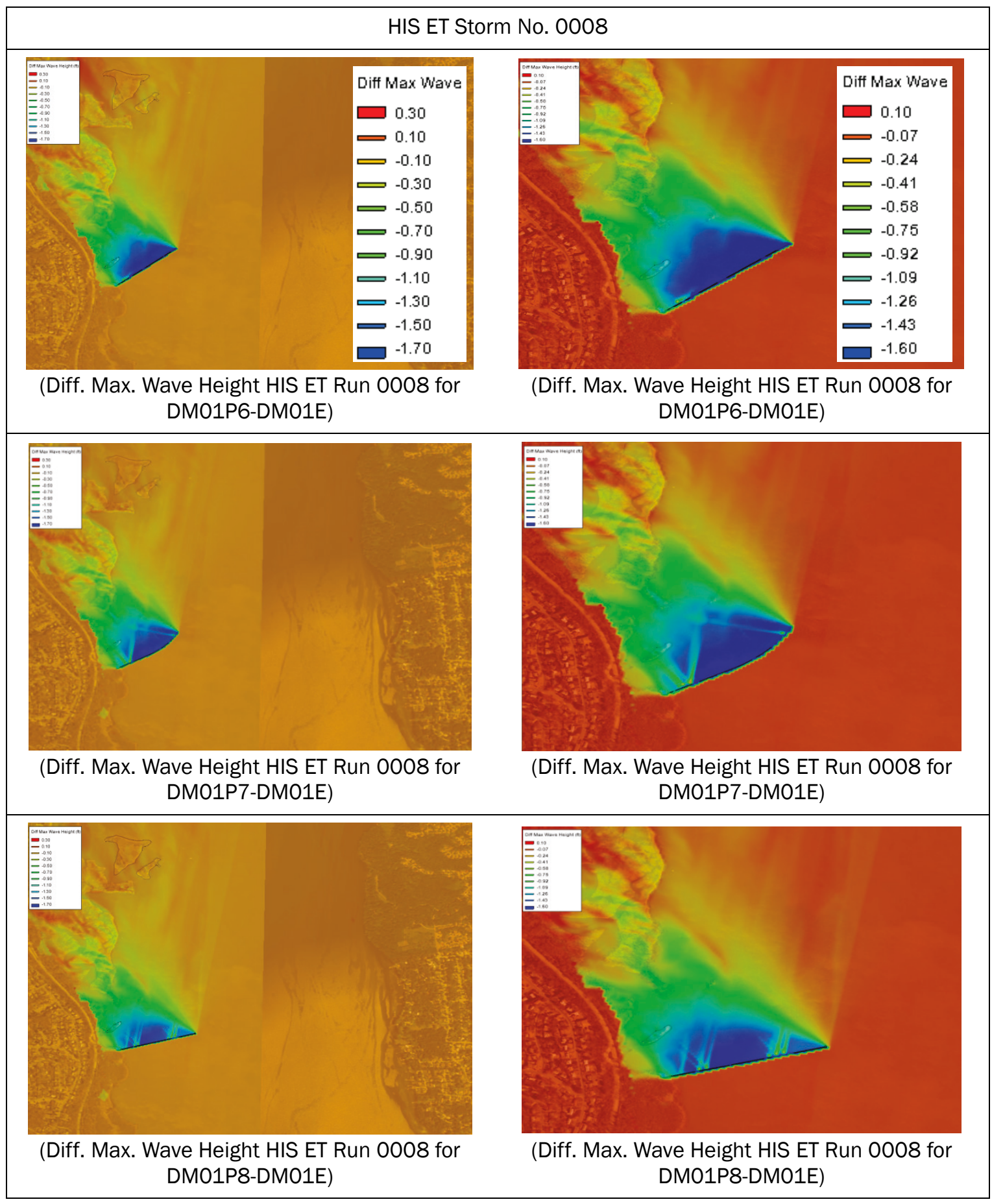


Table 5-100. Difference in maximum significant wave height for HIS ET Storm No. 0038 for all three with-project groin-only mesh configurations (Project - Existing). Note that the color axis range has been decreased to bring out details.

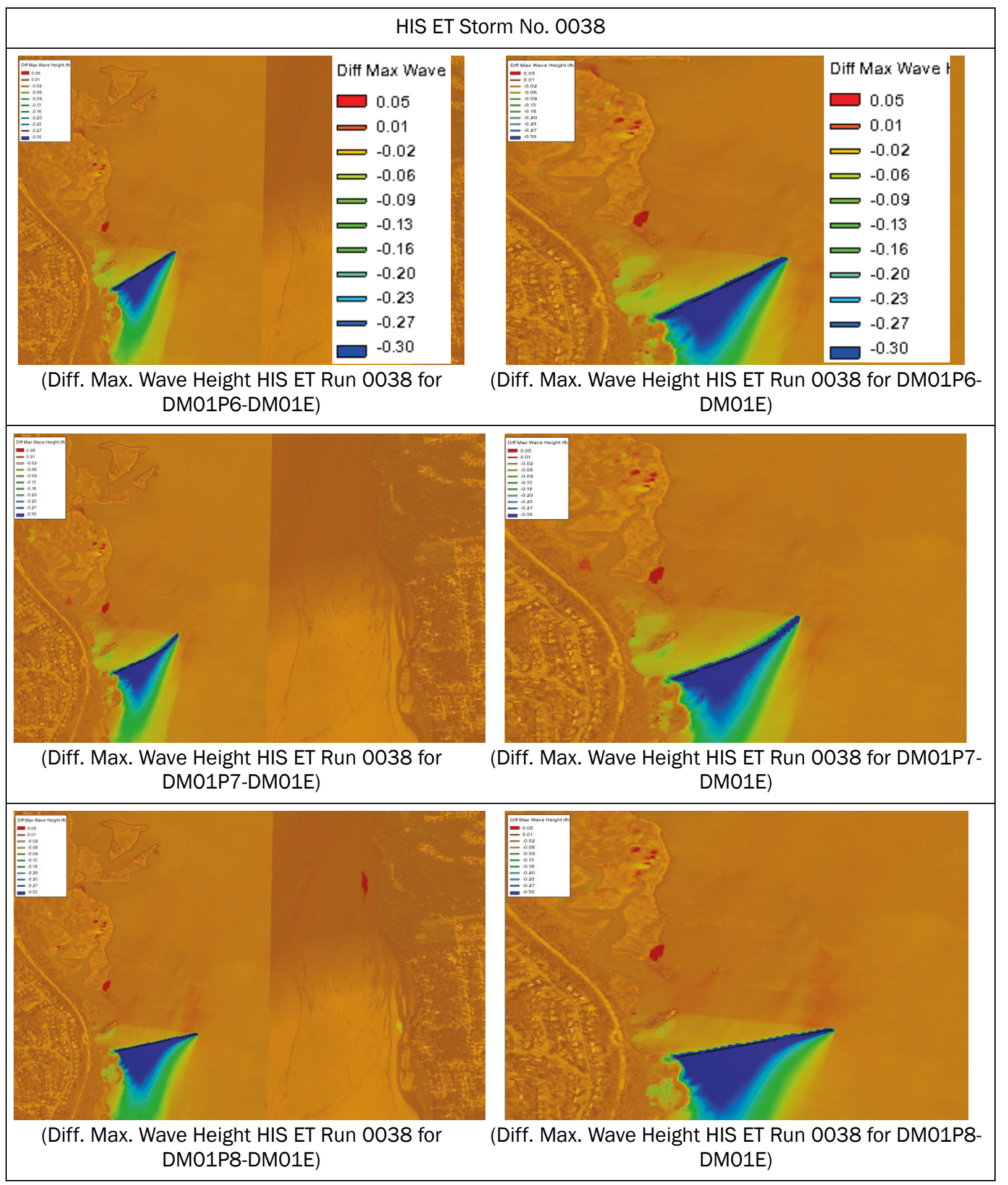


Table 5-101. Difference in maximum significant wave height for HIS ET Storm No. 0051 for all three with-project groin-only mesh configurations (Project - Existing). Note that the color axis range has been decreased to bring out details.

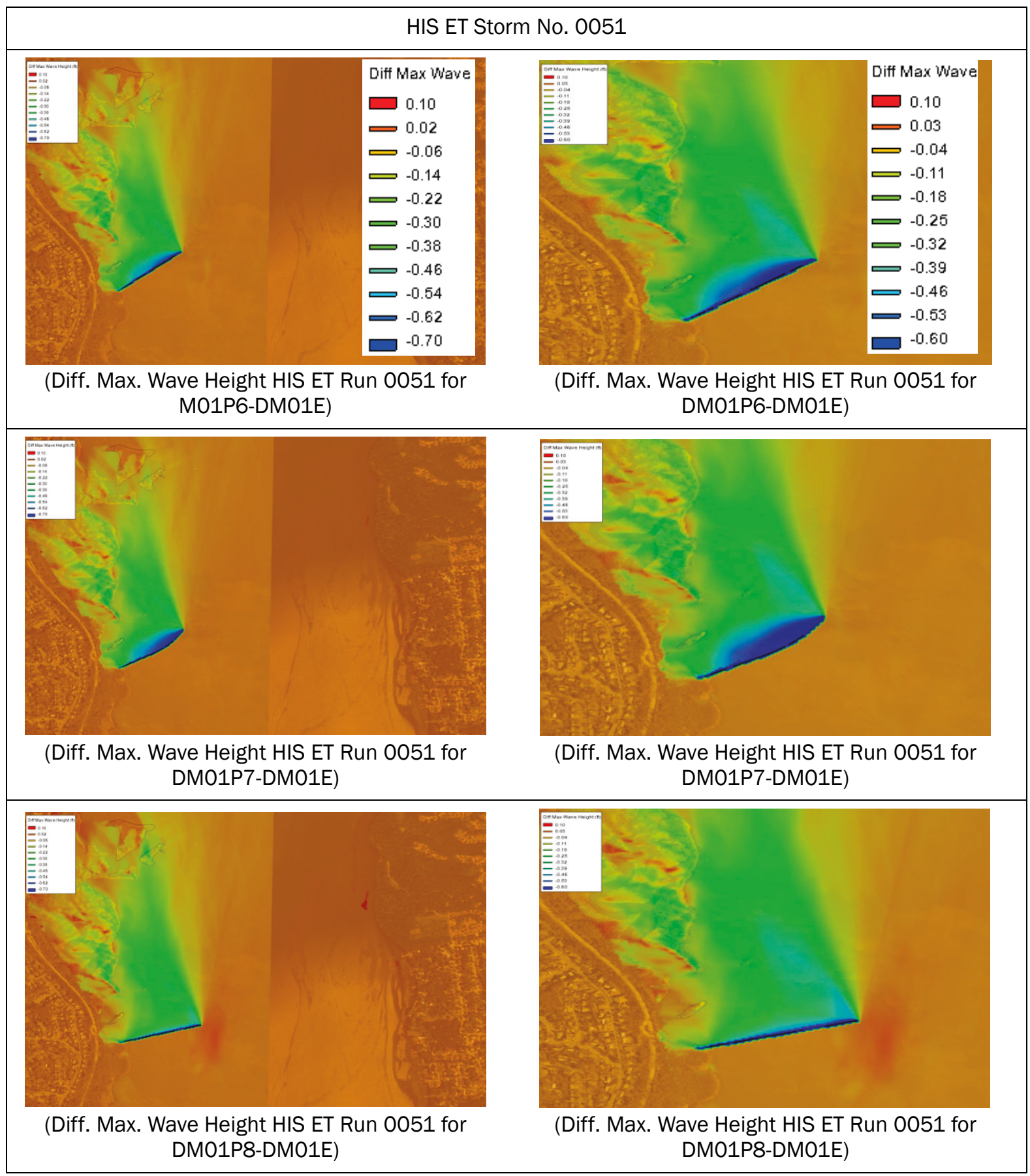


Table 5-102. Difference in maximum significant wave height for HIS ET Storm No. 0054 for all three with-project groin-only mesh configurations (Project - Existing). Note that the color axis range has been decreased to bring out details.

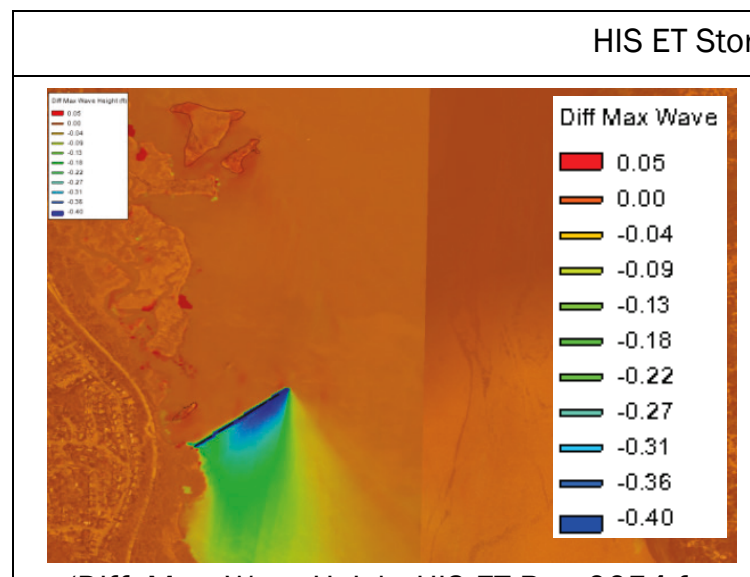

(Diff. Max. Wave Height HIS ET Run 0054 for DM01P6-DM01E)

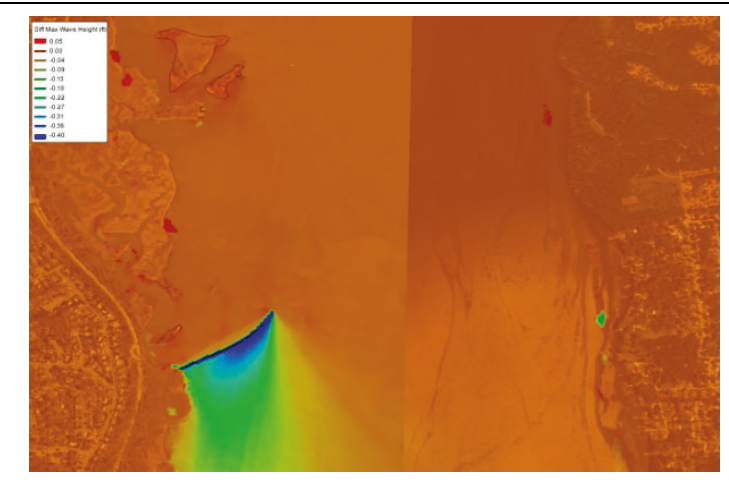

(Diff. Max. Wave Height HIS ET Run 0054 for DM01P7-DM01E)

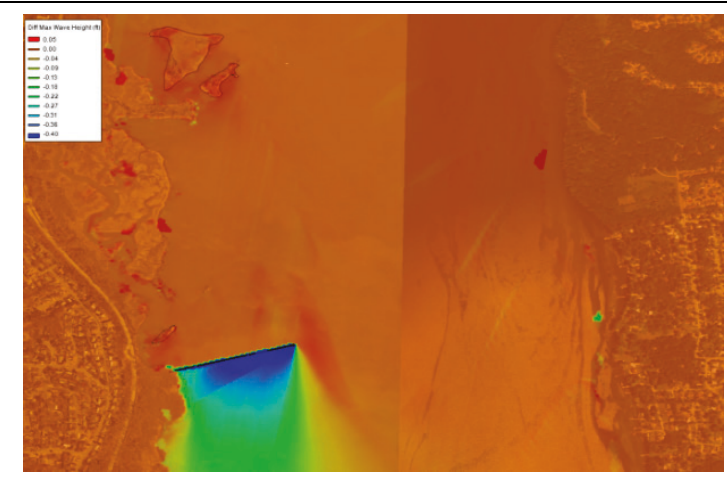

(Diff. Max. Wave Height HIS ET Run 0054 for DM01P8-DM01E)

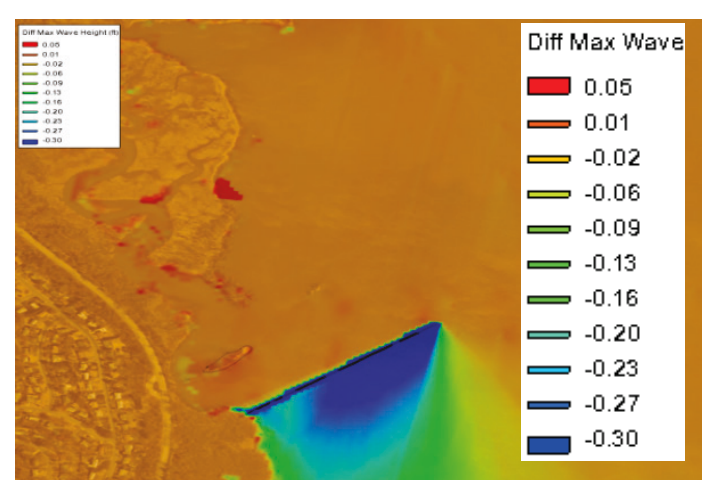

(Diff. Max. Wave Height HIS ET Run 0054 for DM01P6-DM01E)

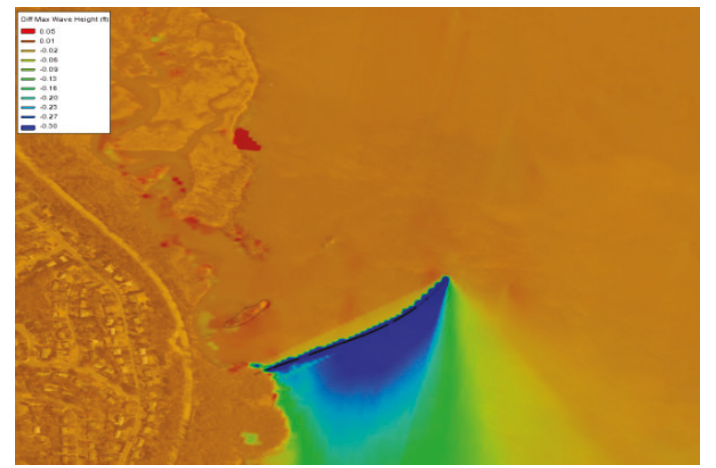

(Diff. Max. Wave Height HIS ET Run 0054 for DM01P7-DM01E)

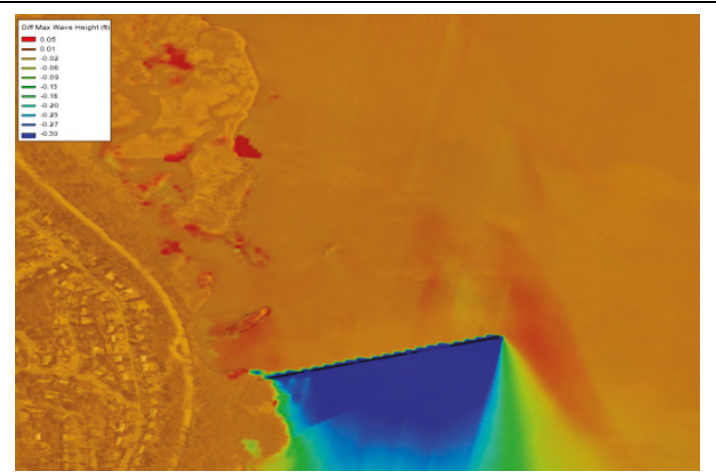

(Diff. Max. Wave Height HIS ET Run 0054 for DM01P8-DM01E) 
Table 5-103. Difference in maximum significant wave height for HIS TP Storm No. 0001 (Hurricane Sandy 2012) for all three with-project groin-only mesh configurations (Project Existing). Note that the color axis range has been decreased to bring out details

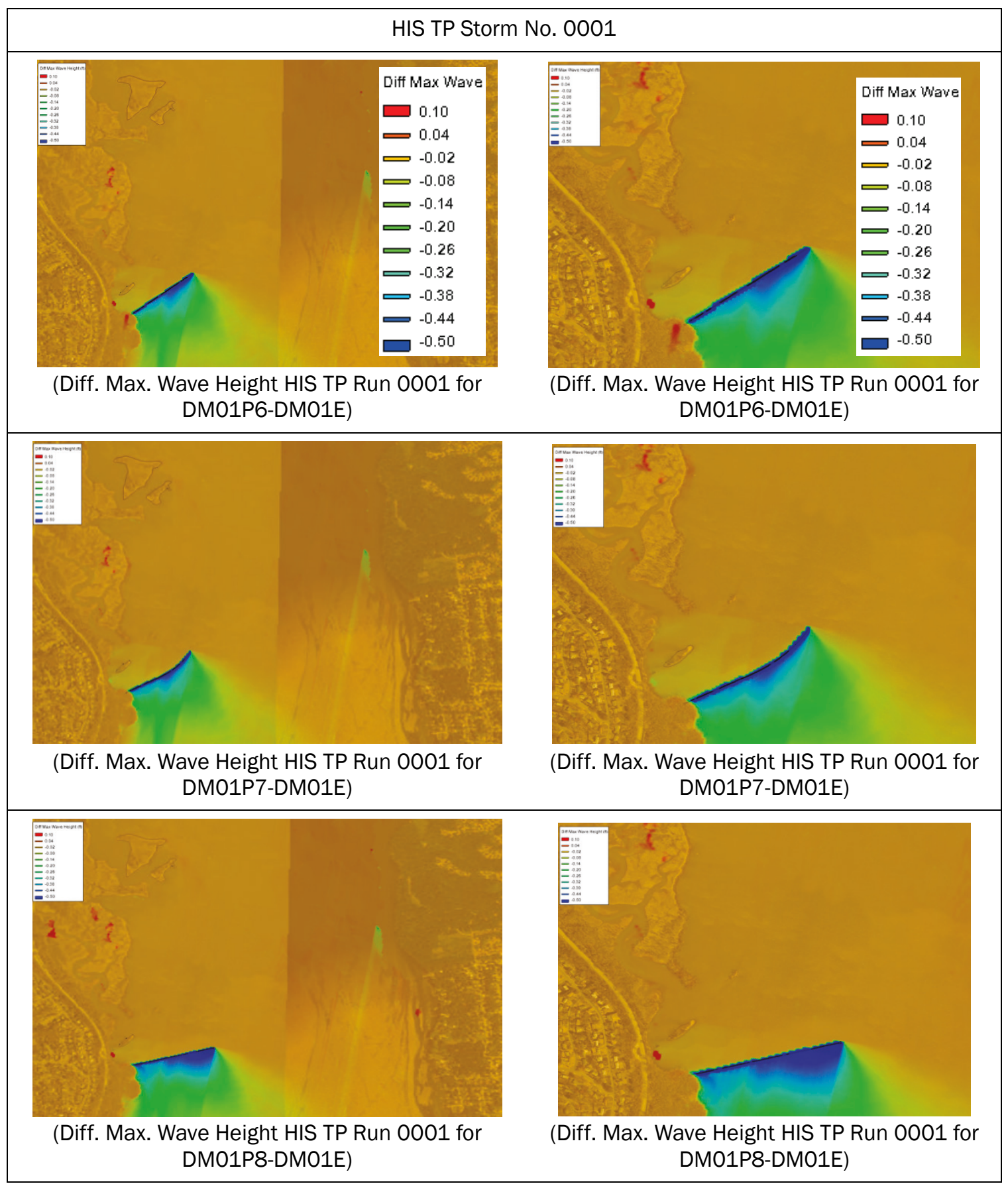


Table 5-104. Difference in maximum significant wave height for HIS TP Storm No. 0003 (Hurricane Isabel 2003) for all three with-project groin-only mesh configurations (Project Existing). Note that the color axis range has been decreased to bring out details.

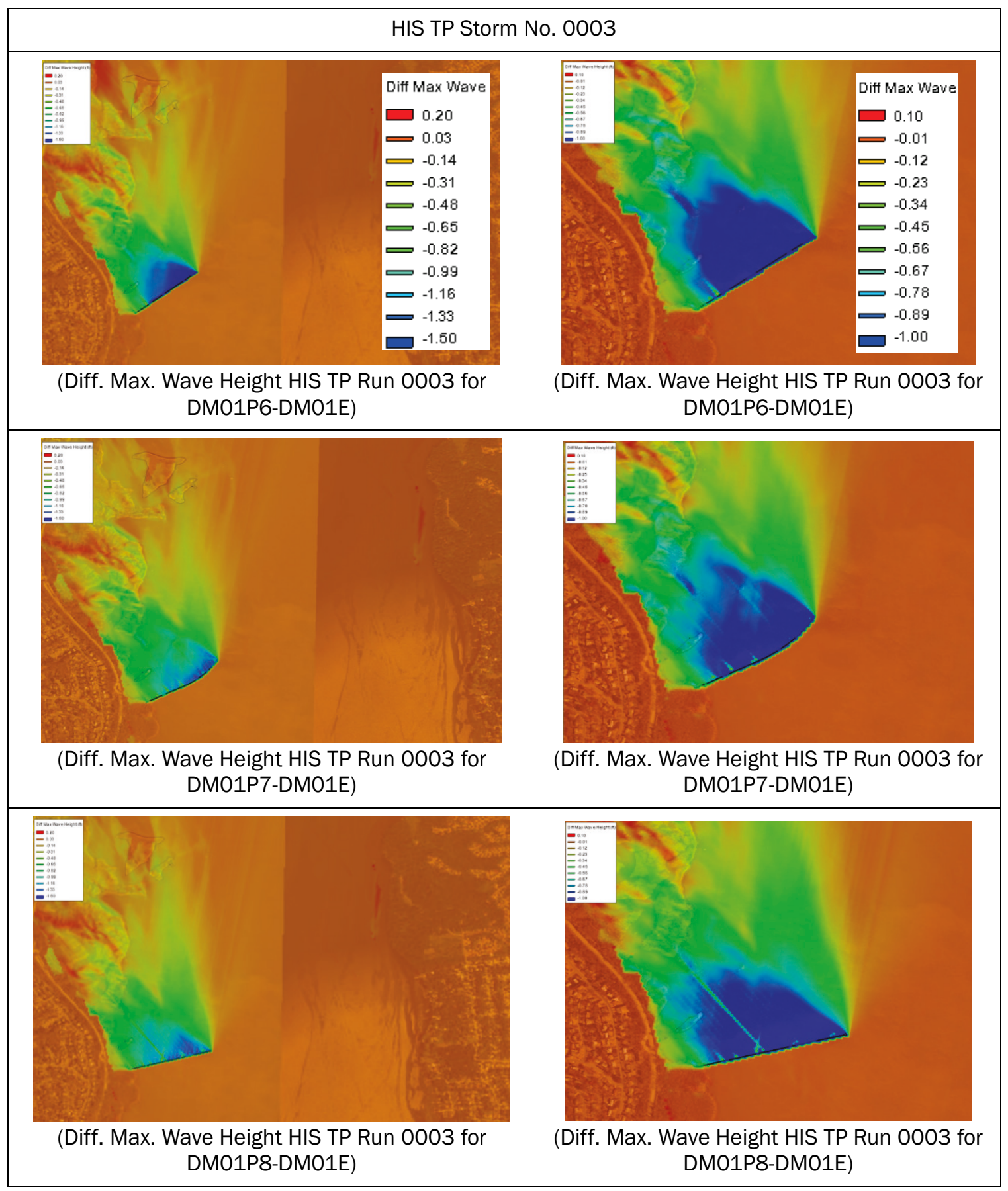




\subsubsection{Time series of hydrodynamic variables and maximum wave heights at selected locations for groin only designs}

The time series of hydrodynamic variables (water level and wave height) at the 18 observation locations were used to investigate the time-dependent variations of the hydrodynamic variables throughout the period of the storms for the groin-only with-project designs. The 18 selected observation stations, as shown in Figure 5-45, are located at the same points as those for the study of the promontory designs marked in Figure 5-4 and Figure 5-5.

By way of examples, results for two of the HIS ET storms, Storms No. 0001 and 0oo8, are shown in Figure 5-46 and Figure 5-47, which present the time series plots for significant wave heights, water levels, and wind speeds at Stn 4 and Stn 6, which are close to the shore of Dyke Marsh. All the groins effectively lower wave heights in the area in the lee of the structures. Since the wind direction in tropical cyclones is rotating, the protected area continually changes as the winds rotate. To quantify the effectiveness of the structures, Table 5-105 provides the values of the differences in wave heights and the percent reduction from those under the current conditions (DMo1E). The wave height reduction $(\eta)$ is calculated by Equation (1).

It is found that all three groins significantly reduce the wave heights (by more than 30\%) at Stns 3, 4, 5, 10, and 11, and by approximately $10 \%$ at Stns 6, 7, and 9. For this storm, none of the groins significantly influence wave fields downstream of the structures and along the eastern bank. The only exception is at Stn 2, which shows that the groin Alt 3 (DMo1P8) reduces water height by approximately 30\% but also increases velocities. The water levels (including storm surges) show no significant change.

For other historical extratropical storms, the tables of maximum wave height values and reduction percentages are given in Table 5-106 through Table 5-109. The performance of the three groins in HIS ET Storms No. 0008 and 0051 is similar to that in HIS ET Storm No. 0001. All the three groin projects show no significant impact from Storms No. 0038 and 0054 on the areas of the Dyke Marsh and the nearshore region of the eastern bank. But the with-project groins all reduce wave energy at Stns 1 and 12 on the side downstream of the structures as the stronger sustained wind blows from the north as the storms make landfall to the east of the Dyke Marsh.

In Figure 5-48, time series of wave heights, water levels, and wind speed at Stns 4 and 6 are shown for HIS TP Storm No. 0001 (Hurricane Sandy 
2012). There is almost no difference between the results under all four conditions (the no-structure and three groins). The values listed in Table 5-110 also confirm these results of no effect at other stations. Similar to HIS ET Storms No. 0038 and 0054, HIS TP Storm No. 0001 reduces wave heights for the area downstream. For HIS TP Storm No. 0003 (Hurricane Isabel 2003), the groins behave similarly to how they do for the HIS ET storms (No. 0001, 0008, and 0051). But the efficiency (wave reduction rate), see Table $5-111$, for this storm is lower than that for HIS TP Storms No. 0001 and No. 0008.

Simulation results of storm surges and waves by three SYN TP storms (No. 0005, 0028, and 0110) are reported: as shown in Figure 5-49, a typical 20-year ARI synthetic storm (No. 0028) has a long period for building up to the peak of the storm. The simulation captures the peak of the storm and its decay after landfall. The values of the differences in waves for the three tropical synthetic storms are provided in Table 5-112 for Storm No. 0005, Table 5-113 for Storm No. 0028, and Table 5-114 for Storm No. 0110, respectively. Those tables show that all the structures decrease wave energy on the leeward side, but the wave height reductions at most stations are less than $30 \%$.

Figure 5-45. The 18 selected locations.

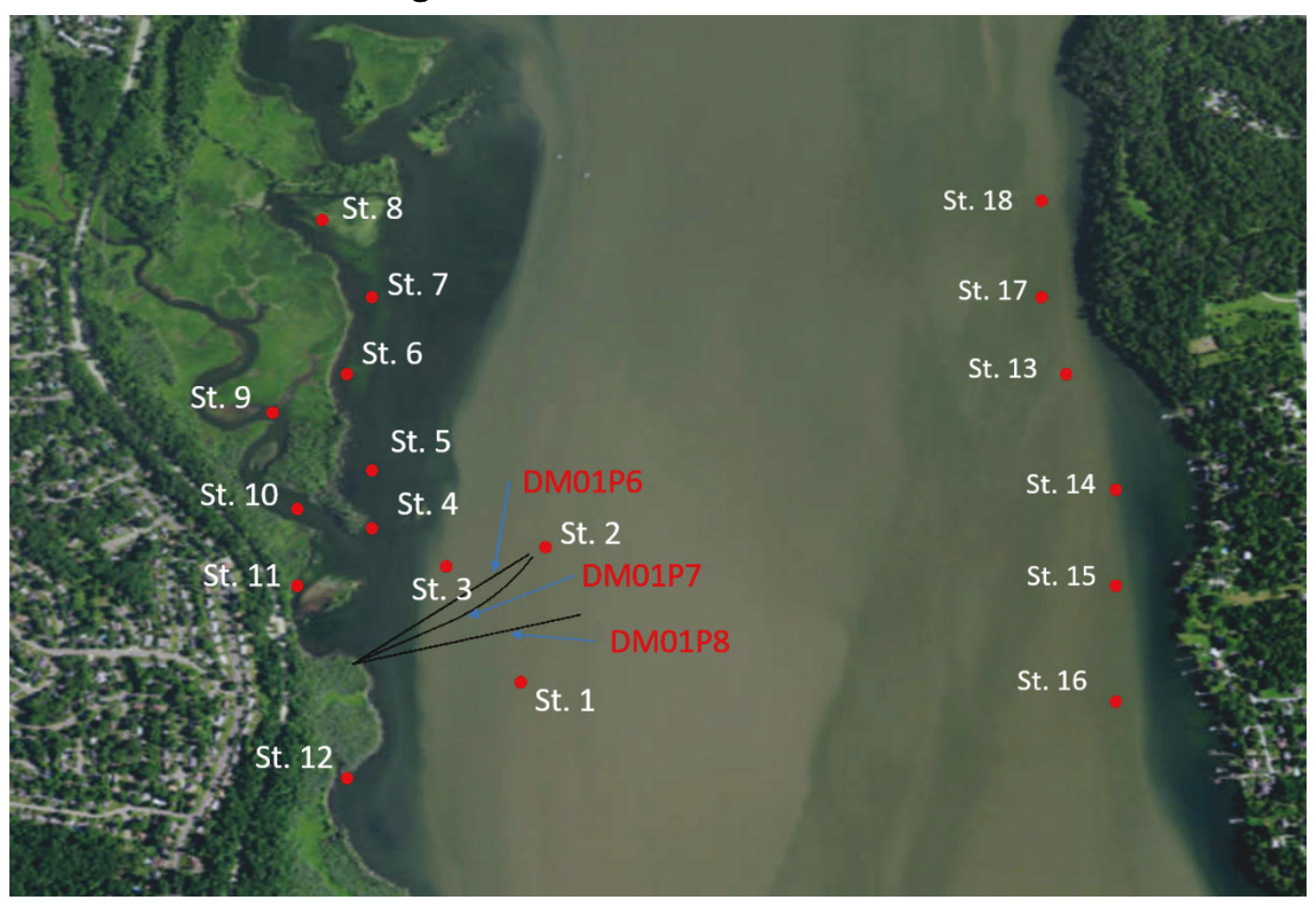


Figure 5-46. Time series of significant wave height $(a, b)$, water level (c, d), and wind speed $(e, f)$ at Stns 4 and 6 for HIS ET Storm No. 0001.

(a) Hs (ft) at Stn 4

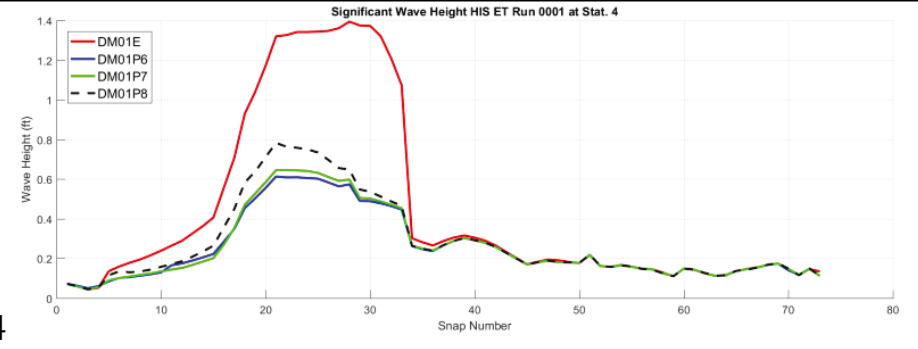

(b) Hs (ft) at Stn 6

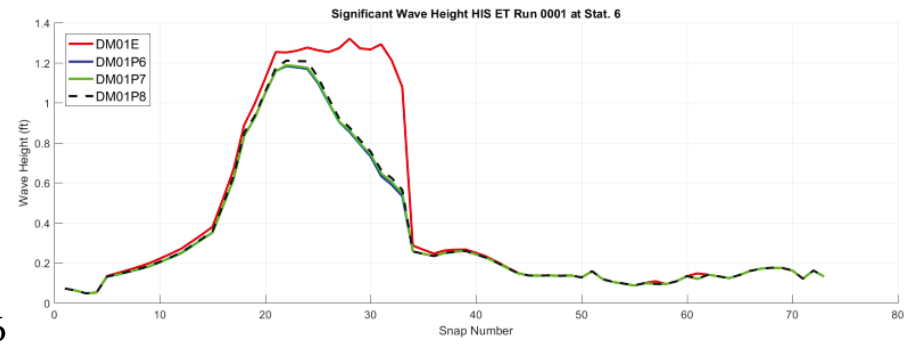

(c) Water Level (ft) at Stn 4

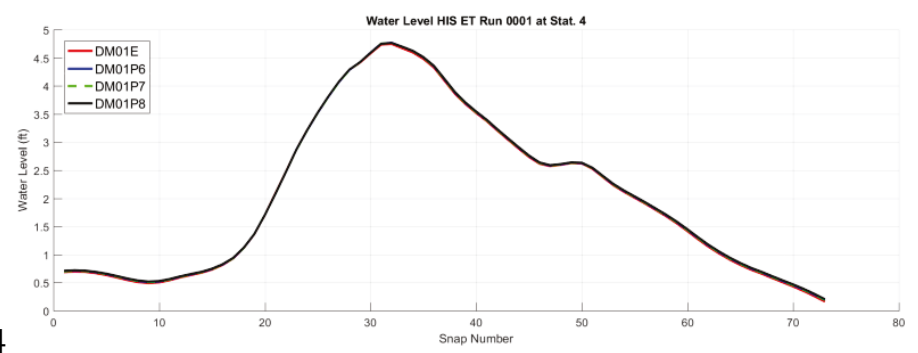

(d) Water Level (ft) at Stn 6

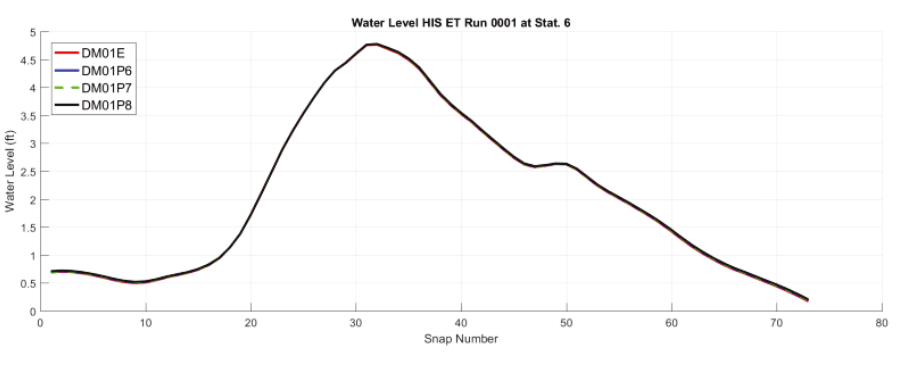

(e) Wind Speed (mph) at Stn 4

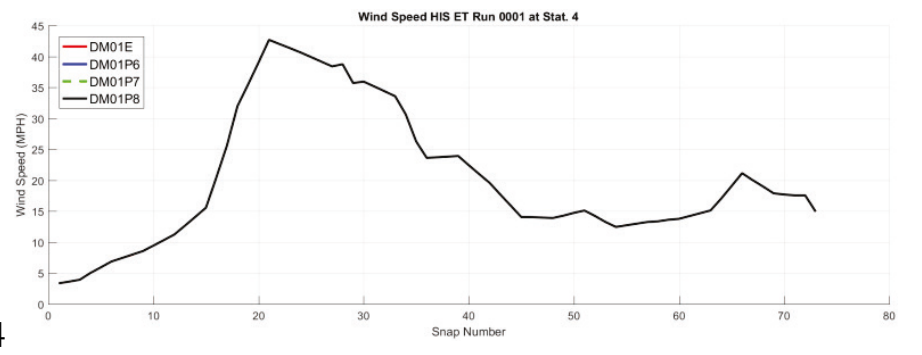

(f) Wind Speed (mph) at Stn 6

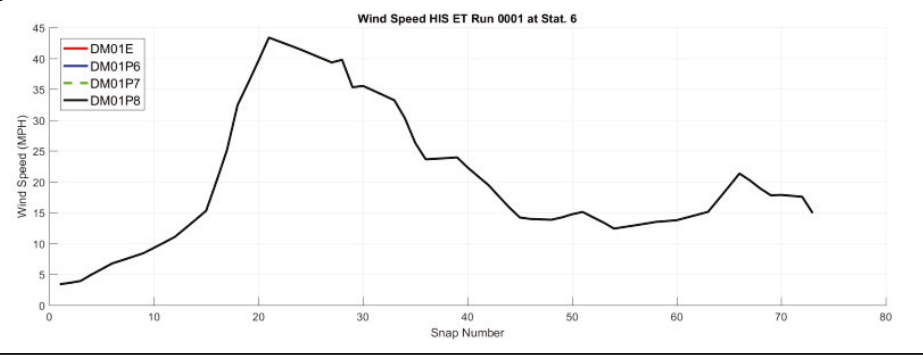


Figure 5-47. Time series of significant wave height (a,b), water level (c, d), and wind speed (e, f) at Stns 4 and 6 for HIS ET Storm No. 0008.

(a) Stn 4

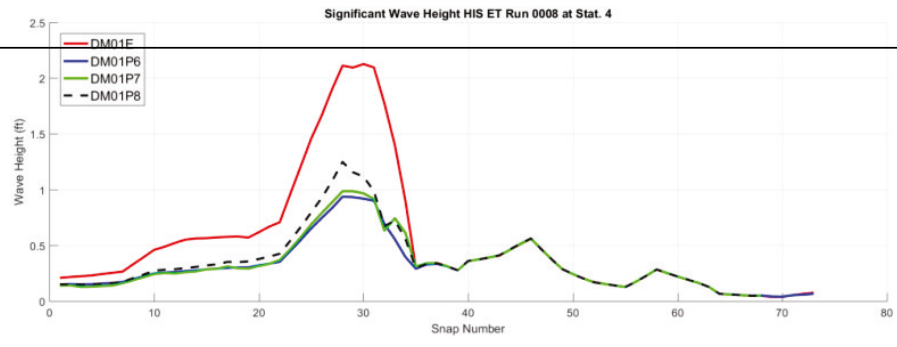

(b) Stn 6

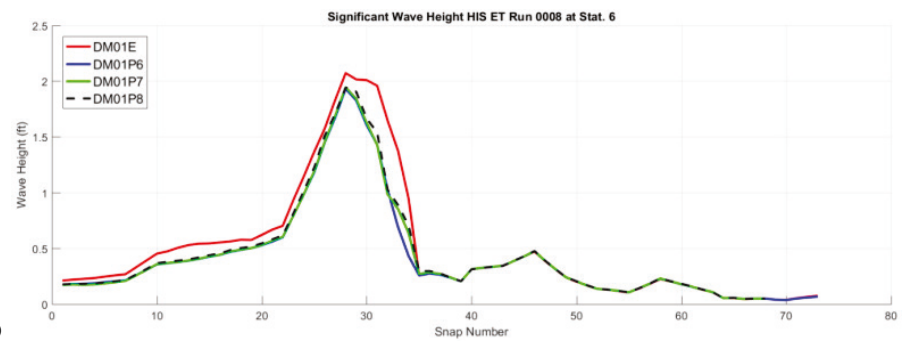

(c) Stn 4

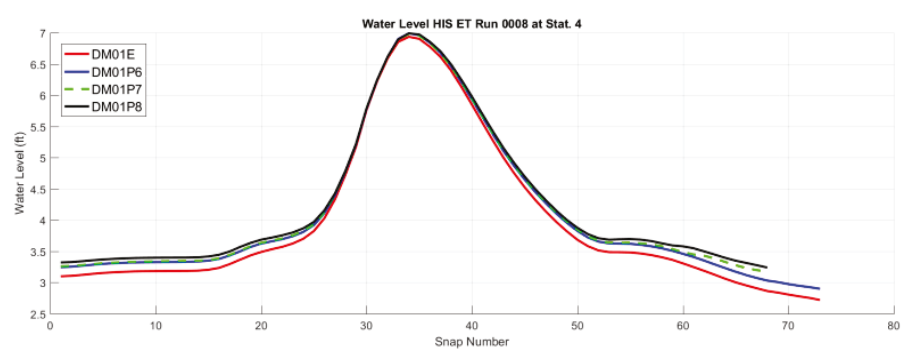

(d) Stn 6

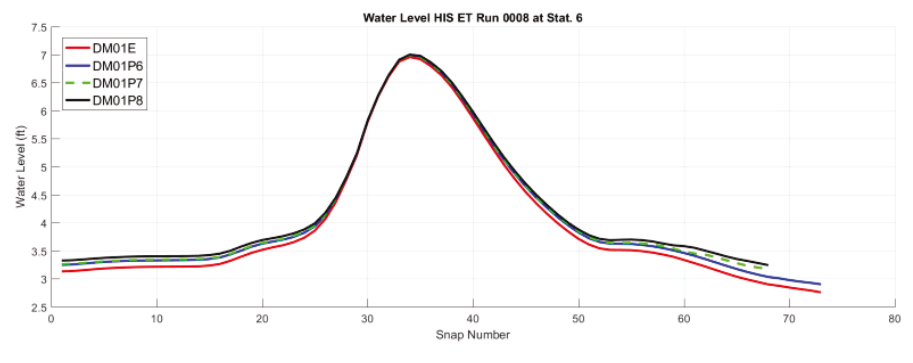

(e) Stn 4

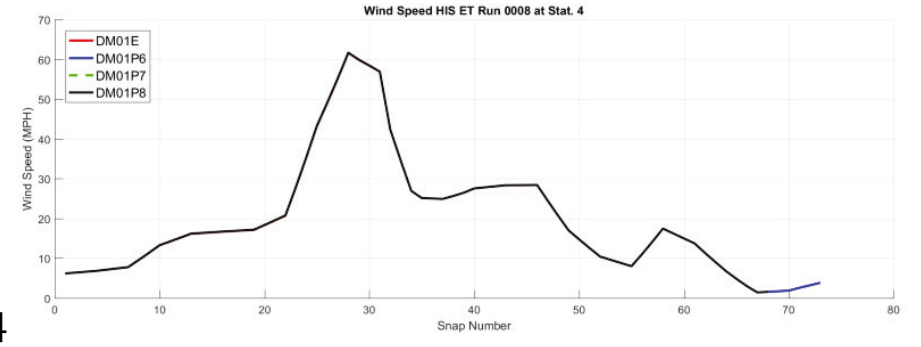

(f) $\operatorname{Stn} 6$

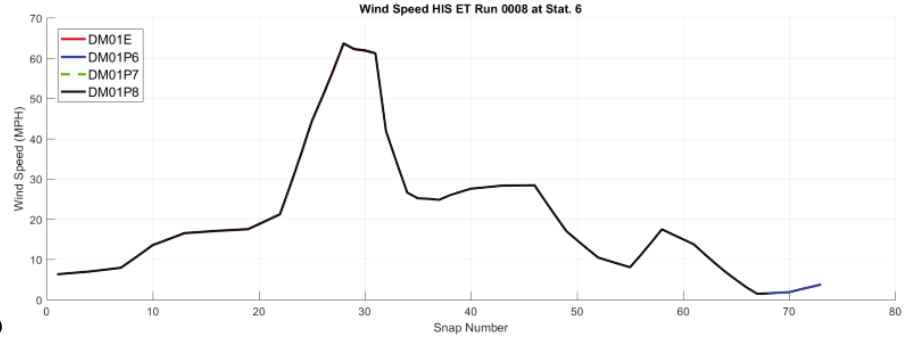


Figure 5-48. Time series of significant wave height $(a, b)$, water level (c, d), and wind speed (e, f) at Stns 4 and 6 for HIS TP Storm No. 0001 (Hurricane Sandy 2012).

(a) Stn 4

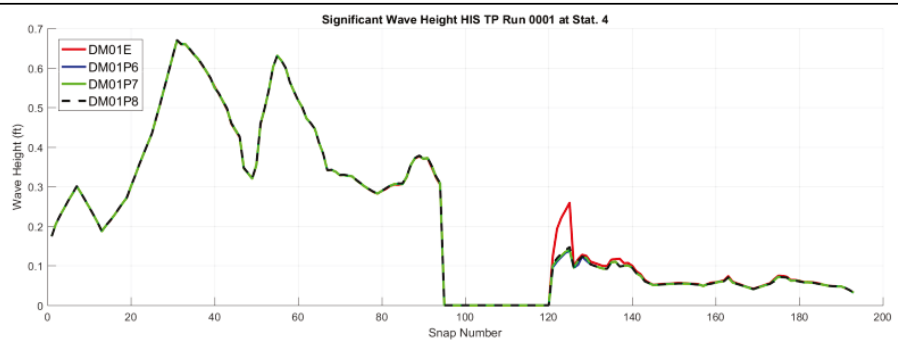

(b) Stn 6

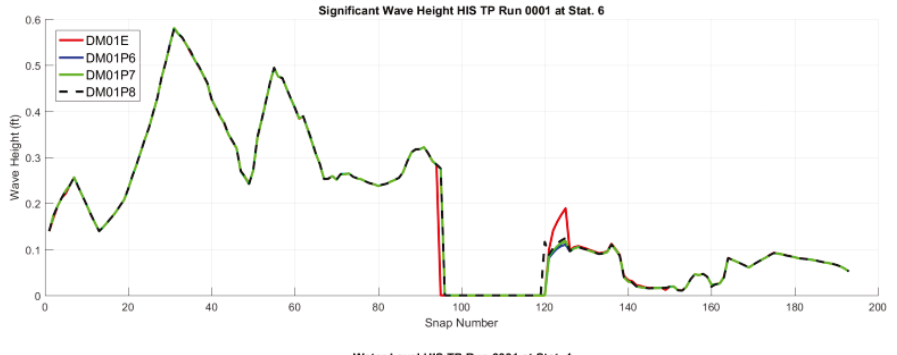

(c) Stn 4

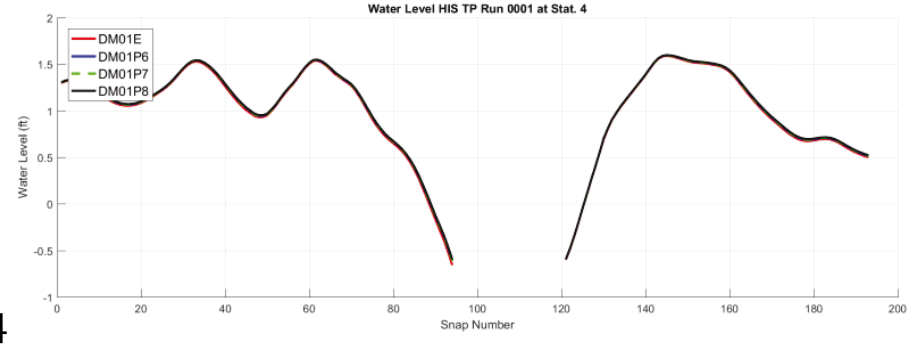

(d) Stn 6

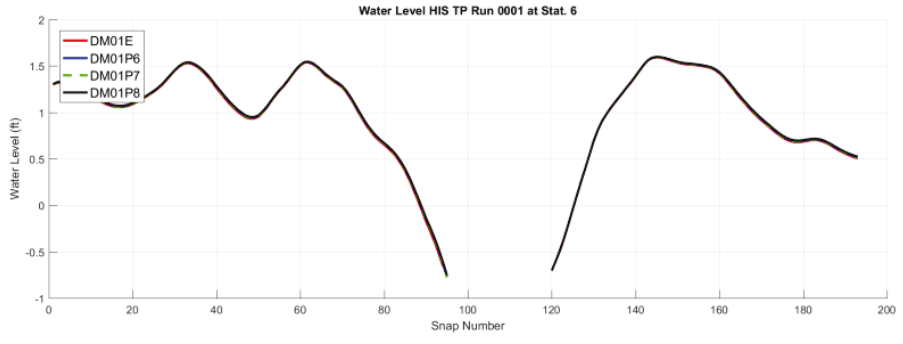

(e) $\operatorname{Stn} 4$

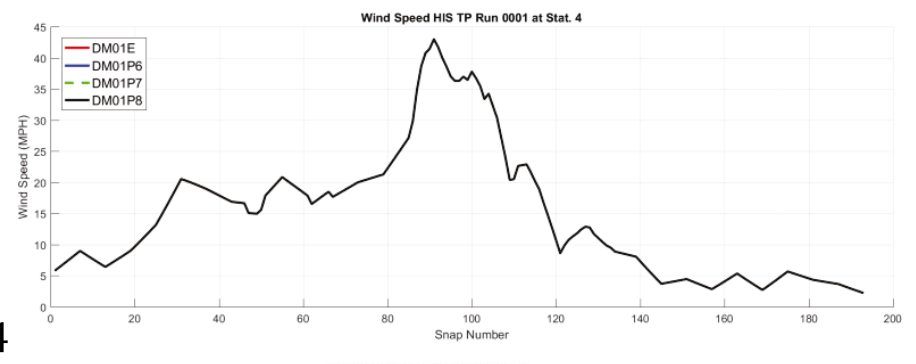

(f) $\operatorname{Stn} 6$

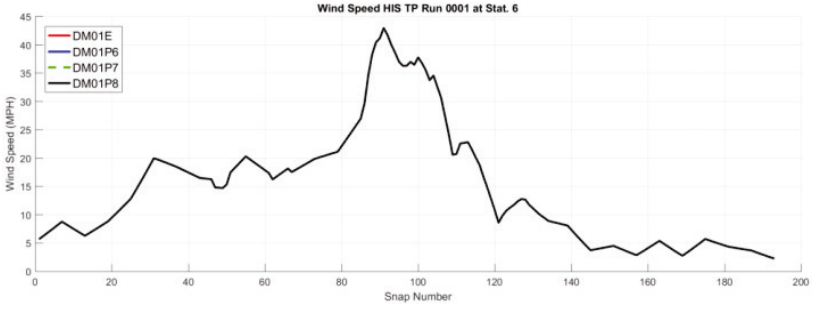


Figure 5-49. Time series of significant wave height (a, b), water level (c, d), and wind speed $(e, f)$ at Stns 4 and 6 for SYN TP Storm No. 0028.

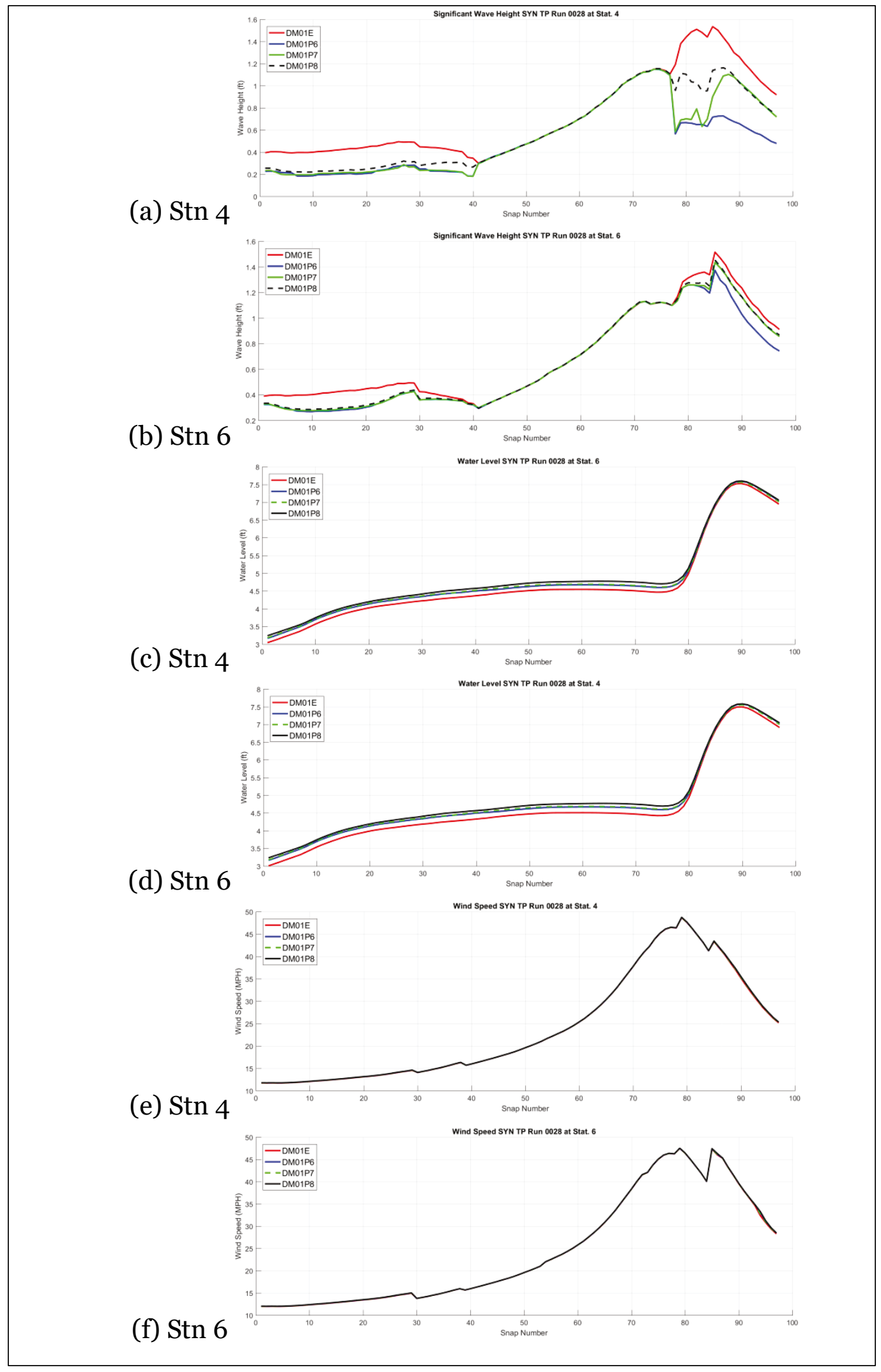


Table 5-105. Differences in significant wave heights (ft) for HIS ET Storm No. 0001 at the 18 selected locations among the cases with and without the groins.

\begin{tabular}{|c|c|c|c|c|c|c|c|}
\hline \multirow{2}{*}{ Station\Grid } & \multirow{2}{*}{ DM01E } & \multicolumn{2}{|c|}{ DM01P6-DM01E } & \multicolumn{2}{c|}{ DM01P7-DM01E } & \multicolumn{2}{c|}{ DM01P8-DM01E } \\
\cline { 3 - 8 } & Value (ft) & Rate (\%) & Value (ft) & Rate (\%) & Value (ft) & Rate (\%) \\
\hline 1 & 1.592 & 0.001 & $0.0 \%$ & 0.000 & $0.0 \%$ & 0.001 & $0.1 \%$ \\
\hline 2 & 1.683 & -0.009 & $-0.5 \%$ & -0.018 & $-1.1 \%$ & -0.488 & $-29.0 \%$ \\
\hline 3 & 1.605 & -1.058 & $-65.9 \%$ & -0.998 & $-62.2 \%$ & -0.830 & $-51.7 \%$ \\
\hline 4 & 1.394 & -0.781 & $-56.0 \%$ & -0.749 & $-53.7 \%$ & -0.611 & $-43.8 \%$ \\
\hline 5 & 1.489 & -0.639 & $-42.9 \%$ & -0.622 & $-41.8 \%$ & -0.477 & $-32.1 \%$ \\
\hline 6 & 1.320 & -0.137 & $-10.4 \%$ & -0.133 & $-10.1 \%$ & -0.110 & $-8.3 \%$ \\
\hline 7 & 1.563 & -0.202 & $-12.9 \%$ & -0.201 & $-12.8 \%$ & -0.199 & $-12.7 \%$ \\
\hline 8 & 1.248 & -0.030 & $-2.4 \%$ & -0.031 & $-2.5 \%$ & -0.027 & $-2.2 \%$ \\
\hline 9 & 0.998 & -0.225 & $-22.6 \%$ & -0.215 & $-21.6 \%$ & -0.185 & $-18.6 \%$ \\
\hline 10 & 0.945 & -0.303 & $-32.1 \%$ & -0.291 & $-30.8 \%$ & -0.242 & $-25.6 \%$ \\
\hline 11 & 0.980 & -0.564 & $-57.6 \%$ & -0.559 & $-57.0 \%$ & -0.561 & $-57.2 \%$ \\
\hline 12 & 1.036 & 0.000 & $0.0 \%$ & 0.000 & $0.0 \%$ & 0.000 & $0.0 \%$ \\
\hline 13 & 1.262 & 0.000 & $0.0 \%$ & 0.000 & $0.0 \%$ & 0.000 & $0.0 \%$ \\
\hline 14 & 1.144 & -0.001 & $-0.1 \%$ & -0.001 & $-0.1 \%$ & -0.001 & $-0.1 \%$ \\
\hline 15 & 1.180 & 0.000 & $0.0 \%$ & 0.000 & $0.0 \%$ & 0.000 & $0.0 \%$ \\
\hline 16 & 1.248 & 0.000 & $0.0 \%$ & 0.000 & $0.0 \%$ & 0.000 & $0.0 \%$ \\
\hline 17 & 1.265 & 0.002 & $0.2 \%$ & 0.000 & $0.0 \%$ & -0.001 & $-0.1 \%$ \\
\hline 18 & 1.295 & 0.000 & $0.0 \%$ & 0.000 & $0.0 \%$ & -0.004 & $-0.3 \%$ \\
\hline
\end{tabular}

Table 5-106. Differences in significant wave heights (ft) for HIS ET Storm No. 0008 at the 18 selected locations among the cases with and without the groins.

\begin{tabular}{|c|c|c|c|c|c|c|c|}
\hline \multirow{2}{*}{ Station\Grid } & & \multicolumn{2}{|c|}{ DM01P6-DM01E } & \multicolumn{2}{c|}{ DM01P7-DM01E } & \multicolumn{2}{c|}{ DM01P8-DM01E } \\
\cline { 3 - 8 } & DM01E & Value (ft) & Rate (\%) & $\begin{array}{c}\text { Value } \\
(\mathrm{ft})\end{array}$ & $\begin{array}{c}\text { Rate } \\
(\%)\end{array}$ & Value (ft) & Rate (\%) \\
\hline 1 & 2.132 & 0.004 & $0.2 \%$ & 0.004 & $0.2 \%$ & 0.003 & $0.1 \%$ \\
\hline 2 & 2.213 & 0.002 & $0.1 \%$ & 0.003 & $0.1 \%$ & -0.287 & $-13.0 \%$ \\
\hline 3 & 2.319 & -1.610 & $-69.4 \%$ & -1.516 & $-65.4 \%$ & -1.187 & $-51.2 \%$ \\
\hline 4 & 2.127 & -1.191 & $-56.0 \%$ & -1.142 & $-53.7 \%$ & -0.879 & $-41.3 \%$ \\
\hline 5 & 2.260 & -0.915 & $-40.5 \%$ & -0.897 & $-39.7 \%$ & -0.641 & $-28.4 \%$ \\
\hline 6 & 2.073 & -0.141 & $-6.8 \%$ & -0.128 & $-6.2 \%$ & -0.130 & $-6.3 \%$ \\
\hline 7 & 2.371 & -0.177 & $-7.5 \%$ & -0.176 & $-7.4 \%$ & -0.164 & $-6.9 \%$ \\
\hline 8 & 2.093 & -0.036 & $-1.7 \%$ & -0.036 & $-1.7 \%$ & -0.031 & $-1.5 \%$ \\
\hline 9 & 1.645 & -0.293 & $-17.8 \%$ & -0.275 & $-16.7 \%$ & -0.217 & $-13.2 \%$ \\
\hline 10 & 1.568 & -0.533 & $-34.0 \%$ & -0.508 & $-32.4 \%$ & -0.365 & $-23.3 \%$ \\
\hline
\end{tabular}




\begin{tabular}{|c|c|c|c|c|c|c|c|}
\hline \multirow{2}{*}{ Station } & & \multicolumn{2}{|c|}{ DM01P6-DM01E } & \multicolumn{2}{c|}{ DM01P7-DM01E } & \multicolumn{2}{c|}{ DM01P8-DM01E } \\
\cline { 3 - 8 } & DM01E & Value (ft) & Rate (\%) & $\begin{array}{c}\text { Value } \\
(\mathrm{ft})\end{array}$ & $\begin{array}{c}\text { Rate } \\
(\%)\end{array}$ & Value (ft) & Rate (\%) \\
\hline 11 & 1.618 & -0.705 & $-43.6 \%$ & -0.644 & $-39.8 \%$ & -0.665 & $-41.1 \%$ \\
\hline 12 & 1.719 & 0.000 & $0.0 \%$ & 0.000 & $0.0 \%$ & -0.002 & $-0.1 \%$ \\
\hline 13 & 1.544 & 0.003 & $0.2 \%$ & 0.003 & $0.2 \%$ & 0.003 & $0.2 \%$ \\
\hline 14 & 1.239 & 0.000 & $0.0 \%$ & 0.000 & $0.0 \%$ & 0.000 & $0.0 \%$ \\
\hline 15 & 1.264 & 0.001 & $0.0 \%$ & 0.001 & $0.1 \%$ & -0.001 & $0.0 \%$ \\
\hline 16 & 1.283 & -0.001 & $-0.1 \%$ & -0.001 & $-0.1 \%$ & -0.001 & $-0.1 \%$ \\
\hline 17 & 1.321 & -0.001 & $-0.1 \%$ & 0.000 & $0.0 \%$ & 0.000 & $0.0 \%$ \\
\hline 18 & 1.296 & -0.001 & $-0.1 \%$ & 0.002 & $0.2 \%$ & 0.000 & $0.0 \%$ \\
\hline
\end{tabular}

Table 5-107. Differences in significant wave heights (ft) for HIS ET Storm No. 0038 at the 18 selected locations among the cases with and without the groins.

\begin{tabular}{|c|c|c|c|c|c|c|c|}
\hline \multirow{2}{*}{ Station \Grid } & \multirow{2}{*}{ DM01E } & Value (ft) & Rate (\%) & Value (ft) & $\begin{array}{c}\text { Rate } \\
(\%)\end{array}$ & Value (ft) & Rate (\%) \\
\cline { 3 - 8 } & 0.842 & -0.016 & $-1.9 \%$ & -0.015 & $-1.8 \%$ & -0.130 & $-15.4 \%$ \\
\hline 1 & 0.867 & -0.001 & $-0.1 \%$ & 0.001 & $0.1 \%$ & -0.002 & $-0.2 \%$ \\
\hline 2 & 1.064 & -0.012 & $-1.1 \%$ & -0.011 & $-1.0 \%$ & 0.000 & $0.0 \%$ \\
\hline 3 & 0.888 & 0.002 & $0.3 \%$ & 0.002 & $0.3 \%$ & 0.003 & $0.4 \%$ \\
\hline 4 & 0.982 & 0.001 & $0.1 \%$ & 0.001 & $0.1 \%$ & 0.002 & $0.2 \%$ \\
\hline 5 & 0.763 & 0.000 & $0.0 \%$ & 0.000 & $0.0 \%$ & 0.001 & $0.1 \%$ \\
\hline 6 & 0.850 & 0.000 & $0.0 \%$ & 0.000 & $0.0 \%$ & 0.000 & $0.0 \%$ \\
\hline 7 & 0.585 & 0.000 & $0.0 \%$ & 0.000 & $0.0 \%$ & 0.000 & $0.0 \%$ \\
\hline 8 & 0.120 & 0.000 & $0.0 \%$ & 0.000 & $0.0 \%$ & 0.000 & $0.0 \%$ \\
\hline 9 & 0.311 & -0.004 & $-1.3 \%$ & -0.004 & $-1.2 \%$ & 0.000 & $0.0 \%$ \\
\hline 10 & Dry & Dry & Dry & & Dry & & Dry \\
\hline 11 & 0.627 & -0.004 & $-0.7 \%$ & -0.004 & $-0.7 \%$ & -0.014 & $-2.2 \%$ \\
\hline 12 & 0.225 & 0.000 & $0.0 \%$ & 0.000 & $0.0 \%$ & 0.000 & $0.0 \%$ \\
\hline 13 & 0.262 & 0.000 & $0.0 \%$ & 0.000 & $0.0 \%$ & 0.000 & $0.0 \%$ \\
\hline 14 & 0.278 & 0.000 & $-0.1 \%$ & 0.000 & $-0.1 \%$ & 0.000 & $0.0 \%$ \\
\hline 15 & 0.304 & 0.000 & $0.0 \%$ & 0.000 & $0.0 \%$ & 0.000 & $0.0 \%$ \\
\hline 16 & 0.269 & 0.000 & $-0.1 \%$ & 0.000 & $-0.1 \%$ & 0.000 & $-0.1 \%$ \\
\hline 17 & 0.259 & 0.000 & $0.0 \%$ & 0.000 & $0.0 \%$ & 0.029 & $11.0 \%$ \\
\hline
\end{tabular}


Table 5-108. Differences in significant wave heights (ft) for HIS ET Storm No. 0051 at the 18 selected locations among the cases with and without the groins.

\begin{tabular}{|c|c|c|c|c|c|c|c|}
\hline \multirow{2}{*}{ Station \Grid } & \multirow{2}{*}{ DM01E } & \multicolumn{2}{|c|}{ DM01P6 } & \multicolumn{2}{c|}{ DM01P7 } & \multicolumn{2}{c|}{ DM01P8 } \\
\cline { 3 - 8 } & Value (ft) & Rate (\%) & Value (ft) & Rate (\%) & Value (ft) & Rate (\%) \\
\hline 1 & 0.894 & -0.002 & $-0.2 \%$ & 0.000 & $0.0 \%$ & 0.000 & $0.0 \%$ \\
\hline 2 & 0.985 & -0.005 & $-0.5 \%$ & -0.008 & $-0.8 \%$ & -0.379 & $-38.5 \%$ \\
\hline 3 & 0.907 & -0.416 & $-45.9 \%$ & -0.400 & $-44.1 \%$ & -0.262 & $-28.9 \%$ \\
\hline 4 & 0.824 & -0.166 & $-20.1 \%$ & -0.167 & $-20.2 \%$ & -0.164 & $-19.8 \%$ \\
\hline 5 & 0.878 & -0.212 & $-24.2 \%$ & -0.212 & $-24.2 \%$ & -0.211 & $-24.1 \%$ \\
\hline 6 & 0.803 & -0.158 & $-19.7 \%$ & -0.158 & $-19.7 \%$ & -0.157 & $-19.6 \%$ \\
\hline 7 & 0.945 & -0.206 & $-21.8 \%$ & -0.208 & $-22.0 \%$ & -0.206 & $-21.8 \%$ \\
\hline 8 & 0.775 & -0.040 & $-5.2 \%$ & -0.039 & $-5.1 \%$ & -0.038 & $-4.9 \%$ \\
\hline 9 & 0.653 & -0.172 & $-26.4 \%$ & -0.170 & $-26.0 \%$ & -0.162 & $-24.9 \%$ \\
\hline 10 & 0.622 & -0.028 & $-4.5 \%$ & -0.024 & $-3.9 \%$ & -0.009 & $-1.5 \%$ \\
\hline 11 & 0.553 & -0.053 & $-9.6 \%$ & -0.050 & $-9.0 \%$ & 0.004 & $0.7 \%$ \\
\hline 12 & 0.635 & -0.002 & $-0.3 \%$ & -0.001 & $-0.1 \%$ & -0.005 & $-0.8 \%$ \\
\hline 13 & 0.919 & -0.001 & $-0.1 \%$ & 0.000 & $-0.1 \%$ & 0.001 & $0.1 \%$ \\
\hline 14 & 0.784 & -0.003 & $-0.4 \%$ & -0.001 & $-0.1 \%$ & 0.001 & $0.1 \%$ \\
\hline 15 & 0.793 & 0.000 & $0.0 \%$ & 0.000 & $0.0 \%$ & 0.001 & $0.1 \%$ \\
\hline 16 & 0.808 & -0.001 & $-0.1 \%$ & 0.000 & $0.0 \%$ & 0.000 & $0.0 \%$ \\
\hline 17 & 0.929 & 0.000 & $0.0 \%$ & 0.001 & $0.1 \%$ & 0.001 & $0.1 \%$ \\
\hline 18 & 0.950 & 0.000 & $-0.1 \%$ & -0.001 & $-0.1 \%$ & 0.000 & $0.0 \%$ \\
\hline
\end{tabular}

Table 5-109. Differences in significant wave heights (ft) for HIS ET Storm No. 0054 at the 18 selected locations among the cases with and without the groins.

\begin{tabular}{|c|c|c|c|c|c|c|c|}
\hline \multirow{2}{*}{ Station\Grid } & \multirow{2}{*}{ DM01E } & \multicolumn{2}{|c|}{ DM01P6-DM01E } & \multicolumn{2}{c|}{ DM01P7-DM01E } & \multicolumn{2}{c|}{ DM01P8-DM01E } \\
\cline { 3 - 8 } & Value (ft) & Rate (\%) & Value (ft) & Rate (\%) & Value (ft) & Rate (\%) \\
\hline 1 & 0.745 & -0.160 & $-21.4 \%$ & -0.172 & $-23.1 \%$ & -0.347 & $-46.5 \%$ \\
\hline 2 & 0.675 & -0.003 & $-0.4 \%$ & -0.004 & $-0.5 \%$ & -0.003 & $-0.4 \%$ \\
\hline 3 & 0.600 & 0.002 & $0.4 \%$ & 0.002 & $0.4 \%$ & 0.002 & $0.3 \%$ \\
\hline 4 & 0.390 & 0.002 & $0.6 \%$ & 0.002 & $0.6 \%$ & 0.003 & $0.8 \%$ \\
\hline 5 & 0.391 & 0.001 & $0.3 \%$ & 0.001 & $0.3 \%$ & 0.002 & $0.4 \%$ \\
\hline 6 & 0.296 & 0.000 & $0.0 \%$ & 0.000 & $0.0 \%$ & 0.000 & $0.1 \%$ \\
\hline 7 & 0.379 & 0.001 & $0.3 \%$ & 0.001 & $0.2 \%$ & 0.002 & $0.5 \%$ \\
\hline 8 & 0.247 & 0.000 & $0.2 \%$ & 0.000 & $0.1 \%$ & 0.001 & $0.2 \%$ \\
\hline
\end{tabular}




\begin{tabular}{|c|c|c|c|c|c|c|c|}
\hline \multirow{2}{*}{ Station } & \multirow{2}{*}{ Grid } & \multicolumn{2}{|c|}{ DM01P6-DM01E } & \multicolumn{2}{c|}{ DM01P7-DM01E } & \multicolumn{2}{c|}{ DM01P8-DM01E } \\
\cline { 3 - 8 } & DM01E & Value (ft) & Rate (\%) & Value (ft) & Rate (\%) & Value (ft) & Rate (\%) \\
\hline 9 & 0.155 & 0.000 & $0.0 \%$ & 0.000 & $0.0 \%$ & 0.000 & $0.0 \%$ \\
\hline 10 & 0.221 & 0.001 & $0.4 \%$ & 0.001 & $0.4 \%$ & 0.001 & $0.4 \%$ \\
\hline 11 & Dry & Dry & & Dry & & Dry & \\
\hline 12 & 0.218 & -0.016 & $-7.2 \%$ & -0.016 & $-7.5 \%$ & -0.018 & $-8.4 \%$ \\
\hline 13 & 0.290 & 0.001 & $0.2 \%$ & 0.000 & $-0.1 \%$ & -0.002 & $-0.6 \%$ \\
\hline 14 & 0.562 & 0.001 & $0.3 \%$ & 0.001 & $0.2 \%$ & 0.003 & $0.5 \%$ \\
\hline 15 & 0.657 & 0.002 & $0.3 \%$ & 0.001 & $0.2 \%$ & 0.003 & $0.5 \%$ \\
\hline 16 & 0.728 & -0.003 & $-0.4 \%$ & -0.003 & $-0.5 \%$ & -0.001 & $-0.2 \%$ \\
\hline 17 & 0.643 & 0.001 & $0.2 \%$ & 0.001 & $0.2 \%$ & 0.002 & $0.3 \%$ \\
\hline 18 & 0.378 & 0.001 & $0.4 \%$ & 0.001 & $0.3 \%$ & 0.002 & $0.6 \%$ \\
\hline
\end{tabular}

Table 5-110. Differences in significant wave heights (ft) for HIS TP Storm No. 0001 (Hurricane Sandy 2012) at the 18 selected locations among the cases with and without the groins.

\begin{tabular}{|c|c|c|c|c|c|c|c|}
\hline \multirow{2}{*}{ Station\Grid } & \multirow{2}{*}{ DM01E } & \multicolumn{2}{|c|}{ DM01P6-DM01E } & \multicolumn{2}{c|}{ DM01P7-DM01E } & \multicolumn{2}{c|}{ DM01P8-DM01E } \\
\cline { 3 - 8 } & Value (ft) & Rate (\%) & Value (ft) & Rate (\%) & Value (ft) & Rate (\%) \\
\hline 1 & 0.914 & -0.173 & $-18.9 \%$ & -0.193 & $-21.1 \%$ & -0.359 & $-39.3 \%$ \\
\hline 2 & 0.916 & 0.000 & $-0.1 \%$ & 0.000 & $0.0 \%$ & 0.001 & $0.1 \%$ \\
\hline 3 & 0.738 & -0.007 & $-0.9 \%$ & -0.005 & $-0.7 \%$ & 0.000 & $0.1 \%$ \\
\hline 4 & 0.669 & 0.001 & $0.1 \%$ & 0.001 & $0.1 \%$ & 0.001 & $0.2 \%$ \\
\hline 5 & 0.719 & 0.001 & $0.1 \%$ & 0.001 & $0.1 \%$ & 0.001 & $0.2 \%$ \\
\hline 6 & 0.579 & 0.000 & $0.1 \%$ & 0.002 & $0.3 \%$ & 0.000 & $0.1 \%$ \\
\hline 7 & 0.597 & 0.000 & $0.0 \%$ & 0.000 & $0.0 \%$ & 0.000 & $0.1 \%$ \\
\hline 8 & 0.394 & 0.000 & $0.1 \%$ & 0.000 & $0.1 \%$ & 0.000 & $0.1 \%$ \\
\hline 9 & 0.235 & 0.000 & $0.0 \%$ & 0.000 & $0.0 \%$ & 0.000 & $0.0 \%$ \\
\hline 10 & 0.285 & 0.001 & $0.2 \%$ & 0.001 & $0.2 \%$ & 0.001 & $0.2 \%$ \\
\hline 11 & Dry & Dry & & Dry & & Dry & \\
\hline 12 & 0.370 & -0.013 & $-3.5 \%$ & -0.014 & $-3.7 \%$ & -0.044 & $-11.8 \%$ \\
\hline 13 & 0.420 & -0.002 & $-0.4 \%$ & -0.002 & $-0.4 \%$ & -0.002 & $-0.4 \%$ \\
\hline 14 & 0.895 & 0.004 & $0.4 \%$ & 0.004 & $0.4 \%$ & 0.007 & $0.8 \%$ \\
\hline 15 & 0.997 & 0.002 & $0.2 \%$ & 0.002 & $0.2 \%$ & 0.005 & $0.5 \%$ \\
\hline 16 & 1.110 & 0.000 & $0.0 \%$ & -0.002 & $-0.2 \%$ & -0.001 & $-0.1 \%$ \\
\hline 17 & 1.211 & -0.076 & $-6.3 \%$ & -0.076 & $-6.3 \%$ & -0.074 & $-6.1 \%$ \\
\hline 18 & 0.597 & 0.000 & $0.1 \%$ & 0.000 & $0.1 \%$ & 0.000 & $0.1 \%$ \\
\hline
\end{tabular}


Table 5-111. Differences in significant wave heights (ft) for HIS TP Storm No. 0003 (Hurricane Isabel 2003) at the 18 selected locations among the cases with and without the groins.

\begin{tabular}{|c|c|c|c|c|c|c|c|}
\hline \multirow{2}{*}{ Station/Grid } & DM01E & \multicolumn{2}{|c|}{ DM01P6-DM01E } & \multicolumn{2}{c|}{ DM01P7-DM01E } & \multicolumn{2}{c|}{ DM01P8-DM01E } \\
\cline { 2 - 8 } & Value (ft) & Value (ft) & Rate (\%) & Value (ft) & Rate (\%) & Value (ft) & Rate (\%) \\
\hline 1 & 2.199 & 0.000 & $0.0 \%$ & 0.000 & $0.0 \%$ & -0.006 & $-0.3 \%$ \\
\hline 2 & 2.314 & -0.012 & $-0.5 \%$ & -0.028 & $-1.2 \%$ & -0.588 & $-25.4 \%$ \\
\hline 3 & 2.214 & -1.365 & $-61.6 \%$ & -0.931 & $-42.0 \%$ & -1.015 & $-45.8 \%$ \\
\hline 4 & 1.977 & -1.016 & $-51.4 \%$ & -0.836 & $-42.3 \%$ & -0.845 & $-42.7 \%$ \\
\hline 5 & 2.077 & -0.838 & $-40.4 \%$ & -0.844 & $-40.6 \%$ & -0.621 & $-29.9 \%$ \\
\hline 6 & 1.875 & -0.153 & $-8.2 \%$ & -0.154 & $-8.2 \%$ & -0.142 & $-7.6 \%$ \\
\hline 7 & 2.207 & -0.241 & $-10.9 \%$ & -0.238 & $-10.8 \%$ & -0.232 & $-10.5 \%$ \\
\hline 8 & 1.897 & -0.042 & $-2.2 \%$ & -0.042 & $-2.2 \%$ & -0.039 & $-2.1 \%$ \\
\hline 9 & 1.601 & -0.384 & $-24.0 \%$ & -0.368 & $-23.0 \%$ & -0.296 & $-18.5 \%$ \\
\hline 10 & 1.486 & -0.549 & $-37.0 \%$ & -0.429 & $-28.9 \%$ & -0.415 & $-27.9 \%$ \\
\hline 11 & 1.413 & -0.405 & $-28.6 \%$ & -0.409 & $-29.0 \%$ & -0.419 & $-29.7 \%$ \\
\hline 12 & 1.543 & 0.001 & $0.1 \%$ & 0.001 & $0.1 \%$ & 0.002 & $0.1 \%$ \\
\hline 13 & 1.811 & 0.000 & $0.0 \%$ & 0.000 & $0.0 \%$ & 0.000 & $0.0 \%$ \\
\hline 14 & 1.613 & -0.002 & $-0.1 \%$ & -0.001 & $0.0 \%$ & -0.001 & $-0.1 \%$ \\
\hline 15 & 1.640 & 0.000 & $0.0 \%$ & 0.001 & $0.0 \%$ & 0.000 & $0.0 \%$ \\
\hline 16 & 1.701 & -0.001 & $-0.1 \%$ & -0.001 & $-0.1 \%$ & -0.002 & $-0.1 \%$ \\
\hline 17 & 1.645 & 0.016 & $0.9 \%$ & 0.016 & $1.0 \%$ & 0.015 & $0.9 \%$ \\
\hline 18 & 1.608 & -0.009 & $-0.5 \%$ & -0.007 & $-0.5 \%$ & -0.010 & $-0.6 \%$ \\
\hline
\end{tabular}

Table 5-112. Differences in significant wave heights (ft) for SYN TP Storm No. 0005 at the 18 selected locations among the cases with and without the groins.

\begin{tabular}{|c|c|c|c|c|c|c|c|}
\hline \multirow{2}{*}{ Station\Grid } & DM01E & \multicolumn{2}{|c|}{ DM01P6-DM01E } & \multicolumn{2}{c|}{ DM01P7-DM01E } & \multicolumn{2}{c|}{ DM01P8-DM01E } \\
\cline { 2 - 8 } & Value (ft) & Value (ft) & Rate (\%) & Value (ft) & Rate (\%) & Value (ft) & Rate (\%) \\
\hline 1 & 0.836 & -0.001 & $-0.1 \%$ & -0.002 & $-0.3 \%$ & 0.007 & $0.9 \%$ \\
\hline 2 & 0.745 & -0.001 & $-0.1 \%$ & -0.001 & $-0.1 \%$ & -0.050 & $-6.7 \%$ \\
\hline 3 & 0.865 & -0.386 & $-44.6 \%$ & -0.361 & $-41.8 \%$ & -0.244 & $-28.2 \%$ \\
\hline 4 & 0.849 & -0.217 & $-25.6 \%$ & -0.219 & $-25.8 \%$ & -0.178 & $-21.0 \%$ \\
\hline 5 & 0.833 & -0.197 & $-23.7 \%$ & -0.161 & $-19.4 \%$ & -0.097 & $-11.7 \%$ \\
\hline 6 & 0.761 & -0.058 & $-7.6 \%$ & -0.040 & $-5.3 \%$ & -0.035 & $-4.5 \%$ \\
\hline 7 & 0.758 & -0.053 & $-7.0 \%$ & -0.040 & $-5.3 \%$ & -0.043 & $-5.7 \%$ \\
\hline 8 & 0.737 & -0.025 & $-3.3 \%$ & -0.016 & $-2.1 \%$ & -0.019 & $-2.5 \%$ \\
\hline
\end{tabular}




\begin{tabular}{|c|c|c|c|c|c|c|c|}
\hline \multirow{2}{*}{ Station } & DM01E & \multicolumn{2}{|c|}{ DM01P6-DM01E } & \multicolumn{2}{c|}{ DM01P7-DM01E } & \multicolumn{2}{c|}{ DM01P8-DM01E } \\
\cline { 2 - 8 } & Value (ft) & Value (ft) & Rate (\%) & Value (ft) & Rate (\%) & Value (ft) & Rate (\%) \\
\hline 9 & 0.772 & -0.166 & $-21.5 \%$ & -0.126 & $-16.3 \%$ & -0.095 & $-12.4 \%$ \\
\hline 10 & 0.818 & -0.184 & $-22.5 \%$ & -0.183 & $-22.4 \%$ & -0.162 & $-19.8 \%$ \\
\hline 11 & 0.874 & -0.323 & $-37.0 \%$ & -0.318 & $-36.3 \%$ & -0.241 & $-27.6 \%$ \\
\hline 12 & 0.857 & -0.002 & $-0.2 \%$ & -0.002 & $-0.2 \%$ & -0.005 & $-0.5 \%$ \\
\hline 13 & 0.446 & -0.001 & $-0.1 \%$ & 0.000 & $0.0 \%$ & 0.003 & $0.7 \%$ \\
\hline 14 & 0.392 & 0.000 & $0.1 \%$ & 0.000 & $-0.1 \%$ & 0.002 & $0.5 \%$ \\
\hline 15 & 0.403 & 0.000 & $0.1 \%$ & 0.000 & $0.0 \%$ & 0.000 & $0.0 \%$ \\
\hline 16 & 0.405 & 0.000 & $0.0 \%$ & 0.006 & $1.5 \%$ & 0.000 & $0.0 \%$ \\
\hline 17 & 0.373 & 0.000 & $0.0 \%$ & 0.000 & $0.0 \%$ & 0.001 & $0.2 \%$ \\
\hline 18 & 0.361 & 0.003 & $0.9 \%$ & 0.001 & $0.3 \%$ & -0.002 & $-0.6 \%$ \\
\hline
\end{tabular}

Table 5-113. Differences in significant wave heights (ft) for SYN TP Storm No. 0028 at the 18 selected locations among the cases with and without the groins.

\begin{tabular}{|c|c|c|c|c|c|c|c|}
\hline \multirow{2}{*}{ Station } & & \multicolumn{2}{|c|}{ DM01P6-DM01E } & \multicolumn{2}{c|}{ DM01P7-DM01E } & \multicolumn{2}{c|}{ DM01P8-DM01E } \\
\cline { 3 - 8 } & DM01E & Value (ft) & Rate (\%) & Value (ft) & Rate (\%) & Value (ft) & Rate (\%) \\
\hline 1 & 1.491 & -0.001 & $-0.1 \%$ & 0.000 & $0.0 \%$ & 0.001 & $0.1 \%$ \\
\hline 2 & 1.478 & 0.002 & $0.1 \%$ & 0.001 & $0.1 \%$ & -0.136 & $-9.2 \%$ \\
\hline 3 & 1.576 & -0.604 & $-38.3 \%$ & -0.592 & $-37.6 \%$ & -0.437 & $-27.7 \%$ \\
\hline 4 & 1.535 & -0.386 & $-25.1 \%$ & -0.385 & $-25.1 \%$ & -0.372 & $-24.2 \%$ \\
\hline 5 & 1.592 & -0.433 & $-27.2 \%$ & -0.361 & $-22.6 \%$ & -0.192 & $-12.1 \%$ \\
\hline 6 & 1.516 & -0.142 & $-9.4 \%$ & -0.081 & $-5.3 \%$ & -0.062 & $-4.1 \%$ \\
\hline 7 & 1.668 & -0.126 & $-7.5 \%$ & -0.091 & $-5.4 \%$ & -0.083 & $-5.0 \%$ \\
\hline 8 & 1.597 & -0.048 & $-3.0 \%$ & -0.018 & $-1.1 \%$ & -0.017 & $-1.1 \%$ \\
\hline 9 & 1.387 & -0.335 & $-24.2 \%$ & -0.201 & $-14.5 \%$ & -0.140 & $-10.1 \%$ \\
\hline 10 & 1.364 & -0.203 & $-14.9 \%$ & -0.201 & $-14.7 \%$ & -0.182 & $-13.4 \%$ \\
\hline 11 & 1.474 & -0.501 & $-34.0 \%$ & -0.501 & $-34.0 \%$ & -0.463 & $-31.4 \%$ \\
\hline 12 & 1.469 & -0.005 & $-0.3 \%$ & -0.007 & $-0.5 \%$ & -0.007 & $-0.4 \%$ \\
\hline 13 & 0.834 & 0.000 & $0.0 \%$ & 0.000 & $0.0 \%$ & 0.000 & $0.0 \%$ \\
\hline 14 & 0.734 & 0.001 & $0.2 \%$ & 0.000 & $-0.1 \%$ & 0.000 & $0.0 \%$ \\
\hline 15 & 0.756 & -0.001 & $-0.1 \%$ & 0.000 & $0.0 \%$ & 0.001 & $0.1 \%$ \\
\hline 16 & 0.756 & 0.000 & $0.0 \%$ & 0.000 & $0.0 \%$ & 0.000 & $0.0 \%$ \\
\hline 17 & 0.712 & 0.000 & $0.0 \%$ & 0.000 & $0.0 \%$ & 0.001 & $0.1 \%$ \\
\hline 18 & 0.728 & 0.000 & $0.0 \%$ & 0.000 & $0.0 \%$ & 0.000 & $0.0 \%$ \\
\hline
\end{tabular}


Table 5-114. Differences in significant wave heights (ft) for SYN TP Storm No. 0110 at the 18 selected locations among the cases with and without the groins. NA means results not available.

\begin{tabular}{|c|c|c|c|c|c|c|c|}
\hline \multirow{2}{*}{ Station\Grid } & \multirow{2}{*}{ DM01E } & \multicolumn{2}{|c|}{ DM01P6-DM01E } & \multicolumn{2}{c|}{ DM01P7-DM01E } & \multicolumn{2}{c|}{ DM01P8-DM01E } \\
\cline { 5 - 8 } & Value (ft) & Rate (\%) & Value (ft) & Rate (\%) & Value (ft) & Rate (\%) \\
\hline 1 & 3.106 & NA & NA & 0.030 & $0.9 \%$ & 0.017 & $0.6 \%$ \\
\hline 2 & 3.126 & NA & NA & 0.009 & $0.3 \%$ & -0.794 & $-25.4 \%$ \\
\hline 3 & 3.050 & NA & NA & -0.793 & $-26.0 \%$ & -1.003 & $-32.9 \%$ \\
\hline 4 & 2.759 & NA & NA & -0.576 & $-20.9 \%$ & -0.765 & $-27.7 \%$ \\
\hline 5 & 2.874 & NA & NA & -0.550 & $-19.1 \%$ & -0.475 & $-16.5 \%$ \\
\hline 6 & 2.596 & NA & NA & -0.199 & $-7.7 \%$ & -0.167 & $-6.4 \%$ \\
\hline 7 & 2.981 & NA & NA & -0.181 & $-6.1 \%$ & -0.165 & $-5.5 \%$ \\
\hline 8 & 2.665 & NA & NA & -0.058 & $-2.2 \%$ & -0.061 & $-2.3 \%$ \\
\hline 9 & 2.350 & NA & NA & -0.315 & $-13.4 \%$ & -0.212 & $-9.0 \%$ \\
\hline 10 & 2.359 & NA & NA & -0.465 & $-19.7 \%$ & -0.596 & $-25.3 \%$ \\
\hline 11 & 2.253 & NA & NA & -0.387 & $-17.2 \%$ & -0.521 & $-23.1 \%$ \\
\hline 12 & 2.159 & NA & NA & 0.002 & $0.1 \%$ & 0.005 & $0.2 \%$ \\
\hline 13 & 2.313 & NA & NA & 0.007 & $0.3 \%$ & 0.010 & $0.4 \%$ \\
\hline 14 & 2.182 & NA & NA & 0.000 & $0.0 \%$ & -0.001 & $0.0 \%$ \\
\hline 15 & 2.250 & NA & NA & -0.001 & $-0.1 \%$ & -0.002 & $-0.1 \%$ \\
\hline 16 & 2.255 & NA & NA & 0.000 & $0.0 \%$ & 0.002 & $0.1 \%$ \\
\hline 17 & 2.263 & NA & NA & 0.002 & $0.1 \%$ & 0.002 & $0.1 \%$ \\
\hline 18 & 1.963 & NA & NA & 0.007 & $0.4 \%$ & 0.003 & $0.2 \%$ \\
\hline
\end{tabular}

\subsubsection{Simulation results for long-term tidal and river flows under constant wind conditions for groin-only designs}

\subsubsection{Results for long-term tidal flows}

By using the same simulation procedure and conditions (Table 5-58) for studying hydrodynamic responses of the project promontories, the 1-month-long tidal simulations with high and low river discharge were also computed for the three proposed groins.

Comparisons of water levels, flow velocities, and tidal current ellipses at the selected observation station are presented in Figure 5-50 through Figure 5-63. Similar to the findings for the promontories, the groins reduce flow velocities in the shadow areas of the structures. Along the 
western bank of the Dyke Marsh, the reduction in current speed by the groins is almost the same as for the longer full promontories. The reduction in current speed from the groins for tidal flows extends as far as Stn 6, which is comparable in approximate length to the structure itself. Only current directions at Stn 1 (Figure 5-52) are slightly different from those of the full promontory (Figure 5-8).

Figure 5-50. Comparisons of water levels (ft) and velocities (ft/s) at Stn 1 for groins.

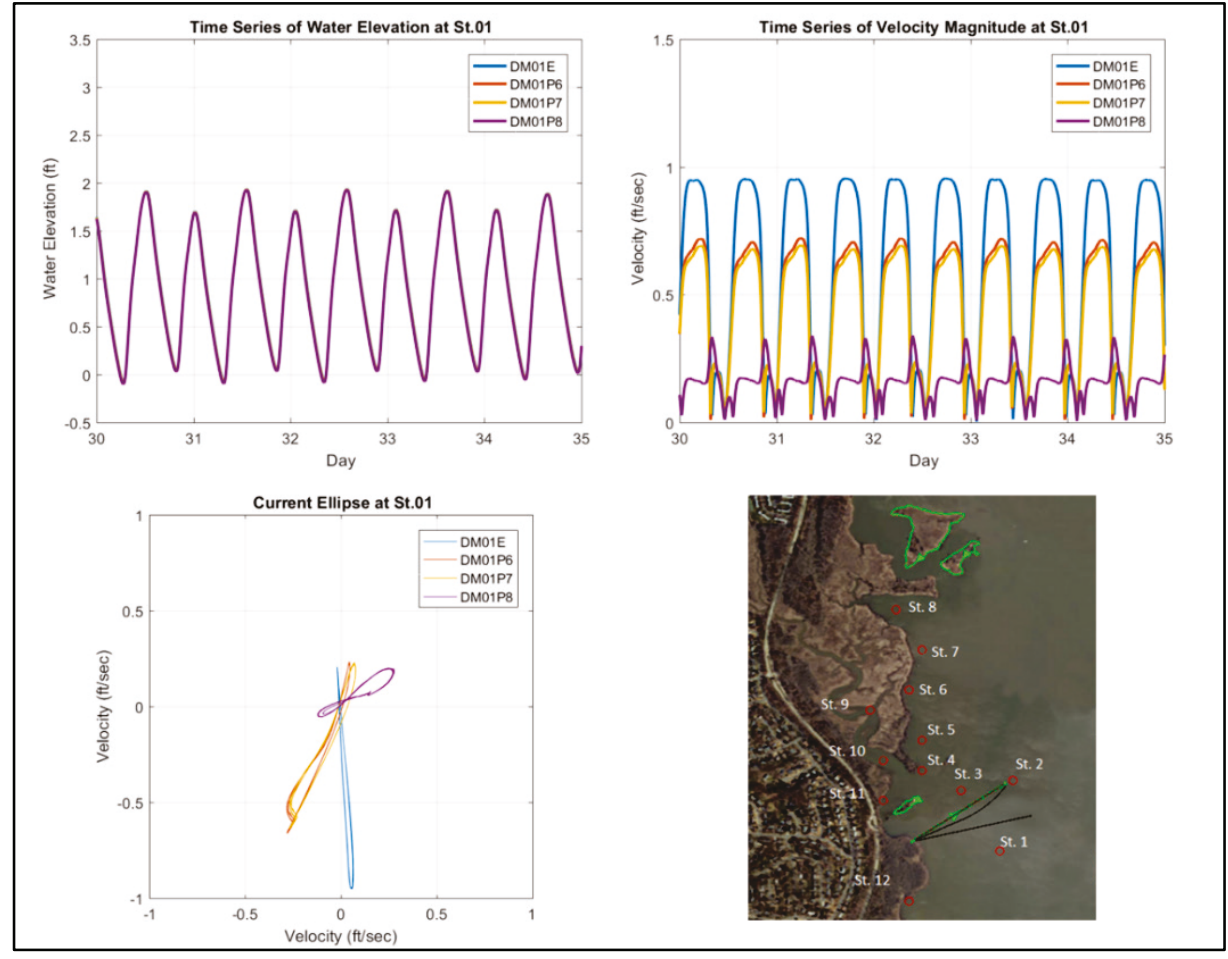


Figure 5-51. Differences in velocity magnitude (ft/s) at Stn 1 with and without structures.

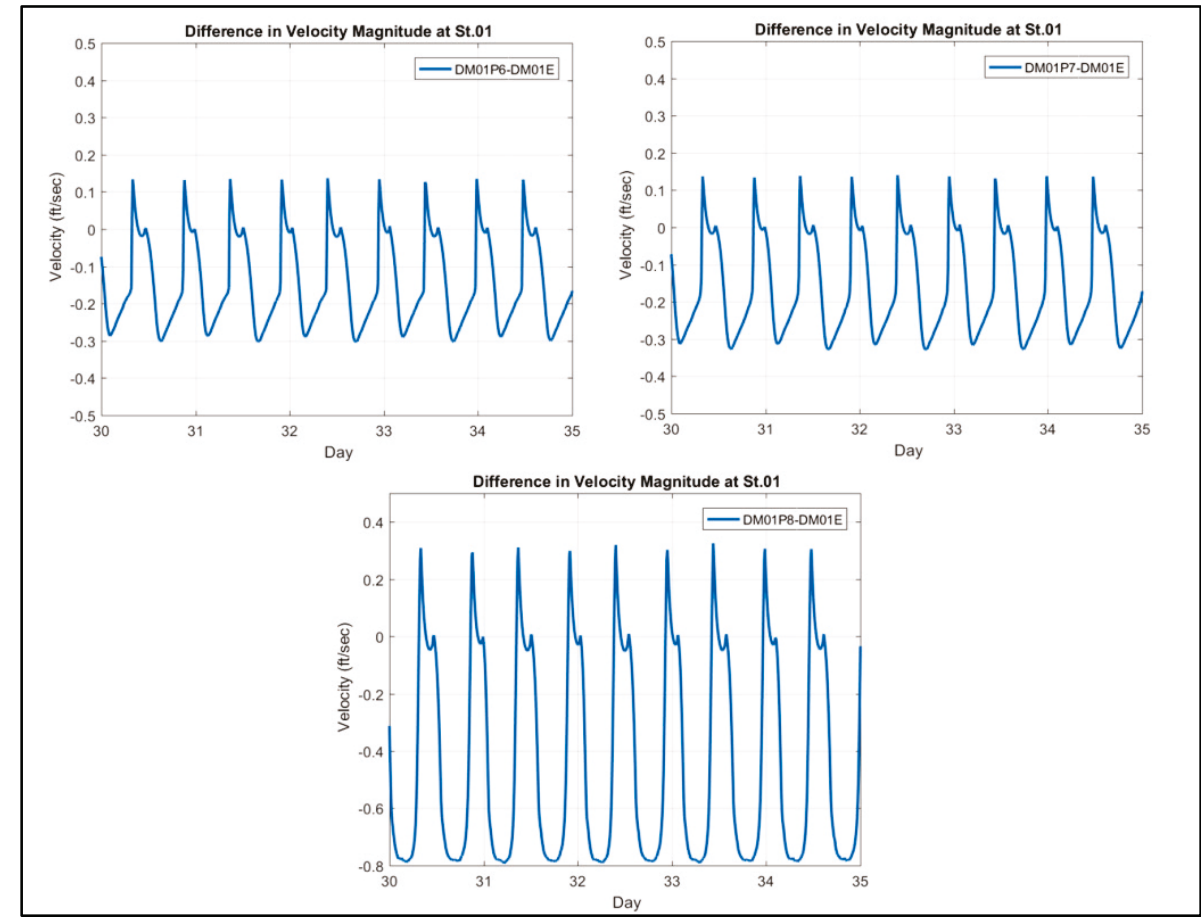

Figure 5-52. Comparisons of water levels (ft) and velocities (ft/s) at Stn 2 for groins.

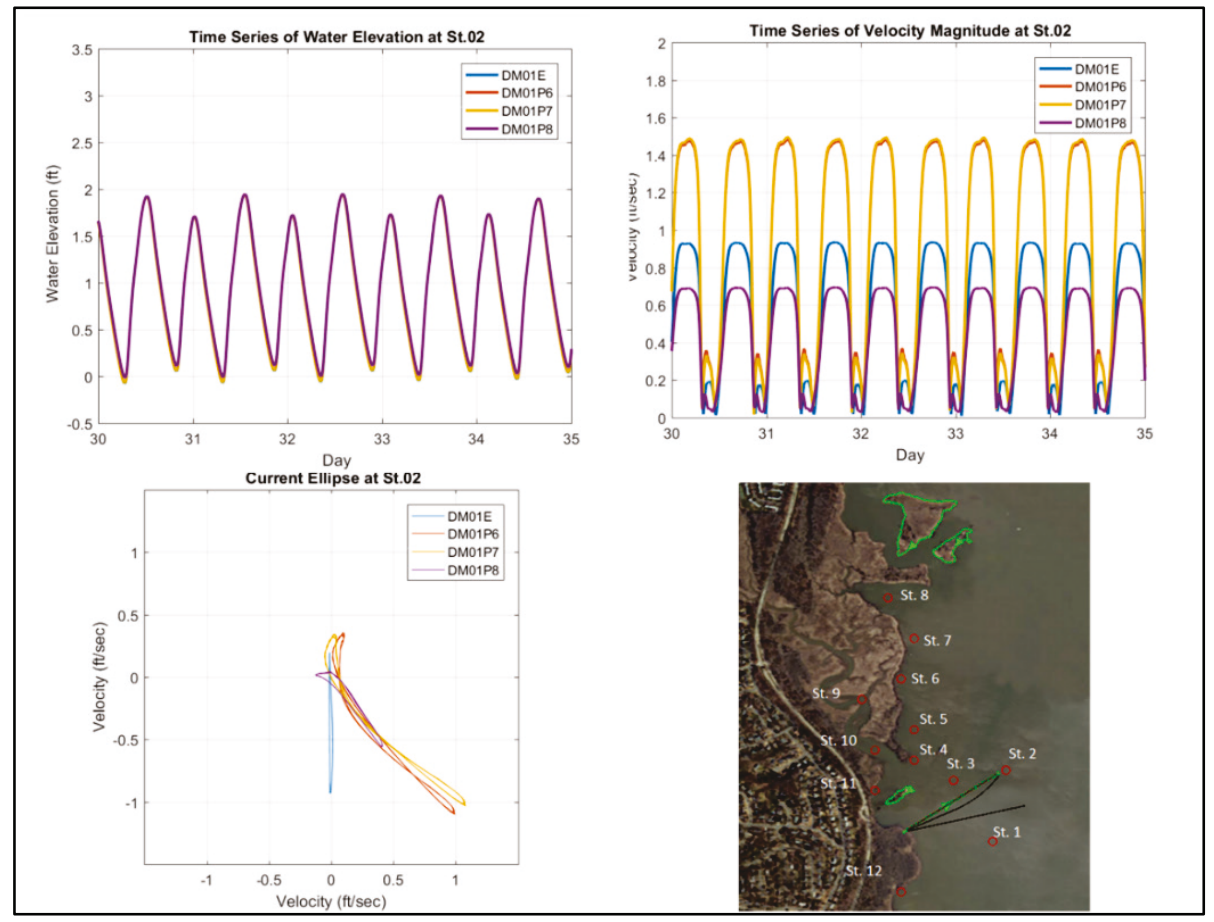


Figure 5-53. Differences in velocity magnitude (ft/s) at Stn 2 with and without structures.

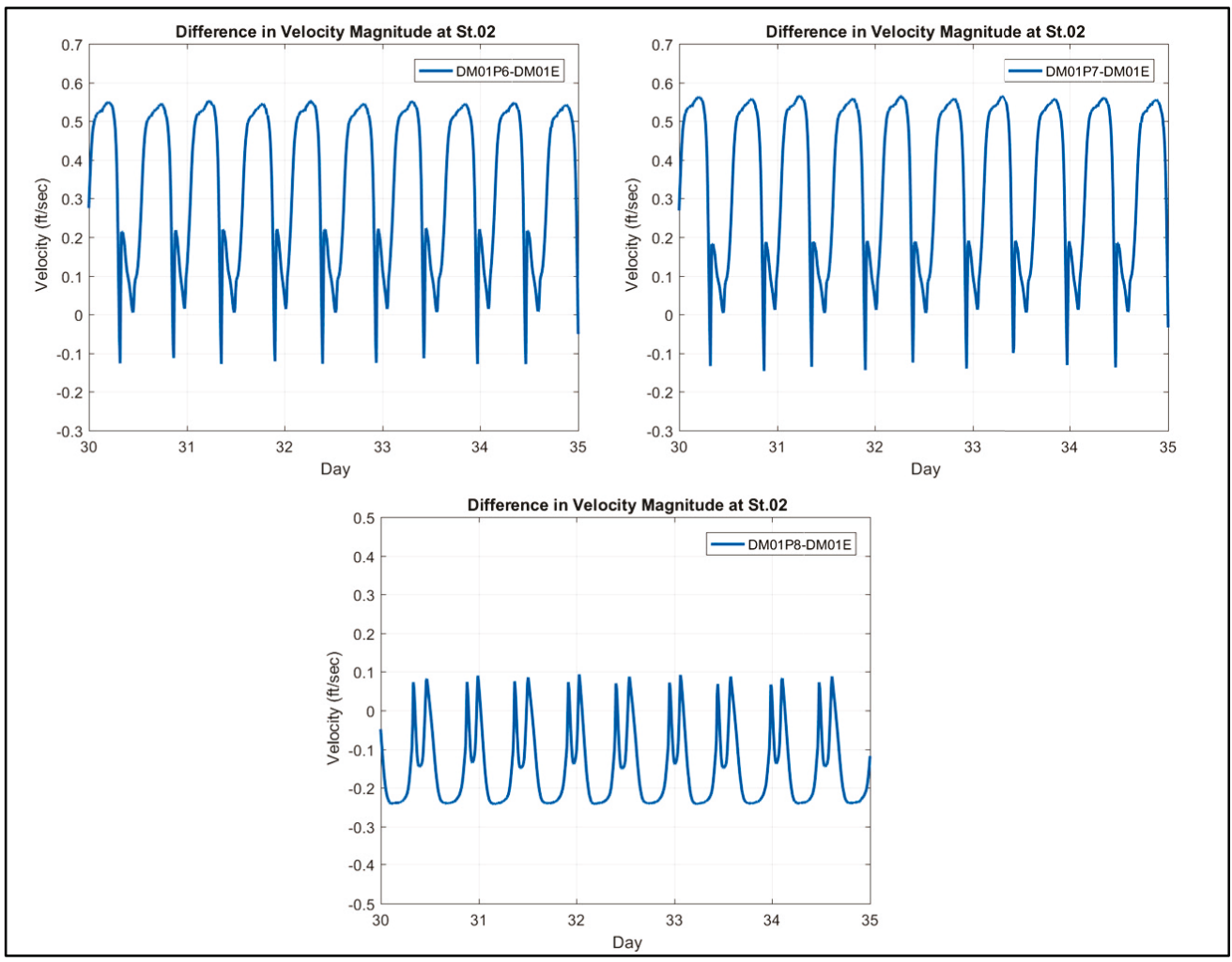

Figure 5-54. Comparisons of water levels ( $\mathrm{ft}$ ) and velocities (ft/s) at Stn 3 for groins.

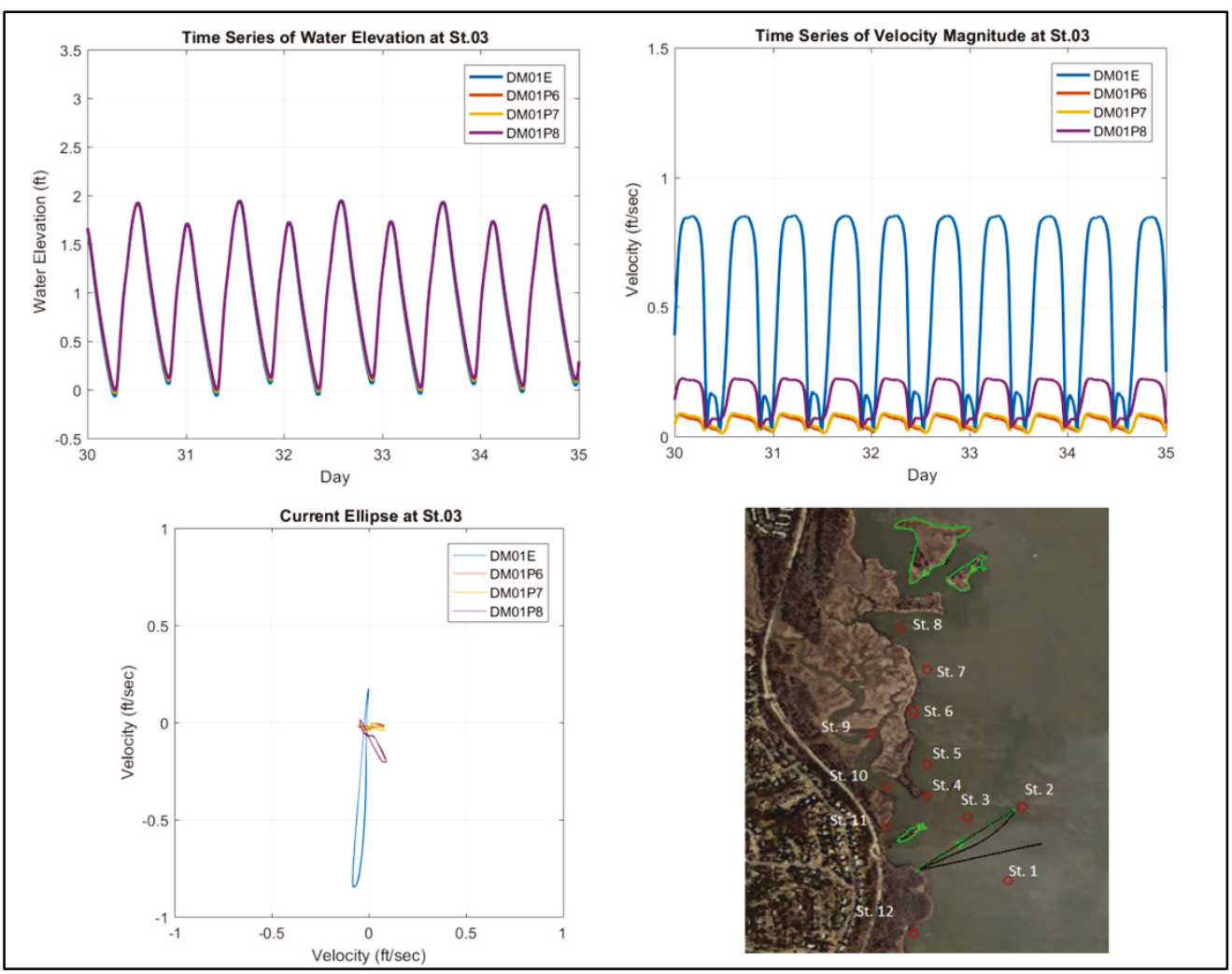


Figure 5-55. Differences in velocity magnitude (ft/s) at $\mathrm{Stn} 3$ with and without structures.

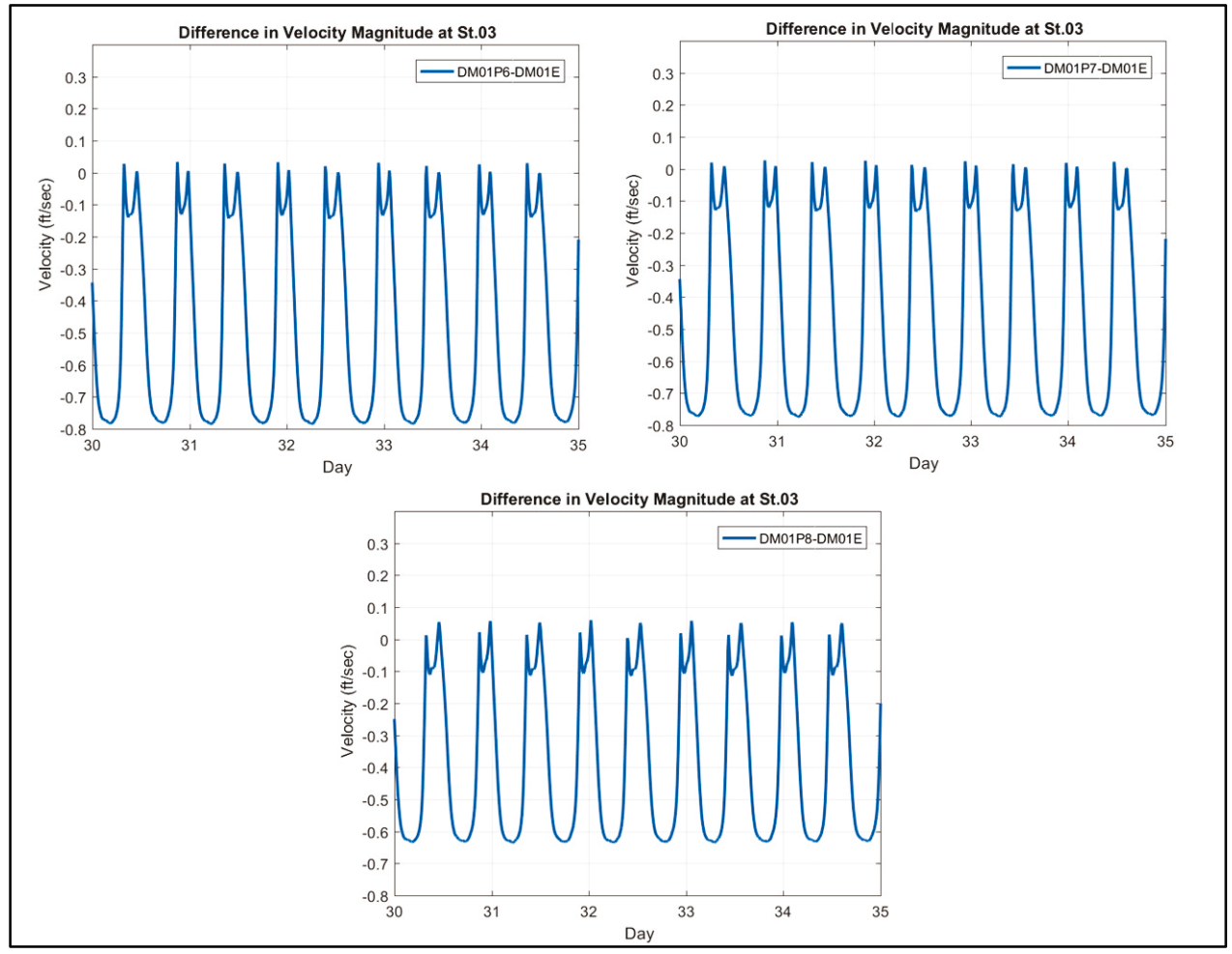

Figure 5-56. Comparisons of water levels ( $\mathrm{ft}$ ) and velocities ( $\mathrm{ft} / \mathrm{s}$ ) at Stn 4 for groins.

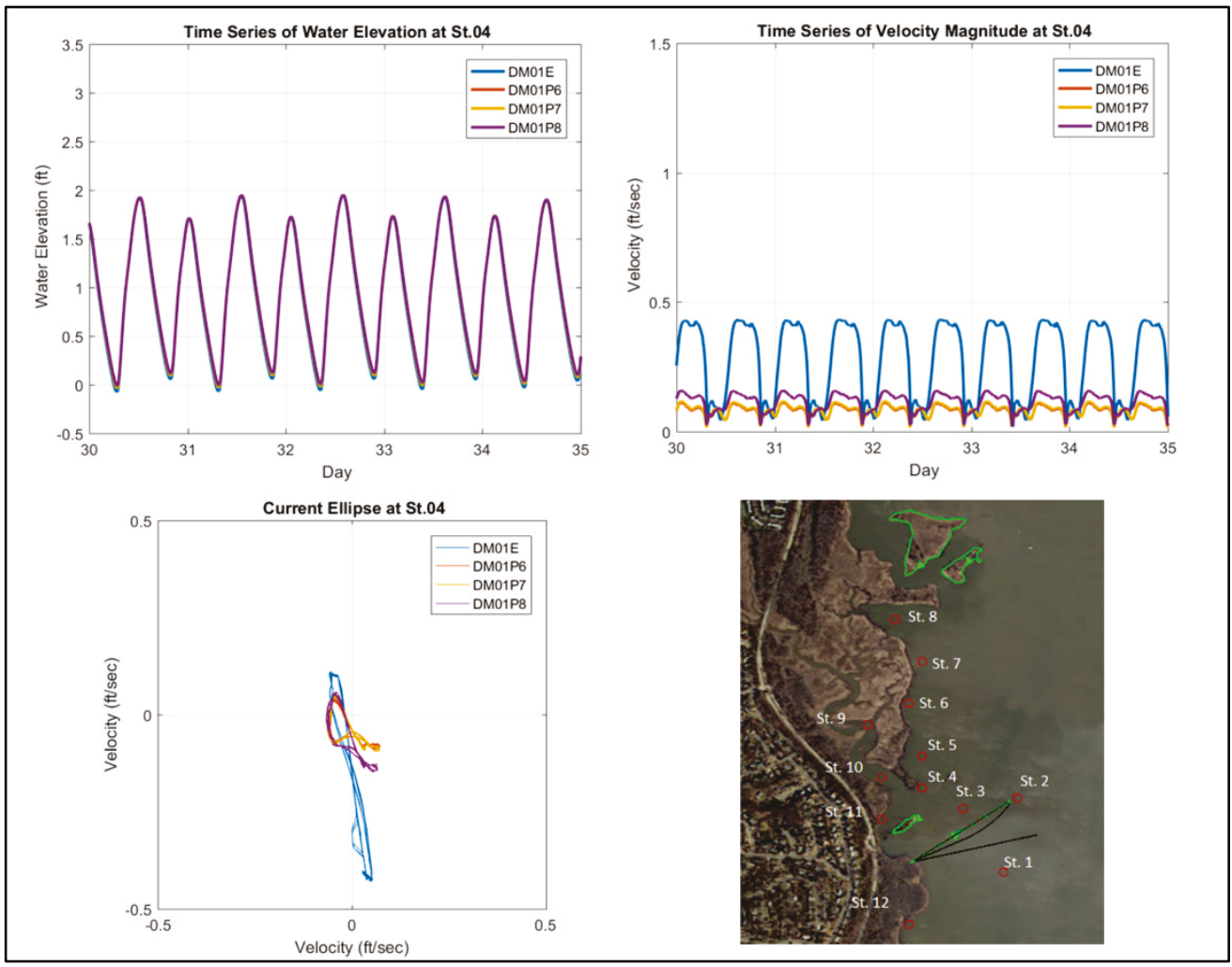


Figure 5-57. Differences in velocity magnitude (ft/s) at Stn 4 with and without structures.

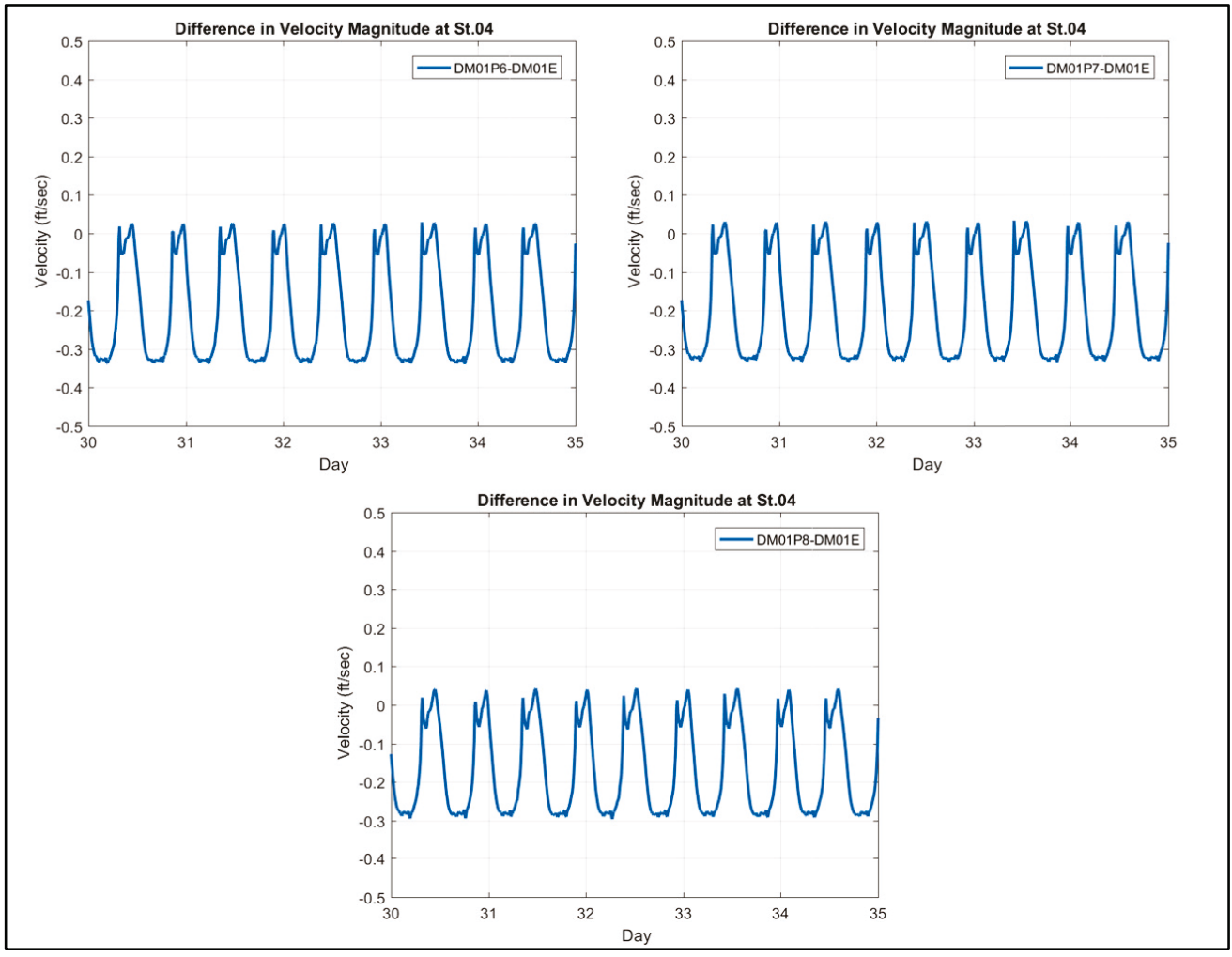

Figure 5-58. Comparisons of water levels (ft) and velocities (ft/s) at Stn 5 for groins.

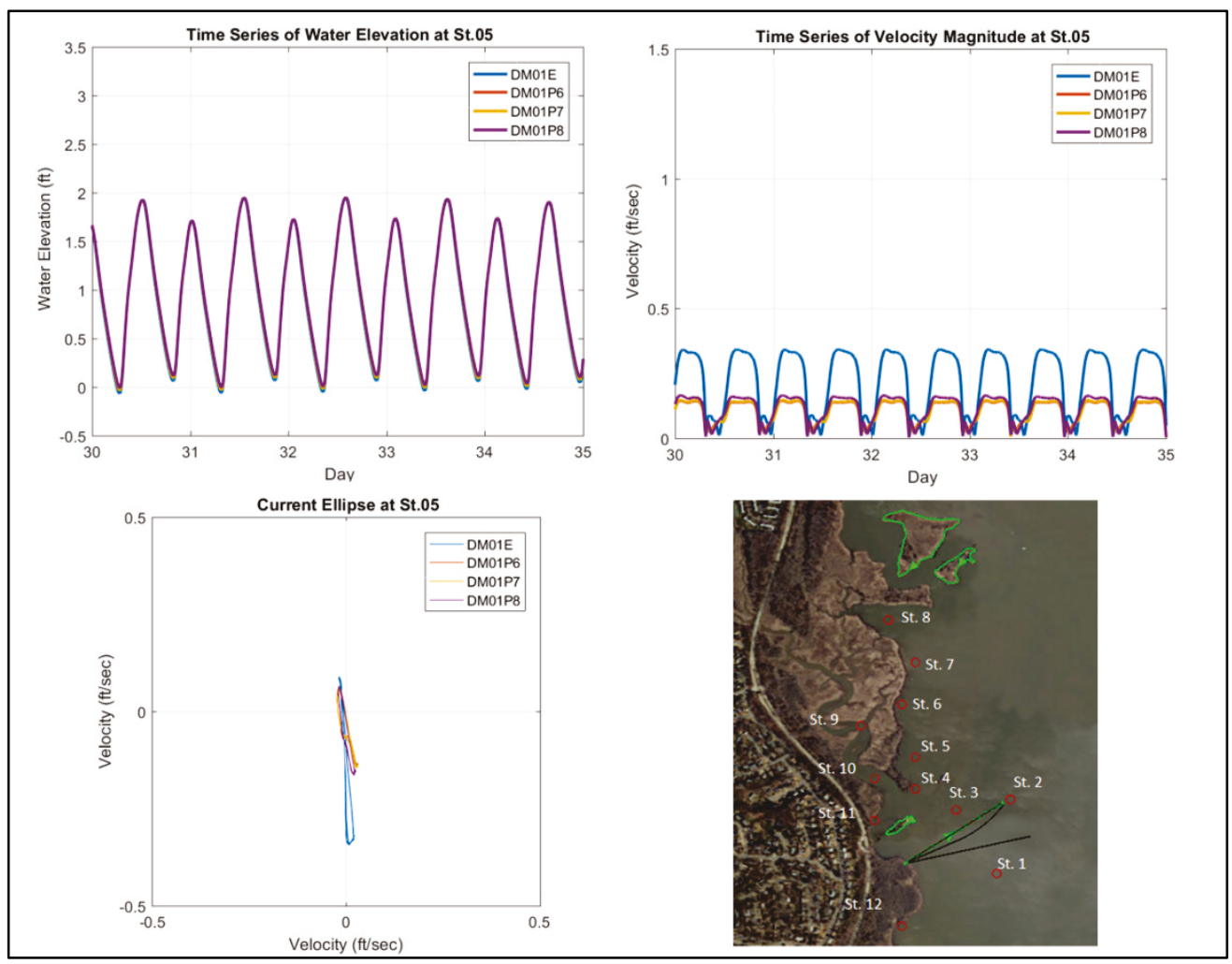


Figure 5-59. Differences in velocity magnitude (ft/s) at Stn 5 with and without structures.

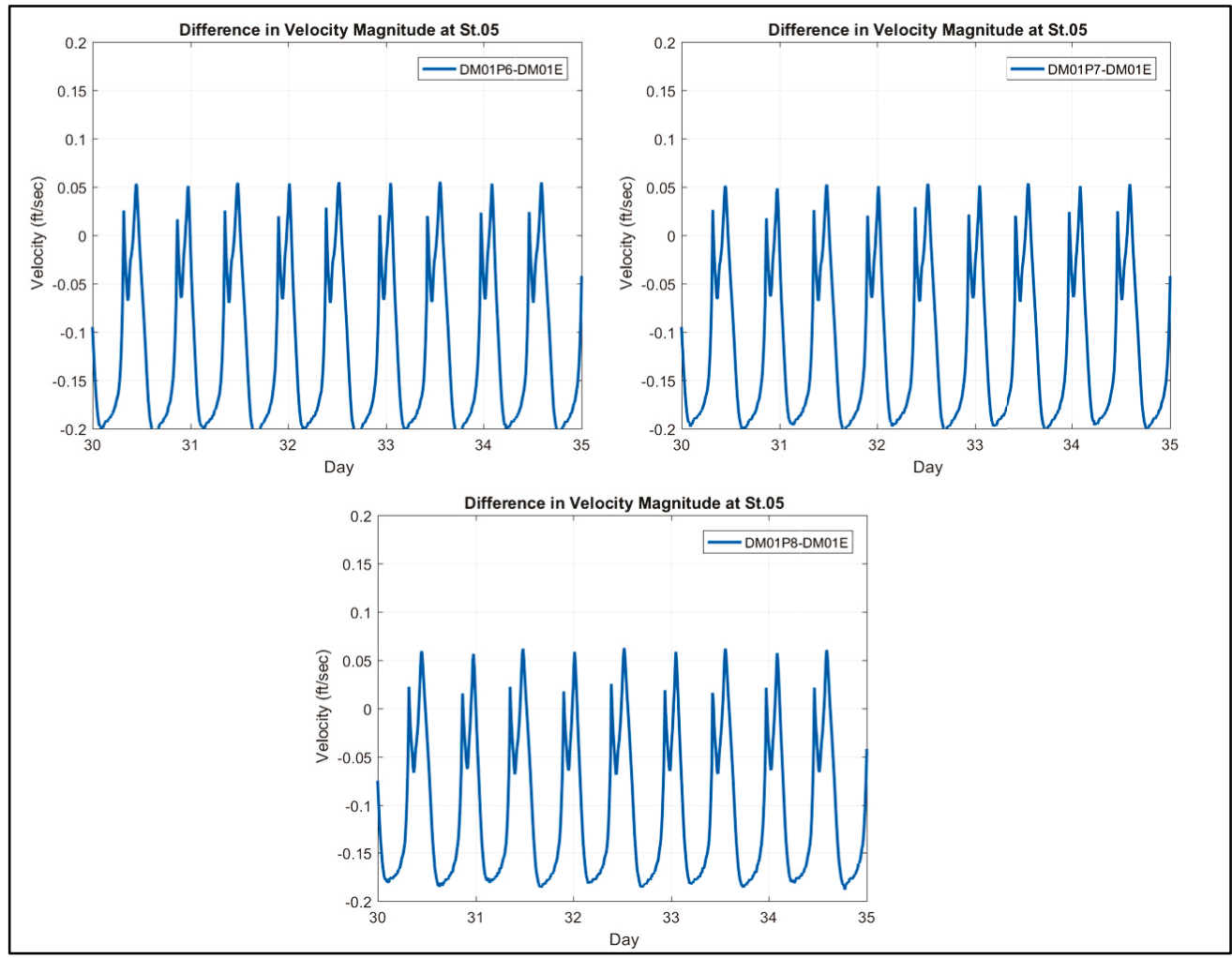

Figure 5-60. Comparisons of water levels (ft) and velocities (ft/s) at Stn 6 for groins.

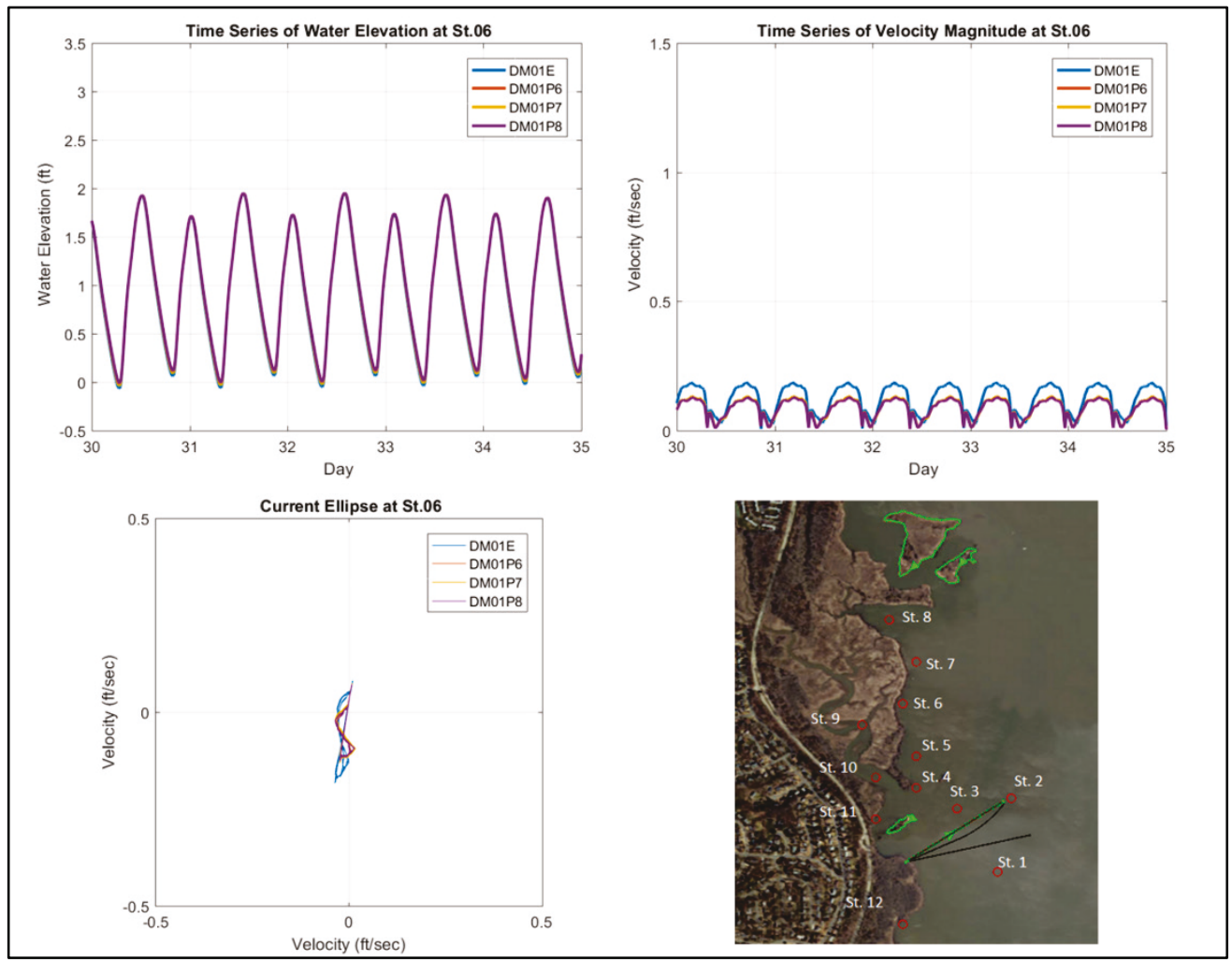


Figure 5-61. Differences in velocity magnitude (ft/s) at $\operatorname{Stn} 6$ with and without structures.

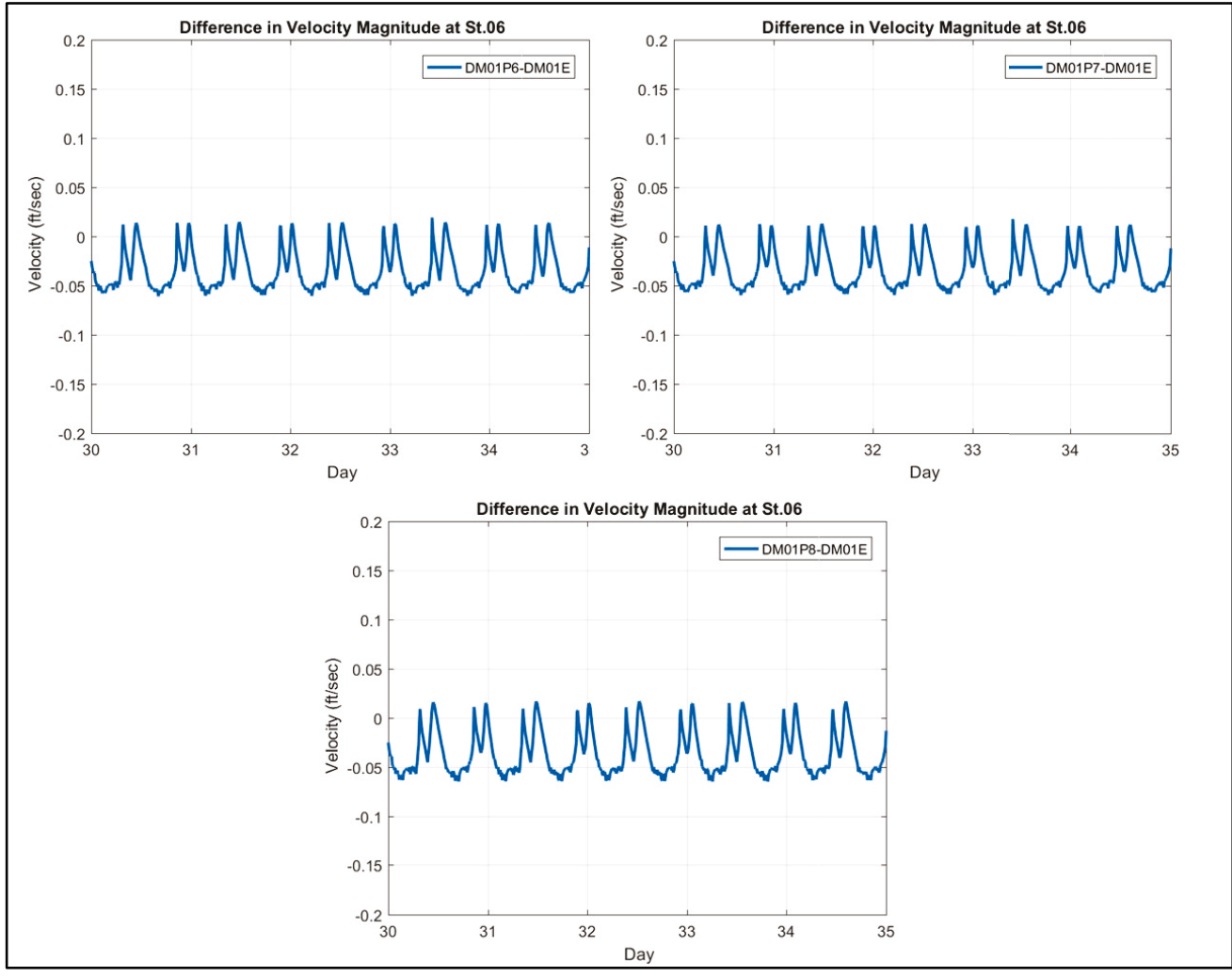

Figure 5-62. Comparisons of water levels $(\mathrm{ft})$ and velocities $(\mathrm{ft} / \mathrm{s})$ at Stn 13 for groins.

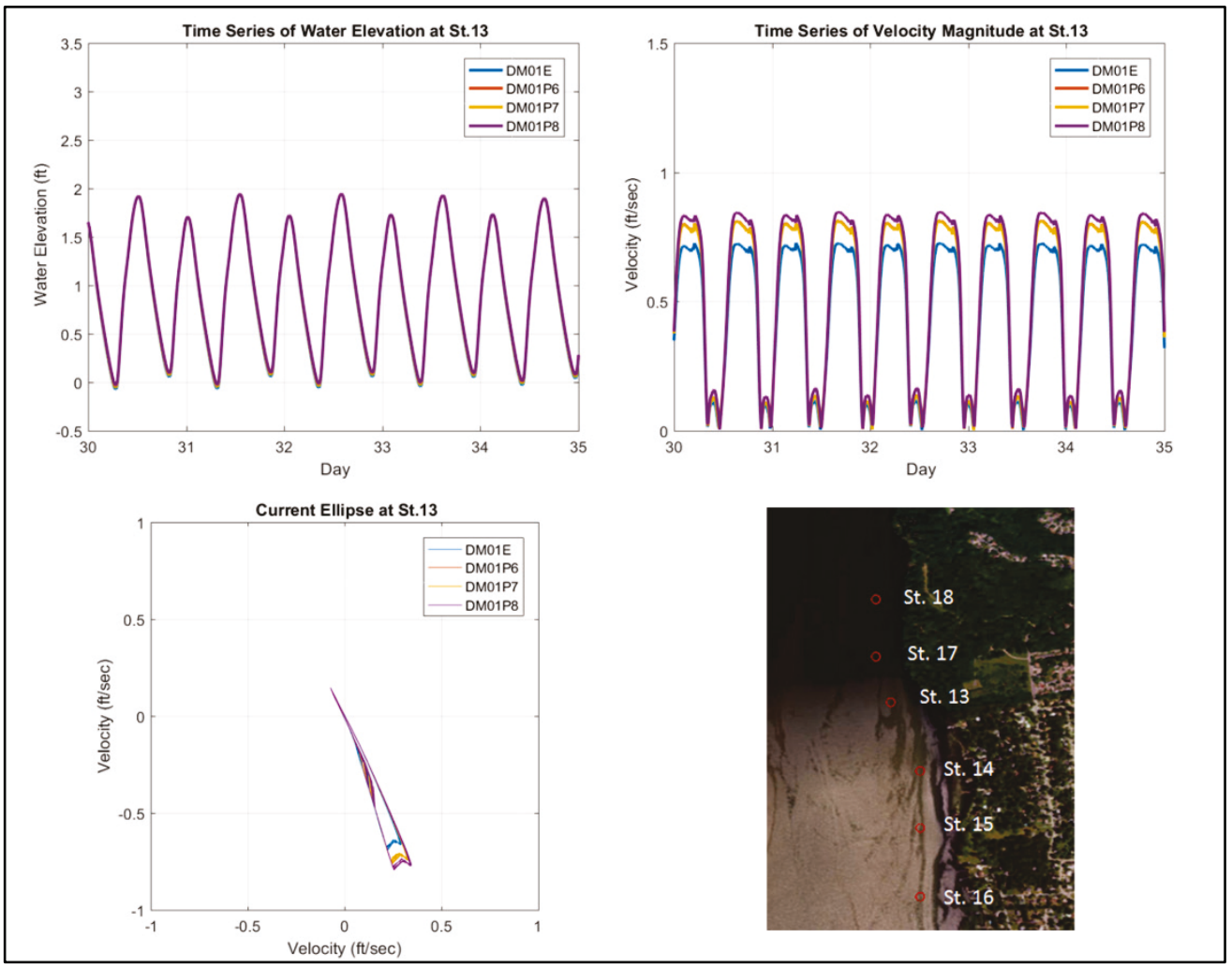


Figure 5-63. Differences in velocity magnitude (ft/s) at Stn 13 with and without structures.

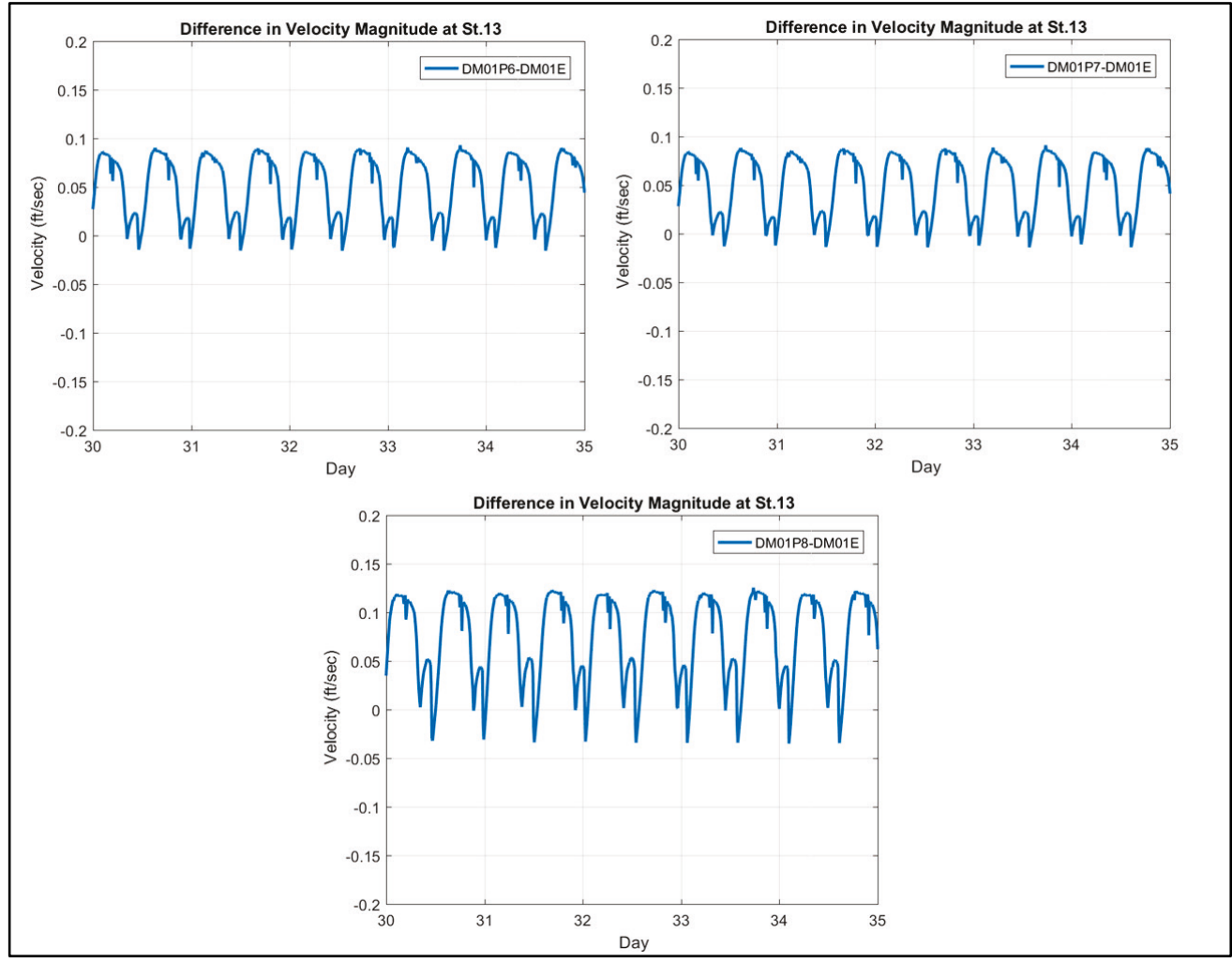

\subsubsection{Results on wind-driven waves for groin designs}

To investigate hydrodynamic responses to the three groin designs with constant winds from various directions, a total of 96 simulations were performed consisting of four mesh configurations, six wind directions, two wind speeds and two flow/tide conditions (see Table 5-58). Similar to the procedure for the promontory designs, each simulation for one design and one wind field was initialized with the previous tidal flow field at the beginning of the 3oth day using the ADCIRC hot start feature. Each wind/wave simulation was for 24 hours under the given constant wind field, with STWAVE wave conditions computed every 30 minutes, and the tides and river flow conditions were kept as they were in the long-term simulations. These cases were designed to model non-storm events under normal flow conditions in order to analyze fetch-limited, wind-driven wave fields in the Dyke Marsh area.

For the high river flow condition $(19,700 \mathrm{cfs})$, simulation velocity results show that the groins reduce current magnitudes in the shadow areas of the structures along the western bank. Figure 5-64 and Figure 5-65 present the current ellipses and flow velocity magnitudes at Stn 3, which is leeward of 
the groin (see Figure 5-45 for the location). The maximum current speed is reduced to approximately $25 \%$ of its without-project condition. Significant wave height at this location is reduced to $33 \%$ of the without-project condition wave height because of blocking by the structures (Figure 5-66). It is found that the groins have a similar capability as the longer promontory design to reduce the wind-driven wave energy and to reduce the velocities in the Potomac River in the area behind the structures. At Stn 5, the groins still impact the flow fields (Figure 5-67 and Figure 5-68). The structures can generally lower the significant wave height down to half (50\%) of that under the current condition (Figure 5-69).

At the eastern bank, the groin installations increase flow velocity compared to the without-project conditions. Figure 5-70 and Figure 5-71 give comparisons of current ellipses and velocity at Stn 15 (see Figure 5-62 for the location). It shows that the maximum flow velocity at this station becomes approximately $33 \%$ faster than the without-project condition, increasing from approximately $0.55 \mathrm{ft} / \mathrm{s}$ to $0.75 \mathrm{ft} / \mathrm{s}$ for the groin Alt 3 configuration. However, as shown in Figure 5-72, the other two groins do not significantly impact the velocity fields on the eastern bank.

For the high river flow condition, the maximum significant wave height values at all the selected 18 stations under the 12 wind conditions are given in Table 5-115. The corresponding wave reduction values of the three groin alternatives at the 18 stations are listed in Table 5-116.

For the low river flow condition $(4,100 \mathrm{cfs})$, the significant wave height values at the 18 stations are listed in Table 5-117. The wave heights for the low flow condition are slightly smaller than those in the high flow. Nevertheless, the same levels of change seen with the higher flow rates are seen with the lower river flow rates. The maximum wave reduction values of the three groins for the 18 stations are listed in Table 5-118. 
Figure 5-64. Current Ellipses at Stn 3 by $20 \mathrm{mph}$ wind from six directions.

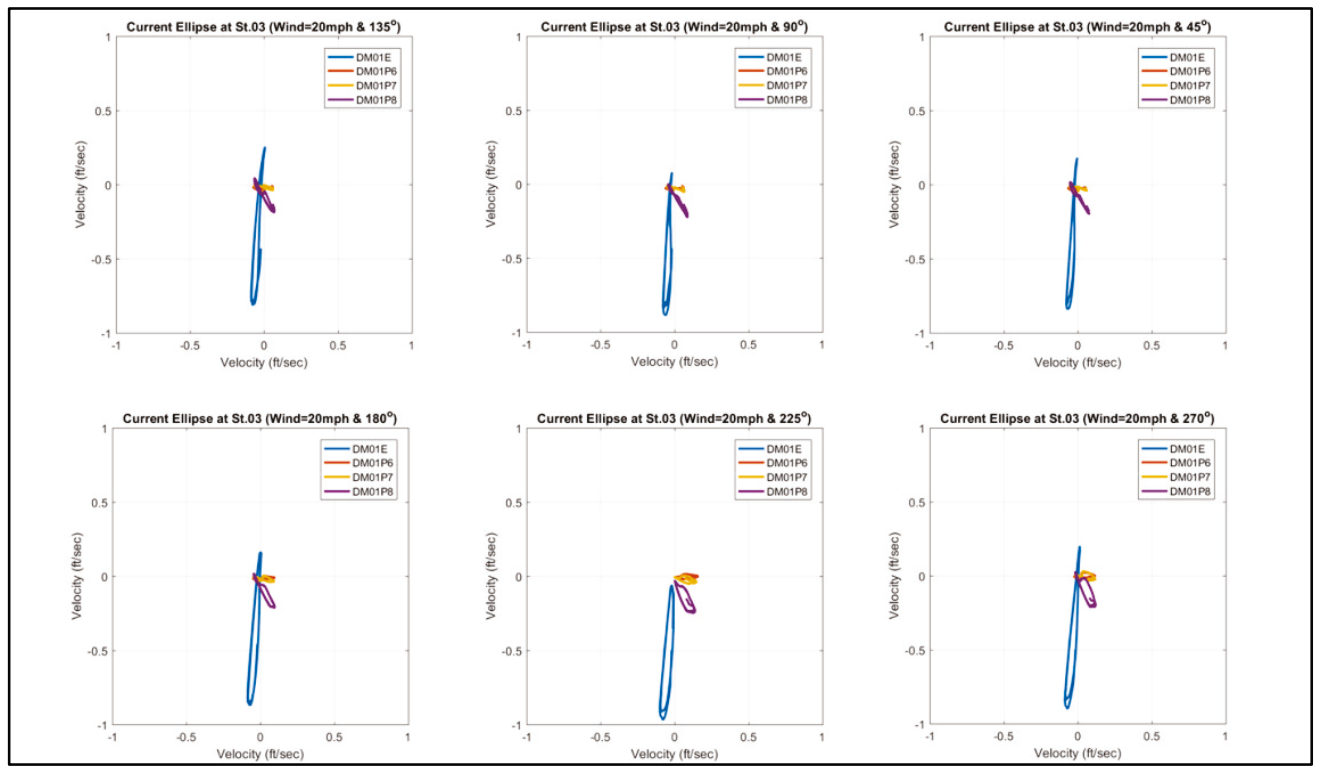

Figure 5-65. Flow velocity magnitudes at Stn 3 by $20 \mathrm{mph}$ wind from six directions.

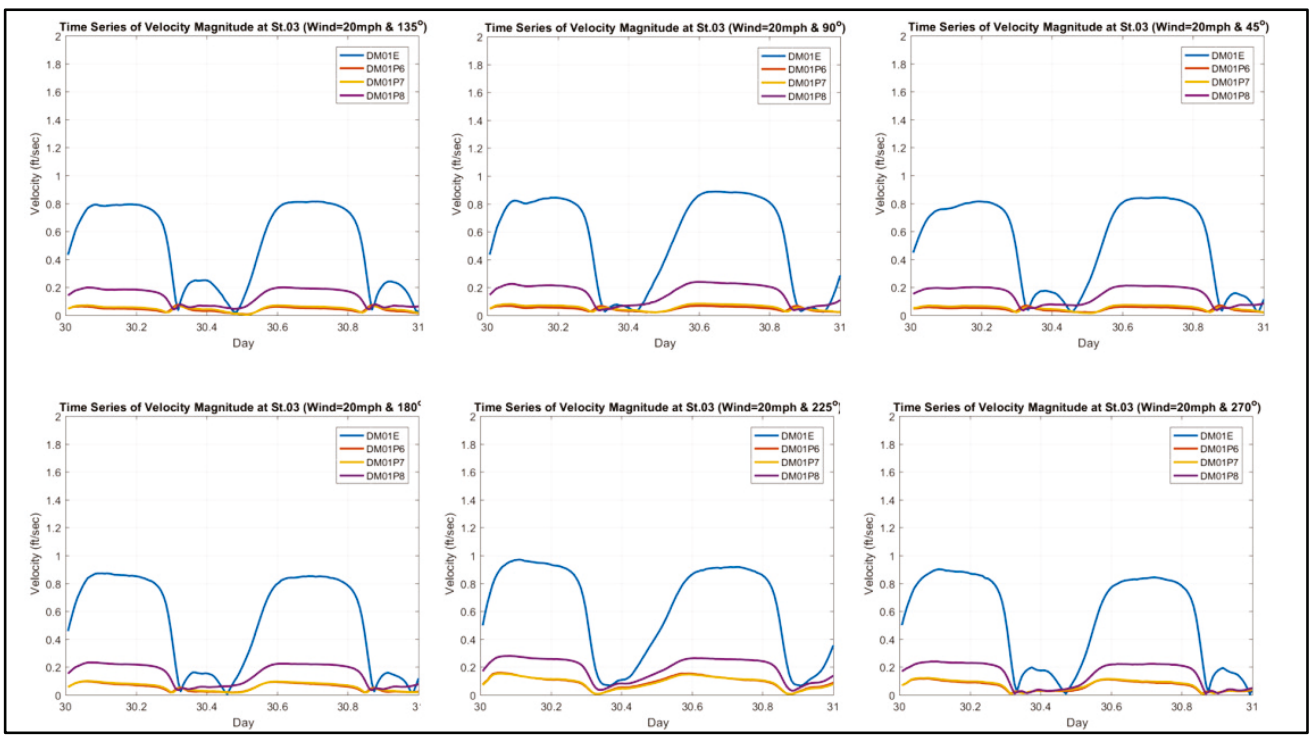


Figure 5-66. Time series of significant wave heights and water levels at Stn 3 by $20 \mathrm{mph}$ wind from south $\left(90^{\circ}\right)$.

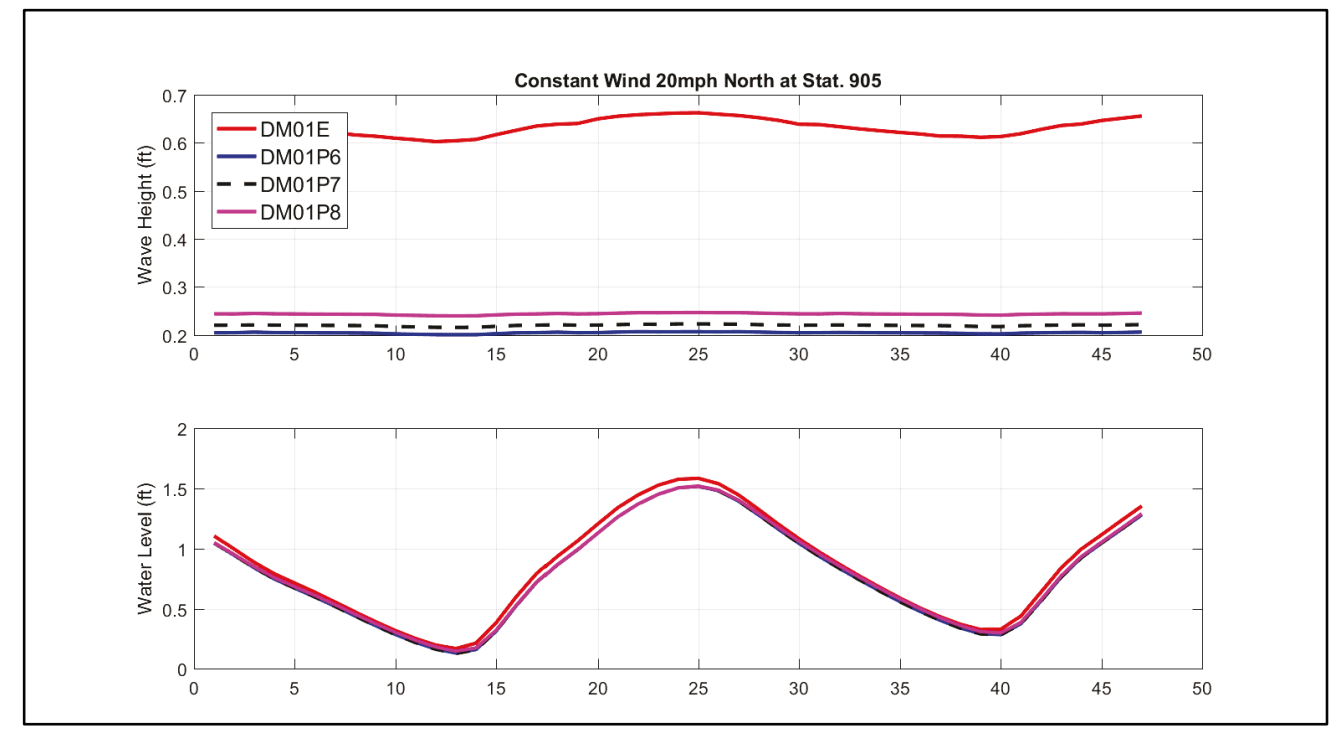

Figure 5-67. Current Ellipses at Stn 5 by $20 \mathrm{mph}$ wind from six directions.

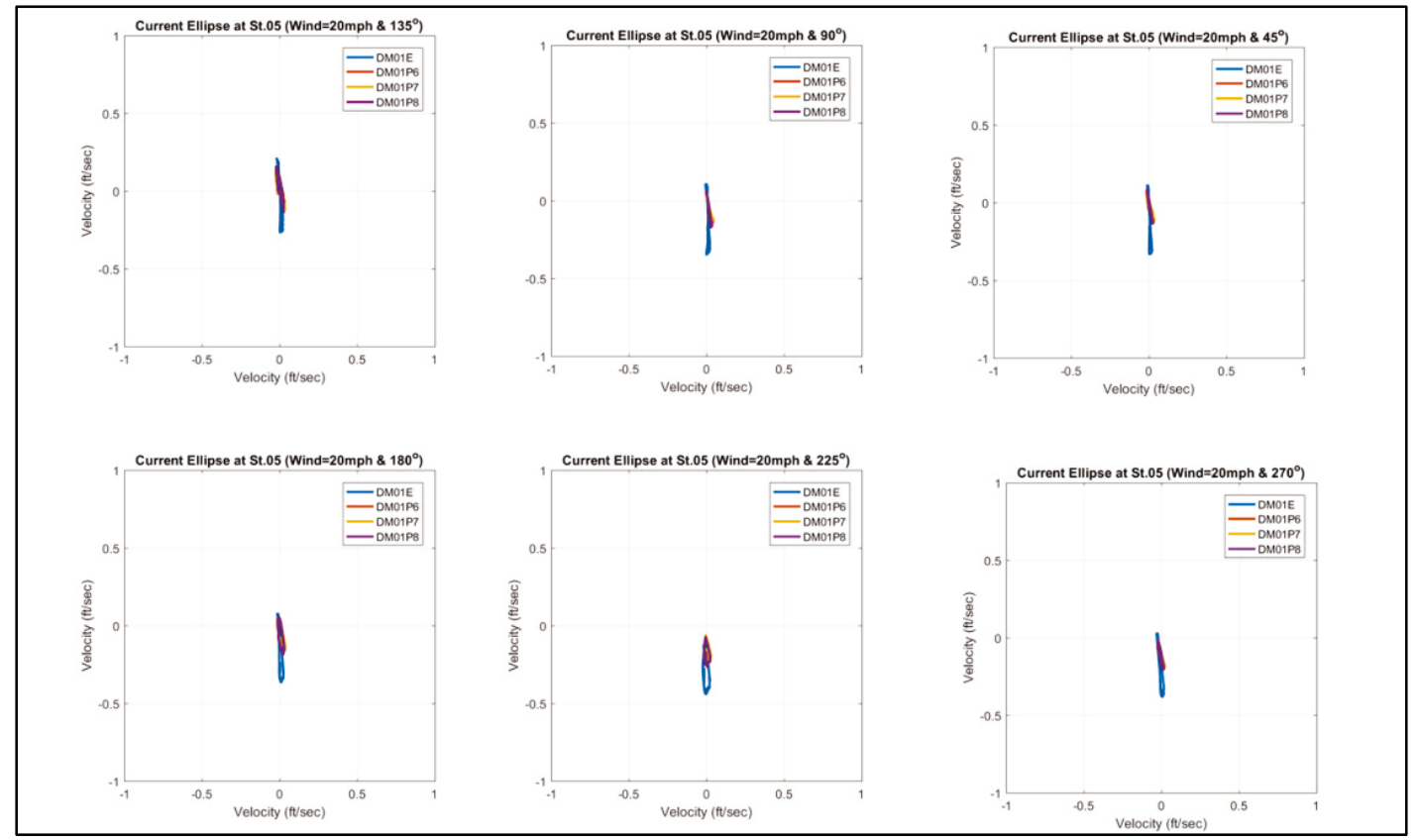


Figure 5-68. Flow velocity magnitudes at Stn 5 by $20 \mathrm{mph}$ wind from six directions.

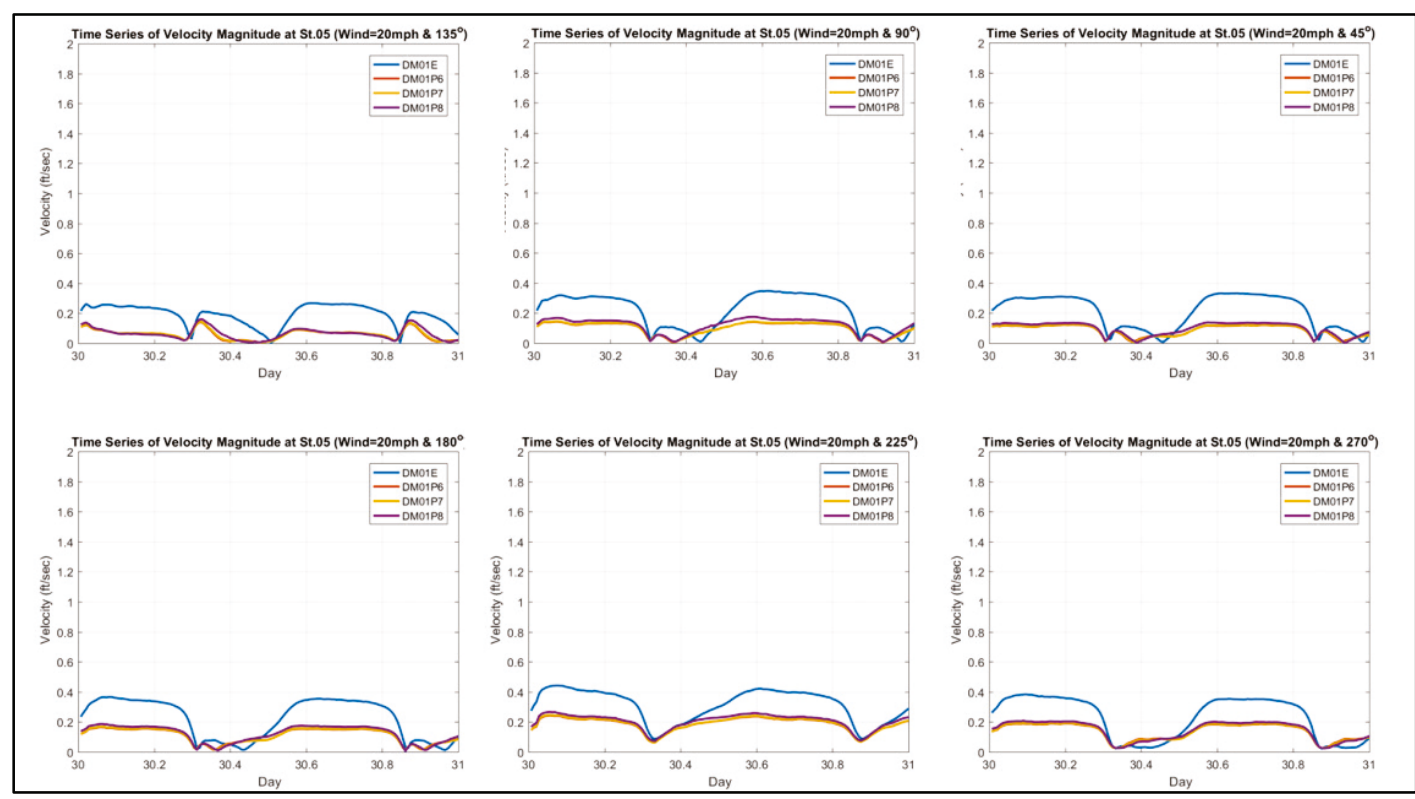

Figure 5-69. Time series of significant wave heights and water levels at Stn 5 by $20 \mathrm{mph}$ wind from south $\left(90^{\circ}\right)$.

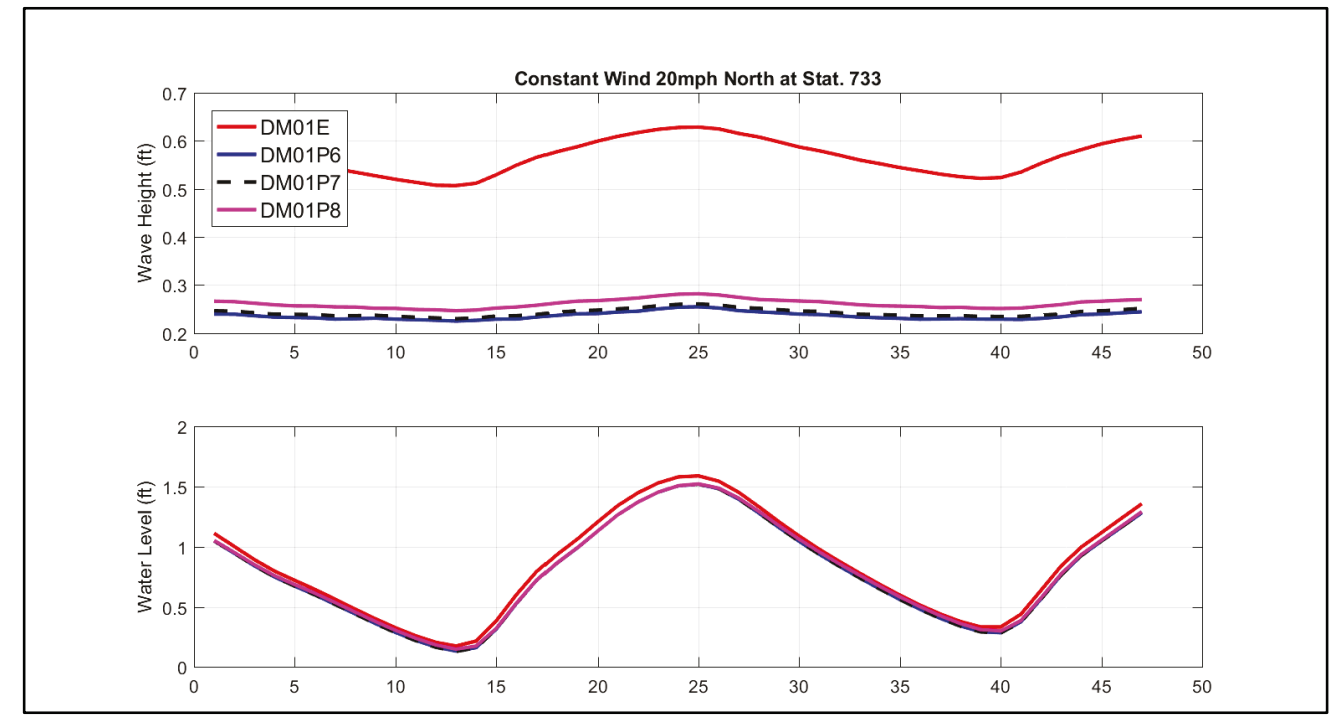


Figure 5-70. Current Ellipses at Stn 15 by $20 \mathrm{mph}$ wind from six directions.

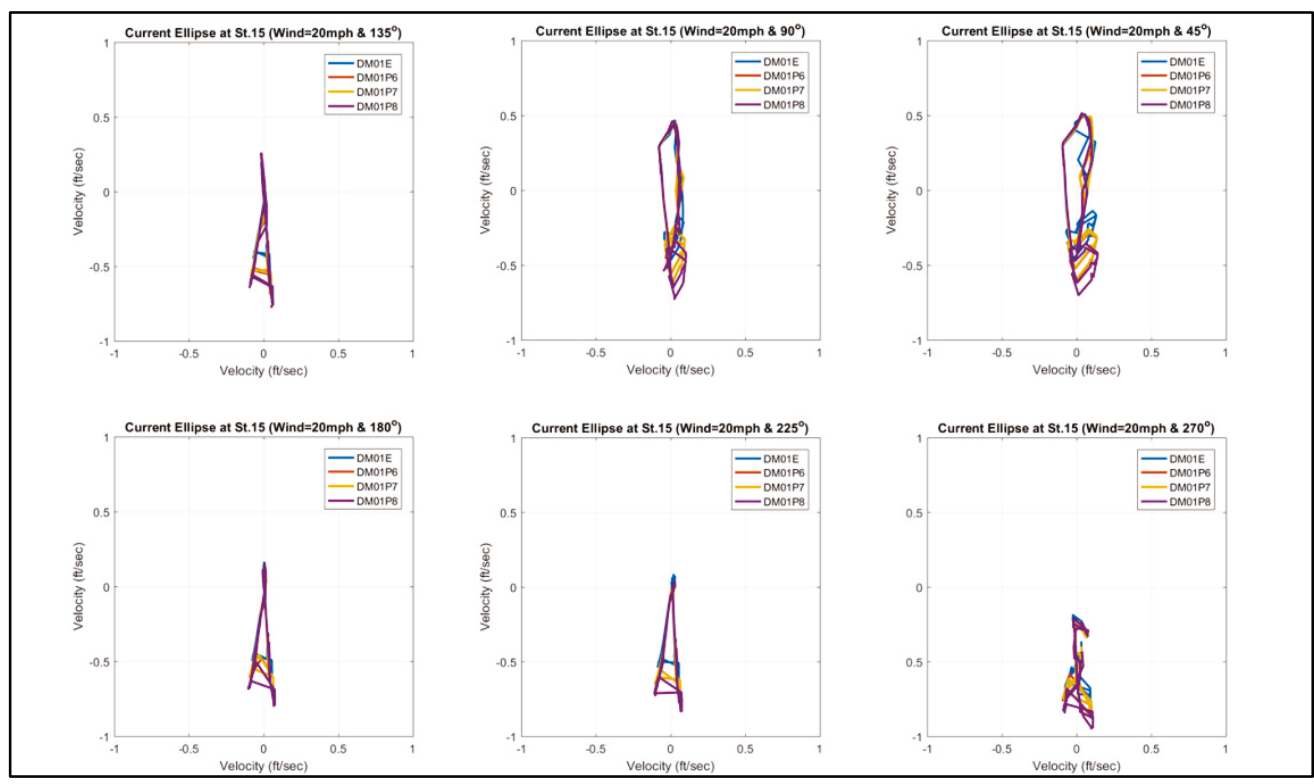

Figure 5-71. Flow velocity magnitudes at Stn 15 by $20 \mathrm{mph}$ wind from six directions.

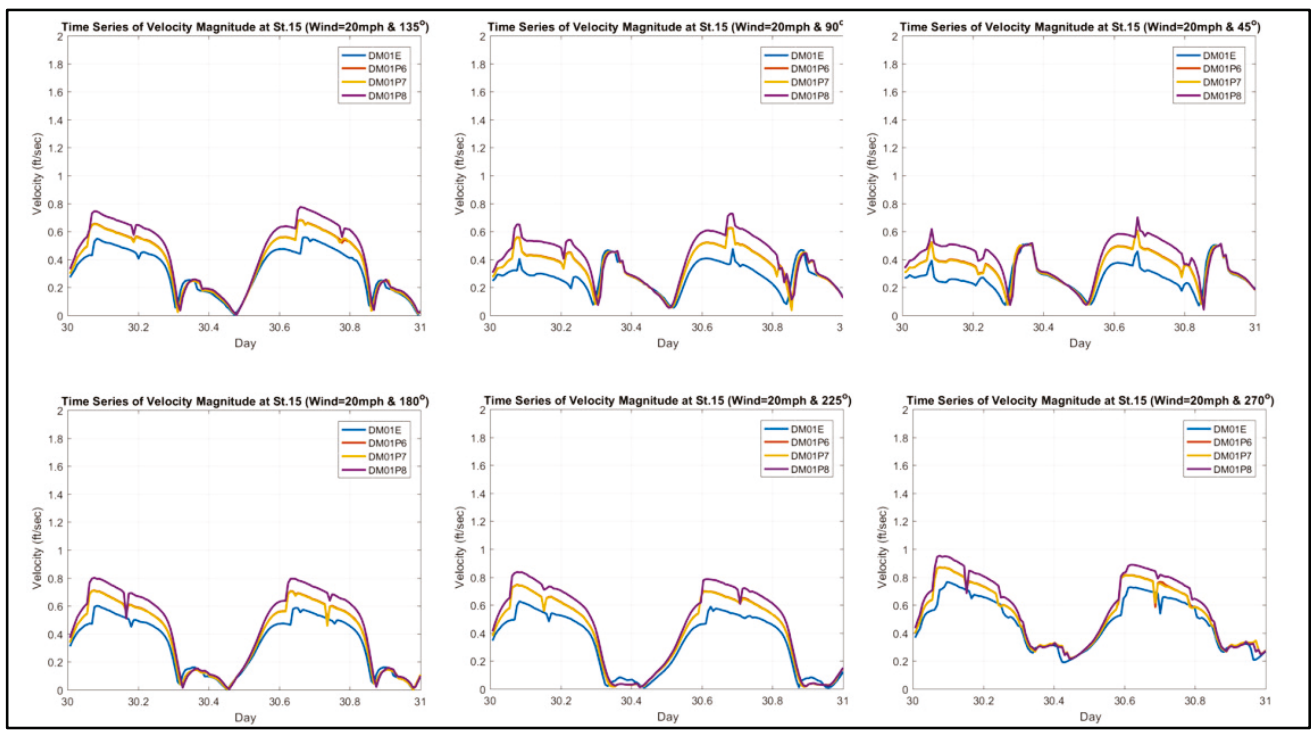


Figure 5-72. Time series of significant wave heights and water levels at Stn 15 by $20 \mathrm{mph}$ wind from south $\left(90^{\circ}\right)$.

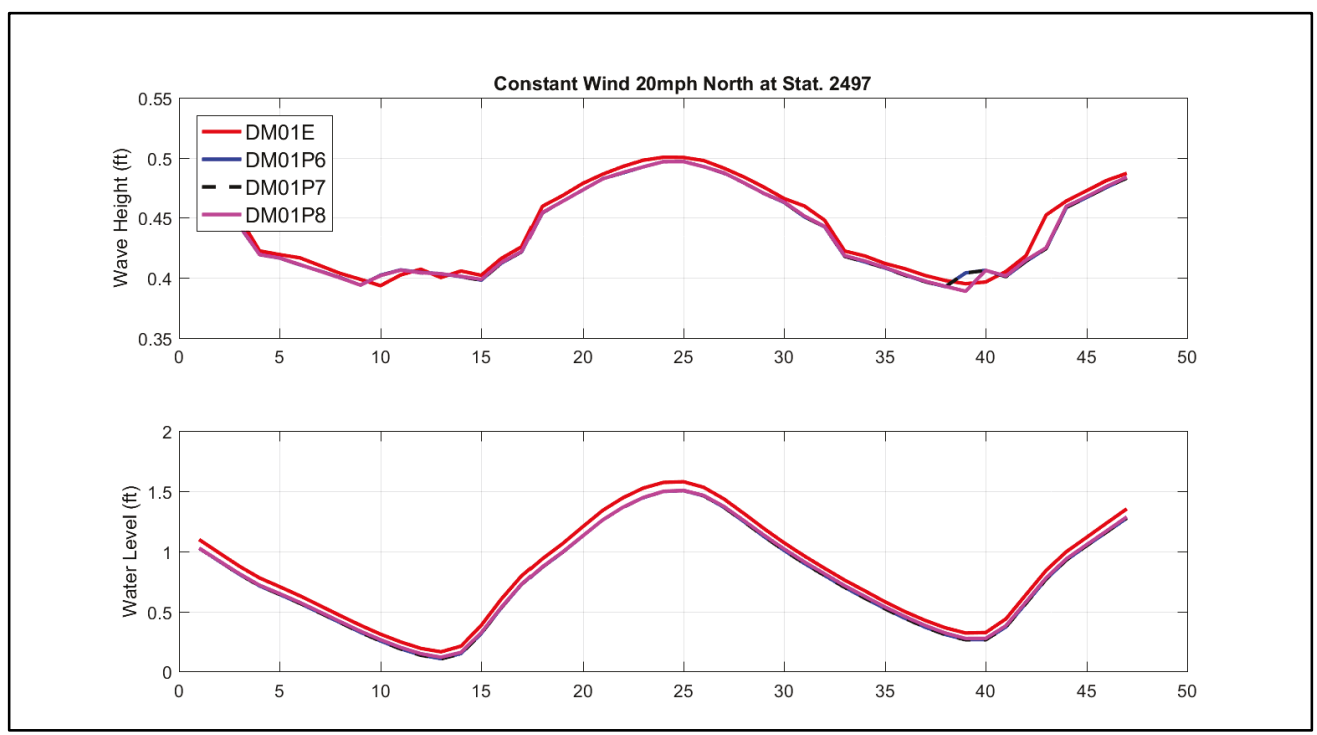


Table 5-115. Maximum significant wave height values in feet at the 18 locations under spring tides and high river flow.

\begin{tabular}{|c|c|c|c|c|c|c|c|c|c|c|c|c|c|c|c|c|c|c|c|}
\hline & Structure & 1 & 2 & 3 & 4 & 5 & 6 & 7 & 8 & 9 & 1 & 11 & 12 & 13 & 14 & 15 & 16 & 17 & 18 \\
\hline \multirow{4}{*}{ 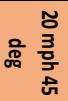 } & DM01E & 0.268 & 0.301 & 0.23 & 0.224 & 0.186 & 0.157 & 0.186 & 0.191 & 0.179 & 0.198 & 0.1 & 0.087 & 0.444 & 0.453 & 0.459 & 0.461 & 0.000 & 0.460 \\
\hline & \begin{tabular}{|l|} 
DM01P6 \\
\end{tabular} & 0.263 & 0.281 & 0.213 & 0.214 & 0.183 & 0.155 & 0.184 & 0.190 & 0.179 & 0.196 & 0.166 & 0.087 & 0.443 & 0.452 & 0.460 & 0.458 & 0.000 & 0.458 \\
\hline & DM01P7 & 0.263 & 0.271 & 0.219 & 0.214 & 0.183 & 0.155 & 0.183 & 0.190 & 0.179 & 0.196 & 0.166 & 0.087 & 0.443 & 0.452 & 0.460 & 0.458 & 0.000 & 0.459 \\
\hline & \begin{tabular}{|l} 
DM01P8 \\
\end{tabular} & 0.263 & 0.255 & 0.225 & 0.214 & 0.183 & 0.155 & 0.183 & 0.191 & 0.179 & 0.196 & 0.166 & 0.088 & 0.440 & 0.452 & 0.459 & 0.457 & 0.000 & 0.456 \\
\hline \multirow{4}{*}{ 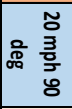 } & DM01E & 0.670 & 0.726 & 0.659 & 0.597 & 0.622 & 0.529 & 0.668 & 0.422 & 0.186 & 0.309 & 0.193 & 0.299 & 0.333 & 0.477 & 0.497 & 0.538 & 0.000 & 0.398 \\
\hline & DM01P6 & 0.670 & 0.723 & 0.207 & 0.229 & 0.255 & 0.258 & 0.456 & 0.354 & 0.178 & 0.195 & 0.176 & 0.299 & 0.332 & 0.477 & 0.497 & 0.537 & 0.000 & $\begin{array}{l}0.397 \\
\end{array}$ \\
\hline & \begin{tabular}{|l|l|l|} 
MM01P7 \\
\end{tabular} & 0.670 & 0.718 & 0.223 & 0.231 & 0.261 & 0.265 & 0.460 & 0.355 & 0.178 & 0.201 & 0.176 & 0.299 & 0.332 & 0.477 & 0.497 & 0.537 & 0.000 & 0.397 \\
\hline & \begin{tabular}{|l|} 
DM01P8 \\
\end{tabular} & \begin{tabular}{l|}
0.670 \\
\end{tabular} & 0.415 & 0.247 & 0.246 & 0.282 & 0.281 & 0.453 & 0.353 & 0.179 & 0.205 & 0.176 & 0.298 & 0.332 & 0.477 & 0.497 & 0.537 & 0.000 & 0.394 \\
\hline \multirow{4}{*}{ 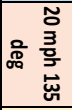 } & DM01E & 0.559 & 0.584 & 0.655 & 0.611 & 0.643 & 0.599 & 0.656 & 0.578 & 0.189 & 0.387 & 0.484 & 0.479 & 0.199 & 0.250 & 0.266 & 0.296 & 0.000 & 0.233 \\
\hline & DM01P6 & 0.559 & 0.584 & 0.291 & 0.293 & 0.420 & 0.535 & 0.606 & 0.565 & 0.188 & 0.269 & 0.220 & 0.479 & 0.199 & 0.250 & 0.266 & 0.296 & 0.000 & 0.233 \\
\hline & DM01P7 & 0.559 & 0.584 & 0.300 & 0.307 & 0.425 & 0.537 & 0.607 & 0.566 & 0.188 & 0.277 & 0.222 & 0.479 & 0.199 & 0.250 & 0.266 & 0.296 & 0.000 & 0.233 \\
\hline & \begin{tabular}{|l|} 
DM01P8 \\
\end{tabular} & 0.559 & 0.503 & 0.365 & 0.378 & 0.487 & 0.547 & 0.608 & 0.568 & 0.189 & 0.300 & 0.237 & 0.479 & 0.199 & 0.250 & 0.266 & 0.296 & 0.000 & 0.233 \\
\hline \multirow{4}{*}{ 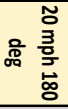 } & DM01E & 0.351 & 0.342 & 0.368 & 0.376 & 0.390 & 0.369 & 0.367 & 0.335 & 0.135 & 0.203 & 0.360 & 0.366 & 0.146 & 0.161 & 0.157 & 0.169 & 0.000 & 0.160 \\
\hline & \begin{tabular}{|l|} 
DM01P6 \\
\end{tabular} & 0.349 & 0.342 & 0.281 & 0.374 & 0.389 & 0.369 & 0.367 & 0.335 & 0.140 & 0.198 & 0.294 & 0.366 & 0.146 & 0.161 & 0.157 & 0.169 & 0.000 & 0.160 \\
\hline & \begin{tabular}{|l|} 
DM01P7 \\
\end{tabular} & 0.349 & 0.342 & 0.286 & 0.374 & 0.389 & 0.369 & 0.367 & 0.335 & 0.141 & 0.198 & 0.298 & 0.366 & 0.146 & 0.161 & 0.157 & 0.169 & 0.000 & 0.160 \\
\hline & DM01P8 & 0.346 & 0.342 & 0.370 & 0.376 & 0.389 & 0.370 & 0.367 & 0.335 & 0.141 & 0.204 & 0.343 & 0.364 & 0.146 & 0.161 & 0.157 & 0.169 & 0.000 & 0.160 \\
\hline \multirow{4}{*}{ 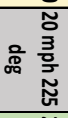 } & DM01E & 0.569 & 0.607 & 0.714 & 0.672 & 0.751 & 0.630 & 0.647 & 0.375 & 0.145 & 0.262 & 0.410 & 0.414 & 0.166 & 0.188 & 0.192 & 0.201 & 0.000 & 0.181 \\
\hline & DMC & 0.563 & 0.608 & 0.693 & 0.672 & 0.752 & & 0.647 & 0.376 & & & 0.406 & 0.411 & & & & & 0.000 & 0.181 \\
\hline & \begin{tabular}{|l} 
DMO1P7 \\
\end{tabular} & $\begin{array}{l}0.564 \\
0.56\end{array}$ & 0.607 & 0.695 & 0.672 & 0.752 & 0.630 & 0.647 & 0.376 & 0.145 & 0.264 & $\begin{array}{l}0.407 \\
0.40\end{array}$ & 0.410 & 0.166 & 0.188 & 0.191 & 0.201 & 0.000 & 0.181 \\
\hline & \begin{tabular}{|l} 
DM01P8 \\
\end{tabular} & 0.426 & 0.608 & 0.714 & 0.673 & 0.752 & 0.631 & 0.647 & 0.376 & 0.145 & 0.269 & 0.412 & 0.397 & 0.166 & 0.188 & 0.192 & 0.201 & 0.000 & 0.181 \\
\hline \multirow{4}{*}{ 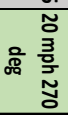 } & DM01E & 0.779 & 0.702 & 0.662 & 0.502 & 0.494 & 0.387 & 0.423 & 0.215 & 0.160 & 0.197 & 0.263 & 0.295 & 0.184 & 0.320 & 0.422 & 0.489 & 0.000 & 0.421 \\
\hline & & 0.629 & 0.702 & 0.660 & 0.503 & 0.494 & 0.385 & 0.423 & 0.216 & & 0.197 & 0.2 & 0.272 & & & & & 0.000 & 0.421 \\
\hline & \begin{tabular}{|l|} 
DMO1P7 \\
\end{tabular} & 0.624 & 0.702 & 0.660 & 0.503 & 0.494 & 0.385 & 0.423 & 0.216 & 0.160 & 0.196 & 0.260 & 0.270 & 0.184 & 0.320 & 0.422 & 0.488 & 0.000 & 0.421 \\
\hline & \begin{tabular}{|l|l|} 
MM01P8 \\
\end{tabular} & 0.396 & 0.702 & 0.662 & 0.503 & 0.494 & 0.386 & 0.424 & 0.214 & 0.160 & 0.197 & 0.262 & 0.256 & 0.184 & 0.320 & 0.423 & 0.489 & 0.000 & 0.421 \\
\hline \multirow{4}{*}{ 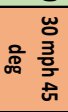 } & DM01E & 0.460 & 0.505 & 0.405 & 0.358 & 0.331 & 0.220 & 0.298 & 0.317 & 0.298 & 0.297 & 0.230 & 0.100 & 0.737 & 0.737 & 0.749 & 0.750 & 0.000 & 0.770 \\
\hline & DMO & 0.459 & 0.457 & 0.359 & 0.342 & 0.316 & 0.216 & 0.290 & 0.317 & & 0.2 & 0.226 & 0.100 & & & 0.750 & & 0.000 & 0.767 \\
\hline & \begin{tabular}{|l} 
DM01P7 \\
\end{tabular} & 0.459 & 0.426 & 0.367 & 0.342 & 0.316 & 0.216 & 0.290 & 0.317 & 0.296 & 0.293 & 0.226 & 0.100 & 0.734 & 0.737 & 0.750 & 0.746 & 0.000 & 0.766 \\
\hline & \begin{tabular}{|l|l|} 
MM01P8 \\
\end{tabular} & 0.459 & 0.426 & 0.375 & 0.342 & 0.316 & 0.217 & 0.291 & 0.318 & 0.297 & 0.293 & 0.226 & 0.101 & 0.729 & 0.736 & 0.749 & 0.745 & 0.000 & 0.762 \\
\hline \multirow{4}{*}{ 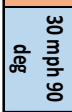 } & DMC & 1.152 & 1.218 & 1.117 & & & 0.866 & & & & & & & & & & & 0.995 & 0.620 \\
\hline & & 1.152 & 1.212 & 0.313 & & t & 0.463 & 0.746 & 0.612 & & 0.3 & 0.2 & 0.5 & & & 0.824 & & 0.995 & .618 \\
\hline & DM01P7 & 1.152 & 1.201 & 0.346 & 0.384 & 0.457 & 0.472 & 0.752 & 0.615 & 0.364 & 0.352 & 0.243 & 0.520 & 0.907 & 0.807 & 0.824 & 0.902 & 0.995 & 0.618 \\
\hline & DM01P8 & 1.152 & 0.678 & 0.388 & 0.404 & 0.481 & 0.486 & 0.744 & 0.615 & 0.368 & 0.360 & 0.245 & 0.520 & 0.906 & 0.807 & 0.824 & 0.902 & 0.993 & 0.611 \\
\hline \multirow{4}{*}{ 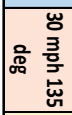 } & DM01E & 0.951 & 1.005 & 1.113 & 0.995 & & 0.981 & 1.089 & 0.946 & & 0.606 & & & & & & 0.495 & 0.000 & 0.315 \\
\hline & \begin{tabular}{|l|} 
DM01 \\
\end{tabular} & 0.951 & 1.005 & .392 & 0.453 & 688 & 0.902 & 1.014 & 0.929 & 316 & 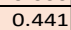 & 0.358 & 0.800 & 0.280 & - & 0.436 & 0.495 & 0.000 & 0.314 \\
\hline & \begin{tabular}{|l|l|l|} 
DM1P7 \\
\end{tabular} & 0.951 & 1.005 & 0.443 & 0.478 & 0.696 & 0.904 & 1.015 & 0.929 & 12 & 0.452 & 0.371 & 0.800 & 0.280 & 0.386 & 0.436 & 0.495 & 0.000 & 0.314 \\
\hline & DM01P8 & 0.950 & 0.874 & 0.592 & 0.603 & 0.817 & 0.919 & 1.016 & 0.928 & & 0.491 & & 0.800 & 0.280 & & 0.436 & 0.495 & 0.000 & 0.315 \\
\hline \multirow{4}{*}{ 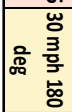 } & DM01E & 0.613 & 0.597 & 0.644 & 0.638 & 0.671 & 0.629 & & & & & & & & 0.223 & 0.224 & & 0.000 & 0.208 \\
\hline & \begin{tabular}{|l} 
DMO \\
\end{tabular} & $\begin{array}{l}0.611 \\
\end{array}$ & $\begin{array}{l}0.5977 \\
.597\end{array}$ & 0.476 & $\begin{array}{l}0.635 \\
0.635\end{array}$ & $\begin{array}{l}0.671 \\
0.67\end{array}$ & 0.629 & 0.630 & 0.573 & 0.182 & 0.306 & $\begin{array}{l}0.489 \\
\end{array}$ & 0.613 & $\begin{array}{l}0.189 \\
0.189\end{array}$ & 0.223 & 0.224 & 0.244 & 0.000 & 0.208 \\
\hline & & 0.611 & 0.597 & 0.492 & 0 & 0 & 0.62 & 0.630 & 0.5 & & 2 & 0.494 & 0.6 & 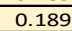 & & 0.224 & 0.244 & 0.000 & .208 \\
\hline & \begin{tabular}{|l}
$\mathrm{Dn}$ \\
\end{tabular} & 0.606 & 0.597 & 0.644 & 0. & 71 & 0. & 0.630 & 0 & & 0.321 & 0.588 & 0.611 & 89 & & 0.224 & 0 & 0.000 & .208 \\
\hline \multirow{4}{*}{ 竞 $\frac{3}{\frac{3}{5}}$} & DM01E & 0.921 & 0.972 & 1.128 & 1.014 & 1.180 & 0.972 & 1.054 & & & & 0.622 & 0.643 & 0.216 & & 0.275 & 0.294 & 0.000 & 0.240 \\
\hline & \begin{tabular}{|l} 
DM01P6 \\
\end{tabular} & 0.910 & 0.972 & $\frac{1.100}{1.102}$ & $\begin{array}{l}1.017 \\
1.017\end{array}$ & $\frac{1.100}{1.182}$ & 0.973 & 1.055 & 0.597 & 0.230 & $\begin{array}{l}0.342 \\
\end{array}$ & 0.614 & 0.643 & 0.216 & 0.265 & 0.275 & 0.294 & 0.000 & 0.240 \\
\hline & DN & 0.910 & 0.972 & 4 & 1.017 & 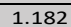 & 0.97 & 1.055 & 0.597 & 0.230 & 0.3 & 0.6 & 0.6 & & & 0.2 & 0.294 & 0.000 & \\
\hline & & 0.7 & 0.9 & 1. & & & 0. & & & & & & 0. & & & 0.275 & 0.294 & 0.000 & 240 \\
\hline \multirow{4}{*}{ 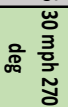 } & DM01E & 1.273 & 1.139 & 1.065 & & 0.816 & 0.631 & 0.688 & 0.313 & 0.210 & 0.284 & 0.389 & 0.456 & 0.239 & 0.519 & 0.674 & 0.781 & 0.000 & 0.676 \\
\hline & \begin{tabular}{|l|l|l|} 
DMO1PG \\
\end{tabular} & 0.997 & 1.140 & 1.063 & 0.818 & $\begin{array}{l}0.816 \\
\end{array}$ & 0.631 & 0.688 & 0.313 & 0.211 & $\begin{array}{l}0.287 \\
\end{array}$ & 0.386 & 0.393 & 0.239 & 0.519 & 0.675 & 0.781 & 0.000 & 0.677 \\
\hline & & 981 & 140 & .063 & -1 & & sin & 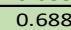 & 0.3 & 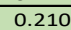 & 0.287 & . & 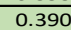 & 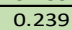 & & 575 & 0.781 & 0.000 & \\
\hline & \begin{tabular}{|l|} 
DM01P8 \\
\end{tabular} & 0.600 & 1.142 & 1.068 & 0.819 & 0.817 & 0.631 & 0.689 & 0.314 & 0.211 & 0.288 & 0.389 & 0.364 & 0.239 & 0.520 & 0.675 & 0.781 & 0.000 & 0.67 \\
\hline
\end{tabular}


Table 5-116. Reduction Rate of maximum significant wave height at the 18 locations under spring tides and high river flow.

\begin{tabular}{|c|c|c|c|c|c|c|c|c|c|c|c|c|c|c|c|c|c|c|c|}
\hline & Structure & 1 & 2 & 3 & 4 & 5 & 6 & 7 & 8 & 9 & 10 & 11 & 12 & 13 & 14 & 15 & 16 & 17 & 18 \\
\hline \multirow{4}{*}{ 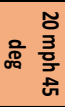 } & DM01E & $\begin{array}{ll}0.268 \\
\end{array}$ & $\begin{array}{l}0.301 \\
\end{array}$ & 0.239 & 0.224 & 0.186 & 0.157 & 0.186 & 0.191 & 0.179 & 0.198 & 0.167 & $\begin{array}{l}0.087 \\
\end{array}$ & 0.444 & 0.453 & 0.459 & 0.461 & Dry & 0.460 \\
\hline & M01P6 & $-2 \%$ & $-7 \%$ & $-11 \%$ & $-5 \%$ & $-2 \%$ & $-2 \%$ & $-1 \%$ & $0 \%$ & $0 \%$ & $-1 \%$ & $0 \%$ & $0 \%$ & $0 \%$ & $0 \%$ & $0 \%$ & $-1 \%$ & Dry & $0 \%$ \\
\hline & DM01P7 & $-2 \%$ & $-10 \%$ & $-8 \%$ & $-5 \%$ & $-2 \%$ & $-2 \%$ & $-1 \%$ & $0 \%$ & $0 \%$ & $-1 \%$ & $0 \%$ & $0 \%$ & $0 \%$ & $0 \%$ & $0 \%$ & $-1 \%$ & Dry & $0 \%$ \\
\hline & \begin{tabular}{|l} 
DM01P8 \\
\end{tabular} & $-2 \%$ & $-15 \%$ & $-6 \%$ & $-5 \%$ & $-2 \%$ & $-1 \%$ & $-2 \%$ & $0 \%$ & $0 \%$ & $-1 \%$ & $0 \%$ & $1 \%$ & $-1 \%$ & $0 \%$ & $0 \%$ & $-1 \%$ & Dry & $-1 \%$ \\
\hline \multirow{4}{*}{ 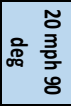 } & DM01E & 0.670 & $\begin{array}{l}0.726 \\
\end{array}$ & 0.659 & 0.597 & 0.622 & 0.529 & 0.668 & 0.422 & 0.186 & 0.309 & 0.193 & 0.299 & 0.333 & 0.477 & 0.497 & 0.538 & Dry & 0.398 \\
\hline & M01P6 & $0 \%$ & $0 \%$ & $-69 \%$ & $-62 \%$ & $-59 \%$ & $-51 \%$ & $-32 \%$ & $-16 \%$ & $-4 \%$ & $-37 \%$ & $-9 \%$ & $0 \%$ & $0 \%$ & $0 \%$ & $0 \%$ & $0 \%$ & Dry & $0 \%$ \\
\hline & \begin{tabular}{|l|} 
DM01P7 \\
\end{tabular} & O\% & $-1 \%$ & $-66 \%$ & $-61 \%$ & $-58 \%$ & $-50 \%$ & $-31 \%$ & $-16 \%$ & $-4 \%$ & $-35 \%$ & $-9 \%$ & $0 \%$ & $0 \%$ & $0 \%$ & $0 \%$ & $0 \%$ & Dry & $0 \%$ \\
\hline & \begin{tabular}{|l} 
DM01P8 \\
\end{tabular} & $0 \%$ & $-43 \%$ & $-63 \%$ & $-59 \%$ & $-55 \%$ & $-47 \%$ & $-32 \%$ & $-16 \%$ & $-4 \%$ & $-34 \%$ & $-9 \%$ & $0 \%$ & $0 \%$ & $0 \%$ & $0 \%$ & $0 \%$ & Dry & $-1 \%$ \\
\hline \multirow{4}{*}{ 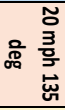 } & DM01E & 0.559 & \begin{tabular}{|c|}
0.584 \\
\end{tabular} & 0.655 & 0.611 & 0.643 & 0.599 & 0.656 & 0.578 & 0.189 & 0.387 & 0.484 & \begin{tabular}{ll|}
0.479 \\
\end{tabular} & 0.199 & 0.250 & 0.266 & 0.296 & .000 & 0.233 \\
\hline & DM & $0 \%$ & $0 \%$ & $-56 \%$ & $-52 \%$ & $-35 \%$ & $-11 \%$ & $-8 \%$ & $-2 \%$ & $-1 \%$ & $-30 \%$ & $-55 \%$ & $0 \%$ & $0 \%$ & $0 \%$ & $0 \%$ & $0 \%$ & Dry & $0 \%$ \\
\hline & DM01P7 & $0 \%$ & $0 \%$ & $-54 \%$ & $-50 \%$ & $-34 \%$ & $-10 \%$ & $-7 \%$ & $-2 \%$ & $-1 \%$ & $-28 \%$ & $-54 \%$ & O\% & $0 \%$ & $0 \%$ & $0 \%$ & $0 \%$ & Dry & $0 \%$ \\
\hline & DM01P8 & O\% & $-14 \%$ & $-44 \%$ & $-38 \%$ & $-24 \%$ & $-9 \%$ & $-7 \%$ & $-2 \%$ & $0 \%$ & $-22 \%$ & $-51 \%$ & $0 \%$ & $0 \%$ & $0 \%$ & $0 \%$ & $0 \%$ & Dry & $0 \%$ \\
\hline \multirow{4}{*}{ 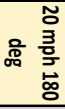 } & DM01E & 0.351 & 0.342 & 0.368 & 0.376 & 0.390 & 0.369 & 0.367 & 0.335 & 0.135 & 0.203 & 0.360 & 0.366 & 0.146 & 0.161 & 0.157 & 0.169 & 0.000 & 0.160 \\
\hline & DMO & $0 \%$ & $0 \%$ & $-24 \%$ & $-1 \%$ & $0 \%$ & $0 \%$ & $0 \%$ & $0 \%$ & $4 \%$ & $-3 \%$ & $-18 \%$ & $0 \%$ & $0 \%$ & $0 \%$ & $0 \%$ & $0 \%$ & Dry & $0 \%$ \\
\hline & \begin{tabular}{|l|l|} 
DM01P7 \\
\end{tabular} & $0 \%$ & O\% & $-22 \%$ & $-1 \%$ & $0 \%$ & $0 \%$ & $0 \%$ & $0 \%$ & $4 \%$ & $-2 \%$ & $-17 \%$ & $0 \%$ & $0 \%$ & $0 \%$ & $0 \%$ & $0 \%$ & Dry & $0 \%$ \\
\hline & \begin{tabular}{|l} 
DM01P8 \\
\end{tabular} & $-1 \%$ & $0 \%$ & $1 \%$ & $0 \%$ & $0 \%$ & $0 \%$ & $0 \%$ & $0 \%$ & $4 \%$ & $1 \%$ & $-5 \%$ & $-1 \%$ & $0 \%$ & $0 \%$ & $0 \%$ & $0 \%$ & Dry & $0 \%$ \\
\hline \multirow{4}{*}{ 竞 } & DMC & 0.569 & 0.607 & 0.714 & 0.672 & 0.751 & 0.630 & 0.647 & 0.375 & 0.145 & 0.262 & 0.410 & 0.414 & 0.166 & 0.188 & 0.192 & 0.201 & 0.000 & 0.181 \\
\hline & DI & $-1 \%$ & $0 \%$ & $-3 \%$ & $0 \%$ & $0 \%$ & $0 \%$ & $0 \%$ & $0 \%$ & $0 \%$ & $2 \%$ & $-1 \%$ & $-1 \%$ & $0 \%$ & $0 \%$ & $0 \%$ & $0 \%$ & Dry & $0 \%$ \\
\hline & DM01P7 & $-1 \%$ & $0 \%$ & $-3 \%$ & $0 \%$ & $0 \%$ & $0 \%$ & $0 \%$ & $0 \%$ & $0 \%$ & $1 \%$ & $-1 \%$ & $-1 \%$ & $0 \%$ & $0 \%$ & $0 \%$ & $0 \%$ & Dry & $0 \%$ \\
\hline & \begin{tabular}{|l|l|} 
MM01P8 \\
\end{tabular} & $-25 \%$ & $0 \%$ & $0 \%$ & $0 \%$ & $0 \%$ & $0 \%$ & $0 \%$ & $0 \%$ & $0 \%$ & $2 \%$ & $0 \%$ & $-4 \%$ & $0 \%$ & $0 \%$ & $0 \%$ & $0 \%$ & Dry & $0 \%$ \\
\hline \multirow{4}{*}{ 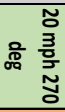 } & DMC & \begin{tabular}{ll|}
0.779 \\
\end{tabular} & $\begin{array}{ll}0.702 \\
\end{array}$ & 0.662 & 0.502 & 0.494 & 0.387 & 0.423 & 0.215 & 0.160 & 0.197 & 0.263 & $\begin{array}{ll}0.295 \\
\end{array}$ & 0.184 & 0.320 & 0.422 & 0.489 & 0.000 & 0.421 \\
\hline & DMO & $-19 \%$ & $0 \%$ & $0 \%$ & $0 \%$ & $0 \%$ & $0 \%$ & $0 \%$ & $0 \%$ & $0 \%$ & $0 \%$ & $-1 \%$ & $-8 \%$ & $0 \%$ & $0 \%$ & $0 \%$ & $0 \%$ & Dry & $0 \%$ \\
\hline & \begin{tabular}{|l|l|l|} 
DMP1 \\
\end{tabular} & $-20 \%$ & O\% & $0 \%$ & $0 \%$ & $0 \%$ & $0 \%$ & $0 \%$ & $0 \%$ & $0 \%$ & $0 \%$ & $-1 \%$ & $-9 \%$ & $0 \%$ & $0 \%$ & $0 \%$ & $0 \%$ & Dry & $0 \%$ \\
\hline & DMO & $-49 \%$ & O\% & $0 \%$ & $0 \%$ & $0 \%$ & $0 \%$ & $0 \%$ & $-1 \%$ & $0 \%$ & $0 \%$ & $0 \%$ & $-13 \%$ & $0 \%$ & $0 \%$ & $0 \%$ & $\%$ & & $0 \%$ \\
\hline \multirow{4}{*}{ 兽 } & DMO & 0.460 & 0.505 & 0.405 & 0.358 & 0.331 & 0.220 & 0.298 & 0.317 & 0.298 & 0.297 & 0.230 & 0.100 & 0.737 & 0.737 & 0.749 & 0.750 & 0.000 & 0.770 \\
\hline & DM01 & $0 \%$ & $-10 \%$ & $-11 \%$ & $-4 \%$ & $-5 \%$ & $-2 \%$ & $-3 \%$ & $0 \%$ & $-1 \%$ & $-1 \%$ & $-2 \%$ & $0 \%$ & $0 \%$ & $0 \%$ & $0 \%$ & $0 \%$ & Dry & $0 \%$ \\
\hline & DM01P7 & $0 \%$ & $-16 \%$ & $-9 \%$ & $-4 \%$ & $-5 \%$ & $-2 \%$ & $-3 \%$ & $0 \%$ & $-1 \%$ & $-1 \%$ & $-2 \%$ & O\% & $0 \%$ & $0 \%$ & $0 \%$ & $-1 \%$ & Dry & $0 \%$ \\
\hline & DMO & $0 \%$ & $-16 \%$ & $-7 \%$ & $-4 \%$ & $-4 \%$ & $-2 \%$ & $\%$ & $0 \%$ & $-1 \%$ & $-1 \%$ & $-2 \%$ & $0 \%$ & $-1 \%$ & $0 \%$ & $0 \%$ & $\%$ & ry & $-1 \%$ \\
\hline \multirow{4}{*}{ 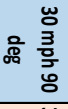 } & & 1.152 & \begin{tabular}{ll|}
1.218 \\
\end{tabular} & 1.117 & 0.969 & 1.040 & 0.866 & .092 & .724 & 0.451 & 0.528 & 0.363 & 0.520 & 0.907 & 0.807 & .824 & 0.902 & 0.995 & 0.620 \\
\hline & DMC & $0 \%$ & $-1 \%$ & $-72 \%$ & $-61 \%$ & $-57 \%$ & $-47 \%$ & $-32 \%$ & $-16 \%$ & $0 \%$ & 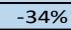 & 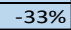 & $0 \%$ & $0 \%$ & $0 \%$ & $0 \%$ & 0 & $\%$ & $0 \%$ \\
\hline & DMO & $0 \%$ & $-1 \%$ & $-69 \%$ & $-60 \%$ & $-56 \%$ & $-45 \%$ & & & & $-33 \%$ & $-33 \%$ & $0 \%$ & $0 \%$ & $0 \%$ & $0 \%$ & $\%$ & $0 \%$ & $0 \%$ \\
\hline & DM & $0 \%$ & $-44 \%$ & $-65 \%$ & $-58 \%$ & $-54 \%$ & & & & & & $-32 \%$ & & $0 \%$ & $0 \%$ & $0 \%$ & $\%$ & $\%$ & $-1 \%$ \\
\hline \multirow{4}{*}{ 崖 } & DM & 0.951 & 1.005 & 1.113 & 0.995 & 1.068 & 0.981 & 1.089 & 0.946 & 0.287 & 0.606 & 0.814 & 0.800 & 0.281 & 0.386 & 0.436 & 0.495 & 0.000 & 0.315 \\
\hline & \begin{tabular}{|l} 
DM01 \\
\end{tabular} & $0 \%$ & $0 \%$ & $-65 \%$ & $-54 \%$ & $-36 \%$ & $-8 \%$ & - & $-2 \%$ & 10 & -2 & 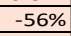 & 0 & $0 \%$ & $0 \%$ & $0 \%$ & & $d$ & $0 \%$ \\
\hline & \begin{tabular}{|l|} 
DM01 \\
\end{tabular} & $0 \%$ & $0 \%$ & $-60 \%$ & $-52 \%$ & & - & -7 & & 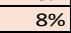 & & & & $0 \%$ & $0 \%$ & 0 & & $\mathrm{Dr}$ & $0 \%$ \\
\hline & DMO & & -1 & & $-39 \%$ & & & & $-2 \%$ & $1 \%$ & & & 0 & $0 \%$ & $0 \%$ & 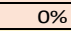 & & Dry & $0 \%$ \\
\hline \multirow{4}{*}{ 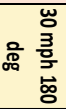 } & DMO & 0.613 & 0.597 & 0.644 & 0.638 & 0.671 & 0.629 & 0.630 & 0.573 & 0.194 & 0.320 & 0.631 & $\begin{array}{ll}0.613 \\
\end{array}$ & 0.189 & 0.223 & 0.224 & 0.245 & 0.000 & 0.208 \\
\hline & & $0 \%$ & $0 \%$ & $-26 \%$ & $-1 \%$ & $0 \%$ & $0 \%$ & 0 & $0 \%$ & -6 & -4 & $-22 \%$ & 0 & $0 \%$ & 0 & 0 & & & $0 \%$ \\
\hline & & $0 \%$ & $0 \%$ & $-24 \%$ & $-1 \%$ & $0 \%$ & $0 \%$ & 0 & $0 \%$ & $-6 \%$ & $-4 \%$ & $-22 \%$ & $0 \%$ & $0 \%$ & $0 \%$ & $0 \%$ & & ry & $0 \%$ \\
\hline & & $-1 \%$ & $0 \%$ & $0 \%$ & $0 \%$ & $0 \%$ & $0 \%$ & $\%$ & $\%$ & $-6 \%$ & $0 \%$ & $-7 \%$ & $0 \%$ & $0 \%$ & $0 \%$ & $0 \%$ & $0 \%$ & Dry & $0 \%$ \\
\hline \multirow{4}{*}{ 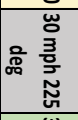 } & DM01E & 0.921 & 0.972 & 1.128 & 1.014 & 1.180 & 0.972 & 1.054 & 0.596 & 0.230 & 0.335 & 0.622 & 0.643 & 0.216 & 0.265 & 0.275 & 0.294 & 0.000 & 0.240 \\
\hline & DM01PG & $-1 \%$ & $0 \%$ & $-2 \%$ & $0 \%$ & $0 \%$ & $0 \%$ & $0 \%$ & $0 \%$ & $0 \%$ & $2 \%$ & $-1 \%$ & $0 \%$ & $0 \%$ & $0 \%$ & $0 \%$ & 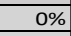 & 8 & $0 \%$ \\
\hline & & $-1 \%$ & 0\% & $-2 \%$ & $0 \%$ & $0 \%$ & $0 \%$ & 0 & $0 \%$ & 0 & 0 & $-1 \%$ & 0 & $0 \%$ & $0 \%$ & 0 & & Dry & $0 \%$ \\
\hline & $\overline{D M}$ & $-22 \%$ & O\% & $0 \%$ & $0 \%$ & $0 \%$ & $0 \%$ & $\%$ & $0 \%$ & $0 \%$ & $\%$ & $0 \%$ & $-3 \% \mid$ & $0 \%$ & $0 \%$ & $0 \%$ & $0 \%$ & Dry & $0 \%$ \\
\hline \multirow{4}{*}{ 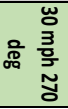 } & DM01E & \begin{tabular}{|c|}
1.273 \\
\end{tabular} & \begin{tabular}{|l|}
1.139 \\
\end{tabular} & 1.065 & 0.817 & 0.816 & 0.631 & 0.688 & 0.313 & 0.210 & 0.284 & 0.389 & $\begin{array}{l}0.456 \\
\end{array}$ & 0.239 & 0.519 & 0.674 & 0.781 & 0.000 & 0.676 \\
\hline & & $-22 \%$ & $0 \%$ & $0 \%$ & $0 \%$ & $0 \%$ & $0 \%$ & $0 \%$ & $0 \%$ & $0 \%$ & $1 \%$ & $-1 \%$ & $-14 \%$ & $0 \%$ & $0 \%$ & 09 & $0 \%$ & 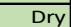 & $0 \%$ \\
\hline & & $-23 \%$ & $0 \%$ & $0 \%$ & $0 \%$ & $0 \%$ & $0 \%$ & & 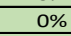 & 0 & & $-1 \%$ & -1 & $0 \%$ & 0 & 0 & & & 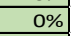 \\
\hline & \begin{tabular}{|l|} 
DMO1P8 \\
\end{tabular} & $-53 \%$ & $0 \%$ & $0 \%$ & $0 \%$ & $0 \%$ & $0 \%$ & $0 \%$ & $0 \%$ & $0 \%$ & $1 \%$ & $0 \%$ & $-20 \%$ & $0 \%$ & $0 \%$ & $0 \%$ & $0 \%$ & Dry & $0 \%$ \\
\hline
\end{tabular}


Table 5-117. Maximum significant wave height values in feet at the 18 locations under summer tides and low river flow.

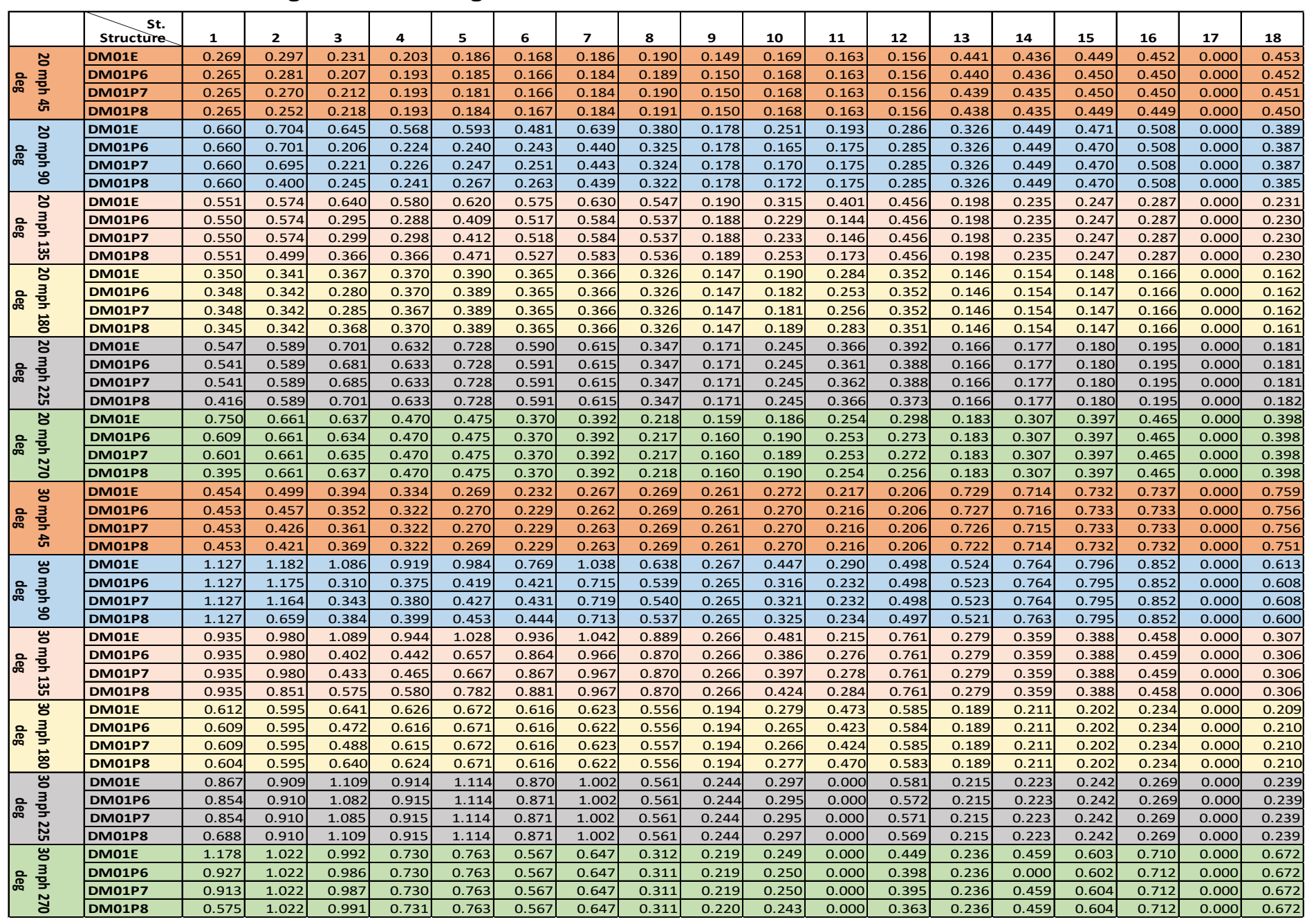


Table 5-118. Reduction Rate of maximum significant wave height at the 18 locations under summer tides and low river flow.

\begin{tabular}{|c|c|c|c|c|c|c|c|c|c|c|c|c|c|c|c|c|c|c|c|}
\hline & $\begin{array}{r}\text { St. } \\
\text { Structure }\end{array}$ & 1 & 2 & 3 & 4 & 5 & 6 & 7 & 8 & 9 & 10 & 11 & 12 & 13 & 14 & 15 & 16 & 17 & 18 \\
\hline \multirow{4}{*}{ 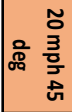 } & DM01E & 0.269 & 0.297 & 0.231 & 0.203 & 0.186 & 0.168 & 0.186 & 0.190 & 0.149 & 0.169 & 0.163 & 0.156 & 0.441 & 0.436 & 0.449 & 0.452 & 0.000 & 0.453 \\
\hline & DM01P6 & $-1 \%$ & $-6 \%$ & $-11 \%$ & $-5 \%$ & $0 \%$ & $-1 \%$ & $-1 \%$ & $0 \%$ & $1 \%$ & $-1 \%$ & $0 \%$ & $0 \%$ & $0 \%$ & $0 \%$ & $0 \%$ & $-1 \%$ & Dry & $0 \%$ \\
\hline & \begin{tabular}{|l|} 
DM01P7 \\
\end{tabular} & $\begin{array}{l}-1 \% \\
\end{array}$ & $-9 \%$ & $-8 \%$ & $-5 \%$ & $-3 \%$ & $-1 \%$ & $-1 \%$ & $0 \%$ & $1 \%$ & $-1 \%$ & $0 \%$ & $0 \%$ & $0 \%$ & $0 \%$ & $0 \%$ & $-1 \%$ & Dry & $0 \%$ \\
\hline & \begin{tabular}{|l|} 
DM01P8 \\
\end{tabular} & \begin{tabular}{|l|}
$-1 \%$ \\
\end{tabular} & $-15 \%$ & $-6 \%$ & $-5 \%$ & $-1 \%$ & $-1 \%$ & $-1 \%$ & $0 \%$ & $1 \%$ & $-1 \%$ & $0 \%$ & $0 \%$ & $-1 \%$ & $0 \%$ & $0 \%$ & $-1 \%$ & Dry & $-1 \%$ \\
\hline \multirow{4}{*}{ 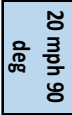 } & DM01E & 0.660 & 0.704 & 0.645 & 0.568 & 0.593 & 0.481 & $\begin{array}{l}0.639 \\
\end{array}$ & 0.380 & 0.178 & 0.251 & 0.193 & 0.286 & 0.326 & 0.449 & 0.471 & 0.508 & 0.000 & 0.389 \\
\hline & \begin{tabular}{|l|} 
DM01P6 \\
\end{tabular} & $0 \%$ & $0 \%$ & $-68 \%$ & $\begin{array}{l}-61 \% \\
\end{array}$ & $-59 \%$ & $-50 \%$ & $-31 \%$ & $-15 \%$ & $0 \%$ & $-34 \%$ & $-9 \%$ & $0 \%$ & $0 \%$ & $0 \%$ & $0 \%$ & $0 \%$ & Dry & $0 \%$ \\
\hline & \begin{tabular}{|l|l|} 
DM01P7 \\
\end{tabular} & $0 \%$ & $-1 \%$ & $-66 \%$ & $-60 \%$ & $-58 \%$ & $-48 \%$ & $-31 \%$ & $-15 \%$ & $0 \%$ & $-32 \%$ & $-9 \%$ & $0 \%$ & $0 \%$ & $0 \%$ & $0 \%$ & $0 \%$ & Dry & $-1 \%$ \\
\hline & DM01P8 & $0 \%$ & $-43 \%$ & $-62 \%$ & $-57 \%$ & $-55 \%$ & $-45 \%$ & $-31 \%$ & $-15 \%$ & $0 \%$ & $-32 \%$ & $-9 \%$ & $0 \%$ & $0 \%$ & $0 \%$ & $0 \%$ & $0 \%$ & Dry & $-1 \%$ \\
\hline \multirow{4}{*}{ 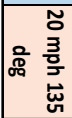 } & DM01E & $\begin{array}{l}0.551 \\
\end{array}$ & 0.574 & 0.640 & 0.580 & 0.620 & 0.575 & 0.630 & 0.547 & 0.190 & 0.315 & 0.401 & 0.456 & 0.198 & 0.235 & 0.247 & 0.287 & 0.000 & 0.231 \\
\hline & DM01P6 & $0 \%$ & $0 \%$ & $-54 \%$ & $-50 \%$ & $-34 \%$ & $-10 \%$ & $-7 \%$ & $-2 \%$ & $-1 \%$ & $-27 \%$ & $-64 \%$ & $0 \%$ & $0 \%$ & $0 \%$ & $0 \%$ & $0 \%$ & Dry & $0 \%$ \\
\hline & DM01P7 & $0 \%$ & $0 \%$ & $-53 \%$ & $-49 \%$ & $-33 \%$ & $-10 \%$ & $-7 \%$ & $-2 \%$ & $-1 \%$ & $-26 \%$ & $-64 \%$ & $0 \%$ & $0 \%$ & $0 \%$ & $0 \%$ & $0 \%$ & Dry & $0 \%$ \\
\hline & \begin{tabular}{|l|l|} 
DM01P8 \\
\end{tabular} & $0 \%$ & $-13 \%$ & $-43 \%$ & \begin{tabular}{|l|}
$-37 \%$ \\
\end{tabular} & $-24 \%$ & $-8 \%$ & $-8 \%$ & $-2 \%$ & $-1 \%$ & $-20 \%$ & $-57 \%$ & $0 \%$ & $0 \%$ & $0 \%$ & $0 \%$ & $0 \%$ & Dry & $-1 \%$ \\
\hline \multirow{4}{*}{ 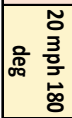 } & DM01E & $\begin{array}{l}0.350 \\
\end{array}$ & 0.341 & 0.367 & 0.370 & 0.390 & 0.365 & $\begin{array}{l}0.366 \\
\end{array}$ & 0.326 & 0.147 & 0.190 & 0.284 & 0.352 & 0.146 & 0.154 & 0.148 & 0.166 & 0.000 & 0.162 \\
\hline & \begin{tabular}{|l|} 
DM01P6 \\
\end{tabular} & \begin{tabular}{|l|}
$-1 \%$ \\
\end{tabular} & $0 \%$ & $-24 \%$ & $0 \%$ & $0 \%$ & $0 \%$ & 0\% & $0 \%$ & $0 \%$ & $-5 \%$ & $\begin{array}{l}-11 \% \\
\end{array}$ & $0 \%$ & $0 \%$ & $0 \%$ & $0 \%$ & $0 \%$ & Dry & $0 \%$ \\
\hline & DM01P7 & $-1 \%$ & $0 \%$ & $-22 \%$ & $-1 \%$ & $0 \%$ & $0 \%$ & $0 \%$ & $0 \%$ & $0 \%$ & $-5 \%$ & $-10 \%$ & $0 \%$ & $0 \%$ & $0 \%$ & $0 \%$ & $0 \%$ & Dry & $0 \%$ \\
\hline & DM01P8 & -1\% & $0 \%$ & $0 \%$ & $0 \%$ & $0 \%$ & $0 \%$ & $0 \%$ & $0 \%$ & $0 \%$ & $-1 \%$ & $0 \%$ & $0 \%$ & $0 \%$ & $0 \%$ & $0 \%$ & $0 \%$ & Dry & $0 \%$ \\
\hline \multirow{4}{*}{ 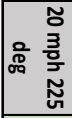 } & DM01E & $\begin{array}{l}0.547 \\
\end{array}$ & 0.589 & 0.701 & 0.632 & 0.728 & 0.590 & 0.615 & 0.347 & 0.171 & 0.245 & 0.366 & 0.392 & 0.166 & 0.177 & 0.180 & 0.195 & 0.000 & 0.181 \\
\hline & DM01P6 & $-1 \%$ & $0 \%$ & $-3 \%$ & $0 \%$ & $0 \%$ & $0 \%$ & $0 \%$ & $0 \%$ & $0 \%$ & $0 \%$ & $-1 \%$ & $-1 \%$ & $0 \%$ & $0 \%$ & $0 \%$ & $0 \%$ & Dry & $0 \%$ \\
\hline & DM01P7 & $-1 \%$ & $0 \%$ & $-2 \%$ & $0 \%$ & $0 \%$ & $0 \%$ & $0 \%$ & $0 \%$ & $0 \%$ & $0 \%$ & $-1 \%$ & $-1 \%$ & $0 \%$ & $0 \%$ & $0 \%$ & $0 \%$ & Dry & $0 \%$ \\
\hline & DM01P8 & $-24 \%$ & $0 \%$ & $0 \%$ & $0 \%$ & $0 \%$ & $0 \%$ & $0 \%$ & $0 \%$ & $0 \%$ & $0 \%$ & $0 \%$ & $-5 \%$ & $0 \%$ & $0 \%$ & $0 \%$ & $0 \%$ & Dry & $0 \%$ \\
\hline \multirow{4}{*}{ 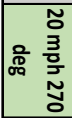 } & DM01E & $\begin{array}{l}0.750 \\
\end{array}$ & 0.661 & 0.637 & $\begin{array}{l}0.470 \\
\end{array}$ & 0.475 & 0.370 & $\begin{array}{l}0.392 \\
\end{array}$ & 0.218 & 0.159 & 0.186 & 0.254 & 0.298 & 0.183 & 0.307 & 0.397 & 0.465 & 0.000 & 0.398 \\
\hline & DM01P6 & \begin{tabular}{|l|}
$-19 \%$ \\
\end{tabular} & $0 \%$ & $0 \%$ & $0 \%$ & $0 \%$ & $0 \%$ & $0 \%$ & $0 \%$ & $0 \%$ & $2 \%$ & $0 \%$ & $-8 \%$ & $0 \%$ & $0 \%$ & $0 \%$ & $0 \%$ & Dry & $0 \%$ \\
\hline & DM01P7 & $-20 \%$ & $0 \%$ & $\%$ & $0 \%$ & $0 \%$ & $0 \%$ & $0 \%$ & $0 \%$ & $0 \%$ & $2 \%$ & $0 \%$ & $-9 \%$ & $0 \%$ & $0 \%$ & $0 \%$ & $0 \%$ & Dry & $0 \%$ \\
\hline & DM01P8 & $-47 \%$ & $0 \%$ & $0 \%$ & $0 \%$ & $0 \%$ & $0 \%$ & $0 \%$ & $0 \%$ & $0 \%$ & $2 \%$ & $0 \%$ & $-14 \%$ & $0 \%$ & $0 \%$ & $0 \%$ & $0 \%$ & Dry & $0 \%$ \\
\hline \multirow{4}{*}{ 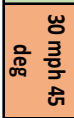 } & DM01E & $\begin{array}{l}0.454 \\
\end{array}$ & 0.499 & 0.394 & 0.334 & 0.269 & 0.232 & \begin{tabular}{|c|}
0.267 \\
\end{tabular} & 0.269 & 0.261 & 0.272 & 0.217 & 0.206 & 0.729 & 0.714 & 0.732 & 0.737 & 0.000 & 0.759 \\
\hline & DM01P6 & $0 \%$ & $-8 \%$ & $-11 \%$ & $-4 \%$ & $0 \%$ & $-1 \%$ & $-2 \%$ & $0 \%$ & $0 \%$ & $-1 \%$ & $0 \%$ & $0 \%$ & $0 \%$ & $0 \%$ & $0 \%$ & $0 \%$ & Dry & $0 \%$ \\
\hline & DM01P7 & $\%$ & $-15 \%$ & $-8 \%$ & $-4 \%$ & $0 \%$ & $-1 \%$ & $-1 \%$ & $0 \%$ & $0 \%$ & $-1 \%$ & $0 \%$ & $0 \%$ & $0 \%$ & $0 \%$ & $0 \%$ & $-1 \%$ & Dry & $0 \%$ \\
\hline & DM01P8 & $0 \%$ & $-16 \%$ & $-6 \%$ & $-4 \%$ & $0 \%$ & $-1 \%$ & $-1 \%$ & $0 \%$ & $0 \%$ & $-1 \%$ & $0 \%$ & $0 \%$ & $-1 \%$ & $0 \%$ & $0 \%$ & $-1 \%$ & Dry & $-1 \%$ \\
\hline \multirow{4}{*}{ 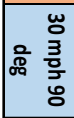 } & DM01E & \begin{tabular}{|l|}
1.127 \\
\end{tabular} & 1.182 & 1.086 & $\begin{array}{l}0.919 \\
\end{array}$ & 0.984 & 0.769 & $\begin{array}{l}1.038 \\
\end{array}$ & 0.638 & 0.267 & 0.447 & 0.290 & 0.498 & 0.524 & 0.764 & 0.796 & 0.852 & 0.000 & 0.613 \\
\hline & DM011 & $0 \%$ & $-1 \%$ & $-71 \%$ & $-59 \%$ & $-57 \%$ & $-45 \%$ & $-31 \%$ & $-16 \%$ & $-1 \%$ & $-29 \%$ & $-20 \%$ & $0 \%$ & $0 \%$ & $0 \%$ & $0 \%$ & $0 \%$ & Dry & $-1 \%$ \\
\hline & DM01P7 & O\% & $-1 \%$ & $-68 \%$ & $-59 \%$ & $-57 \%$ & $-44 \%$ & $-31 \%$ & $-15 \%$ & $-1 \%$ & $-28 \%$ & $-20 \%$ & $0 \%$ & $0 \%$ & $0 \%$ & $0 \%$ & $0 \%$ & Dry & $-1 \%$ \\
\hline & \begin{tabular}{|l|} 
DM01P8 \\
\end{tabular} & $0 \%$ & $-44 \%$ & $-65 \%$ & $-57 \%$ & $-54 \%$ & $-42 \%$ & $-31 \%$ & $-16 \%$ & $-1 \%$ & $-27 \%$ & $-19 \%$ & $0 \%$ & $-1 \%$ & $0 \%$ & $0 \%$ & $0 \%$ & Dry & $-2 \%$ \\
\hline \multirow{4}{*}{ 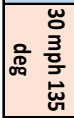 } & DM01E & 0.935 & 0.980 & 1.089 & 0.944 & $\begin{array}{l}1.028 \\
\end{array}$ & 0.936 & 1.042 & 0.889 & 0.266 & 0.481 & 0.215 & 0.761 & 0.279 & .359 & 0.388 & 0.458 & 0.000 & 0.307 \\
\hline & \begin{tabular}{|l|l|} 
DM01P6 \\
\end{tabular} & $0 \%$ & $0 \%$ & $-63 \%$ & $-53 \%$ & $-36 \%$ & $-8 \%$ & $-7 \%$ & $-2 \%$ & $0 \%$ & $-20 \%$ & $28 \%$ & $0 \%$ & $0 \%$ & $0 \%$ & $0 \%$ & $0 \%$ & Dry & $0 \%$ \\
\hline & DM01P7 & $0 \%$ & $0 \%$ & $-60 \%$ & $-51 \%$ & $-35 \%$ & $-7 \%$ & $-7 \%$ & $-2 \%$ & $0 \%$ & $-17 \%$ & $29 \%$ & $0 \%$ & $0 \%$ & $0 \%$ & $0 \%$ & $\%$ & Dry & $0 \%$ \\
\hline & DM01 & $0 \%$ & $-13 \%$ & $-47 \%$ & $-39 \%$ & $-24 \%$ & $-6 \%$ & $-7 \%$ & $-2 \%$ & $0 \%$ & $-12 \%$ & $32 \%$ & $0 \%$ & $0 \%$ & $0 \%$ & $0 \%$ & $0 \%$ & Dry & $0 \%$ \\
\hline \multirow{4}{*}{ 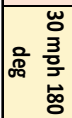 } & DM01E & 0.612 & 0.595 & 0.641 & 0.626 & 0.672 & 0.616 & 0.623 & 0.556 & 0.194 & 0.279 & 0.473 & 0.585 & 0.189 & 0.211 & 0.202 & 0.234 & 0.000 & 0.209 \\
\hline & DM01P6 & $0 \%$ & $0 \%$ & $-26 \%$ & $-2 \%$ & $0 \%$ & $0 \%$ & $0 \%$ & $0 \%$ & $0 \%$ & $-5 \%$ & $-11 \%$ & $0 \%$ & $0 \%$ & $\%$ & $0 \%$ & $0 \%$ & Dry & $1 \%$ \\
\hline & DM01P7 & $0 \%$ & $0 \%$ & $-24 \%$ & $-2 \%$ & $0 \%$ & $0 \%$ & $0 \%$ & $0 \%$ & $0 \%$ & $-5 \%$ & $-10 \%$ & $0 \%$ & $0 \%$ & $0 \%$ & $0 \%$ & $0 \%$ & Dry & $1 \%$ \\
\hline & DM01PE & $-1 \%$ & $0 \%$ & $0 \%$ & $0 \%$ & $0 \%$ & $0 \%$ & $0 \%$ & $0 \%$ & $0 \%$ & $-1 \%$ & $-1 \%$ & $0 \%$ & $0 \%$ & $0 \%$ & $0 \%$ & $0 \%$ & Dry & $0 \%$ \\
\hline \multirow{4}{*}{ 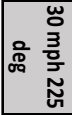 } & DM01E & $\begin{array}{l}0.867 \\
\end{array}$ & 0.909 & 1.109 & 0.914 & 1.114 & 0.870 & 1.002 & 0.561 & 0.244 & 0.297 & 0.000 & 0.581 & 0.215 & 0.223 & 0.242 & 0.269 & 0.000 & 0.239 \\
\hline & DM01P6 & $-1 \%$ & $0 \%$ & $-2 \%$ & $0 \%$ & $0 \%$ & $0 \%$ & $0 \%$ & $0 \%$ & $0 \%$ & $-1 \%$ & Dry & $-2 \%$ & $0 \%$ & $0 \%$ & $0 \%$ & $0 \%$ & Dry & $0 \%$ \\
\hline & DM01P7 & $-1 \%$ & $0 \%$ & $-2 \%$ & 0 & $0 \%$ & $0 \%$ & $0 \%$ & $0 \%$ & $0 \%$ & $-1 \%$ & Dry & $-2 \%$ & $0 \%$ & $0 \%$ & $0 \%$ & $0 \%$ & Dry & $0 \%$ \\
\hline & \begin{tabular}{|l|l|} 
MM01P8 \\
\end{tabular} & $-21 \%$ & $0 \%$ & $0 \%$ & $0 \%$ & $0 \%$ & $0 \%$ & $0 \%$ & $0 \%$ & $0 \%$ & $0 \%$ & Dry & $-2 \%$ & $0 \%$ & $0 \%$ & $0 \%$ & $0 \%$ & Dry & $0 \%$ \\
\hline
\end{tabular}




\section{Summary}

To evaluate seven different with-project designs for restoring the promontory at Dyke Marsh, state-of-the-art high-fidelity numerical modeling for water surface elevations, velocities, and wave heights were performed using the CSTORM Modeling System and making use of data derived from the NACCS. A total of 13 storms (5 HIS ET storms, 6 SYN TP storms and 2 HIS TP storms) were used to make comparisons of water surface elevations, velocities and significant wave heights between withoutproject and seven with-project alternatives in the Dyke Marsh area. Two sets of one-month-long tidal/river flow simulations using tides and river flows only were performed to assess non-storm conditions and represent typical flow patterns (non-storm events) representative of spring (high flow) and summer (low flow) conditions. Twelve wind fields (6 directions and 2 wind speeds) were then used to force a shorter one-day simulation that also included wave impacts. Again these events were simulated to represent typical conditions for not only the circulation fields but also the wave fields. In general, each of the seven with-project alternatives caused little change to water elevations and all produced lower wave heights in the shadow zone of the structure (either to the north or south) depending on the direction of the wind. As was expected, the depth-averaged water velocities were increased at the tip of the structures as flow accelerated around the end of the structures. The increase in water velocities might need to be investigated in more detail to ascertain the likelihood of scour being induced. For the structure alternatives that extended furthest from the western bank of the river, the depth-averaged velocities on the adjacent eastern bank of the river were increased more significantly than with the shorter alternatives. Due to less of an increase in water velocities, the shorter alternatives would be less likely to increase erosion on the eastern bank than the longer structures.

The modeling results provided in this study should be sufficient for NAB to use in selecting a with-project design alternative from the seven designs modeled. Follow-on studies to quantify the potential of scour happening around the ends of the structure due to increased water velocities may be considered. In addition, ecological plant viability and sediment transport modeling could provide additional insights into how the marsh might respond to the new flow and wave conditions under a with-project condition. 


\section{References}

Cialone, Mary A., T. C. Massey, Mary E. Anderson, Alison S. Grzegorzewski, Robert E. Jensen, Alan Cialone, David J. Mark, Kimberly C. Pevey, Brittany L. Gunkel, and Tate O. McAlpin. 2015. North Atlantic Coast Comprehensive Study (NACCS) Coastal Storm Model Simulations: Waves and Water Levels. ERDC/CHL TR-1514. Vicksburg, MS: U.S. Army Engineer Research and Development Center.

Finite Element Surface Water Modeling System (FESWMS). 2017. Finite-Element Surface-Water Modeling System for Two-Dimensional Flow in the Horizontal Plane. Accessed 17 July 2017. https://water.usgs.gov/software/FESWMS-2DH/.

Froehlich, D. C. 1989. HWo31.D - Finite Element Surface-Water Modeling System: TwoDimensional Flow in a Horizontal Plane-Users Manual. FHWA-RD-88-177. Washington, DC: Federal Highway Administration.

Garratt, J. R. 1977. "Review of Drag Coefficients over Oceans and Continents." Mon. Wea. Rev. 105: 915-929.

Homer, C. G., J. A. Dewitz, L. Yang, S. Jin, P. Danielson, G. Xian, J. Coulston, N. D. Herold, J. D. Wickham, and K. Megown. 2015. "Completion of the 2011 National Land Cover Database for the Conterminous United States-Representing a Decade of Land Cover Change Information." Photogrammetric Engineering and Remote Sensing 81(5): 345-354.

Komen, G. J. L., M. Donelan, K. Hasselmann, S. Hasselmann, and P. A. E. M. Janssen. 1994. Dynamics and Modeling of Ocean Waves. Cambridge, MA: Cambridge Univ. Press.

Litwin, R. J., J. P. Smoot, M. J. Pavich, H. W. Markewich, Erik Oberg, Ben Helwig, Brent Steury, V. L. Santucci, N. J. Durika, N. B. Rybicki, K. M. Engelhardt, Geoffrey Sanders, Stacey Verardo, A. J. Elmore, and J. Gilmer. 2011. Analysis of the Deconstruction of Dyke Marsh, George Washington Memorial Parkway, Virginia-Progression, Geologic and Manmade Causes, and Effective Restoration Scenarios. Open-File Report 2010-1269. Reston, VA: U.S. Geological Survey.

Litwin, R. J., J. P. Smoot, M. J. Pavich, E. Oberg, B. Steury, B. Helwig, H. W. Markewich, V. L. Santucci, and G. Sanders. 2013. "Rates and Probable Causes of Freshwater Tidal Marsh Failure, Potomac River Estuary, Northern Virginia, USA.” Wetlands 33: 1,037-1,061.

Luettich, R. A., Jr., J. J. Westerink, and N. W. Scheffner. 1992. ADCIRC: An Advanced Three-Dimensional Circulation Model for Shelves, Coasts, and Estuaries. Technical Report DRP-92-6. Vicksburg, MS: U.S. Army Engineer Research and Development Center.

Massey, T. C., M. E. Anderson, J. M. Smith, J. Gomez, and R. Jones. 2011. STWAVE: Steady-State Spectral Wave Model User's Manual for STWAVE, Version 6.o. ERDC/CHL SR-11-1. Vicksburg, MS: U.S. Army Engineer Research and Development Center. 
Massey, T. C., T. V. Wamsley, and M. A. Cialone. 2012. "Coastal Storm Modeling System Integration." In Proceedings of Solutions to Coastal Disasters Conference 2011, 99-108. https://doi.org/10.1061/41185(417)10.

Nadal-Caraballo, N. C., J. A. Melby, V. M. Gonzalez, and A. T. Cox. 2015. Coastal storm Hazards from Virginia to Maine. ERDC/CHL TR-15-5. Vicksburg, MS: U.S. Army Engineer Research and Development Center.

National Land Cover Database (NLCD). 2016. National Land Cover Database 2011. Accessed 1 Dec 2016. https://www.mrlc.gov/viewerjs/.

National Oceanic and Atmospheric Administration (NOAA). 2016. Vertical Datum Transformation. Accessed 26 Nov 2016. https://vdatum.noaa.gov/.

Smith, J. M., A. R. Sherlock, and D. T. Resio. 2001. STWAVE: Steady-State Spectral Wave Model User's Manual for STWAVE, Version 3.o. ERDC/CHL SR-01-1. Vicksburg, MS: U.S. Army Engineer Research and Development Center.

Smith, J. M. 2007. Full-Plane STWAVE with Bottom Friction: II. Model Overview. ERDC/CHL CHETN-I-75. Vicksburg, MS: U.S. Army Engineer Research and Development Center.

U.S. Geological Survey-National Elevation Dataset (USGS-NED). 2016. USGS ${ }_{3} D$ Elevation Program (3DEP). Accessed 25 Nov 2016. https://nationalmap.gov/3DEP/index.html.

Water Resources Development Act of 1974. 1974. Section 86(a), Public Law 93-251. 93rd Congress, H.R. 10203.

Water Resources Development Act of 2007. 2007. Section 5147, Public Law 110-114, 110th Congress, H.R. 1495.

Westerink J. J, R. A. Luettich, J. C. Feyen, J. H. Atkinson, C. Dawson, H. J. Roberts, M. D. Powell, J. D. Dunion, E. J. Kubatko, and H. Pourtaheri. 2008. "A Basin to Channel Scale Unstructured Grid Hurricane Storm Surge Model Applied to Southern Louisiana." Monthly Weather Rev. 136(3): 833-864. 


\section{Appendix}

This appendix contains additional details about the bathymetric and topographic data sets supplied from $\mathrm{NAB}$, specifically from the following:

- U.S. Army Corps of Engineers, Baltimore District (USACE NAB) ${ }^{1}$

- National Park Service (NPS) ${ }^{2}$

- University of Maryland Center for Environmental Science (UMCES) ${ }^{3}$

The datasets from NAB included a text-ASCII file of XYZ locations from the NAB 2016 survey. The data was referenced to MLW and was from the NAB operations survey crew that performed the survey in March of 2016. This bathymetry was collected in MLW (feet) for the 1983 to 2001 Tidal Epoch and used a horizontal datum of NAD83 with locations given in State Plane coordinates for Virginia State Plane North, in feet.

The dataset also contained text-ASCII files of XYZ locations from the NPS survey. One of the files contained near shore values that were from a survey conducted by the NPS in February of 2009. Those data were converted from a vertical datum in NAVD88 meters to MLW (feet) for the 1983 to 2001 Tidal Epoch. The horizontal datum was converted from UTM in NAD83 meters to NAD83 State Plane coordinates for Virginia State Plane North, in feet. In addition, a second text-ASCII file had XYZ points created by hand, tracing along the low tide shoreline by the NPS using aerial imagery. The trace points were converted from NAVD88 meters to MLW (feet) for the 1983 to 2001 Tidal Epoch. The horizontal datum was converted from UTM in NAD83 meters to NAD83 State Plane coordinates for Virginia State Plane North (feet).

\footnotetext{
1 U.S. Army Corps of Engineers, Baltimore District (USACE NAB). 2016. A 2016 Bathymetric "Condition Survey, Dyke Marsh, Fairfax County, Virginia" was performed by Operations Division of the Baltimore District on March 1 - 9, 2016, using an Odom hydrotrac depth sounder, $200 \mathrm{KHZ}$ transducer and trimble GPS system.

2 National Park Service (NPS). 2009. A February 4-10, 2009 bathymetric survey performed by Normandeau Associates, Inc. for the National Park Service, via The Louis Berger Group, Inc. In addition, Digital Ortho Mosaic photos from September 2009 were used to digitize the shoreline for this dataset.

3 University of Maryland Center for Environmental Science (UMCES). 2012. A The terrestrial surface LIDAR was collected by the West Virginia University - Natural Resource Analysis Center under contract by the University of Maryland Center for Environmental Science on March 14, 2012.
} 
The lidar dataset was from UMCES and was supplied in a text-ASCII file containing XYZ point locations. The data were targeted at and fieldchecked to conform with the NAVD88 and NAD83 (feet) datum. A digital elevation model (DEM) was constructed from the complete data set, and then a $25 \mathrm{ft}$ resolution grid was sampled from the DEM. The grid was then converted to a vertical datum of MLW (feet) for the 1983 to 2001 Tidal Epoch, with a horizontal datum of NAD83, Virginia State Plane North (feet).

Please note that some of the lidar did not capture small portions of some of the islands and peninsulas of the marsh. For those areas, values taken from similar marsh elevations in the zero MLW line from the NPS ${ }^{1}$ dataset were applied to complete the DEM.

\footnotetext{
1 National Park Service (NPS). 2009. A February 4-10, 2009 bathymetric survey performed by Normandeau Associates, Inc. for the National Park Service, via The Louis Berger Group, Inc. In addition, Digital Ortho Mosaic photos from September 2009 were used to digitize the shoreline for this dataset.
} 


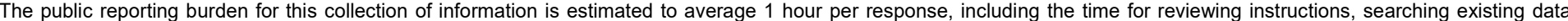

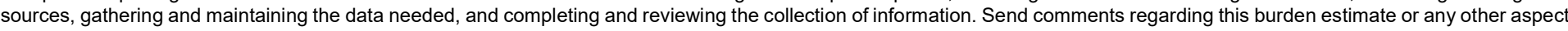

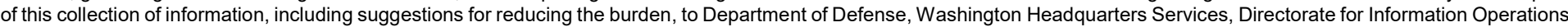

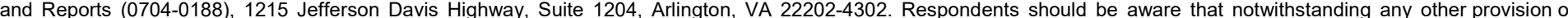
law, no person shall be subject to any penalty for failing to comply with a collection of information if it does not display a currently valid OMB control number.

PLEASE DO NOT RETURN YOUR FORM TO THE ABOVE ADDRESS.

\begin{tabular}{l|l|l}
\hline $\begin{array}{l}\text { 1. REPORT DATE } \\
\text { October } 2018\end{array}$ & $\begin{array}{l}\text { 2. REPORT TYPE } \\
\text { Final Report }\end{array}$ & 3. DATES COVERED (FrOm - To)
\end{tabular}

\section{TITLE AND SUBTITLE}

CSTORM-MS Storm Surge and Wave Modeling Comparison for Proposed Dyke Marsh

Promontory Restoration 5a. CONTRACT NUMBER

5b. GRANT NUMBER

5c. PROGRAM ELEMENT NUMBER

5d. PROJECT NUMBER

327615

5e. TASK NUMBER

5f. WORK UNIT NUMBER

8. PERFORMING ORGANIZATION REPORT

NUMBER

ERDC/CHL TR-18-15

10. SPONSOR/MONITOR'S ACRONYM(S)

USACE NAB

11. SPONSOR/MONITOR'S REPORT NUMBER(S)

\section{DISTRIBUTION/AVAILABILITY STATEMENT}

Approved for public release; distribution is unlimited.

\section{SUPPLEMENTARY NOTES}

\section{ABSTRACT}

The U.S. Army Corps of Engineers, Baltimore District (NAB), is currently engaged in the Dyke Marsh Project for the National Park Service. Dyke Marsh is located along the Potomac River south of Alexandria, VA. The U.S. Army Engineer Research and Development, Coastal and Hydraulics Laboratory, conducted a numerical modeling study to compute differences in hydrodynamic conditions (water surface elevations, depth-averaged water velocities, and wave heights, periods, and directions) between existing conditions and seven alternative with-project conditions for Dyke Marsh. Modeling results suggested that several of the alternative with-project condition designs were viable in terms of the NAB goals to provide protection to the marsh from damaging waves and currents. All the designs decreased wave heights in the shadow zones of the structures, and none significantly altered water levels. The shorter-length project designs provided reasonable levels of protection to the marsh while not significantly increasing water velocities on the opposite (eastern) shoreline of the Potomac River. Detailed model results from each of the alternative with-project condition designs are presented herein

\section{SUBJECT TERMS}

Alexandria (Va.), Hydrodynamics, Mount Vernon (Va.), Potomac River, Restoration ecology, Storm surges—-Mathematical models, Wetlands

\section{SECURITY CLASSIFICATION OF:}

\begin{tabular}{|l|c|c|}
\hline a. REPORT & b. ABSTRACT & c. THIS PAGE \\
Unclassified & Unclassified & Unclassified \\
\hline
\end{tabular}

17. LIMITATION OF ABSTRACT

SAR
18. NUMBER OF PAGES

230 19a. NAME OF RESPONSIBLE PERSON Thomas C. Massey

19b. TELEPHONE NUMBER (Include area code) 601-634-2406 